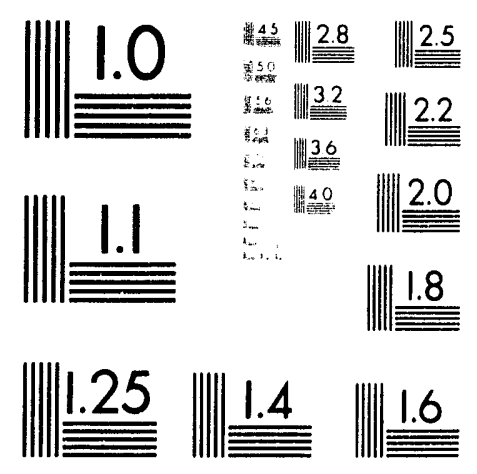



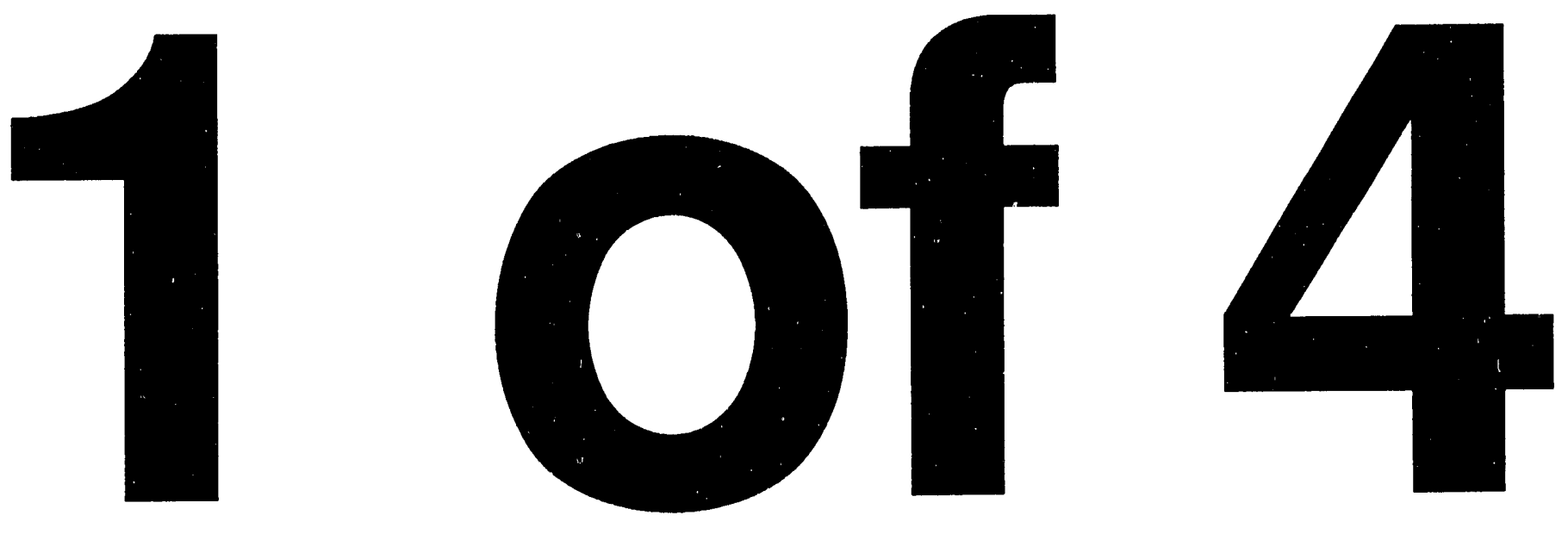


\section{Paducah Gaseous Diffusion Plant environmental report for 1992}

Sep 1993

Martin Marietta Energy Systems, Inc., Oak Ridge, TN (United States)

Reproduced and Distributed by:

U.S. DEPARTMENT OF ENERGY

Office of Scientific and Technical Information P.O. Box 62

Oak Ridge, TN 37831 
ES/ESH-36

KY/E-164

\title{
PADUCAH GASEOUS DIFFUSION PLANT ENVIRONMENTAL REPORT FOR 1992
}

\author{
Project director \\ F. C. Kornegay \\ Project coordinator \\ D. C. West \\ Technical coordinator \\ W. D. Malis \\ Coordinating editor \\ C. M. Horak
}

Date Published: September 1993

Prepared by

Environmental, Safety, and Health Compliance

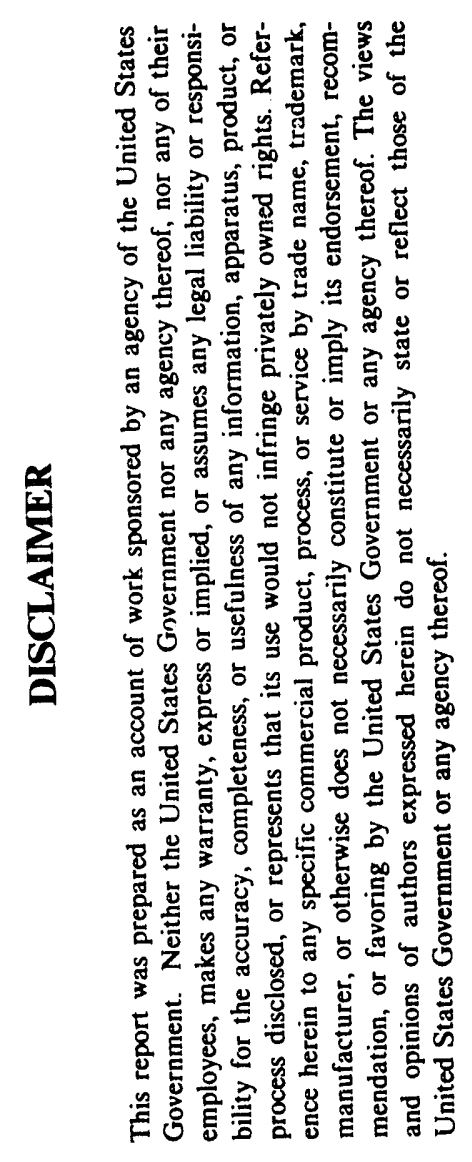
and Environmental Management Staffs

MARTIN MARIETTA ENERGY SYSTEMS, INC.

$$
\text { P.O. Box } 2008
$$

Oak Ridge, Tennessee 37831-6285

$$
\text { and the }
$$

Environmental Management Associate Division

Paducah Gaseous Diffusion Plant

MARTIN MARIETTA ENERGY SYSTEMS, INC.

$$
\text { P.O. Box } 1410
$$

Paducah, Kentucky 42.001

for the

U.S. DEPARTMENT OF ENERGY

under contract DE-AC05-76OR00001

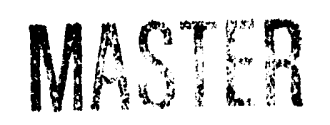




\section{Contents}

List of Figures $\ldots \ldots \ldots \ldots \ldots \ldots \ldots \ldots \ldots \ldots \ldots \ldots \ldots$

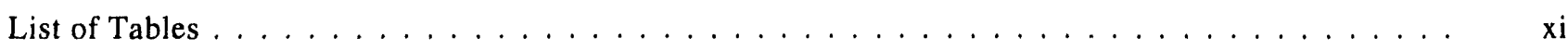

Executive Summary $\ldots \ldots \ldots \ldots \ldots \ldots \ldots \ldots \ldots \ldots \ldots \ldots$ xvii

Compliance Summary $\ldots \ldots \ldots \ldots \ldots \ldots \ldots \ldots \ldots \ldots \ldots \ldots \ldots \ldots$

Acronyms and Abbreviations $\ldots \ldots \ldots \ldots \ldots \ldots \ldots \ldots \ldots \ldots \ldots \ldots \ldots \ldots \ldots \ldots \ldots$

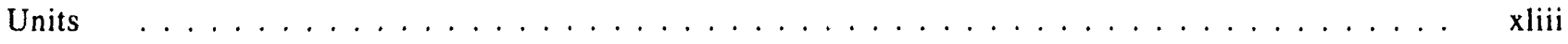

\section{Part 1: Narrative, Summaries, and Conclusions}

1. Site Description and Setting

1.1 Operations on the Paducah Gaseous Diffusion Plant (PGDP) Site . . . . . . . . . . . 1-3

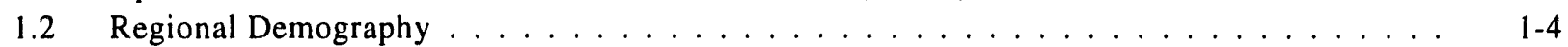

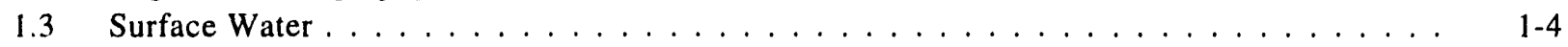

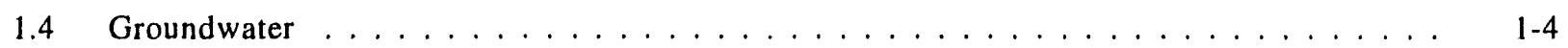

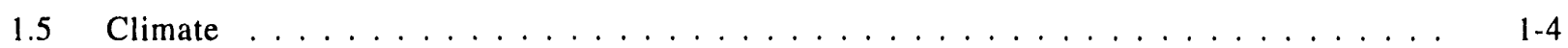

1.6 Applicable Environmental Requirements . . . . . . . . . . . . . . . . . 1-6

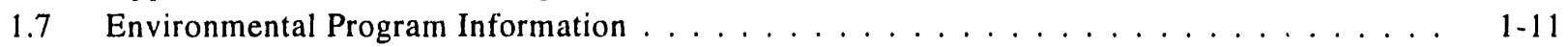

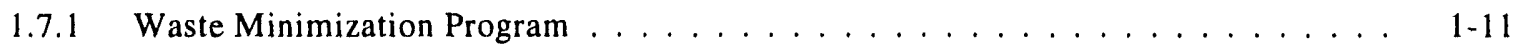

1.7 .21993 Program Plan . . . . . . . . . . . . . . . . . . . . $1-12$

1.7.3 Long-Term Program Strategy . . . . . . . . . . . . . . . . . . 1-13

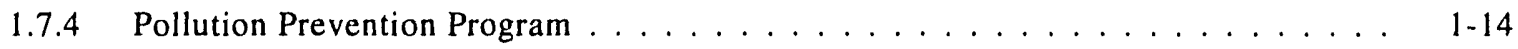

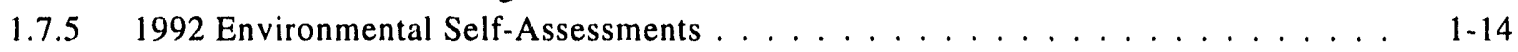

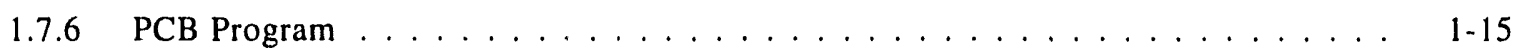

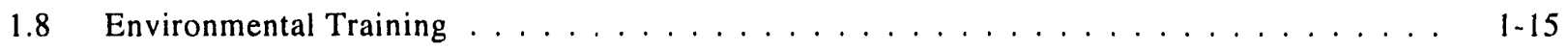

1.9 Reference .............................. 1-15

2. Potential Radiation Dose to the Public

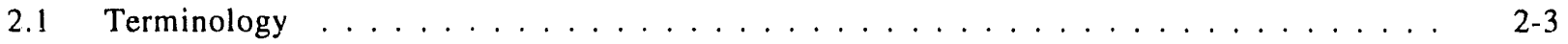

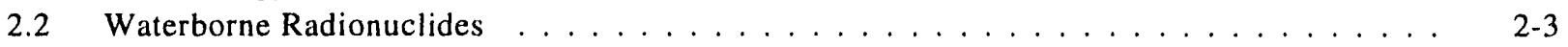

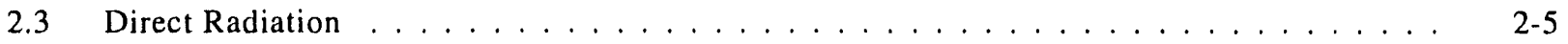




\section{Environmental Report-.Paducah}

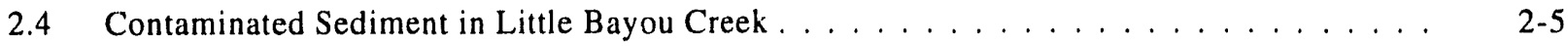

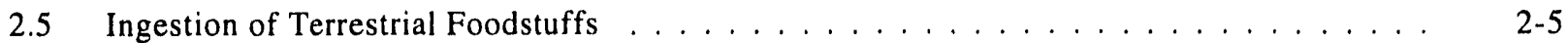

2.6 Airborne Radionuclides . . . . . . . . . . . . . . . . . . . . . . . . . . . . . 2-6

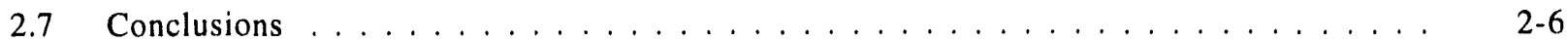

2.8 References . . . . . . . . . . . . . . . . . . . . . . . . . $2-6$

3. Airborne Discharges, Ambient Air Monitoring, Meteorological Monitoring, and External Gamma Radiation

3.1 Airborne Discharges . . . . . . . . . . . . . . . . . . . . . . . . . . . $3-4$

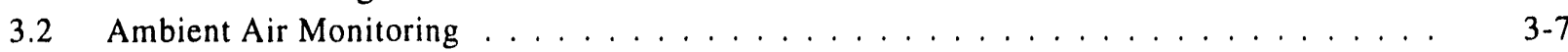

3.3 Meteorological Monitoring . . . . . . . . . . . . . . . . . . . . $3-9$

3.4 External Gamma Radiation Monitoring . . . . . . . . . . . . . . . . . . . . . 3-9

3.4.1 Thermoluminescent Dosimeter Sampling Program . . . . . . . . . . . . . . 3-9

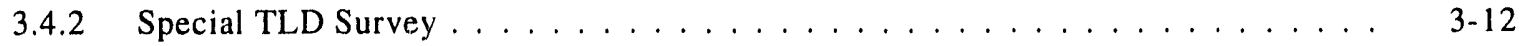

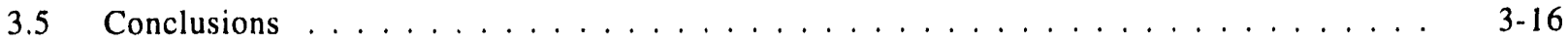

3.6 References . . . . . . . . . . . . . . . . . . . . . . . . 3-17

4. Surface Water

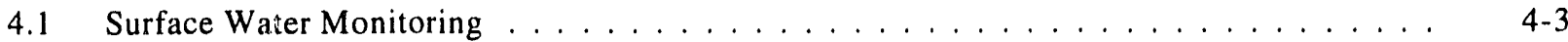

4.2 Kentucky Pollutant Discharge Elimination

System Monitoring . . . . . . . . . . . . . . . . . . . . . . . 4 4-7

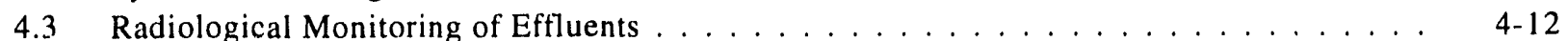

4.3.1 DOE Order 5400.5, "Radiological Sampling" . . . . . . . . . . . . . . 4-12

4.3.2 Agreement In Principle Activities-Off-Site and Effluent

Surface Water Sampling ... . . . . . . . . . . . . . . . . $4-12$

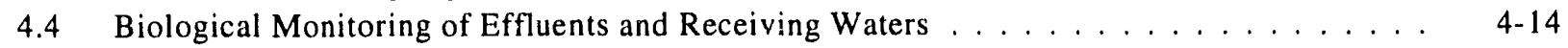

4.4 .1 Study Area . . . . . . . . . . . . . . . . . . . . 4 4-15

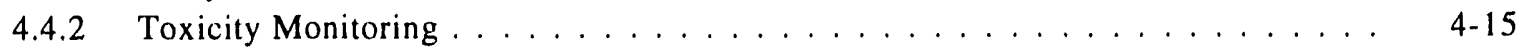

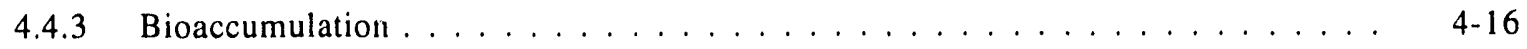

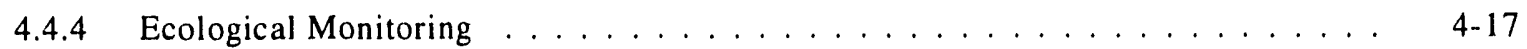

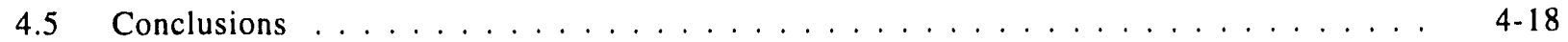

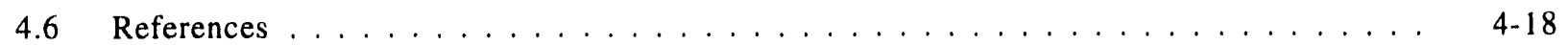

5. Groundwater

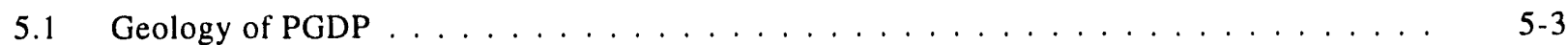

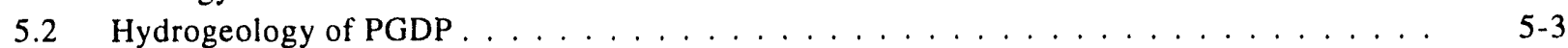

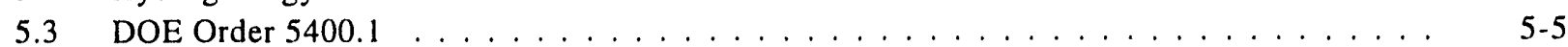

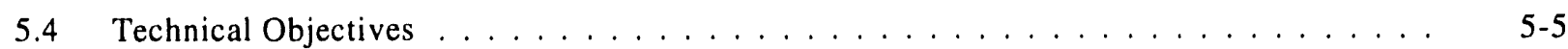

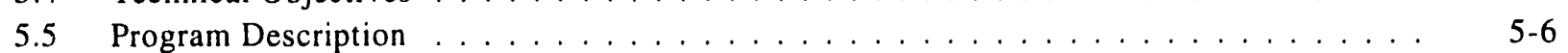

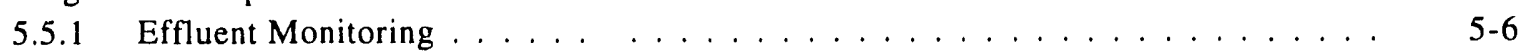

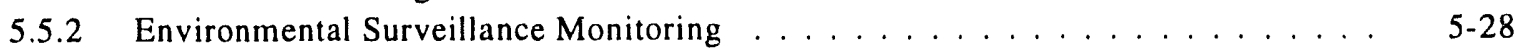

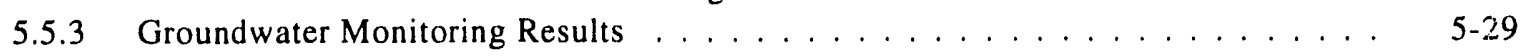

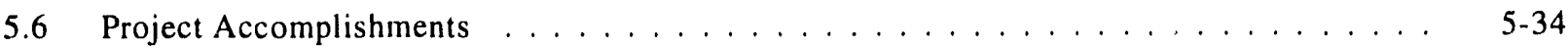

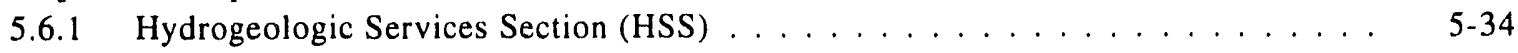

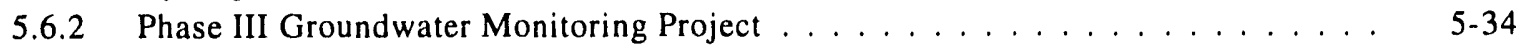

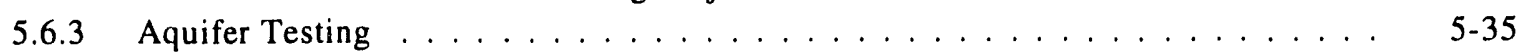

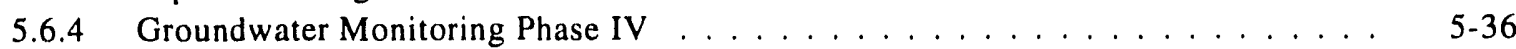

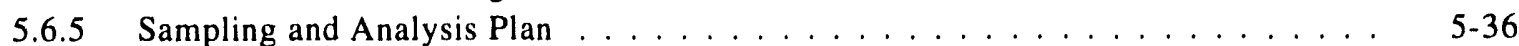




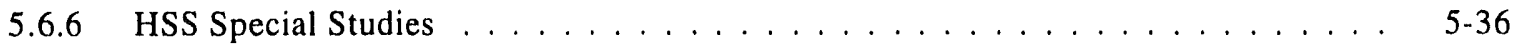

5.6 .7 Related Activities . . . . . . . . . . . . . . . . . . . . 5-36

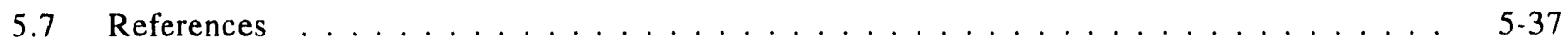

6. Biological Monitoring

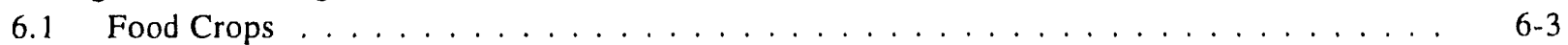

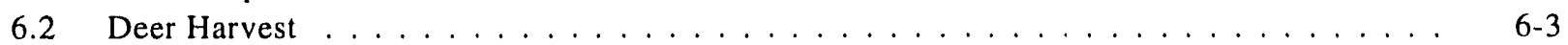

6.3 vegetation ............................ 6.6

7. Soil and Sediment Monitoring

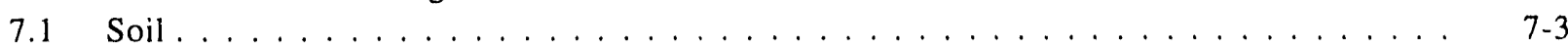

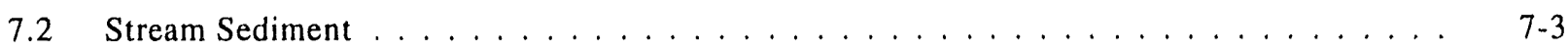

7.3 References ........................... 7.7

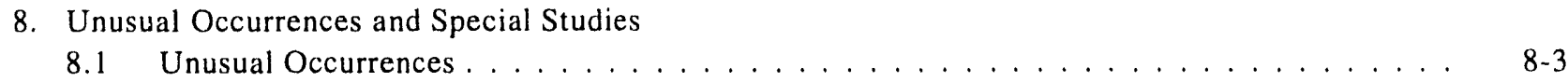

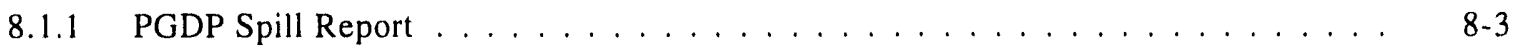

8.1 .2 Radionuclide Releases . . . . . . . . . . . . . . . . . . 8 8-6

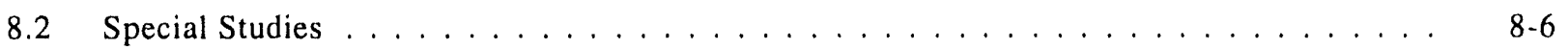

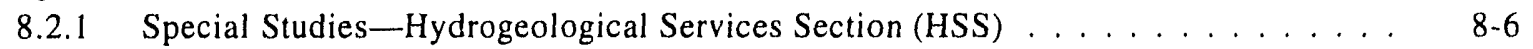

8.2 .2 Environmental Advisory Committee . . . . . . . . . . . . . . . . 8-8

8.2 .3 Neighborhood Council . . . . . . . . . . . . . . . . . . . . . . $8-9$

8.2 .4 Waste Minimization Program . . . . . . . . . . . . . . . . . . . 8.9

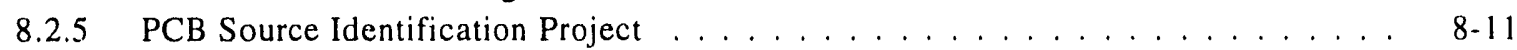

8.2.6 C-310 Purge and Product Building Stack Effluent Sampling Project . . . . . . . . 8-11

8.2.7 Clean Air Act Amendments of 1990 Activities . . . . . . . . . . . . . . . . 8-12

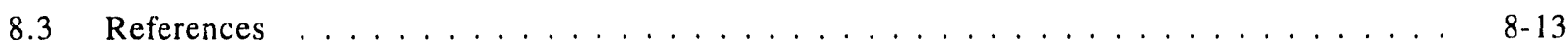

9. Solid Waste Management Program

9.1 Description . . . . . . . . . . . . . . . . . . . . . . 9-3

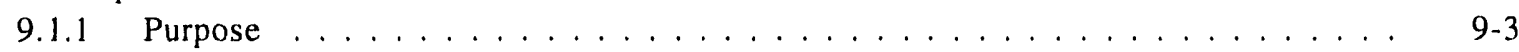

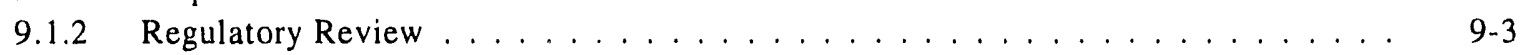

9.1 .3 Compliance Activities . . . . . . . . . . . . . . . . . . . 99

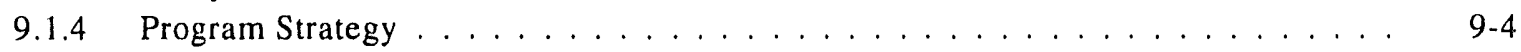

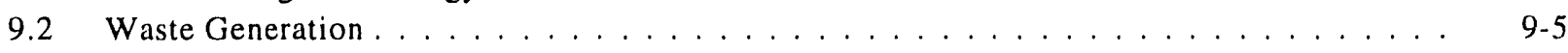

9.2.1 Types of Waste Generated . . . . . . . . . . . . . . . . . . . $9-5$

9.2 .2 Waste-Generating Activities . . . . . . . . . . . . . . . . . . $9-5$

9.2 .3 Waste Generation Summary . . . . . . . . . . . . . . . . . . $9-6$

9.3 Waste Management Activities . . . . . . . . . . . . . . . . . . . . . . $9-6$

9.3.1 Waste Management System . . . . . . . . . . . . . . . . . . $9-6$

9.3.2 Waste Management Facilities . . . . . . . . . . . . . . . . . . . . . . 9-7

9.3 .3 Off-Site Waste Disposal Activities . . . . . . . . . . . . . . . . . . . . . . . 9-9

9.3 .4 Waste Placed in Storage . . . . . . . . . . . . . . . . . . . . . . . . . 9 9-9

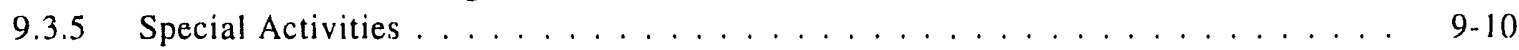

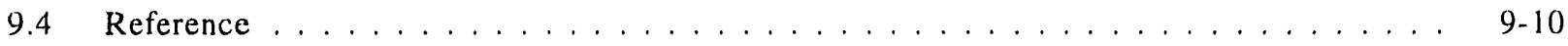

10. Quality Assurance

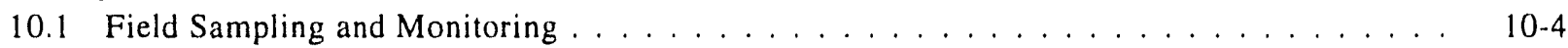

10.1.1 Basic Concepts and Practices . . . . . . . . . . . . . . . . 10-4 


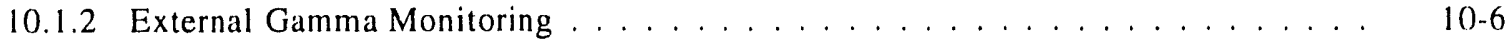

10.1.3 Air Monitoring . . . . . . . . . . . . . . . . . . . . . . . . . . . . 10-6

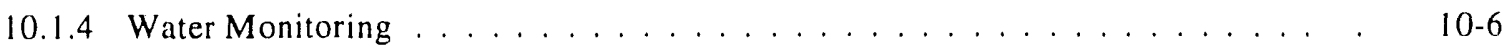

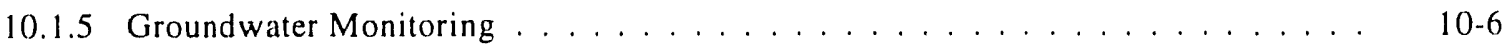

10.1 .6 Biological Monitoring . . . . . . . . . . . . . . . . . . . . . . . 10-6

10.1.7 Soil and Sediment Sampling . . . . . . . . . . . . . . . . . . 10-7

10.1.8 Solid Waste Monitoring, Site Characterizations, and Spill Cleanup . . . . . . . . 10-7

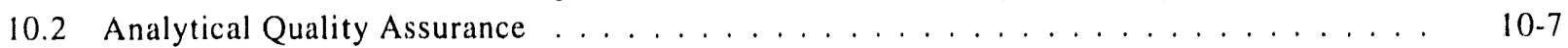

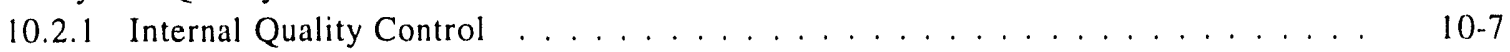

10.2.2 External Quality Control . . . . . . . . . . . . . . . . . . 10-8

10.2.3 Independent Quality Control . . . . . . . . . . . . . . . . . 10-8

10.3 Quality Incidents . . . . . . . . . . . . . . . . . . . . . . 10-9

10.3.1 Environmental Protection Agency Discharge Monitoring Report

Quality Assurance Program . . . . . . . . . . . . . . . . . 10-9 1

10.3.2 Proficiency Environmental Testing Program . . . . . . . . . . . . . . . 10-9

10.3.3 Proficiency Analytical Testing Program ... . . . . . . . . . . . 10-10

10.3.4 Environmental Measurements Laboratory Program . . . . . . . . . . . . . 10-10

10.3.5 Environmental Measurements Systems Laboratory-Las Vegas Program . . . . . 10-10

10.4 Documentation Quality Assurance . . . . . . . . . . . . . . . . . . 10-10

10.5 References . . . . . . . . . . . . . . . . . . . . . . . 10-11

Part 2: Data presentation

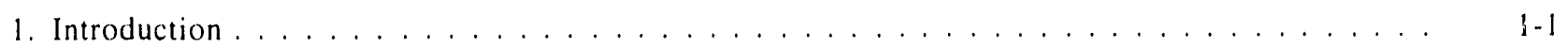

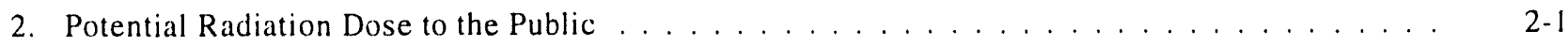

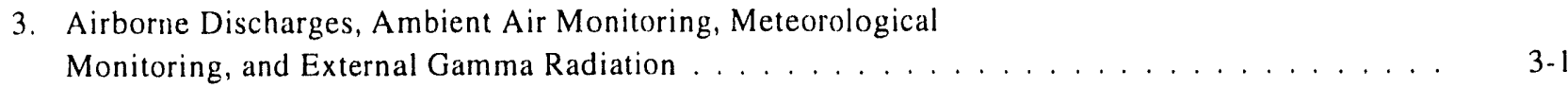

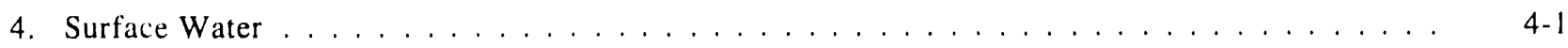

5. Groundwater $\ldots \ldots \ldots \ldots \ldots \ldots \ldots \ldots \ldots \ldots \ldots \ldots \ldots \ldots \ldots \ldots$

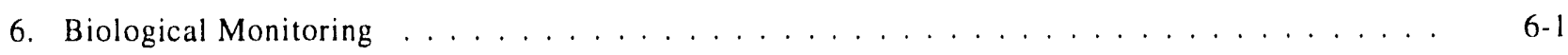

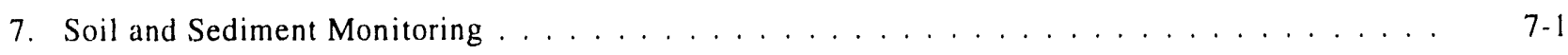

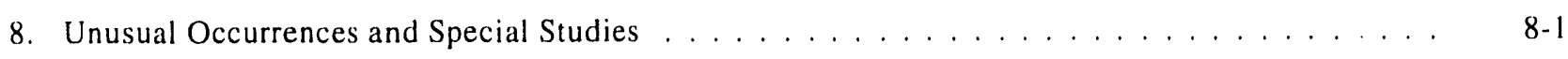

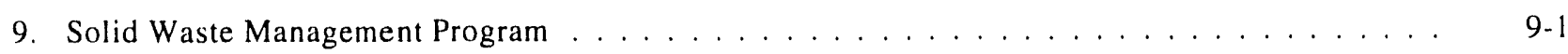

10. Quality Assurance . . . . . . . . . . . . . . . . . . . 10-1

Appendix A: Paducah Gaseous Diffusion Plant Chemical Release Data . . . . . . . . . . . . A A

Appendix B: Errata for the Paducah Gaseous Difjusion Plant Environmental Report for 1991 _. . . . B-I 


\section{List of Figures}

Figure

Page

\section{Part 1: Narrative, Summaries, and Conclusions}

1 Millicuries of uranium released to the atmosphere from PGDP operations, 1988-1992 . . . . xix

2 Millicuries of technetium released to the atmosphere from PGDP operations, 1988-1992 _ . . xix

3 Uranium concentrations in PGDP liquid effluents in 1992 (percentage of derived

concentration guide $) \ldots \ldots \ldots \ldots \ldots \ldots \ldots \ldots \ldots \ldots \ldots$

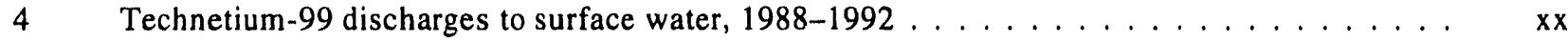

1.1 Map showing the location of the U.S. DOE's Paducah Reservation in Kentucky . . . . . . . 1-5

1.2 Map showing the location of PGDP in relationship to the geographic region $\ldots \ldots \ldots$

1.3 Population distribution projected to 1992 in a $16-\mathrm{km}(10-$ mile) radius of PGDP $\ldots \ldots \ldots$

1.4 Population density projected to 1992 in a $16-\mathrm{km}(10$-mile) radius of PGDP . . . . . . . $1-7$

1.5 Population distribution projected to 1992 in an $80-\mathrm{km}(50$-mile) radius of PGDP $\ldots \ldots$. . . $1-8$

1.6 Population density projected to 1992 in an $80-\mathrm{km}(50$-mile) radius of PGDP $\ldots \ldots \ldots$

1.7 Local PGDP surface hydrology systems $\ldots \ldots \ldots \ldots \ldots \ldots \ldots$

1.8 The regional area primary surface hydrology system $\ldots \ldots \ldots \ldots \ldots \ldots \ldots$

2.1 Pathways between radioactive material released to the atmosphere and to individuals . . . . 2 2-4

2.2 Pathways between radioactive material released to the groundwater and to individuals $\ldots \ldots .2-4$

3.1 Location of major air emissions sources at PGDP $\ldots \ldots \ldots \ldots \ldots \ldots$

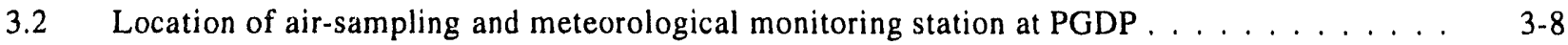




\section{Environmental Report-Paducah}

3.3 Wind rose (10-m level) showing the wind speed frequency distribution data (with $93.1 \%$ of possible data) used for the 1992 estimates

3.4 Wind rose (60-m level) showing the wind speed frequency distribution data (with $93.1 \%$ of possible data) used for the 1992 estimates $\ldots \ldots \ldots \ldots \ldots \ldots \ldots$

3.5 Thermoluminescent dosimeter locations at PGDP $\ldots \ldots \ldots \ldots \ldots \ldots$

3.6 Quality control thermoluminescent dosimeter locations at PGDP $\ldots \ldots \ldots \ldots \ldots$

3.7 PGDP external gamma radiation, 1988-1992

$4.1 \quad$ PGDP site surface hydrology systems $\ldots \ldots \ldots \ldots \ldots \ldots \ldots \ldots \ldots \ldots \ldots$

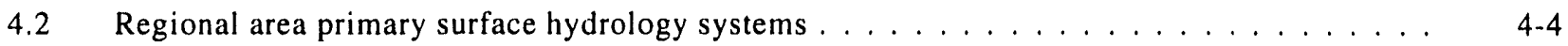

4.3 Surface water monitoring locations at PGDP $\ldots \ldots \ldots \ldots \ldots$

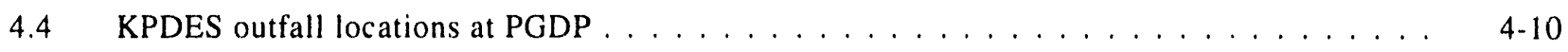

4.5 Kentucky Pollutant Discharge Elimination System noncompliances: $1990-1992 \ldots \ldots$. . . . 48

5.1 Schematic north-south section showing regional stratigraphic relationships at PDGP

(from Phase III Groundwater Investigation) $\ldots \ldots \ldots \ldots \ldots \ldots \ldots \ldots \ldots$

5.2 Wells sampled by PGDP in 1992 (by sectors) $\ldots \ldots \ldots \ldots \ldots \ldots$

5.3 Northwestern sector-wells sampled by PGDP during $1992 \ldots \ldots \ldots \ldots$

5.4 Northeastern sector-wells sampled by PGDP during $1992 \ldots \ldots \ldots \ldots$

5.5 Western sector-wells sampled by PGDP during $1992 \ldots \ldots \ldots \ldots \ldots \ldots$

5.6 Eastern sector-wells sampled by PGDP during $1992 \ldots \ldots \ldots \ldots \ldots \ldots \ldots$

5.7 Southwestern sector-wells sampled by PGDP during $1992 \ldots \ldots \ldots \ldots \ldots \ldots$

5.8 Southeastern sector-wells sampled by PGDP during $1992 \ldots \ldots \ldots \ldots \ldots \ldots$

5.9 Plant site-wells sampled by PGDP during $1992 \ldots \ldots \ldots \ldots \ldots \ldots \ldots$

5.10 Approximate locations of groundwater sampling wells around the $\mathrm{C}-404$ area $\ldots \ldots$ 5-16

5.11 UST investigation monitoring well locations (from CDM Federal Programs

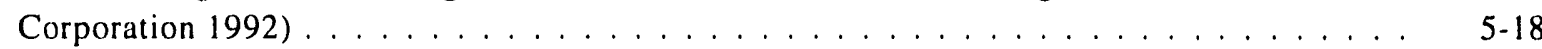

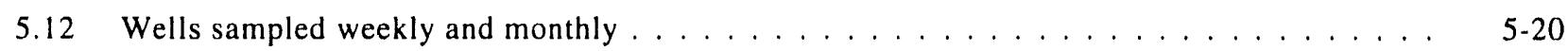

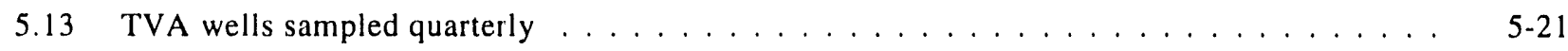


5.14 Residential and TVA groundwater sampling locations where ${ }^{99} \mathrm{Tc}$ and/or TCE were detected . . . . . . . . . . . . . . . . . . . . . . . . . 5-22

5.15 Concentration of TCE from July 1988 to December 1992 in MW66 . . . . . . . . . . . 5-30

5.16 Concentration of ${ }^{19} \mathrm{Tc}$ from July 1988 to December 1992 in MW66 . . . . . . . . . . . 5-30

5.17 Concentrtion of TCE and ${ }^{99} \mathrm{Tc}$ from July 1988 to December 1992 in MW66 ........ . . . .

5.18 Concentration of benzene, toluene, ethyl benzene, and xylene from August 1989 to November 1992 in MW96 . . . . . . . . . . . . . . . . . . . . . . . . . . 5-33

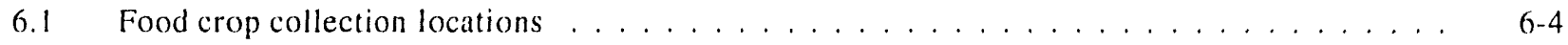

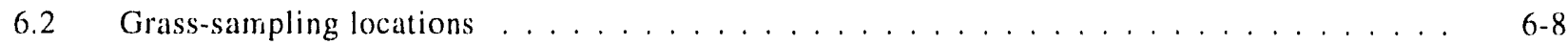

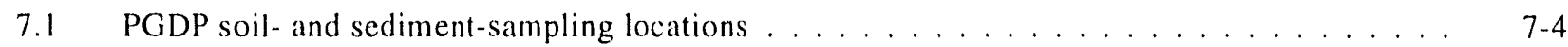

7.2 Routes of trace metals in an aquatic ecosystem . . . . . . . . . . . . . . .

8.1 Spills or releases at PGDP in $1992 \ldots \ldots \ldots$

10.1 Environmental Monitoring Department organization chart ...............10-5 


\section{List of Tables}

Table

Page

Part 1: Narrative, Summaries, and Conclusions

1992 Paducah Gaseous Diffusion Plant permit summary $\ldots \ldots \ldots \ldots$ xxiv

1.1 Environmental Department of Energy (DOE) order compliance status . . . . . . . . . . . 1-11

2.1 Summary of annual dose from radiological contaminants $\ldots \ldots \ldots \ldots \ldots$

1992 PGDP stack emissions summary $\ldots \ldots \ldots \ldots \ldots \ldots \ldots \ldots$

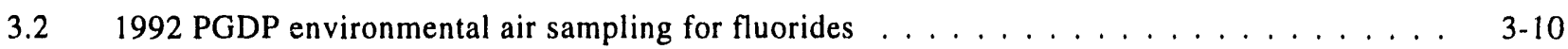

3.3 1992 PGDP environmental air sampling for radioactivity $\ldots \ldots \ldots \ldots \ldots$

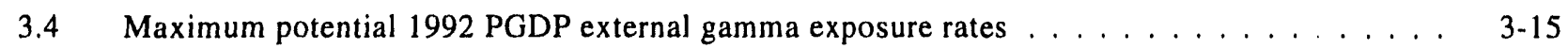

3.51992 quality control data for PGDP external gamma exposure $\ldots \ldots \ldots \ldots \ldots$

4.1 Summary of collection and analysis frequencies of surface water samples in $1992 \ldots \ldots$. . . . .

4.2 Kentucky Pollutant Discharge Elimination System outfalls at PGDP . . . . . . . . . . . . 4-9

4.3 Compliance experience under interim Kentucky Pollutant Discharge Elimination

System (KPDES) limits for $1992 \ldots \ldots \ldots \ldots \ldots \ldots \ldots \ldots \ldots \ldots$

4.41992 state surface water measurements $\ldots \ldots \ldots \ldots \ldots \ldots \ldots \ldots \ldots \ldots$

5.1 Comparison of general characteristics of groundwater effluent and groundwater

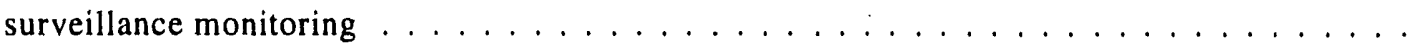

5.2 Resource Conservation and Recovery Act monitoring wells at the C-404 area . . . . . . 5 5-17

5.3 Wells included in the CERCLA/ACO well monitoring program $\ldots \ldots \ldots \ldots$

5.4 Quarterly analytical parameters for groundwater monitoring at PGDP . . . . . . . . 5-25 


\section{Environmental Report-Paducah}

5.5 Annual analytical parameters for groundwater monitoring at PGDP $\ldots \ldots \ldots \ldots$

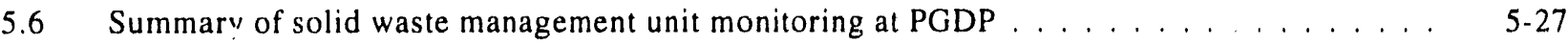

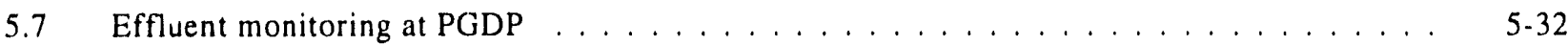

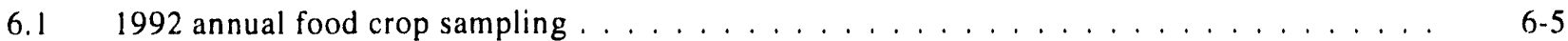

6.21992 annual deer harvest - muscle analysis $\ldots \ldots \ldots \ldots \ldots \ldots$

6.31992 annual deer harvest-liver analysis $\ldots \ldots \ldots \ldots \ldots \ldots \ldots$

6.4 PGDP fluoride in grass for 1992 (dry weight) $\ldots \ldots \ldots \ldots \ldots \ldots \ldots$

7.1 Summary of collection and analysis frequencies of soil and sediment

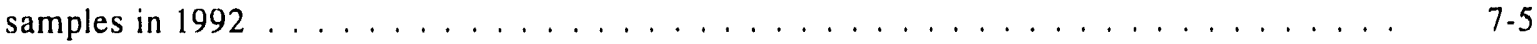

7.2 Concentrations of uranium in soil at PGDP, $1987-1992 \ldots \ldots \ldots \ldots \ldots$

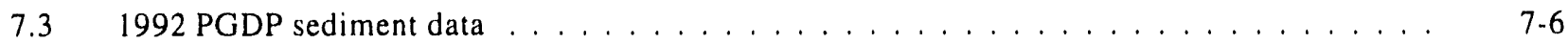

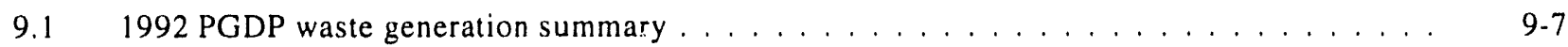

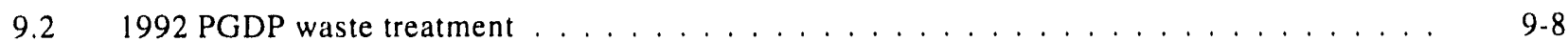

9.31992 PGDP on-site waste disposal $\ldots \ldots \ldots \ldots \ldots \ldots \ldots \ldots \ldots \ldots$

9.41992 PGDP off-site waste disposal $\ldots \ldots \ldots \ldots \ldots \ldots \ldots \ldots \ldots$

\section{Part 2: Data Presentation}

2.11992 annual dose estimation-worst-case ingestion of groundwater $\ldots \ldots \ldots$

2.2 1992 annual dose estimation-worst-case incidental ingestion of sediment in Little Bayou Creek . . . . . . . . . . . . . . . . . . . . . . . . . . . . . . . . . 2-3

$2.3 \quad 1992$ annual dose estimation -worst-case ingestion of deer tissue $\ldots \ldots \ldots \ldots$

2.41992 annual dose estimation-worst-case ingestion of food crops $\ldots \ldots \ldots \ldots$

2.51992 annual dose estimation-worst-case direct radiation in K011 effluent ditch . . . . . $2-5$

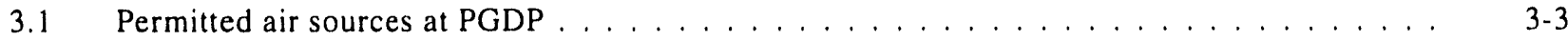

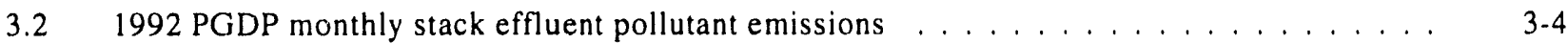

3.31992 PGDP annual stack effluent pollutant emissions $\ldots \ldots \ldots \ldots \ldots$ 
3.4 Comparison of selected actual emissions and limits/standards $\ldots \ldots \ldots \ldots \ldots$

4.1 Interim limitations for Agreed Order-Paducah Gaseous Diffusion Plant $\ldots \ldots \ldots$

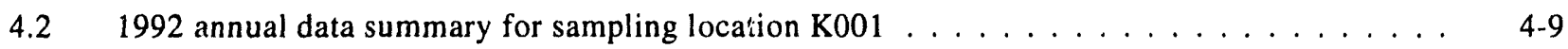

4.31992 annual data summary for sampling location $\mathrm{K} 002 \ldots \ldots \ldots \ldots$

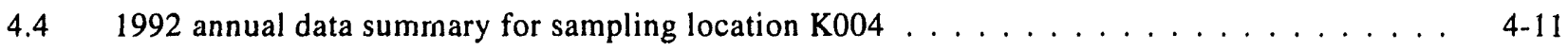

4.51992 annual data summary for sampling location $\mathrm{K} 006 \ldots \ldots \ldots \ldots \ldots \ldots$

4.61992 annual data summary for sampling location $\mathrm{K} 008 \ldots \ldots \ldots \ldots \ldots \ldots$

4.71992 annual data summary for sampling location $\mathrm{K} 009 \ldots \ldots \ldots \ldots \ldots$

4.81992 annual data summary for sampling location $\mathrm{K} 010 \ldots \ldots \ldots \ldots \ldots \ldots$

$4.9 \quad 1992$ annual data summary for sampling location $\mathrm{K} 011 \ldots \ldots \ldots \ldots \ldots$

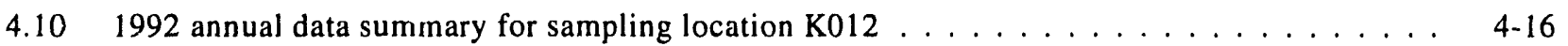

4.111992 annual data summary for sampling location $\mathrm{K} 013 \ldots \ldots \ldots \ldots \ldots$

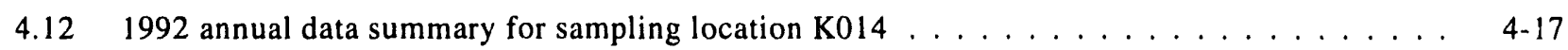

4.131992 annual data summary for sampling location $\mathrm{K} 015 \ldots \ldots \ldots \ldots$

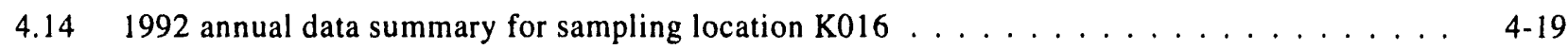

4.151992 annual data summary for sampling location $\mathrm{K} 017 \ldots \ldots \ldots \ldots$

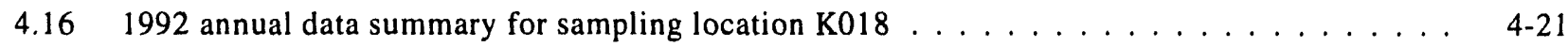

4.171992 annual data summary for sampling location $\mathrm{SW} 1 \ldots \ldots \ldots \ldots$

4.181992 annual data summary for sampling location $\mathrm{sW} 5 \ldots \ldots \ldots \ldots \ldots \ldots$

4.191992 annual data summary for sampling location $\mathrm{SW} 10 \ldots \ldots \ldots \ldots \ldots$

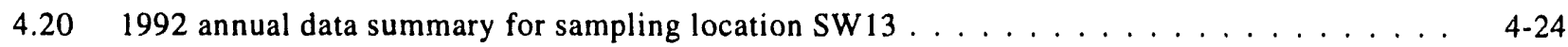

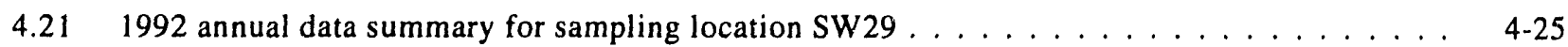

4.221992 annual data summary for sampling location $\mathrm{SW} 30 \ldots \ldots \ldots \ldots \ldots \ldots$

4.231992 annual data summary for sampling location $\mathrm{SW} 45 \ldots \ldots \ldots \ldots \ldots$

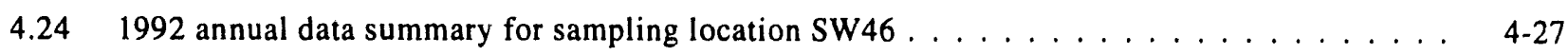




\section{Environmental Report-Paducah}

4.251992 radionuclide concentrations in effluents $\ldots \ldots \ldots \ldots \ldots \ldots \ldots \ldots \ldots \ldots$

4.261992 radionuclide concentrations in water $\ldots \ldots \ldots \ldots \ldots \ldots \ldots \ldots \ldots$

4.271992 Paducah Gaseous Diffusion Plant major discharges to surface waters $\ldots \ldots \ldots$. . . . $4-28$

4.28 1992 Paducah Gaseous Diffusion Plant (PGDP) state Cabinet of Human Resources (CHR) radiochemical data comparison for surface water . . . . . . . 4 4-29

5.1 Results of 1992 quarterly C-404 Resource Conservation and Recovery Act

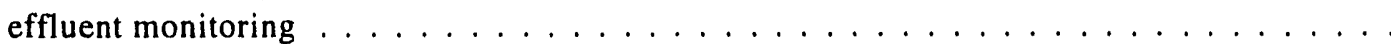

5.2 Results of 1992 effluent monitoring at underground storage tanks $\ldots \ldots \ldots \ldots$

5.3 Results of 1992 semiannual and annual environmental surveillance monitoring $\ldots \ldots \ldots$. . . . 5 - 10

5.4 Results of 1992 weekly, monthly, bimonthly, semiannual, and annual ACO/CERCLA

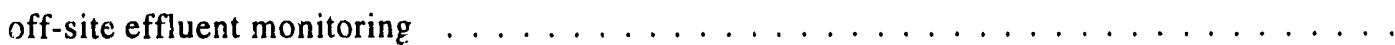

5.5 Results of 1992 quarterly, semiannual, and annual effluent monitoring at solid waste management units . . . . . . . . . . . . . . . . . . . . . .

5.6 Results of 1992 quarterly, semiannual, and annual effluent monitoring of organic and inorganic parameters at solid waste management units . . . . . . . . . . . . . .

5.7 Results of 1992 quarterly, semiannual, and annual effluent monitoring of metals at solid waste management units $\ldots \ldots \ldots \ldots \ldots \ldots \ldots$

5.8 Results of 1992 quarterly, semiannual, and annual effluent monitoring of radionuclides at solidwaste management units $\ldots \ldots \ldots \ldots \ldots \ldots \ldots$

5.9 Results of 1992 quarterly, semiannual, and annual effluent monitoring at solid waste management units . . . . . . . . . . . . . . . . . . . .

5.10 Results of 1992 Phase III groundwater monitoring $\ldots \ldots \ldots \ldots \ldots \ldots$

5.11 Results of 1992 Paducah Gaseous Diffusion Plant (PGDP) state Cabinet of Human Resources (CHR) radiochemical data comparison for groundwater . . . . . . . . . . . . .

10.1 PGDP environmental analysis procedures for air $\ldots \ldots \ldots \ldots \ldots \ldots$

10.2 PGDP environmental analysis procedures for water $\ldots \ldots \ldots \ldots \ldots$

10.3 PGDP atomic absorption and inductively coupled plasma environmental analysis procedures for water (lowest conceneration reported)

10.4 PGDP environmental analysis procedures for biota $\ldots \ldots \ldots \ldots \ldots$

10.5 PGDP environmental analysis procedures for soil and sediment $\ldots \ldots \ldots \ldots \ldots \ldots$ 
10.6 PGDP analysis procedures for off-site well waters $\ldots \ldots \ldots \ldots \ldots$

10.7 PGDP analysis procedures for field measurements $\ldots \ldots \ldots \ldots \ldots$

10.8 PGDP internal measurement control program laboratory control data (inorganic) $\ldots \ldots$. . .

10.9 PGDP internal measurement control program laboratory control data (organic) $\ldots \ldots$. . . . 10-9

10.10 U.S. Environmental Protection Agency (EPA) Performance Evaluation Discharge Monitoring Report-Quality Assurance Study Number 012 for the Paducah

Gaseous Diffusion Plant, January $1992 \ldots \ldots$. . . . . . . . . . . . . . . . . 10

10.11 January 1992 Analytical Products Group, Inc., Proficiency Environmental

Testing Program

10.12 March 1992 Analytical Products Group, Inc., Proficiency Environmental

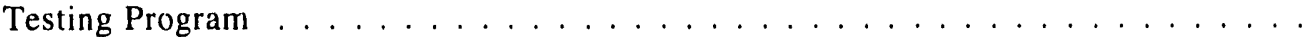

10.13 May 1992 Analytical Products Group, Inc., Proficiency Environmenta!

Testing Program $\ldots \ldots \ldots \ldots \ldots \ldots \ldots \ldots$

10.14 July 1992 Analytical Products Group, Inc., Proficiency Environmental

Testing Program . . . . . . . . . . . . . . . . . . . . . 10-20

10.15 September 1992 Analytical Products Group, Inc., Proficiency Environmental

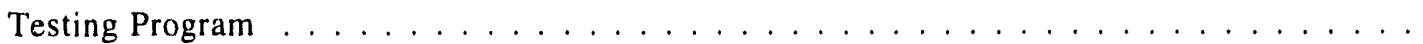

10.16 November 1992 Analytical Products Group, Inc., Proficiency Environmental

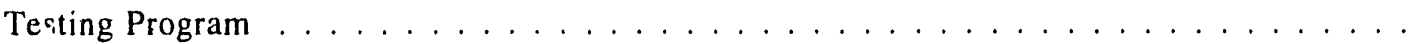

10.17 January 1992 National Institute for Occupational Safety and Health (NIOSH) Proficiency

Analytical Testing (PAT) Program . . . . . . . . . . . . . . . . . . .

10.18 April 1992 National Institute for Occupational Safety and Health (NIOSH) Proficiency Analytical Testing (PAT) Program . . . . . . . . . . . . . . . . . . . . .

10.19 July 1992 National Institute for Occupational Safety and Health (NIOSH) Proficiency Analytical Testing (PAT) Program . . . . . . . . . . . . . . . . . . . . . . . . . . . .

10.20 October 1992 National Institute for Occupational Safety and Health (NIOSH) Proficiency Analytical Testing (PAT) Program

10.21 March 1992 Environmental Measurements Laboratory (EML) Semiannual Report of the Department of Energy Operational Safety, Health, and Environment Division Quality Assessment Program

10.22 September 1992 Environmental Measurements Laboratory (EML) Semiannual Report of the Department of Energy Operational Safety, Health, and Environment Division Quality Assessment Program 


\section{Environmental Report-Paducah}

10.231992 Environmental Measurements Systems Laboratory-Las Vegas (EMSL-LV)

Intercomparison Study . . . . . . . . . . . . . . . . . . . . 10-33

Appendix A: Paducah Gaseous Diffusion Plant 1992 chemical release information . . . . . . . . . . A A-4 


\section{Executive Summary}

\section{Scope and Purpose}

This two-part report, Paducah Gaseous Diffusion Plant Environmental Report for 1992, is published annually. It reflects the results of an environmental monitoring program designed to quantify potential increases in the concentration of contaminants and potential doses to the resident human population.

The Paducah Gaseous Diffusion Plant (PGDP) overall goal for environmental management is to protect the environment and PGDP's neighbors and to maintain full compliance with all current regulations. The current environmental strategy is to identify any deficiencies and to develop a system to resolve them. The long-range goal of environmental management is to minimize the source of pollutants, reduce the generation of waste, and minimize hazardous waste by substitution of materials.

\section{Monitoring Networks}

Environmental-monitoring systems at PGDP include emission-monitoring networks for airborne and aqueous discharges, groundwater monitoring, solid waste characterization, and environmental surveillance networks for air, surface water, groundwater, vegetation, food crops, fish, wildlife, soil, and surface stream sediments.

Effluent and waste monitoring includer

- regular laboratory analysis of delivered coal and a sulfur dioxide $\left(\mathrm{SO}_{2}\right)$ monitor on steam plant stacks;

- a network of 20 sampling locations for monitoring plant wastewater prior to discharge;
- a sampling program for identification and characterization of solid waste streams generated by plant operations;

- an ongoing sampling program of stored wastes and sludges to characterize these materials in support of Resource Conservation and Recovery Act (RCRA) and Comprehensive Environmental Response, Compensation, and Liability Act (CERCLA) activities;

- 73 PGDP groundwater-monitoring wells and 57 residential wells; and

- C-310 stack sampling for radionuclide and fluoride emissions.

Environmental Surveillance networks include

- 12 air-sampling stations (4 fence-line and 8 off-site),

- 5 surface water-sampling locations,

- 18 vegetation-sampling locations (4 fence-line and 14 off-site),

- fish samples from several locations on Big and Little Bayou creeks,

- 10 soil-sampling locations [4 fence-line, 4 that are $8 \mathrm{~km}$ (5 miles) from PGDP, and 2 that are 13 to $15 \mathrm{~km}$ (8 to 9 miles) from PGDP],

- 6 stream-sediment-sampling locations,

- 15 gamma-radiation-monitoring locations (4 fence-line and 11 off-site),

- a Biological Monitoring Program with several monitoring locations, and

- 2 groundwater-monitoring wells and 18 residential wells.

The results of analyses and investigations are presented in this report, and the major findings are summarized in the following subsections. 


\section{External Gamma Radiation}

Ambient gamma radiation levels are monitored with thermoluminescent dosimeters (TLDs) at 15 locations surrounding PGDP. The mean exposure rate, as measured by the TLDs, for indicator locations at or beyond the reservation boundary is $\sim 50 \mathrm{mrem} / y e a r$. The average background exposure in Kentucky is 60-70 mrem/year. In 1992, there was a significantly lower difference between means observed between indicator and background exposure rates at the $95 \%$ confidence level. Because the levels of gamma radiation cannot be distinguished from background, quantifiable measurements using TLDs are difficult to obtain.

In addition to routine TLD monitoring, a special long-term radiation assessment was performed in 1991 on the off-site portions of the plant drainage system, which had previously shown elevated levels of rar!ioactive contamination. TLDs were placed in the field for 92 to 107 days. Dose rates on Little Bayou Creek ranged from background levels to approximately twice background.

\section{Airborne Discharges and Meteorological Monitoring}

PGDP has 27 air pollution emission sources that are listed on the Kentucky Division for Air Quality (KDAQ) operating permit. Air pollution control equipment used at PGDP includes venturi scrubbers, water sprays, electrostatic precipitators, filters, and chemical traps (i.e., sodium fluoride $(\mathrm{NaF})$ and aluminum oxide $\left.\left(\mathrm{Al}_{2} \mathrm{O}_{3}\right)\right]$.

The C- 600 steam plant is the primary source of conventional pollutants. Emissions are controlled through the use of electrostatic precipitators on units 2 and 3 operating with a collection efficiency of $-97 \%$, based on stack test data and emission information from the KDAQ. Unit 1 may be operated with natural gas or fuel oil. Units 2 and 3 may be operated with coal or fuel oil. Fugitive emissions from coal and ash handling are controlled with water sprays.

Radioactive air emission estimates are now required from all sources because of the National Emission Standards for Hazardous Air Pollutants regulation and the Federal Facilities Compliance Agreement between PGDP and the U.S.
Environmental Protection Agency (EPA). All emissions are now included in the 1992 report, both measured and estimated. Previous reports included emissions from only the C-310 purge and product building stack. During 1992, measurements and estimates showed that $1.42 \mathrm{~kg}(2.11 \mathrm{mCi})$ of uranium were released to the atmosphere from all activities at PGDP. Seventy-three percent of this increase came from estimates of releases from the C- 400 decontamination building. Additional information regarding these changes in reporting can be found in Part 1, Sect. 3.5. Even though trend data are not comparable to previous years' reports, the data are shown in Fig. 1. Also, $12.3 \mathrm{mg}(0.206 \mathrm{mCi})$ of technetium were estimated and measured in all sources of PGDP emissions. No new introductions of technetium-99 ( $\left.{ }^{9 y} \mathrm{Tc}\right)$ to the cascade have occurred. The 1992 data are down from the $3.06 \mathrm{mCi}$ released in 1991, even though other sources are included because the C-310 stack is the major source of ${ }^{49} \mathrm{Tc}$ emissions. Trend data are shown in Fig. 2. Air dispersion modeling performed for PGDP by Oak Ridge National Laboratory (ORNL) indicates that the 50-year committed effective dose equivalent for the most affected resident from all sources is $0.0045 \mathrm{mrem}$. This dose is small $(2,222$ times less $)$ compared to the EPA standard of $10 \mathrm{mrem}$. The population collective effective dose equivalent (50-mile radius) in 1992 was 0.0017 person-rem from PGDP operations, estimated from air emission data.

Air dispersion modeling is the accepted way of predicting the impact on air quality from a source. To provide accurate meteorological data, a meteorological tower was installed at PGDP using data transferred to a computer. Wind and other meteorological parameters were monitored to provide data for dose calculations for the 1992 report.

PGDP operates 12 ambient air samplers surrounding the plant to monitor concentrations of fluorides and radioactive particulates. All fluoride concentrations measured in 1992 were well below Kentucky air quality standards.

\section{Waterborne Discharges and Surface Water Monitoring}

The Clean Water Act is administered for PGDP by the Kentucky Division of Water (KDOW) through the Kentucky Pollutant Discharge Elimination 


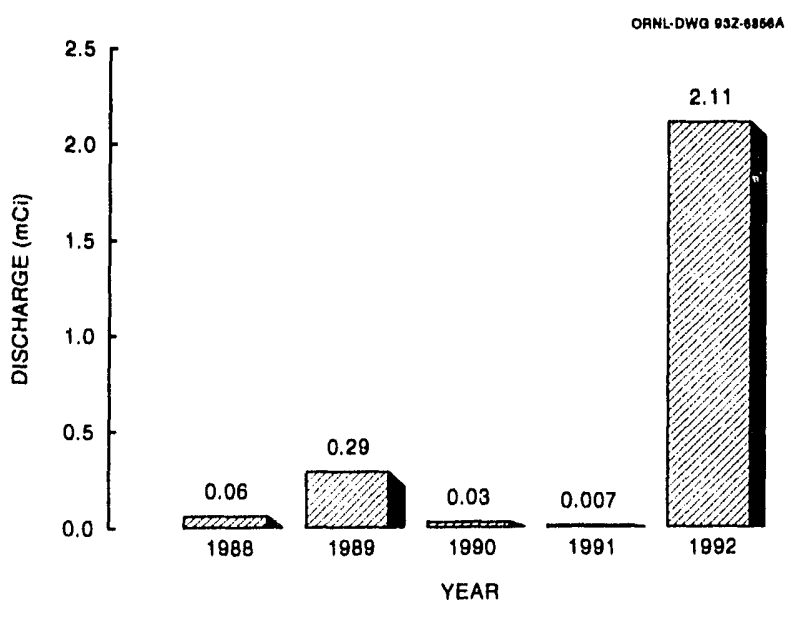

Fig. 1. Millicuries of uranium released to the atmosphere from PGDP operations, 1988-1992.

System (KPDES) permitting program. A KPDES permit and Agreed Order allow PGDP to discharge effluents into Big and Little Bayou crecks. During 1992, PGDP experienced a compliance rate on limit exceedances of $99.5 \%$ with the KPDES Agreed Order limits. The 1991 compliance rate was also $99.5 \%$.

The number of noncompliances with limits dropped from 33 in 1990 to 24 in 1991 and to 10 in 1992. Parameters intermittently not in compliance include total residual chlorine, $\mathrm{pH}$, total suspended solids, and trichloroethylene.

Sodium thiosulfate feed stations have caused the number of total residual chlorine noncompliances to decrease from 12 in 1990 to 1 in 1991 and 1992. Erosion control devices, such as silt fences, hay bales, and filter fabric, have been installed at construction sites. Improved oversight and erosion control devices have improved the control of total suspended solids. Studies have indicated that slightly elevated $\mathrm{pH}$ in PGDP effluents is not causing $\mathrm{pH}$ in the receiving streams to be elevated above water quality criteria.

Biological monitoring, a requirement of the Agreed Order, was conducted by the University of Kentucky in collaboration with ORNL. Planned and implemented by the University of Kentucky, the monitoring program was patterned after the Biological Monitoring and Abatement Program (BMAP) developed by ORNL for the three U.S. Department of Energy (DOE) facilities in Oak Ridge, Tennessee. The purpose of the BMAP is to determine

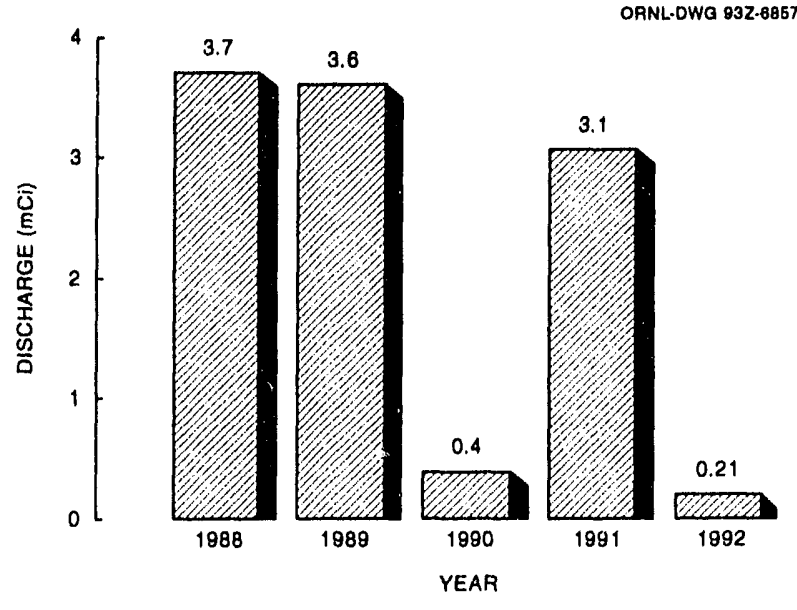

Fig. 2. Millicuries of technetium released to the atmosphere from PGDP operations, 1988-1992.

the effects of plant effluents on aquatic life in the receiving streams. The findings of the program were consolidated into a three-year report in 1990 and were submitted to KDOW. ORNL conducted an evaluation of the findings and presented its evaluation to KDOW in 1991. Another report will be published in 1993.

Rais logical effluent monitoring as required by DOE Order 5400.5 was also performed during 1992. Comparisons of radiological results from upstream Big Bayou Creek with downstream Big and Little Bayou creek locations indicated elevated levels of uranium, gross alpha, and uranium-235 $\left({ }^{235} \mathrm{U}\right)$ in Little Bayou Creek, probably a result of the release of small amounts of uranium in plant effluents and gross beta in Big Bayou Creek. Total discharge estimates of uranium and ${ }^{99} \mathrm{Tc}$ in liquid plant effluents for the past five years are indicated in Figs. 3 and 4, respectively.

\section{Groundwater Monitoring}

The scope of groundwater monitoring at PGDP encompasses both effluent monitoring and environmental surveillance monitoring objectives. Effluent monitoring was conducted for solid waste management units, underground storage tanks, and a RCRA interim-status burial ground. Significant support was also provided for a groundwater investigation conducted under a CERCLA 


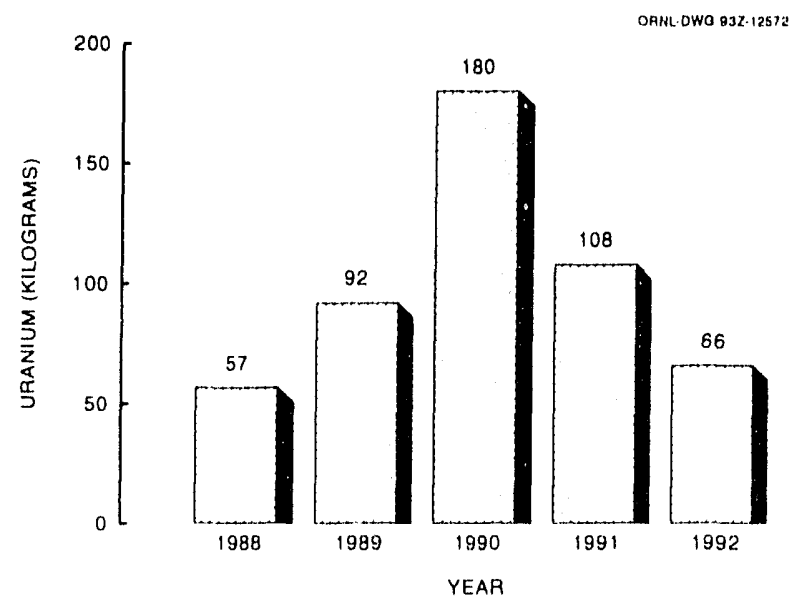

Fig. 3. Uranium discharges to surface water, 1988-1992.

Administrative Consent Order ( $A C O)$. Much of this investigation has components of environmental surveillance monitoring that will be continued until the conclusion of the investigation in 1992.

Several noteworthy groundwater activities were begun or completed in 1992. Groundwater Phase III field activities were completed, and a final report was issued in 1992. This project included soil borings, installation of wells, aquifer testing, and documentation of a site conceptual model. Groundwater Phase IV was initiated to design a plan to address uncertainties concerning the MoNairy Formation, the next aquifer below the previously investigated regional gravel aquifer. The Phase II ACO-mandated Site Investigation was completed with the issuance of the report. A Sampling and Analysis Plan was developed to coordinate all needs for groundwater analytical data.

\section{Other Monitoring}

\section{Biological Monitoring}

Vegetation samples are collected at 18 locations surrounding the plant and are analyzed for fluorides. The primary objective of vegetation sampling is to determine the total fluorides in the vegetation for comparison with the fluoride-in-foliage section of the Kentucky air pollution control regulations. All samples taken in 1992 were well below the $60 \mu \mathrm{g} / \mathrm{g}$

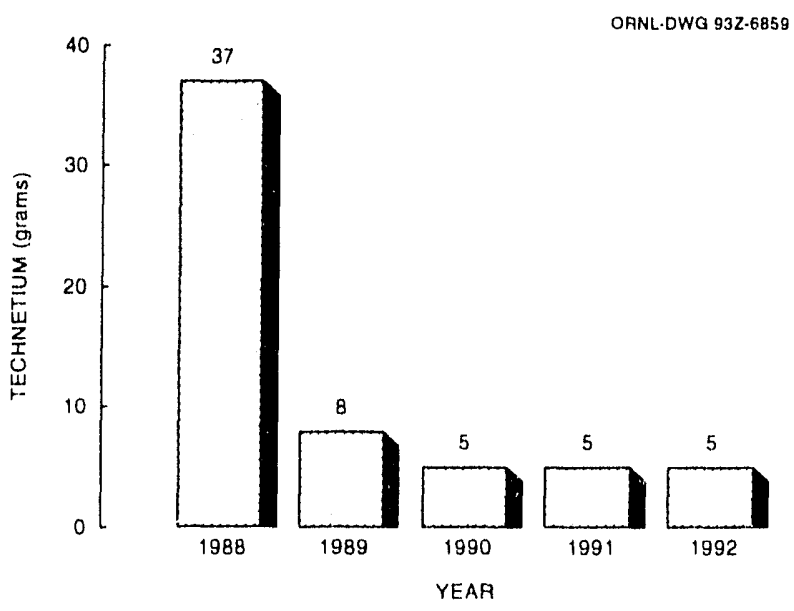

Fig. 4. Technetium-99 discharges to surface water, 1988-1992.

standard. Samples taken from outside the fenced area range from less than $5.2 \%$ to less than $9.3 \%$ of the standard.

During 1992, food crops and deer from the PGDP area were analyzed to determine if there was evidence of increases in the concentration of contaminants to a degree that standards were exceeded. Dose calculations were performed as outlined in Sect. 2. The dose from ingestion of each type of food crop was significantly less than 1 mrem per year. The calculated worst-case dose from ingestion of all types of food crops over a one-year period was $0.4 \mathrm{mrem} / \mathrm{year}$. Ingestion of deer meat under the assumptions discussed in Sect. 2 would result in a dose estimated at less than natural background.

\section{Soil and Sediment Sampling}

Concentrations of uranium in the soil, annually sampled from 10 locations, showed no significant difference from past data. There was no evidence of concentrations in the predominant wind directions higher (at 95\% confidence level) than concentrations upwind of the plant. No detectable concentrations of technetium-99, thorium-230, neptunium-237, or plutonium-239 were present at any of the sampling locations.

The downstream sediment-monitoring location on Big Bayou Creek indicated uranium levels 3.5 times higher than the upstream Big Bayou Creek 


\section{Environmental Report-Paducah}

location. Uranium levels at the downstream annual sediment-monitoring location on Little Bayou Creek were 36 times higher than the upstream Little Bayou Creek location. Also, polychlorinated biphenyls (PCBs) were detected in Little Bayou Creek. Big and Little Bayou creeks and KPDES outfall dituin? have been investigated during ACO activities. Remedic! alternatives have been drafted and are being reviewed by the EPA and the Kentucky Department for Environmental Protection.

\section{Annual Dose Estimate}

The maximum individual dose calculated using worst-case estimates for each potential pathway was $4 \mathrm{mrem} /$ year. The major contributors to these estimates were ingestion of sediments and direct radiation. Data are summarized in Part 1, Table 2.1, and are discussed in Part 1, Sect. 2.

\section{Unusual Occurrences}

During 1992, PGDP experienced 573 spills or releases of various materials. A record of each incident is kept in the plant shift superintendent's office. Most of the spills-a total of 311-were PCBs from ventilation duct gaskets. All gasket leaks were inside buildings. Troughs were installed beneath leaking gaskets immediately upon discovery. Highlights of some incidents are given in Subsects. 8.1.1 through 8.1.11. 


\section{Compliance Summary Environmental Compliance Activity U.S. Department of Energy}

\section{Paducah Gaseous Diffusion Plant}

\section{Background and Overview}

The Paducah Gaseous Diffusion Plant (PGDP) operates in conformance with requirements established by a number of federal and state statutes and regulations, executive orders, U.S. Department of Energy (DOE) orders, and compliance and settlement agreements. Compliance status with regard to major environmental statutes is summarized below.

DOE Ordei 5400.1, "General Environmental Protection Program," defines the mandatory environmental standards in effect at DOE operations. These envirommental standards fall into three categories: (1) those imposed by federal statutes, regulations, and requirements; (2) those imposed by state and local statutes, regulations, and requirements applicable to DOE; and (3) those imposed by DOE directives. This summary addresses the standards that are significant for PGDP environmental compliance.

Several federal, state, and local agencies are responsible for enforcing environmental laws and regulations at PGDP. DOE itself, through directives to field offices and compliance audits, is the initiating organization. Principal among other regulating agencies are the U.S. Environmental Protection Agency (EPA) Region IV and the Kentucky Department for Environmental Protection (KDEP). These agencies issue permits, review compliance reports, participate in joint monitoring programs, inspect facilities and operations, and oversee compliance with applicable environmental laws and regulations. A summary of PGDP permits is shown in Table 1.

The EPA develops, promulgates, and enforces environmental protection regulations and technology-based standards as directed by statutes passed by the U.S. Congress. In some instances, the EPA has delegated regulatory auhority to the KDEP when the Kentucky program meets or exceeds EPA requirements. Where regulatory authority is not delegated, EPA Region IV is responsible for reviewing and evaluating compliance with EPA regulations as they pertain to PGDP.

Although significant progress has been made toward achieving fuil regulatory compliance at PGDP, much remains to be done. Ongoing self-assessments of compliance status and implementation of corrective actions continue to identify environmental issues. These issues are discussed openly with the regulatory agencies to ensure that compliance with all environmental regulations will be attained.

\section{Compliance Status}

\section{DOE Order Compliance for Calendar Year 1992}

An assessment of DOE order compliance was completed by PGDP on September 30, 1992.

Instructions for the assessment came from the Martin 
Table 1. 1992 Paducah Gaseous Diffusion Plant permit summary

\begin{tabular}{|c|c|c|c|}
\hline Type of permit & Issuer & $\begin{array}{l}\text { Expiration } \\
\text { date }\end{array}$ & $\begin{array}{l}\text { Permit } \\
\text { number }\end{array}$ \\
\hline Kentucky Pollutant Discharge Elimination System & Kentucky Division of Water & & KY0004049 \\
\hline RCRA $^{a}$ Hazardous Waste Mianagement Permit & $\begin{array}{l}\text { Kentucky Division of Waste } \\
\text { Management }\end{array}$ & $8 / 19 / 2001$ & KY 8890008982 \\
\hline RCRA Part B post-closure & $\begin{array}{l}\text { Kentucky Division of Waste } \\
\text { Management }\end{array}$ & $N A^{b}$ & KY/H35, Rev. 1 \\
\hline Residential landfill & $\begin{array}{l}\text { Kentucky Division of Waste } \\
\text { Management }\end{array}$ & Pending & 073.14 \\
\hline Inert landfill & $\begin{array}{l}\text { Kentucky Division of Waste } \\
\text { Management }\end{array}$ & Pending & 073.15 \\
\hline Air Operating Permit & $\begin{array}{l}\text { Kentucky Division for Air } \\
\text { Quality }\end{array}$ & None & $0-85-110$ \\
\hline Permit-By-Rule (applies to the following) & NA & NA & $\mathrm{NA}$ \\
\hline C-616 chromium reduction facility & & & \\
\hline C-400-D line precipitation unit & & & \\
\hline C-403 neutralization pit & & & \\
\hline Clean metal scrap yard & & & \\
\hline Waste treatment lagoons at C-611 & & & \\
\hline Liquid pollution abatement lagoons at C-616 & & & \\
\hline C-410-C neutralizaton pit & & & \\
\hline Regulated scrap metal yard & & & \\
\hline
\end{tabular}

"Resource Conservation and Recovery Act.

${ }^{b}$ Not applicable.

Marietta Energy Systems, Inc. (Energy Systems) Standards Development and Management Office. The orders were prioritized using the Energy Systems Risk Prioritization Matrix with level A, B, and C categories. Level A comprises those orders involving environmental, safety, and health issues; safety; and quality assurance, with potential for significant risk or impact. These orders were further subdivided into requirement units (RUs) that appear to be performed by a single functionai area. Overall compliance for category A orders was $59 \%$ in full compliance, $23 \%$ in partial compliance, $6 \%$ in noncompliance, and $11 \%$ not applicable. An evaluation of orders in category $A$ that apply to environmental areas minus those not applicable showed $65 \%$ in full compliance, $24 \%$ in partial compliance, and $11 \%$ in noncompliance. All noncompliant RUs pertain to three DOE orders: 1540.2, "Hazardous Material
Packaging for Transport"; 5480.3, "Safety

Requirements for the Packaging and T'ransportation of Hazardous Materials, Hazardous Substances, and Hazardous Wastes"; 5480.4, "Environmental Protection, Safety, and Health Protection Standards." Funding has been requested to increase or reach fuil compliance with these orders but funding has not yet been made available based on risk-priority allocation of funds by program offices. More detail on the breakdown of the category $\mathrm{A}$ orders can be found in Part 1, Sect. 1, Table 1.1, of this report. The status of three major DOE orders is discussed as follows.

\section{DOE Order 5400.1, "General Environmental Protection Program"}

DOE Order 5400.1 provides directives for compliance with EPA, state, and local environmental 


\section{Environmental Report-Paducah}

regulations and establishes requirements for internal environmental protection programs. PGDP maintains compliance with this order through implementation of regulatory requirements of the Clean Air Act (CAA), Clean Water Act (CWA), Resource Conservation and Recovery Act (RCRA), Toxic Substances Control Act (TSCA), Safe Drinking Water Act (SDWA), and other federal and state environmental statutes.

Internal environmental management programs include notification and reports such as the Radioactive Effluent and On-Site Discharge Data Report submitted annually to Waste Information Systems Branch, EG\&G Idaho Inc., Idaho Falls, Idaho; the 5-year plan as required by Office of Management and Budget Circular A-105; the Annual Site Environmental Report; and reports of significant nonroutine releases of hazardous substances consistent with DOE Order 5000.3A. A long-range Environmental Protection Implementation Plan (EPIP) is prepared and updated annually as is the Environmental Monitoring Plan (EMP). The EPIP defines specific environmental objectives, including the means and schedules for accomplishment. The EMP defines a comprehensive system to provide effluent monitoring and environmental surveillance at PGDP. It is designed to meet federal and state regulation requirements as well as those internal to PGDP and DOE. The environmental media in pathways significant to the exposure of man and the environment are included in the monitoring program, specifically surface water, groundwater, air, and biological media.

Quality assurance and data evaluation are primary considerations for PGDP monitoring, surveillance, and sampling activities. Independent data verification is conducted; this area is targeted for increased attention in the future. Audits of monitoring and sampling activities by state and federal regulatory agencies have been positive; no significant findings have been issued.

\section{DOE Order 5400.5, "Radiation Protection of the Public and the Environment"}

DOE Order 5400.5 provides guidance and establishes radiation protection standards and practices designed to protect the public and the environment against undue risk from operations of DOE and DOE subcontractors. The order requires that off-site radiation doses not exceed $100 \mathrm{mrem} / \mathrm{year}$ from all exposure pathways. During 1992, the worst-case estimated dose was $3.77 \mathrm{mrem} /$ year, including a $2.78 \mathrm{mrem}$ dose from sediments and direct radiation in Little Bayou Creek. PGDP conducts various modeling and dose-calculation activities to address the potential for multiple-pathway exposures of the public.

PGDP surface water discharges were all below the derived concentration guides (DCGs) for specific radionuclides listed in the order. Some PGDP stormwater and wastewater discharges from areas with legacy contamination at times exceeded the internal investigation level of $10 \%$ of the DCG during 1992. These areas are targeted for further investigation and remediation under the ongoing Environmental Restoration Program.

Reporting requirements under this order are demonstrated through the occurrence reporting system and publication of the annual environmental report.

\section{DOE Order 5820.2A, "Radioactive Waste Management"}

DOE Order 5820,2A was issued in September 1988 with the following policy statement:

"Radioaclive and mixed wastes shall be managed in a manner that assures protection of the health and safety of the public, DOE and contractor employees, and the environment. The generation, treatment, storage, transportation, and/or disposal of radioactive wastes, and the other pollutants or hazardous substances they contain, shall be accomplished in a manner that minimizes the generation of such wastes across program office functions and complies with all applicable federal, state, and local environmental, safety, and health laws and regulations and DOE requirements."

Compliance requirements established in Chapter II, "Management of Transuranic Waste"; Chapter III, "Management of Low-Level Waste"; and Chapter VI, "Waste Management Plan Outline," are directly applicable to PGDP. Requirements covered in Chapter V, "Decommissioning of Radioactively Contaminated Facilities," are provided by the Environmental Restoration Program. A Waste 
Management Strategic Plan, KY/W-6, was issued in March 1992. The document details waste management program stiategies and compliance requirements for PGDP to ineet the intent of all applicable sections of the order.

All waste categories listed in the order require establishment of programs to segregate and minimize the generation of wastes. The PGDP program is detailed in Paducah Gaseous Diffusion Plant Wastc Minimization Plan For 1992, KY/W-10, issued in August 1992.

\section{Clean Air Act (CAA)}

PGDP has an ongoing program to maintain compliance with all regulations resulting from the CAA. As an integral pait of this program, PGDP completed a vent/stack survey that identified all the air emission points at PGDP. (Though unlikely, additional emission points may be identified during future surveys.) The vent/stack survey is the first phase of completing an air emission inventory. The second phase will be the establishment of a data base for the emission points. The third phase will be inputting into the data base the various emission parameters from each emission point. This inventory data base will provide information to indicate compliance with permit and regulatory limits.

In 1992 there were no documented fluoride emissions above permitted limits from the C-310, product withdrawal facility, purge vent stack.

Emissions from the C-600, steamplant, boilers caused by malfunctions, startups, and shutdowns that temporarily exceeded the standards were reported in accordance with Kentucky Division for Air Quality (KDAQ) regulations.

PGDP received Notices of Violation (NOVs) on August 17 and 18 for opacity greater than $20 \%$ from coal-hauling activities and for failure to allow inspectors necessary entry and inspection of a building that housed shutdown air pollution sources. The coal-hauling trucks reduced speed, and water was applied to the coal-haul road to reduce the fugitive dust. The inspectors were initially denied entry to the shutdown air pollution sources apparently because of miscommunication between the inspectors and PGDP staff. The building did contain classified information, and the inspectors did not have clearances. After PGDP Security ascertained that the classified information was not accessible to the uncleared inspectors, the inspectors entered and inspected the facility on August 19. The KDAQ was generally agreeable to minor delays in entering facilities because of reasons such as locating a key or a facility supervisor. The KDAQ has also been provided with a list of PGDP management names to contact if a KDAQ employee believes that access is being denied unreasonably. 'The KDAQ's final correspondence on the matter states that the KDAQ maintains its right of entry and inspection and that the inspector is reapplying for a security clearance. Coal hauling was terminated shortly after the inspection, so the KDAQ has requested that PGDP notify them to arrange a follow-up inspection for evaluation of the corrective actions ifter resumption of receipt of coal. The KDAQ has indicated that the delay or denial of entry for any reason is unsatisfactory. (PGDP expects to resume coal hauling in October 1993. At that time, the KDAQ will be notified so that a follow-up inspection can be performed.) The access issue was discussed at an agreement-in-principle meeting in October 1992.

The KDAQ issued PGDP an operating permit for 27 emission points on September 30, 1985. An ongoing effort to identify and evaluate air contaminant sources through the development of an air emission inventory has indicated many more sources than are listed on the 1985 permit. Therefore, as the result of developing an air emission inventory, PGDP submitted an existing source operating permit application for several sources on May 11, 1992. During 1992, a total of four applications were submitted to the KDAQ.

\section{Clean Water Act (CWA)}

The CWA applies to all nonradiological discharges to navigable surface waters. At PGDP, the regulations are applied through a Kentucky Pollutant Discharge Elimination System (KPDES) permit for effluent discharges to Big Bayou and Little Bayou creeks. The Kentucky Division of Water (KDOW) issued KPDES Permit No. KY0004049 to PGDP in September 1992. This permit became effective on November 1, 1992, and is enforced by the KDOW. At the request of PGDP, the state of Kentucky granted a stay of permit limits for $\mathrm{pH}$, metals, and temperature in October 1992. PGDP is working with KDOW to approve an Agreed Order concerning the 
establishment of final limits for these parameters. All other conditions stated in the permit are in effect.

Effluent discharges occur at 17 outfalls. Noncompliances in 1992 were for total residual chlorine, trichloroethylene, $\mathrm{pH}$, and total suspended solids. A total of 16 noncompliances occurred in 1992, 10 exceedances of effluent limits and 6 from other sources such as holding time or oil sheen violations. A project has been completed that routes discharges from the east side of the plant to a holding lagoon to control chlorine in the effluents. All water analytical results generated from environmental restoration activities and plant operations must be reviewed and approved for discharge by the Environmental Compliance Department. High priority has been placed on erosion control at construction projects to stop suspended solids violations. Effluent limits for those parameters exceeding effluent limits have been increased, and it is expected that compliance with new limits will be maintained. The compliance rate of PGDP with KPDES permit limits during 1992 was $99.5 \%$.

\section{Resource Conservation and Recovery Act (RCRA)}

Hazardous waste facilities at PGDP are operated under a permitted status granted by the state of Kentucky (Facility ID No. KY8890008982). The Part $B$ permit identifies 5 storage and 15 treatment units on the plant site. The closure of the C-746-B, south warehouse, waste chemical storage area was closed in 1991. Closure of the C-720, maintenance and stores building, degreaser task began in 1992.

In calendar year (CY) 1993, the Annual Hazardous Waste Report for CY 1992 was completed and submitted to the Kentucky Division of Waste Management (KDWM) prior to the March 1993 deadline. The annual report identifies both waste generated that was shipped off-site and waste generated that remains on-site. An NOV was issued in September 1992 for the omission of recirculating cooling water blowdown from the annual hazardous waste reports between 1984 and 1989 . In response to the NOV, PGDP revised those reports.

The KDWM performed a site inspection in August and September 1992. The purpose of the inspection was to conduct PGDr's annual RCRA inspection. The inspectors spent four days reviewing documentation, conducting field investigations of
RCRA treatment and storage units, and interviewing personnel throughout the plant. No findings were discovered, and this was the first time in the history of PGDP that the annual RCRA inspection did not result in the issuance of an NOV.

RCRA permitting activities for CY 1992 include a major modification to PGDP's Hazardous Waste Management Permit. The modified Part B permit portion of the overall permit included the addition of the C-404 low-level radioactive waste landfill, 12 additional treatment units for fluorescent lamps, a new waste stream listing, and other cosmetic changes to the original permit. The KDWM issued PGDP a modified permit on October 1, 1992. The modified Hazardous and Solid Waste Amendments portion included a revised schedule reflecting new due dates for submittal of RCRA facility investigation (RFI) work plans.

\section{Toxic Substances Control Act (TSCA)}

Polychlorinated biphenyls (PCBs) are used at PGDP and are regulated under TSCA 140 CFR Pt. 761 (Title 40 Code of Federal Regulations)]. Authorized uses of PCBs under TSCA at PGDP include use in dielectric fluid in electrical transformers and capacitors. Also, PCBs at less than 50 parts per million (ppm) have been identified in lubricant and hydraulic systems on-site. To track the PCB concentration in equipment on-site, a data base was established during 1992. The eventual goal of this data base will be to account for the PCB concentration in oil-containing equipment on-site for spill and waste management purposes. The Calendar Year 1991 PCB Annual Document was issued on July 1, 1992, to the PGDP DOE Site Office. The document includes an inventory of all regulated $\mathrm{PCB}$ waste and in-service equipment. The goal of PGDP is to phase out the use of PCB-containing items to the maximum extent practicable as quickly as possible. PGDP has more than 8,000 large high-voltage $P C B$ capacitors in-service. A replacement project has been initiated to replace all these PCB capacitors by September 1994.

On February 20, 1992, a TSCA Federal Facilities Compliance Agreement was approved between DOF: Headquarters and EPA Headquarters (EPA/HQ). The compliance agreement resolved issues associated with TSCA regulations, including the reuse of $\mathrm{PCBs}$ in ventilation duct gaskets, historical PCB oil spills 


\section{Environmental Report-Paducah}

on process building floors, storage of uranium-contaminated PCB wastes beyond the TSCA one-year limit, the presence of PCBs above regulatory limits in three hydraulic systems in the $\mathrm{C}-340, \mathrm{UF}_{6}$ reduction facility (inactive), building, and leaking $\mathrm{PCB}$ capacitors inside switchyard potential devices. PGDP is in compliance with the terms of the TSCA compliance agreement.

Quarterly progress reports were issued during 1992 that included summaries of the reporting requirements of the TSCA compliance agreement. The quarterly reports will be combined into an annual compliance agreement report, which is due to EPA/HQ by July 1, 1993. Many activities associated with compliance measures in the TSCA FFCA were completed during 1992. Certifications regarding the on-site historic $\mathrm{PCB}$ disposal site investigation and personnel protective clothing and equipment were submitted to EPA/HQ on March 17, 1992. PCB waste storage compliance certifications were submitted to EPA/HQ on August 11, 1992. Replacement of all devices with potential leaking PCB capacitors was completed August 24, 1992, and notification was made to EPA/HQ on November 18, 1992. This project was completed approximately nine months ahead of schedule. Quarterly air sampling for PCB was conducted in process buildings, and no results exceeded the TSCA compliance agreement reportable quantity of $0.5 \mu \mathrm{g} / \mathrm{m}^{3}$. Aiso, trough installation on leaking motor exhaust duct gasket flanges is proceeding on schedule.

During February 1992, magnesium fluoride process waste in the $\mathrm{C}-340$ building was found to contain detectable concentrations of PCBs. The most likely source of the contamination was a hydraulic system that is now drained but that had contained regulated PCB fluid. On June 25, 1992, the EPA granted approval to manage the waste as unregulated under TSCA, which closed this issue. The approval was based upon the contamination occurring prior to April 18, 1978; this date being the effective date of federal PCB regulations.

Two large PCB-contaminated electrical motors were declared waste during 1991, and no containers were available to properly package the motors in accordance with 40 CFR Pt. 761.65. Approval was received from the EPA regional TSCA coordinator during March 1992 for use of alternate packaging methods to store large PCB wastes. The motors were packaged in these containers during 1992, and this issue was closed.

During June 1991, the C-746-A PCB waste storage facility was discovered to have a leaking roof. Title 40 CFR 761.65(b)(I)(i) requires these facilities to have adequate roofs and walls to prevent rainwater from reaching the stored $\mathrm{PCBs}$ and $\mathrm{PCB}$ items. A project was completed that replaced the roof on this facility during June 1992 to enable a certification of storage compliance to be submitted to the EPA. However, since this time minor leakage during periods of heavy rain has reoccurred. The same problem has been identified with the C-746-B, south warehouse, and C-733, waste oil and chemical storage facility, storage facilities. These roofs are the only outstanding TSCA issue being carried as open noncompliances. An EPA Region IV interpretation of the regulations given on November 23, 1992, stated that a major storage violation could result if a situation existed that could expose PCBs to precipitation. Therefore, efforts are continuing to repair the roofs to ensure no leakage during rains.

Numerous environmental audits were conducted during 1992 at PGDP by Energy Systems Environmental Compliance, DOE/NE-33, and internal inspectors. No major findings were identified that require extensive resources to correct. The majority of the findings were marking and storage noncompliances that could be corrected within 24 hours of discovery.

\section{Comprehensive Environmental Response, Compensation, and Liability Act (CERCLA)}

An administrative consent order ( $A C O$ ) was executed in 1988 between the EPA and DOE under Sects. 104 and 106 of CERCLA. The ACO was executed in response to the discovery of off-site groundwater contamination in residential wells north of PGDP. The contaminants in the wells are trichloroethylene (TCE), a degreasing solvent used at PGDP, and technetium-99 $\left({ }^{99} \mathrm{Tc}\right)$, a man-made radionuclide produced during the fission of uranium. The source of ${ }^{99} \mathrm{Tc}$ at PGDP was the enrichment of reprocessed uranium from nuclear reactors at other DOE facilities. The major requirements of the ACO include monitoring of residential wells potentially affected by contamination; provision of alternative drinking water supplies to residents with 


\section{Environmental Report-Paducah}

contaminated wells; and investigation of the nature, extent, and source of the contamination. Residential wells are sampled on a weekly, monthly, or bimonthly basis for TCE and ${ }^{99} \mathrm{Tc}$; wells potentially affected by the contamination are also sampled monthly for gross alpha and gross beta contamination. Samples are analyzed by the on-site laboratory, and the results are reported to the well-owners. In the event that contamination that originated at PGDP is detected above plant action levels, which are established at the analytical laboratory detection limits of $25 \mathrm{pCi} / \mathrm{L}$ or $1 \mathrm{mg} / \mathrm{L}$ of ${ }^{99} \mathrm{Tc}$, a response is initiated by PGDP. Residents are notified immediately; state and EPA officials are also notified. Alternative water supplies are provided through connections to municipal water systems, or in the event that there is a time lag between discovery and the ability to complete connections, bottled water is made available. DOE pays the cost of installation of water systems and the monthly charges for water service to residents with contaminated wells. The plant has several programs proceeding to investigate the nature and extent of contamination. These include the investigation of solid waste management units under the Hazardous and Solid Waste Amendments Permit; the characterization of the northwest plume using direct push sampling technologies to provide data needed to select the locations for the hydraulic containment system; and investigations of the northeast plume as a part of the Groundwater Monitoring Phase IV Study. More information on environmental restoration CERCLA activities may be found in the "Current Issues" section of this summary and in Part 1, Sects. 5 and 8 , particularly Sects. 5.5.13, 5.6.7.1, and 8.2.1 of the 1992 PGDP Environmental Report.

\section{CERCLA Section 103(a)}

On October 21, 1991, a request was issued to EPA Region IV and to the KDOW seeking concurrence on the reporting mechanism for oil sheens on KPDES outfall ditches and on Big and Little Bayou creeks. To date no response has been received. PGDP submitted the Spill Prevention and Control Countermeasures Plan to EPA Region IV and to the KDEP. Three releases were reportable to the National Response Center because reportable quantities were exceeded.

\section{Emergency Planning and Community Right-To-Know Act (EPCRA)}

The EPCRA [also referred to as the Superfund Amendments and Reauthorization Act Title III] requires that inventory and environmental release information of certain chemicals at a facility be reported to federal, state, and local authorities. This information is used for emergency planning and to provide information to the public. EPCRA requires that local and state emergency planning commissions be informed of the amount of hazardous and extremely hazardous substances that are present at PGDP and that a material safety data sheet (MSDS) be available for each chemical upon request. The regulation also requires that releases of toxic chemicals to the environment be reported each calendar year if chemical threshold limits are met. Two releases were reported under EPCRA Sect. 304 during 1992.

The Emergency and Hazardous Chemical Inventory Report was submitted to the state and local emergency planning commissions in March 1993. MSDSs are kept on site and are available upon request through the PGDP Hazard Communication Program. Detailed information on the Toxic Chemical Release Report for 1992 is presented in Appendix A of the Paducah Gaseous Diffusion Plant Environmental Report for 1992.

\section{National Environmental Policy Act (NEPA)}

NEPA implementation is a decision making process that considers the need for a proposed action and an alternative action with emphasis on minimizing environmental impacts. It establishes policy, sets goals, and provides means for carrying out the policy. NEPA contains "action forcing" provisions to ensure that federal agencies act according to the letter and spirit of the act.

Through the implementation of NEPA, the plant has a practicable means (consistent with the requirements of the act and other essential considerations of national policy) to restore and enhance the quality of the human environment and to avoid or minimize any possible effects of its actions upon the quality of the human environment. 
NEPA compliance personnel review all engineering service orders, engineering service requests, and work orders and submit appropriate NEPA documentation to DOE for project approval. Compliance with NEPA is maintained by following the guidelines set forth by the Council on Environmental Quality, DOE, and Energy Systems.

During 1992, NEPA compliance personnel completed 95 NEPA review checklists. Categorical exclusion (CX) determinations were issued in 110 cases, and $96 \mathrm{CX}$ approvals were received. Five environmental assessment (EA) determinations were submitted to DOE for review and approval: Plant Laboratory Facility-ESO 17846, CFC-114 Replacement-ESO 17977, Groundwater Pump and Treat Demonstration-18045-RA, Uranium Enrichment (UE) Waste Storage Facilities-NEPA No. 92-011, and Environmental Restoration (ER) Waste Storage Facilities-DEPA No. 92-012. One environmental impact statement determination was submitted to DOE for review and approval: CFC-114 Replacement-ESO 17977. Three EA determinations were approved by DOE: UF" Cylinder and Storage Yards-ESO 17628, UE Waste Storage Facilities-NEPA No. 92-011, and ER Waste Storage Facilities-NEPA No. 92-012. Four EAs were presented to DOE during the year: Solid Waste Landfill-ESO 18007 , Groundwater Pump and Treat Demonstration--18045-RA, UE Waste Storage Facilities-NEPA No. 92-(011, and ER Waste Storage Facilities--.NEPA No. 92-(0)12.

\section{Federal Insecticide, Fungicide, and Rodenticide Act}

No restricted-use pesticides are used by PGDP personnel. If application of a restricted-use pesticide at the plant is necessary, a certified contractor will be used to make the application. General-use pesticides applied by plant personnel are applied in a manner consistent with the product labeling. All product warnings and cautions are strictly adhered to. Applications of pesticides by plant and contractor personnel must be approved by the plant pesticide coordinator. Napchlor-G is a fungicide that was used at PGDP as a wood preservative for cooling towers. The Waste Management Operations Department at PGDP is seeking a vendor that will dispose of the Napchlor-G being held on-site.

\section{Safe Drinking Water Act}

PGDP operates a "nontransient, noncommunity" public water system subject to regulation by the KDOW. The PGDP water treatment facility is a Class II facility. Ten on-site operators have Class II or higher certification. Monthly operational reports are provided to the KDOW describing operational activity for the facility. The ongoing training required to maintain certification is provided by a program developed in-house. The state of Kentucky has approved the program as meeting KDOW requirements.

In 1992, surveys of the sanitary water supply system indicate that the plant's drinking water meets all state and federal regulations for maximum contaminant levels for the required inorganic parameters. In 1992, PGDP completed a quarterly survey of the sanitary water system for eight regulated volatile organic compounds (VOCs). In one quarter of sampling, 1,2-dichloroethane was detected, but the concentration was below the maximum contaminant limit set by drinking water regulations. Because the VOC was detected in a sample, PGDP will continue quarterly sampling of VOCs for at least three consecutive years in accordance with KDOW Jrinking water regulations.

\section{Current Issues}

\section{CAA Compliance}

PGDP, in conjunction with the DOE Oak Ridge Field Office (DOE-OR) and the three Oak Ridge facilities, submitted a radionuclide National Emission Standards for Hazardous Air Pollutants (NESHAP) compliance plan to EPA Region IV in March 1990. Because of the enormous number of potential radiological air emission points (albeit small ones) and the difficulty of initially evaluating each point and periodically confirming the insignificant emissions, the plan requested approval to use ambient air samplers to collect data and demonstrate compliance with the 10-millirem (mrem) standard established in the regulation. On February 8, 1991, DOE-OR received correspondence from the EPA stating that ambient air sampling could not be used to demonstrate compliance with any portion of the regulation except computation of dose. Therefore, PGDP and the Oak Ridge facilities are required to 
perform stack sampling on each emission point or submit evidence that the emissions from each stack result in a dose less than $0.1 \mathrm{mrem}$. A revised compliance plan was submitted to the EPA in May 1991.

PGDP negotiated an FFCA with EPA Region IV to comply with 40 CFR Pt. 61, Subpart H (NESHAP regulations), which pertains to airborne radionuclides from DOE facilities. The FFCA was signed by DOE and the EPA in May 1992. The FFCA stated requirements for PGDP to document compliance with the monitoring provisions of the regulation. The regulation requires continuous measurement of radionuclides from each emission point having the potential to emit radionuclides that would result in a dose of $0.1 \mathrm{mrem}$ (assuming no pollution controls) to the most affected person or persons outside the plant.

At present, PGDP has documented one source, the C-310, product withdrawal facility, stack, with potential emissions that would result in the $0.1-\mathrm{mrem}$ dose. PGDP has concluded that the emissions, at the point of sampling, are gaseous. The C-310 stack is sampled continuously by a potassium hydroxide impinger train, which is not an EPA-approved (isokinetic) sampling method for particulate emissions. Isokinetic stack sampling was performed in February 1992 to determine the presence or absence of particulates in the C-310 stack. Although uranium was collected on the sample filter, the concentrations were lower than comparable samples collected in the existing PGDP impinger train, indicating that PGDP is not underestimating uranium emissions. Furthermore, previous PGDP laboratory experience indicates that unless the uranium sample media-in this case a particulate filter-is "conditioned" prior to collecting a sample, the UF gas will coat the sample media, thus providing a positive bias for the presence of particulates. PGDP submitted the stack sampling results to the EPA on April 4, 1992, and received a response from the EPA indicating the C- 310 stack sampling system is satisfactory. Thus no upgrade is required.

PGDP has fulfilled all the obligations in the FFCA and forwarded certification to the EPA. On March 26, 1993, PGDP received correspondence from EPA Region IV acknowledging that all conditions of the NESHAP FFCA have been completed. PGDP is in compliance with $40 \mathrm{CFR} \mathrm{Pt}$. 61, Subpart H. The 1992 dose from the PGDP air emission sources is significantly below the 10-mrem/year standard for the most exposed member of the public. The maximum effective dose equivalent to the most affected individual from airborne emissions was $0.0045 \mathrm{mrem}$.

For some sources, compliance is demonstrated by throughput/usage information. Documentation of compliance (through implementation of throughput/usage logbooks) is increasing throughout the plant.

\section{CAA Current Issues}

On December 10, 1992, the EPA proposed a rule to implement Sect. 608 of the CAA Amendments of 1990 (the act). This section of the act contained a prohibition on the intentional release of Class I and Class II ozone-depleting compounds during maintenance activities. Certain de minimis releases associated with good faith attempts to recapture or recycle are not subject to the prohibition. The prohibition was effective July 1, 1992. According to the PGDP Chief Counsel, the recovery activities at PGDP are in compliance with the prohibition as stated in the act. However, to more explicitly implement the prohibition, the EPA, in the proposed rule, established vacuum requirements for recovery of Class I and Class II stratospheric ozone-depleting compounds during maintenance activities. CFC-114, which is used as a coolant for the enrichment cascade, is a Class 1 compound. The vacuum requirement for $\mathrm{CFC}-114$ was established in the proposed rule at 25 inches of mercury. Whether PGDP can achieve this vacuum during CFC-114 recovery in the cascade coolant system is questionable. Furthermore, certain maintenance scenarios could result in smaller releases than if the provisions of the proposed rule were strictly followed. The final rule that will establish the vacuum requirements is expected to be published in April or May 1993. Therefore, personnel from the PGDP Air Compliance Program coordinated a meeting with EPA/HQ to discuss the potential problems. Representatives from the Paducah DOE Site Office, the Portsmouth Gaseous Diffusion Plant, the Oak Ridge K-25 Site, Energy Systems, Central Environmental, and DOC Headquarters attended the meeting. Although no formal decision was rendered, the EPA did indicate that it would favorably consider 
the issues discussed at the meeting when developing the final ruie.

\section{CWA Compliance}

The Corps of Engineers (COE) PCB Source Identification Project was completed in 1992 (see Sect. 8.2.4 for more details). A report summarizing this investigation was submitted to the KDOW in November 1992. The results from the study indicated that the source of PCBs at PGDP is not from ongoing operations at the facility but from accumulation of PCBs from historical releases in creek sediment surrounding the plant. A new study to identify the areas in Little Bayou and Big Bayou creeks where $\mathrm{PCB}$ contamination in the sediment has occurred will be conducted by the COE. This study will be completed in fall 1993.

PGDP is working with KDOW to establish final permit limits for metals, $\mathrm{pH}$, and temperature that will satisfy both parties as well as protect the environment. An Agreed Order ( $\mathrm{AO}$ ) between the state of Kentucky and PGDP is being negotiated. PGDP has contracted Oak Ridge National Laboratory to study the impact of each of the previously mentioned parameters on the waters of Little Bayou and Big Bayou creeks. The results from these studies will be presented to KDOW for the determination of permit limits. (A draft AO has been submitted by PGDP to KDOW. KDOW is still reviewing the draft AO. KDOW has concerns about the compliance schedule submitted by PGDP.)

\section{RCRA Compliance}

The Hazardous and Solid Waste Amendments (HSWA) permit became effective on August 19, 1991. To date, no violations of PGDP's HSWA permit have occurred. The HSWA permit provides a schedule for compliance for the submittal of RFI work plans to the EPA and KDWM. PGDP met its first deadline on June 12, 1992, by submitting an RFI work plan for waste area groupings 5 and 11. Other deadlines for the RFI work plans have been extended by a minor modification to the HSWA permit.

The RCRA Hazardous Waste Permit Modification, effective October 30, 1992, included conditions that require groundwater monitoring for the $\mathrm{C}-404$ low-level waste facility radionuclides and a mechanism for triggering DOE into compliance monitoring and corrective action. Because DOE takes the position that by statute radionuclides are not regulated under a RCRA permit, these permit conditions have been appealed to the Natural Resources and Environmental Protection Cabinet. The case has been assigned to a hearing officer, and at present the legal issues are being briefed by both DOE and the Commonwealth of Kentucky.

In 1992 there were three RCRA NOVs issued to DOE by the state of Kentucky:

1. On January $28,1992, \mathrm{KDWM}$ issued an NOV for the improper storage of hazardous waste in a degreaser in Building C-720, maintenance and stores building. The sludge residue in the bottom of the degreaser was hazardous for trichlorethylene. PGDP submitted a closure plan to KDWM in March 1992, to resolve the NOV. The plan was approved by KDWM, and PGDP is in the process of implementing the plan to properly clean and close the degreaser and associated units.

2. An NOV was issued ior the deficient waste-reporting practices associated with the annual hazardous waste reports from 1984 through 1990. PGDP did not disclose to KDWM waste that was either treated or stored in a "permit-by-rule" unit. There was some confusion as PGDP believed it was exempt from the waste-reporting criteria associated with the permit-by-rule facilities. PGDP revised the reports from the aforementioned years and submitted them to KDWM. PGDP and KDWM recognize the NOV as resolved, and no further corrective action is warranted.

3. PGDP received an NOV on November 4, 1992, for the improper storage of hazardous waste in the C-750-C underground storage tank (UST). The tank was used to collect used oil destined for a recycling facility. However, trichloroethylene was inadvertently placed in the tank causing the unit to be subject to all hazardous waste regulations. These regulations state that a facility must have a permit to store a hazardous waste for greater than 90 days. The C-750-C UST has been inactive for more than 90 days, and PGDP has submitted a closure plan to KDWM to comply with the NOV. The plan is being reviewed by KDWM. Once the plan is approved, PGDP will implement the provisions of the plan to clean and close the unit. 


\section{Environmental Report-Paducah}

The Annual Hazardous Waste Report was completed and submitted to the KDWM before March 1, 1993. The report contains a list of all hazardous wastes generated during CY 1992 that were either shipped off-site or that still remain on-site.

On March 29, 1990, the EPA promulgated the toxicity characteristic rule. This rule requires companies that generate or manage hazardous wastes to determine whether any of their wastes exhibit the new toxicity characteristic and to develop compliance strategies for management of this waste. The toxicity characteristic leachate procedure (TCLP) replaces the extraction procedure toxicity test that was previously used to determine the characteristic of toxicity. PGDP has wastes stored that were previously characterized with the extraction procedure toxicity procedure and that require re-characterization. PGDP also has wastes in storage and waste streams not characterized in accordance with the toxicity characteristic rule.

An FFCA for TCLP waste characterization was signed by PGDP, DOE, and the EPA. The FFCA has an effective date of April 3, 1992. An implementation plan required by the FFCA for PGDP was forwarded to the EPA by the required deadline of April 24, 1992. This plan details the roles and responsibilities for the proper characterization of certain wastes over a ten-year period. The first two years of this agreement are committed to dealing with the administrative concerns such as budget, hiring of personnel, conducting an inventory of certain wastes, and so forth. The actual characterization of the wastes will not begin until CY 1994.

\section{TSCA Compliance}

A TSCA compliance agreement between DOE and EPA/HQ was executed on February 20, 1992. Four issues covered by this agreement are being corrected through interim compliance measures identified in the agreement. The current status of implementation is outlined in the preceding Compliance Status Section.

\section{Unauthorized Use of PCBs in Ventilation Duct Gaskets}

Buildings at PGDP contain ventilation duct systems for heating and cooling of both personnel space and process equipment. The gaskets in a number of these systems contain varying levels of PCBs. As a result, the gaskets constitute non-totally enclosed PCB systems, which are prohibited by 40 CFR 761.20(a). The agreement outlined a compliance schedule for replacement of the gaskets and thereby resolved this issue.

\section{Historical PCB Oil Spills}

In the past, oil from ventilation duct gaskets leaked onto the concrete floors of the process buildings and associated equipment under the ducts before it was discovered that the leaked oil was PCB contaminated. The agreement outlined a compliance schedule for disposal of historical PCB-contaminated oil spill material and thereby resolved this issue.

\section{Unauthorized Mixed TSCA Waste Storage}

Uranium-contaminated PCB mixed wastes are being stored in excess of the one-year limit imposed by TSCA because of a lack of treatment and mixed-waste disposal capabilities. The EPA issued a complaint to Energy Systems about this issue on October 3, 1990. The agreement outlined a compliance schedule for disposal of the waste and thereby resolved this issue. The complaint filed against Energy Systems has been also been resolved with no liability for PGDP.

\section{Unauthorized Use of PCBs in Hydraulic Systems}

Two hydraulic systems with PCB labels affixed were found in $\mathrm{C}-340$ during an inspection conducted by PGDP personnel during February 1991. Because of a lack of documentation indicating that these systems were below $50 \mathrm{ppm}$ PCBs, samples were taken of residual oil in the systems' reservoir. After the inspection, documentation was found indicating that the systems had been drained and placed on standby status in 1982. Results of samples taken in February 1991 showed PCB concentrations in excess of $50 \mathrm{ppm}$, which is an unauthorized use of PCBs under TSCA and is not in compliance with 40 CFR Pt. 761.30(e). The TSCA FFCA outlined a compliance schedule for demolition of the systems and thereby resolved this issue. 


\section{Land Disposal Restrictions (LDRs)}

In 1984, Congress mandated the EPA to implement a progressive schedule of restrictions on the landfilling of hazardous wastes. These restrictions, implemented in five phases beginning in 1986, prohibit the disposal of hazardous wastes unless first treated to meet regulatory treatment standards. Storage of "thirds" hazardous wastes was allowed after May 8, 1992, only if the wastes would be treated and disposed in the near future. Because many of the hazardous wastes at PGDP are subject to DOE's May 17, 1991, moratorium on off-site shipment of radioactive hazardous waste, there is no ultimate disposal site for many of PGDP's wastes, and their further generation became a violation of RCRA regulations. PGDP and the EPA entered into an FFCA covering all LDR wastes on June 30, 1992. The agreements set forth several deliverables to the EPA primarily dealing with treatment of LDR wastes. A waste minimization plan along with plans that detail treatability studies for wastes both with and without treatment technologies have been forwarded to the EPA. Quarterly and annual update reports are due to the EPA on these plans so that the EPA may track PGDP's progress. PGDP has provided all data required by the FFCA. Also, a case-by-case extension for thirds mixed wastes was proposed by the EPA through notice in the Federal Register. The EPA allowed for an extension until May 8, 1993, for thirds mixed wastes.

Mixed and hazardous waste subject to the L.DRs of RCRA have been stored in some areas of PGDP for longer than one year in violation of the regulation. These wastes are subject to LDR storage prohibitions that permit storage only for accumulation of sufficient quantities to facilitate proper treatment, recycling, or disposal. LDR waste remains in storage in the RCRA-permitted storage facilities at PGDP. LDR waste is stored only in permitted facilities.

\section{CERCLA Compliance}

In July 1988, the Kentucky Radiation Control Branch, in conjunction with the Purchase District Health Department, sampled several residential groundwater wells north of PGDP in response to concerns from a local citizen regarding the quality of water in his private well. Subsequent analyses of these samples revealed the presence of elevated gross beta levels indicative of potential radionuclide contamination. On August 9, 1988, these results were reported to $P G D P$, which responded by sampling several private groundwater wells around the plant on August 10, 1988. Upon analysis, some of the samples collected by PGDP were found to contain elevated levels of both TCE and ${ }^{94} \mathrm{Tc}$; it was concluded that ${ }^{99} \mathrm{Tc}$ was the source of the elevated gross beta levels. Subsequently, PGDP initiated a two-phased site investigation, as agreed to in an ACO drafted under Sects. 104 and 106 of CERCLA, to identify the nature and extent of off-site contamination at PGDP.

Phase I of the site investigation, which extended from summer 1989 to March 1991, evalualed the extent of off-site contamination at PGDP through extensive groundwater monitoring and surface water sampling. Results of the Phase I activities are reported in Results of the Site Investigation, Phase I (CH2M Hill 1991). Phase II of the site investigation, which extended from November 1990 to October 1991, focused on identification and characterization of the on-site sources contributing to the off-site contamination, determined the level of risk to human health and the environment from exposure to contaminated media and biota, and developed an initial list of remedial alternatives. Results of the Phase II site investigation are reported in Results of Site Investigation, Phase II (CH2M Hill 1992a). In general, the principle findings of the site investigation include:

- TCE and ${ }^{19} \mathrm{Tc}$ are the primary contaminants in groundwater at PGDP.

- A northwest and northeast groundwater plume extending off-site was delineated.

- PCBs and radionuclides were the primary contaminants detected in surface water and sediment in outfalls, ditches, and creeks.

- Twenty-one on-site sources were identified as contributors to the off-site contamination.

Risks to human health and the environment from exposure to contamination originating at PGDP were reported in Results of the Public Health and Ecological Assessment, Phase II (CH2M Hill 1992b). This report used data collected during the site investigation to quantitatively assess risks to human health and to ecological health from contaminants migrating from PGDP. A range of preliminary 


\section{Environmental Report-Paducah}

remedial alternatives that may be used to address the contamination reported in the Phase II report $(\mathrm{CH} 2 \mathrm{M}$ Hill 1992a) was developed during the ACO activities. This material is presented in Summary of Alternatives for Remediation of Off-Site Contamination at the Paducah Gaseous Diffusion Plant, Paducah, Kentucky (SAIC 1991).

In response to the initial report in July 1988 that samples collected by the state revealed groundwater contamination in a local residential well, PGDP immediately instituted the following interim actions:

- provided temporary bottled water to affected residences,

- sampled all surrounding residential wells to determine the extent of residential well contamination,

- extended the city water line to affected residences as a permanent source of water, and

- began routine sampling of residential wells around PGDP.

Upon completion of the site investigation and in response to the risks identified in the Results of the Public Health and Ecological Assessment, Phase II, PGDP initiated the development of several additional interim actions designed to prevent further off-site migration of contaminants and to reduce risks to human health and the environment. These include the proposed construction of a pilot hydraulic containment system for the northwest groundwater plume [detailed in Technical Memorandum for the Interim Remedial Action of the Northwest Plume, and Proposed Plan for the Interim Remedial Action of the Northwest Plume (Draft) (SAIC 1993)]; the proposed construction of institutional controls (posting and fencing) for those outfalls, creeks, and lagoons to which the public can gain access and in which there may be contaminated sediment, surface water, and/or biota [detailed in Interim Action Workplan for Institutional Control of Offsite Contamination in Surface Water Outfalls, Creeks, and Lagoons (SAIC 1992)]; proposed construction of sediment control devices around the scrap yards and adjacent ditches to limit sediment movement at PGDP [detailed in Interim Corrective Measure Work Plan for Containment of Scrap Yard Sediment Runoff (SAIC 1993)]; and proposed measures for the North-South Diversion Ditch [detailed in Interim Corrective Measures Work Plan for the North-South

\author{
Diversion Ditch, Virginia Ave. to C-616-C Lift \\ Station (SAIC 1993)].
}

The Phase I and Phase II documentation and the proposed response actions previously identified are intended to meet the objectives of the ACO. Schedules for additional response actions pertaining to off-site contamination are outlined in the draft Site Management Plan (PGDP 1993). The Site Management Plan has been developed to serve as the primary strategy document for the Environmental Restoration Program. The schedules in the plan will become enforceable through a schedule of compliance in a federal facilities agreement (FFA), once it is finalized. The FFA is an enforcement agreement between the EPA, the state of Kentucky, and DOE that establishes the procedural and regulatory framework for remediation activities at PGDP. The draft FFA for PGDP was received from the EPA in May 1993, and is under review by PGDP, Oak Ridge, and DOE Headquarters personnel.

Comments on the draft are due to the EPA and the state on August 2, 1993, with initial negotiations planned for early August.

PGDP was proposed for inclusion on the federal facilities portion of the National Priorities List (NPL) in May 1993. The facility scored a 56.9 on the Hazard Ranking System 2. A score of 28.5 is required for listing a facility on the NPL. Upon listing, CERCLA wil! become the primary driver for remediation at PGDP. However, federal facilities are not eligible to receive money from the federal "Superfund" for cleanup activities. An FFA, which is required to be developed for facilities listed on the NPL, is being developed by the EPA, the state of Kentucky, and DOE.

\section{NEPA Compliance}

NEPA establishes guidelines and responsibilities for addressing environmental considerations during project planning, design, and construction. PGDP will to the extent possible use all practical means, consistent with the requirements of the act and other essential considerations of national policy, to restore and enhance the quality of the human environment and avoid or minimize any adverse effects of its actions on the quality of the human environment.

A number of options are available to projects, depending upon their scope. When evaluating a project, NEPA compliance personnel initially 
complete a checklist to help determine the level of documentation the project may require. The checklist may lead to a request for a $\mathrm{CX}$, an EA, or an environmental impact statement. DOE will determine the type of document required.

A number of executive orders and federal environmental protection statutes are integrated into NEPA programs to ensure that the resources they are concerned with are protected against any adverse environmental impacts that might result from a plant activity or project. They include Executive Order 11988, Floodplain Management; Executive Order 11990, Protection of Wetlands; the Endangered Species Act; the Fish and Wildlife Coordination Act; the Farmland Protection Policy Act; the National Historic Preservation Act, which protects national historic landmarks; the American Indian Religious Freedom Act, which protects the freedoms of Native Americans; and the Wild and Scenic Rivers Act.

\section{Environmental Audits}

In June 1992, a compliance sampling inspection was conducted at PGDP by the KDOW. No noncompliances were identified. The annual inspection to review PGDP emission points by KDAQ was conducted in August 1992. T'wo NOVs resulted, one concerning lugitive dust emissions from a coal-haul road and the other concerning dental of access to a restricted facility. Both violations have been addressed and are considered resolved.

The annual RCRA inspection was conducted in September 1992. RCRA training, hazardous waste storage areas, and other aspects of the RCRA Part $B$ permit were reviewed. No noncompliances resulted from the inspection.

A team of 22 inspectors from Central Staff Environmental Compliance and Martin Marietta Corporate conducted an audit of PGDP environmental programs during the week of October 5, 1992.

Twenty noncompliances and 48 negative observations resulted. Thirteen positive findings were also noted. None of these deficiencies were categorized as Priority I (i.e., a threat or a potential threat to public health or the environment).

In addition to many external (DOE, Central staff, etc.) audits, PGDP maintains an aggressive internal self-assessment program. This program ensures continued improvements and regulatory compliance. Also, many "lessons learned" are incorporated into the assessment program.

\section{DOE Tiger Team Assessment of PGDP}

Secretary of Energy James D. Watkins' ten-point initiative to strengthen safety, environmental protection, and waste management activities at DOE production, research, and testing facilities resulted in the Tiger Team Assessment of PGDP, June 18-29 and July 9-20, 1990. An action plan developed in response to the Tiger Team Assessment, PGDP Action Plan Response to Compliance Assessment Team Findings, was approved by Watkins on January 7, 1991.

During its assessment, the Tiger Team reported no noncompliance issues of a magnitude that would necessitate curtailing overall operations at the plant. The Tiger Team identified a total of 199 findings and 4 noteworthy practices. Of the 199 findings, 62 pertained to environmental issues, 123 involved saffety and health issues, and 14 were related to management issues, 3 of which addressed DOE: matters.

As of March 29, 199.3, 37 of the 62 environmental findings have been closed. Completion is past due for 1 finding, and 24 findings are not scheduled for completion al this time.

$A$ verification inspection was performed by Energy Systems on March 20, 1992, 10 assess the status of actions being taken to resolve findings cited in the original action plan and to document progress in implementation. Team members reviewed documents, conducted interviews, and observed activities in various facilities to determine the extent to which PGDP has implemented the actions agreed to in the original implementation plan. The verification inspection team noted that the plant is making progress in meeting the milestones of the action plan. A number of generic issues were identified that have delayed implementation of action plans. These issues were identified as staffing, temporary measures for long-term corrective actions, long-term planning, documentation, and funding. 


\section{Environmental Report-Paducah}

\section{References}

CH2M Hill. 1991. Results of the Site Investigation, Phase I, at the Paaucah Gaseous Diffusion Plant, Paducah, Ky., KY/ER-4, Paducah Gaseous Diffusion Plant, Paducah, Ky.

CH2M Hill. 1992a. Results of the Site Investigation, Phase II, at the Paducah Gaseous Diffusion Plant, Paducah, Kentucky, KY/SUB/13B-97777C P-03/1991/1, Paducah Gaseous Diffusion Plant. Paducah, Ky.

$\mathrm{CH} 2 \mathrm{M}$ Hill. 1992b. Results of the Public Health and Ecological Assessment, Phase II, at the Paducah Gaseous Diffusion Plant, Paducah, Kentucky, KY/SUB/13B-97777C P-03/1991/1, Paducah Gaseous Diffusion Plant, Paducah, Ky.

Paducah Gaseous Diffusion Plant (PGDP). Decenber 1992. Site Management Plan (Draft), KY/EK-17, Paducah Gaseous Diffusion Plant, Paducah, Ky.

Science Applications International Corporation (SAIC). March 1992. Interim Action Workplan for Institutional Control of Offsite Contamination Surface Water Outfalls, Creeks, and Lagoons at the Paducah Gaseous Diffusion Plant, Paducah Gaseous Diffusion Plant, Paducah, Ky.

Science Applications International Corporation

(SAIC). January 8, 1993. Interim Corrective

Measure Work Plan for the North-South

Diversion Ditch Virginia Ave, to C-616-C Lift

Station, DOE/OR/06-1116, Paducah Gaseous

Diffusion Plant, Paducah, $\mathrm{Ky}$.

Science Applications International Corporation (SAIC). February 1993. Interim Corrective Measure Work Piun for Containment of Scrap Yard Sediment Runoff, DOE/OR/06-1114, Paducah Gaseous Diffusion Plant, Paducah, Ky. Science Applications International Corporation (SAIC). March 17, 1993. Proposed Plan for Interim Rernedial Action of the Northwest Plume, DOE/OR/06-1127, Paducah Gaseous Diffusion Plant, Paducah, Ky.

Science Applications International Corporation (SAIC). March 17, 1993. Technical Memorandum for Interim Remedial Action of the Northwest Plume, DOE-OR 1031, Paducah Gaseous Diffusion Plant, Paducah, Ky. 


\title{
Acronyms and Abbreviations
}

\author{
ACO \\ Administrative Consent Order \\ ADI \\ ALARA \\ ANSI \\ AOC \\ APG \\ Av \\ acceptable daily intake \\ as low as reasonably achievable \\ American National Standards Institute \\ area of concern \\ Analytical Products Group, Inc. \\ average \\ AVLIS \\ atomic vapor laser isotope separation \\ BBK \\ $\mathrm{BE}$ \\ BMAP \\ BMP \\ $\mathrm{BN}$ \\ BOD5 \\ BTEX \\ Big Bayou Creek \\ boundary east \\ Biological Monitoring and Abatement Program \\ Biological Monitoring Program \\ boundary north \\ biological oxygen demand (5 day) \\ benzene, toluene, ethylbenzene, and xylene \\ CAA \\ CEDE \\ CERCLA \\ CFC \\ CHR \\ $\mathrm{CO}$ \\ COD \\ COE \\ CWA \\ CX \\ CY \\ Clean Air Act \\ committed effective dose equivalent \\ Comprehensive Environmental Response, Compensation, and Liability Act \\ chlorofluorocarbon \\ Cabinet for Human Resources \\ carbon monoxide \\ chemical oxygen demand \\ Corps of Engineers \\ Clean Water Act \\ categorical exclusion \\ calendar year \\ DCG \\ derived concentration guide \\ DMR \\ Discharge Monitoring Report \\ DNAPL \\ dense nonaqueous phase liquid \\ DOE \\ U.S. Department of Energy \\ DOE-ORO \\ U.S. Department of Energy Oak Ridge Operations \\ DOT \\ U.S. Department of Transportation \\ EA \\ EAD \\ EDE \\ EMD \\ EML \\ Environmental Assessment \\ environmental assessment determination \\ effective dose equivalent \\ Environmental Monitoring Department \\ Environmental Measurements Laboratory \\ EMP \\ Environmental Monitoring Plan
}




\section{Environmental Report-Paducah}

Energy Systems
EPA
ER
ERP
ES\&H
ESD
ISO
ESP

FDA

FFCA

IIIFRA

ISSAR

IFY

GC/MS

GR

GiWPP

HAP

HARM

HEPA

$\mathrm{HF}$

IISS

HSWA

ICP

ICRP

IC25

IRIS

KAR

KDAQ

KDEP

KDOW

KDWM

KPDES

L.BC

LCR

LDR

LDS

I.L.D

L.LW

LUK

MAK

Max

MCL

MDL

Min

MOU

MW
Martin Marietta Energy Systems, Inc.

U.S. Environmental Protection Agency

Environmental Restoration

Environmental Restoration Program

Environmental Safety and Health

Environmental Sciences Division

Engineering Service Order

electrostatic precipitator

Food and Drug Administration

Federal Facilities Compliance Agreement

Federal Insecticide, Fungicide, and Rodenticide $A c t$

Facility Safety Analysis Report

fiscal year

gais chromatograph/mass spectrometer

Grahamville

Groundwater Protection Program Plan

hazardous air pollutants

Hazardous Atmospheric Release Model

high-efficiency particulate air

hydrogen fluoride

Hydrogeologic Services Section

Hazardous Solid Waste Amendments

inductively coupled plasma

International Commission on Radiological Protection

$25 \%$ inhibition concentration

Integrated Risk Information System

Kentucky Administrative Regulations

Kentucky Division for Air Quality

Kentucky Department for Environmental Protection

Kentucky Division of Water

Kentucky Division of Waste Management

Kentucky Pollutant Discharge Elimination System

Little Bayou Creek (also LUK)

lowest concentration reported

land disposal restricted

laboratory data system

lower limit of detection

low-level waste

Little Bayou Creek (also LBC)

Massac Creek

maximum

maximum contaminant

minimum detection level

minimum

memorandum of understanding

monitoring well 


\begin{tabular}{|c|c|}
\hline NEPA & National Environmental Policy Act \\
\hline NESHAP & National Emission Standards for Hazardous Air Pollutants \\
\hline $\mathrm{NIOSH}$ & National Institute for Occupational Safety and Health \\
\hline NIST & National Institute of Standards and Technology \\
\hline NOEC & no-observed-effect concentration \\
\hline NOV & Notice of Violation \\
\hline $\mathrm{NO}_{\mathrm{x}}$ & nitrogen oxides \\
\hline NPDES & National Pollutant Discharge Elimination System \\
\hline NPL & National Priorities List \\
\hline NRC & National Response Center \\
\hline OCB & oil circuit breaker \\
\hline ODSs & ozone-depleting substances \\
\hline ORNL & Oak Ridge National Laboratory \\
\hline ORO & Oak Ridge Operations \\
\hline PAT & Proficiency Analytical Testing \\
\hline PCB & polychlorinated biphenyl \\
\hline PD & potential device \\
\hline PE & plant east \\
\hline PEC & Performance Evaluation Committee \\
\hline PET & Proficiency Environmental Testing \\
\hline PGDP & Paducah Gaseous Diffusion Plant \\
\hline PIP & Plant Improvement Program \\
\hline PN & plant north \\
\hline PPE & personal protective equipment \\
\hline PVC & polyvinylchloride \\
\hline PW & plant west \\
\hline QA & quality assurance \\
\hline QC & quality control \\
\hline QSS & Quality Support Section \\
\hline RCRA & Rcsource Conservation and Recovery Act \\
\hline $\mathrm{RCW}$ & recirculating cooling water \\
\hline RfD & reference dose \\
\hline RFI & RCRA Facility Investigation \\
\hline RGA & regional gravel aquifer \\
\hline $\mathrm{RI} / \mathrm{FS}$ & Remedial Investigation/Feasibility Study \\
\hline RMW & radioactive mixed waste \\
\hline RUs & requirement units \\
\hline SARA & Superfund Amendments and Reauthorization Act \\
\hline SCS & Spill Containment System \\
\hline SDWA & Safe Drinking Water Act \\
\hline SEN & Secretary of Energy Notice \\
\hline SGS & shallow groundwater system \\
\hline SIE & specific ion electrode \\
\hline SMP & Site Management Plan \\
\hline $\mathrm{SO}_{2}$ & sulfur dioxide \\
\hline SS & Safeguards and Security \\
\hline SWMU & solid waste management unit \\
\hline
\end{tabular}




\section{Environmental Report-Paducah}

$\begin{array}{ll}\text { TC } & \text { technetium } \\ \text { TCA } & \text { trichloroethane } \\ \text { TCE } & \text { trichloroethylene } \\ \text { TCL } & \text { Target Compound List } \\ \text { TCLP } & \text { Toxicity Characteristic Leachate Procedure } \\ \text { TLD } & \text { thermoluminescent dosimeter } \\ \text { TOC } & \text { total organic carbon } \\ \text { TSCA } & \text { Toxic Substances Control Act } \\ \text { TSS } & \text { total suspended solids } \\ \text { TQM/UEPIP } & \text { Total Quality ManagementUranium Enrichment Performance Improvement Project } \\ \text { TUC } & \text { chronic toxicity unit } \\ \text { TVA } & \text { Tennessee Valley Authority } \\ & \\ \text { UCRS } & \text { Upper Continental Recharge System } \\ \text { UF6 } & \text { uranium hexafluoride } \\ \text { UK } & \text { University of Kentucky } \\ \text { USFWA } & \text { U.S. Fish and Wildlife Service } \\ \text { USGS } & \text { U.S. Geological Survey } \\ \text { UST } & \text { underground storage tank } \\ & \\ \text { VOC } & \text { volatile organic compound } \\ \text { WMIS } & \text { Waste Management Information System } \\ \text { WKWMA } & \text { West Kentucky Wildlife Management Area }\end{array}$




\section{Units}

\begin{tabular}{ll}
$\mathrm{Bq}$ & Becquerel \\
$\mathrm{Btu}$ & British thermal unit \\
${ }^{\circ} \mathrm{C}$ & degrees celsius \\
$\mathrm{cfm}$ & cubic feet per minute \\
$\mathrm{Ci}$ & curie \\
$\mathrm{cm}$ & centimeter \\
$\mathrm{cm}^{2}$ & square centimeter \\
$\mathrm{cm}^{3}$ & cubic centimeter \\
$\mathrm{CY}$ & calendar year \\
$\mathrm{d}$ & day \\
${ }^{\circ} \mathrm{F}$ & degrees Fahrenheit \\
$\mathrm{ft}$ & foot \\
$\mathrm{ft}^{2}$ & square foot \\
$\mathrm{ft}$ & cubic foot \\
$\mathrm{FY}$ & fiscal year \\
$\mathrm{g}$ & gram \\
$\mathrm{gal}$ & gallon \\
$\mathrm{gpd}$ & gallons per day \\
$\mathrm{gpm}$ & gallons per minute \\
$\mathrm{h}$ & hour \\
$\mathrm{ha}$ & hectare \\
$\mathrm{in}$. & inch \\
$\mathrm{kg}$ & kilogram \\
$\mathrm{kt.l}$ & kilometer \\
$\mathrm{km}$ & square kilometer \\
$\mathrm{L}$ & liter \\
$\mathrm{lb}$ & pound \\
\hline
\end{tabular}

$\begin{array}{ll}\mathrm{m} & \text { meter } \\ \mathrm{M} & \text { million } \\ \mathrm{m}^{2} & \text { square meter } \\ \mathrm{m}^{3} & \text { cubic meter } \\ \mathrm{mCi} & \text { millicurie } \\ \mathrm{mg} & \text { milligram } \\ \mathrm{Mgd} & \text { million gallons per day } \\ \mathrm{mile} & \text { square mile } \\ \mathrm{min} & \text { minute } \\ \mathrm{mL} & \text { milliliter } \\ \mathrm{mm} & \text { millimeter } \\ \mathrm{mrad} & \text { millirad } \\ \mathrm{mrem} & \text { millirem } \\ \mathrm{oz} & \text { ounces } \\ \mu \mathrm{Ci} & \text { microcurie } \\ \mu \mathrm{g} & \text { microgram } \\ \mathrm{NTU} & \text { nephelometric turbidity unit } \\ \mathrm{pCi} & \text { picocuric } \\ \mathrm{ppb} & \text { parts per billion } \\ \mathrm{ppm} & \text { parts per million } \\ \mathrm{ppt} & \text { parts per trillion } \\ \mathrm{s} & \text { second } \\ \mathrm{SU} & \text { standard unit } \\ \mathrm{temp} & \text { temperature } \\ \mathrm{TUa} & \text { acute toxicity units } \\ \mathrm{yd} & \text { cubic yard } \\ & \end{array}$

\begin{tabular}{|c|c|c|c|c|c|}
\hline \multicolumn{6}{|c|}{ Conversion Table } \\
\hline Multiply & By & To obtain & Multiply & By & To obtain \\
\hline acre & 0.405 & ha & ha & 2.47 & acres \\
\hline in. & 2.54 & $\mathrm{~cm}$ & $\mathrm{~cm}$ & 0.394 & in. \\
\hline $\mathrm{ft}$ & 0.305 & $\mathrm{~m}$ & $\mathrm{~m}$ & 3.28 & $\mathrm{ft}$ \\
\hline mile & 1.61 & $\mathrm{~km}$ & $\mathrm{~km}$ & 0.621 & mile \\
\hline $\mathrm{lb}$ & 0.4536 & $\mathrm{~kg}$ & $\mathrm{~kg}$ & 2.205 & $\mathrm{lb}$ \\
\hline liq qt-U.S. & 0.946 & $\mathrm{~L}$ & $\mathrm{~L}$ & 1.057 & lig qt-U.S. \\
\hline $\mathrm{ft}^{2}$ & 0.093 & $\mathrm{~m}^{2}$ & $\mathrm{~m}^{2}$ & 10.764 & $\mathrm{ft}^{2}$ \\
\hline $\operatorname{mile}^{2}$ & 2.59 & $\mathrm{~km}^{2}$ & $\mathrm{~km}^{2}$ & 0.386 & mile ${ }^{2}$ \\
\hline $\mathrm{ft}^{3}$ & 0.028 & $m^{3}$ & $m^{3}$ & 35.31 & $\mathrm{ft}^{3}$ \\
\hline $\mathrm{Bq}$ & 27 & $\mathrm{pCi}$ & $\mathrm{pCi}$ & 0.037 & $\mathrm{~Bq}$ \\
\hline $\mathrm{nCi}$ & $1 \times 10^{3}$ & $\mathrm{pCi}$ & $\mathrm{pCi}$ & $1 \times 10^{-3}$ & $\mathrm{nCi}$ \\
\hline $\mathrm{dpm} / \mathrm{L}$ & $0.45 \times 10^{-9}$ & $\mu \mathrm{Ci} / \mathrm{cm}^{3}$ & $\mu \mathrm{Ci} / \mathrm{cm}^{3}$ & $2.22 \times 10^{9}$ & $\mathrm{dpm} / \mathrm{L}$ \\
\hline $\mathrm{pCi} / \mathrm{L}$ (water & $10^{-9}$ & $\mu \mathrm{Ci} / \mathrm{mL}$ (water) & $\mu \mathrm{Ci} / \mathrm{mL}$ (water) & $10^{9}$ & $\mathrm{pCi} / \mathrm{L}$ (water) \\
\hline $\mathrm{pCi} / \mathrm{m}^{3}$ (air) & $10^{-12}$ & $\mu \mathrm{Ci} / \mathrm{cm}^{3}$ (air) & $\mu \mathrm{Ci} / \mathrm{cm}^{3}$ & $10^{12}$ & $\mathrm{pCi} / \mathrm{m}^{3}$ (air) \\
\hline $\mathrm{mCi} / \mathrm{km}^{2}$ & 1 & $\mathrm{nCi} / \mathrm{m}^{2}$ & $\mathrm{nCi} / \mathrm{m}^{2}$ & 1 & $\mathrm{mCi} / \mathrm{km}^{2}$ \\
\hline sievert (Sv) & 100 & rem & rem & 0.01 & sievert $(\mathrm{S} v)$ \\
\hline
\end{tabular}


PART 1: Narrative, Summaries, and Conclusions 


\section{Site Description and Setting}

1.1 Operations on the Paducah Gaseous

Diffusion Plant (PGDP) Site . . . . . . . . . . 1-3

1.2 Regional Demography . . . . . . . . . . . . . 1-4

1.3 Surface Water . . . . . . . . . . . . . . 1-4

1.4 Groundwater . . . . . . . . . . . . . . . . . 1-4

1.5 Climate . . . . . . . . . . . . . . . . . . 1-4

1.6 Applicable Environmental Requirements ... 1-6

1.7 Environmental Program Information ....... 1-11

1.7.1 Waste Minimization Program ...... 1-11

1.7.2 1993 Program Plan ... . . . . . . . . . 1-12

1.7.3 Long-Term Program Strategy . . . . . . 1-13

1.7.4 Pollution Prevention Program ...... . 1-14

1.7.5 1992 Environmental

Self-Assessments . . . . . . . . . . . 1-14

1.7.6 PCB Program . . . . . . . . . . . . . 1-15

1.8 Environmental Training . . . . . . . . . . . 1-15

1.9 Reference . . . . . . . . . . . . . . . . 1-15 


\section{Site Description and Setting}

This report presents environmental data and supporting narratives for the U.S. Department of Energy's (DOE's) Paducah Reservation Environmental Monitoring Program during 1992. Part 1 includes all narrative descriptions, summaries, and conclusions and is intended to be a "stand-alone" report for the reader who does not want to review in detail all of the 1992 data. Part 2 includes the detailed data summarized in a format designed to ensure that environmental data of interest to regulators or the public are represented in the tables. Narratives are generally not includcu in Part 2.

\subsection{Operations on the Paducah Gaseous Diffusion Plant (PGDP) Site}

PGDP is an active uranium enrichment facility consisting of a diffusion cascade and extensive support facilities. Construction of PGDP began in 1951. The plant began operating in 1952 and was fully operational by 1955 , supplying enriched uranium for commercial reactors and military defense reactors. Enriched uranium is uranium in which the concentration of the fissionable ${ }^{235} \mathrm{U}$ has been increased. Natural uranium is mostly ${ }^{238} \mathrm{U}$ with about $0.72 \%{ }^{235} \mathrm{U}$ and $0.0051 \%{ }^{234} \mathrm{U}$. Uranium mills process the ores to produce a concentrated uranium oxide, $\mathrm{U}_{3} \mathrm{O}_{8}$, that is then commercially converted to gaseous uranium hexafluoride $\left(U F_{6}\right)$ for enrichment at a gaseous diffusion plant. The enrichment mechanism is based on the fact that a $U_{6}$ molecule containing ${ }^{235} \mathrm{U}$ is slightly lighter than a $\mathrm{UF}_{6}$ molecule containing ${ }^{238} \mathrm{U}$. As the $\mathrm{UF}_{6}$ molecules move through the miles of tubing in a cascade system, slightly more ${ }^{235} \mathrm{U}$ than ${ }^{238} \mathrm{U}$ escapes through the small holes in the tubing. As the process of cascading is repeated, the ${ }^{235} \mathrm{U}$ concentration increases. About two-thirds of the ${ }^{235} \mathrm{U}$ in the natural ore is removed during enrichment, so there are two product streams: enriched uranium and depleted uranium tailings.

At present, uranium enriched at PGDP is further enriched at another DOE gaseous diffusion plant managed by Martin Marietta Energy Systems, Inc. (Energy Systems), in Portsmouth, Ohio. Most of the uranium from PGDP is ultimately designated for the commercial sector as fuel for nuclear power reactors in the United States and abroad. Typical ${ }^{235} \mathrm{U}$ enrichment for fuel use is $3 \%$ for commercial power reactors, $60 \%$ for the production reactor at the Savannah River site, and $97.3 \%$ for naval reactors. Depleted uranium is used for components in both nuclear and conventional weapons.

Extensive support facilities are required to maintain the diffusion process. These include a steam plant, four electrical switchyards, four sets of cooling towers, a chemical cleaning and decontamination facility, water and wastewater treatment plants, a chromium reduction facility, maintenance and laboratory facilities, and two active landfills. Several inactive facilities also are located on the plant site.

The area surrounding PGDP is predominantly rural. Residences and farms surround the plant. Immediately adjacent to PGDP is the West Kentucky Wildlife Management Area (WKWMA), which is used by a considerable number of hunters and fishers each year. Approximately 200 deer are harvested from the area each year through hunting. About 20 of the 35 ponds in the wildlife management area support fishing. One of the existing WKWMA ponds will be converted into a handicap access area. Work began in 1992 on the area's modification. PGDP was able to expedite and reduce the cost and effort of the project. An agreement allowed a subcontractor to excavate soil from the pond area for use in a plant project. This reduced the effort and time for the WKWMA in earth 


\section{Environmental Report-Paducah, Part 1}

moving and fulfilled the need of the plant for clean soil while reducing transportation costs because of the pond's proximity to the plant. Figures 1.1 and 1.2 show the geographic location of PGDP.

\subsection{Regional Demography}

The WKWMA and lightly populated farmland are in the immediate environs of PGDP. The population within the $80-\mathrm{km}$ (50-mile) radius is about 300,500 persons. Of these, about 39,500 live within $16.1 \mathrm{~km}$ (10 miles) of the plant; about 104,000 live within $32.2 \mathrm{~km}$ (20 miles). The unincorporated communities of Grahamville and Heath are located 2 to $3 \mathrm{~km}$ ( 1.24 to 1.86 miles) east of the plant. Portions of 28 counties, 11 of which are in Kentucky, 4 in Missouri, 10 in Illinois, and 3 in Tennessee, are included within an $80-\mathrm{km}$ (50-mile) radius of the plant. The largest cities in the region are Paducah, Kentucky, located $\sim 16$ air kilometers (10 miles) east of the plant, and Cape Girardeau, Missouri, located $\sim 64$ air kilometers (40 miles) to the west (U.S. Department of Commerce April 1991).

Figures 1.3-1.6 show the local and regional demography by sectors and annuli as well as by density.

\subsection{Surface Water}

PGDP is located in the western part of the Ohio River basin. The confluence of the Ohio River with the Tennessee River is approximately $24.1 \mathrm{~km}$ (15 miles) upstream of the site, and the confluence of the Ohio River with the Mississippi River is approximately $90.1 \mathrm{~km}$ (35 miles) downstream. PGDP is located within the drainage areas of Big Bayou and Little Bayou creeks, which meet about $4.8 \mathrm{~km}$ (3 miles) north of the site and discharge into the Ohio River. (See Figs. 1.7 and 1.8.)

PGDP is located on a local drainage divide; surface flow is east-northeast toward Little Bayou Creek and west-northwest toward Big Bayou Creek. Big Bayou Creek is a perennial stream whose drainage extends from approximately $4 \mathrm{~km}$ (2.5 miles) south of PGDP to the Ohio River. The creek flows toward the river along a $14.5-\mathrm{km}$ ( 9 -mile) course that passes along the western boundary of the plant. Little Bayou Creek, an intermittent stream, originates in the wildlife management area and flows north toward the Ohio River along a $10.5-\mathrm{km}$ (6.5-mile) course that includes parts of the eastern boundary of the plant. Big Bayou Creek has a 4819-ha (11,910-acre) drainage basin, and the watershed for Little Bayou Creek consists of about 2428 ha (6000 acres).

During dry weather much of the flow in both creeks is from liquid releases from PGDP. Effluents from PGDP operations constitute about $85 \%$ of the normal flow in Big Bayou Creek and 100\% in Little Bayou Creek.

\subsection{Groundwater}

The regional gravel aquifer (RGA) is the uppermost aquifer underlying most of PGDP and the contiguous area north. This groundwater flow system is developed primarily in Pleistocene sands and gravels of the lower member of the Continental Deposits, occurring between 13 and $33 \mathrm{~m} \mathrm{(43}$ and $100 \mathrm{ft}$ ) beneath PGDP. The upper member of the Continental Deposits is predominately composed of silt and clay with interbedded sand and gravel lenses. A layer of loess 3 to $10 \mathrm{~m}$ ( 10 to $30 \mathrm{ft}$ ) thick overlies the Continental Deposits at the surface. The Continental Deposits rest upon terraces cut by the ancestral Tennessee and Tennessee-Ohio rivers. Terrace escarpments under the south end of PGDP form the southern limit of the RGA.

Groundwater flow in the loess and the upper member of the Continental Deposits is primarily oriented downward because of the discontinuous nature of the interbedded sand and gravel lenses and the significantly lower potentiometric surface of the RGA. Within the RGA, flow is directed north, discharging into the Ohio River.

\subsection{Climate}

Paducah is located in the humid continental zone. Summers are generally dry; precipitation occurs mainly in the spring and fall. Winters are characterized by moderately cold days; the average temperature during the coldest month, January, is about $1.7^{\circ} \mathrm{C}\left(35^{\circ} \mathrm{F}\right)$. Summers are warm and humid; the average temperature in July is about $26^{\circ} \mathrm{C}\left(79^{\circ} \mathrm{F}\right)$. Yearly precipitation averages about $120 \mathrm{~cm}$ (47 in.). The prevailing wind direction is south-southwest. 
ORNL-DWG 92M-5978

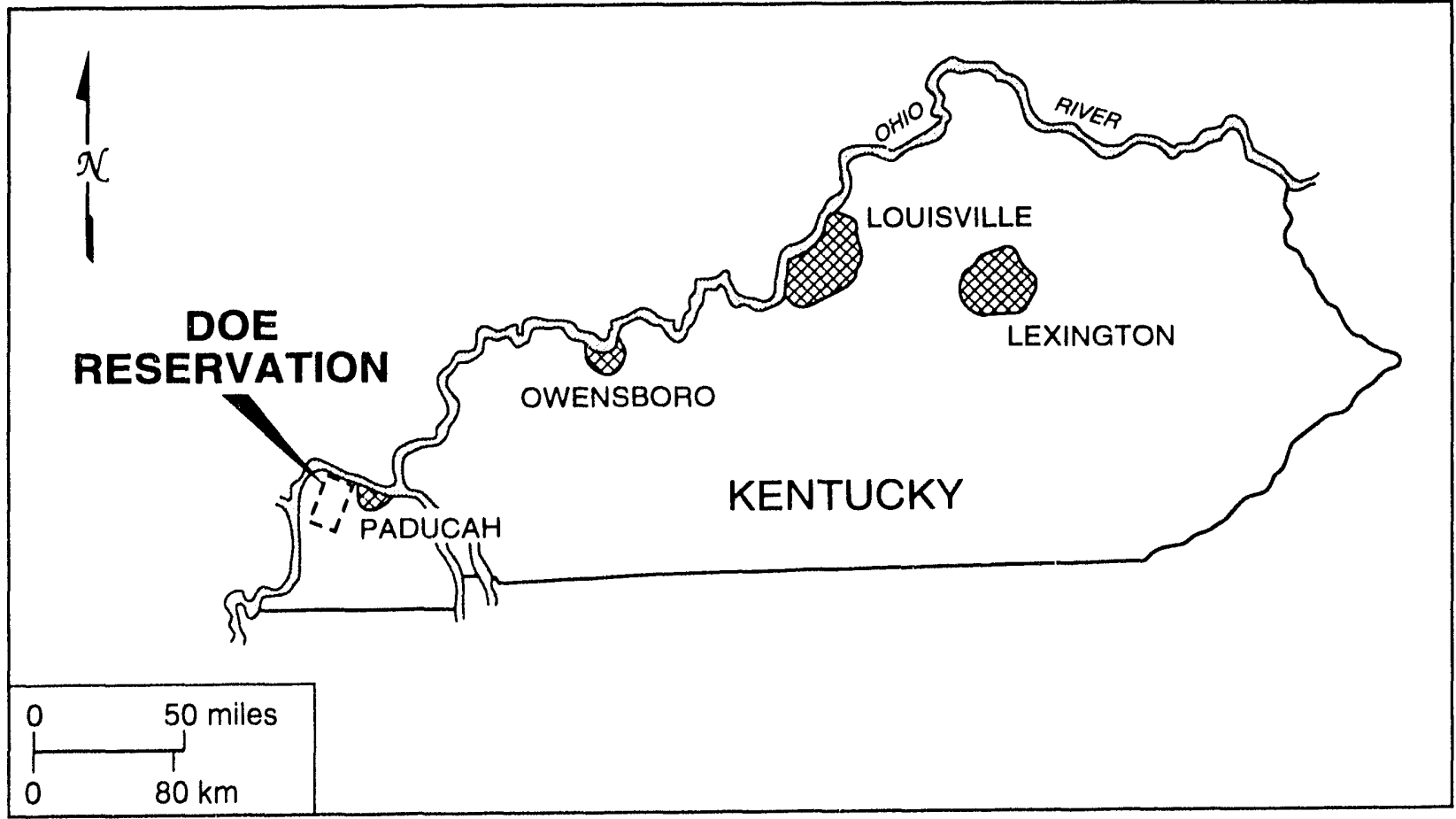

Fig. 1.1. Map showing the location of the U.S. DOE's Paducah Reservation in Kentucky.

ORNL-DWG 92M-5977

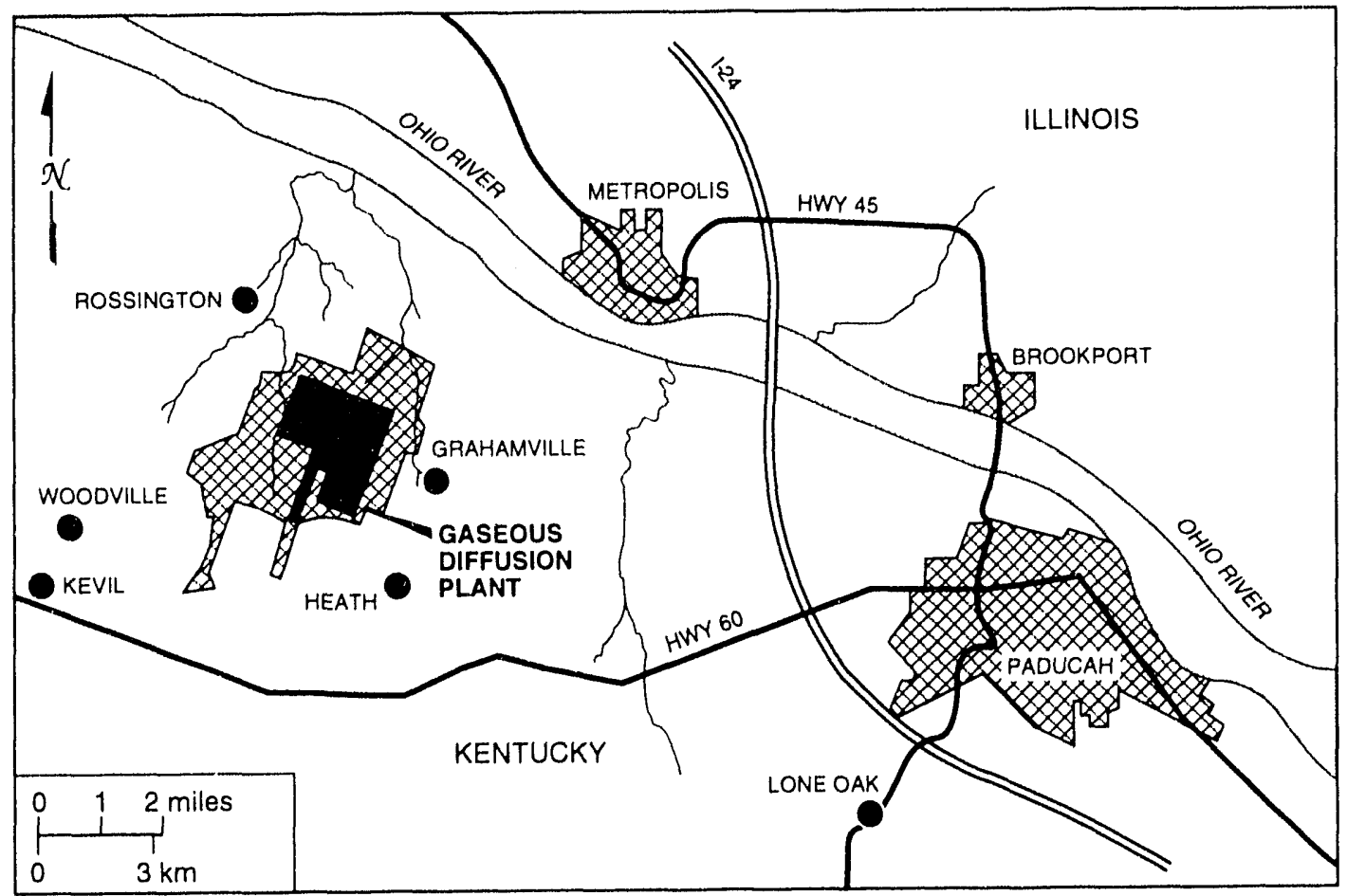

Fig. 1.2. Map showing the location of PGDP in relationship to the geographic region. 


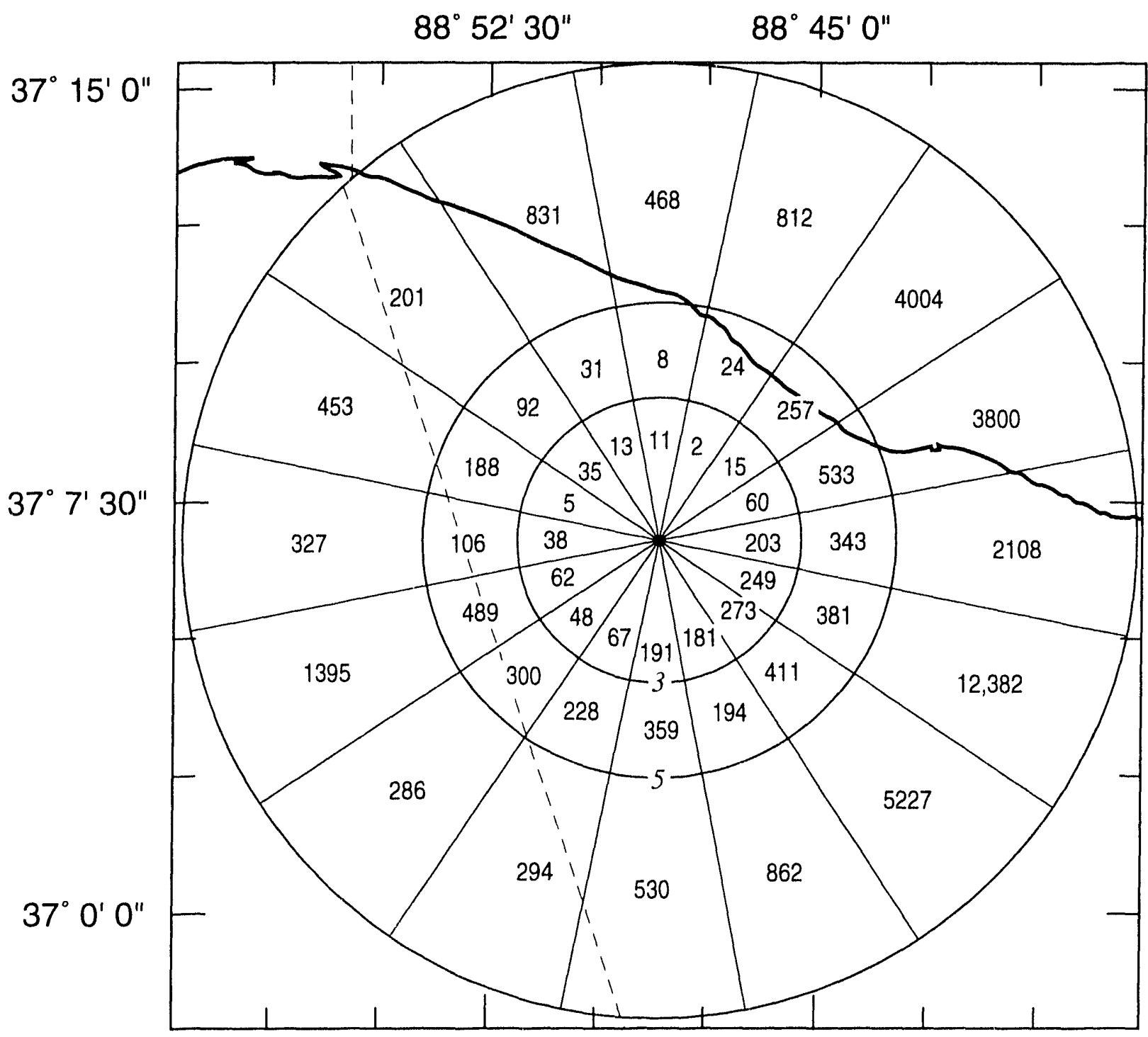

10 MILES

Fig. 1.3. Population distribution projected to 1992 in a 16-km (10-mile) radius of PGDP.

\subsection{Applicable Environmental Requirements}

It is PGDP policy to minimize or eliminate waste generation and to protect people and the environment. Internal procedures have been established and implemented to accomplish these tasks. Under the authority of the Atomic Energy Act, DOE has issued numerous environmental orders covering waste minimization, pollution control, effluent and environmental monitoring, and periodic reporting.
These orders are listed in Table 1.1 and are discussed in Sect. 1.7. Federal regulations that are designed to implement various federal laws and that apply to PGDP include the Clean Air Act; the Clean Water Act; the Toxic Substances Control Act (TSCA); the National Emissions Standards for Hazardous Air Pollutants; the Resource Conservation and Recovery Act (RCRA); the Safe Drinking Water Act; the Superfund Amendments and Reauthorization Act; the National Environmental Policy Act; and the Comprehensive Environmental Response, 


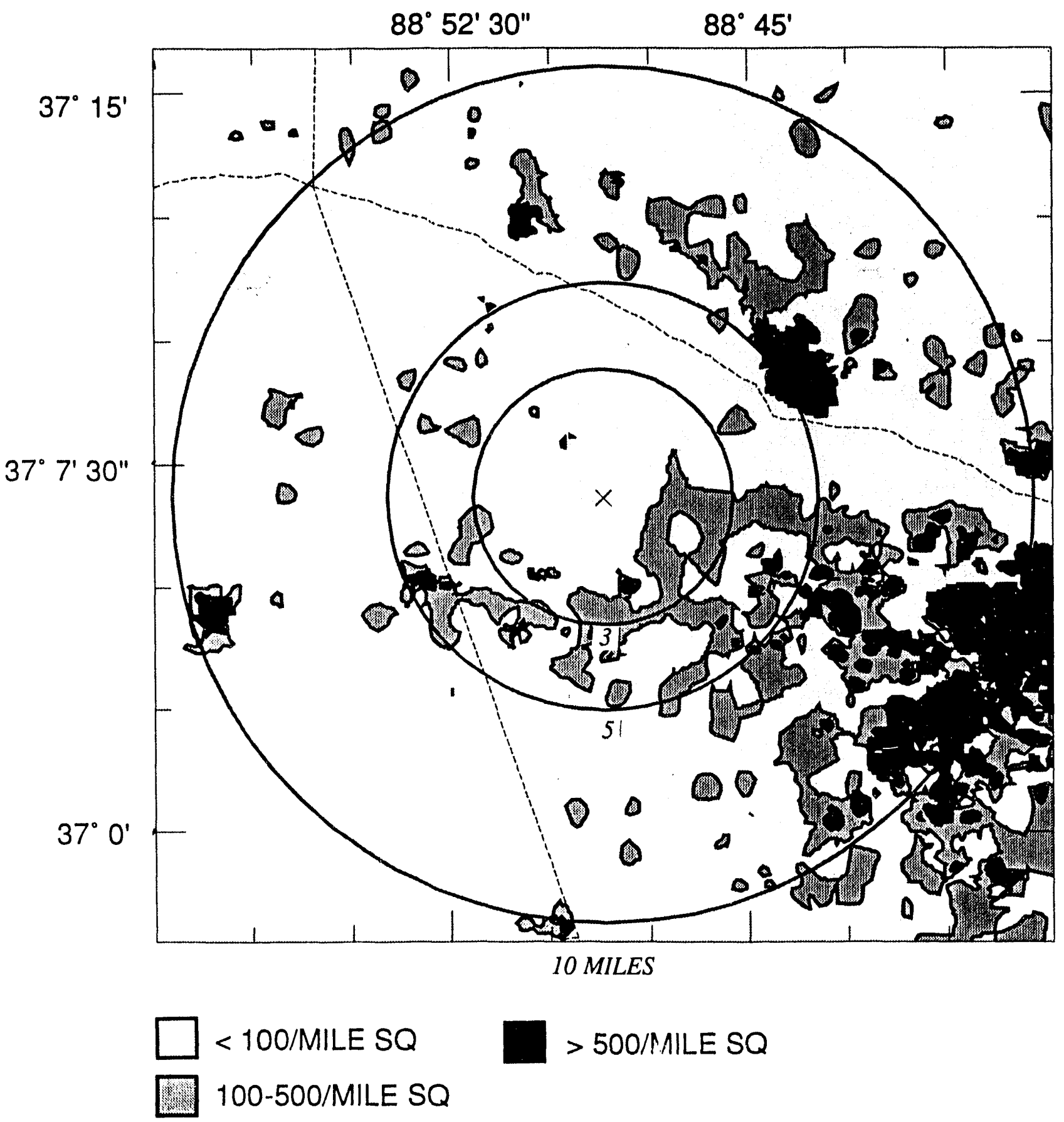

Fig. 1.4. Population density projected to 1992 in a $16-\mathrm{km}$ (10-mile) radius of PGDP. 
ORNL.DWG 93M-9604

$89^{\circ} 30^{\prime} \quad 89^{\circ} 15^{\prime} \quad 89^{\circ} 0^{\prime} \quad 88^{\circ} 45^{\prime} \quad 88^{\circ} 30^{\prime} \quad 88^{\circ} 15^{\prime} \quad 88^{\circ} 0^{\prime}$

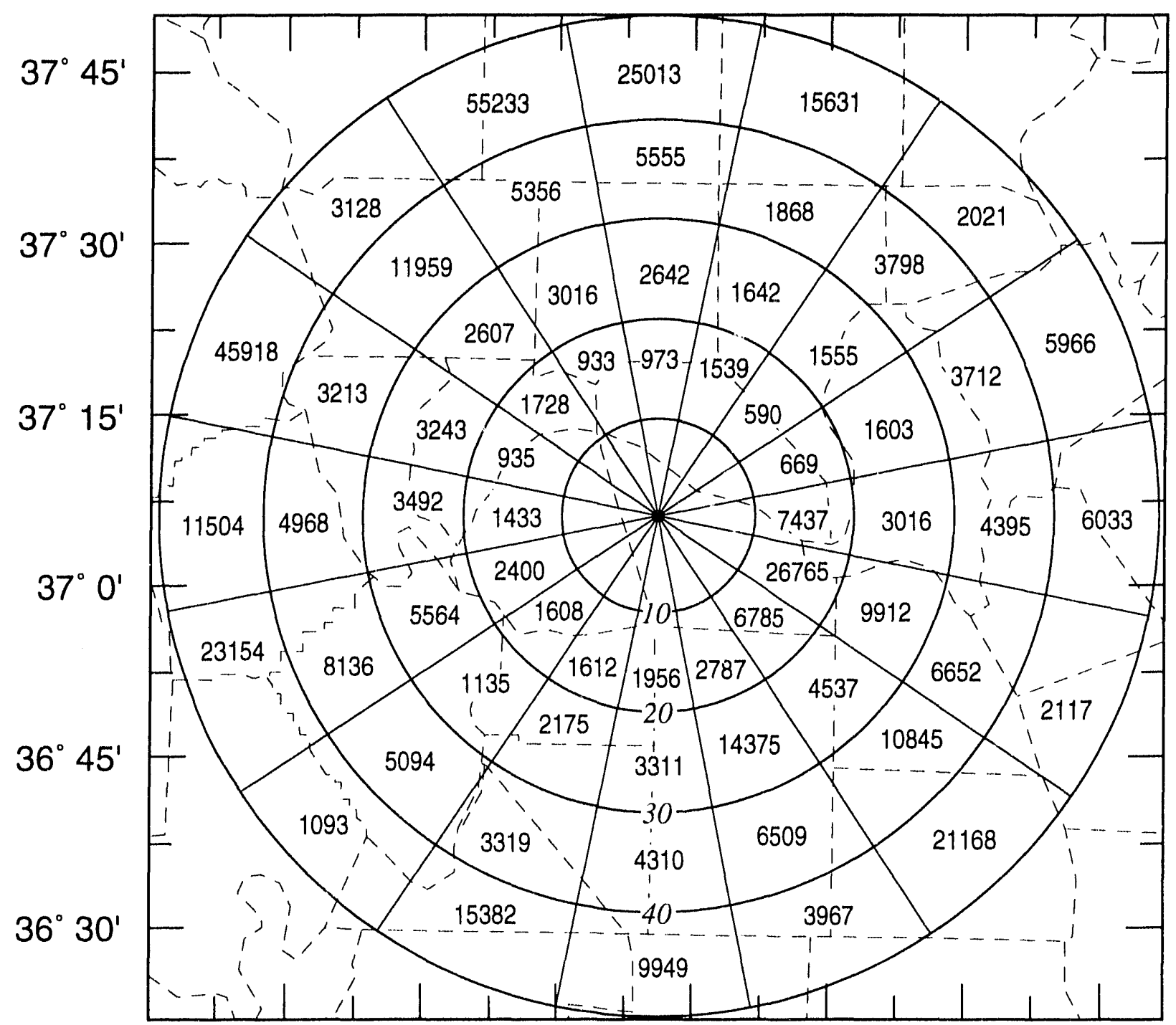

50 MILES

Fig. 1.5. Population distribution projected to 1992 in an 80-km (50-mile) radius of PGDP. 
$89^{\circ} 45^{\prime} \quad 89^{\circ} 30^{\prime} \quad 89^{\circ} 15^{\prime} \quad 89^{\circ} 00^{\prime} \quad 88^{\circ} 45^{\prime} \quad 88^{\circ} 30^{\prime} \quad 88^{\circ} 15^{\prime} \quad 88^{\circ} 00^{\prime}$

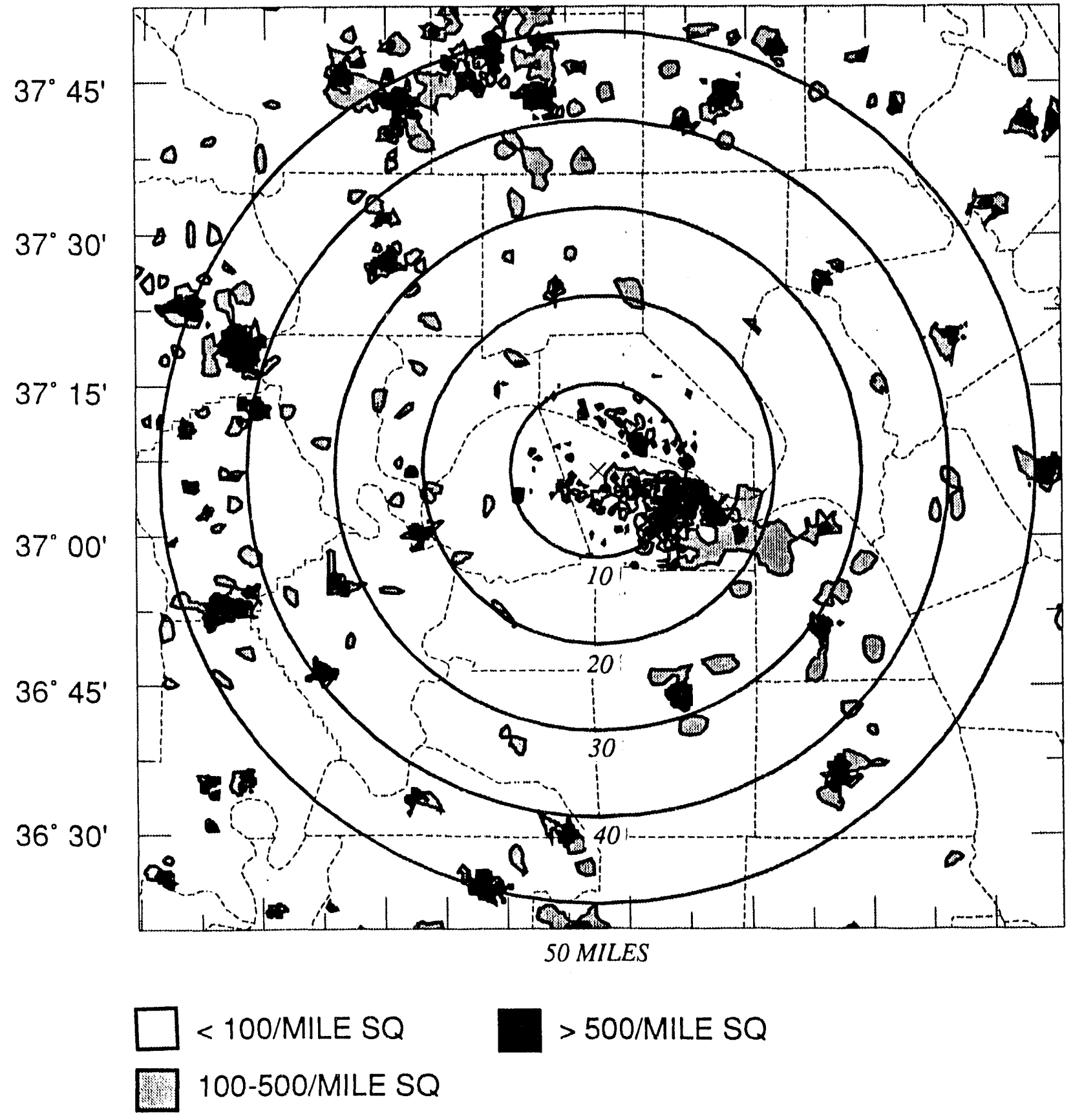

Fig. 1.6. Population density projected to 1992 in an 80-km (50-mile) radius of PGDP. 
1992 Environmental Report-Paducah, Part 1

ORNL-DWG 87M-8429R

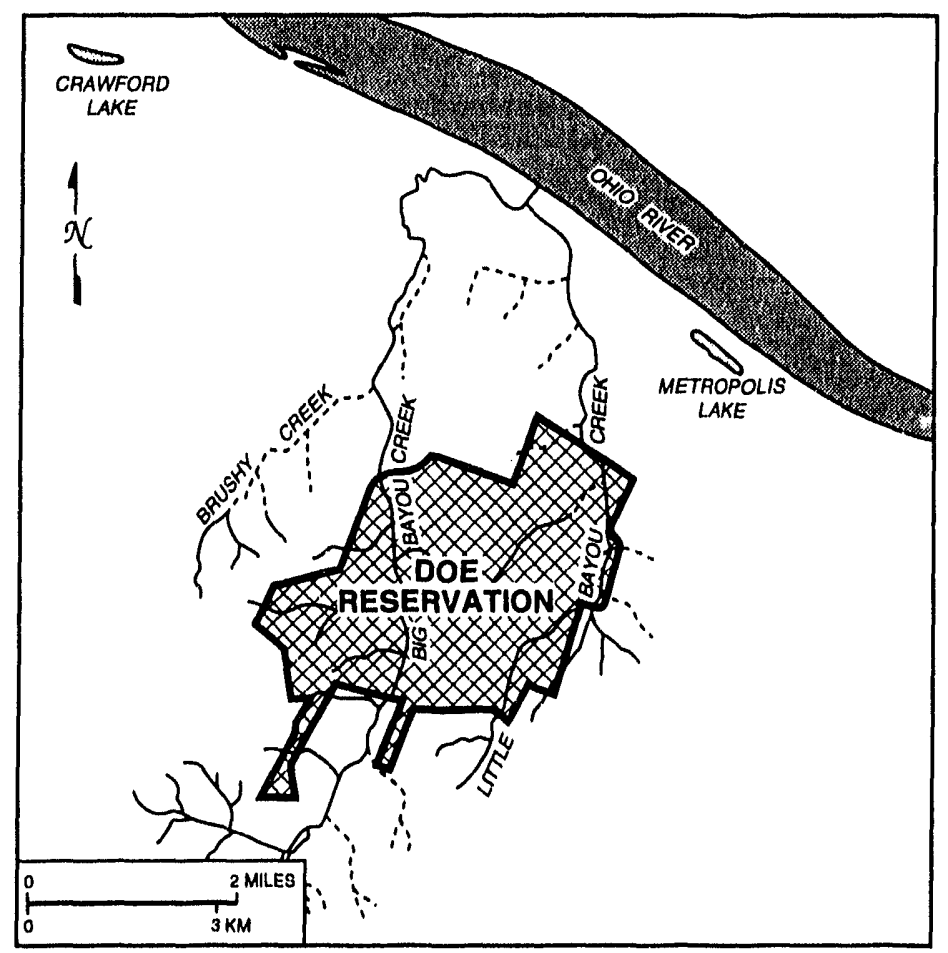

Fig. 1.7. Local PGDP surface hydrology systems. (Broken lines represent wet-weather streams.)

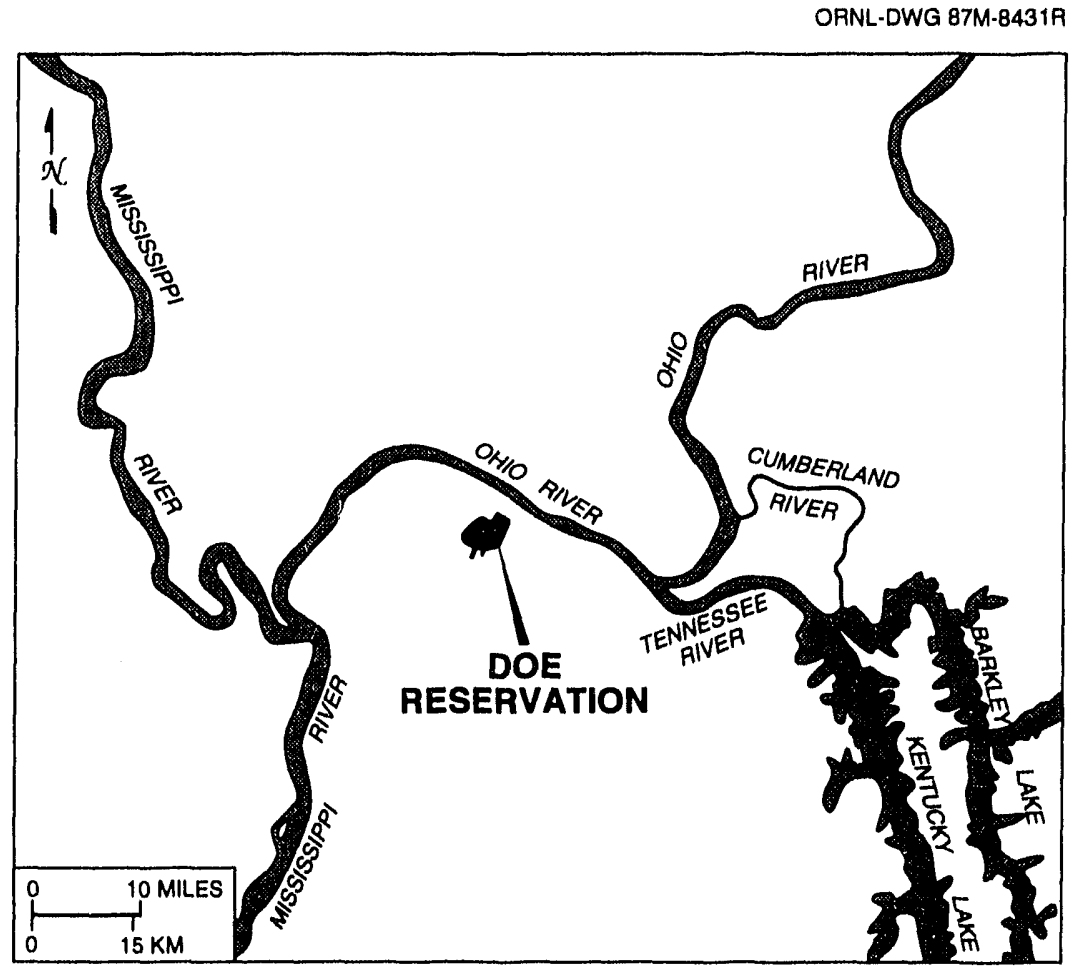

Fig. 1.8. The regional area primary surface hydrology system. 
Table 1.1. Environmental Department of Energy (DOE) order compliance status

\begin{tabular}{cccccc}
\hline DOE Order & Total RUs $^{b}$ & Full compliance & Partial compliance & Noncompliance & Not applicable \\
\hline 1540.2 & 24 & 0 & 6 & 13 & 5 \\
5400.1 & 20 & 17 & 0 & 0 & 3 \\
5400.3 & 1 & 0 & 0 & 0 & 1 \\
5400.4 & 6 & 4 & 2 & 0 & 0 \\
5400.5 & 29 & 17 & 0 & 0 & 12 \\
$5440.1 \mathrm{E}$ & 1 & 1 & 0 & 0 & 0 \\
$5480.1 \mathrm{~B}$ & 1 & 0 & 0 & 0 & 1 \\
5480.3 & 66 & 1 & 17 & 8 & 56 \\
5480.4 & 132 & 61 & 13 & 2 & 8 \\
5484.1 & 20 & 12 & 0 & 0 & 0 \\
$5500.1 \mathrm{~B}$ & 7 & 7 & 0 & 0 & 1 \\
$5500.2 \mathrm{~B}$ & 23 & 20 & 2 & 0 & 0 \\
$5700.6 \mathrm{~B}$ & 12 & 0 & 12 & 0 & 56 \\
\hline
\end{tabular}

"1540.2, "Hazardous Material Packaging for Transport"; 5400.1 , "General Environmental Protection Program"; 5400.3, "Hazardous and Radioactive Mixed Waste Program"; 5400.4, "Comprehensive Environmental Response, Compensation, and Liability Act Requirements"; 5400.5, "Radiation Protection of the Public and the Environment"; 5440.1E, "National Environmental Policy Act Compliance Program"; 5480.1B, "Environmental, Safety, and Health Programs"; 5480.3, "Safety Requirements for the Packaging and Transportation of Hazardous Materials, Hazardous Substances, and Hazardous Wastes"; 5480.4, "Environmental Protection, Safety, and Health Protection Standards"; 5484.1, "Environmental Protection, Safety, and Health Protection Information Reporting Requirements"; 5500.1B, "Emergency Management System"; 5500.2B, "Emergency Categories, Classes, and Notification and Reporting Requirements"; and 5700.6B, "Quality Assurance."

${ }^{b}$ Requirement units.

Compensation, and Liability Act. Kentucky environmental laws are implemented by regulations of the Cabinet for Natural Resources and Environmental Protection. Wastewater discharges; hazardous waste treatment, storage, and disposal; and waste management facilities are all permitted by the Cabinet for Natural Resources and Environmental Protection.

\subsection{Environmental Program Information}

\subsubsection{Waste Minimization Program}

Waste minimization is defined as any action that minimizes the volume or toxicity of a waste by avoiding or reducing its generation or by recycling it. Waste reduction is defined as waste minimization plus treatment that reduces the volume or toxicity of the waste. The PGDP Waste Minimization Program will include both waste minimization and waste reduction efforts.

RCRA requires the minimization of hazardous wastes; annual reporting on the progress of the program is required. DOE Order 5400.3 requires implementation of a waste minimization program for hazardous and mixed wastes. DOE Order 5820.2A requires DOE facilities to establish an auditable waste minimization program for all low-level waste (LLW) generators. DOE Order 5400.1 requires the preparation of a waste reduction program plan that must be reviewed annually and updated every 3 years. A new report required by Secretary of Energy Notice (SEN)-37-92, "Waste Minimization Crosscut Plan," will replace the DOE Order 5400.1 reporting requirements in 1993.

\subsubsection{Program Objectives}

The PGDP Waste Minimization Program was started in 1987. The program was given additional emphasis in 1992 through the creation of a full-time position of plant Waste Minimization Program manager. The Pollution Prevention Awareness Program will include the Waste Minimization Program.

The Waste Minimization Program includes both waste minimization and waste reduction activities and has the following objectives: 


\section{Environmental Report-Paducah, Part 1}

- the identification of waste minimization and reduction opportunities,

- the establishment of waste minimization and reduction goals,

- the prioritization of waste minimization and reduction efforts.

- the initiation of waste minimization and reduction projects (including pilot projects),

- the identification of waste minimization and reduction responsibilities and resource requirements, and

- the tracking and reporting of waste minimization and reduction projects and results.

\subsubsection{Program Organization}

The PGDP Waste Minimization Program is administered by the plant Waste Minimization Program manager in the Environmental and Waste Management Division. Record keeping and reporting are accomplished through the Waste Management Operations Department, which is also in the Environmental and Waste Management Division.

\subsubsection{Program Implementation}

In conjunction with the environmental policy departments and the Waste Management Operations Department, the Waste Minimization Program manager identifies waste streams that are high-priority minimization or reduction candidates based on the following factors:

- availability of storage space,

- waste stream hazard,

- availability of treatment and disposal facilities (both on- and off-site),

- regulatory compliance issues, and

- management and disposal costs.

Following the identification and prioritization of projects, the project listing is divided into two categories: projects that can be accomplished with existing resources and those that require additional resources. A project team for each individual project is established and chaired by the Waste Minimization Program manager. The project teams include members from the responsible organizations or facilities: Technical Operations and Technical Services divisions, the Process and Long-Range
Technical Support programs, the Waste Management Operations Department, and other organizations when necessary.

Large projects may take the form of a formal Total Quality Management (TQM) project. This is most likely to be the case when a significant investment in funding may be required or when the project could result in significant changes in facilities, systems, or operational procedures.

Following completion of the TQM or pilot project, the project team will make a recommendation to the Waste Minimization Program manager and to plant management concerning the project. Management will then make the final decision on whether to fully implement the project.

Projects undertaken for the Waste Minimization Program during 1992 are discussed in Subsect. 8.2.4 of this report.

\subsubsection{Program Plan}

\subsubsection{FY 1993 Program Goals}

The following plant milestones have been established for PGDP for FY 1993:

- Reduce PGDP waste generation as follows:

Polychlorinated biphenyl (PCB),

$\mathrm{PCB} /$ radioactive waste $\quad 10 \%$

Hazardous/mixed:

$\begin{array}{ll}\text { Waste oil } & 20 \% \\ \text { Aerosol cans } & 20 \% \\ \text { Solvent-laden rags } & 20 \% \\ \text { Photography wastes } & 20 \% \\ \text { Liquid paint wastes } & 20 \%\end{array}$

- Update the FY 1992 Waste Minimization Plan to reflect FY 1992 program changes.

- Submit an action plan identifying the necessary steps to eliminate use of Trichloroethylene and Trichloroethane from PGDP.

\subsubsection{Method of Accomplishing 1993 Goals}

During the latter part of 1992, each division was asked to appoint a person to serve as a waste minimization coordinator. The job function of the division coordinator will be to assist the Waste Minimization Program manager in accomplishing

\section{1-12 Site Description and Setting}


tasks within each division. Information flow for waste reduction projects and waste reduction project documentation will also be required from each coordinator.

A waste minimization implementation plan was issued that details divisional waste reduction and recycling project goals. Commitment dates were set, and persons responsible for implementation of each action were assigned. All projects will be tracked through the corrective actions data base, which issues monthly reminders of actions due to correct deficiencies and meet milestones.

The Waste Minimization Program manager will work with the Waste Management Operations Department to develop and implement an improved tracking procedure for reporting requirements. This effort will be coordinated with the various site representatives and with the TQM team that is developing the multisite data base.

\subsubsection{Long-Term Program Strategy}

The long-term strategy for the Waste Minimization Program includes working toward the FY 1993 goals on an ongoing basis. Several other long-term goals and strategies have also been identified.

\subsubsection{LLW Minimization}

The strategy for minimizing LLW includes

- establishment of nonradioactive material management areas,

- prevention of packaging material from entering radiological areas,

- replacement of pallets used in radiological areas,

- compaction or incineration of combustible LLW,

- compaction of noncombustible LLW,

- movement of metal working and equipment repair out of radiological areas where possible,

- decontamination of contaminated scrap metal, and

- investigation of wet-scrubbing for floor cleaning and elimination of the use of solid floor-sweeping compounds.

\subsubsection{Hazardous and Mixed Wastes}

Mixed waste streams are highly variable at PGDP - a large number of small-quantity waste streams exist. The major wastes include chlorinated solvents, aerosol cans, paint wastes, and laboratory wastes. The mixed waste reduction strategy includes

- establishment of nonradioactive material management areas (involving the reclassification of mixed wastes to hazardous wastes),

- elimination of chlorinated solvents in process buildings and shops,

- elimination of chlorinated solvents in the C-400 cleaning building's large vapor degreasers,

- paint waste recycling, and

- aerosol can replacement.

Although most of these projects are specific to a particular waste stream, a detailed review of all mixed waste streams will also be conducted to identify other potential minimization opportunities.

\subsubsection{PCB and PCB/Radioactive Wastes}

$\mathrm{PCB}$ and $\mathrm{PCB} /$ radioactive waste generation is controlled by regulatory requirements. The most significant waste generation activities include spill cleanup, site cleanups (under the Environmental Restoration Program), and equipment removal. Little opportunity exists for waste minimization in these areas, although some compaction of trash may be feasible. For the foreseeable future, however, efforts will be concentrated on the identification of technologies for the treatment of $\mathrm{PCB} /$ radioactive solid wastes. Liquid wastes will continue to be disposed of at the Oak Ridge TSCA incinerator.

\subsubsection{Residential Wastes}

Minimization of the generation of residential waste is unlikely. Increases in plant population will result in waste increases. However, disposal volume may be minimized through off-site recycling (of paper, cardboard, etc.) and through the continued 


\section{Environmental Report-Paducah, Part 1}

compaction of wastes prior to landfilling. The off-site disposal of some residential wastes such as cafeteria food wastes will reduce PGDP landfill usage but will not be true waste minimization or reduction.

\subsubsection{Data Management}

Better data management techniques will be required to track Waste Minimization Program and waste reduction results. A method of identifying causes for waste generation is essential. At present it is not possible to differentiate between spill cleanup, site cleanup, special projects, and routinely generated wastes with sufficient accuracy. Setting definitive waste minimization goals will be difficult until wastes over which PGDP has no control can be distinguished from those over which the plant does have control. The development of a better tracking and reporting system will take 1 to 2 years and is a long-term goal of the Waste Minimization Program.

\subsubsection{Pollution Prevention Program}

The PGDP Pollution Prevention Program is also directed by the plant Waste Minimization Program manager. Although the Waste Minimization Program focuses on the reduction of contained and solid wastes requiring handling by the Waste Management Department and on- or off-site disposal, the Pollution Prevention Program focuses on the reduction of direct discharges of wastes to the environment through air and water discharges.

The first step in implementing the program was taken in mid FY 1992-a review of air and water discharge point inventories and the Superfund Amendments and Reauthorization Act reporting requirements for chemical releases. This review identified opportunities for discharge reductions through process and operational improvements.

\subsubsection{Environmental Self-Assessments}

The Environmental Self-Assessment Program at PGDP is a multi-faceted program that includes internal environmental audits conducted by plant audit teams, internal audits conducted by audit teams from outside the plant, as well as programmatic audits and surveillances conducted by PGDP's Envir $:$ amental and Waste Management Division.
During CY 1992, two internal audits were performed to determine the effectiveness of PGDP's RCRA, TSCA, Clean Air Act, Clean Water Act, asbestos, and related sampling and record keeping programs. The first audit was conducted by a plant team in July 1992, and the second was conducted by a corporate team from Oak Ridge in October 1992. No major findings were discovered during the audits, and both teams indicated the audited programs had shown noticeable improvement.

During March 1992, a complete file and record audit of the RCRA Training Program was conducted. In addition, record audits for RCRA Part B-required tank inspections and for RCRA-required air emissions sampling were conducted during the months of June and July, respectively. Deficiencies discovered during these audits were corrected, strengthening the overall compliance capabilities of each program.

Another important segment of the overall self-assessment program is the monthly surveillances performed by personnel within the Environmental and Waste Management Division. These surveillances focus on specific segments of the various environmental programs and are performed on an unannounced basis.

An assessment of DOE order compliance was completed by Energy Systems for PGDP on September 30, 1992. Instructions for the assessment came from the Standards Development and Management Office. The orders were prioritized using the Energy Systems Risk Prioritization Matrix with level $A, B$, and $C$ categories, with level $A$ comprising those orders involving environmental, safety, and health issues; safety; and quality assurance with potential for significant risk or impact. These orders were further subdivided into requirement units (RUs) that appear to be performed by a functional area. Overall compliance for category A orders was $47 \%$ in full compliance, $9 \%$ in partial compliance, $5 \%$ in noncompliance, and $18 \%$ not applicable. An evaluation of orders in category $\mathrm{A}$ that apply to environmental areas minus those not applicable showed $65 \%$ in full compliance, $24 \%$ in partial compliance, and $11 \%$ in noncompliance. All noncompliant RUs occurred in three DOE orders: 1540.2, "Hazardous Material Packaging for Transport"; 5480.3, "Safety R equirements for the Packaging and Transportation of Hazardous

\section{1-14 Site Description and Setting}


Materials, Hazardous Substances, and Hazardous Wastes"; and 5480.4, "Environmental Protection, Safety, and Health Protection Standards." More detail on the breakdown of the category A orders can be found in Table 1.1.

\subsubsection{PCB Program}

The PCB Program at PGDP exists to ensure full compliance with regulations under TSCA by providing oversight for all plant operations. PCBrelated compliance problems will exist at PGDP until all sources of PCBs are removed or eliminated. Several steps have been taken toward this goal, including the reclassification or removal of electrical equipment and hydraulic systems containing PCBs, the use of dedicated equipment to prevent "crosscontamination," and the sampling of incoming oils and oil-containing equipment.

Although the program is geared primarily toward eliminating the sources of $\mathrm{PCB}$ compliance problems, PCBs and PCB items are used extensively at PGDP, especially in electrical equipment. Therefore, the program also must oversee the proper storage of $\mathrm{PCB}$ materials and wastes, the cleanup of PCB spills, the proper uses of PCB equipment and materials, and the implementation of compliance agreements such as the U.S. Environmental Protection Agency (EPA)-DOE Headquarters TSCA Federal Facilities Compliance Agreement.

Many systems, both electrical and otherwise, contain PCBs from detectable quantities to percentage levels. Seventy-two process transformers contain PCBs in concentrations above $500 \mathrm{ppm}$. One process lubricant oil system and several smaller systems contain detectable quantities of PCBs. Large, high-voltage PCB capacitors are used extensively throughout the process buildings and electrical switchyards. However, as previously stated, steps to reclassify or eliminate these items are under way. Many switchyard transformers have been treated to remove or lower the PCB concentrations through EPA-approved methods or have been taken out of service completely. An engineering project is under way to remove all switchyard capacitors and process capacitors containing PCBs. An engineering st.rvice order has been initiated to perform a risk assessment on the continued use of PCB transformers in the process buildings. Guidance is provided to line organizations, and procedures have been revised to ensure that incoming "new" oils and oil-containing systems continue to be certified as non-PCB by analysis before acceptance at the plant.

\subsection{Environmental Training}

CY 1992 saw full implementation of RCRA training as required by the PGDP Part B Permit and 401 KAR 34:020, Sect. 7.

Through a Part B Permit modification approved by the Kentucky Division of Waste Management, the list of plant personnel requiring RCRA training was revised and entered into a data base tracking system. A list is generated periodically from the data base that identifies individuals who are due training and the deadline date by which they must receive the training.

Using this system, PGDP was able to bring the required $R C R A$ training into full compliance as evidenced by a Septemoer 1992 Kentucky Division of Waste Management audit confirming that compliance had been accomplished.

In addition, 1992 saw the implementation of an improved data base tracking system for RCRA training and the initiation of a revision to the RCRA training procedure directed at clarifying roles and responsibilities and improving documentation.

Training for Environmental and Waste Management staff was provided through off-site classes covering such topics as a RCRA overview, regulations, emergency response, spill cleanup, health hazard recognition, and safety associated with PCBs and various environmentally pertinent issues.

\subsection{Reference}

U.S. Department of Commerce, Bureau of the Census. April 1991. 1990 Census of Population and Housing Public Law 94-171 Data, Washington, D.C. 


\section{Potential Radiation Dose to the Public}

2.1 Terminology $\ldots \ldots \ldots \ldots \ldots \ldots \ldots \ldots$

2.2 Waterborne Radionuclides ......... 2-3

2.3 Direct Radiation $\ldots \ldots \ldots \ldots$. . . . . . . .

2.4 Contaminated Sediment

in Little Bayou Creek . . . . . . . . . . . . . . . 2-5

2.5 Ingestion of Terrestrial Foodstuffs . . . . . $2-5$

2.6 Airborne Radionuclides . . . . . . . . . . . 2-6

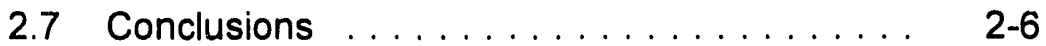

2.8 References . . . . . . . . . . . . . . . . . 2-7 


\section{Environmental Report-Paducah, Part 1}

\section{Potential Radiation Dose to the Public}

Paducah Gaseous Diffusion Plant (PGDP) discharges effluents, some of which are radioactive and some of which are chemically or biologically reactive. Waste minimization and pollution abatement systems reduce these effluents, and emission and environmental monitoring is used to evaluate these controls, to determine compliance with regulations, and to allow estimates of the radiation and chemical doses received by members of the public.

U.S. Department of Energy (DOE) Order 5400.5 limits the dose to members of the public to less than $100 \mathrm{mrem} /$ year effective dose equivalent from all pathways resulting from the operation of a DOE facility. Knowledge of the demography and land use of the area surrounding the plant and identification of on-site sources have indicated certain radionuclides and exposure pathways by which groups of people can be exposed to radiation. Figures 2.1 and 2.2 give a comprehensive view of the pathways between radioactive materials released to the environment and human beings. In practice, only a few pathways are the major sources of exposure in any given situation. A preliminary assessment of risk from PGDP contaminants to the health of the public living off-site was conducted by $\mathrm{CH} 2 \mathrm{M}$ Hill for the Phase I Site Investigation (CH2M Hill 1990). This study identified four primary pathways that could potentially contribute greater than $1 \%$ to the total off-site dose: groundwater ingestion, sediment ingestion, ingestion of wildlife and food crops, and exposure to direct radiation. To assess fully the potential dose to the public, a hypothetical group of extreme characteristics is used to postulate an upper limit to the dose of any real group. The assumptions used to calculate the dose from those exposures are summarized in Tables 2.1 through 2.6 in Part 2. In addition, the dose from all pathways from atmospheric releases is also calculated as required for compliance with the National Emission Standards for Hazardous Air Pollutants regulations. All dose estimates were rounded to approximate significant figures.

\subsection{Terminology}

Committed effective dose equivalent (CEDE) is the total internal dose (measured in mrem) received over a 50-year period resulting from the intake of radionuclides in a 1 -year period. The CEDE is the product of the annual intake $(\mathrm{pCi})$ and the dose conversion factor for each radionuclide $(\mathrm{mrem} / \mathrm{pCi})$.

Collective effective dose equivalent is a measure in person-rems of long-term radiation effects over a wide area. It is calculated by multiplying the average dose within defined areas by the number of persons living in that area.

Effective dose equivalent includes the committed effective dose equivalent from internal deposition of radionuclides and the dose from penetrating radiation from sources external to the body. This is a riskequivalent value and can be used to estimate the health-effects risk to the exposed individual.

\subsection{Waterborne Radionuclides}

Liquid effluents are monitored to determine the total quantity of waterborne radionuclides released to the environment. The concentrations of various radionuclides are measured in the creeks and in groundwater near the plant. A survey of surface water and groundwater users in the vicinity of PGDP was conducted in 1990 to determine the number of residents using water wells within a 4-mile radius of PGDP and to determine the number of surface water 


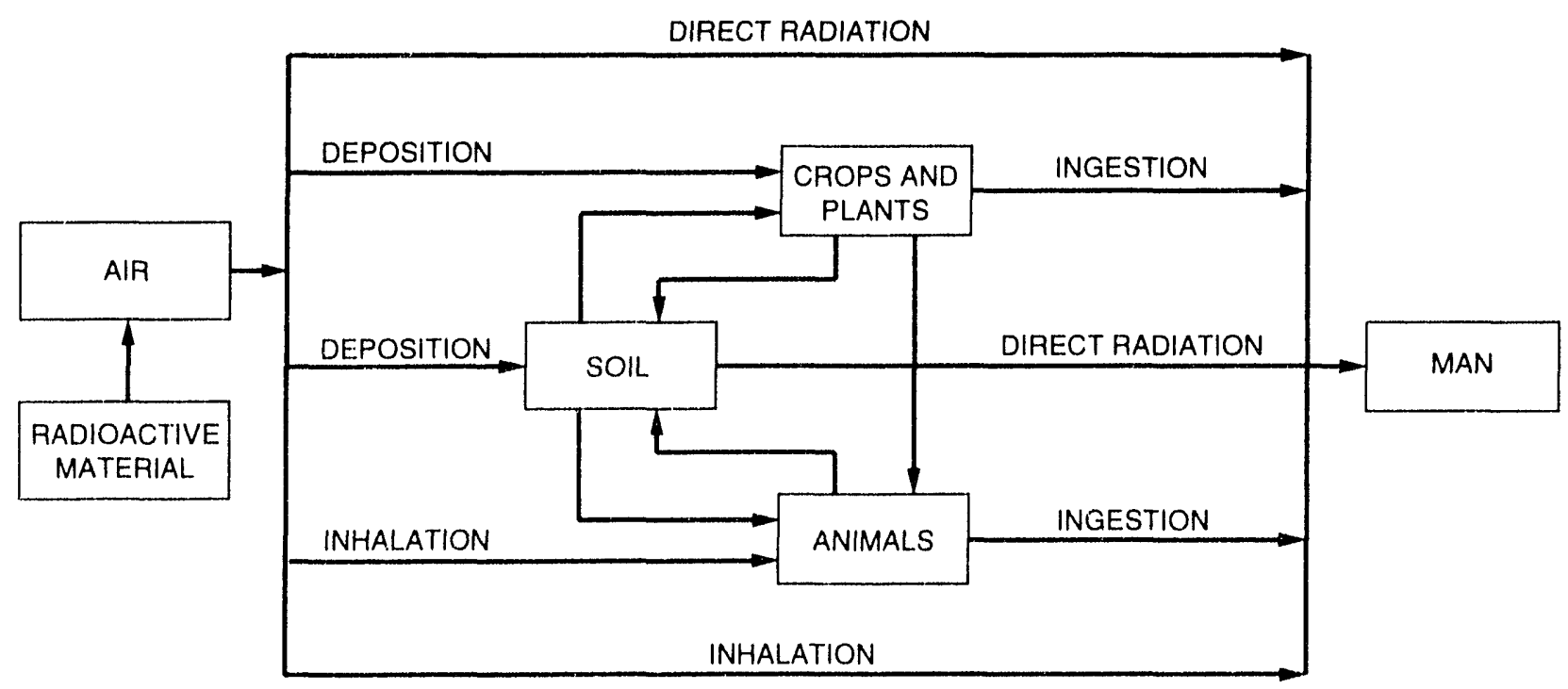

Fig. 2.1. Pathways between radioactive material released to the atmosphere and to individuals.

ORNL-DWG $91 \mathrm{M}-8277$

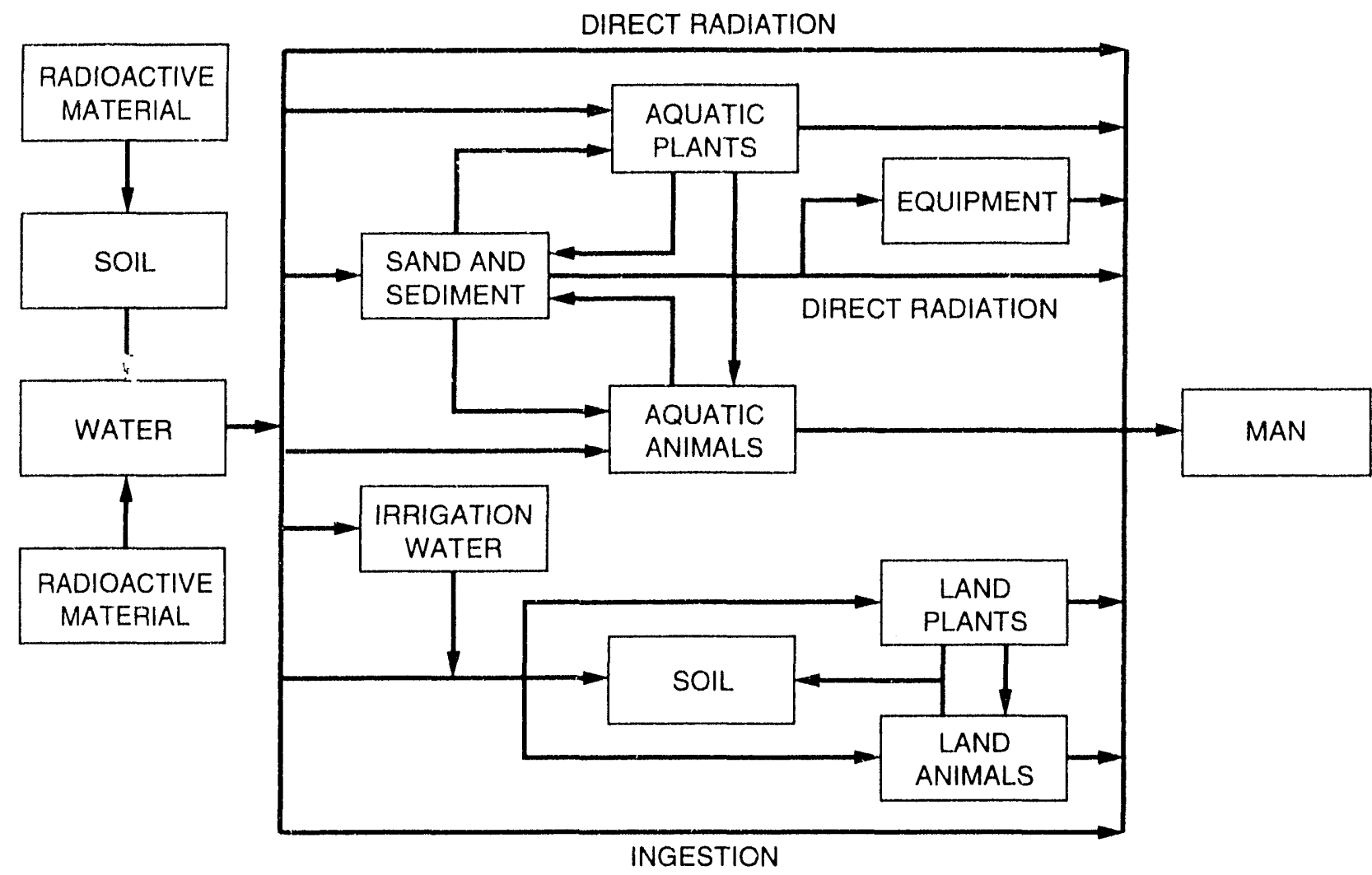

Fig. 2.2. Pathways between radioactive material released to the groundwater and to individuals. 


\section{Environmental Report-Paducah, Part 1}

intakes on the Ohio River within 15 miles downstream of the plant.

No residents or businesses that responded to the questionnaire reported using a private surface water intake on the Ohio River or on Little or Big Bayou creeks for any part of their water supply. Private groundwater wells were the major water supply of residents surrounding PGDP. Most residents reported using water from their residential wells for drinking, irrigation, and domestic uses.

A dose to the maximally exposed individual from consuming well water can be calculated using the assumptions outlined in Table 2.1 in Part 2. Under conditions of continuous exposure, members of the public are assumed to ingest $730 \mathrm{~L}$ of drinking water per year. Based on this criterion, the dose to the maximally exposed individual from drinking well water contaminated with technetium at the PGDP detection limit $(25 \mathrm{pCi} / \mathrm{L})$ would be $0.024 \mathrm{mrem} /$ year. This dose can be compared with the dose from ingestion of water contaminated at the Safe Drinking Water Act level of $900 \mathrm{pCi} / \mathrm{L}{ }^{99} \mathrm{Tc}$. This dose would be $0.85 \mathrm{mrem} /$ year. A risk estimation was prepared for the Phase I Site Investigation to assess the potential risk to individuals who might have been previously exposed to contaminated groundwater.

\subsection{Direct Radiation}

The exposure pathway for external gamma radiation was evaluated using the results of a 1991 thermoluminescent dosimeter survey covering the banks of Little Bayou Creek. The banks were determined to have elevated radioactive contamination or elevated count rates. The dose values are the product of the exposure rate $(\mathrm{mR} / \mathrm{h})$ from the radiological survey and the exposure time at a particular location.

To determine a realistic exposure time for the Little Bayou Creek area, several assumptions were used. During 1992, the West Kentucky Wildlife Management Area (WKWMA) allowed hunting and dog trials in this area for a period ranging from September 1 to March 30 (213 days). For exposure in the creeks, an individual was assumed to hunt every day during this period and spend a total of one-half hour in the Little Bayou Creek bed. This exposure time is probably exaggerated because signs are posted in this area stating that prolonged exposure could result in a dose above background. Using the maximum exposure rate measured in the Kentucky Pollutant Discharge Elimination System 011 ditch that discharges into Little Bayou Creek as the worst-case estimate for Little Bayou Creek, the dose above background to this maximally exposed individual would be $2 \mathrm{mrem} / \mathrm{year}$. These assumptions are summarized in Table 2.5 in Part 2. Even using these extreme assur.ptions, the dose is within the guideline value of less than $10 \mathrm{mrem} / \mathrm{year}$ from any one pathway.

\subsection{Contaminated Sediment in Little Bayou Creek}

Exposure to contaminated sediment in Little Bayou Creek could occur during fishing, hunting, or other recreational activities. Contact and exposure may occur primarily through incidental ingestion of contaminated sediment or inhalation of contaminated particles. According to the exposure assumptions in Table 2.2 in Part 2, and the maximum detected concentration of each radionuclide in the sediment samples, the worst-case dose would be received by an individual who was assumed to spend time in the WKWMA every day during the season as in Sect. 2.3. The estimated total dose above background would be $2 \mathrm{mrem} /$ year from this pathway.

\subsection{Ingestion Of Terrestrial Foodstuffs}

Terrestrial wildlife, such as deer, can come into contact with contaminated soil, ingest plants that have taken up contaminants or have become coated with contaminated dust, or ingest contaminated water. Hunting is permitted in the WKWMA surrounding PGDP, and the limit for deer harvest is two deer per person per season. Assuming that an individual kills two average-weight deer and consumes the edible portions of those deer during the year, the dose to this individual based on the maximum detected concentrations of each radionuclide in the deer muscle would be $10.4 \mathrm{mrem} /$ year. The only radionuclides present above the detection limits were uranium isotopes. This ingestion dose can be compared to the calculated background dose of $16.6 \mathrm{mrem} / y e a r$, which includes radionuclides that are naturally occurring. 


\section{Environmental Report-Paducah, Part 1}

Background deer were taken from TVA Land Between the Lakes, an area unaffected by PGDP operations. Therefore, when the analyzed dose occurring naturally is subtracted from the WKMA dose the contribution to dose from PGDP operations is negligible, in this case, zero. Dose calculations are summarized in Table 2.3 in Part 2.

Similarly, ingestion doses from homegrown fruits and vegetables were calculated using the assumptions summarized in Table 2.4 in Part 2. Using the maximum detected concentrations of each radionuclide in all three food types, the worst-case individual dose above background is calculated to be $0.4 \mathrm{mrem} / y e a r$. This assumes that an individual ate a portion of each food crop every day of the year.

\subsection{Airborne Radionuclides}

In addition to the primary pathways, radioactive emissions to air are monitored to determine the extent to which the general public could be exposed and to demonstrate compliance with U.S. Environmental Protection Agency (EPA) regulations and DOE directives on radiation exposure to the public. The airborne radioactivity from PGDP operations is normally too low to be detected in the presence of natural background radiation in the environment. Therefore, potential doses to the public are calculated through use of a dispersion model. This model calculates how measured quantities of released radionuclides mix with the atmosphere, where they travel, how they are diluted, and where they may deposit. Once the dispersion is calculated, population data and concentration/dose conversion factors are used to calculate individual and population doses. These doses include exposure from all pathways represented in Fig. 2.1.

The calculations were made using the AIRDOS-EPA suite of computer codes, which are part of the CAP- 88 assessment package recommended by the EPA. The computer codes used plant-specific radionuclide emission data for 1992 , meteorological data collected during 1992 at the 60-m station at the Paducah site, and dose conversion factors specified in the CAP- 88 codes. Organ weighing factors used in estimating effective dose equivalents are also based on International Commission on Radiological Protection (ICRP) recommendations (ICRP 1977).
The calculated 5()-year committed effective dose equivalent to the maximally exposed individual is estimated to be 0.0045 mrem (well below the 10-inrem limit). The dose to the maximally exposed individual, who, under most circumstances, is the person living closest to the plant in the predominant wind direction, is calculated each year. The maximally exposed individual for 1992 is located 2097 in $(6700 \mathrm{ft})$ north of the plant site.

The primary pathway of exposure is inhalation. The primary contributors to the inhalation dose are the uranium isotopes ${ }^{234} \mathrm{U}$ and ${ }^{238} \mathrm{U}$.

The collective dose equivalent is a good measure of long-term radiation effects over a wide area. The collective effective dose equivalent in 1992 for the 500,502 persons residing within $80 \mathrm{~km}$ (50 miles) of the plant site was estimated to be $1.7 \times 10^{-3}$ person-rem from PGDP emissions. This can be compared with a collective dose for the same population of $2 \times 10^{5}$ person-rem/year from natural background radiation.

\subsection{Conclusions}

Table 2.1 summarizes the annual dose from radiological contaminants that could potentially be received by a member of the public living near PGDP, assuming worst-case exposure from all major pathways. The calculated maximum combined dose to an individual is $4 \mathrm{mrem} / \mathrm{year}$. This level is well below the DOE annual dose limit of $100 \mathrm{mrem} /$ year. The major contributors to the dose are direct external radiation from and ingestion of sediment in or near the Little Bayou Creek bed. This area has been posted to notify the public of the elevated radiation levels.

\subsection{References}

CH2M Hill. 1990. Draft Results of the Site Investigation Phase I at the Paducah Gaseous Diffusion Plant, Paducah, Ky., KY/ER-4, Paducah Gaseous Diffusion Plant, Paducah, Ky.

Environmental Regulatory Guide for Radiological Effluent Monitoring and Environmental Surveillance. January 1991. DOE/EH-0173T, U.S. Department of Energy.

International Commission on Radiological Protection (ICRP). 1977. Annals of the ICRP I, ICRP Publication 26, Pergamon, Oxford, N.Y. 
1992 Environmental Report-Paducah, Part 1

Table 2.1. Summary of annual dose from radiological contaminants

\begin{tabular}{lcc}
\multicolumn{2}{c}{ Worst-case combined exposure pathways } \\
\hline Pathway & Dose (mrem/year) $)^{a}$ & Portion of total \\
\hline Ingestion of well water & 0.024 & $<0.01$ \\
Ingestion of sediments & 2 & 0.5 \\
Ingestion of food crops & 0.4 & 0.1 \\
Ingestion of deer meat & $0^{b}$ & 0 \\
Direct radiation- & & 0.5 \\
Little Bayou Creek & 2 & $<0.01$ \\
Atmospheric releases & 0.0045 & \\
Total annual dose above & & \\
background-all pathways & $4^{a}$ & \\
\hline
\end{tabular}

${ }^{a}$ Dose values were rounded to yield the correct number of significant digits based on the data from Tables 2.1 through 2.5 in Part 2 and from estimated significant figures in atmospheric releases per DOE/EH-0173T, Environmental Regulatory Guide for Radiological Effluent Monitoring and Environmental Surveillance.

${ }^{b}$ Calculated dose for reservation deer was less than the background or reference deer; therefore, the dose was assumed to be zero. 


\section{Airborne Discharges, Ambient Air Monitoring, Meteorological Monitoring, and External Gamma Radiation}

3.1 Airborne Discharges . . . . . . . . . . . . 3-4

3.2 Ambient Air Monitoring . . . . . . . . . . . 3-7

3.3 Meteorological Monitoring . . . . . . . . . 3-9

3.4 External Gamma Radiation Monitoring . . . . . 3-9

3.4.1 Thermoluminescent Dosimeter Sampling Program . . . . . . . . . . . . 3-9

3.4.2 Special TLD Survey ... . . . . . . . . 3-12

3.5 Conclusions $\ldots \ldots \ldots \ldots \ldots \ldots \ldots \ldots \ldots$ 3-16

3.6 References . . . . . . . . . . . . . . . . . . . 3-17 


\section{Airborne Discharges, Ambient Air Monitoring, Meteorological Monitoring, and External Gamma Radiation}

Environmental monitoring is an integral part of the Paducah Gaseous Diffusion Plant (PGDP) air pollution control program. The federal Clean Air Act (CAA), Kentucky Division for Air Quality (KDAQ) regulations, and U.S. Department of Energy (DOE) orders require identification of potential and actual sources of air pollution, controls to abate pollution to within specified limits, and measurements to demonstrate the results. The identification, controls, and emission or throughput limits are included in the regulatory agency's permit. Twenty-seven sources are listed on the PGDP operating permit; however, not all sources were operated in 1992. Table 3.1 in part 2 lists the permitted sources and the types of control equipment used for air pollution prevention.

The primary goal of the Air Compliance Program is to identify each air contaminant emission point at PGDP, to quantify the emissions from the source, to document compliance with the applicable regulation, and to submit this information, usually in the form of a permit application or registration, to the appropriate regulatory agency. In October 1992 PGDP completed a vent/stack survey, which is the first phase of the establishment of an Air Emission Inventory. The goal of the vent/stack survey was to identify all potential air contaminant emission points at PGDP. The second phase of the Air Emission Inventory is to establish a computer data base to compile and track data pertaining to each emission point. Additional employees have been added to the PGDP air program whose initial responsibility will be the establishment of the data base. The third phase of the inventory will be to obtain and input into the data base all pertinent information from each emission point. The data base will contain information such as (but not limited to) location, potential pollutants, permit status, stack parameters, estimate of emissions, and basis of the estimate. The emission estimates from this data base will be useful in budgetary concerns because the CAA Amendments of 1990 will require the KDAQ to impose a fec on sources based on tons of pollutant emitted.

From the vent/stack survey, PGDP has identified additional emission points that require permit review. Additional employees have been hired whose primary responsibility is preparation of permit applications for submittal to the KDAQ. PGDP has not received an updated operating permit since January 1986. However, PGDP will continue to submit application addenda to the KDAQ to ensure compliance with KDAQ regulations. After promulgation of the Air Toxics Regulations in November 1986, PGDP submitted an additional comprehensive Air Toxics Review application to the KDAQ in May 1988. PGDP submitted a permit application for the sources identified in the 1991 vent/stack survey in May 1992. These applications increased the number of emission points that had been evaluated at PGDP to 133, and each evaluation has indicated compliance with the Air Toxics Regulations in terms of emission limits and ambient air impact. PGDP emission points increased to 133 after submittal of the May 1992 application. After the vent/stack survey was completed in October 1992, PGDP found no additional existing sources that required permit applications.

PGDP submitted two construction permit applications in 1992, but after review the KDAQ determined that no construction permits would be required to operate these sources. One permit 


\section{Environmental Report-Paducah, Part 1}

application was submitted on the C-728 steam/motor cleaning facility to update the original registration submitted in December 1990. By the end of the year, a total of 142 emission points had been evaluated at PGDP.

The release of contamination into the atmosphere is minimized by avoiding any unnecessary waste generation and by applying effective control technology to meet all permit conditions and the DOE requirement to maintain radionuclide emissions as low as reasonably achievable (ALARA). This control program to reduce emissions is evaluated continually. Table 3.4 in Part 2 compares selected actual emissions with limits or standards set by regulations or permits. The primary basis for evaluating the control achieved is by emissions sampling and ambient air monitoring. Performance of control devices also may be checked by state or federal inspections. The data generated by stack emissions sampling were used to calculate radiation doses to the nearest neighbors and the surrounding population (see Sect. 2).

\subsection{Airborne Discharges}

The CAA of 1977 requires the U.S. Environmental Protection Agency (EPA) to administer through the states a program that requires operators of air contaminant sources to obtain permits to construct and operate. After receiving and reviewing an application for a plant-wide operating permit, the KDAQ issued permit No. 0-85-110 to PGDP on September 30, 1985, granting operation of an air contaminant source. The permit lists 27 emission points and has no expiration date. Not all of the emission points were active in 1992; the major sources in operation (see Fig. 3.1) were

- the cascade purge vent/stack at the C-310 purge and product building,

- two vapor degreasers in the $\mathrm{C}-4(0)$ cleaning building, and

- two coal- and oil-fired boilers and one gas- and oil-fired boiler in the C- 600 steam plant.

ORNL-DWG 87M-6707月

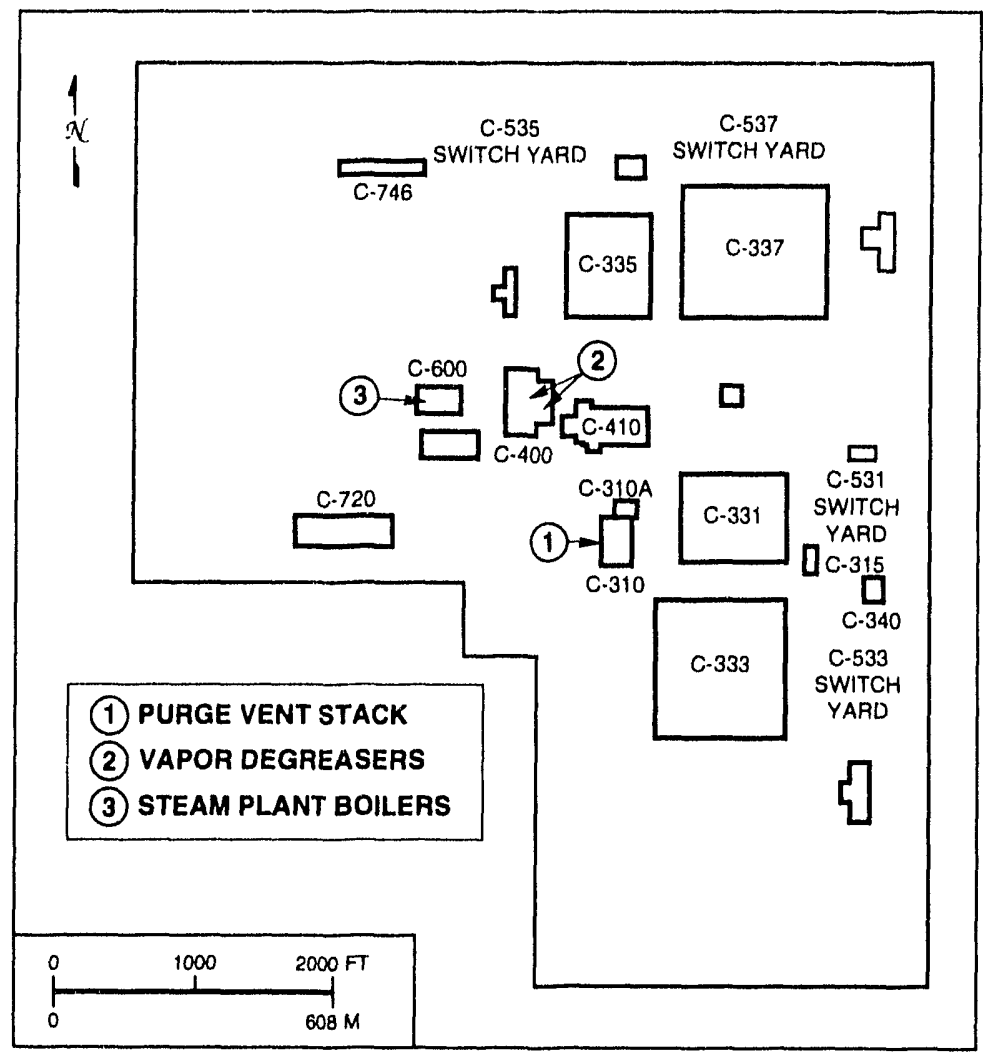

Fig. 3.1. Location of major air emissions sources at PGDP.

\section{3-4 Airborne, Ambient Air, Meteorological, and External Gamma}




\section{Environmental Report-Paducah, Part 1}

Other air emissions reported include those resulting from boiler startup and shutdown, fire-training exercises, chemical spills, process leaks, paint spray booths, or emissions above normal levels (i.e., accidental releases).

The pollution parameters that must be quantified to demonstrate compliance with permits or the DOE ALARA policy are particulates, opacity, sulfur dioxide, volatile organic compounds (VOCs), radionuclides, and fluorides. Certain processes also are regulated by throughput limits and usage rates. The 1992 cumulative radiological emissions and steam plant emissions are tabulated by source in Table 3.1. Beginning with this year's report, this tabulation also includes minor grouped radionuclide sources, which are required to be reported to the EPA by the radionuclide National Emission Standards for Hazardous Air Pollutants (NESHAP) regulation. Emissions from these minor group sources were estimated using methods contained in the NESHAP regulation. These methods are extremely conservative and in all likelihood overestimate the actual emissions by a great deal. C-600 steam plant emissions routinely reported are sulfur dioxide $\left(\mathrm{SO}_{2}\right)$, nitrogen oxides $\left(\mathrm{NO}_{\mathrm{x}}\right)$, particulates, carbon monoxide, nonmethane VOCs, and methane. The $\mathrm{SO}_{2}$ is continuously monitored in the stack in terms of pounds of $\mathrm{SO}_{2}$ per million Btu input to the boiler. Data from the continuous $\mathrm{SO}_{2}$ monitor and fuel usage data are combined to determine monthly and annual emissions. Emissions other than $\mathrm{SO}_{2}$ are calculated from fuel usage using emission factors from EPA guidance document AP-42, Compilation of Air Pollution Emission Factors. The excess combustion air averages about $20 \%$ and is minimized to control $\mathrm{NO}_{x}$ in the flue gases and 10 optimize boiler efficiency. Monitoring is not required for total suspended particulates. The KDAQ permit limit of $20 \%$ opacity is achieved by use of electrostatic precipitators (ESPs) operating at $97 \%$ efficiency for particulate removal. Performance tests and emission factor calculations have shown emission levels of less than $0.05 \mathrm{~kg}(0.1 \mathrm{lb})$ of total suspended particulates per million Btu boiler input. A PGDP procedure requires monthly visible emission evaluations of boiler stack effluent by EPA method 9 for documentation of the $20 \%$ opacity limit.

The ESPs provide minimal stack particulate emissions while the boilers are operating, but visible emissions occur during malfunctions, startups, shutdowns, and some maintenance activities. These periods are brief and infrequent and by regulation are reported to the KDAQ prior to the activities if possible. Table 3.1 shows the total steam plant emissions. Tables 3.2 and 3.3 in Part 2 present monthly emissions of selected parameters as well as annual and historical data.

The C-310 stack is used as the vent for the cascade system. Gases of low molecular weight travel up the cascade to be released through the C-310 stack. Gaseous fluorides and traces of radionuclides are released in small quantities. High-speed centrifugal separation and chemical traps are used to control stack emissions. The stack gases are continuously sampled, and samples are analyzed daily, except on weekends and holidays. Tables 3.2 and 3.3 in Part 2 list monthly and annual emission rates and historical data for selected parameters.

Stack-sampling trend analysis performed on the C-310 stack indicates a dramatic decrease in uranium emissions since 1983. In 1983 the average monthly uranium emission was $336 \mathrm{~g}$. Discounting anomalous averages caused by system upsets and testing, this monthly average decreased each year to an average monthly emission of $0.4 \mathrm{~g}$ in 1991. Because of operational difficulties in the product withdrawal building alumina traps, the uranium emissions increased to an average of $2.3 \mathrm{~g} / \mathrm{month}$ for 1992. In September 1990, as a result of a statistical study, the lower limit of detection of uranium was established at $0.07 \mathrm{~g}$ per day. For the remainder of 1990 all emissions that were reported as $<0.07 \mathrm{~g}$ per daly were included in the calculations of dose resulting from uranium emissions. In other words, if the sample result was reported as $<0.07 \mathrm{~g}$ of uranium, $0.07 \mathrm{~g}$ of uranium was included in the dose calculation. For 1991 and subsequent years, only those emissions that were actually detected (i.e., equal to or greater than $0.07 \mathrm{~g}$ per day) were reported. If the sample result indicated $<0.07 \mathrm{~g}$ of uranium, no uranium was detected in that sample. This method of reporting uran' ${ }^{\prime}$,m emissions for dose calculations is consistent with ihe method of calculating dose from ingestion of food crops, sediment, water, and wildlife in the area of PGDP. Section 7.3.4 of the Environmental Regulatory Guide for Radiological Effluent Monitoring and Environmental Surveillance 
1992 Environmental Report-Paducah, Part 1

Table 3.1. 1992 PGDP stack emissions summary

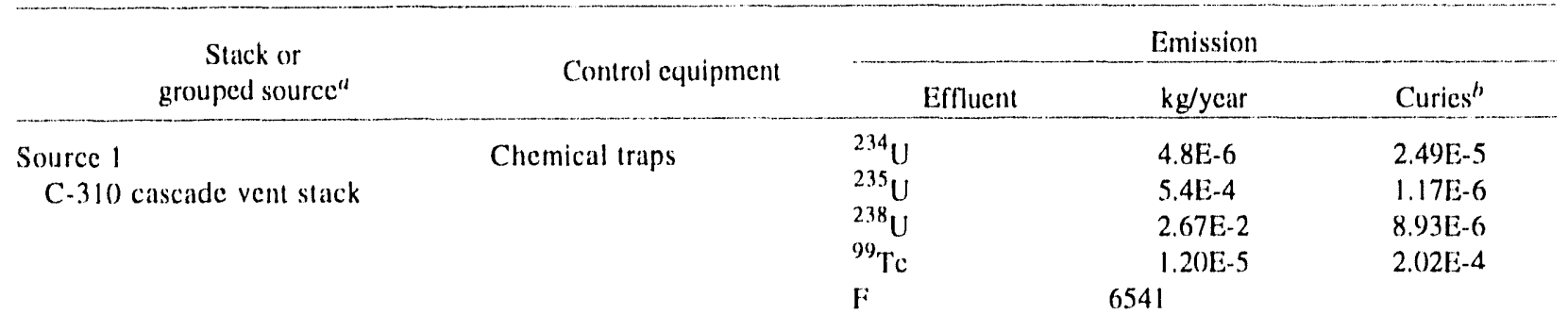

Grouped minor sources

Source 2

Scal exhausts (2)

Wel air exhausts (1)

Wet air/scal exhaust (4)

Source 3

Cylinder valve conriection operations

Source 4

Cylinder valve connection not included above (i.e., not served by a stack)

Source 5

C.40) decontamination activity

Source 6

C.710 laboratory hoods

Source 7

Building ventilation
Chemical traps

HEPA'

HEPA vacuums

${ }^{234} \mathrm{U}$
${ }^{235} \mathrm{U}$
${ }^{238} \mathrm{U}$
${ }^{239} \mathrm{Pu}$

3.11E-6

$3.53 \mathrm{E}-4$

$1.73 \mathrm{E}-2$

$3.65 \mathrm{E}-8$

Not distinguishable from zero.

$\begin{array}{lll}{ }^{234} \mathrm{U} & 1.22 \mathrm{E}-7 & 7.62 \mathrm{E}-7 \\ { }^{235} \mathrm{U} & 1.38 \mathrm{E}-5 & 2.99 \mathrm{E}-8 \\ { }^{238} \mathrm{U} & 6.79 \mathrm{E}-4 & 2.28 \mathrm{E}-7\end{array}$

${ }^{234} \mathrm{U}$

$235 \mathrm{U}$

${ }^{238} \mathrm{U}$

${ }^{237} \mathrm{~Np}$

${ }^{239} \mathrm{Pu}$

230) $\mathrm{Th}$

${ }^{99} \mathrm{Tc}$

None

$234 \mathrm{U}$

${ }^{235} \mathrm{U}$

${ }^{236} \mathrm{U}$

${ }^{238} \mathrm{U}$

None

No curic emission was determined for this source. However, based on Ilealth Physics Building air samples, all radionuclide concentrations were $\leq 2 \%$ of the most stringent derived air concentrations (DACs) listed in DOE Order 548().11. Based on this DAC, and and a 1992 dilution factor for off-site exposure, building ventilation emissions result in an off-site dose of only $0.0000079 \mathrm{mrem}(0.18 \%$ of the plant-wide dose).

Use of low-sulfur coal,

Sulfur dioxide

388,648

Nitrogen oxides

258,696

control of excess air, clectrostatic

Particulatcs

22,550

Carbon monoxide
1.27E-3

$4.99[-5$

$3.80 \mathrm{E}-4$

$3.81 \mathrm{E}-7$

1.03E-7

$2.66 \mathrm{E}-7$

$3.95 \mathrm{E}-6$

$2.66 \mathrm{E}-4$

1.(04E-5

$8.85 \mathrm{E}-8$

$7.23 \mathrm{E}-5$
8,164

"See Fig. 3.1 for major sources.

${ }^{b}$ Based on a product assay of $2.0 \%{ }^{235} \mathrm{U}$.

rHigh-elficiency particulate air. 
addresses less-than-detectable values; however, this guidance specifically addresses statistical analyses, not dose assessment.

PGDP operates two vapor degreasers in the C-400 cleaning building. One of the degreasers is large enough $|1.5 \times 6.9 \times 5.4 \mathrm{~m}(5 \times 23 \times 18 \mathrm{ft})|$ to accommodate the largest components of gaseous diffusion process equipment. This degreaser uses trichloroethylene (TCE) as a cleansing agent. The TCE is contained in troughs at the north and south ends of the degreaser. The troughs also contain steam coils that vaporize the TCE. The TCE vapor then migrates to the center of the degreaser (between the troughs) where the equipment to be cleaned is situated. Condensing coils are located near the top of the degreaser to condense and to recycle the vaporized TCE after it has been used to degrease the equipment.

The smaller degreaser $11.5 \times 1.8 \times 1.5 \mathrm{~m}(5 \times$ $6 \times 5 \mathrm{ft}$ ) 1 uses $1,1,1$-trichloroethane (TCA) as the degreasing agent. Steam coils that vaporize the 1,1,1-TCA are located in the bottom of the degreaser. Condensing coils are used to condense and to recycle the vaporized $1,1,1$-TCA after use.

Both degreasers have movable covers that minimize degreasing agent losses except during equipment insertion or removal. However, losses of degreasing agents are inevitable because of the large area exposed and the high volatility of the agents. These losses are calculated and reported as plant emissions. The Air Toxics Operating Application (submitted to the KDAQ in 1988) assumed that $90 \%$ of the agents are lost to the atmosphere and the rest are contained in the degreaser sludge. A less volatile aqueous degreaser is being lested at various locations in the plant as an alternative. PGDP's 3-year hazardous air pollutant reduction plan, which was submitted in March 1993, and takes credit for the elimination of TCE and TCA use in the vapor degreasers at $\mathrm{C}-400$. This is part of an action plan to eliminate plant-wide TCE and TCA usage by the end of March 1994.

In November 1986 the KDAQ promulgated two Air Toxics Regulations. These regulations established emission limits for specific substances considered toxic. The first regulation applies to facilities constructed before November 11, 1986, and lists 92 regulated substances. The second regulation applies to facilities constructed after November 11, 1986, and lists more than 730 regulated substances. In conjunction with an environmental subcontractor, PGDP submitted an Operating Permit Application with Air Toxics Review to the KDAQ on April 27, 1988. This application contained calculations stating that PGDP's toxic emissions are either below the significant emission level and thus exempt from the regulations or below the threshold ambient limit as shown by computer modeling and in compliance with the regulations. The KDAQ Permit Review Branch has this application for review; however, it is far behind in reviewing its backlog of operating permit applications. Air Toxics Compliance will be tracked by the Air Emission Inventory Data Base.

1992 data compiled to fulfill requirements of the Superfund Amendments and Reauthorization Act of 1986 are included in the Appendix.

\subsection{Ambient Air Monitoring}

PGDP maintains and operates an ambient air monitoring system to assess the impact on the ambient air of various air contaminants emitted by PGDP. The results of the data generated by the ambient air monitoring system are also used to demonstrate compliance with the ambient air quality standards for gaseous fluorides established by the KDAQ.

Ambient air is sampled continuously for gaseous fluorides and radioactive particulates at the following locations:

- plant north (PN), plant south (PS), plant east (PE), and plant west (PW) within the plant fence;

- boundary north (BN) and boundary east (BE) at the plant boundary;

- one north (IN), one south (IS), one west (IW), one east (IE), and one southeast (ISE) at I mile from the plant fence; and

- Grahamville (GR), the nearest community.

Figure 3.2 shows these locations. The sample collectors (consisting of filters treated with sodium carbonate for ambient collection of fluoridesi are exchanged and analyzed each week for alpha and beta activity and for fluoride concentrations. To ensure data accuracy, samples are discarded without analysis if final sample flow decreases more than $40 \%$ from the initial flow rate, if the sampler is found not to be 


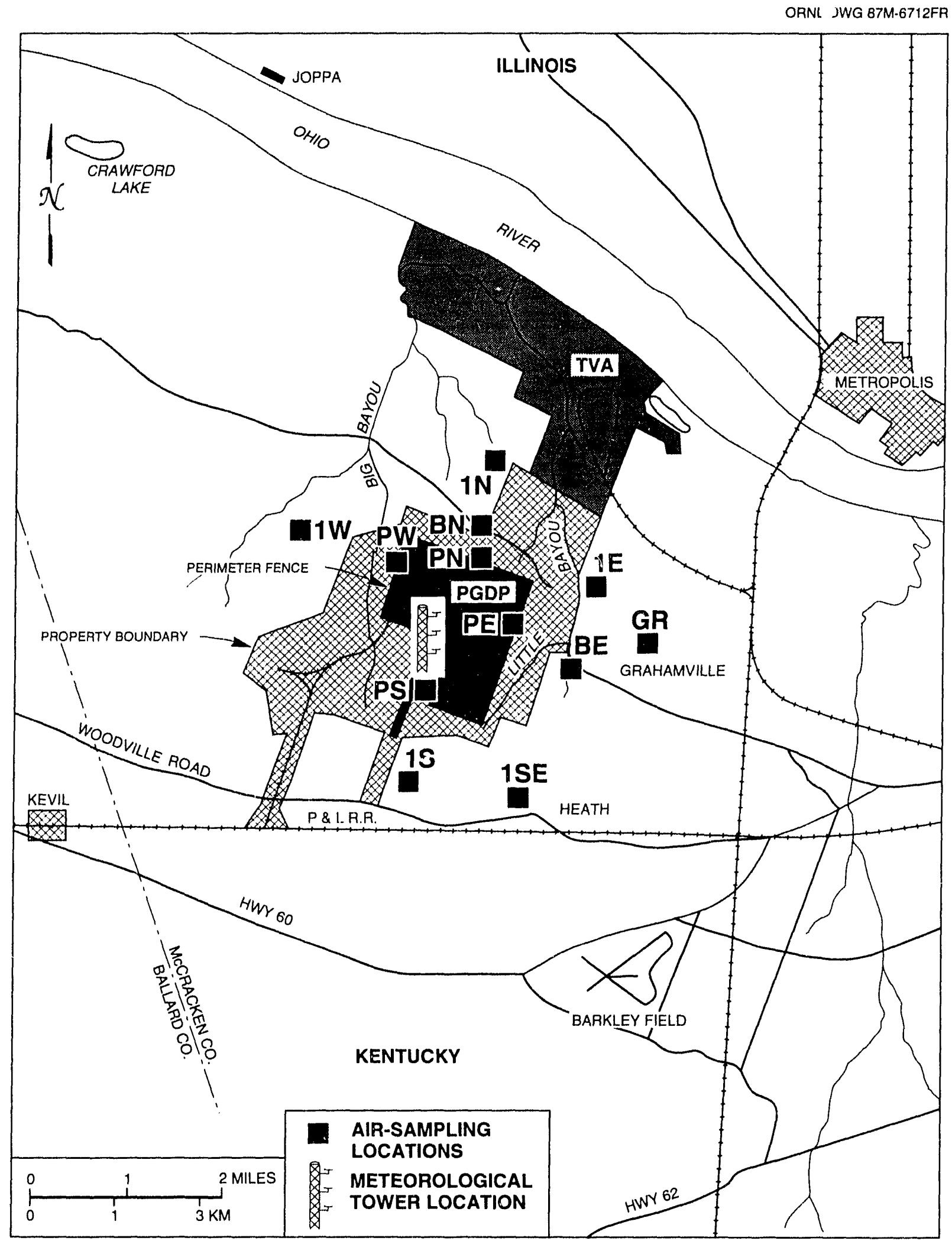

Fig. 3.2. Location of air-sampling and meteorological monitoring station at PGDP. 


\section{Environmental Report-Paducah, Part 1}

running, or if upoil opening the filter holder the analyst finds the filter cracked (Coker 1988).

After the sample filters have been collected from the ambient air monitoring stations, they are stored for at least $168 \mathrm{~h}$ to permit decay of the short-lived daughters of naturally occurring radon and thoron. They are then analyzed for alpha and beta activity by an automatic low-background alpha/beta proportional counter (PGDP 1990). After the radioactivity measurements have been made, the filters are leached with water and fluoride content is measured by specific ion electrode analysis (PGDP 1979). The results of the analyses are logged into a computer data base and used to demonstrate compliance with KDAQ gaseous fluoride ambient air quality standards. In response to the Tiger Team Assessment performed in 1990), PGDP has proposed some improvements in the ambient air monitoring program. An ambient air monitoring plan has been developed to implement these improvements to the monitoring system. An engineering project has been approved to purchase and install new monitoring equipment in 1993. Tables 3.2 and 3.3 provide a summary of 1992 ambient air measurements. All fluoride samples were well below the Kentucky ambient air quality standards for fluorides. The highest annual average for fluorides was $0.147 \mathrm{ppb}$ at the PN site. This concentration was well below the annual arithmetic mean standard of $500 \mathrm{ppb}$ for fluorides. The maximum weekly concentration of fluorides of $0.631 \mathrm{ppb}$ at the plant north location was $32 \%$ of the KDAQ secondary fluoride maximum weekly standard of $2 \mathrm{ppb}$.

\subsection{Meteorological Monitoring}

Representative meteorological data are required at DOE facilities by DOE Order 5400.1 to support environmental monitoring activities. This information is essential to characterize atmospheric transport and diffusion conditions in the vicinity of PGDP and to represeni other meteorological conditions (e.g., precipitation, temperature, and atmospheric moisture) that are important to environmental surveillance activities such as air quality and radiation monitoring.

On-site meteorological data are used at PGDP in calculating radiation doses to the public (see Sect. 2). In addition, on-site meteorological data are used by various groups within the plant-for example, by
Environmental Restoration to correlate precipitation with groundwater flow and by Power Operations to investigate electrical equipment failures.

A $60-\mathrm{m}$ tower located south of the C- 100 administration building contains instrumentation at heights of $10 \mathrm{~m}$ and $60 \mathrm{~m}(32.8 \mathrm{ft}$ and $196.9 \mathrm{ft})$.

Appropriate meteorological parameters such as wind speed and direction, temperature, barometric pressure, relative humidity, and rainfall are monitored to provide both valuable data on atmospheric stability and also other data essential to reliable atmospheric dispersion modeling. Figures 3.3 and 3.4 show wind roses generated by the tower (see Subsect. 3.5).

Computer-aided atmospheric dispersion modeling uses emission and meteorological data to determine the impacts of plant operations. It is used to simulate the transport of air contaminants and to predict the effects of abnormal airborne emissions from a given source. In addition, PGDP can postulate a multitude of emergency scenarios and estimate effects of unplanned releases on employees and population centers downwind of the source. PGDP uses the Hazardous Atmospheric Release Model II computer program for predicting off-site concentrations of unplanned heavy-gas releases.

\subsection{External Gamma Radiation Monitoring}

One of the potential pathways of exposure for population groups living within the vicinity of DOE facilities is exposure to external radiation. Dose rates from penetrating radiation (gamma rays) were measured at a number of locations in the PGDP environs during 1992. Long-term measurements were made using thermoluminescent dosimeters (TLDs). Instantaneous dose rates were also measured with hand-held meters during radiation surveys conducted at numerous locations on and around the PGDP site.

\subsubsection{Thermoluminescent Dosimeter Sampling Program}

During 1992 TLDs were placed in the environment to obtain data on external gamma radiation. These TLDs react to gamma and neutron radiation and, to some extent, to cosmic radiation. Fifteen monitoring dosimeters were in use during 
Table 3.2. 1992 PGDP environmental air sampling for fluorides

\begin{tabular}{lccccc}
\hline & & \multicolumn{5}{c}{ Concentration (ppb) } \\
\cline { 3 - 7 } Point $^{a}$ & $\begin{array}{c}\text { Number of } \\
\text { samples }\end{array}$ & Min & Max & $\begin{array}{c}\text { Percent of } \\
\text { standard }\end{array}$ & A $v^{c}$ \\
\hline PN & 53 & $0.053^{d}$ & 0.631 & 31.5 & 0.147 \\
PE & 52 & 0.052 & 0.330 & 16.5 & 0.125 \\
PS & 52 & 0.055 & 0.150 & 7.5 & 0.080 \\
PW & 51 & 0.062 & 0.275 & 13.8 & 0.086 \\
BN & 52 & 0.058 & 0.141 & 7.1 & 0.084 \\
BE & 52 & 0.055 & 0.128 & 6.4 & 0.074 \\
IN & 53 & 0.055 & 0.116 & 5.8 & 0.072 \\
IE & 49 & 0.051 & 0.097 & 4.8 & 0.063 \\
ISE & 52 & 0.049 & 0.126 & 6.3 & 0.066 \\
IS & 53 & 0.048 & 0.114 & 5.7 & 0.066 \\
IW & 53 & 0.050 & 0.121 & 6.1 & 0.068 \\
GR & 52 & 0.046 & 0.139 & 7.0 & 0.073 \\
\hline
\end{tabular}

${ }^{a}$ See Fig. 3.2.

${ }^{b}$ Kentucky Secondary Air Quality Standard (401 KAR 53:010) for maximum 1-week average is 2.0 $\mathrm{ppb}$ as hydrogen fluoride.

${ }^{c}$ Kentucky Primary Air Quality Standard (401 KAR 53:010) for annual arithmetic mean is $500 \mathrm{ppb}$.

${ }^{d}$ Several samples at every location were below detection limits. In these cases, the detection limit is used as the minimum value.

Table 3.3. 1992 PGDP environmental air sampling for radioactivity

\begin{tabular}{|c|c|c|c|c|c|c|c|}
\hline \multirow{2}{*}{ Point $^{a}$} & \multirow{2}{*}{$\begin{array}{l}\text { Number of } \\
\text { samples }\end{array}$} & \multicolumn{3}{|c|}{$\begin{array}{c}\text { Gross alpha } \\
\left(\mu \mathrm{Ci} / \mathrm{mL} \times 10^{-14}\right)\end{array}$} & \multicolumn{3}{|c|}{$\begin{array}{c}\text { Gross beta } \\
\left(\mu \mathrm{Ci} / \mathrm{mL} \times 10^{-13}\right)\end{array}$} \\
\hline & & $\operatorname{Min}^{b}$ & $\operatorname{Max}$ & Av & $\operatorname{Min}^{b}$ & $\operatorname{Max}$ & Av \\
\hline PN & 53 & -0.71 & 0.62 & 0.13 & -0.30 & 0.58 & 0.20 \\
\hline PE & 52 & -0.38 & 0.76 & 0.14 & -0.35 & 0.47 & 0.19 \\
\hline PS & 52 & -0.41 & 0.74 & 0.15 & -0.20 & 0.14 & 0.20 \\
\hline PW & 51 & -0.22 & 1.07 & 0.16 & -0.23 & 0.46 & 0.15 \\
\hline $\mathrm{BN}$ & 52 & -0.50 & 1.65 & 0.16 & -0.20 & 1.28 & 0.23 \\
\hline $\mathrm{BE}$ & 52 & -0.22 & 0.51 & 0.12 & -0.34 & 0.55 & 0.18 \\
\hline IN & 53 & -0.97 & 1.17 & 0.26 & -0.30 & 0.13 & 0.22 \\
\hline $1 \mathrm{E}$ & 49 & -0.24 & 0.90 & 0.15 & -0.01 & 1.30 & 0.23 \\
\hline ISE & 52 & -0.04 & 0.85 & 0.13 & -0.29 & 0.76 & 0.22 \\
\hline is & 53 & -0.33 & 0.69 & 0.13 & -0.19 & 1.72 & 0.23 \\
\hline $1 \mathrm{~W}$ & 53 & -0.28 & 0.69 & 0.15 & -0.20 & 1.15 & 0.22 \\
\hline GR & 52 & -0.41 & 1.55 & 0.20 & -0.33 & 0.69 & 0.21 \\
\hline
\end{tabular}

${ }^{a}$ See Fig. 3.2.

${ }^{b}$ Because of fluctuation in the instrument used to analyze for radioactivity, the background count is higher than that for the sample; this accounts for the negative counts. 

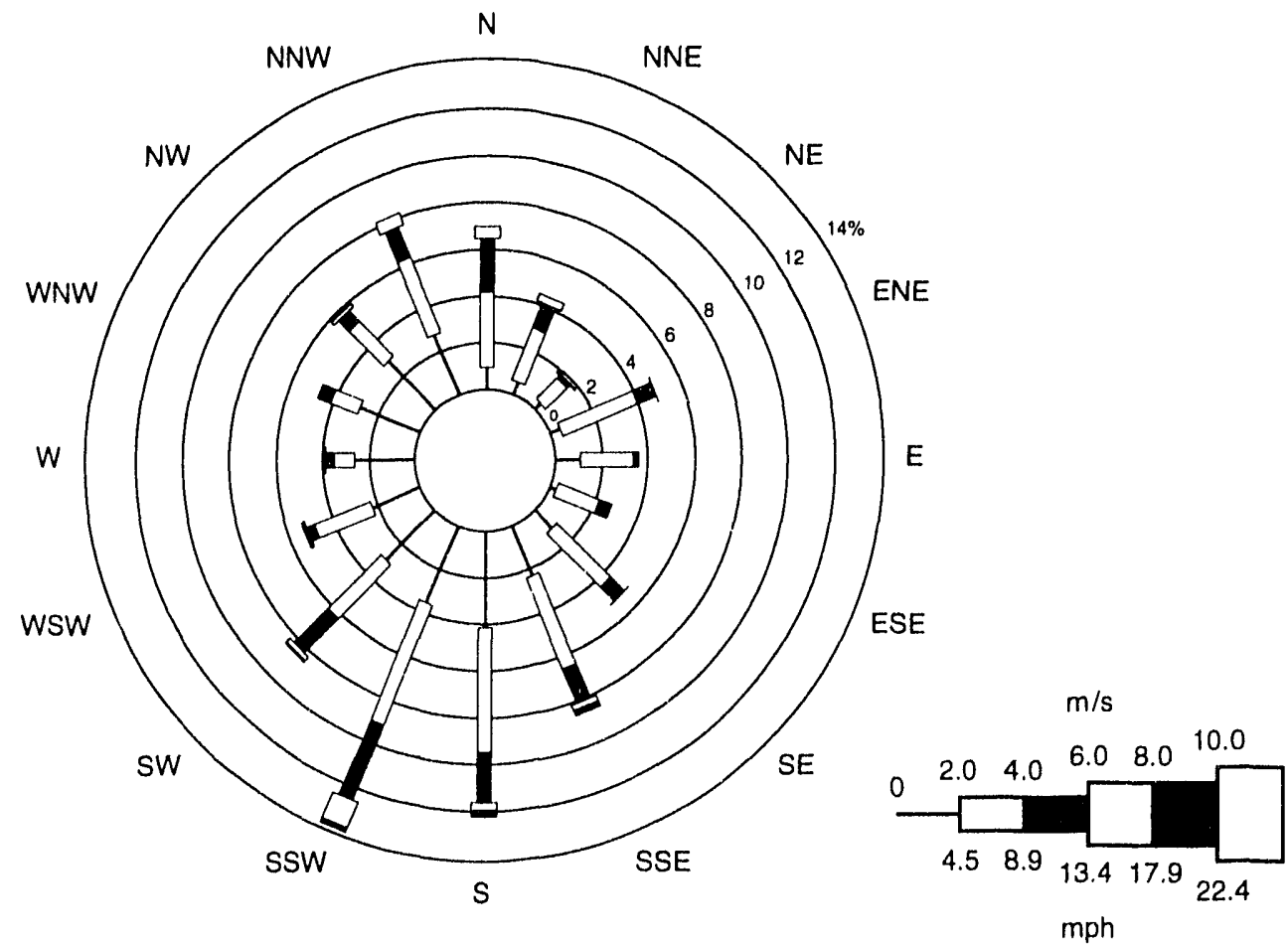

Fig. 3.3. Wind rose $(10-\mathrm{m}$ level) showing the wind speed frequency distribution data (with 93.1\% of possible data) used for the 1992 estimates.

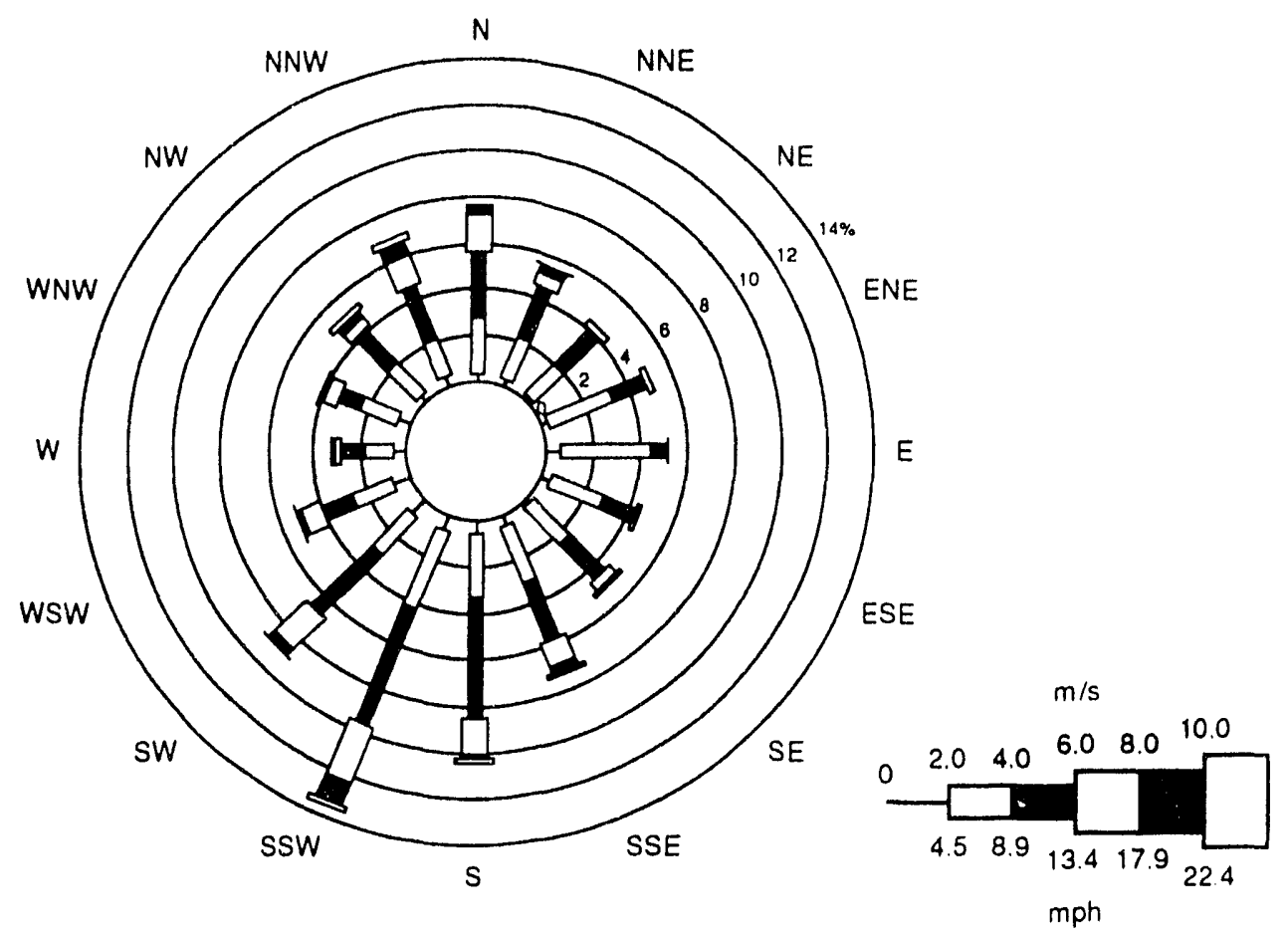

Fig. 3.4. Wind rose (60-m level) showing the wind speed frequency distribution data (with $93.1 \%$ of possible data) used for the 1992 estimates. 


\section{Environmental Report-Paducah, Part 1}

1992. Figure 3.5 provides the locations of the monitoring dosimeters. Ten quality control TLDs were also in use during each quarter; Fig. 3.6 shows their locations.

The external gamma radiation program is conducted using guidance from American National Standards Institute Standard N545-1975. The TLDs are identified, annealed, calibrated, packaged, and shipped by Oak Ridge National Laboratory (ORNL). When they arrive at PGDP, they are promptly positioned in the PGDP environment approximately $1 \mathrm{~m}(3 \mathrm{ft})$ above the ground. The TLD packages are placed in four types of locations: along the plant perimeter fence, at the reservation boundary, at nearby residences or communities, and at two background locations more distant from the site. After the quarterly exposure period, the TLDs are collected and returned to ORNL for exposure determination.

Although the TLD exposures were measured in microroentgens per hour $(\mu R / h)$, measured doses are also reported in dose equivalent units (mrem) to allow comparison with dose standards and dose equivalents reported elsewhere in this document. To convert to mrem/year, some exposure period must be assumed. To allow for comparison, continuous exposure has been assumed at all locations. In reality, exposure will vary depending on public access to a particular location. Table 3.4 shows the average exposure rates for each TLD location. Table 3.5 lists quality control data for the TLDs. The mean exposure rate for indicator locations as measured by the TLDs (excluding perimeter fence data) is approximately $5.8 \mu \mathrm{R} / \mathrm{h}$. When that rate is compared with the mean background exposure rates, the indicator locations are significantly lower at the $95 \%$ confidence level.

Assuming continuous exposure at this level ( $5.8 \mu \mathrm{R} / \mathrm{h}$ ), the external whole body dose would be approximately $50 \mathrm{mrem} / \mathrm{year}$. This corresponds to the average external whole body dose estimated to be received by people throughout Kentucky and Tennessee, which is between 60 and $70 \mathrm{mrem} / \mathrm{year}$ (Klement et al. August 1972). Dose rates at the plant perimeter were somewhat higher than the background rates. The higher exposure rates at locations near the perimeter fence were attributed to direct radiation from the uranium cylinder storage and handling areas. Although the rates are elevated, these areas have only limited access and actually allow for very low exposure periods.

Because of the extremely small amounts of gamma radiation emitted by PGDP compared with natural background radiation, accurate measurements using TLDs are difficult to obtain. Therefore, the exposure rates measured by the TLD system during 1992 have a high level of uncertainty. However, the data indicate that levels of gamma radiation both at and beyond the plant perimeter have not increased significantly over time. Figure 3.7 compares the trend over a 5 -year period at each location. The radiation fields surrounding the cylinder storage yard are also somewhat static. The change seen in Table 3.4 and Fig. 3.7 for location 2 occurred because the TLD was inadvertently placed in a shielded position in 1990 and 1991. 1992 data returned to the expected level when this was corrected.

\subsubsection{Special TLD Survey}

In addition to the routine TLD monitoring, a special long-term radiation assessment was performed during 1991 by $\mathrm{CH} 2 \mathrm{M}$ Hill on the off-site portions of the plant drainage system that had shown elevated levels of radioactive contamination in the Phase I walk-over survey. TLDs were placed along the creek beds of Little Bayou Creek, the off-site portion of the north/south diversion ditch, and the off-site portion of outfall ditch Kentucky Pollutant Discharge Elimination System (KPDES) 011. Big Bayou Creek and other plant outfall ditches were also surveyed during Phase I, but the results showed little evidence of elevated direct gamma radiation above background levels and were not included in this assessment.

The TLDs were placed in the field beginning on April 1, 1991, and remained for times ranging from 92 to 107 days. TLD sampling locations were designed to provide comprehensive coverage of the creek beds and to further characterize locations with elevated contamination levels. Stations were established at regular intervals of approximately $550 \mathrm{ft}$ and, where possible, stations were alternated from one side of the creek to the other.

The average background dose rate of $6.7 \mu \mathrm{R} / \mathrm{h}$ was used for comparison with the field dose rate results from the sample locations. The highest dose rate $(28.0 \mu \mathrm{R} / \mathrm{h})$ was detected near the confluence of

\section{3-12 Airborne, Ambient Air, Meteorological, and External Gamma}


1992 Environmental Report-Paducah, Part 1

ORNL-DWG 89M-6360R2

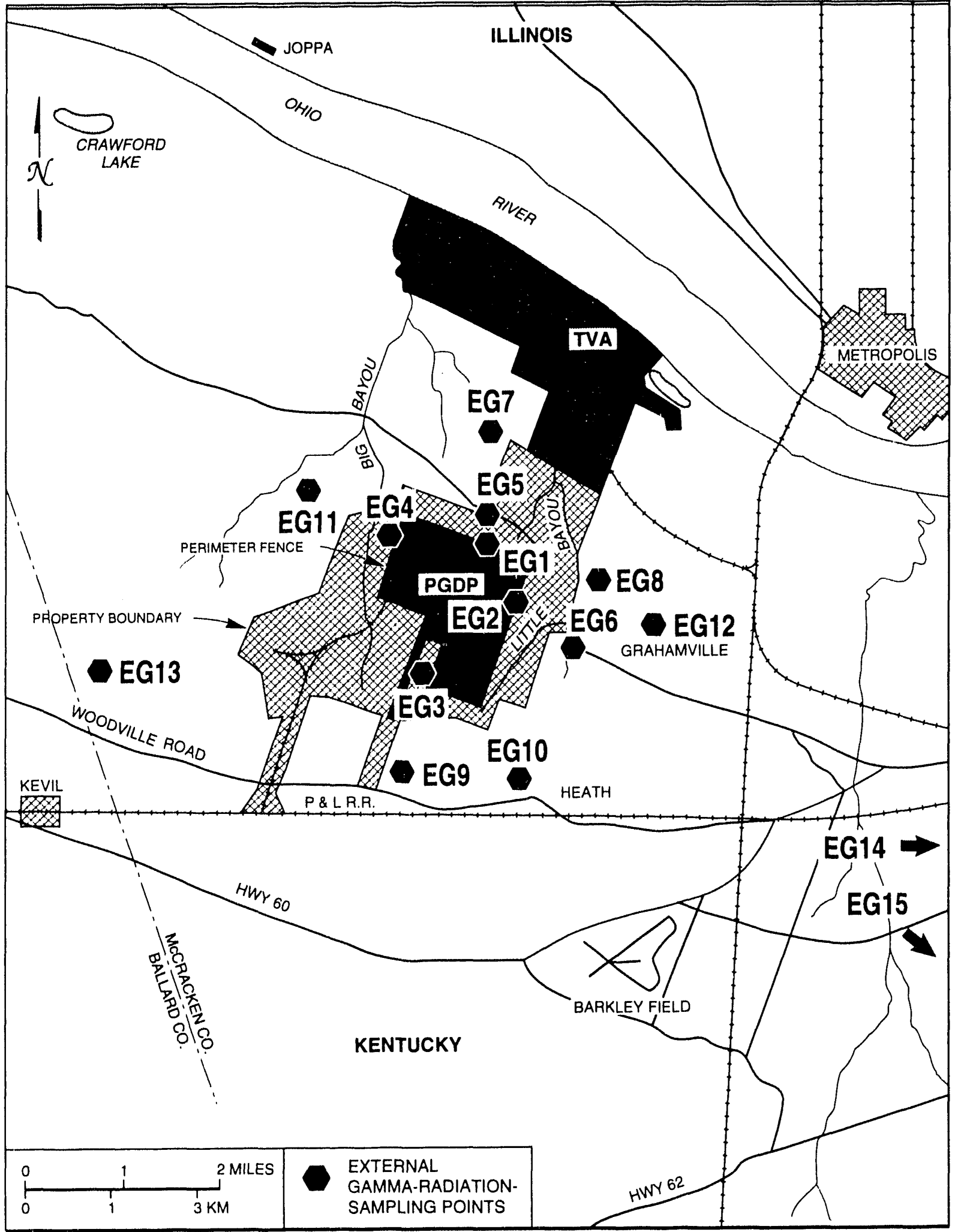

Fig. 3.5. Thermoluminescent dosimeter locations at PGDP. 
ORNL-DWG 89M-6361R2

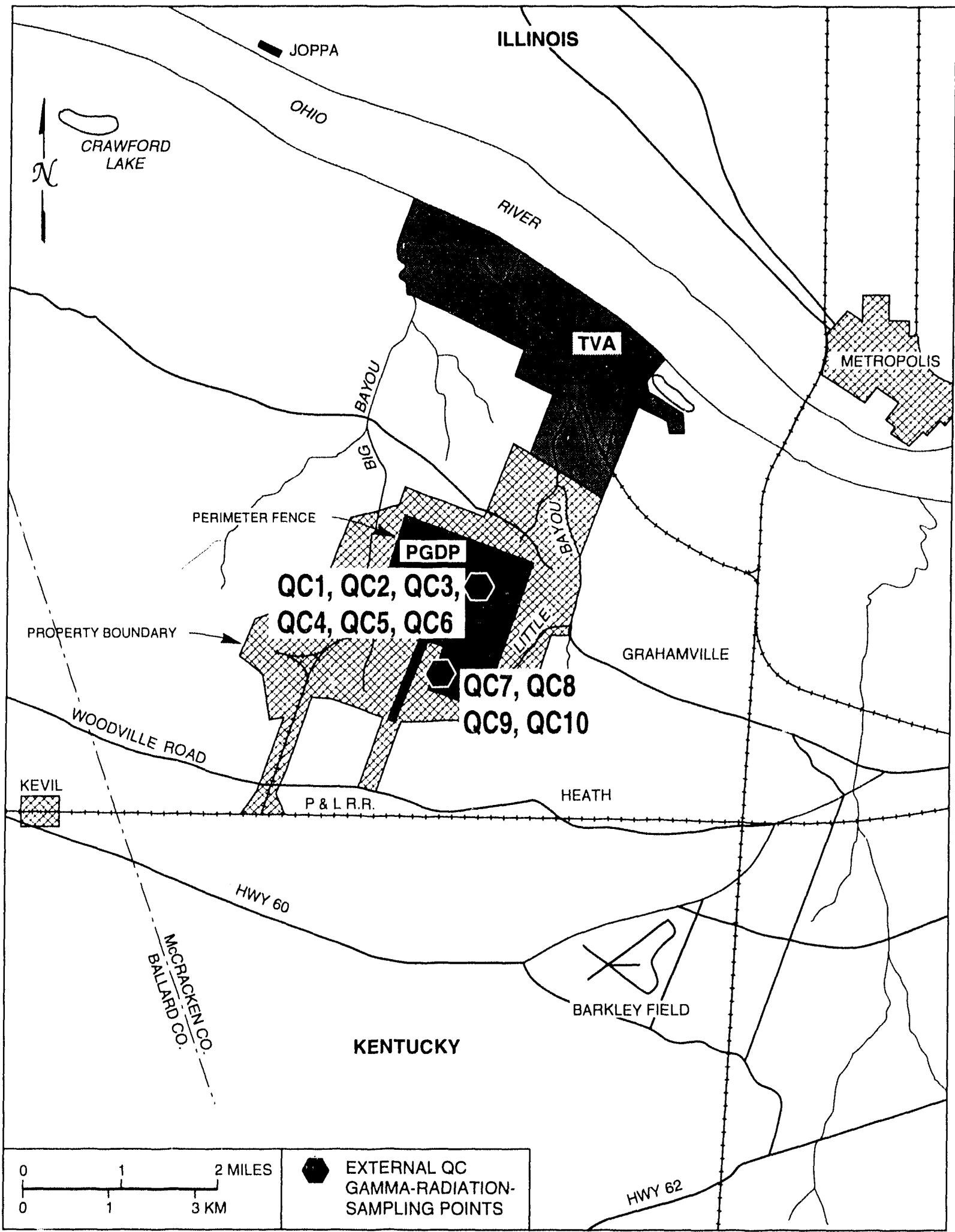

Fig. 3.6. Quality control thermoluminescent dosimeter locations at PGDP. 
Table 3.4. Maximum potential 1992 PGDP external gamma exposure rates

\begin{tabular}{llcc}
\hline & & \multicolumn{2}{c}{ Average } \\
\cline { 3 - 4 } Point $^{a}$ & \multicolumn{1}{c}{ Location } & $(\mu \mathrm{R} / \mathrm{h})$ & $($ mrem/year) \\
\hline & & 5.83 & 51.2 \\
EG1 & Air sampler perimeter north (PN) & 27.6 & 242 \\
EG2 & Air sampler perimeter east (PE) & 40.2 & 353 \\
EG4 & Air sampler perimeter south (PS) & 19.1 & 168 \\
EG5 & Air sampler perimeter west (PW) & 6.28 & 55.2 \\
EG6 & Air sampler boundary north (BN) & 4.24 & 37.2 \\
EG7 & Air sampler boundary east (BE) & 5.09 & 44.7 \\
EG8 & Air sampler 1 mile east (1E) & 4.95 & 43.5 \\
EG9 & Air sampler 1 mile south (1S) & 6.82 & 59.9 \\
EG10 & Air sampler 1 mile southeast (1SE) & 6.41 & 56.3 \\
EG11 & Air sampler I mile west (IW) & 6.40 & 56.2 \\
EG12 & Air sampler in Grahamville & 6.86 & 60.3 \\
EG13 & House in Magruder Village & 5.41 & 47.5 \\
EG14 & House in Paducah near Noble Park & 6.76 & 59.4 \\
EG15 & House south of Paducah on Oaks Road & 6.20 & 54.5 \\
\hline
\end{tabular}

aSee Fig. 3.5.

Table 3.5. 1992 quality control data for PGDP external gamma exposure

\begin{tabular}{|c|c|c|c|c|c|c|}
\hline Point $^{a}$ & Location and description & $\begin{array}{l}\text { First quarter } \\
\qquad(\mu \mathrm{R} / \mathrm{h})\end{array}$ & $\begin{array}{l}\text { Second quarter } \\
(\mu R / h)\end{array}$ & $\begin{array}{l}\text { Third quarter } \\
(\mu \mathrm{R} / \mathrm{h})\end{array}$ & $\begin{array}{l}\text { Fourth quarter } \\
\qquad(\mu R / h)\end{array}$ & $\begin{array}{l}\text { Average } \\
(\mu \mathrm{R} / \mathrm{h})\end{array}$ \\
\hline QCl & Office cycle, C-710 & 3.4 & 2.7 & 1.7 & 1.5 & 2.3 \\
\hline \multirow[t]{2}{*}{ QC2 } & $1 / 2$ office cycle, C-710 & 1.5 & 3.0 & 2.5 & 0.5 & 1.9 \\
\hline & & & & & & $83 \%$ agreement \\
\hline QC3 & Freezer cycle, C-710 & 2.5 & 2.2 & 3.0 & 2.3 & 2.5 \\
\hline \multirow[t]{2}{*}{ QC4 } & $1 / 2$ freezer cycle, $\mathrm{C}-710$ & 1.5 & 3.0 & 3.3 & 0.5 & 2.1 \\
\hline & & & & & & $84 \%$ agreement \\
\hline QC5 & Oven cycle, C-710 & 0.8 & 6.1 & 5.5 & 4.0 & 4.1 \\
\hline \multirow[t]{2}{*}{ QC6 } & 1/2 oven cycle, C-710 & 0.7 & 5.5 & 5.8 & 2.5 & 3.6 \\
\hline & & & & & & $88 \%$ agreement \\
\hline QC7 & Light dependence, unwrapped & 37.0 & 36.6 & 42.9 & 44.0 & 40.1 \\
\hline \multirow[t]{2}{*}{ QC8 } & Light dependence, wrapped & 45.9 & 44.4 & 50.1 & 44.4 & 46.2 \\
\hline & & & & & & $87 \%$ agreement \\
\hline QC9 & $\begin{array}{l}\text { Light dependence, unwrapped } \\
\text { spiked } 100 \text { mrem }\end{array}$ & 61.9 & 87.5 & 76.6 & 89.7 & 78.9 \\
\hline QC10 & $\begin{array}{l}\text { Light dependence, wrapped } \\
\text { spiked } 100 \text { mrem }\end{array}$ & 78.3 & 80.1 & 80.4 & 70.4 & $\begin{array}{c}77.3 \\
\text { 98\% agreement }\end{array}$ \\
\hline
\end{tabular}

${ }^{a}$ See Fig, 3.6. 


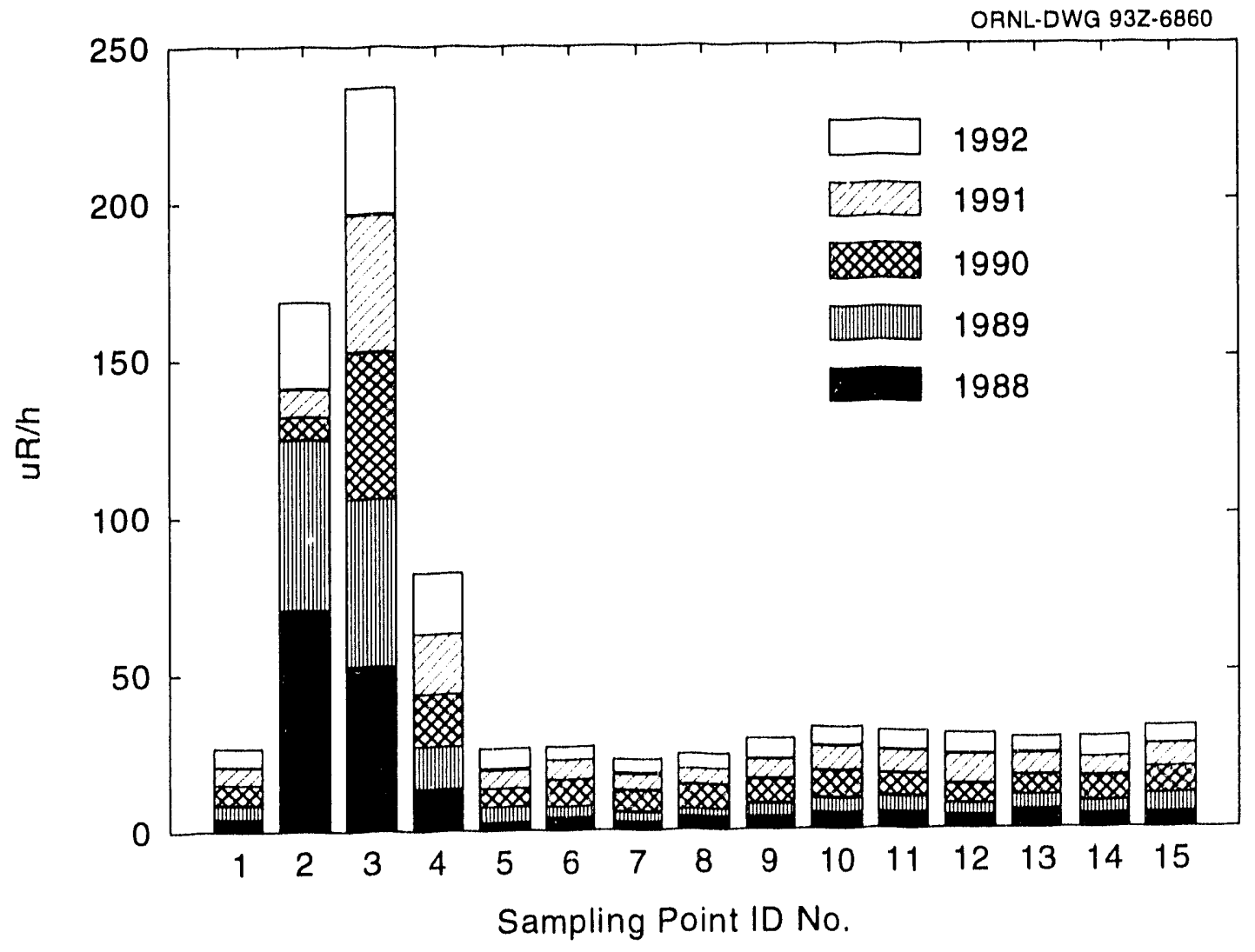

Fig. 3.7. PGDP external gamma radiation, 1988-1992.

KPDES 011 and Little Bayou Creek. The area where the north/south diversion ditch extends away from the plant boundary was also elevated at approximately three times background. Dose rates on Little Bayou Creek ranged from background levels to a maximum level of approximately twice background.

\subsection{Conclusions}

During $1992,2.11 \mathrm{mCi}(1.42 \mathrm{~kg})$ of uranium were released to the atmosphere from all activities at PGDP. Previous reports have included only rileasured emissions from the C-310 stack. However, because of the NESHAP regulation and the Federal Facilities Compliance Agreement between PGDP and the EPA, emission estimates from all sources are included in the 1992 report and will be included in subsequent reports. The methods used to estimate these emissions are approved by the EPA, are very conservative, and in all likelihood overestimate emissions from these unmonitored sources. Therefore, although the results indicate an increase in emissions, this perceived increase is caused by the inclusion of emissions from all known PGDP sources. For example, emission estimates for the C-400 decontamination building indicate a uranium emission of $1.70 \mathrm{mCi}(1.16 \mathrm{~kg})$. This emission estimate was based on the EPA method contained in 40 CFR 61, Appendix D, in which a determination is made of the curies "used" at a facility, and an area specified emission factor is applied to this number to arrive at an estimated emission. This estimation method is very conservative and most probably indicates emissions higher than actually occur. A comparison can be drawn between PSDP's actual uranium emissions and the new limit (or standard) for DOE-owned facilities established by EPA under the NESHAP regulations. In December 1989 EPA established a standard of $10 \mathrm{mrem}$ effective dose equivalent to the most affected off-site person. This means that PGDP must not expose the most affected off-site person to radionuclides from atmospheric releases that would result in an annual effective dose equivalent of 10 mrem or more. Air dispersion 


\section{Environmental Report-Paducah, Part 1}

modeling performed for PGDP by ORNL indicates that the annual effective dose equivalent for the most affected resident from all sources at PGDP is 0.0045 mrem, which is 2,222 times less than the EPA standard of 10 mrem.

During 1992, $0.202 \mathrm{mCi}(12.3 \mathrm{mg})$ of technetium were released from PGDP operations. The majority (98\%) of the ${ }^{94} \mathrm{Tc}$ emissions were from the C-310 stack. Although no direct correlation has been established, ${ }^{99} \mathrm{Tc}$ emissions from the C-310 stack seem to increase with an increase in ambient temperature and also with fluctuations of fluoride levels in the cascade. There has been no new introduction of ${ }^{49} \mathrm{Tc}$ into the cascade and no increase of ${ }^{99} \mathrm{Tc}$ in product withdrawal.

Minute quantities of ${ }^{2311} \mathrm{Th}$ and ${ }^{2.37} \mathrm{~Np}$ were also released to the atmosphere from the $\mathrm{C}-310$ stack in 1992. Thorium-230 is a product of uranium decay, and neptunium is a contaminant that remains in the enrichment cascade as a result of past use of reactor returns as feed material. This practice was discontinued in the 1970s. These radionuclides are present in the cascade in small amounts, but occasionally they migrate up the cascade and are emitted from the C-310 stack. Emissions are in such small amounts that daily or monthly sample analysis produces no detectable concentrations. Therefore, a composite sample is analyzed on a quarterly basis. Even on this infrequent schedule of composite sample analyses, emissions of thorium were above detection limits only during the first and fourth quarters of 1992. Neptunium was detected in the fourth quarter emissions. According to the sample analysis, $0.002 \mathrm{~g}$ of ${ }^{237} \mathrm{~Np}$ and $0.0002 \mathrm{~g}$ of ${ }^{2311} \mathrm{Th}$ were emitted during 1992. C-310 samples from the remainder of the year indicated no detectable emissions of ${ }^{239} \mathrm{Pu}$.
Even though the mass amounts of ${ }^{2311} \mathrm{Th}$ and ${ }^{2.37} \mathrm{~Np}$ were minute compared to the uranium emissions (which were only $1.42 \mathrm{~kg}$ ), the activity per mass quantity and the dose per activity level of these radionuclides resulted in the bulk of the $\mathrm{C}-310$ off-site dose being attributed to these radionuclides. However, the total dose from the C-310 stack was only $9.4 \mathrm{E}-5 \mathrm{mrem}$, which is 5 orders of magnitude less than the EPA limit of $10 \mathrm{mrem} / \mathrm{year}$ from DOE facilities.

Ambient air concentrations of gaseous fluorides were well below state ambient air standards.

The stack monitoring data, their characteristics, and the joint frequency distribution of winc, speed, stability, and wind direction are needed to calculate the amount of exposure of the surrounding population to plant emissions. The wind roses shown in Figs. 3.3 and 3.4 summarize the wind-speed frequency distribution data for the 1992 dose model estimates (see Sect. 2).

\subsection{References}

Coker, C. B. 1988. Environmental Air Sampling, ES-1.R0, Paducah Gaseous Diffusion Plant, Paducah, Ky.

Klement, Alfred W., Jr., et al. August 1972. Estimates of lonizing Radiation Doses in the United States 1960-2000, Office of Radiation Programs, Rockville, Md.

Paducah Gaseous Diffusion Plant (PGDP). 1979. Fluoride in Ambient Air. Gaseous and Water Soluble Particulate Treated Filter-SIE Method, EC-2360, Paducah, Ky.

Paducah Gaseous Diffusion Plant (PGDP). 1990. Low-Level Gross Alpha and Beta Activity on Air Filters, R-1-8, Paducah, Ky. 


\section{Surface Water}

4.1 Surface Water Monitoring $\ldots \ldots \ldots \ldots \ldots$ 4-3

4.2 Kentucky Pollutant Discharge

Elimination System Monitoring

4.3 Radiological Monitoring of Effluents ... . . . . 4-12

4.3.1 DOE Order 5400.5, "Radiological

Sampling"

4.3.2 Agreement In Principle Activities-

Off-Site and Effluent Surface

Water Sampling . . . . . . . . . . . . 4 4-12

4.4 Biological Monitoring of Effluents and

Receiving Waters . . . . . . . . . . . . . 4 4-14

4.4.1 Study Area . . . . . . . . . . . . . . 4-15

4.4.2 Toxicity Monitoring . . . . . . . . . . 4 4-15

4.4.3 Bioaccumulation ............. 4-16

4.4.4 Ecological Monitoring . . . . . . . . 4-17

4.5 Conclusions $\ldots \ldots \ldots \ldots \ldots \ldots \ldots \ldots$ 4-18

4.6 References ................... 4-18 


\section{Surface Water}

Paducah Gaseous Diffusion Plant (PGDP) is located in the western part of the Ohio River basin. Surface drainage from the site is to two small tributaries of the Ohio River: Big Bayou Creek on the west and Little Bayou Creek on the east (see

Fig. 4.1). These two streams join north of the site and discharge to the Ohio River at about river kilometer 1524 (river mile 945), which is about $56 \mathrm{~km}$ (35 miles) upstream from the confluence of the Ohio and Mississippi rivers. These creeks exhibit widely fluctuating discharge characteristics that are closely tied to local precipitation. Natural runoff makes up a small portion of the flow in Big Bayou and Little Bayou creeks during the dry periods. The PGDP site is not located in the Ohio River 100-year floodplain [elevation $101.6 \mathrm{~m}(333.3 \mathrm{ft})$ ], nor would it be affected by the historical high-water elevation of $104.2 \mathrm{~m}(341.8 \mathrm{ft})$. Figures 4.1 and 4.2 show the local PGDP surface hydrology systems and the regional area primary surface hydrology.

The vast majority of liquid effluents at PGDP consist of once-through cooling water, although a variety of liquid effluents (uranium contaminated as well as noncontaminated) result from activities associated with uranium precipitation and facility-cleaning operations. Conventional liquid discharges such as domestic sewage, steam plant wastewaters, and coal-pile runoff also exist. Routine monitoring activities provide data to quantify total discharges to surface water; to demonstrate compliance with federal, state, and U.S. Department of Energy (DOE) requirements; and to assist in evaluating the effectiveness of effluent treatment and control programs.

\subsection{Surface Water Monitoring}

SW13, the north/south diversion ditch (see Fig. 4.3), is monitored weekly. This ditch receives coal-pile runoff and the C-400 decontamination solution filtrate. A continuous leak sampler was used for the 7-d composite until September 16, 1992, when grab samples were substituted for the composite because of silting of the ditch with fly ash. The composite and grab samples are analyzed for the weekly parameters listed in Table 4.1. Each week a 100-mL sample is poured into a yearly composite container. At the end of each year, the composite sample is analyzed for the annual parameters listed in Table 4.1. (Because these data are not used for comparison to regulatory limits, the fact that holding times are exceeded is not of concern.) Analysis of samples indicates elevated levels of uranium and alpha and beta activity. However, the north/south diversion ditch is on-site and flows into the C-616 liquid pollution abatement facility, full-flow lagoon before discharging through outfall 001 , where monitoring occurs in accordance with the Kentucky Pollutant Discharge Elimination System (KPDES) permit.

Monthly sampling is conducted at upstream Big Bayou Creek (SW1), downstream Big Bayou (SW5), downstream Little Bayou (SW10), upstream Ohio River (SW29), and downstream Ohio River (SW30). Background water quality is sampled at Big Bayou Creek Location 1 (SW1). Tables 4.1 through 4.26 in Part 2 provide surface water monitoring data.

Data comparisons were made using a one-tail (upper) $t$ test at $95 \%$ confidence level for radiological 
ORNL-DWG 87M-8429R

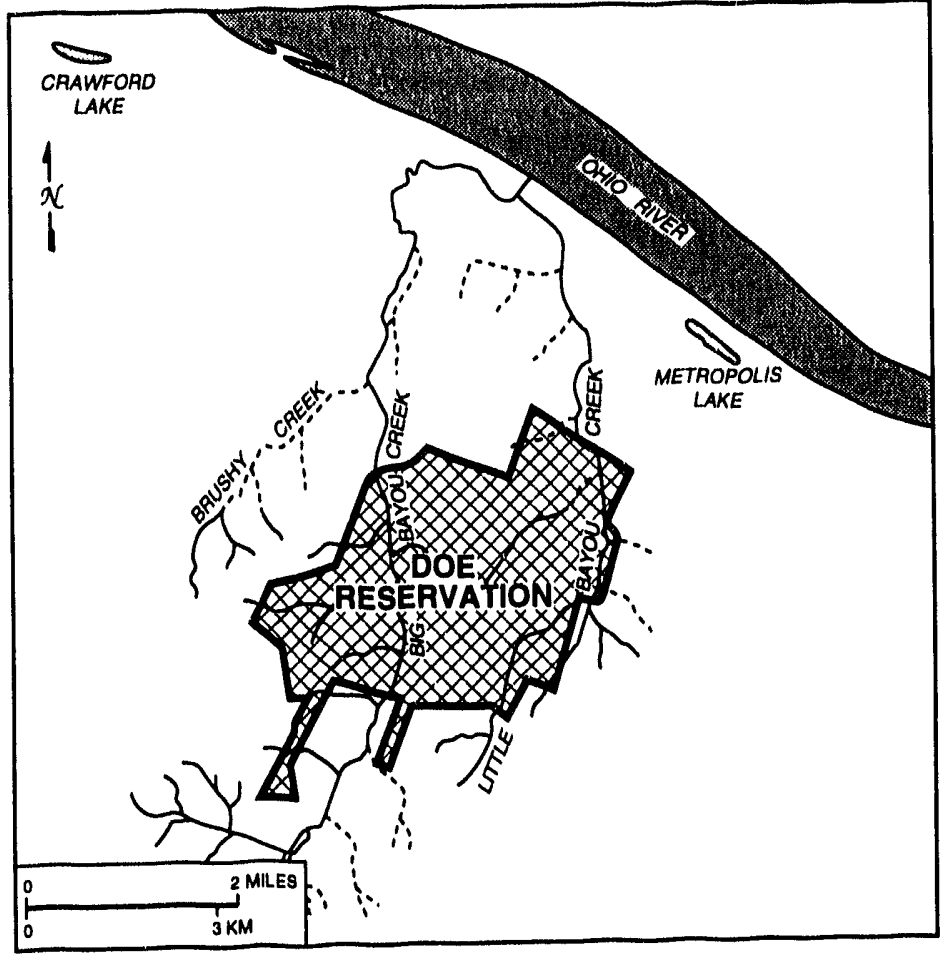

Fig. 4.1. PGDP site surface hydrology systems.

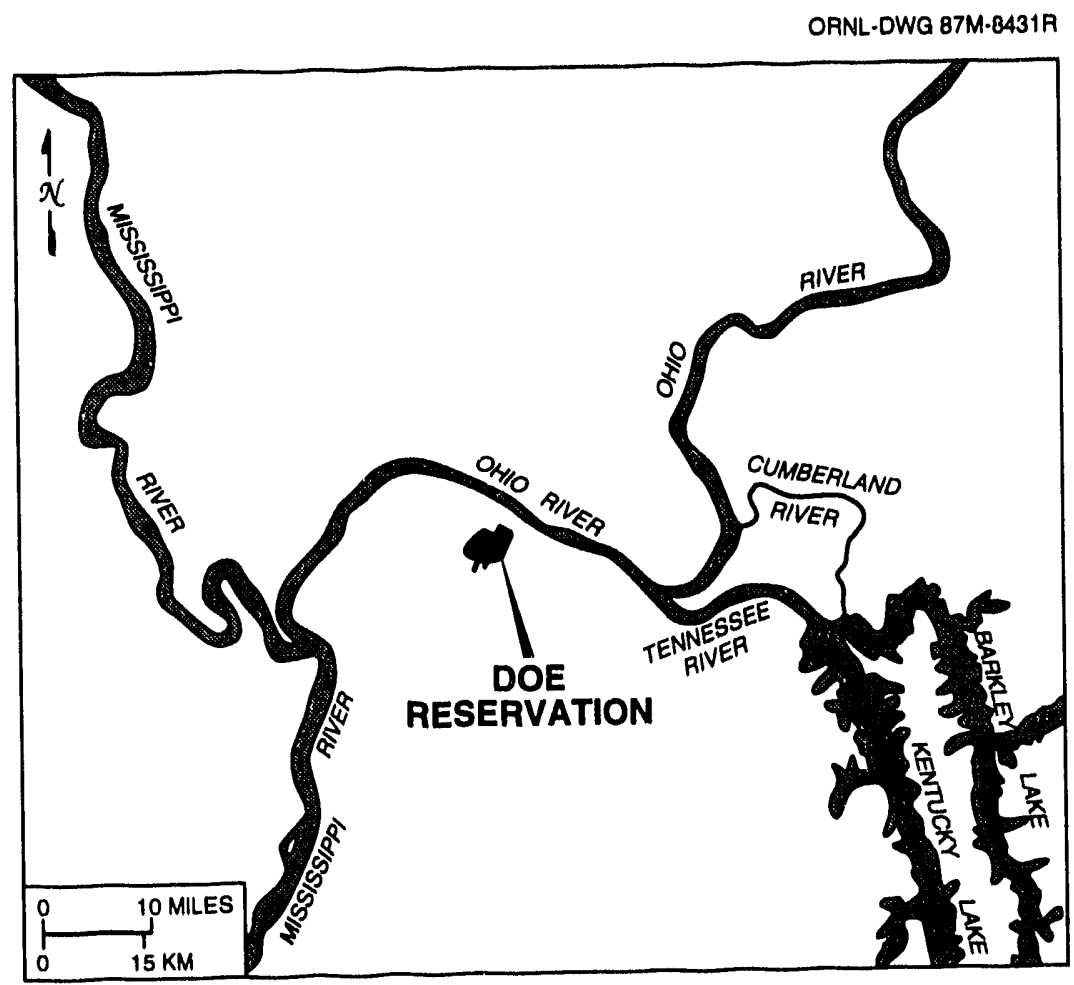

Fig. 4.2. Regional area primary surface hydrology systems. 
ORNL.DWG 89M-6359R3

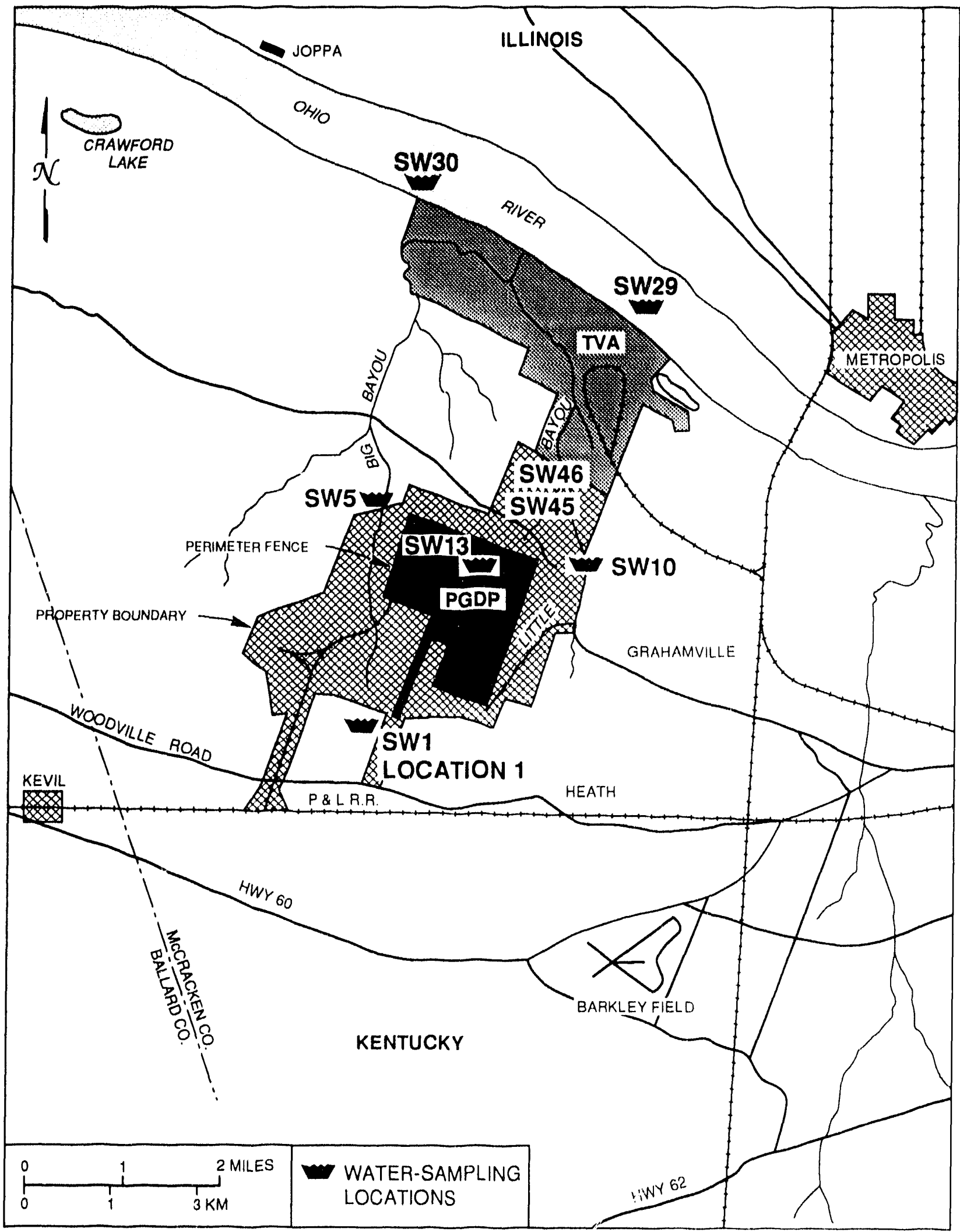




\section{Environmental Report-Paducah, Part 1}

Table 4.1. Summary of collection and analysis frequencies of surface water samples in 1992

\begin{tabular}{|c|c|c|c|c|}
\hline Station $^{a}$ & Parameter & Collection frequency & Sample type & Analysis frequency \\
\hline \multicolumn{5}{|c|}{ C-746-S and C-746-T landfill runoff } \\
\hline $\begin{array}{l}\text { Location } 1 \\
\text { (SW1), } \\
\text { Location 2, } \\
\text { Location } 3\end{array}$ & $\begin{array}{l}\text { Chloride, sulfate, pH, Na, } \\
\text { U, TOC, }{ }^{b} \text { TSS, }{ }^{c} \text { TDS }{ }^{d} \\
\text { total solids, specific } \\
\text { conductivity, gross } \\
\text { alpha and beta }\end{array}$ & Quarterly & Grab & Quarterly \\
\hline \multicolumn{5}{|c|}{ Surface water locations } \\
\hline SW29 & $\begin{array}{l}\mathrm{NO}_{3}-\mathrm{N}, \mathrm{SO}_{4} \text {, chloride, } \\
\mathrm{Cr}^{6+}, \mathrm{pH}, \mathrm{PO}_{4}-\mathrm{P}, \mathrm{U}, \mathrm{F}^{-}, \\
\text {dissolved alpha and } \\
\text { beta, suspended alpha } \\
\text { and beta, }{ }^{99} \mathrm{Tc},{ }^{239} \mathrm{Pu}, \\
{ }^{237} \mathrm{~Np},{ }^{235} \mathrm{U}\end{array}$ & Monthly & Grab & Monthly \\
\hline SW30 & $\begin{array}{l}\mathrm{NO}_{3}-\mathrm{N}, \mathrm{SO}_{4}, \text { chloride, } \\
\mathrm{Cr}^{6+}, \mathrm{pH}, \mathrm{PO}_{4}-\mathrm{P}, \mathrm{U}, \mathrm{F}^{-} \\
\text {dissolved alpha and } \\
\text { beta, } 1,2 \text {-dichloroethane, } \\
{ }^{235} \mathrm{U},{ }^{237} \mathrm{~Np}^{239} \mathrm{Pu},{ }^{99} \mathrm{Tc}, \\
\text { suspended alpha and beta }\end{array}$ & Monthly & Grab & Monthly \\
\hline SW13 & $\begin{array}{l}\mathrm{NO}_{3}-\mathrm{N}, \mathrm{PO}_{4}-\mathrm{P}, \text { chloride, } \\
\mathrm{Cr}^{6+}, \mathrm{pH}, \mathrm{U}, \mathrm{F}^{-} \\
\text {dissolved aipha and } \\
\text { beta, suspended alpha } \\
\text { and beta, } \mathrm{SO}_{4},{ }^{235} \mathrm{U},{ }^{99} \mathrm{Tc}, \\
\text { temperature }\end{array}$ & Weekly & $\begin{array}{l}\text { Grab and } \\
7-d \\
\text { composite }\end{array}$ & Weekly \\
\hline SW13 & $\begin{array}{l}\mathrm{U}, \mathrm{Ni}, \mathrm{Hg}, \mathrm{Cd}, \mathrm{As}, \mathrm{Ba}, \mathrm{Cu}, \\
\mathrm{Pb}, \mathrm{Se}, \mathrm{Ag} \text {, dissolved } \\
\text { alpha and beta, suspended } \\
\text { alpha and beta, }{ }^{99} \mathrm{Tc} \text {, } \\
{ }^{237} \mathrm{~Np},{ }^{239} \mathrm{Pu},{ }^{230} \mathrm{Th}, \% \\
{ }^{235} \mathrm{U}, \mathrm{Cr}, \mathrm{ICP}{ }^{e} \text { metals scan }\end{array}$ & Annually & $\begin{array}{l}\text { Annual } \\
\quad \text { composite }\end{array}$ & Annually \\
\hline SW1 & 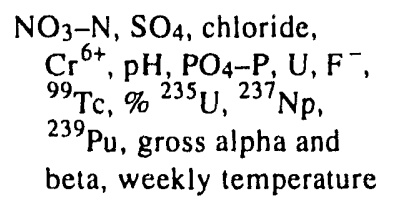 & Monthly & Grab & Monthly \\
\hline SW5, SW10 & $\begin{array}{l}\text { Gross alpha and beta, } \\
{ }_{99} \mathrm{Tc}, \%{ }^{235} \mathrm{U},{ }^{237} \mathrm{~Np}, \\
{ }^{239} \mathrm{Pu}\end{array}$ & Monthly & Grab & Monthly \\
\hline
\end{tabular}

${ }^{a}$ See Fig. 4.3.

tTotal organic carbon.

'Total suspended solids.

"Total dissolved solids.

eInductively couplea plasma spectrometer. 


\section{Environmental Report-Paducah, Part 1}

results comparing downstream Big Bayou (SW5) and Little Bayou (SW10) creeks to reference or background data taken at upstream Big Bayou Creek (SW1). The only exception was for assay or weight percent ${ }^{235} \mathrm{U}$, which was made using a two-tailed $t$ test at $95 \%$ confidence level. In all instances except ${ }^{235} U$, the critical determinant increases over natural background. Uranium-235 being present on the site at both enriched and depleted assays may impact the creeks by raising or lowering the background assay. The data show statistically significantly elevated levels of gross alpha activity, uranium, and ${ }^{235} \mathrm{U}$ at downstream location SW10. SW5 location was elevated only for gross beta. The results evaluated for gross alpha and beta were obtained by combining gross results to the sum of the dissolved and suspended measurements. The activity at SW 10 is most likely related to the elevated uranium levels in Little Bayou Creek, which reflect plant discharges in effluents. Additional indications of plant influence can be found in the lower ${ }^{235} \mathrm{U}$ results, which indicate that the uranium in the creek is tails (lower than normal) assay material. Data results do not indicate a cause or source for the elevated beta in Big Bayou Creek (SW5). No other radiological analyses at either location were different from the reference location this year although in the past technetium has been elevated. No measurement for 1992 gross alpha or gross beta exceeded the $15 \mathrm{pCi} / \mathrm{L}$ alpha and $50 \mathrm{pCi} / \mathrm{L}$ beta safe drinking water limits nor did uranium exceed $4 \%$ of the DOE DCG.

Two locations on the Ohio River, SW29 and SW30, are monitored monthly for the parameters listed in Table 4.1. These data are presented in Tables 4.21 and 4.22 in Part 2. Samples tested for 1,2-dichloroethane, discharged by an upstream Ohio River industrial complex, were $<5 \mu \mathrm{g} / \mathrm{L}$.

The surface runoff from the C-746-S residential landfill and the C-746-T inert landfill is monitored quarterly. Sampling is performed to comply with Kentucky Division of Waste Management requirements for landfill operations. Data comparisons were made using a one-tail (upper) $t$ test at $95 \%$ confidence level for nonradiological results comparing ach landfill location (SW45 and SW46) to reference or background data taken at upstream Big Bayou Creek (SW1). The critical determinant is increases over natural background. The data show significantly elevated levels of fluorides $(F)$ at both locations along with elevated sulfate $\left(\mathrm{SO}_{4}\right)$, dissolved solids, and uranium at SW45. Although elevated uranium levels should also elevate the alpha and beta levels, it should be understood that the analytical procedures are much more sensitive to uranium than alpha and beta activity. Moreover, particularly when solids are present, as the elevated dissolved solids indicate, shielding of radiation occurs, causing variability that would mask low uranium concentration effects.

\subsection{Kentucky Pollutant Discharge Elimination System Monitoring}

The Clean Water Act is administered for PGDP by the Kentucky Division of Water (KDOW) through the KPDES Wastewater Discharge Permitting Program. The earlier National Pollutant Discharge Elimination System (NPDES) permit (KY0004049) was issued by Region IV of the U.S. Environmental Protection Agency (EPA) and became effective February 15, 1975. The permit was revised February 4, 1977, and was to expire in 1980. Although PGDP had applied for a new permit at the time the old one expired, no system was in place at the KDOW to replace the old NPDES, and a new permit could not be issued. PGDP operated under the original 1975 permit until October 22, 1986, when the state of Kentucky issued the KPDES permit (KY0004049). On November 5, 1986, the state permit was adjudicated because the permit limits were not achievable. Monitoring then resumed under the old NPDES permit. As a part of the negotiations associated with the adjudication process, an Agreed Order was proposed that would include interim limits while a biological monitoring study (see Subsect. 4.4) was being carried out at PGDP. Table 4.1 in Part 2 shows interim limits, sampling frequency, and the type of sample required by the Agreed Order. The Agreed Order becam - effective October 12, 1987. Monitoring then resumed under the KPDES permit with the Agreed Order modifications. The KPDES permit expired in October 1991; however, monitoring continued under the KPDES Agreed Order. By submitting permit renewal documents in May 1991. PGDP complied with regulations that allow the continued discharge of wastewatcr under the auspices of the expired permit. 


\section{Environmental Report-Paducah, Part 1}

Monitoring of 17 individual outfalls was conducted in accordance with the KPDES Agreed Order. Table 4.2 lists all outfalls and their contributing processes; Fig. 4.4 depicts the location of the outfalls. Table 4.1 in Part 2 cites the effluent limits set forth by the Agreed Order.

Tables 4.2 through 4.15 in Part 2 give the yearly minimum, maximum, and average for each outfall monitored. Because no flow occurred at outfall 003 in 1992, no monitoring data were obtained. Flow from the north/south diversion ditch is normally channeled through outfall 0 ') 1 by way of a lift station that pumps the effluent through the C-616 full-flow lagoon; however, during a rainfall with flows greater than 10 year/24 h (i.e., a maximum daily average flow over a 10 -year occurrence interval), the lift station overflows to outfall 003 . This is the only time that outfall 003 discharges and is monitored. Outfall 005 is not monitored regularly because its effluent flows into the C-611 secondary lagoon. Outfall 006, the C-611 secondary lagoon, is monitored for the same parameters as those required by outfall 005 . Outfall 007, a septic field for the C-611 water treatment plant, is not allowed to experience any discharge. Outfall 014 was monitored once in 1992. This U-shaped lagoon experiences flow only when the $C-611$ sludge lagoon is dredged (i.e., every 2 or 3 years) and the filter backwash is directed to outfall 014 . Monitoring of outfall 014 occurs at this time.

During 1992, PGDP achieved a compliance rate on limit exceedances of $99.50 \%$, out of 1984 analytical results, with KPDES Agreed Order limits. (The 1991 compliance rate was $99.5 \%$.) A total of approximately 4800 analyses were performed; the additional analyses reflect "report only" requirements. The total number of noncompliances in 1992 was 16 , with 10 coming from limit exceedances and 6 from other sources such as holding time exceedances. Table 4.3 indicates the noncompliances experienced under the Agreed Order. The noncompliances during 1992 were for total residual chlorine, trichloroethylene, $\mathrm{pH}$, and total suspended solids. Six unpermitted discharges and administrative errors also occurred.

One total residual chlorine noncompliance occurred in 1992 for which no cause could be assigned. Two total suspended-solids noncompliances occurred because of rain resuspending sediment in effluent waters. The KPDES permit, which became effective November 1, 1992, does not contain limits for total suspended solids from rainfall runoff outfalls. However, PGDP daily inspects each outfall area to ensure that no oil sheens or erosion problems occur. Remedial actions are taken if problems are identified.

Four pH noncompliances occurred. Two of the four exceedances were related to algal growth that was unrelated to PGDP. A fish kill in the C-611 lagoon related to a process upset in January 1992 contributed to one $\mathrm{pH}$ excursion. A malfunctioning pump used in sanitary water treatment processing caused excess soda ash, a water-softening agent, to be discharged to the C-611 lagoon. More than 800 small fish, mainly shad and sunfish, died. Biologists from Oak Ridge National Laboratory (ORNL) investigated the incident and estimated that less than $10 \%$ of the lagoon's sunfish population was affected. The lagoon contains a large population of sunfish in poor condition because of overcrowding (ORNL 1992). The other $\mathrm{pH}$ noncompliance occurred when a normally capped line was leaking water to outfall 014 . The filter backwash water, which normally flows to outfall 006 had a $\mathrm{pH}$ of 9.5. The Agreed Order $\mathrm{pH}$ limit at outfall 014 was 9.0. The $\mathrm{pH}$ limit at outfall 006 was 10.4 . Repairs were made to the leaking line.

During an April 1992 groundwater pump test, water containing trichloroethylene was released to outfall 008 , causing three trichloroethylene noncompliances. The KPDES Agreed Order limit of $27 \mathrm{mg} / \mathrm{L}$ was exceeded, with the highest concentration being $87 \mathrm{mg} / \mathrm{L}$. The KPDES permit, which became effective November 1, 1992, contains a limit of $81 \mathrm{mg} / \mathrm{L}$ for trichloroethylene. Measures have been taken to reduce the chances of this problem recurring.

One holding time was missed in February. The holding time for a turbidity sample collected at outfall 006 was exceeded. The KLOW was notified in the monthly discharge monitoring report of this occurrence. Five unpermitted uischarges happened in 1992. One unpermitted discharge in February 1992 was a spill of recirculating cooling water containing chromium to outfall 013. In August 1992 chi..ed water containing sodium molybdate was discharged to outfall 008 as a result of a coil drain valve that was inadvertently opened. On September 21, 1992, more

\section{4-8 Surface Water}


Table 4.2. Kentucky Pollutant Discharge Elimination System outfalls at PGDP

\begin{tabular}{|c|c|c|}
\hline Location $^{a}$ & Drainage source & Contributing process \\
\hline 001 & $\begin{array}{l}\text { C- } 616, \text { C- } 600, \text { C- } 400, \text { C- } 410 \\
\text { C- } 635, \text { C- }-335, \text { C- } 337, \text { C-535, } \\
\text { C- } 537, \text { C-746-A, C-747-A, } \\
\text { C- } 635-6\end{array}$ & $\begin{array}{l}\text { Recirculating cooling water blowdown } \\
\text { treatment effluent, coal-pile runoff, } \\
\text { once-through cooling water, surface runoff, } \\
\text { roof and floor drains, treated } \\
\text { uranium solutions, sink drains }\end{array}$ \\
\hline 002 & C-360, C-637, C-337-A & $\begin{array}{l}\text { Once-through cooling water, roof and } \\
\text { floor drains, sink drains, extended } \\
\text { aeration sewage treatment system }\end{array}$ \\
\hline 003 & North edge of plant & $\begin{array}{l}\text { Storm overflow of north/south diversion } \\
\text { ditch discharges }\end{array}$ \\
\hline 004 & $\begin{array}{l}\text { C-615 sewage treatment plant, } \\
\text { C-710, C-728, C-750, C-100, } \\
\text { C- } 620, \text { C- } 400\end{array}$ & $\begin{array}{l}\text { Domestic sewage, laboratory sink drains, } \\
\text { motor cleaning, garage drains, } \\
\text { laundry, machine coolant treatment } \\
\text { filtrate, condensate blowdown, } \\
\text { once-through cooling water }\end{array}$ \\
\hline 005 & C-611 primary sludge lagoon & $\begin{array}{l}\text { Water treatment plant sludge, sand filter } \\
\text { backwash, laboratory sink drains }\end{array}$ \\
\hline 006 & C-611 secondary lagoon & $\begin{array}{l}\text { Water treatment plant sludge, sand filter } \\
\text { backwash, laboratory sink drains } \\
\text { from outfall } 005\end{array}$ \\
\hline 007 & Outfall eliminated & \\
\hline 008 & $\begin{array}{l}\text { C-743, C-742, C-741, C-723, } \\
\text { C-721, C-728, C-729, C-400, } \\
\text { C- } 420, \text { C-410, C-727, C-411, } \\
\text { C- } 331, \text { C-310, C-724, C-744, } \\
\text { C- } 600, \text { C- } 405, \text { C-409, C-631, } \\
\text { C- } 720\end{array}$ & $\begin{array}{l}\text { Surface drainage, roof and floor drains, } \\
\text { once-through cooling water, paint shop } \\
\text { discharge, condensate, instrument shop } \\
\text { cleaning area, metal-cleaning rinse } \\
\text { water, sink drains }\end{array}$ \\
\hline 009 & $\begin{array}{l}\text { C-810, C-811, C-331, C-333, C-310, } \\
\text { C-100, C-102, C-101, C-212, } \\
\text { C-200, C-300, C-320, C-302, } \\
\text { C- } 750, \text { C- } 710, \text { C- } 720\end{array}$ & $\begin{array}{l}\text { Surface drainage, roof and floor drains, } \\
\text { condensate, once-through cooling water, } \\
\text { sink drains }\end{array}$ \\
\hline 010 & $C-531, C-331$ & $\begin{array}{l}\text { Switchyard runoff, roof and floor drains, } \\
\text { condensate, sink drains }\end{array}$ \\
\hline 011 & $\begin{array}{l}\text { C-340, C-533, C-532, C-315, } \\
\quad \text { C-333, C-331 }\end{array}$ & $\begin{array}{l}\text { Once-through cooling water, roof and floor } \\
\text { drains, switchyard runoff, condensate, } \\
\text { sink drains }\end{array}$ \\
\hline 012 & C-633, C-533, C-333-A & $\begin{array}{l}\text { Roof, floor, and sink drains } \\
\text { runoff; condensate; surface runoff; } \\
\text { extended aeration sewage treatment } \\
\text { system }\end{array}$ \\
\hline 013 & Southeast corner of plant & Surface runoff \\
\hline 014 & C-611 U-shaped sludge lagoon & Sand filter backwash, sanitary water \\
\hline 015 & West central plant areas & Surface runoff \\
\hline 016 & Southwest corner of plant & Surface runoff \\
\hline 017 & Extreme south area of plant & Surface runoff \\
\hline 018 & Landfill at north of plant & Surface runoff \\
\hline
\end{tabular}

${ }^{a}$ See Fig. 4.4. 


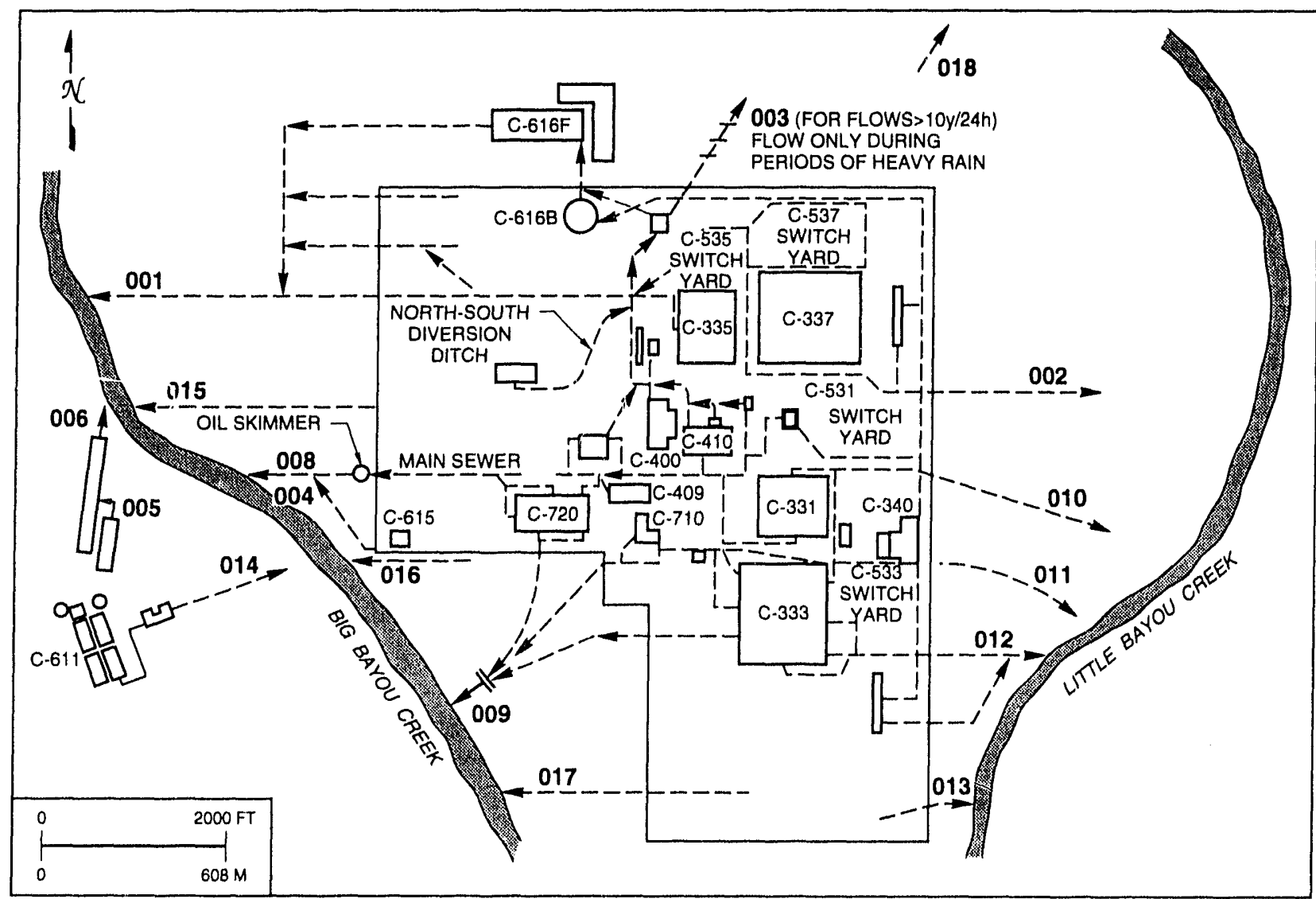

Fig. 4.4. KPDES outfall locations at PGDP.

than 2 in. of rain fell in approximately 40 minutes. Runoff from the coal pile flowed through outfalls 008 and 015 . At the time, coal-pile runoff was allowed to flow only through outfall 001 . The KPDES permit has been amended to allow coal-pile runoff to flow through outfalls 008 and 015 . Fire-training water was inadvertently discharged through outfall 016 during October fire-training exercises. The KPDES permit was later amended to allow this activity.

In February 1992, a fish kill occurred in the C-616 full-flow lagoon. ORNL biologists investigated the kill at the request of PGDP. Although the number of dead fish exceeded 400 , the event was not ecologically significant. Mortality probably affected less than $10 \%$ of the bluegill population in the lagoon. Based on both field sampling and laboratory examinations, the lagoon contains a very large, stunted, and starving population of bluegill that are in poor condition because of overcrowding. The exact cause of death for the bluegill could not be determined. A toxicity test of the water conducted with fathead minnows and Ceriodaphnia revealed no toxic effects. This information suggests that the kill was not related to chemical discharges from PGDP operations. However, the field observations, population dynamics, condition factors, blood analyses, and pathological examinations suggest that starvation is the primary stressor in the lagoon (Ryon 1992).

During 1992 the Polychlorinated Biphenyl (PCB) Source Identification Project concluded. Details are included in Subsect. 8.2.4.

nn November 1, 1992, a revised KPDES permit becan ifective. The permit, which provides for chemical and toxicity testing, contains difficult to meet metals, $\mathrm{pH}$, temperature, biomonitoring, and phosphorous limits. The metal effluent limits contained in the PGDP permit were based on water quality criteria with a zero flow receiving stream. PGDP adjudicated the portions of the permit that 


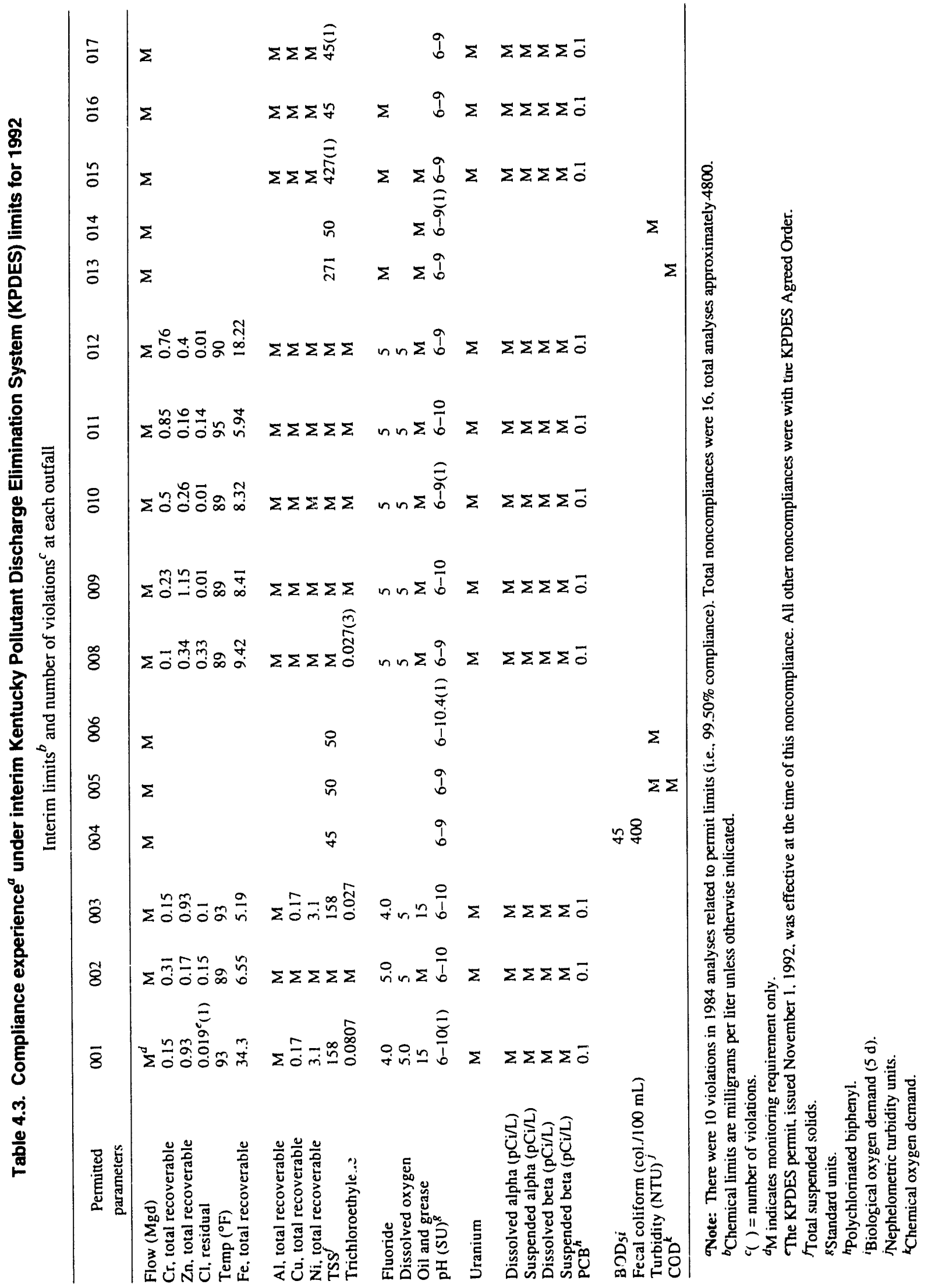




\section{Environmental Report-Paducah, Part 1}

contained effluent limits that were not attainable and implemented those portions of the permit not under adjudication. KDOW granted a stay from the adjudicated limits while an Agreed Order is negotiated. PGDP, at the request of KDOW, prepared a draft Agreed Order and submitted it to KDOW. KDOW is reviewing and revising the draft and will provide PGDP with comments soon.

\subsection{Radiological Monitoring of Effluents}

\subsubsection{DOE Order 5400.5, "Radiological Sampling"}

Radiological liquid effluent monitoring was conducted periodically by random grab sampling and laboratory analyses. Although no specific effluent limits are indicated for radiological parameters in the KPDES permit, DOE Order 5400.5 sets guidelines for allowable concentrations of radiological species in various effluents and requires radiological monitoring to protect the public health.

In addition to sampling required by the KPDES permit, each continuous-flow sampling point with annual average radionuclide concentrations greater than $1 \%$ of the Derived Concentration Guide (DCG) for any radionuclide was sampled weekly. Uranium was the only radionuclide measured in PGDP effluents with concentrations greater than $1 \%$ of the DCG. Monitoring of outfalls 010 and 012 for uranium, historically done on a quarterly basis, was increased to weekly to generate a sufficient quantity of data to characterize these discharges.

Tables 4.25 and 4.26 in Part 2 give the yearly minimum, maximum, and average concentrations of uranium and technetium at each effluent-monitoring location. Each radionuclide is compared with the DCG and is presented as a percentage of that standard. The average concentrations were small percentages of the corresponding DCGs for both uranium and technetium at all locations.

Routine monitoring also provides data to estimate the total radionuclide discharge to suriace waters. Because current monitoring provides only instantaneous measurements for both concentration of radionuclides and flow, a large uncertainty is associated with this estimation. During 1992, $66 \mathrm{~kg}$ of uranium were discharged to surface waters, a decrease from the 1991 discharge of $108 \mathrm{~kg}$. Technetium releases to surface waters remained relatively constant at $4.7 \mathrm{~g}$ in 1992 . Table 4.27 in Part 2 shows monthly data for the major contributors to the total discharge during 1992.

\subsubsection{Agreement In Principle Activities-Off-Site and Effluent Surface Water Sampling}

A quarterly sampling event takes place in which the state of Kentucky Cabinet for Human Resources (CHR) travels to the PGDP area and obtains samples from off-site and on-site surface water locations. PGDP personnel accompany the CHR. Split samples are taken at all scheduled locations. Samples from selected locations are analyzed immediately although most samples are reserved as backups. CHR results are reviewed, and backups are analyzed if problems are detected. These sampling events are conducted because the state of Kentucky wants to have independent verification that public health is protected. This protection is achieved at PGDP by meeting the DOE Order 5400.5 DCGs of $100 \mathrm{mrem}$ per year. Safe drinking water limits do not apply to PGDP surface water sampling because the effluent ditches, Big and Little Bayou creeks, are not drinking water sources for any residents. The KPDES Permit has no effluent limits for radiological analytes, only a requirement to report results of sampling events. DOE orders 5400.1 and 5400.5 define effluent and surveill. nce monitoring requirements to provide confidence that the DCGs are not exceeded.

For monitoring purposes, PGDP uses estimates of DCG levels to determine sampling frequencies. Effluent monitoring is based on two categories for continuous discharges, greater than $1 \%$ and less than $1 \%$ of the DCGs. Intermittent discharges (ditches that discharge only during rainfall) are also based on two categories, greater than $1 \%$ and less than $1 \%$ of the DCGs.

In 1992, there were no continuous points above $10 \%$ of the DCGs. KPDES continuous discharge points 001 and 011 were between 1 and $10 \%$; points 008 and 009 were less than $1 \%$. KPDES intermittent effluent discharge point 015 was greater than $10 \%$; 010 and 018 were between 1 and $10 \%$; and 002,012 , 013,016 , and 017 were less than $1 \%$. Off-site or surveillance locations in 1992 indicated that Big Bayou Creek was less than $1 \%$ and that Little Bayou

\section{4-12 Surface Water}




\section{Environmental Report-Paducah, Part 1}

Creek was greater than $1 \%$ of the DCGs. Although PGDP monitors for other radionuclides (neptunium-239, plutonium-239, and thorium-230) and screens with alpha and beta measurements, uranium and technetium $-99\left({ }^{99} \mathrm{Tc}\right)$ are the primary effluent concerns. No ${ }^{94} \mathrm{Tc}$ averages measured in the past have even approached $1 \%$ of the DCGs.

Therefore, all DCG-level monitoring is based on uranium concentrations, and all alpha and beta values are assumed to come from uranium with the beta corrected based on any ${ }^{99} \mathrm{Tc}$ information. The DCG levels from DOE Order 5400.5 are $600 \mathrm{pCi} / \mathrm{L}$ for total uranium and $100,000 \mathrm{pCi} / \mathrm{L}$ for ${ }^{99} \mathrm{Tc}$.

The purpose of having corroborative sampling between PGDP and the CHR is to provide quality assurance on the activity for the state and for PGDP by showing that sampling and analytical techniques provide data leading to equivalent decisions. This assurance is difficult to provide because of the screening nature of the analytical tests performed by the state. The state uses gross alpha and gross beta activity, ${ }^{99} \mathrm{Tc}$, and man-made radionuclide analyses to monitor PGDP activities. PGDP uses direct measurements for radionuclides of concern to characterize surface water into the previously mentioned categories along with screening techniques or less frequent sampling for specific radionuclides to verify that no other radionuclides are being discharged. The alpha and beta activities are highly variable and subject to difficulties in analysis and data interpretation because of the following:

- Solid interferences-The presence of solids in a sample can cause both negative and positive interferences in the analysis of alpha and beta activity. Results can be biased high because of the presence of natural urarium, ${ }^{41} \mathrm{~K}$, and radionuclides from fallout. Results can also be biased low because of shielding effects. Alpha and beta energy is absorbed by the solids, not allowing the energy to reach the detector, thus lowering the analyzed value. Results can also he biased either high or low because of spiking corrections. Spikes, or standard material, are added to sample portions to estimate recovery. Variability in solids between the spike water and the sample water can produce correction factors that can significantly change the final result.
- Background influences-Even though background is measured and the result corrected, there is potential for shifts in background during analytical runs that can cause significant differences in low-level analyses where background and sample counts are somewhat equivalent.

For these reasons, only relative comparisons of PGDP's direct DCG estimates with screening activity measurements are possible. State samples taken from runoff locations are from pooled areas; however, PGDP takes samples for DCG levels during flow periods. The state also takes samples from areas that PGDP does not monitor. These areas on Big and Little Bayou creeks, the KPDES ditches not requiring radiological monitoring, and the blocked-off 003 ditch are not included in evaluations.

Variations in comparative data are discussed in this report, either explaining the cause of the differences or pointing out the differences if the cause is unknown. Detailed results from the corroborative sampling for gross alpha and beta uctivity and ${ }^{99} \mathrm{Tc}$ along with data comparisons of state and PGDP maximum and minimum reported results are shown in Part 2, Table 4.28. Table 4.4 (Part 1) contains the comparative data for PGDP DCGs to state gross alpha measurements. Gross alpha was selected because of the effect of ${ }^{99} \mathrm{Tc}$, a beta enitter, on gross beta analyses. KPDES points are listed in declining order by 1992 DCG estimations from Table 4.25 in Part 2. Off-site points are listed with upstream and downstream state data. Table 4.4 shows the state measurements decreasing, as expected, according to PGDP's 1992 DCG sstimates. There are four differences, three of which are readily explainable. State results for outfalls 001,011 , and 010 are lower than PGDP results. The differences are attributable to differences in sampling frequencies. PGDP sampled outfalls 001 and 011 weekly during 1992 for a total of 52 analyses however, outfall 010 was sampled only eight times. The state monitored quarterly for a total of four analyses. The range of PGDP's results for these outfalls (see Table 4.28 in Part 2) overlaps the state values, which indicates that discharges do occur at the measured state levels. Outfall 010 also receives water routed from outfall 011 during periods of maintenance on 011 facilities. PGDP takes samples weekly when this occurs. The 
Table 4.4. 1992 state surface water measurements

\begin{tabular}{|c|c|c|}
\hline \multirow[t]{2}{*}{ PGDP sampling location } & \multicolumn{2}{|c|}{$\begin{array}{l}\text { State gross alpha measurement range } \\
(\mathrm{pCi} / \mathrm{L})\end{array}$} \\
\hline & Min & Max \\
\hline \multicolumn{3}{|c|}{ Effluent monitoring ${ }^{a}$} \\
\hline $\mathrm{KPDES}^{b} 015$ & 25 & 129 \\
\hline KPDES 011 & $<1$ & 8 \\
\hline KPDES 001 & $<4$ & 8 \\
\hline KPDES 018 & 8 & 45 \\
\hline KPDES 010 & $<1$ & 8 \\
\hline KPDES 012 & 4 & 8 \\
\hline KPDES 017 & 3 & 4 \\
\hline KPDES 002 & $<1$ & 2 \\
\hline KPDES 016 & 1 & 11 \\
\hline KPDES 008 & $<1$ & 2 \\
\hline KPDES 013 & $<2$ & 3 \\
\hline KPDES 009 & & All $<1$ \\
\hline \multicolumn{3}{|c|}{ Off-site monitoring } \\
\hline Little Bayou Creek, upstream (L-9) & & All $<1$ \\
\hline Big Bayou Creek, upstream (L-1) & & All $<1$ \\
\hline Little Bayou Creek, downstream (L-11) & 1 & 6 \\
\hline Big Bayou Creek, downstream (L-4) & 3 & 8 \\
\hline
\end{tabular}

${ }^{a}$ Listed in declining order according to 1992 percent of Derived Concentration Guide estimates (see Table 4.25 in Part 2).

${ }^{b}$ Kentucky Pollutant Discharge Elimination System.

state did not take samples during this rerouting of effluents. PGDP has no definitive explanation for the higher than expected value of $11 \mathrm{pCi} / \mathrm{L}$ at outfall 016. This value is above the 1992 PGDP range listed in Table 4.28 of Part 2. PGDP believes this was caused by the state's practice of sampling from pooled areas at runoff locations, and outfall 016 is a runoff location. The off-site state results show higher measurements for Big Bayou Creek than for Little Bayou Creek, contrary to PGDP estimates. Again, this is attributed to increased sampling (13 measurements to 4 ) and therefore better estimations. The PGDP measurements listed in Tables 4.18 and 4.19 in Part 2 show average uranium concentrations in Big and Little Bayou creeks at $<0.005$ and $0.019 \mathrm{mg} / \mathrm{L}$, respectively, and these values are used for DCG monitoring.

\subsection{Biological Monitoring of Effluents and Receiving Waters}

On September 24, 1987, the Commonwealth of Kentucky Natural Resources and Environmental Protection Cabinet issued an Agreed Order, which required the development of a Biological Monitoring Program (BMP) for PGDP. The PGDP BMP was implemented in 1987 by the University of Kentucky. Beginning in fall 1991, the Environmental Sciences Division at ORNL assumed responsibility for the PGDP BMP. The overall goals of the BMP are to (1) demonstrate that the effluent limitations established for PGDP protect and maintain the use of Little Bayou and Big Bayou creeks for growth and propagation of fish and other aquatic life, (2) characterize putential health and environmental 


\section{Environmental Report-Paducah, Part 1}

impacts, (3) document the effects on stream biota resulting from operation of pollution abatement facilities, and (4) make recommendations on any necessary improvements for effluent treatability. In September 1992, a renewed KPDES permit was issued to PGDP. As of this writing, many of the provisions of the permit have been stayed, and a new Agreed Order is in draft form. The renewed permit requires quarterly toxicity monitoring of continuous and intermittent outfalls. A BMP is not required in either the draft Agreed Order or the renewed permit. However, biological monitoring of the DOE facilities at PGDP is required in DOE Order 5400.1. Data collected under the BMP will also be used to support three studies proposed in the draft Agreed Order.

The BMP for PGDP consists of three major tasks: (1) effluent and ambient toxicity monitoring, (2) bioaccumulation studies, and (3) ecological surveys of stream communities (i.e., benthic macroinvertebrates and fish). This report includes Environmental Sciences Division/ORNL activities from December 1990 to November 1992. A detailed description of the program and results will be published in the first report of the PGDP BMP in the spring of 1993.

\subsubsection{Study Area}

PGDP is located in the western part of the Ohio River basin. Surface drainage from PGDP enters Big Bayou and Little Bayou creeks, which are two small tributaries to the Ohio River. Big Bayou Creek is a perennial stream with a drainage basin extending from about $4 \mathrm{~km}$ south of PGDP to the Ohio River. Part of the creek's $14.5-\mathrm{km}$ course flows along the western boundary of the plant. Little Bayou Creek originates in the West Kentucky Wildlife Management Area and flows north for $10.5 \mathrm{~km}$ toward the Ohio River; its course includes part of the eastern boundary of the plant. Four continuously flowing outfalls (001, 006, 008, and 009) discharge to Big Bayou Creek. Outfalls 002, 010, 011, and 012 are combined at the C-617 lagoon and discharged via outfall 011 to Little Bayou Creek. Effluent from outfalls 013,015,016,017, and 018 regularly discharges to Big Bayou and Little Bayou creeks during rainfall events.

Three sites on Big Bayou Creek located $12.5 \mathrm{~km}$, $10.0 \mathrm{~km}$, and $9.1 \mathrm{~km}$ (BBK 12.5, BBK 10.0, and $B B K$ 9.1) from the mouth of the creek, one site on
Little Bayou Creek located $7.2 \mathrm{~km}$ (LUK 7.2) from the mouth of the creek, and one off-site reference station on Massac Creek located $13.8 \mathrm{~km}$ from the mouth of the creek (MAK 13.8) were routinely sampled to assess the ecological health of the stream and to evaluate ambient toxicity. Three additional sites (BBK 2.8, LIIK 9.0, and LUK 4.3) were sampled as part of the bioaccumulation monitoring task. Toxicity monitoring and benthic macroinvertebrate sampling were conducted quarterly, and fish community sampling and bioaccumulation sampling were conducted twice annually in the spring and fall. KPDES effluents evaluated for toxicity included $001,004,006,008$, 009, 011, 013, 015, 016, 017, and 018.

\subsubsection{Toxicity Monitoring}

Ceriodaphnia and fathead minnow toxicity tests of effluents from the continuously flowing outfalls $(001,004,006,008,009$, and 011$)$, the intermittently flowing outfalls $(013,015,016,017$, and 018), and ambient sites (BBK 12.5, BBK 10.0, BBK 9.1, LUK 7.2, and MAK 13.8) were conducted quarterly beginning in October 1991. All of the ambient sites and outfalls except 016 were evaluated five times; outfall 016 was evaluated four times. Tests with Ceriodaphnia and fathead minnows were typically conducted concurrently. A no-observed-effect concentration (NOEC; that concentration causing no reduction in survival or growth of fathead minnows or survival or reproduction of Ceriodaphnia) and a $25 \%$ inhibition concentration (IC25; that concentration causing a $25 \%$ reduction in fathead minnow growth or Ceriodaphnia survival compared to a control) were determined for each test. The NOEC was used as a compliance end point for tests conducted under the draft Agreed Order (prior to September 1992). The lower the NOEC, the more toxic an effluent. The chronic toxicity unit (TUc $=100 / \mathrm{IC} 25)$ is required as a compliance end point in the renewed permit (September 1992 to the present). Because Little Bayou and Big Bayou creeks have been determined to have low flows of zero, an NOEC $<100 \%$ or a TUc $>1.2$ would be considered a noncompliance and an indicator of potential for instream toxicity.

Effluent from the continuous outfalls was rarely toxic (NOEC $<100 \%$ or TUc $>1.2$ ) to Ceriodaphnia, and effluent from the intermittent outfalls was never 


\section{Environmental Report-Paducah, Part 1}

toxic to Ceriodaphnia. When toxicity was observed in the outfalls, no toxicity was observed in the ambien sites. Effluent from the continuous and intermittent outfalls was occasionally toxic (NOEC $<100 \%$ or TUc $>1.2$ ) to fathead minnows. Effluent from all of the continuous outfalls except 001 was toxic in February 1992. However, during this same test period, fathead minnow survival was reduced only at BBK 12.5 (above PGDP) and LUK 7.2. It is hypothesized that a pathogenic organism is the cause of low fathead minnow survival at these sites because treatment with ultraviolet light eliminated the toxicity. Likewise, it was hypothesized that a natural pathogen was the cause of "toxicity" to fathead minnows at all sites during the October 1991 test. Toxicity observed in the effluent from outfalls 004, 006, 008, and 009 was not present at the ambient sites. Effluent from outfall 009 was also toxic to fathead minnows in October 1992, but no instream toxicity was observed at BBK 9.1. Toxicity of the intermittent outfalls may be caused by high suspended solids. Ambient toxicity tests were not conducted concurrently with the intermittent outfalls. Tests with filtered and nonfiltered effluent during 1993-1994 will provide additional insight into the toxicity of the intermittent outfalls.

\subsubsection{Bioaccumulation}

The objectives of the bioaccumulation monitoring were to (1) continue PCB tracking studies in fish from Big Bayou and Little Bayou creeks, (2) confirm elevated mercury concentrations in fish in Big Bayou Creek and establish appropriate reference site concentrations, and (3) conduct screening analyses to detect other contaminants that may be of concern to consumers in fish from these streams.

Longear sunfish were collected for PCB and mercury analysis from Big Bayou Creek, Little Bayou Creek, and Massac Creek during April 1992. Hinds Creek (Tennessee) served as a source of uncontaminated reference fish. PCB contamination was evident in longear sunfish collected from both Big Bayou and Little Bayou creeks. Mean PCB concentrations in sunfish from sites downstream of PGDP discharges exceeded those from the reference sites. The highest mean concentration occurred in fish from the site in Little Bayou Creek immediately downstream from outfall 011. In Big Bayou Creek, the highest mean PCB concentration was found in fish from BBK 9.1, below outfall 001, but fish from BBK 10.0 also contained PCB contamination. For both creeks, there was a strong downstream gradient in PCB contamination in sunfish. Along with a close association between the degree of contamination and proximity to outfalls demonstrated to be PCB sources in the past, this suggests that the pattern of contamination is sustained by continuing low-level contamination of waters discharged to the creeks, rather than a result of residual $\mathrm{PCB}$ contamination in sediments of the creeks themselves. Continued regular monitoring of $\mathrm{PCB}$ concentrations in fish is needed to detect any consistent trend over time.

Mean concentrations of mercury in redbreast sunfish from the reference site in Tennessee (Hinds Creek) were less than $50 \%$ of those observed at any local reference site (Big Bayou Creek or Massac Creek). Mean mercury concentrations in Hinds Creek fish differed significantly from concentrations in fish from Big Bayou Creek and Massac Creek. Mercury concentrations in fish from sites in Big Bayou Creek below PGDP were similar and exceeded that in local reference site fish. The slightly elevated concentrations of mercury in fish from Big Bayou Creek below PGDP may be a result of mercury in PGDP effluents, but they may also be a consequence of differences in the biogeochemical processing of mercury downstream from the plant.

Concentrations of metals measured in fillets of longear sunfish from Big Bayou Creek and Little Bayou Creek are typical of those observed in previous monitoring and generally ditfer little (with several exceptions) from concentrations observed in fish from the Hinds Creek reference site.

Concentrations of arsenic, cadmium, copper, lead, selenium, and zinc were lower than the national geometric mean concentrations observed for whole body analyses of fish in the U.S. Fish and Wildlife Service National Contaminant Biomonitoring Program. Concentrations of antimony, cadmium, chromium, nickel, selenium, and silver were well below screening levels used in the EPA Integrated Risk Information System (IRIS). Beryllium and arsenic were not detected in PGDP fish (berylluum detection limit was at the IRIS screening level; arsenic detection limit was ten times the screening level). Those metals for which IRIS screening levels are not published (copper, lead, thallium, uranium, 
and zinc) were found at concentrations similar to or lower than those that typically occur in foods such as marine fish or mammalian muscle. Detection of elevated concentrations of uranium in fish from Little Bayou Creek is consistent with the observed elevated concentrations of uranium in this creek.

\subsubsection{Ecological Monitoring}

Prior to ORNL's initiation of the Instream Monitoring Task, a site selection study was conducted in early December 1990. This study included visits to 24 potential reference stream sites outside the PGDP boundaries and 5 stream sites adjacent to PGDP. Based on the site visits, biota surveys, and previous work conducted by the University of Kentucky, five stream sites were included in the Instream Monitoring Task.

Beginning in September 1991, benthic macroinvertebrate samples were collected at quarterly intervals from five stream sites. The services of a subcontractor will be retained in mid-1993 to process invertebrate samples. Samples are being stored and maintained at a benthic invertebrate sample chain-of-custody facility at ORNL in Oak Ridge, Tennessee. Processing will involve (1) sorting the invertebrates from the debris in each sample, (2) identifying taxa to the lowest practical level (genus in most cases), and

(3) enumerating the individuals within each taxon.

Fish population and community studies can be used to assess the ecological effects of changes in water quality and habitat. The initial objectives of the instream fish monitoring task were to (1) characterize spatial and temporal patterns in the distribution and abundance of fishes in Little Bayou and Big Bayou creeks and (2) document the effects of PGDP operations on fish community structure and function. Quantitative sampling of the fish populations at four sites in the Bayou watershed (BBK 12.5, BBK 10.0, $B B K$ 9.1, and LUK 7.2) and at one site in a reference stream, Massac Creek (MAK 13.8), was conducted by electrofishing on September 22-25, 1991, and March 15-17, 1992. Data from these samples were used to estimate species richness, population size (numbers and biomass per unit area), length frequency, and condition factors. Qualitative fish sampling was conducted by electrofishing on March 17 and June 9, 1992. Data from these samples were used to determine the species richness and number of specimens (relative abundance) based on sampling a known length of stream.

Data on the fish communities of Big Bayou and Little Bayou creeks downstream of PGDP were compared to data from reference sites on Big Bayou Creek above PGDP and on Massac Creek. These comparisons indicated a slight but noticeable degradation in the communities downstream of PGDP. The fish communities at BBK 10.0 and BBK 9.1 showed signs of impact. The fish community at BBK 10.0 had a low mean and total species richness compared to the reference site (MAK 13.8). At both sites, there were few sensitive species at low densities, and tolerant species were more common and abundant than at the reference site. The presence of hybrid sunfish at both sites indicates that the communities were under some reproductive stress. Finally, condition factors at each site were higher than at MAK 13.8. The high condition factor combined with a large population of central stonerollers at BBK 10.0 indicates that there is some nutrient enrichment at this site.

The fish community at LUK 7.2 was generally in poor condition compared to the BBK 12.5 reference site. The mean and total species richness values were low, and the community lacked any catostomide species. Sensitive species were absent, and several tolerant species were present at considerable densities. Because the site is on a smaller stream, some of these deficiencies might be expected; . however, overall the community was poorer than at BBK 9.1 but not as affected as BBK 10.0. The poor conditions found at LUK 7.2 did not appear to continue at the downstream qualitative site, LUK 4.3. Species richness was comparable to MAK 13.8, particularly in terms of sensitive species. The community was well represented in all families, except perhaps catostomids, and significant absences in feeding guilds were not demonstrated. The relative abundance and catch-per-effort data were similar to quantitative data at MAK 13.8 and BBK 9.1.

The fish communities associated with PGDP streams indicate depressed conditions. The greatest impacts occurred at sites closest to the plant, which suggests that PGDP effluents may be the cause. The low species richness and few sensitive species can be caused by poor water quality (e.g., high temperatures or chlorine levels) or reflect degraded habitat conditions. Biomass and density respond quickly to 


\section{Environmental Report-Paducah, Part 1}

improvements in degraded conditions and it will be important to follow changes in these parameters, particularly at the most stressed sites.

\subsection{Conclusions}

Compliance with KPDES Agreed Order limits has increased from $99.5 \%$ in 1991 to $99.8 \%$ in 1992. Figure 4.5 shows a comparison of 1992, 1991, and 1990 noncompliances. The Plant Effluent Chlorine and Temperature Control Project will continue to alleviate chlorine and temperature noncompliances. Continued emphasis on erosion control should cause total suspended solids noncompliances to decrease. Because occasional elevated $\mathrm{pH}$ levels are not causing biological harm to the receiving streams, an alternate $\mathrm{pH}$ range will be pursued during the KPDES permit renewal process.

Radiological monitoring of plant effluents indicates that uranium and technetium values are below the DCGs stated in DOE Order 5400.5.
Comparisons of radiological results from upstream Big Bayou Creek with downstream Big Bayou and Little Bayou creeks and landfill runoff locations indicate that Little Bayou Creek has elevated levels of $U,{ }^{235} \mathrm{U}$, and alpha and beta activity. Big Bayou Creek has only elevated beta, whereas the two landfill runoff locations have elevated uranium levels. The alpha and beta results are probably caused by the release of small amounts of uranium and technetium in plant effluents.

\subsection{References}

Birge, W. J., D. J. Price, and D. P. Keogh. December 1991. Biological Monitoring Program for the Paducah Gaseous Diffusion Plant, Annual Report for Fiscal Period December 1990 through December 31, 1991, University of Kentucky, Lexington.

Birge, W. J., T. M. Short, and J. R. Lauth. December 1990. Biological Monitoring Program for the

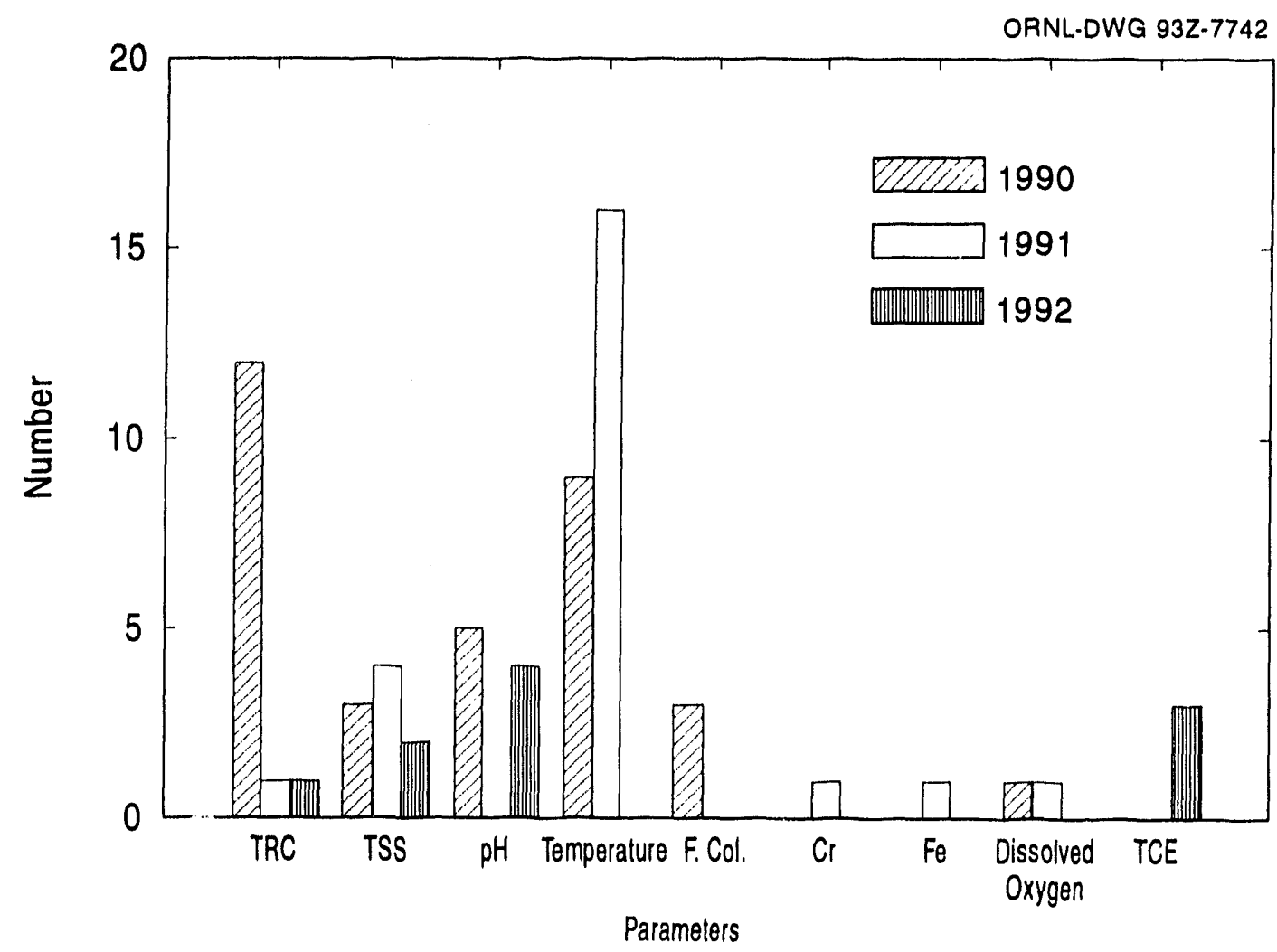

Fig. 4.5. Kentucky Pollutant Discharge Elimination System noncompliances: 1990-1992. (TRC = total residual chlorine; TSS $=$ total suspended solids; $F$. Col. = fecal coliform; $T C E=$ trichloroethylene.) 


\section{Fnvironmental Report-Paducah, Part 1}

Paducah Gaseous Diffusion Plant, Three-Year Report (draft), University of Kentucky, Lexington.

Eischen, M. A., et al. 1978. Environmental Studies at the Paducah Gaseous Diffusion Plant, Paducah. Kentucky, Battelle Columbus Laboratories, Columbus, Ohio.

Kazas, L. A., ed. 1993. First Report on BMP at PGDP, Oak Ridge National Laboratory, Oak Ridge, Tenn.

Oak Ridge National Laboratory (ORNL). January 22 , 1992. Report on Fish Kill Investigations at PGDP, January 8-9, 1992, Oak Ridge, Tenn.
Ryon, M. G. March 6, 1992. Report on Investigation of Fish Kill, February 24-25, 1992, Oak Ridge National Laboratory, Oak Ridge, Tenn.

Walton, B. T., et al. June 1991. Paducah Gaseous Diffusion Plant Biological Monitoring Program 1988-1990: Findings and Recommendations, Oak Ridge National Laboratory, Oak Ridge, Tenn.

Walton, B. T., et al. April 1991. PGDP/KPDES Permit Renewal Proposed Biological Monitoring Program (draft), Oak Ridge National Laboratory, Oak Ridge, Tenn. 


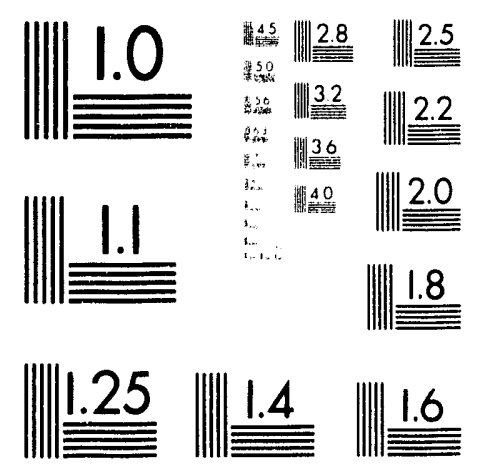



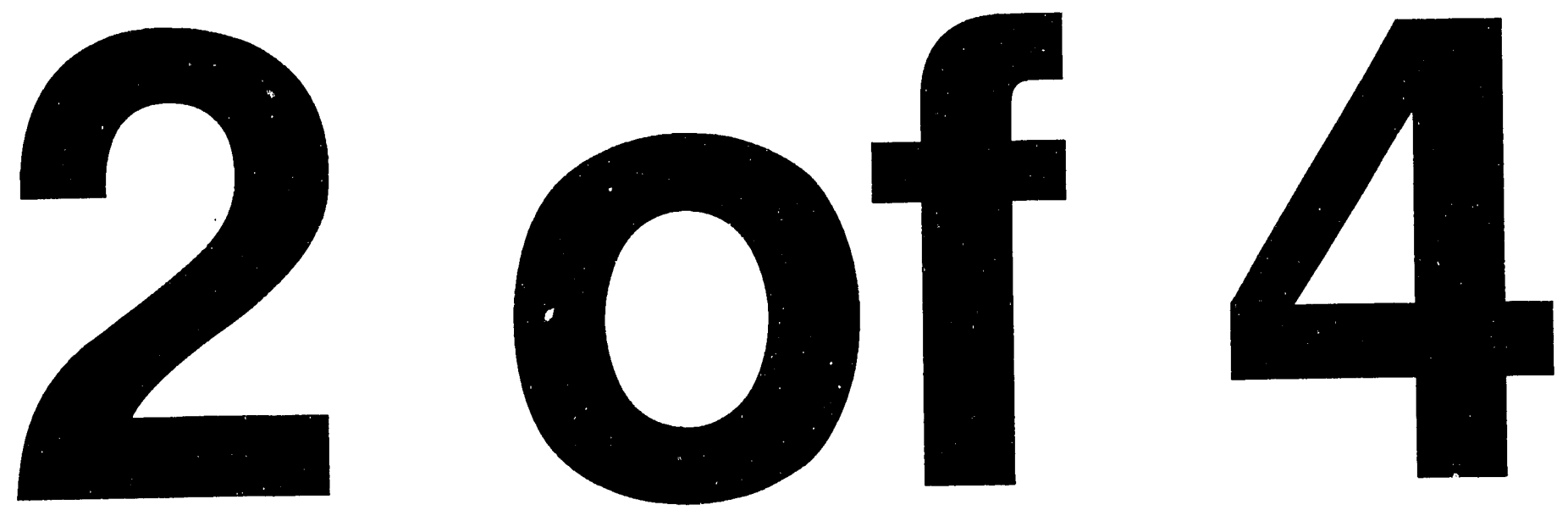


\section{Groundwater}

5.1 Geology of PGDP . . . . . . . . . . . . . 5-3

5.2 Hydrogeology of PGDP . . . . . . . . . 5-3

5.3 DOE Order $5400.1 \ldots \ldots \ldots \ldots \ldots \ldots$

5.4 Technical Objectives . . . . . . . . . . 5-5

5.5 Program Description $\ldots \ldots \ldots \ldots \ldots$

5.5.1 Effluent Monitoring .......... 5-6

5.5.2 Environmental Surveillance

Monitoring . . . . . . . . . . . . . 5-28

5.5.3 Groundwater Monitoring Results . . . . 5-29

5.6 Project Accomplishments . . . . . . . . . 5-34

5.6.1 Hydrogeologic Services

Section (HSS) . . . . . . . . . . . . . 5-34

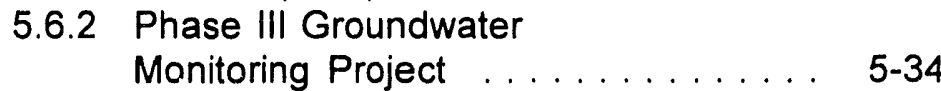

5.6.3 Aquifer Testing . . . . . . . . . . . . . . 5-35

5.6.4 Groundwater Monitoring Phase IV . . . . 5-36

5.6.5 Sampling and Analysis Plan ... . . . . 5-36

5.6.6 HSS Special Studies ... . . . . . . . . 5 5-36

5.6 .7 Related Activites . . . . . . . . . . 5 5-36

5.7 References . . . . . . . . . . . . . . . . . 5-37 


\section{Environmental Report-Paducah, Part 1}

\section{Groundwater}

Monitoring and protection of groundwater resources at the Paducah Gaseous Diffusion Plant (PGDP) are required by federal and state regulations and by U.S. Department of Energy (DOE) orders. Monitoring efforts have been initiated at PGDP to reflect these requirements. Characterization activities have also been undertaken that will resolve the recognized deficiencies in understanding of the site geology and hydrogeology. These activities are intended to develop a thorough understanding of the subsurface environment to aid in developing technically effective monitoring strategies.

\subsection{Geology of PGDP}

PGDP, located in the Jackson Purchase region of western Kentucky, lies within the northern tip of the Mississippi Embayment portion of the Gulf Coastal Plain Province. The Mississippi Embayment is a large sedimentary trough oriented nearly north-south that received sediments during the Cretaceous and Tertiary geologic time periods.

In the PGDP area, bedrock is overlain by the Upper Cretaceous McNairy Formation, which consists of interbedded and interlensing sand, silt, and clay. Paleocene Porters Creek Clay occurs in the southern portions of the site above the McNairy Formation and predominately consists of dark gray to black clay. The Porters Creek Clay subcrops along a buried terrace slope that extends east-west across the site. Eocene sediments, consisting of interbedded and interlensing sand, silt, and clay, overlie the Porters Creek Clay in the extreme southern end of the DOE reservation. The Cretaceous through Eocene strata dip gently to the south-southwest toward the axis of the embayment.

A unit designated as the continental deposits was laid down in the region during the late Tertiary and
Quaternary periods, creating an angular unconformity with the underlying sediments. A basal gravel facies (lower continental deposits) and an upper, fine-grained clastic facies (upper continental deposits) are recognized in the continental deposits. The continental deposits are interpreted as originating from an alluvial fan that covered most of the Jackson Purchase region (Olive 1980).

In response to base-level changes during Pleistocene glaciations, stream systems eroded and later alluviated their valleys, reworking the continental deposits at different elevations. A thicker sequence of Pleistocene continental deposits, representing a valley fill, underlies most of PGDP and extends northward to the Ohio River. Figure 5.1 presents a schematic cross-section that illustrates regional stratigraphic relationships in the vicinity of PGDP.

\subsection{Hydrogeology of PGDP}

The local groundwater flow system at PGDP exists within the Cretaceous through Pleistocene sediments and Holocene alluvium. Four specific components have been identified as part of the groundwater flow system: the McNairy Flow System, the Terrace Gravels, the Regional Gravel Aquifer (RGA), and the Upper Continental Recharge System (UCRS).

The McNairy Flow System, formerly termed the deep groundwater system, consists of interbedded and interlensing sand, silt, and clay of the McNairy Formation. Sand facies account for 40 to $50 \%$ of the total formation thickness of approximately $225 \mathrm{ft}$. The Terrace Gravels consist of shallow Pliocene-aged gravel deposits in the southern portion of the plant site. These deposits usually lack sufficient thickness and saturation to constitute an aquifer. 
1992 Environmental Report-Paducah, Part 1
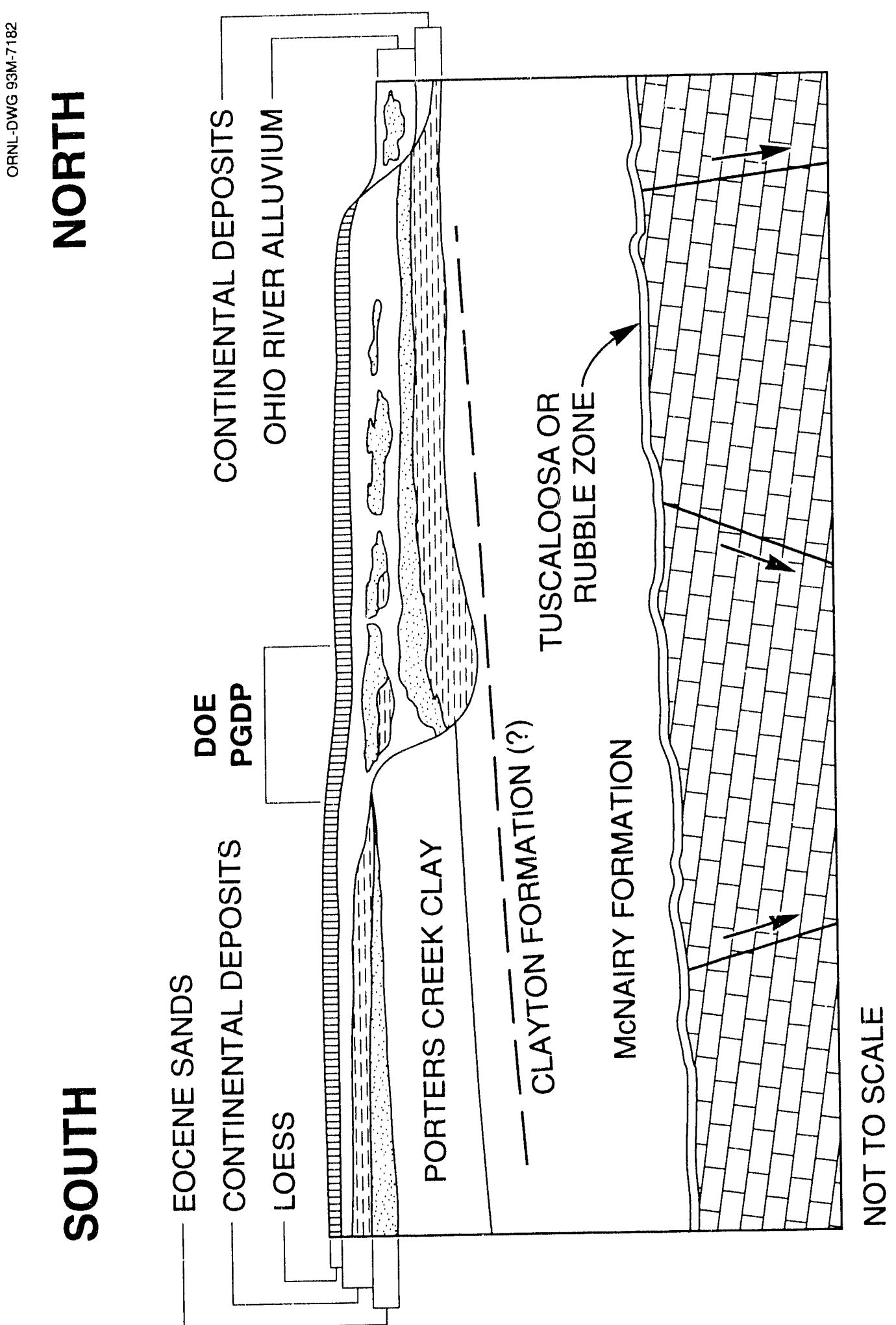

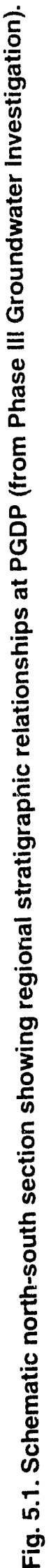




\section{Environmental Report-Paducah, Part 1}

The RGA consists of the Quaternary sand and gravel facies of the lower continental deposits and Holocene alluvium found adjacent to the Ohio River, which are of sufficient thickness and saturation to constitute an aquifer. These deposits have an average thickness of $30 \mathrm{ft}$ and range up to $50 \mathrm{ft}$ along an axis that trends east-west through the plant site. The RGA is the primary aquifer used locally by private residences located north of PGDP for drinking water and other domestic uses, irrigation of gardens, and watering of livestock. The UCRS, formerly termed the shallow groundwater system, predominantly consists of clayey silt with interbedded sand and gravel of the upper continental deposits. Groundwater flow in the UCRS is predominately downward, to recharge the RGA.

Topographically controlled recharge and discharge areas to the south and north, respectively, bound the locial groundwater flow system. One areat of recharge occurs south of PGDP within the area underlain by the Eocene sands and has resulted in a groundwater divide. Flow originates south of PGDP within the Eocene sands and the Pliocene terrace gravels. Groundwater within the Pliocene gravels either discharges to local streams or recharges the RGA. From the plant site, groundwater flows northward in the RGA toward the Ohio River, which is the local base level for the system.

\subsection{DOE Order 5400.1}

DOE Order 540)(). I outlines requirements for groundwater monitoring at all DOE facilities and specifies the development of three documents relating to groundwater monitoring: a Groundwater Protection Program Plan, a Groundwater Monitoring Plan, and an Environmental Monitoring Plan. The Groundwater Protection Program Plan (Clausen et al. 1992a) and the Groundwater Monitoring Plan (Early, Sigmon, and Williams 1989) for the PGDP site have been completed.

The general objective of the Groundwater Protection Program Plan is to formalize and give structure to the PGDP Groundwater Protection Program by identifying specific responsibilities and assigning them to various entities within the plant who are matrixed to the program. Environmental Restoration and Environmental Management initiatives are coordinated within the plan to the greatest extent possible.

The general objective of the Groundwater Monitoring Plan is to provide a comprehensive blueprint for DOE to follow at each facility that targets the environmental protection of groundwater, is consistent with DOE's commitment to operate its facilities in an environmentally safe manner, and complies with all applicable and relevant environmental laws. The Groundwater Monitoring Plan fulfills these objectives for PGDP by providing a monitoring plan that accomplishes the following:

- develops an appropriate level of understanding of site geology and groundwater hydrology and of how pathways and rates of contaminant migration from existing waste disposal sites to the underlying aquifer;

- provides the frimework within which an integrated strategy for long-term monitoring of existing disposal sites can be developed to aid evaluation of remedial action alternatives; and

- creates al data base and fundamental geotechnical understanding of the site to facilitate future waste disposal decisions.

An Environmental Monitoring Plan has also been developed for the PGDP site. This plan contains the rationale and design criteria for the site monitoring programs, the extent and frequency of monitoring and measurements, procedures for laboratory analyses, quality assurance requirements, program implementation procedures, and directions for the preparation and disposition of reports. The Environmental Monitoring Plan was approved by DOE in July 1992.

\subsection{Technical Objectives}

The primary objectives of groundwater monitoring at PGDP are to detect as early as possible any contamination resulting from past and present land disposal of wastes and to provide the basis for developing groundwater quality assessments if contamination is detected. Additional objectives outlined in DOE Order 5400.1 require that groundwater monitoring at all DOE facilities "determine and document the effects of operations on ground water quality and quantity." The order 


\section{Environmental Report-Paducah, Part 1}

specifically requires groundwater monitoring to be conducted on-site and in the vicinity of $\mathrm{DOE}$ facilities to accomplish tlie following:

- obtain data to determine baseline conditions of groundwater quality and quantity;

- demonstrate compliance with, and implementation of, all applicable regulations and DOE orders;

- provide data to permit early detection of groundwater pollution or contamination;

- provide a reporting mechanism for detected groundwater pollution or contamination;

- identify existing and potential groundwater contamination sources and maintain surveillance of these sources; and

- provide data for making decisions about land disposal practices and the management and protection of groundwater resources.

\subsection{Program Description}

The monitoring and protection of groundwater resources at $P$ GDP are required by federal and state regulations, and by DOE orders. Federal groundwater regulations generally are promulgated and enforced by the U.S. Environmental Protection Agency (EPA). PGDP lies within EPA Region IV jurisdiction, which encompasses the southeastern United States. The EPA Region IV headquarters are located in Atlanta, Georgia.

Many state groundwater regulations are promulgated and enforced by the Kentucky Division of Waste Management (KDWM), located in Frankfort, Kentucky. A KDWM field office for western Kentucky is located in Paducah, Kentucky. Some interactions between PGDP and KDWM concerning groundwater involve the Hazardous Waste Branch of the KDWM in Frankfort.

Groundwater monitoring activities at PGDP are described as "effluent monitoring" or "environmental surveillance monitoring." Effluent monitoring as applied to groundwater is monitoring to achieve compliance with one or more federal or state regulations, or permit conditions. Included under this heading are groundwater monitoring at either interim-status or permitted-status Resource Conservation and Recovery Act (RCRA) units; monitoring of RCRA $3004(\mathrm{u} / \mathrm{v})$ facilities; monitoring in conjunction with Comprehensive Environmental Response, Compensation, and Liability Act (CERCL.A) actions (e.g., Remedial Investigation/Feasibility Studies); monitoring around landfills in compliance with permit regulations; and monitoring around underground storage tanks (USTs). In addition, groundwater monitoring in response to administrative orders or a memorandum of understanding (e.g., an Agreed Order between the facility and EPA) is included as effluent monitoring.

Environmental surveillance monitoring is defined as perimeter exit pathway monitoring and off-site water-well monitoring. Perimeter exit pathway monitoring is conducted to aid understanding of the effects of facility operations on the regional groundwater quality and quantity. In addition to verifying compliance with regulatory requirements at the DOE reservation boundary, perimeter exit pathway monitoring provides a means of detecting previously unidentified on-site ground water quality problems. Off-site water-well monitoring is conducted to address public concerns about off-site ground water contamination, especially of drinking water sources.

The general characteristics that differentiate groundwater effluent monitoring and surveillance monitoring are summarized in Table 5.1. Subsections 5.5.1 and 5.5.2 describe the existing effluent and environmental surveillance monitoring conducted by PGDP. For a more detailed description of the groundwater monitoring requirements prescribed by the applicable regulations and DOE orders, refer to the Groundwater Protection Program. Figures 5.2 through 5.10 show the locations of all wells sampled during PGDP's 1992 groundwater monitoring activities. Analytical results from the sampling described in Subsects. 5.5.1 and 5.5.2 are included in Tables 5.1 through 5.11 in Part 2.

\subsubsection{Effluent Monitoring}

\subsubsection{RCRA Interim Status and Permit Monitoring Programs}

RCRA groundwater monitoring is required under two separate sections of the regulations, applying to units that are under interim status or are regulated (and therefore have a RCRA permit). The 
Table 5.1. Comparison of general characteristics of groundwater effluent and groundwater surveillance monitoring

\begin{tabular}{lc}
\hline \multicolumn{1}{c}{ Groundwater effluent monitoring } & Groundwater surveillance monitoring \\
\hline $\begin{array}{l}\text { Regulation-, permit-, or investigation-driven } \\
\begin{array}{l}\text { Monitors individual units, facilities, } \\
\text { or waste area groupings }\end{array}\end{array}$ & DOE order-driven \\
$\begin{array}{l}\text { Monitoring locations are generally on site } \\
\text { Short-, intermediate-, and/or long-term monitoring }\end{array}$ & $\begin{array}{c}\text { Monitoring locations are at the plant } \\
\text { perimeter and off-site }\end{array}$ \\
$\begin{array}{l}\text { Constantly changes sites, adds and deletes wells, } \\
\text { changes parameters, changes frequencies }\end{array}$ & Permanent monitoring \\
\hline
\end{tabular}

Commonwealth of Kentucky is an authorized state and maintains the permitting and enforcement authority for the PGDP RCRA units.

At present, the only RCRA facility at PGDP that requires groundwater monitoring is the $\mathrm{C}-404$ low-level radioactive waste burial ground. The C-404 burial ground operated until 1986, when routine testing programs indicated that the gold dissolver precipitate disposed of in early 1986 was hazardous, as determined by extraction procedure toxicity tests. The burial ground was covered with a RCRA clay cap and certified closed as a hazardous waste landfill in 1987.

In June 1989, a postclosure permit application was prepared and submitted to KDWM. Twelve detection monitoring wells were subsequently installed to monitor groundwater quality during the required postclosure care period (see Fig. 5.10 and Table 5.2). The detection wells were installed in the UCRS and the underlying regional gravel aquifer, which is considered to be the uppermost aquifer. A statistical evaluation of the indicator parameters was conducted using quarterly sample results from the initial year of monitoring. The evaluation indicated that monitoring well 88 (MW88) had significantly greater levels of contamination for trichloroethylene (TCE), technetiurn-99 ( $\left.{ }^{99} \mathrm{Tc}\right)$, uranium, and arsenic than MW94, which was assumed to be upgradient. As a result, the Commonwealth of Kentucky determined that additional information was needed to support the postclosure permit application.
An assessment monitoring plan for C-404 was proposed to the state. The plan included further assessment of the plume, using the groundwater investigation being conducted at PGDP pursuant to a CERCLA Administrative Order by Consent (ACO) between DOE and the EPA. Additionally, sampling for Appendix IX analytes was to be performed at C-404.

PGDP began preparation of an updated postclosure permit application in 1991, based on the results of the additional assessment and monitoring. The updated postclosure plan (permit modification application) was submitted to the KDWM in 1992. The additional quarterly ground water monitoring results indicated that a release to the uppermost aquifer (RGA) had not occurred, so the permit modification application was prepared pursuant to detection monitoring requirements for permitted facilities.

Monitoring continues at this unit on a quarterly basis. Table 5.1 in Part 2 contains the quarterly sampling results for the C-404 wells during 1992.

\subsubsection{UST Monitoring}

In July 1989, petroleum hydrocarbons were discovered by Energy Systems in a plant monitoring well located approximately $500 \mathrm{ft}$ northeast of the C-750 garage. Tank tightness tests were conducted on two underground fuel tanks, C-750-A and C-750-B, and results confirmed that the two USTs were 


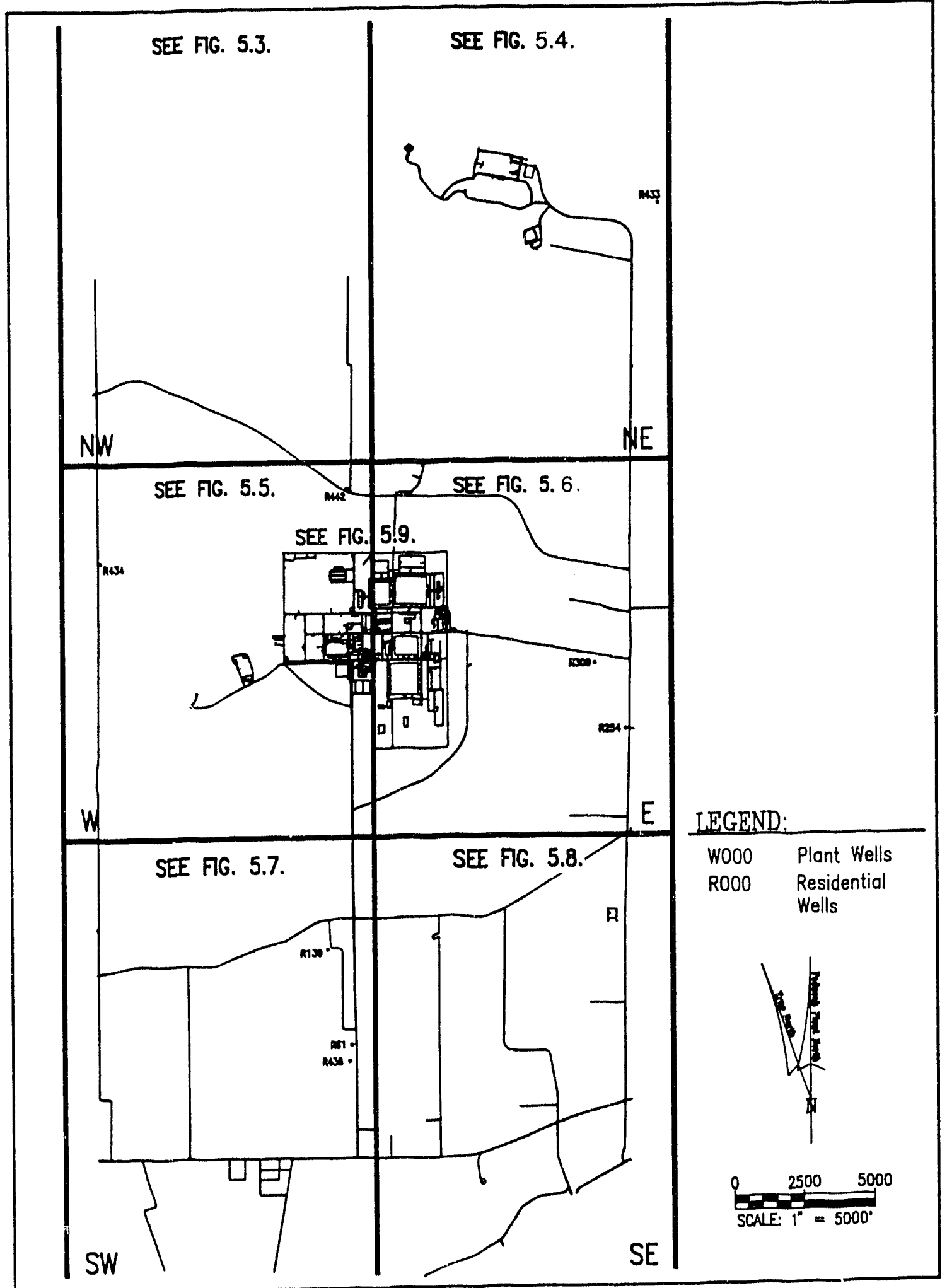

Fig. 5.2. Wells sampled by PGDP in 1992 (by sectors). 


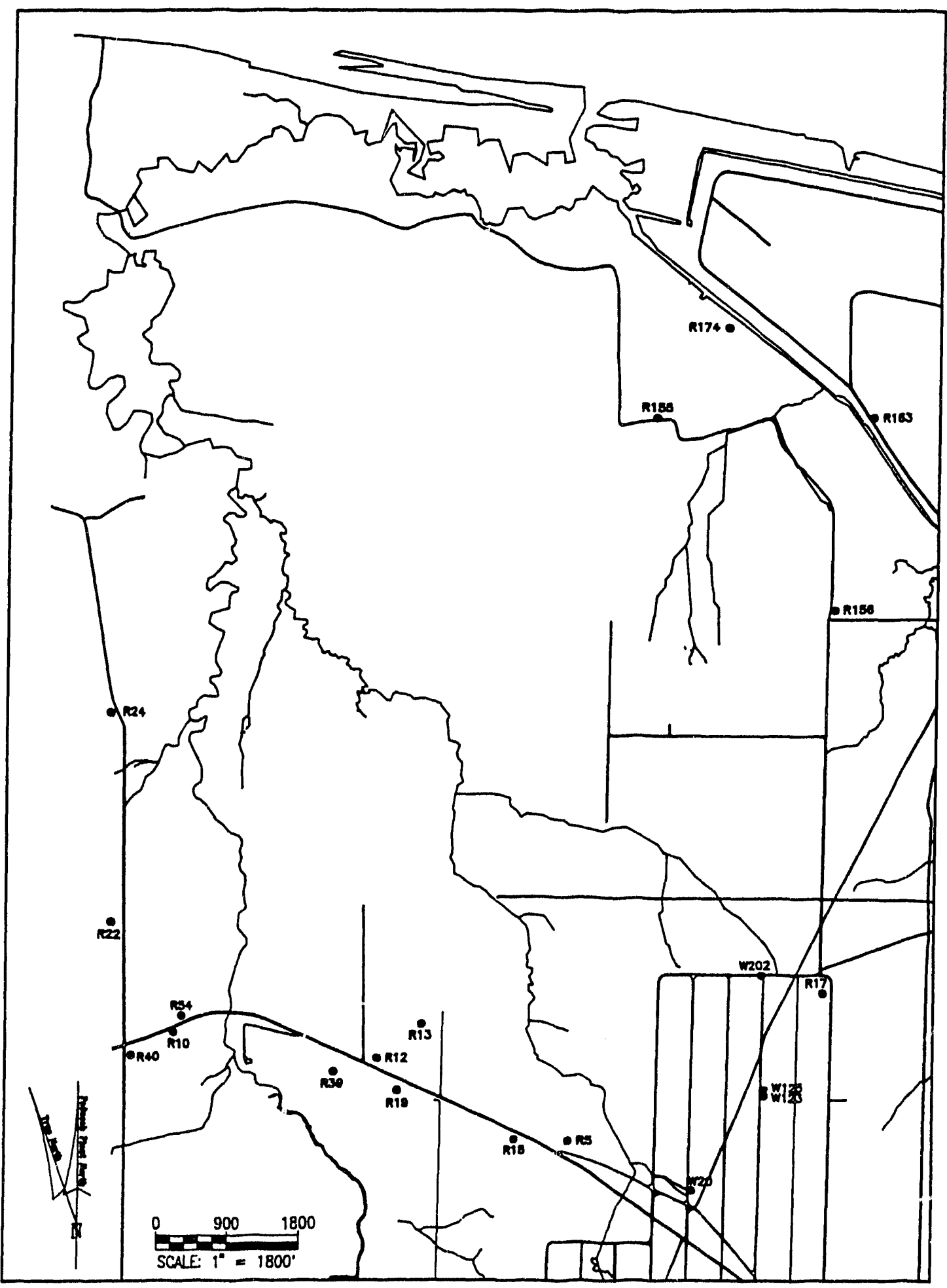

Fig. 5.3. Northwestern sector-wells sampled by PGDP during 1992. 


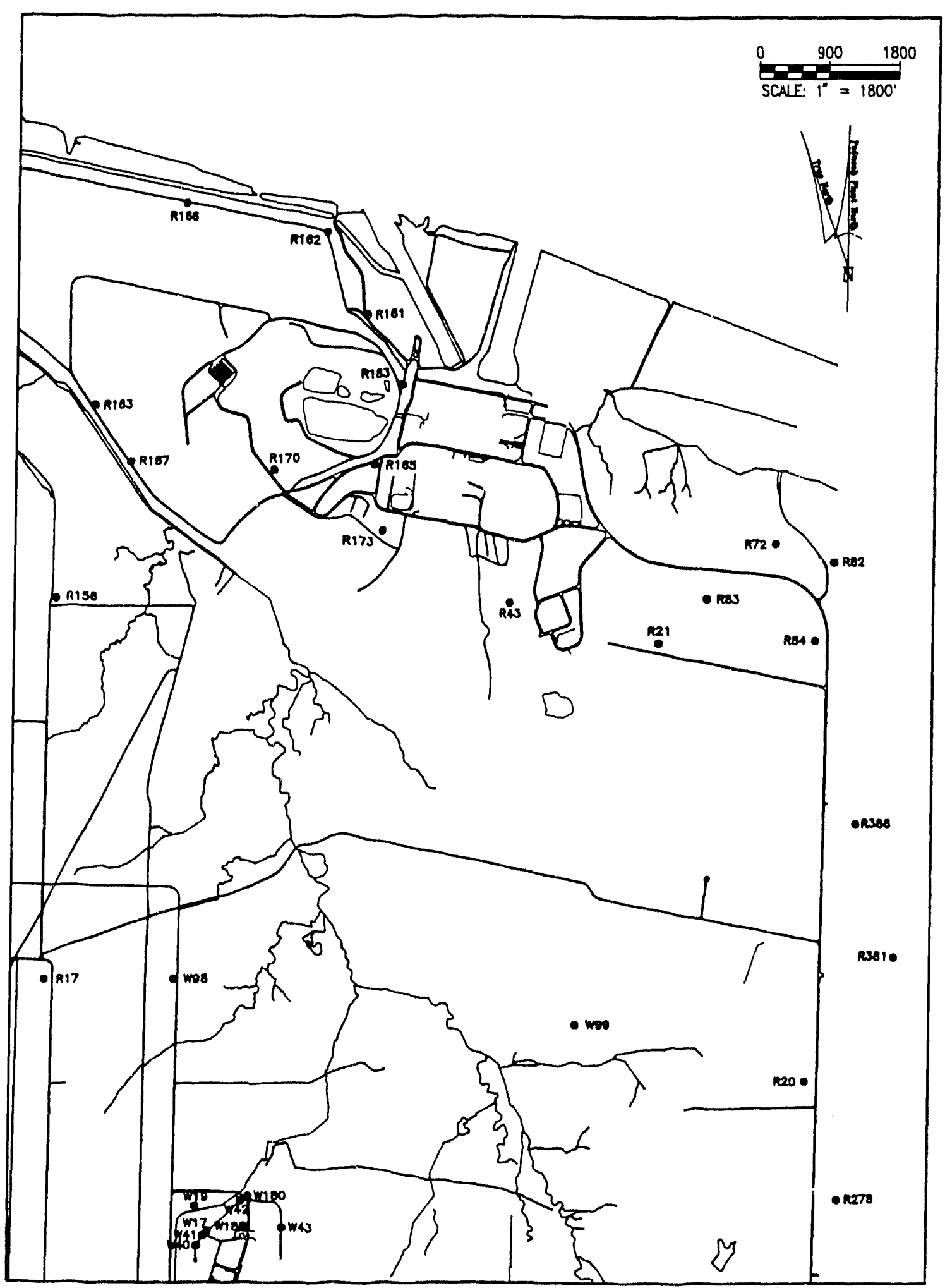

Fig. 5.4. Northeastern sector-wells sampled by PGDP during 1992. 


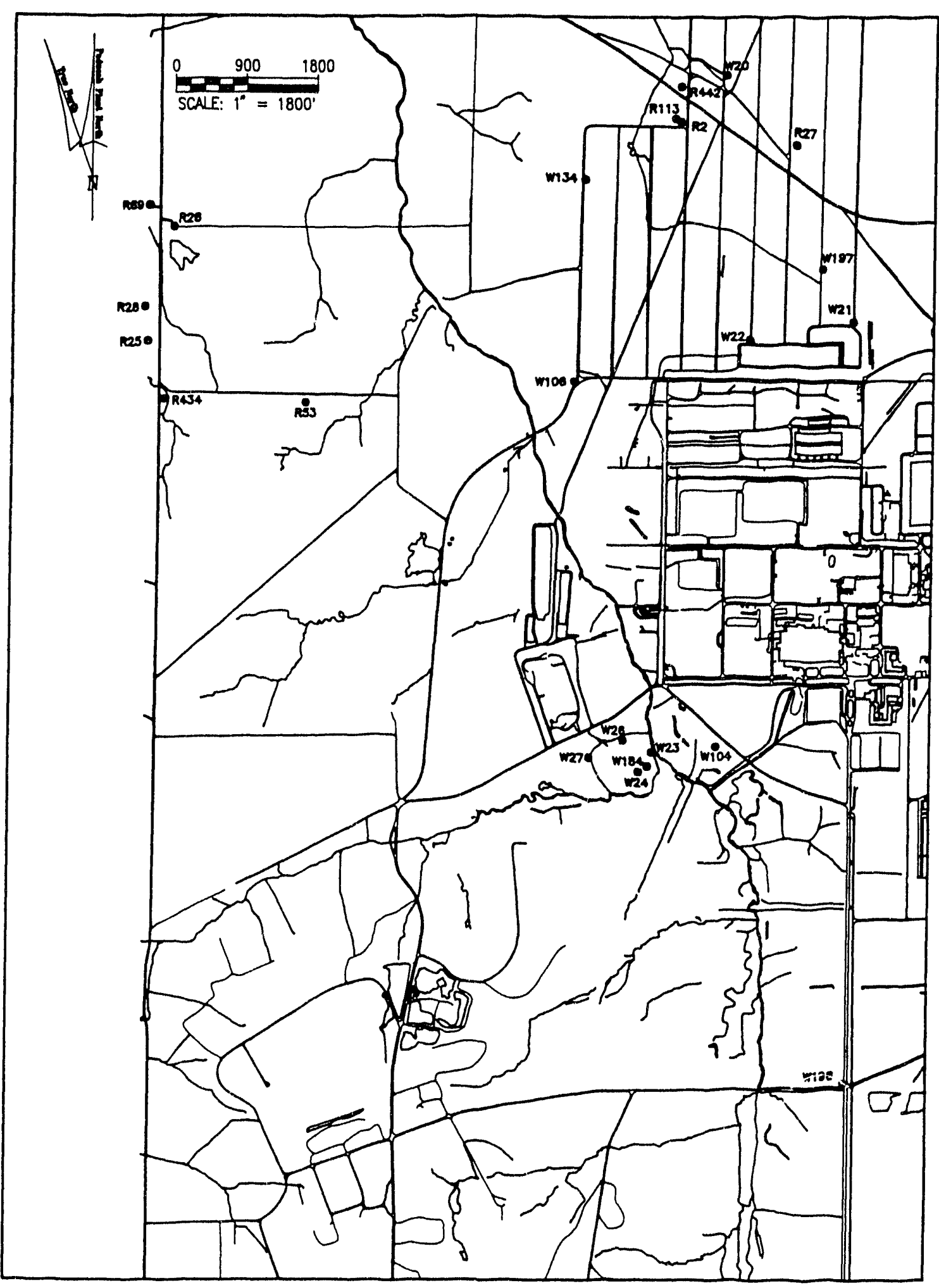

Fig. 5.5. Western sector-wells sampled by PGDP during 1992. 


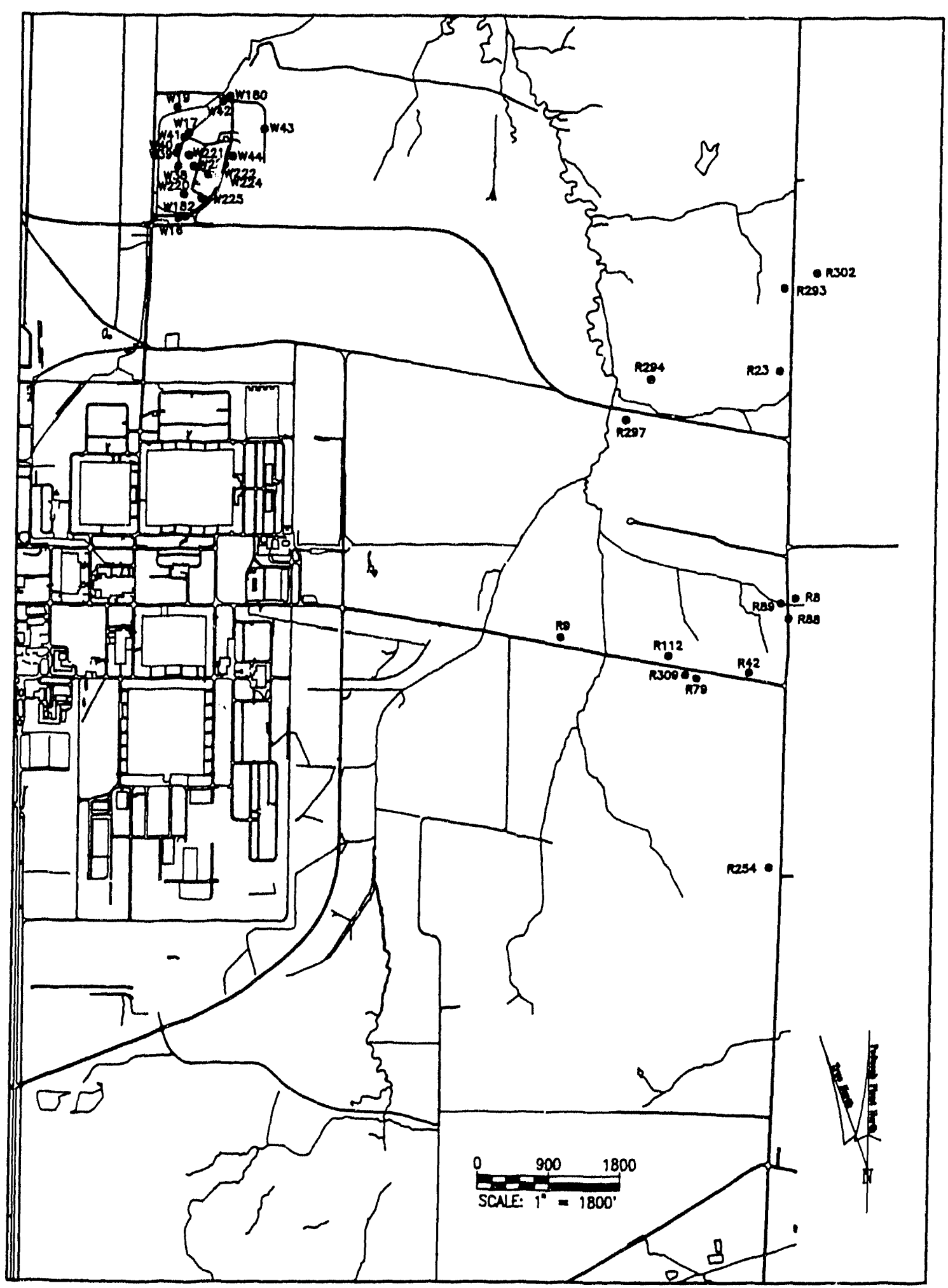

Fig. 5.6. Eastern sector-wells sampled by PGDP during 1992. 


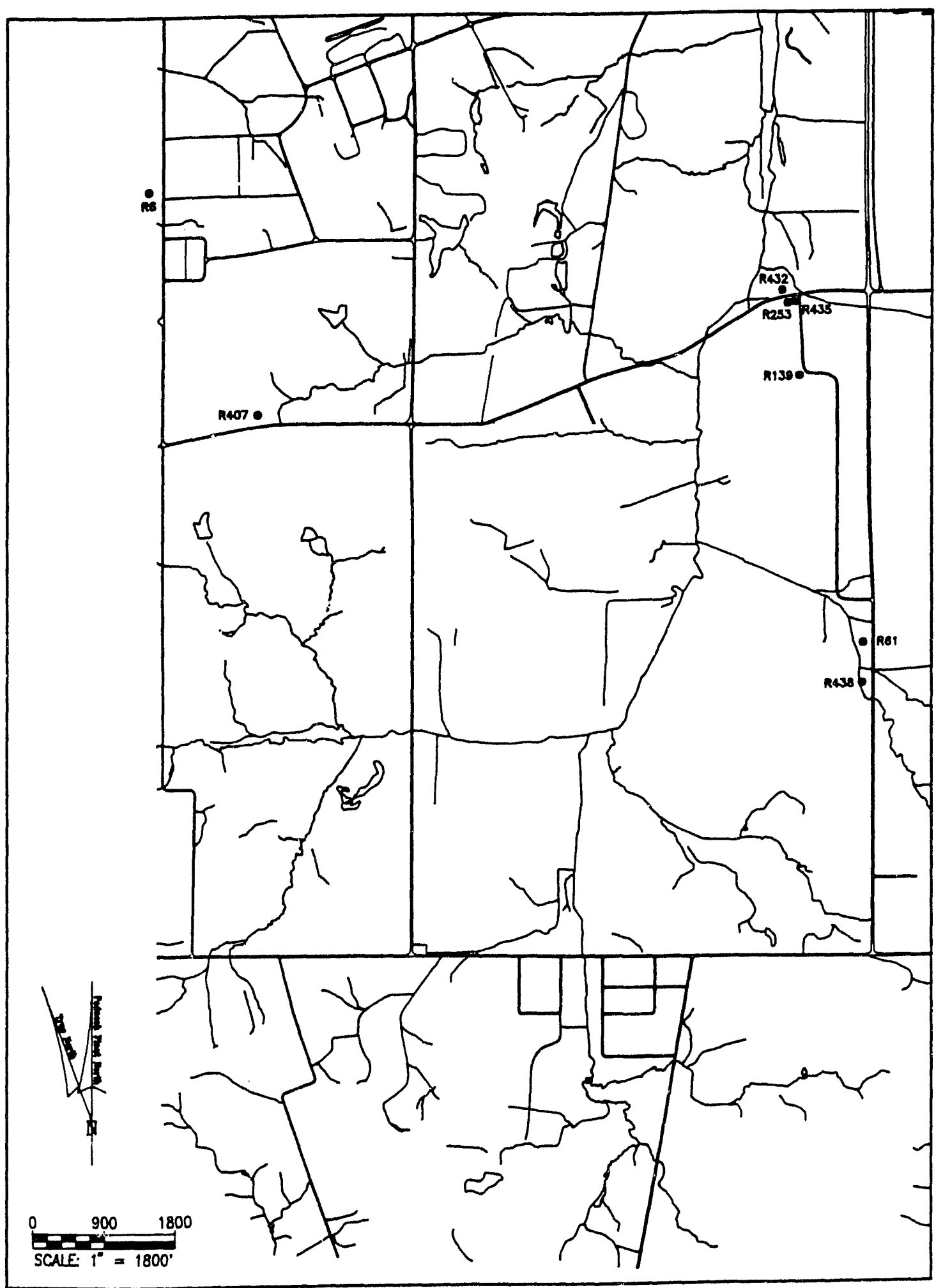

Fig. 5.7. Southwestern sector-wells sampled by PGDP during 1992. 


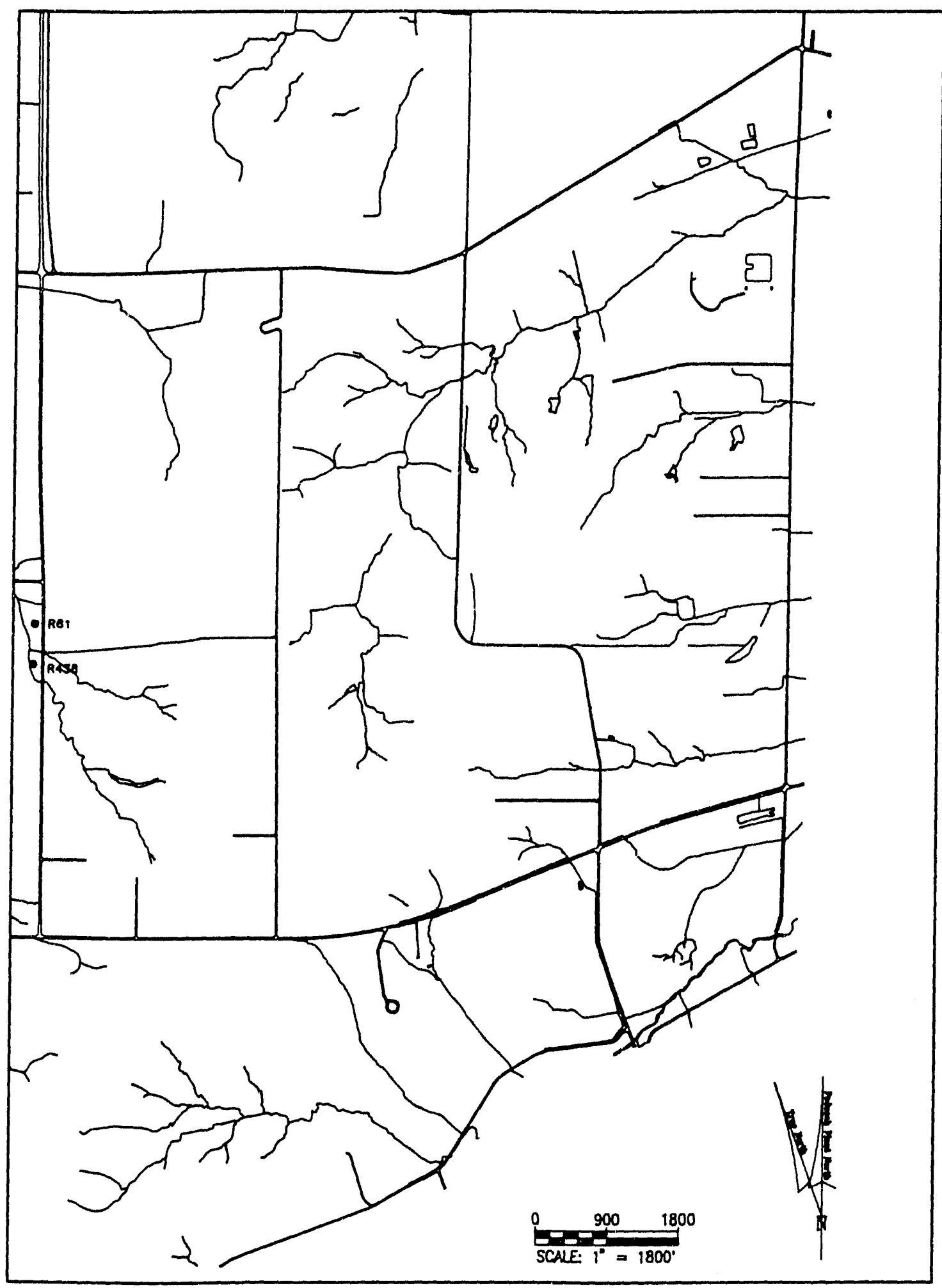

Fig. 5.8. Southeastern sector-wells sampled by PGDP during 1992.

\section{5-14 Groundwater}




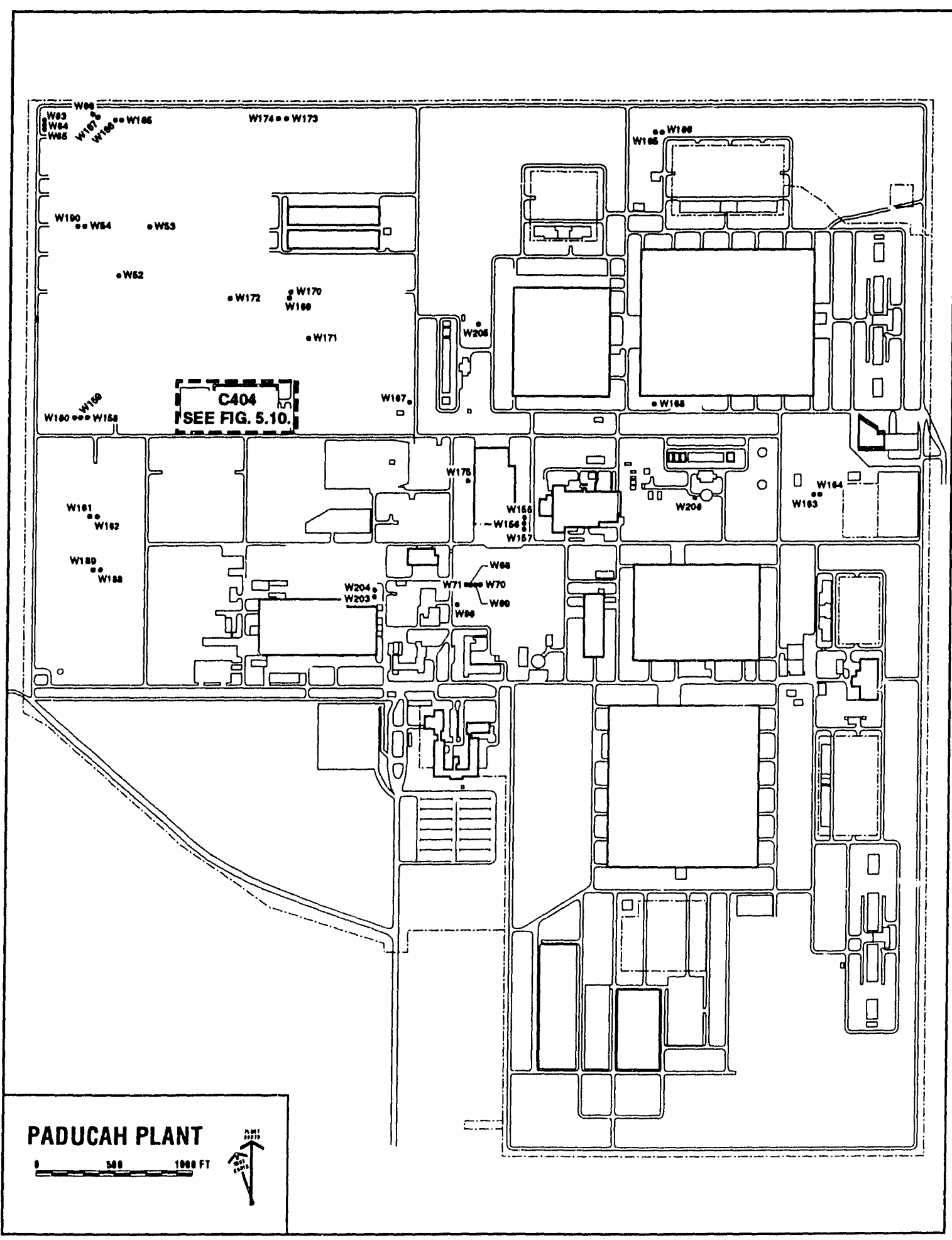

Fig. 5.9. Plant site-wells sampled by PGDP during 1992. 
1992 Environmental Report-Paducah, Part 1

ORNL-DWG 90M-12466R

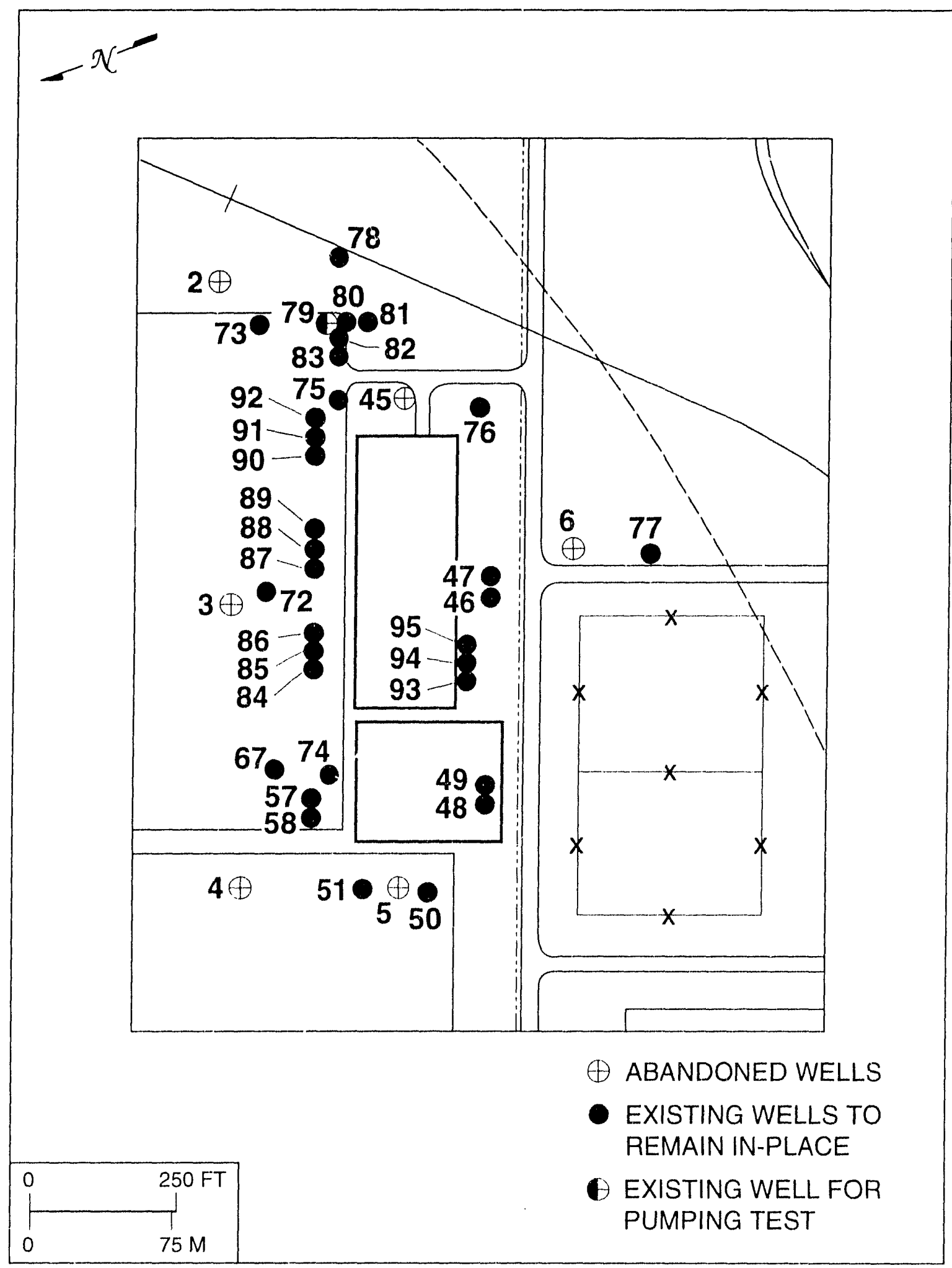

Fig. 5.10. Approximate locations of groundwater sampling wells around the C-404 area. 


\section{Table 5.2. Resource Conservation and Recovery Act monitoring wells at the C-404 area}

\begin{tabular}{ll}
\hline Well & Monitored zone \\
\hline 84 & RGA $^{a}$ \\
85 & UCRS $^{b}$ \\
86 & RGA \\
87 & RGA \\
88 & UCRS \\
89 & RGA \\
90 & RGA \\
91 & UCRS \\
92 & RGA \\
93 & RGA \\
94 & UCRS \\
95 & RGA \\
\hline
\end{tabular}

${ }^{u}$ Regional gravel aquifer.

bUpper Continental Recharge System.

leaking. Both tanks were immediately taken out of service, and the fuel remaining in them was removed.

In August 1989, a preliminary site characterization was initiated by CDM Federal Programs Corporation to define the level of contamination present in soil and groundwater in the area surrounding the two USTs. Results of the initial site characterization confirmed the presence of soil and groundwater contamination in the vicinity of the C-750 garage that may have been the result of releases from the USTs. In the spring of 1991, the two leaking USTs were removed and soil samples were collected from the walls and floor of the excavation areas. These samples were analyzed and also revealed the presence of contamination from petroleum hydrocarbon releases possibly originating from the USTs.

During 1991 and 1992, 13 new monitoring wells were installed in the UCRS under the UST program. The site investigation focused on the two USTs at the C-750 garage and three additional USTs in the general vicinity. In addition to the 13 monitoring wells, 4 background and 9 investigative soil borings were taken at various depths to assess the extent of the contamination from the known leaking tanks and to monitor for releases from 3 other tanks in the area. The locations of the UST monitoring wells are shown in Fig. 5.11.
Results of the site investigation indicate that groundwater contamination from leaking USTs is limited to the UCRS, which is not considered to be an aquifer and is not a source of drinking water in the PGDP area. A more detailed description of the results of the site investigation can be found in the final draft of the Site Investigation Report, which was submitted to the Commonwealth of Kentucky in September 1992.

\subsubsection{CERCLA/ACO Monitoring}

\subsection{Off-Site Well Monitoring}

With the discovery of contamination in the groundwater north of the plant in August 1988, DOE and the EPA entered into an ACO under CERCLA Sects. 104 and 106 to determine the nature and extent of off-site contamination. The EPA ACO, Docket No. 88-35-c, Part V, Sect. J, 2 and 3, requires monthly sampling of potentially affected wells and plant well MW66 for TCE, ${ }^{99} \mathrm{Tc}$, and gross alpha and beta activity. Any levels exceeding the national interim primary drinking water standards for alpha activity $(>15 \mathrm{pCi} / \mathrm{L})$ and beta activity $(>50 \mathrm{pCi} / \mathrm{L}$ ) must be analyzed further to determine the cause. Extensive groundwater monitoring of residential and plant wells 
ORNL-DWG 93M-7181

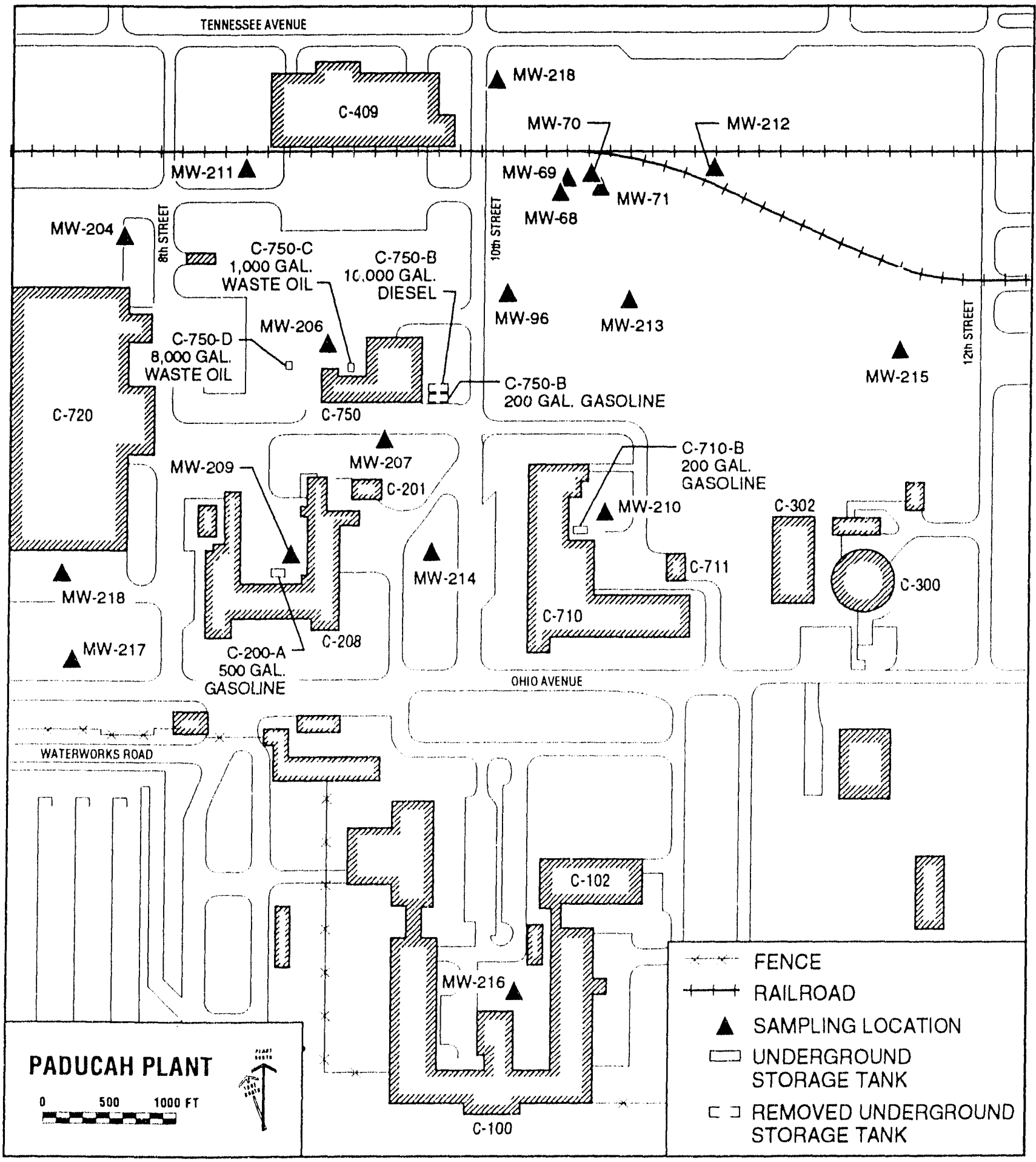

Fig. 5.11. UST investigation monitoring well locations (from CDM Federal Programs Corporation 1992). 


\section{Environmental Report-Paducah, Part 1}

was initiated in 1988. More than 400 plant and off-site wells were sampled and analyzed for TCE and ${ }^{99} \mathrm{Tc}$.

Based on the results of this initial sampling, PGDP established a sampling program that exceeds the EPA ACO requirements. This program includes

- monthly sampling for the wells already showing contamination,

- weekly sampling of wells with the highest potential for contamination,

- bimonthly sampling of wells with little chance of contamination,

- quarterly sampling of Tennessee Valley Authority (TVA) monitoring wells, and

- monthly sampling of uncontaminated residential wells because of their proximity to TVA monitoring wells showing contamination.
Table 5.3 lists the wells included within each category.

Ongoing sampling of residential wells performs two functions: detecting the spread of contamination to other wells and gaining additional information about those wells already contaminated. Each sample is analyzed for TCE and ${ }^{99} \mathrm{Tc}$. Residents are notified of the result of each sample. The residences' well water is also sampled regularly for gross alpha and beta activity. Steps are taken to supply alternate water supplies if the action levels are exceeded. An off-site drinking water well is considered contaminated if any sample has levels above the DOE-PGDP action limits of $25 \mathrm{pCi} / \mathrm{L}$ for ${ }^{919} \mathrm{Tc}$ and $1 \mu \mathrm{g} / \mathrm{L}$ for TCE. Residential wells sampled weekly and monthly are shown in Fig. 5.12. TVA monitoring wells sampled quarterly are shown in Fig. 5.13.

Figure 5.14 shows the location of any residential or TVA well having TCE or ${ }^{99} \mathrm{Tc}$ contamination.

Table 5.3. Wells included in the CERCLA/ACO ${ }^{a}$ well monitoring program

\begin{tabular}{|c|c|c|c|c|}
\hline $\begin{array}{c}\text { Monthly } \\
\text { (contaminated) }\end{array}$ & Weekly & Bimonthly & $\begin{array}{l}\text { Annual and } \\
\text { semiannual }\end{array}$ & $\begin{array}{c}\text { Monthly } \\
\text { (uncontaminated) }\end{array}$ \\
\hline $\mathrm{R} 2 \mathrm{~b}$ & R10 & R8 & R90 & R6 \\
\hline $\mathrm{R} 4$ & $\mathrm{R} 12$ & R9 & RI & R2! \\
\hline R5 & $\mathrm{R} 13$ & $\mathrm{R} 20$ & $R 100$ & R43 \\
\hline R 17 & R14 & $\mathrm{R} 22$ & R161 & $\mathrm{R} 72$ \\
\hline R18 & $R 19$ & $\mathrm{R} 23$ & $\mathrm{R} 162$ & R82 \\
\hline $\mathrm{R} 113$ & R39 & R24 & R 163 & $\mathrm{R} 83$ \\
\hline W $38^{\circ}$ & $\mathrm{R} 40$ & $\mathrm{R} 25$ & R 165 & R84 \\
\hline W41 & R54 & R26 & R 167 & $\mathrm{R} 302$ \\
\hline W43 & R294 & $\mathrm{R} 28$ & $\mathrm{R} 170$ & \\
\hline W44 & & $\mathrm{R} 41$ & $\mathrm{R} 173$ & \\
\hline \multirow[t]{11}{*}{ W66 } & & $\mathrm{R} 42$ & $\mathrm{R} 174$ & \\
\hline & & R53 & $\mathrm{R} 183$ & \\
\hline & & R69 & R.381 & \\
\hline & & R79 & & \\
\hline & & R88 & & \\
\hline & & R89 & & \\
\hline & & $\mathrm{R} 112$ & & \\
\hline & & $\mathrm{R} 278$ & & \\
\hline & & $R 293$ & & \\
\hline & & R368 & & \\
\hline & & R386 & & \\
\hline
\end{tabular}

${ }^{a}$ Comprehensive Environmental Response, Compensation, and Liability Act/Administrative Consent Order.

${ }^{b} \mathrm{R}=$ residential wells or Tennessee Valley Authority monitoring wells.

$\mathrm{W}=\mathrm{PGDP}$ monitoring wells. 
ORNL-DWG 89M-8335R2

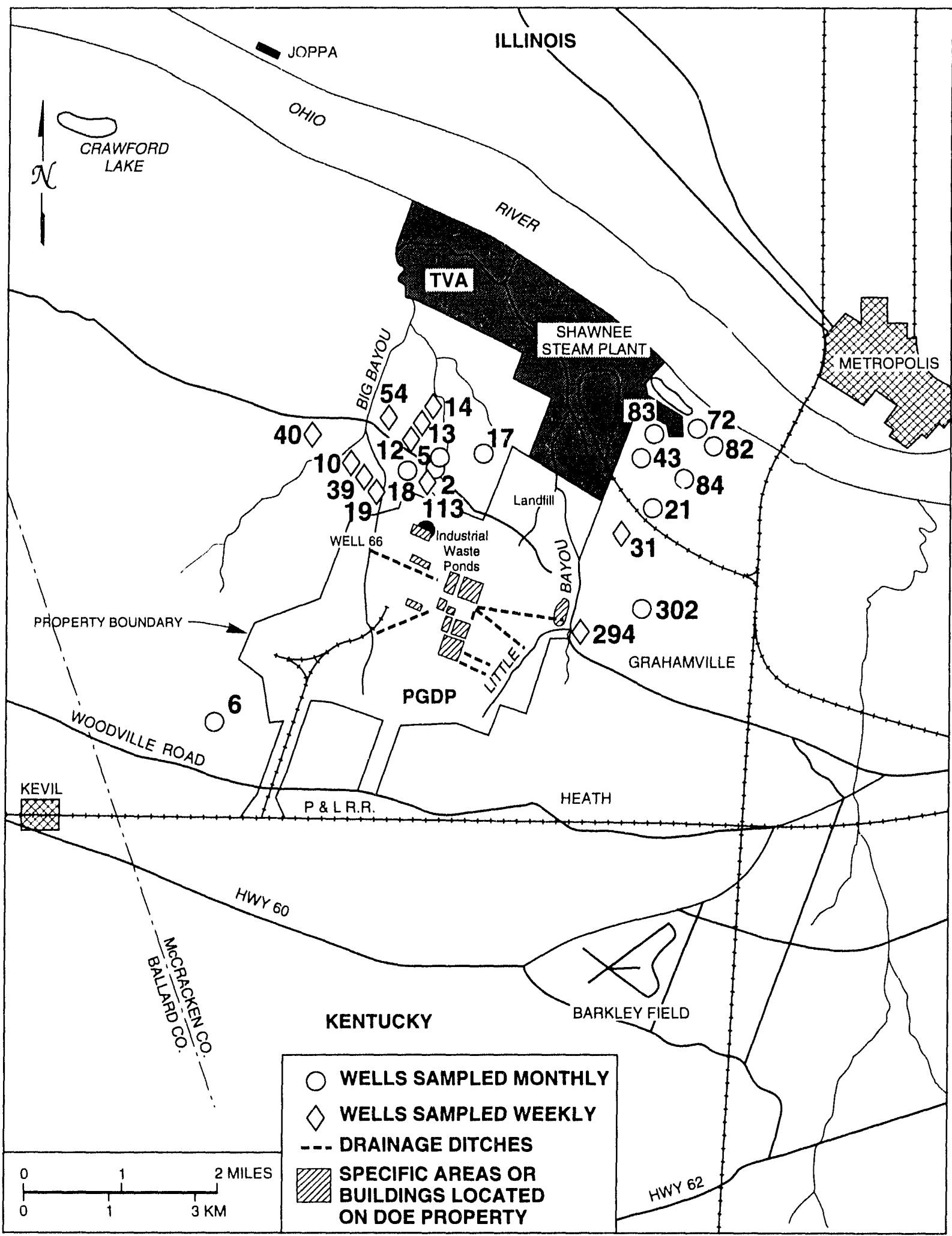

Fig. 5.12. Wells sampled weekly and monthly. 
1992 Environmental Report-Paducah, Part 1

ORNL-DWG 89M-8412R

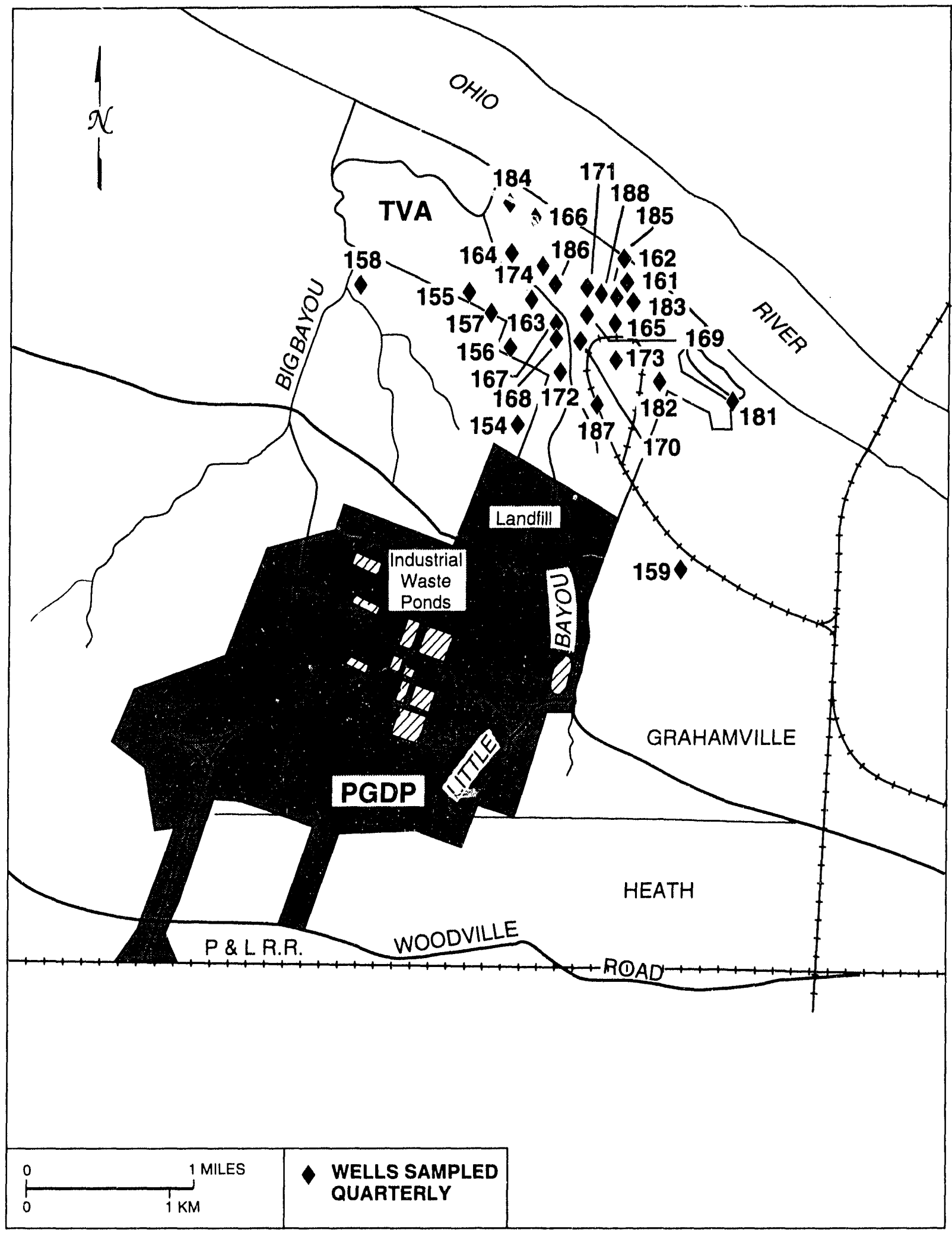

Fig. 5.13. TVA wells sampled quarterly. 
ORNL-DWG B9M-8336R3

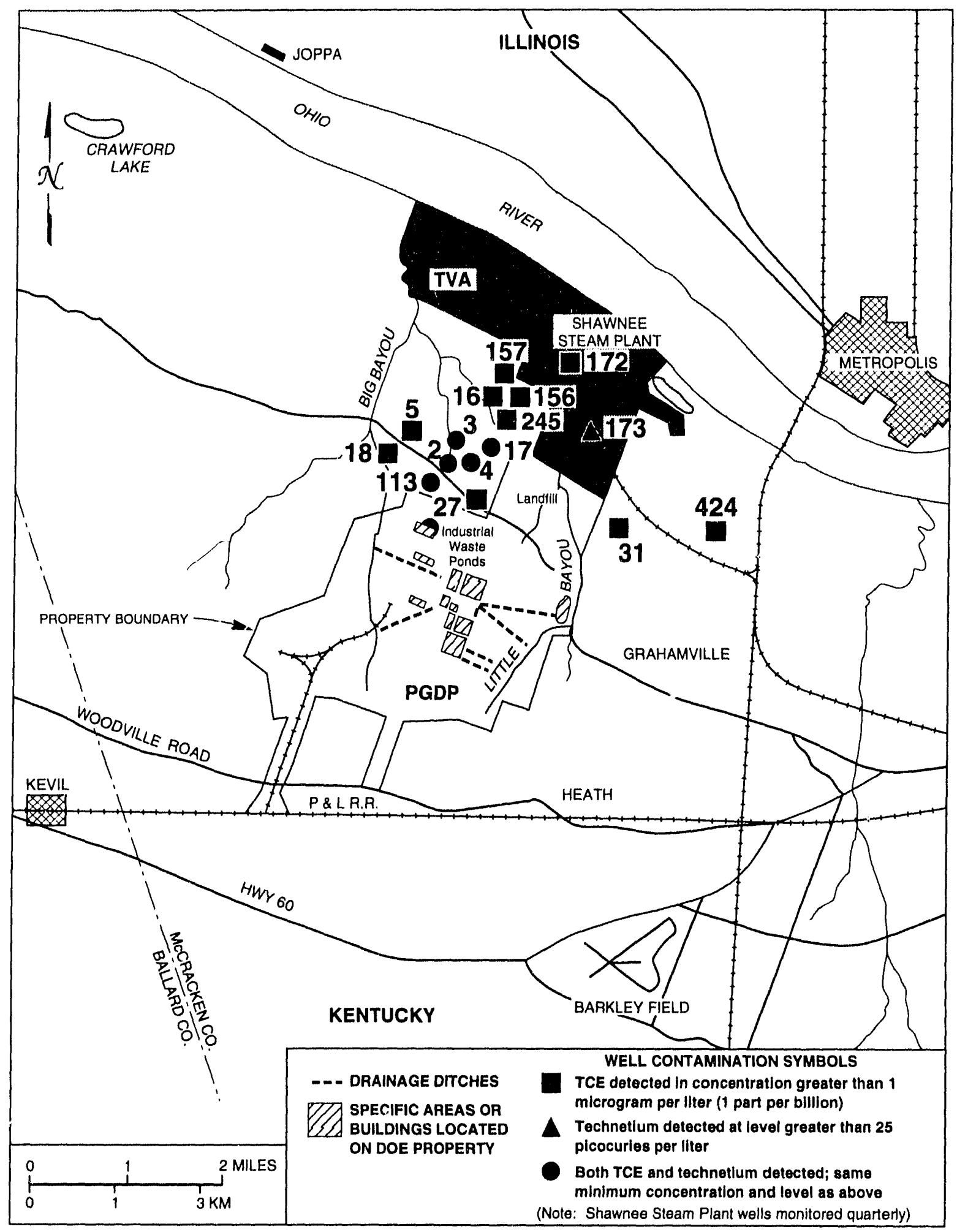

Fig. 5.14. Residential and TVA groundwater sampling locations where ${ }^{99} \mathrm{TC}$ and/or TCE were detected.

\section{5-22 Groundwater}




\section{Environmental Report-Paducah, Part 1}

Data generated by this sampling program (Tables 5.3 through 5.5 in Part 2) are used primarily to protect the health of affected residents by giving advance warning of increases in levels of contamination so that appropriate actions can be taken. These data, in combination with data from plant monitoring wells, are also used by plant personnel and consultants as qualitative indicators of the nature and extent of off-site groundwater contamination.

\subsection{Site Investigation for Groundwater Contamination}

In addition to extensive groundwater sampling, the $\mathrm{ACO}$ also required a site investigation to determine the nature and extent of off-site contamination and to assess remedial alternatives for possible on-site sources of contamination. DOE and Martin Marietta Energy Systems, Inc. (Energy Systems), contracted with $\mathrm{CH} 2 \mathrm{M}$ Hill to develop and implement a work plan for the site investigation that would determine the nature and extent of off-site contamination in order to protect human health and the environment. Phase II of the two-part investigation was completed in 1991. A complete discussion of the site investigation and findings can be found in the final Phase II Report issued in April 1992 (CH2M Hill 1992).

The major findings of the $\mathrm{CH} 2 \mathrm{M}$ Hill site investigation include the following:

- The contaminants in the on-site shallow groundwater system (UCRS) are primarily ${ }^{99} \mathrm{Tc}$ and TCE, with frequently detectable ${ }^{234} \mathrm{U}$ and ${ }^{23 .} \mathrm{U}$, and occasionally detectable toluene. High concentrations of TCE may indicate the presence of dense nonaqueous phase liquids at two on-site locations.

- Contaminants were detected in the off-site shallow groundwater system (these results were not confirmed in split samples). TCE was detected in the immediate vicinity of the northwest corner of the plant. Low levels of TCE and ${ }^{49} \mathrm{Tc}$ were detected near the landfill north of the plant.

- The primary contaminants in the regional gravel aquifer off site are TCE and ${ }^{9 y} \mathrm{TC}$. The groundwater contamination is migrating toward the Ohio River.
- Both ${ }^{234} \mathrm{U}$ and ${ }^{236} \mathrm{U}$ were detected in several wells in the deep groundwater system at the detection limit during Phase I. Phase II sampling showed these parameters to be near reference background values. Additionally, no uranium was detected in the RGA or UCRS of these same well clusters.

- Potential sources of TCE and ${ }^{199} \mathrm{Tc}$ contamination were found on site.

- Of the 21 waste management units found to be contributing to off-site contamination, 9 were identified as contributing only to groundwater contamination, 9 were identified as contributing only to surface water contamination, and 3 were found to be contributing to groundwater, surface water, and sediment contamination.

\subsection{Agreement in Principle Activities-Off-Site Residential Groundwater Sampling}

A quarterly sampling event takes place in which the state of Kentucky Cabinet for Human Resources (CHR) travels to the PGDP area and obtains samples from residential wells. The state of Kentucky wanted to have independent verification that public health was protected, which is achieved by meeting the i $5 \mathrm{pCi} / \mathrm{L}$ alpha and $50 \mathrm{pCi} / \mathrm{L}$ beta primary drinking water limits listed in the ACO or, if these are exceeded, identifying the specific radionuclide so health concerns rnay be evaluated. The purpose of having corroborative sampling between the PGDP and state CHR is to provide quality assurance on the activity for the state and PGDP by showing that sampling and analytical techniques provide data leading to equivalent decisions.

The only situations investigated are those in which either the state CHR or PGDP, but not both, show exceedances of alpha and beta limits after correction for specific radionuclide contribution. Minor variations in comparative data are discussed in this report, either explaining the cause(s) of the differences or pointing out those differences if the cause is unknown. Detailed results from the corroborative sampling along with data comparisons of state and PGDP maximuın and minimum reported results are shown in Part 2, Table 5.11. 


\section{Environmental Report-Paducah, Part 1}

An investigation would oceur if any of the following criteria are met:

- The gross alpha minus the contribution of alpha from quantified radionuclides (uranium is most likely at PGDP) is greater than $15 \mathrm{pCi} / \mathrm{L}$ and is not corroborated by the other source's result.

- The gross beta minus the contribution of beta from quantified radionuclides (technetium is most likely at PGDP) is greater than $50 \mathrm{pCi} / \mathrm{L}$. and is not corroborated by the other source's result.

- The ${ }^{99} \mathrm{Tc}$ value reported is greater than $25 \mathrm{pCi} / \mathrm{L}$ by one but not the other; $25 \mathrm{pC}$. $/$ L . is the level at which PGDP provides water to area residents.

- The ${ }^{\omega}$ TC value reported is greater than $900 \mathrm{pCi} / \mathrm{L}$. by one but not the other; $9(0) \mathrm{pCi} / \mathrm{L}$, is the level above which drinking water limits are exceeded.

In 1992, one comparative result exceeded the preceding criteria; therefore, an investigation was initiated. Sample location R2 showed significant alpha differences and in two instances exceeded the $15 \mathrm{pCi} / \mathrm{L}$ limit although PGDP data were consistently below this level. The difference was attributed to a phenomenon known as crosstalk between the alpha and beta measurements. When simultaneous counting occurs in the detector, approximately $2 \%$ of the signal from either the alpha or beta is registered in the other area. This crosstalk is not constant and varies with changes in the mixture of the carrier gas. To correct for this, a known source or standard must be run along with the samples being quantified. When alpha and beta levels are approximately equal, the effect cancels out. In instances such as R2 where there is little alpha and elevated beta because of the ${ }^{\text {"w }} \mathrm{Tc}$ present, corrections must be made. These results were discussed with the state CHR. The CHR confirmed that they do not make crosstalk corrections, attributed the difference to this phenomenon, and agreed that the $15 \mathrm{pCi} / \mathrm{L}$ limits had not been exceeded. Additionally, no questions have arisen from the state about the equivalency of these data used to verify PGDP's monitoring of off-site residential health effects.

\subsubsection{State Solid Waste Disposal Regulations}

Compliance monitoring requirements exist for facilities C-746-S (new sanitary landfill) and C-746-T (inert landfill), permitted by the KDWM. Sample frequency and analytes are dictated by the specific permit for each facility. Wells 16 through 19, 38 through 44 , and 220 through 225 serve as monitoring stations for these facilities (see Fig. 5.10). These wells are sampled quarterly for the constituents in Table 5.4 and anmually for the additional constituents in Table 5.5. Groundwater is analyzed for chloride during the first and third quarters of each year.

The C-746-T landfill was closed on June 29 , 1992. However, closure has not yet been certified. The Environmental Restoration Division will assume responsibility for postclosure compliance monitoring once it is certified closed in accordance with the state permit requirements.

In the summer of 1992, six monitoring wells were installed in the RGA to provide active and postclosure monitoring for the $\mathrm{C}-746$ landfill. These monitoring wells (MW220 through MW225) are intended to provide the quarterly sampling required for the permitting of a new landlill site (Cell 3 of the C-746-S landfill), scheduled to begin receiving waste in July 1993. They will also provide for postclosure groundwater monitoring for Cell 2 , a closed cell at the C-746-S landfill.

\subsubsection{RCRA $3004(u / v)$}

Additional groundwater monitoring to be performed at PGDP relates to RCRA $3004(\mathrm{u} / \mathrm{v})$ and CERCLA requirements for characterizing contamination from all nonregulated sources [i.e., solid waste management units (SWMUs) not regulated under a $\mathrm{RCRA}$ permit or in interim status at a facility that has had releases that may contaminate groundwater. Results of this monitoring will be used to determine and implement remedial actions as necessary to protect human health and the environment. Prescriptive regulations, such as those governing RCRA interim status and regulated units, 
1992 Environmental Report-Paducah, Part 1

Table 5.4. Quarterly analytical parameters for groundwater monitoring at PGDP

\begin{tabular}{ll}
\multicolumn{1}{c}{ Parameters } & \multicolumn{1}{c}{ Methods } \\
\hline Chromium & W-100 \\
Copper & SC-ENV-4 \\
Dissolved alpha & R-4 \\
Dissolved beta & R-4 \\
Fluoride & SA-F-5 \\
Iron & SC-ENV-4 \\
Lead & SC-ICAP-1 \\
Nickel & SC-ICAP-1 \\
Nitrate & W-50 \\
Organic carbon, total & W-150 \\
Organic halogens, total & SC-TOX-1 or SC-TOX-2 \\
pH & Meter \\
Polychlorinated biphenyl & AL-OP-1 \\
Sulfate & W-50 \\
Suspended alpha & R-4 \\
Suspended beta & R-4 \\
Technetium-99 & R-46 \\
Temperature & Meter \\
Trichloroethylene & AL-OP-3 or AL-OP-4 \\
Uranium & SA-U-8 \\
Water color & SA-CLR-1 \\
Water conductivity & SA-COND-1 \\
Water depth & \\
Water turbidity & W-170 \\
Zinc & SC-ICAP-1 \\
\hline & \\
\hline &
\end{tabular}

Table 5.5. Annual analytical parameters for groundwater monitoring at PGDP

\begin{tabular}{ll}
\hline \multicolumn{1}{c}{ Parameters } & \multicolumn{1}{c}{ Methods } \\
\hline Americium-24I & R-52 \\
Cadmium & SC-ENV-4 \\
Calcium & SC-ENV-4 \\
Chloride & W-50 \\
Chromium, hexavalent & W-100 \\
Cobalt-60 & R-52 \\
Dissolved solids & W-140 \\
Magnesium & SC-ICAP-1 \\
Manganese & SC-1CAP-1 \\
Phosphate & W-50 \\
Selenium & SC-ENV-1 \\
Sodium & SC-ICAP-1 \\
Water alkalinity & W-12 \\
\hline
\end{tabular}




\section{Environmental Report-Paducah, Part 1}

do not exist for remedial action groundwater monitoring at this time.

Currently, over 180 SWMUs and areas of concern (AOCs) have been identified at PGDP. The SWMUS/AOCs have been categorized into two groups: SWMUs suspected of contributing to off-site contamination and SWMUs not suspected of contributing to off-site contamination. As part of the Phase II Site Investigation, 21 SWMUs were identified as sources of primary contaminants that are contributing to off-site contamination. These SWMUs were evaluated in a draft Public Health and Ecological Assessment that was completed in December 1991. A range of potential remedial alternatives that may be used to address the contamination at each of the 21 SWMUs was presented in a draft Alternatives Evaluation Report (SAIC 1991), which will be used to support the feasibility studies for these units.

SWMUs not suspected of contributing to off-site contamination have been grouped into RCRA waste area groups and are scheduled for RCRA facility investigation (RFI) work plan development pursuant to the Hazardous Solid Waste Amendments (HSW A) Corrective Action Program. Development of RFI work plans for the first three scheduled RFIs was initiated during 1992. The remaining SWMUs either are operative RCRA-regulated units that will be addressed according to RCRA regulations during closure or require no further action because contaminant concentrations are below RFI action levels. To date, no groundwater monitoring has been initiated at SWMUs pursuant to RCRA $3004(\mathrm{u} / \mathrm{v})$ and CERCLA requirements.

In 1992, a Site Management Plan (SMP) for the Environmental Restoration Program at PGDP was developed in preparation for the Federal Facilities Agreement. The SMP has been developed to serve as the primary strategy document for remediation activities at PGDP. The SMP will drive all schedules once the Federal Facilities Agreement is in place. The plan establishes remedial action priorities for the SWMUS/AOCs and also establishes schedules for the various regulatory documents to be generated during the remedial action process at PGDP. Those SWMUs suspected of presenting the greatest risk to public health or the environment are to be investigated first.

\subsubsection{SWMU Monitoring}

Groundwater monitoring is conducted at several SWMUs at PGDP. A total of 49 wells monitor SWMUs, including wells located at the active C.746-S and C-746-T landfills (Table 5.6). Well installation began at selected units in 1979 and continued through the mid-1980s. This monitoring effort was initially based in part on DOE orders that required monitoring at low-level radioactive waste sites.

SWMU monitoring wells are monitored quarterly for the constituents listed in Table 5.4 and annually for the additional constituents listed in Table 5.5, with the exception of wells 23 through 27 at the inactive C-746-K sanitary landfill. Wells 23 through 27 are sampled annually for the constituents listed in Table 5.5. As indicated earlier, many of these units are targeted for investigation under the HSWA permit. As characterization continues during these projects, monitoring at these facilities will be changed accordingly.

On January 30, 1992, leachate seeps were observed by PGDP personnel in a ditch on the southwest side of the $(-746 \cdots \mathrm{K}$ landfill, an inactive capped sanitary landfill. Sampling identified metals and volatile organics (TCE and its degradation by-products) in the leachate. Immediately upon discovering the seep, PGDP personnel installed a sandbag dam to prevent any further release of solids to an unnamed tributary of Big Bayou Creek. A new seep site located on the bank of the unnamed tributary was sampled on February 16, 1992. Results indicated a $\mathrm{pH}$ of 2.3 for the leachate. On the recommendation of the Kentucky Division of Water and the Kentucky Department for Environmental Protection, further actions were taken to contain the leachate-contaminated water, including the installation of a solid precipitate filter in the ditch. PGDP committed to submit an Interim Measures Work Plan to KDWM and the EPA in accordance with guidance from the HSWA permit. The landfill investigation was moved up in priority and will be conducted by the Environmental Restoration Division under the HSWA permit in the first scheduled RFI. Interim corrective measures taken while the RFI work plan awaits approval included repair of the landfill 
1992 Environmental Report-Paducah, Part 1

Table 5.6. Summary of solid waste management unit monitoring at PGDP

Unit

burial ground
Monitoring wells/ interval monitored

\section{radioactive waste}

burial ground

SWMU 5: C-746-F

classified burial

yard

SWMU 7: C-747-A

burial ground

SWMU 8: C-746-K inactive sanitary landfill

SWMU 9: C-746-S

new sanitary landfill

MW85/UCRS $^{c}$ this landfill until 1982. A 15.24-cm (6-in.)
Used from the late 1950s to the mid-1970s

for the disposal of uranium scrap, some

of which was pyrophoric (i.e., easily

ignitable in air). To stabilize the uranium, it

was submerged in waste oil.

Used as a low-level waste burial ground until 1986. The waste was discovered to be hazardous in 1986. The unit was certified closed in 1987 as a hazardous waste landfill. A postclosure permit application, first submitted in 1989, was resubmitted in 1992 .
$\mathrm{MW} 48 / \mathrm{RGA}^{a}$

MW49/UCRS $^{b}$

MW50/RGA

MW51/RGA

MW57/UCRS

MW67/RGA

MW46/RGA

MW47/UCRS

$\mathrm{MW84/RGA}^{c}$

$\mathrm{MW} 6 / \mathrm{RGA}^{\mathrm{c}}$

$\mathrm{MW} 87 / \mathrm{RGA}^{c}$

MW88/UCRS $^{c}$

$\mathrm{MW}^{\mathrm{N} 9 / \mathrm{RGA}^{c}}$

$\mathrm{MW}$ 90/RGA ${ }^{c}$

MW91/UCRS ${ }^{c}$

$\mathrm{MW} 2 / \mathrm{RGA}^{c}$

MW93/RGA $^{c}$

MW94/UCRS $^{c}$

MW95/RGA $^{c}$

Used for the disposal of cascade equipment,

MW52/RGA

MW53/RGA

paper, and electronic media (such

as computer disks) that are classified or

may reveal classified information.

Used for the disposal of all types of waste material from plant operations.

MW22/RGA

MW63/RGA

MW64/UCRS

MW65/RGA

MW66/RGA

Used for the disposal of fly ash from 1951 to 1982. Sanitary trash was also placed in

$\mathrm{MW}^{23 / \mathrm{PCC}^{d}}$

MW24/PCC

MW26/PCC

cap was placed on this landfill in 1982.

Additional cap material was added in 1992

MW27/PCC

to repair grade.

Used for the disposal of nonhazardous putrescible

MW16/UCRS

MW17/RGA

MW 18/UCRS

MW 19/RGA

MW38/RGA

MW39/RGA

MW40/RGA

MW41/RGA

MW42/RGA

MW220/RGA

MW221/RGA

MW222/RGA

MW223/RGA

MW224/RGA

MW225/RGA 


\section{Environmental Report-Paducah, Part 1}

Table 5.6 (continued)

\begin{tabular}{|c|c|c|}
\hline Unit & Description & $\begin{array}{l}\text { Monitoring wells/ } \\
\text { interval monitored }\end{array}$ \\
\hline $\begin{array}{l}\text { SWMU 12: C-747-A inactive } \\
\text { burial area, uranium } \\
\text { tetrafluoride }\left(\mathrm{UF}_{4}\right) \\
\text { drum yard }\end{array}$ & $\begin{array}{l}\text { Consists of a large waste pile of crushed } \\
\mathrm{UF}_{4} \text { drums. }\end{array}$ & MW22/RGA \\
\hline $\begin{array}{l}\text { SWMU 13: C-746-P scrap } \\
\text { metal yard }\end{array}$ & $\begin{array}{l}\text { Used to accumulate uncontaminated scrap metal } \\
\text { for sale to reclaimers. }\end{array}$ & $\begin{array}{l}\text { MW22/RGA } \\
\text { MW63/RGA } \\
\text { MW64/UCRS } \\
\text { MW65/RGA } \\
\text { MW66/RGA }\end{array}$ \\
\hline $\begin{array}{l}\text { SWMU 14: C-746-E } \\
\text { contaminated scrap } \\
\text { yard }\end{array}$ & $\begin{array}{l}\text { Contains contaminated scrap metal generated } \\
\text { during plant operations. Scrap material is } \\
\text { separated by metal type. Most contamination is } \\
\text { from depleted, natural, or slightly enriched } \\
\text { uranium on the metal surfaces. }\end{array}$ & MW22/RGA \\
\hline $\begin{array}{l}\text { SWMU 15: C-746-C } \\
\text { scrap yard }\end{array}$ & $\begin{array}{l}\text { Contains scrap metal of all types. The } \\
\text { contamination is mostly from depleted, natural, } \\
\text { or slightly enriched uranium. }\end{array}$ & MW22/RGA \\
\hline $\begin{array}{l}\text { SWMU 17: C-616-E } \\
\text { sludge lagoon }\end{array}$ & $\begin{array}{l}\text { On-grade surface impoundment that receives } \\
\text { sludge from the C- } 616 \text { chromium } \\
\text { reduction facility. }\end{array}$ & MW21/RGA \\
\hline $\begin{array}{l}\text { SWMU 18: C-616-F } \\
\text { full-flow lagoon }\end{array}$ & $\begin{array}{l}\text { On-grade surface impoundment that receives overflow } \\
\text { from the C-616-E sludge lagoon and liquid } \\
\text { effluent from the clarifiers at the C- } 616 \text { chromate } \\
\text { reduction facility. In addition, effluents } \\
\text { from the C- } 400 \text { cleaning and decontamination building } \\
\text { and coal-pile runoff are piped to this impoundment. }\end{array}$ & MW22/RGA \\
\hline $\begin{array}{l}\text { SWMU 30: C-747-A } \\
\text { burn area }\end{array}$ & $\begin{array}{l}\text { Used for burning combustible wastes until } \\
\text { approximately } 1970 \text {. This unit is located in } \\
\text { the vicinity of the C-747-A burial ground. }\end{array}$ & $\begin{array}{l}\text { MW63/RGA } \\
\text { MW64/UCRS } \\
\text { MW65/RGA } \\
\text { MW66/RGA }\end{array}$ \\
\hline
\end{tabular}

\footnotetext{
${ }^{a}$ Regional gravel aquifer.

${ }^{b}$ Upper Continental Recharge System.

${ }^{c}$ Resource Conservation and Recovery Act (RCRA) quality monitoring wells.

${ }^{d}$ Porters Creek clay.
}

cap. Additional cap material was added during September and October 1992. Continued sampling of groundwater and surface water in the C-746-K area will determine if additional corrective actions should be taken in 1993 to address the seepage problem.

\subsubsection{Environmental Surveillance Monitoring}

Implementation of groundwater surveillance monitoring (as prescribed by DOE Order 5400.1 and as previously defined) was initially scheduled to begin in 1991. The Groundwater Surveillance Plan describes in detail an expanded analytical program for 12 monitoring wells-4 existing wells and 8 proposed wells - for exit-pathway monitoring along the northern boundary of the DOE reservation. Environmental surveillance monitoring activities have been delayed until 1993. Environmental surveillance monitoring will be a continuation of some of the sampling activities that concluded with the completion of the ACO-driven site investigation.

\section{5-28 Groundwater}




\section{Environmental Report-Paducah, Part 1}

The Groundwater Investigation Phase III, completed in 1992, included installation of monitoring wells to provide interim perimeter monitoring until the proposed environmental surveillance monitoring activities can be funded.

\subsubsection{Groundwater Monitoring Results}

Upon discovery of contamination in the groundwater north of PGDP in August 1988, DOE and the EPA entered into an ACO under CERCLA Sects. 104 and 106. The intent of the ACO was to determine the nature and extent of off-site contamination near PGDP. Subsequent investigations, including the Phase I and Phase II ACO Site Investigations by $\mathrm{CH} 2 \mathrm{M}$ Hill (1990 and 1992) and the Phase III Groundwater Monitoring Study conducted by the Environmental Restoration Department's Hydrogeological Services Section (HSS) (1992), have led to the identification of several on-site and three off-site TCE and ${ }^{99} \mathrm{Tc}$ plumes of groundwater contamination. A brief discussion of the three off-site plumes in the RGA follows. A more detailed discussion of the plumes can be found in the Groundwater Investigation Phase III Report (Clausen et al. 1992b).

The Northwest Plume emanates from the northwest corner of PGDP and extends toward the Ohio River for approximately 3 miles, underlying an area of about 1.6 miles $^{2}$. Contamination within the Northwest Plume consists principally of TCE and ${ }^{99} \mathrm{Tc}$, the apparent source of which is the C-747-A burial ground area. Contaminant levels range up to $6200 \mu \mathrm{g} / \mathrm{L} \mathrm{TCE}$ and $3670 \mathrm{pCi} / \mathrm{L}{ }^{99} \mathrm{Tc}$ near the source of the plume. Analyses of TCE and ${ }^{99} \mathrm{Tc}$ levels over time in MW66 at PGDP indicate that wide fluctuations in concentration have occurred since 1988 (Figs. 5.15 and 5.16). However, the TCE concentration and ${ }^{99} \mathrm{Tc}$ activity show a general decreasing trend through mid-1992. The ratio of TCE concentration to ${ }^{99} \mathrm{Tc}$ activity appears to remain relatively constant (Fig. 5.17).

Another off-site plume, the Northeast TCE Plume, consists only of TCE contamination and extends off-site to the northeast of the plant. The boundaries of the Northeast Plume are not well defined, but the plume appears to underlie an area of approximately 1.2 miles $^{2}$. The plume trends oblique in the inferred groundwater flow path. At present, the difference in contaminant migration direction and the apparent groundwater flow direction has not been resolved. Future investigations will address the cause of this apparent contradiction. The Northeast TCE Plume is believed to have multiple sources. Possible sources include the $\mathrm{C}-400$ cleaning building, the C-745 Kellogg storage building, and the C-333 process building area. Undiscovered source areas of TCE could also be responsible for the plume.

An off-site ${ }^{99} \mathrm{Tc}$ plume has been identified in the area directly east of the Northwest Plume. RGA monitoring wells located east of the Northwest Plume (MW200 and MW98) have detectable levels of ${ }^{99} \mathrm{Tc}$ but not detectable TCE. The plume ranges in width from approximately $800 \mathrm{ft}$ near the plant boundary to approximately $1600 \mathrm{ft}$ at the Shawnee Steam Plant. Three possible sources have been postulated for the off-site ${ }^{99} \mathrm{Tc}$ plume: the C-616-F lagoon, a source near the northwest corner of the plant such as the C-746-E contaminated scrap yard, or a source farther to the south such as the C-749 or C-404 burial grounds.

A summary of the results of groundwater monitoring at SWMUs is presented in the following paragraphs. Table 5.7 lists the parameters analyzed, the recommended regulatory limits, and the wells that exceeded the reference limit at least once during 1992.

Groundwater at the C-746-K inactive sanitary landfill is monitored by four monitoring wells-MW23, MW24, MW26, and MW27 (see Fig. 5.5). All four wells had total zinc concentrations above the reference value (Table 5.7 in Part 2). This is believed to be the result of corrosion of the galvanized steel casing material. Total iron, total manganese, and fluoride were other analytes that commonly exceeded reference levels. A monitoring well installed for the Phase II Site Investigation, MW 184, is also in the C-746-K area. MW 184 had total manganese and total iron concentrations above reference levels.

Groundwater in the C-746-S and C-746-T areas is monitored by wells MW 16 through MW 19, MW38 through MW44, and MW220 through MW225 (see Fig. 5.6). TCE was detected above the reference level from the RGA wells MW41 and MW44 (Table 5.6 in Part 2). None of the wells monitored had ${ }^{99} \mathrm{Tc}$ activities above reference levels. Total iron was above the reference level in all wells except MW40 
1992 Environmental Report-Paducah, Part 1

ORNL-DWG 93M-7177

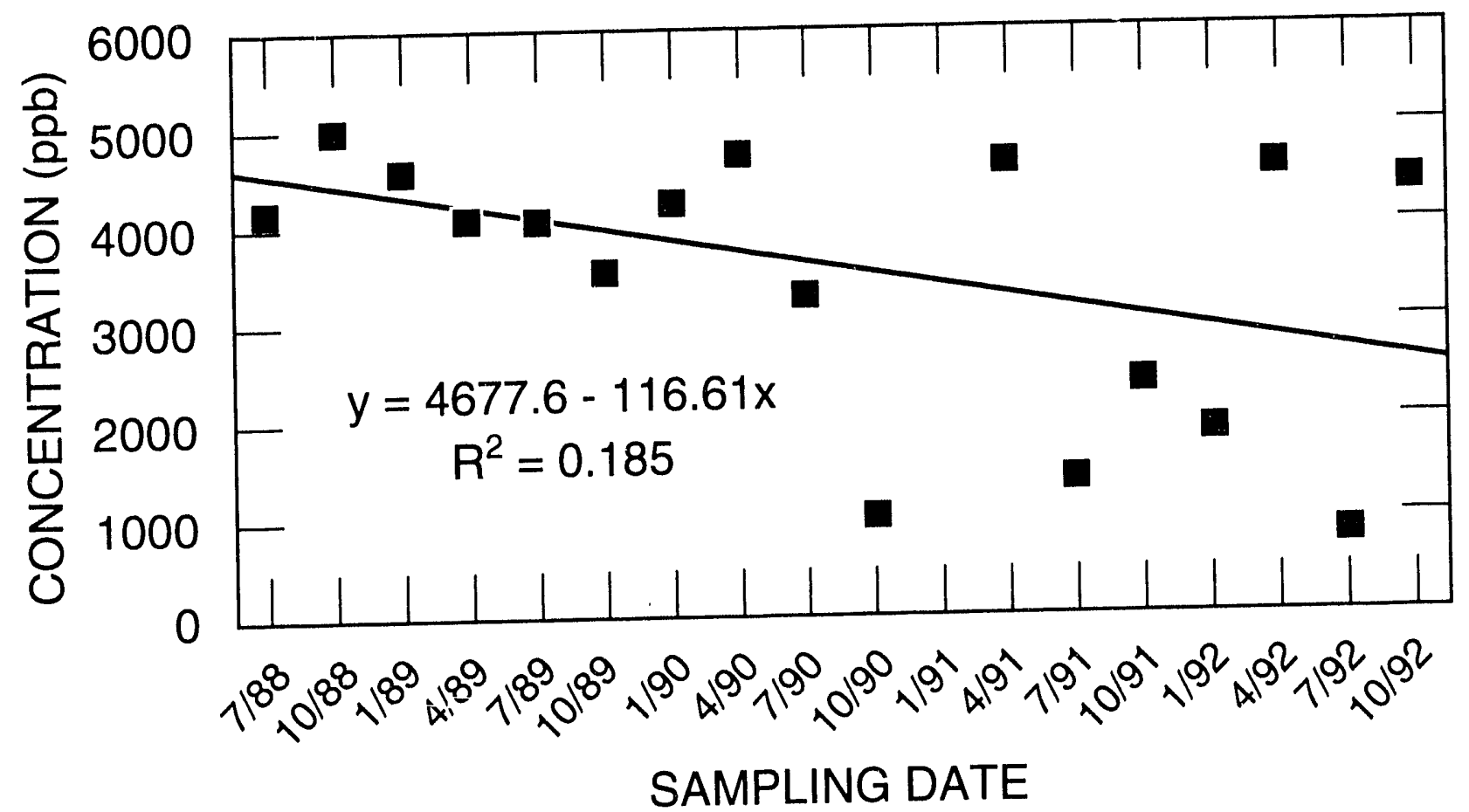

Fig. 5.15. Concentration of TCE from July 1988 to December 1992 in MW66.

ORNL-DWG 93M-7178

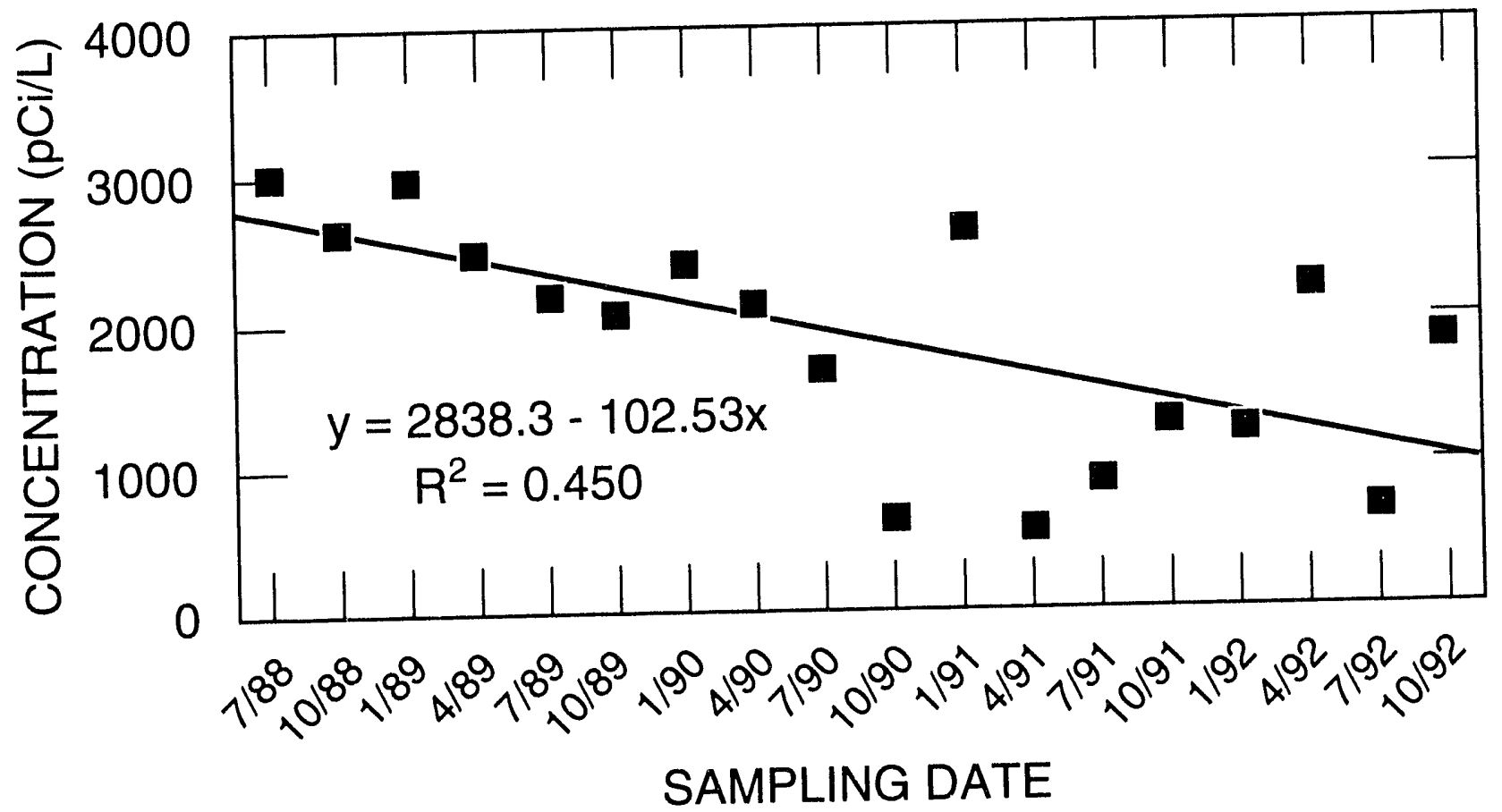

Fig. 5.16. Concentration of ${ }^{99} \mathrm{Tc}$ from July 1988 to December 1992 in MW66. 


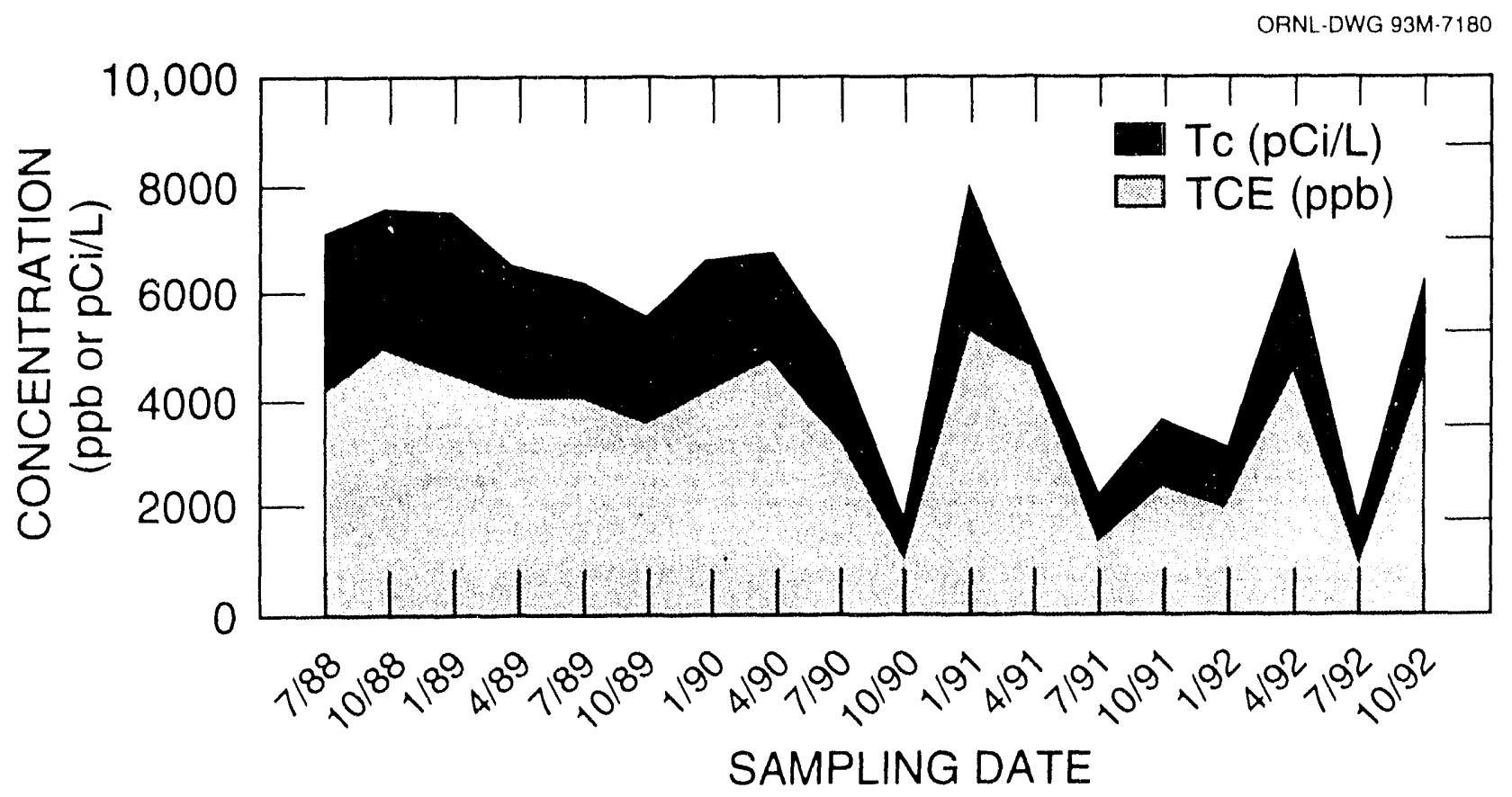

Fig. 5.17. Concentration of TCE and ${ }^{99}$ Tc from July 1988 to December 1992 in MW66.

and $M W 43$. Copper was found above the reference level in MW17.

Wells MW21 and MW22 are focalted near the C-616 lagoons and monitor the R(AA. TCle levels in MW22 exceeded the reference level. MW21 had no detectable TCE. Neither well had "Tis above the reference level. MW21 and MW22 (see Fig. 5.5) had total iron levels above reference level. Sulfate concentrations in MW2 1 continued to remain above the reference level.

Monitoring wells MW63 through MW66 (see Fig. 5.9) are associated with the C.746-P scrap metal yards. TCE and "Te were ahove the reference levels in RCiA MWG6.

Groundwater at the C-746-F burial area is monitored hy RGA MW52 through MW54 (see Fig. 5.9). Total iron and total manganese were the only constituents detected above reference levels (Tables 5.7 and 5.9 in Part 2). MW52 and MW.54 had detectable activities of ${ }^{49} \mathrm{Tc}$, but the activity was below reference levels

MW47, MW52, MW68, MW64, MW71, and MW96 (see Figs. 5.9 and 5.10) were monitored for petroleum products and other constituents during
1992 (Table 5.2 in Part 2). Only ethyl benzene was detected above reference levels (in MW96). A plot of total benzene, toluene, ethyl benzene, and xylene concentration in MW96 for the period August 1989 (1) July 1992 indicates a gradual downward trend (Fig. 5.18). TCE was present above reference levels in MW47, MW68, and MW71. Detectable levels of "Te were found in MW68 and MW7!.

MW84 through MW95 (see Fig. 5.10) are RCRA quality wells that monitor groundwater at the C. $4($ ) 4 low-level radioactive waste burial ground. (Sampling results for these wells can be found in Table $5.1 \mathrm{in}$ Part 2.) MW85, MW88, MW91, and MW94 monitor the UCRS. During 1992, TCE and "ro levels were above the reference levels for MW88 and MW94 Monitoring well MWYI had TCE concentrations above the reference level and detectable levels of "9.TL, Monitoring well MW85 had detectable levels of "9.6. hut no detectable TCL: MW84, MW86, MW87. MW89, MW9(), MW92. MW93, and MW95 monitor the RCiA. MW95 had TCl: concentrations above reference level and elevated ${ }^{* 4}$ Tc concentrations. MW84 had detectable "To concentrations below the 


\section{Environmental Report-Paducah, Part 1}

Table 5.7. Effluent monitoring at PGDP ${ }^{a}$

\begin{tabular}{|c|c|c|c|}
\hline Parameter & $\begin{array}{c}\text { Applicable } \\
\text { value }\end{array}$ & Reference & $\begin{array}{c}\text { Wells exceeding reference value } \\
\text { at least once during } 1992\end{array}$ \\
\hline Arsenic, total & $0.05 \mathrm{mg} / \mathrm{L}$ & 1 & None \\
\hline Bentene & $5 \mu \mathrm{g} / \mathrm{L}$ & 1 & None \\
\hline Cadmium, total & $0.005 \mathrm{mg} / \mathrm{L}$ & 1 & MW26 \\
\hline Chromium, total & $0.1 \mathrm{mg} / \mathrm{L}$ & 1 & MW47, MW71 \\
\hline Copper, total & $1.0 \mathrm{mg} / \mathrm{L}$ & 2 & MW17, MW47 \\
\hline Iron, total & $0.30 \mathrm{mg} / \mathrm{L}$ & 2 & $\begin{array}{l}\text { MW16-24, MW26, MW27, MW29, } \\
\text { MW38, MW39, MW41, } \\
\text { MW42, MW46-48, MW50-54, } \\
\text { MW57, MW62-64, MW66, MW69, } \\
\text { MW71, MW154, MW184, MW220-225 }\end{array}$ \\
\hline Manganese, total & $0.05 \mathrm{mg} / \mathrm{L}$ & 2 & $\begin{array}{l}\text { MW24, MW27, MW29, MW } 38-40 \\
\text { MW } 48, M W 50-54, M W 57, M W 62, \\
M W 64, M W 184\end{array}$ \\
\hline Nickel, total & None & $b$ & $b$ \\
\hline Lead, total & $0.05 \mathrm{mg} / \mathrm{L}$ & 1 & MW26, MW47 \\
\hline Zinc, total & $5.0 \mathrm{mg} / \mathrm{L}$ & 2 & MW23, MW24, MW26, MW27 \\
\hline Arsenic, dissolved & None & $b$ & $b$ \\
\hline Cadmium, dissolved & None & $b$ & $b$ \\
\hline Lead, dissolved & None & $b$ & $b$ \\
\hline Selenium dissolved & None & $b$ & $b$ \\
\hline Chromium, hexavalent & None & $b$ & $b$ \\
\hline Calcium & None & $b$ & $b$ \\
\hline Magnesium & None & $b$ & $b$ \\
\hline Sodium & None & $b$ & $b$ \\
\hline $\mathrm{pH}$ & $6.5-8.5 \mathrm{SU}^{\mathrm{r}}$ & 2 & $\begin{array}{l}\text { MW27, MW29 } \\
\text { MW41-44, MW46-48, MW50-54, MW59--61, } \\
\text { MW63, MW65-71, MW84-95, MW154, } \\
\text { MW 184, MW220-225 }\end{array}$ \\
\hline Temperature & None & $b$ & $b$ \\
\hline Water turbidity & $5 \mathrm{NTU}^{d}$ & 1 & $\begin{array}{l}\text { MW16-20, MW23, MW24, MW26, } \\
\text { MW27, MW39, MW41, MW46, } \\
\text { MW50-52, MW54, MW57, MW62-64, } \\
\text { MW66, MW68, MW69, MW154, } \\
\text { MW184 }\end{array}$ \\
\hline Water color & 15 units & 2 & $\begin{array}{l}\text { MW18, MW19, MW21, MW23, } \\
\text { MW24, MW26, MW27, MW } 39 \\
\text { MW46, MW47, MW50-52, MW54, } \\
\text { MW64, MW69 }\end{array}$ \\
\hline Water conductivity & None & $b$ & $b$ \\
\hline Water alkalinity $\left(\mathrm{CaCO}_{3}\right)$ & None & $b$ & $b$ \\
\hline Dissolved solids, total & $500 \mathrm{mg} / \mathrm{L}$ & 2 & MW47, MW 159 \\
\hline Chloride & $250 \mathrm{mg} / \mathrm{L}$ & 2 & None \\
\hline Fluoride & $4.0 \mathrm{mg} / \mathrm{L}$ & 1 & MW26 \\
\hline Nitrate as nitrogen & $10 \mathrm{mg} / \mathrm{L}$ & 1 & None \\
\hline Phosphate as phosphorus & None & $b$ & $b$ \\
\hline Sulfate & $250 \mathrm{mg} / \mathrm{L}$ & 2 & $M W 21, M W 47$ \\
\hline Organic carbon, total & None & $b$ & $b$ \\
\hline Organic halide, total & None & $b$ & 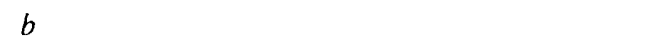 \\
\hline Trichloroethylene & $5 \mu \mathrm{g} / \mathrm{L}$ & 4 & $\begin{array}{l}\text { MW20, MW22, MW41, MW44, } \\
\text { MW47, MW66, MW68, MW71, } \\
\text { MW88, MW91, MW94, MW95, } \\
\text { MW108, MW109, MW114, MW117. } \\
\text { MW154, R2, R113 }\end{array}$ \\
\hline
\end{tabular}


1992 Environmental Report-Paducah, Part 1

Table 5.7 (continued)

\begin{tabular}{llll}
\hline \multicolumn{1}{c}{ Parameter } & \multicolumn{1}{c}{$\begin{array}{c}\text { Applicable } \\
\text { value }\end{array}$} & Reference & $\begin{array}{c}\text { Wells exceeding reference value } \\
\text { at least once during 1992 }\end{array}$ \\
\hline $\begin{array}{l}\text { Polychlorinated biphenyl } \\
\text { Ethyl benzene }\end{array}$ & $\begin{array}{l}\text { None } \\
700 \mu \mathrm{g} / \mathrm{L}\end{array}$ & $b$ & $b$ \\
Toluene & $2,000 \mu \mathrm{g} / \mathrm{L}$ & 1 & MW96 \\
Xylene & $10,000 \mu \mathrm{g} / \mathrm{L}$ & 1 & None \\
Americium-24l & $1 \mathrm{pCi} / \mathrm{L}$ & None \\
Cobalt-60 & $200 \mathrm{pCi} / \mathrm{L}$ & 3 & None \\
Radon-222 & $300 \mathrm{pCi} / \mathrm{L}$ & 3 & None \\
& & 3 & R10, R12, R13, R14, R19, R29, R39, R40, R54, R93, \\
Technetium-99 & $4,000 \mathrm{pCi} / \mathrm{L}$ & 3 & None \\
Dissolved alpha & None & $b$ & $b$ \\
Suspended alpha & None & $b$ & $b$ \\
Dissolved beta & None & $b$ & $b$ \\
Suspended beta & None & $b$ & $b$ \\
Gross beta & $50 \mathrm{pCi} / \mathrm{L}$ & 1 & MW66, R2, R17, R113 \\
\hline
\end{tabular}

${ }^{a}$ References:

1. 40 CFR 141. Safe Drinking Water Act-National Primary Drinking Water Regulations, as amended.

2. 40 CFR 143. Safe Drinking Water Act-National Secondary Drinking Water Regulations, as amended.

3. Four percent of Derived Concentration Guides (DCGs) for Air and Water, DOE Order 5400.5 (4 mrem/year).

4. U.S. Environmental Protection Agency, National Primary Drinking Water Regulations; Synthetic Organic Chemicals, Fed. Regist. 54(97) (May 22, 1989).

${ }^{b}$ Not analyzed.

'Standard units.

${ }^{d}$ Nephelometric turbidity units.

ORNL-DWG 93M-7179

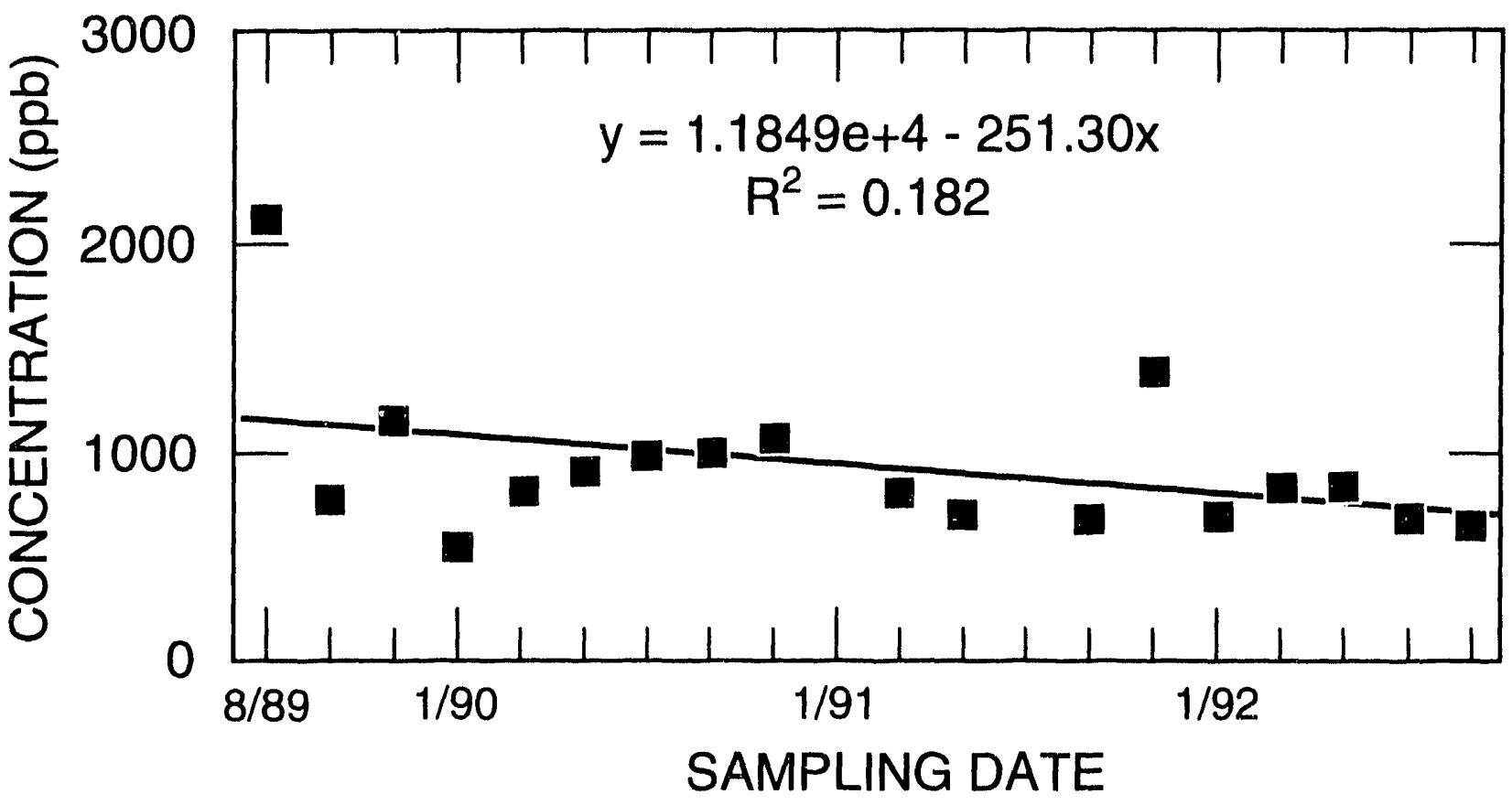

Fig. 5.18. Concentration of benzene, toluene, ethyl benzene, and xylene from August 1989 to November 1992 in MW96. 


\section{Environmental Report-Paducah, Part 1}

drinking water standard of $900 \mathrm{pCi} / \mathrm{L}$ ) but no detectable TCE.

One other monitoring well in the $\mathrm{C}-404$ and C.749 areas, MW47, continued to have elevated TCE and ${ }^{91}$ 'Tc levels (Table 5.6 in Part 2). Total chromium, total copper, total dissolved solids, total iron, and total lead levels also were above reference levels in MW47. MW46, MW48, MW50, MW51, and MW57 showed total iron and total manganese concentrations above reference levels (Tables 5.7 and 5.9 in Part 2).

\subsection{Project Accomplishments}

Work continues under the auspices of the Groundwater Protection Plan to address recognized deficiencies in the understanding of the site hydrogeology and geology (Early et al. 1989). Activities consist of specific projects performed and directed by the HSS and the coordination of related activities conducted by other organizations. These activities are designed to complement existing compliance and restoration initiatives. Information obtained from related activities is assimilated and analyzed to address global deficiencies identified in the Groundwater Monitoring Plan.

The next two subsections describe special projects conducted by the HSS during 1992 and related projects that have assisted in further characterization of the site.

\subsubsection{Hydrogeologic Services Section (HSS)}

The HSS has three main responsibilities: to oversee and maintain the PGDP Groundwater Protection Program, to provide technical oversight and input on Environmental Restoration projects, and to provide technical services as requested to line organizations within the plant. The first responsibility includes implementation of the Groundwater Management Plan, which identifies deficiencies in the understanding of the site groundwater flow system and prescribes activities to address these deficiencies. Toward this end, several activities designed to complement ongoing compliance and environmental restoration activities were conducted and/or completed during 1992.

\subsubsection{Phase III Groundwater Monitoring Project}

The primary objectives of the Phase III Groundwater Monitoring Project are to complement previous monitoring efforts and site investigations by addressing basic deficiencies in the current understanding of site geology and hydrogeology and to provide interim perimeter monitoring for the DOE reservation. Phase III Groundwater Monitoring field activities were conducted from fall 1991 through spring 1992. A final report detailing the activities and findings of the project was issued on November 25 , 1992.

The Phase III Project supports development of the site conceptual model of groundwater flow and contaminant migration by providing field data that fill many of the significant data gaps remaining after completion of previous site-initiated studies. The project was designed to address the following data gaps:

- the potentiometric surface in areas of uncertainty;

- quantification of various hydraulic parameters of the RGA, particularly in an area of suspected high hydraulic conductivity located in the vicinity of the C-333 building; and

- the continuity of the shallowest aquifer over the buried terrace located near the southern boundary of PGDP.

The following field activities were performed as part of the Phase 111 Groundwater Investigation:

- Installation of groundwater surveillance monitoring wells in the RGA to provide interim perimeter monitoring for the DOE reservation.

- Installation of piezometers and monitoring wells in the RGA to provide potentiometric data where few or no data currently exist. Groundwater samples from the monitoring wells were analyzed for TCE and ${ }^{(w)} \mathrm{Tc}$ to assist in plume mapping and to aid in identifying sources of contamination.

- Installation of a background monitoring well cluster, with individual monitoring wells completed in the UCR.S, the RGA, and the McNairy Formation. This cluster was located between PGDP and the old Kentucky Ordnance Works, near the base of the buried terrace slope.

\section{5-34 Groundwater}




\section{Environmental Report-Paducah, Part 1}

- Installation of soil borings to provide detailed lithologic information (six soil borings were located approximately perpendicular to the buried terrace slope to assist in characterizing the feature).

- Installation of piezometers, pressure transducers, and a high-capacity pumping well for conducting an aquifer pump test in the RGA.

A number of conclusions regarding site geology and hydrogeology were reached as a result of information obtained during the Phase III Groundwater Monitoring Project. A few of the more important conclusions include the following:

- Interpretation of Phase III soil-boring data has provided additional support for the view that a buried river terrace exists near the southern boundary of the plant. The soil-boring logs have further characterized the location and slope of the terrace and have provided additional evidence of the discontinuity of the shallow sediments across the terrace slope. The RGA is either truncated or grades laterally into the Pliocene terrace gravels, resulting in restricted flow across the terrace, as evidenced by the steep hydraulic gradient observed there.

- Monitoring wells located downgradient and in areas peripheral to PGDP have provided contaminant measurements useful in defining the limits of groundwater contamination at PGDP. Recent data from on-site and off-site groundwater monitoring wells, including the Phase III wells, suggest that there are between five and nine distinct contaminant plumes resulting from PGDP activities. Three of these plumes extend off site. Hydraulic head measurements made during this project have provided additional information useful for further characterizing groundwater flow. These head measurements also have confirmed that the water table is very low under portions of the mid-plant area.

- Deep soil borings installed for the Phase III Project provided additional lithologic and hydrogeologic data concerning the McNairy Formation. The Phase III borings encountered very fine- to medium-grained, well-sorted sand with thin clay layers in the McNairy Formation. Further characterization of the McNairy, particularly the upper portion of the formation, is considered a critical data need and will be addressed in a future investigation (the Phase IV Groundwater Investigation).

Additional conclusions based on the results of the Phase III aquifer testing are discussed in Subsect. 5.6.1.2.

In addition to summarizing the findings of the project, the Groundwater Investigation Phase III Report provides an overview of the hydrogeologic, geologic, and geochemical data obtained in past investigations. The report also presents the current conceptual model for groundwater flow and contaminant migration at PGDP.

\subsubsection{Aquifer Testing}

Aquifer testing was performed in 1992 as an integral part of the Phase III Groundwater Monitoring Project. Terran Corporation was contracted by Energy Systems to design and conduct the aquifer testing program west of the C-333 building. The field work was performed during March and April 1992, and a final report presenting the results of the testing was issued in June 1992.

The primary objective of the testing was to determine the inydraulic properties of the RGA in the area west of building C-333 at PGDP. These properties include the transmissivity and storativity of the RGA, leakance of the overlying confining unit into the RGA, the boundary effects of the buried terrace south of the C-333 area, and the anisotropic transmissivity tensor components of the RGA at the test site. Water levels were measured with seven 2-in.-diam piezometers and three buried pressure transducers located in the area surrounding the pumped well. A complete description of the testing program and an analysis of the data can be found in the final report. The major findings of the aquifer testing program were:

- Leakance through the clay aquitard above the RGA was calculated and found to be substantial under pumping conditions. This suggests that either the aquitard is relatively permeable or that high permeability "windows" exist in the aquitard in portions of the test area. Because the aquitard is acting more as a semiconfining unit than as a confining unit, 


\section{Environmental Report-Paducah, Part 1}

the overlying UCRS can contribute flow to the RGA, particularly under pumping conditions.

- TCE concentrations in the $2000 \mu \mathrm{g} / \mathrm{L}$ range were encountered at the pumped well during the pump test. This may indicate an undiscovered source area of TCE: existing either south or east of the $\mathrm{C}-333$ building.

- The range of RGA hydraulic conductivity values $(1000)$ to $1200 \mathrm{ft} / \mathrm{d})$ is higher than previous field tests have encountered. The hydraulic conductivity values derived from the C-333 pumping test indicate that highly permeable zones exist within the $R G A$ in the C- -333 lest area.

\subsubsection{Groundwater Monitoring Phase IV}

Preliminary work on the conceptual design of the Groundwater Monitoring Phase IV Project was begun in 1992. Phase IV will be designed specifically 10 address uncertainties concerning the hydraulic properties of the McNairy Formation and will consist of installing additional monitoring wells and piczometers. The project also may involve the abandonment of selected monitoring wells that have been determined to have questionable construction. The use of geophysical well logging in these monitoring wells prior to plugging and abandoning them is being explored as a potential method of improving lithologic and hydrogeologic characterization of the subsurface at each well site.

\subsubsection{Sampling and Analysis Plan}

A groundwater sampling and analysis plan for PGDP was written in 1992 and received final approval in early 1993. The plan specifies (1) which wells will be sampled, (2) frequency of sample collection, and (3) parameters in groundwater to be analyzed for from each sample event. Procedures for formal request and documentation of changes to sampling schedules are included in the plan.

\subsubsection{HSS Special Studies}

During 1992, HSS hydrogeologists have continued their efforts to remain up to date on research that may be applicable to PGDP site characterization and remediation selection activities. To this end, they have developed working relationships with several experts in groundwater flow, contaminant transport and fatc, and innovative remedial technologies. Researchers at the University of Waterloo have provided valuable information concerning their ongoing research into hydraulic containment reactive curtain technologies. Wo:k will continue on evaluating the applicability of these technologies to the groundwater contamination problem at PCiDP.

Among the other activities completed or initiated by the HSS during 1992 was a borehole flowmeter study. TVA was retained by Energy Systems 10 perform electromagnetic boreholo flowmeter testing in the RGA. The flowmeter testing was performed at PGDP in August 1992, and a final report presenting the results will be issued in early 1993.

The primary objective of the borehole flowmeter testing was 10 more accurately characterize the spatial variability of hydraulic conductivity in the RGA. Measurements were made under both pumping and nonpumping conditions in two wells. The flow measurements obtained under ambient conditions were assumed to represent the natural vertical flow existing in each well. The flow measurements made under pumping conditions were used to characterize the vertical distribution of horizontal hydraulic conductivity in the RGA.

The results of the borehole flowmeter testing reveal that large vertical variations in hydraulic conductivity exist in the RGA. Testing under pumping conditions indicted the presence of a $2-10$ 3-ft-thick, highly permeable sand layer at the top of the RGA. This sand layer may be up to I0 times more permeable than the underlying gravel layers within the RCA. The data obtained from the flowmeter tests will provide information critical to defining the preferred pathways for contaminant movement at PGDP.

Two additional studies were directed by HSS during 1993, a groundwater modeling study performed by GeoTrans and the Northwest Plume study. These special studies are discussed in Subsect. 8.2.1 and so are not addressed here.

\subsubsection{Related Activities}

Efforts are made to coordinate all related activities to ensure that maximum information is gained in order to achieve the overall technical and programmatic goals of the Groundwater Protection Program. This is accomplished by assigning a

\section{5-36 Groundwater}




\section{Environmental Report-Paducah, Part 1}

hydrogeologist within the HSS to a particular related project. The HSS staff member tracks the project and provides technical input to ensure that the specific project objectives and the overall Groundwater Protection Program objectives are met to the extent possible. Discussion of specific projects follows.

\subsubsection{Environmental Restoration Program (CERCLA, UST, HSWA)}

A number of projects conducted or completed in 1992 by the Environmental Restoration Program affect the Groundwater Protection Program. These include the CERCLA/ACO Phase II Site Investigation, the C-750) UST Site Investigation, and investigations required under HSWA.

The Phase II Site Investigation was conducted by CH2M Hill in 1990 and 1991. A final report detailing the results of the investigation was submitted to the EPA in April 1992. On August 13, 1992, and October 2, 1992, PGDP received comments on the Final Phase II Site Investigation Report from EPA Region IV and the Commonwealth of Kentucky (Kentucky Department for Environmental Protection), respectively. The EPA has required that the Phase Il Report be supplemented, in the form of Remedial Investigation Addenda to be developed on an operable unit basis. The final Phase II Report will be used for supporting the addenda documents.

During 1992, the HSS provided support for an investigation focused on five USTs located in the south-central portion of PGDP near the C-750 garage, the C-200 guard and fire headquarters, and the C-710 technical services building. CDM Federal Programs Corporation conducted the UST investigation. The final site investigation report was submitted to DOE and the KDWM on September 10, 1992. A draft corrective action plan, developed by Science Applications International Corporation, was submitted for regulatory review in December 1992.

Progress was made during 1992 in the scheduling of a HSWA investigation of SWMUs at PGDP. SWMUs have been segregated into waste area groups and scheduled for RFI work plan development pursuant to the HSWA Corrective Action Program.
Two or more waste area groups are to be addressed by each RFI. During 1992, contractors developed the first three draft RFI work plans. Two were submitted to the EPA and the Commonwealth of Kentucky for regulatory review.

\subsection{References}

CH2M Hill Southeast. 1990. Draft Results of the Site Investigation, Phase l, Paducah Gaseous Diffusion Plant, KY/ER-4, December 1990).

CH2M Hill Southeast. 1992. Results of the Site Investigation, Phase II, Paducah Gaseous Diffusion Plant, KY/SUB/13B-97777C P-03/1991/1, April 1992.

Clausen, J. L., Davis, K. R., Douthitt, J. W., and Phillips, B. E. 1992a. Paducah Gaseous Diffusion Plant Groundwater Protection Program Plan, KY/ER-2 (Rev. 1), January 1992.

Clausen, J. L., Douthitt, J. W., Davis, K. R., and Phillips, B. E. 1992b. Report of the Paducah Gaseous Diffusion Plant Groundwater Investigation Phase III, KY/E-150), November 1992.

Early, T. O., Sigmon, C. F., and Williams, R. T. 1989. Groundwater Monitoring Plan for the Paducah Gaseous Diffusion Plant, Paducah, Kentucky, Battelle Columbus Laboratories, Columbus, Ohio.

Freeze, R. A., and Witherspoon, P. A. 1967. Theoretical Analysis of Regional Groundwater Flow, 2. Effect of Water-Table Configuration and Subsurface Permeability Variation. Water Resources Research 3(2), p. 62.3-6.34.

Olive, W. W. 1980. Geologic Maps of the Jackson Purchase Region, Kentucky, U.S. Geological Survey Miscellaneous Investigation Series, Map 1-1217, U.S. Geological Survey, Reston, Virginia.

Science Applications International Corporation. 1991. Draft Summary of Alternatives for Remediation of Offsite Contamination at the Paducah Gaseous Diffusion Plant, Paducah, Ky', DOE/OR-1013, Paducah, Kentucky. 


\section{Biological Monitoring}

6.1 Food Crops $\ldots \ldots \ldots \ldots \ldots \ldots \ldots \ldots \ldots \ldots$ 6-3

6.2 Deer Harvest $\ldots \ldots \ldots \ldots \ldots \ldots \ldots \ldots$ 6-3

6.3 Vegetation $\ldots \ldots \ldots \ldots \ldots \ldots \ldots \ldots \ldots$ 6-6 


\section{Biological Monitoring}

\subsection{Food Crops}

The Paducah Gaseous Diffusion Plant (PGDP) staff sampled food crops during 1992 from the vicinity of the plant. Food crop samples collected included corn, squash, tomatoes, beans, peppers, carrots, and eggplant. Figure 6.1 shows the locations where samples were obtained. Locations were selected to correspond to the most prevalent wind directions. One additional location was used north of the plant in the direction of the groundwater contamination plume. Background locations were selected approximately 10 miles west of the plant for comparison to the indicator locations.

Each sample was analyzed for ${ }^{239} \mathrm{Pu},{ }^{99} \mathrm{Tc},{ }^{230} \mathrm{Th}$, ${ }^{237} \mathrm{~Np},{ }^{2.35} \mathrm{U},{ }^{234} \mathrm{U}$, and ${ }^{238} \mathrm{U}$. Table 6.1 shows the concentration of various radionuclides detected (by wet weight basis) in edible vegetation. Only the radionuclides that were present above the detection limit (at 99\% confidence level) were included.

The radionuclides detected- $-{ }^{234} U,{ }^{238} \mathrm{U}$, and ${ }^{230} \mathrm{Th}$-are all known to be naturally occurring in soil. Because the sampling method does not require washing of the vegetables prior to analysis, the percent contribution from the uptake of radionuclides into the plant could not be determined.

\subsection{Deer Harvest}

In August 1992 four deer were harvested in the West Kentucky Wildlife Management Area (WKWMA) to monitor the effects of PGDP on the ecology of the surrounding area. A new procedure for deer sampling was tested during 1992. Deer samples were collected by WKWMA personnel from deer taken by hunters in the area. This new procedure allowed the plant to sample deer in older age groups and deer that were outside the buffer areas surrounding PGDP. WKWMA and PGDP personnel were reluctant to sample older deer, particularly bucks, in the special summer sampling events because these are considered the trophy animals that draw hunters to the area. Expanding outside the buffer areas was deemed acceptable for two reasons: (1) deer home range areas are encompassing both buffer and hunting areas, and (2) contaminants would have more time to bioaccumulate in older deer, thus increasing the likelihood of detection in this surveillance activity. Three deer obtained as background samples from the Land Between the Lakes in 1992 were used for reference. Liver and muscle samples were analyzed for radionuclides, metals, and polychlorinated biphenyls (PCBs). In addition, bone and thyroid samples were analyzed for radionuclides and fat samples for PCBs. The liver, muscle, and fat tissue are evaluated for radiological or chemical risks if analyses reveal detectable levels above background or reference deer. These types of tissues are considered consumable by hunters. Bone and thyroid are used as indicators of contamination only. The results for all detected analytes in muscle and liver samples are summarized in Tables 6.2 and 6.3 .

The only radionuclide results that were statistically different from zero in edible portions of deer tissue were for uranium isotopes. The mean concentration of ${ }^{234} \mathrm{U}$ in edible portions of reservation deer was 0.29 ( 0.30 muscle, 0.28 liver $) \mathrm{pCi} / \mathrm{g}$. The data indicate no significant difference (at $95 \%$ confidence level) between the average concentrations of uranium isotopes in reservation deer and in background deer. Detectable concentrations of uranium isotopes and ${ }^{91} \mathrm{Sr}$, a radionuclide present in the atmosphere from worldwide fallout, were found in most bone samples. No detectable levels of ${ }^{99} \mathrm{Tc}$, reservation and background, were found in the thyroids of the deer. 
1992 Environmental Report-Paducah, Part 1

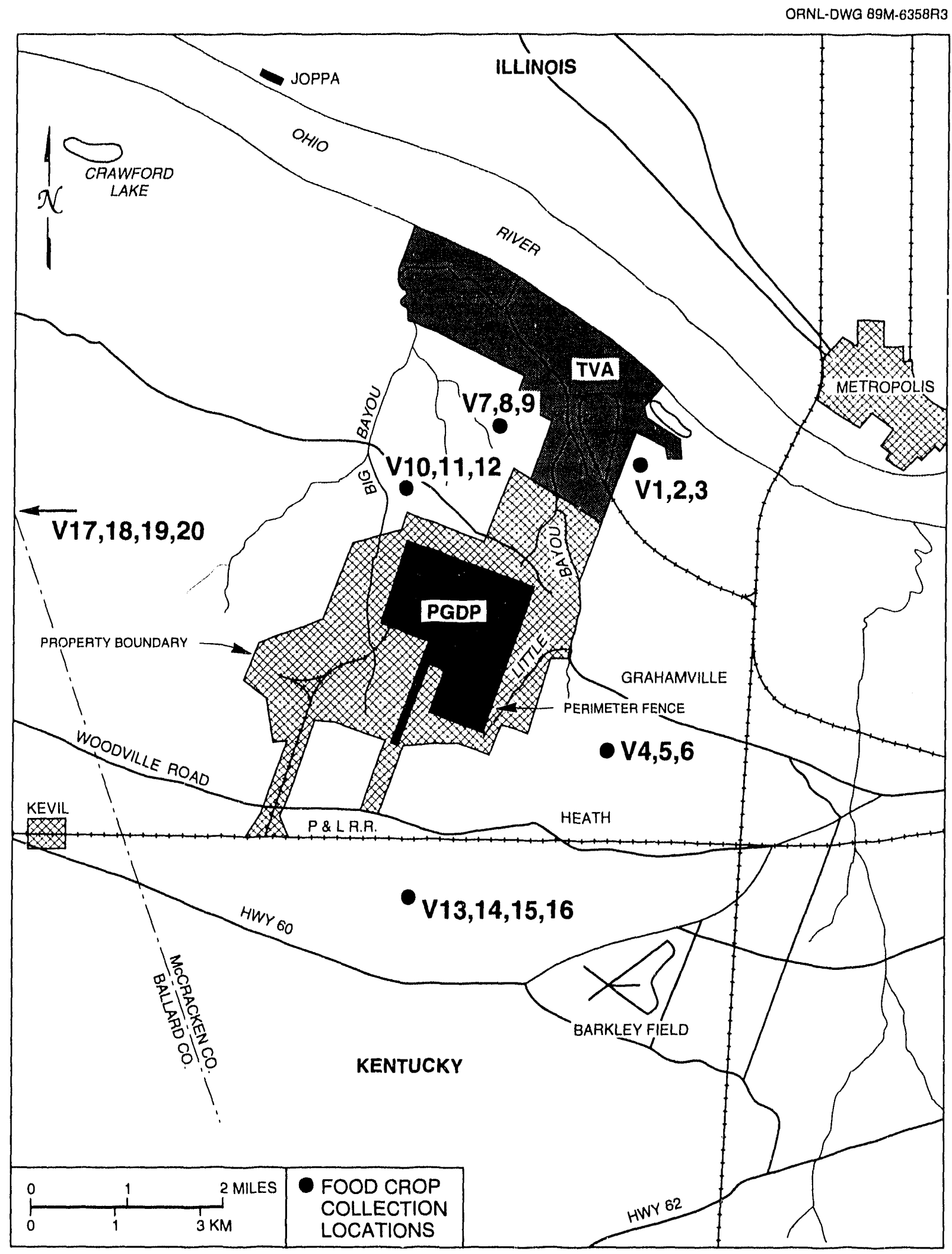

Fig. 6.1. Food crop collection locations. 
1992 Environmental Report-Paducah, Part 1

Table 6.1. 1992 annual food crop sampling

\begin{tabular}{lccccccc}
\hline $\begin{array}{c}\text { Location } \\
\text { (sample) }\end{array}$ & $\begin{array}{c}{ }^{237} \mathrm{~Np} \\
(\mathrm{pCi} / \mathrm{g})\end{array}$ & $\begin{array}{c}{ }^{239} \mathrm{Pu} \\
(\mathrm{pCi} / \mathrm{g})\end{array}$ & $\begin{array}{c}{ }^{99} \mathrm{Tc} \\
(\mathrm{pCi} / \mathrm{g})\end{array}$ & $\begin{array}{c}{ }^{230} \mathrm{Th} \\
(\mathrm{pCi} / \mathrm{g})\end{array}$ & $\begin{array}{c}{ }^{234} \mathrm{U} \\
(\mathrm{pCi} / \mathrm{g})\end{array}$ & $\begin{array}{c}{ }^{235} \mathrm{U} \\
(\mathrm{pCi} / \mathrm{g})\end{array}$ & $\begin{array}{c}{ }^{238} \mathrm{U} \\
(\mathrm{pCi} / \mathrm{g})\end{array}$ \\
\hline 1 Corn & $b$ & $b$ & $b$ & $b$ & 0.027 & $b$ & $b$ \\
2 Tomato & $b$ & $b$ & $b$ & $b$ & 0.004 & $b$ & $b$ \\
3 Squash & $b$ & $b$ & $b$ & $b$ & $b$ & $b$ & $b$ \\
4 Corn & $b$ & $b$ & $b$ & $b$ & 0.006 & $b$ & $b$ \\
5 Tomato & $b$ & $b$ & $b$ & 0.010 & 0.010 & $b$ & $b$ \\
6 Beans & $b$ & $b$ & $b$ & $b$ & $b$ & $b$ & $b$ \\
7 Corn & $b$ & $b$ & $b$ & $b$ & 0.007 & $b$ & $b$ \\
8 Squash & $b$ & $b$ & $b$ & $b$ & $b$ & $b$ & $b$ \\
9 Tomato & $b$ & $b$ & $b$ & $b$ & 0.005 & $b$ & $b$ \\
10 Tomato & $b$ & $b$ & $b$ & $b$ & 0.007 & $b$ & 0.004 \\
11 Pepper & $b$ & $b$ & $b$ & $b$ & $b$ & $b$ & $b$ \\
12 Beans & $b$ & $b$ & $b$ & $b$ & $b$ & $b$ & $b$ \\
13 Tomato & $b$ & $b$ & $b$ & $b$ & $b$ & $b$ & $b$ \\
14 Corn & $b$ & $b$ & $b$ & $b$ & $b$ & $b$ & $b$ \\
15 Mixed & $b$ & $b$ & $b$ & $b$ & $b$ & $b$ & $b$ \\
16 Squash & $b$ & $b$ & $b$ & 0.004 & $b$ & $b$ & $b$ \\
17 Carrot & $b$ & $b$ & $b$ & $b$ & 0.007 & $b$ & 0.005 \\
18 Tomato & $b$ & $b$ & $b$ & $b$ & 0.004 & $b$ & $b$ \\
19 Corn & $b$ & $b$ & $b$ & $b$ & $b$ & $b$ & $b$ \\
20 Eggplant & $b$ & $b$ & $b$ & $b$ & $b$ & $b$ & $b$ \\
\hline
\end{tabular}

${ }^{a}$ See Fig. 6.1.

${ }^{b}$ Only radionuclides that are present above detection limits (at $99 \%$ confidence level) are included.

Table 6.2. 1992 annual deer harvest-muscle analysis

(Confidence that analytes are present in samples is $99 \%$ )

\begin{tabular}{|c|c|c|c|c|c|c|c|c|c|c|c|}
\hline Deer & $\begin{array}{c}\mathrm{Al} \\
(\mu \mathrm{g} / \mathrm{g})\end{array}$ & $\begin{array}{c}\mathrm{Cd} \\
(\mu \mathrm{g} / \mathrm{g})\end{array}$ & $\begin{array}{c}\mathrm{Cr} \\
(\mu \mathrm{g} / \mathrm{g})\end{array}$ & $\begin{array}{c}\mathrm{Cu} \\
(\mu \mathrm{g} / \mathrm{g})\end{array}$ & $\begin{array}{c}\mathrm{Fe} \\
(\mu \mathrm{g} / \mathrm{g})\end{array}$ & $\begin{array}{c}\mathrm{Ni} \\
(\mu \mathrm{g} / \mathrm{g})\end{array}$ & $\begin{array}{c}\mathrm{Pb} \\
(\mu \mathrm{g} / \mathrm{g})\end{array}$ & $\underset{(\mu \mathrm{g} / \mathrm{g})}{\mathrm{Zn}}$ & $\begin{array}{c}{ }^{234} \mathrm{U} \\
(\mathrm{pCi} / \mathrm{g})\end{array}$ & $\begin{array}{c}{ }^{235} \mathrm{U} \\
(\mathrm{pC} \mathrm{C} / \mathrm{g})\end{array}$ & $\begin{array}{c}{ }^{238} \mathrm{U} \\
(\mathrm{pCi} / \mathrm{g})\end{array}$ \\
\hline \multicolumn{12}{|c|}{ Indicator } \\
\hline 1 & 0.75 & $a$ & 0.06 & 1.40 & 28 & 0.03 & $a$ & 61 & 0.24 & $a$ & $a$ \\
\hline 2 & 1.10 & $a$ & 0.07 & 1.30 & 37 & $a$ & $a$ & 100 & 0.17 & $a$ & $a$ \\
\hline 3 & 1.10 & $a$ & 0.11 & 2.10 & 93 & 0.12 & $910.00^{b}$ & 39 & 0.60 & 0.17 & 0.15 \\
\hline 4 & 1.10 & $a$ & 0.06 & 1.20 & 33 & $a$ & 0.07 & 69 & 0.18 & $a$ & $a$ \\
\hline \multicolumn{12}{|c|}{ Background } \\
\hline 5 & 2.00 & $a$ & 0.07 & 1.60 & 30 & $a$ & 0.02 & 28 & $a$ & $a$ & $a$ \\
\hline 6 & 0.89 & $a$ & 0.07 & 1.50 & 38 & 0.16 & $a$ & 57 & 0.68 & 0.32 & 0.19 \\
\hline 7 & 1.50 & $a$ & 0.15 & 3.10 & 85 & $a$ & 0.02 & 89 & 0.08 & $a$ & $a$ \\
\hline
\end{tabular}

${ }^{a}$ Not detected.

${ }^{b}$ Results of analyses on recovered deer meat did not confirm this result. 


\section{Environmental Report-Paducah, Part 1}

Table 6.3. 1992 annual deer harvest-liver analysis

(Confidence that analytes are present in samples is $99 \%$ )

\begin{tabular}{|c|c|c|c|c|c|c|c|c|c|c|c|}
\hline Deer & $\begin{array}{c}\mathrm{Al} \\
(\mu \mathrm{g} / \mathrm{g}) \\
\end{array}$ & $\begin{array}{c}\mathrm{Cd} \\
(\mu \mathrm{g} / \mathrm{g})\end{array}$ & $\begin{array}{c}\mathrm{Cr} \\
(\mu \mathrm{g} / \mathrm{g})\end{array}$ & $\begin{array}{c}\mathrm{Cu} \\
(\mu \mathrm{g} / \mathrm{g})\end{array}$ & $\begin{array}{c}\mathrm{Fe} \\
(\mu \mathrm{g} / \mathrm{g})\end{array}$ & $\begin{array}{c}\mathrm{Ni} \\
(\mu \mathrm{g} / \mathrm{g})\end{array}$ & $\begin{array}{c}\mathrm{Pb} \\
(\mu \mathrm{g} / \mathrm{g})\end{array}$ & $\begin{array}{c}\mathrm{Zn} \\
(\mu \mathrm{g} / \mathrm{g})\end{array}$ & $\begin{array}{c}{ }^{234} \mathrm{U} \\
(\mathrm{pCi} / \mathrm{g})\end{array}$ & $\begin{array}{c}{ }^{235} \mathrm{U} \\
(\mathrm{pCi} / \mathrm{g})\end{array}$ & $\begin{array}{c}{ }^{238} \mathrm{U} \\
(\mathrm{pCi} / \mathrm{g})\end{array}$ \\
\hline \multicolumn{12}{|c|}{ Indicator } \\
\hline 1 & 0.72 & $a$ & 0.05 & 0.92 & 300 & $a$ & $a$ & 33 & 0.17 & $a$ & $a$ \\
\hline 2 & 5.80 & 0.15 & 0.13 & 61.00 & 68 & 0.23 & $0.60^{b}$ & 30 & 0.19 & $a$ & a \\
\hline 3 & $a$ & 0.36 & 0.13 & 34.00 & 75 & 0.18 & $0.56^{b}$ & 29 & 0.68 & $a$ & $a$ \\
\hline 4 & a & $a$ & 0.03 & 0.74 & 250 & 0.20 & 0.05 & 29 & 0.09 & $a$ & $a$ \\
\hline \multicolumn{12}{|c|}{ Background } \\
\hline 5 & $a$ & $a$ & 0.06 & 0.85 & 440 & $a$ & $a$ & 23 & 0.12 & $a$ & $a$ \\
\hline 6 & $a$ & 0.21 & 0.07 & 57.00 & 140 & $a$ & 0.04 & 37 & 1.08 & 0.30 & 0.22 \\
\hline 7 & 0.09 & $a$ & 0.08 & 0.80 & 330 & $a$ & 0.03 & 25 & 0.22 & $a$ & $a$ \\
\hline
\end{tabular}

"Not detected.

"Although these results could not be checked, they are questionable because of the information in footnote $a$ in Table 6.2 .

Analytical data on concentrations of PCBs and 27 metals were also evaluated. Because all PCB concentrations were below the reporting limits, no evaluation was made of potential PCB intake. Eight metals are listed in Tables 6.2 and 6.3 for muscle and liver tissue. These 8 were selected from the list of 27 metals because they are potentially dischargeable from PGDP and as such are listed on the Kentucky Pollutant Discharge Elimination System Permit. Detectable levels, significantly higher than background, were seen in the liver for aluminum, nickel, and lead and in muscle for lead. The presence of detectable aluminum and nickel resulted from improvements in analytical techniques rather than from increases in concentrations in the environment except for the deer No. 2 liver result for aluminum. Assessment of risk was not performed for aluminum because this level $(5.8 \mathrm{mg} / \mathrm{kg}$ or $\mu \mathrm{g} / \mathrm{g})$, using the ingestion rate and frequency in Sect. 2, Table 2.4, would result in a yearly intake of aluminum from this source equivalent to three doses of over-the-counter antacid liquid or tablets. The quantification limit for pre-1992 data was higher than the detectable results reported in 1992. The lead results are above previous quantification levels and indicate bioaccumulation from some source or sources in the area. When results of preliminary risk assessments from Oak Ridge National Laboratory (ORNL) showing potential health effects were received, PGDP became concerned and completed the following immediate actions, which did not confirm the originally reported levels. Reanalyses of the original two deer samples by ORNL confirmed the presence of lead, but subsequent analyses on unused meat and bone from both deer retrieved from the hunters by WKWMA and state wildlife personnel and analyzed by ORNL and a university laboratory used by the state did not confirm the presence of lead. The results of all analyses have been reported to the Department of Energy (DOE) and through DOE to the state. PGDP participated in a meeting with DOE, state wildlife personnel, and the Army Corps of Engineers to determine if any future actions were required to protect public health. Although it was decided that no immediate actions were required, PGDP will also participate in future studies to confirm the negative lead results. The Corps of Engineers is responsible for evaluating the Kentucky Ordnance Works site, which originally occupied the site of WKWMA and PGDP, for potential hazards and inclusion to the National Priority List for cleanup.

\subsection{Vegetation}

Vegetation (grass) samples are collected at 18 locations every 3 months. The samples are returned

\section{6-6 Biological Monitoring}




\section{Environmental Report-Paducah, Part 1}

to the laboratory, air dried, and analyzed for fluorides. The primary objective of vegetation sampling is to determine the total fluorides in foliage for comparison with the fluoride-in-foliage section of the Kentucky air pollution control regulations.

Figure 6.2 shows the locations of the grass-sampling points. These locations represent the perimeter fence, property boundary, and $1.6-$ and $8-\mathrm{km}$ (1- and 5-mile) distances as related to the primary emission point. Table 6.4 summarizes the analyses.

Samples collected outside the fenced area are compared with the Kentucky Ambient Air Quality Standard of $60 \mu \mathrm{g} / \mathrm{g}$ for a 2 -month average. All samples were well below the $60-\mu \mathrm{g} / \mathrm{g}$ standard. Samples taken outside the fenced area range from less than 5.2 to $9.3 \%$ of the standard.

Table 6.4. PGDP fluoride in grass for 1992 (dry weight)

Growing season is April through September

\begin{tabular}{lccccccc}
\hline Point & $\begin{array}{c}\text { Number of } \\
\text { samples }\end{array}$ & $\begin{array}{c}\text { Min } \\
(\mu \mathrm{g} / \mathrm{g})\end{array}$ & $\begin{array}{c}\text { Max } \\
(\mu \mathrm{g} / \mathrm{g})\end{array}$ & $\begin{array}{c}\text { Annual av } \\
(\mu \mathrm{g} / \mathrm{g})\end{array}$ & $\begin{array}{c}\text { Av during } \\
\text { growing season } \\
(\mu \mathrm{g} / \mathrm{g})\end{array}$ & $\begin{array}{c}\mathrm{Std}^{b} \\
(\mu \mathrm{g} / \mathrm{g})\end{array}$ & $\%$ Std \\
\hline $\mathrm{G} 1$ & 4 & 5.8 & 15.0 & 10.8 & 7.6 & $c$ & $c$ \\
$\mathrm{G} 2$ & 4 & 7.5 & 12.0 & 8.8 & 7.6 & $c$ & $c$ \\
$\mathrm{G} 3$ & 4 & $<3.0^{d}$ & 6.0 & $<4.6$ & $<3.9$ & $c$ & $c$ \\
$\mathrm{G} 4$ & 4 & $<3.0$ & 5.2 & $<4.1$ & $<3.1$ & $c$ & $c$ \\
$\mathrm{G} 5$ & 4 & $<3.0$ & 8.1 & $<5.7$ & $<5.6$ & 60 & $<9.3$ \\
$\mathrm{G} 6$ & 4 & 4.6 & 5.1 & 4.8 & 4.9 & 60 & $<8.2$ \\
G7 & 4 & $<3.0$ & 5.8 & $<4.0$ & $<4.4$ & 60 & $<7.3$ \\
$\mathrm{G} 8$ & 4 & $<3.0$ & 8.1 & $<4.8$ & $<5.6$ & 60 & $<9.3$ \\
$G 9$ & 4 & $<3.0$ & 5.2 & $<4.5$ & $<3.9$ & 60 & $<6.5$ \\
G10 & 4 & $<3.0$ & 7.2 & $<5.0$ & $<4.0$ & 60 & $<6.7$ \\
G11 & 4 & $<3.0$ & 4.2 & $<3.3$ & $<3.1$ & 60 & $<5.2$ \\
G12 & 4 & $<3.0$ & 9.0 & $<5.3$ & $<3.7$ & 60 & $<6.2$ \\
G13 & 4 & $<3.0$ & 3.9 & $<3.5$ & $<3.6$ & 60 & $<6.0$ \\
G14 & 4 & $<3.0$ & 3.9 & $<3.3$ & $<3.2$ & 60 & $<5.3$ \\
G15 & 4 & $<3.0$ & 14.6 & $<6.8$ & $<3.8$ & 60 & $<6.3$ \\
G16 & 4 & $<3.0$ & 5.4 & $<3.9$ & $<4.2$ & 60 & $<7.0$ \\
G17 & 4 & $<3.0$ & 5.0 & $<4.3$ & $<4.0$ & 60 & $<6.7$ \\
G18 & 4 & $<3.0$ & 8.0 & $<5.2$ & $<3.7$ & 60 & $<6.2$ \\
\hline
\end{tabular}

${ }^{a}$ See Fig. 6.2.

${ }^{b}$ Kentucky Ambient Air Quality Standards (401 KAR 53:010): Fluoride measured on forage is not to exceed an average of $40 \mu \mathrm{g} / \mathrm{g}$ over the growing season, $60 \mu \mathrm{g} / \mathrm{g}$ for a 2 -month average, or $80 \mu \mathrm{g} / \mathrm{g}$ for a 1 -month average (dry weight).

${ }^{c}$ Sampling locations are on government property inside the plant security fence.

${ }^{d}$ Lower limit of detection is $3 \mu \mathrm{g} \mathrm{F} / \mathrm{g}$. 


\section{Environmental Report-Paducah, Part 1}

ORNL-DWG 87M-6712ER

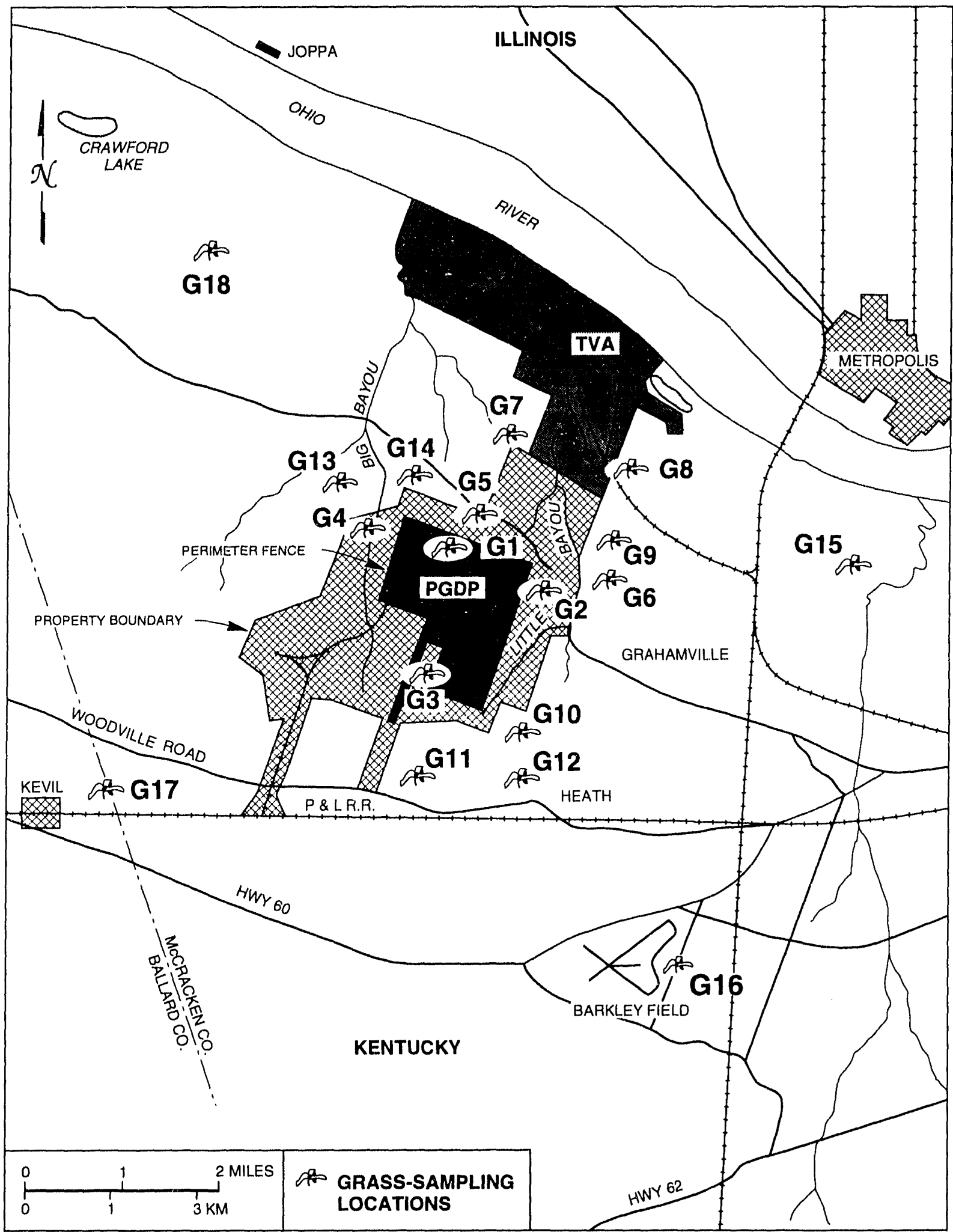

Fig. 6.2. Grass-sampling locations. 


\section{Soil and Sediment Monitoring}

7.1 Soil $\ldots \ldots \ldots \ldots \ldots \ldots \ldots \ldots \ldots \ldots \ldots \ldots$

7.2 Stream Sediment $\ldots \ldots \ldots \ldots \ldots \ldots \ldots \ldots$ 7-3

7.3 References . . . . . . . . . . . . . . 7-7 
1992 Environmental Report-Paducah, Part 1

\section{Soil and Sediment Monitoring}

Soil and sediment data are collected at Paducah Gaseous Diffusion Plant (PGDP) to show the accumulation of any airborne or waterborne pollutants. Although sampling procedures are designed to minimize the well-known variability found in soils and sediments, the significance of individual units of data is small. If trends exist, data collected over a period of years may reveal them.

\subsection{Soil}

Soil samples are taken annually at 10 locations-north, south, east, and west at the property boundary and at distances of $8 \mathrm{~km}$ ( 5 miles) beyond the property boundary (Fig. 7.1). Remote (background) samples are taken at two locations 13 to $15 \mathrm{~km}$ (8.08 to 9.32 miles) from PGDP. Each sampling site was selected because the soil appeared or was known to have been undisturbed for a number of years. Two $1-\mathrm{m}^{2}\left(11-\mathrm{ft}^{2}\right)$ areas are measured out, $3 \mathrm{~m}(10 \mathrm{ft})$ apart. The vegetation to a height of 10 to $20 \mathrm{~mm}$ ( 0.4 to 0.8 in.) above the soil is removed. Soil samples to a depth of $5 \mathrm{~cm}$ ( $2 \mathrm{in}$.) are taken from the center and from each corner of the $1-\mathrm{m}^{2}$ area. The plugs of soil are composited into a labeled plastic bag. Table 7.1 lists sampling locations and parameters for analysis.

Table 7.2 lists the concentrations of uranium in soil samples from 1987 through 1992. Although other analyses are performed and results summarized, only uranium is presented in a tabular form because it is considered to be the element of concern in PGDP air emissions. The 1992 uranium concentrations show no apparent differences from past data and are within the range for concentration and assay expected for naturally occurring uranium. The range of soil analyses during 1992 was from a low of $1.5 \mu \mathrm{g} / \mathrm{g}$ at the north boundary to a high of $4.0 \mu \mathrm{g} / \mathrm{g}$ at the site $8 \mathrm{~km}$ north of the plant. There were no significant differences, at the $95 \%$ confidence level, between upwind (S3, S4, S7, S8, S9, S10) and downwind (S1, S2, S5, S6) locations. Radionuclide analyses were also performed for ${ }^{99} \mathrm{Tc},{ }^{230} \mathrm{Th},{ }^{237} \mathrm{~Np}$, and ${ }^{239} \mathrm{Pu}$. No detectable concentrations of these radionuclides were seen at any of the sampling sites.

In addition to radiochemical analyses, each soil sample was analyzed for 35 metals and polychlorinated biphenyl (PCB). Detectable concentrations of $\mathrm{PCB}$ were again found in two property boundary samples, S3 and S4.

Concentrations above reference locations of $\mathrm{Ag}, \mathrm{Be}$, $\mathrm{Cr}, \mathrm{Fe}, \mathrm{K}, \mathrm{Na}$, and $\mathrm{P}$ were detected in the $\mathrm{S} 5$ sample. Concentrations of $\mathrm{Na}, \mathrm{Pb}$, and $\mathrm{Th}$ were detected in the S5 sample. Concentrations of silver were elevated in the S8 sample. No other apparent differences were noted between samples from at or near the property boundary and the remote locations.

\subsection{Stream Sediment}

The stream bottom is a very important constituent of the aquatic environment. If a pollutant is a suspended solid or attached to suspended sediment, it can settle to the bottom (thus creating the need for sediment sampling), it can be filtered by certain organisms, or it can become attached to plant surfaces. Pollutants in solution can adsorb on suspended organic and inorganic solids or be assimilated by plants and animals. The suspended solids, dead biota, or excreta settle to the bottom and become part of the organic substrate that supports the bottom-dwelling community of organisms. Figure 7.2 shows possible exposure routes of trace metals 
ORNL-DWG 87M-6712BR4

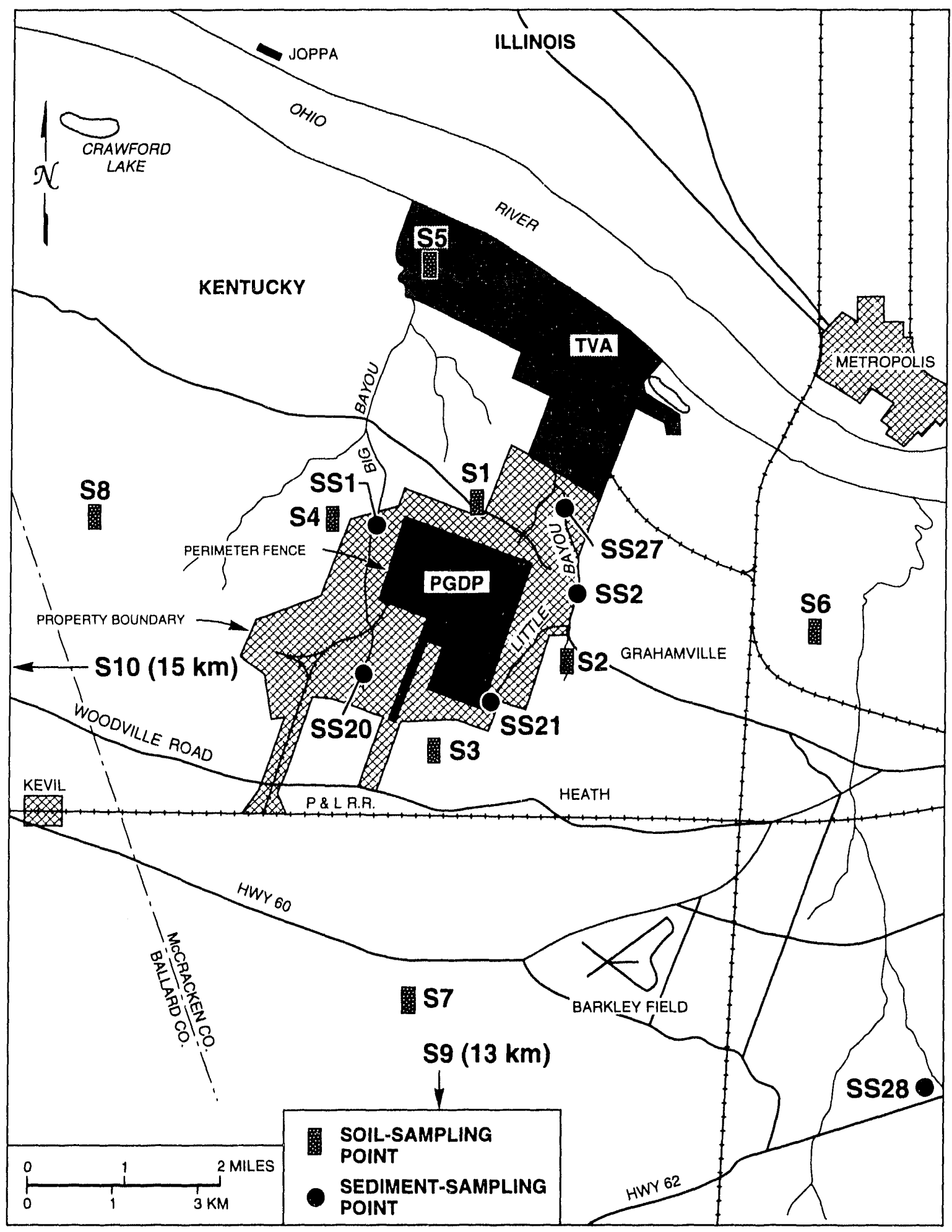

Fig. 7.1. PGDP soil- and sediment-sampling locations. 


\section{Environmental Report-Paducah, Part 1}

Table 7.1. Summary of collection and analysis frequencies of soil and sediment samples in 1992

\begin{tabular}{|c|c|c|c|c|}
\hline Station & Parameter & $\begin{array}{l}\text { Collection } \\
\text { frequency }\end{array}$ & Sample type & $\begin{array}{l}\text { Analysis } \\
\text { frequency }\end{array}$ \\
\hline \multicolumn{5}{|c|}{ Soil ${ }^{a}$} \\
\hline $\begin{array}{l}\mathrm{S} 1, \mathrm{~S} 2, \mathrm{~S} 3, \mathrm{~S} 4, \mathrm{~S} 5 \\
\mathrm{~S} 6, \mathrm{~S} 7, \mathrm{~S} 8, \mathrm{~S} 9 \\
\mathrm{~S} 10\end{array}$ & $\begin{array}{l}\mathrm{U}^{239}{ }^{23 \mathrm{Pu}},{ }^{237} \mathrm{~Np},{ }^{137} \mathrm{Cs},{ }^{235} \mathrm{U},{ }^{230} \mathrm{Th}, \\
{ }^{99} \mathrm{Tc},{ }^{40} \mathrm{~K}, \mathrm{PCB},{ }^{b} \mathrm{Ag}, \mathrm{Al}, \mathrm{Ba}, \\
\mathrm{Bc}, \mathrm{Bi}, \mathrm{Ca}, \mathrm{Cd}, \mathrm{Co}, \mathrm{Cr}, \mathrm{Cu}, \mathrm{Fc} \\
\mathrm{K}, \mathrm{Li}, \mathrm{Mg}, \mathrm{Mn}, \mathrm{Mo}, \mathrm{Na}, \mathrm{Nb}, \mathrm{Ni}, \\
\mathrm{P}, \mathrm{Pb}, \mathrm{Ru}, \mathrm{Sb}, \mathrm{Si}, \mathrm{Sn}, \mathrm{Sr}, \mathrm{Ta} \\
\text { Th, Ti, Tl, V, W, Zn, } \mathrm{Zr}, \mathrm{As}\end{array}$ & Annually & Grab & Annually \\
\hline \multicolumn{5}{|c|}{ Sediment ${ }^{2}$} \\
\hline $\begin{array}{l}\text { SS1, SS2, SS20, SS21, } \\
\text { SS27, SS28 }\end{array}$ & $\begin{array}{c}{ }^{137} \mathrm{Cs},{ }^{40} \mathrm{~K},{ }^{237} \mathrm{~Np},{ }^{239} \mathrm{Pu},{ }^{99} \mathrm{Tc},{ }^{230} \mathrm{Th}, \\
\mathrm{U},{ }^{235} \mathrm{U}, \mathrm{PCB}, \mathrm{Ag}, \mathrm{Al}, \mathrm{Ba}, \mathrm{Bc}, \mathrm{Bi}, \\
\mathrm{Cd}, \mathrm{Ca}, \mathrm{Co}, \mathrm{Cr}, \mathrm{Cu}, \mathrm{Fc}, \mathrm{K}, \mathrm{I}, \mathrm{Li}, \\
\mathrm{Mg}, \mathrm{Mn}, \mathrm{Mo}, \mathrm{Na}, \mathrm{Nb}, \mathrm{Ni}, \mathrm{P}, \mathrm{Pb}, \\
\mathrm{Ru}, \mathrm{Sb}, \mathrm{Si}, \mathrm{Sn}, \mathrm{Sr}, \mathrm{Ta}, \mathrm{Th}, \mathrm{Ti}, \\
\mathrm{Tl}, \mathrm{V}, \mathrm{W}, \mathrm{Zn}, \mathrm{Zr}, \mathrm{As}\end{array}$ & Annually & Grab & Annually \\
\hline
\end{tabular}

"See Fig. 7.1.

${ }^{h}$ Polychlorinated biphenyls.

Table 7.2. Concentrations of uranium in soil at PGDP, $1987-1992^{a}$ $(\mu \mathrm{g} / \mathrm{g})$

\begin{tabular}{lllllll}
\hline Location & 1987 & 1988 & 1989 & 1990 & 1991 & 1992 \\
\hline
\end{tabular}

Property boundary

$\begin{array}{lllllll}\text { S1 (north) } & 4.8 & 4.9 & 2.2 & 5.0 & 4.3 & 1.5 \\ \text { S2 (cast) } & 3.4 & 4.6 & 2.4 & 3.9 & 4.1 & 3.5 \\ \text { S3 (south) } & 5.5 & 4.3 & 5.6 & 7.1 & 4.3 & 3.4 \\ \text { S4 (west) } & 2.5 & 2.2 & 1.4 & 3.3 & 2.9 & 2.6\end{array}$

$8 \mathrm{~km}$ from plant

$\begin{array}{lllllll}\text { S. } \text { (norlh) } & 3.9 & 4.2 & 2.2 & 4.3 & 4.2 & 4.0 \\ \text { S6 (cast) } & 2.6 & 2.3 & 1.1 & 2.5 & 3.0 & 2.5 \\ \text { S7 (south) } & 2.7 & 2.5 & 1.2 & 2.8 & 2.9 & 2.6 \\ \text { S8 (west) } & 2.8 & 3.4 & 1.2 & 2.9 & 3.3 & 3.1\end{array}$

$131015 \mathrm{~km}$ from plant

\begin{tabular}{lllllll} 
S9 (south) & 2.4 & 2.5 & 0.8 & 2.2 & 2.8 & 2.0 \\
Sil(west) & 2.9 & 2.1 & 0.7 & 2.7 & 2.9 & 2.4 \\
\hline
\end{tabular}

${ }^{a}$ See Fig. 7.1. 


\section{Environmental Report-Paducah, Part 1}

ORNL-DWG 86M-9977R2

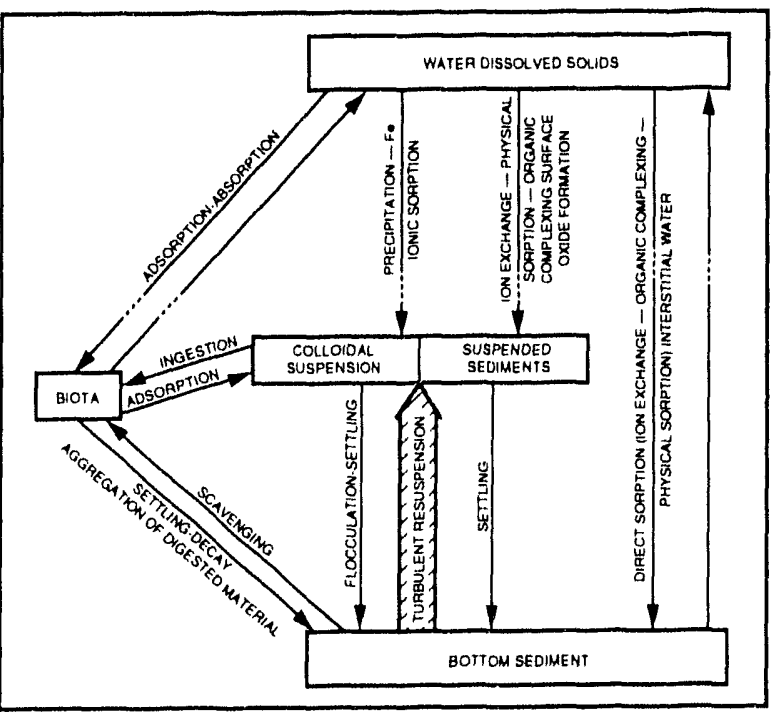

Fig. 7.2. Routes of trace metals in an aquatic ecosystem. Source: Jinks and Eisenbud 1972.

(including uranium) in an aquatic ecosystem (Jinks and Eisenbud 1972).

Sediments play a significant role in aquatic ecology by serving as a repository for radioactive or chemical substances that pass via the bottom-feeding biota to the higher trophic levels. Soluble pollutants introduced into a body of water reach the bottom sediment primarily by adsorption on suspended solids that later deposit on the bottom. The deposited remains of biota that have absorbed pollutants may also be an important source of radioactive and chemical pollutants that enter the food chain.

Sediment samples were taken from six locations. Figure 7.1 shows the location of each sampling point. At each location a clean sampling scoop is used to obtain a sample from the bottom of the stream or lagoon, taking as few rocks as possible.

Approximately $2 \mathrm{~kg}(4.5 \mathrm{lb})$ of sediment is placed in a new plastic bag. The samples are dried and delivered to the analytical laboratory. Table 7.1 lists a summary of the frequencies of collection and analyses.

Table 7.3 shows the $1992 \mathrm{PCB}$ and radionuclide data. The locations have been changed from 1991 and past reports because of the initiation of portions of the PGDP Environmental Monitoring Plan. None of the locations contained levels of ${ }^{99} \mathrm{Tc},{ }^{237} \mathrm{~Np},{ }^{239} \mathrm{Pu}$, or ${ }^{2310} \mathrm{~T} \mathrm{~T}$ above analytical lower reporting limits. Levels of uranium at SS2, downstream Little Bayou Creek, are 36 times higher than at SS21, upstream Little

Table 7.3. 1992 PGDP sediment data

\begin{tabular}{lccccccc}
\hline Location $^{a}$ & $\begin{array}{c}\text { Technetium-99 } \\
(\mathrm{pCi} / \mathrm{g})\end{array}$ & $\begin{array}{c}\text { Neptunium-237 } \\
(\mathrm{pCi} / \mathrm{g})\end{array}$ & $\begin{array}{c}\text { Plutonium-239 } \\
(\mathrm{pCi} / \mathrm{g})\end{array}$ & $\begin{array}{c}\text { Thorium-230 } \\
(\mathrm{pCi} / \mathrm{g})\end{array}$ & $\begin{array}{c}\text { Uranium-235 } \\
(\mathrm{wt} \%)\end{array}$ & $\begin{array}{c}\text { Uranium } \\
(\mu \mathrm{g} / \mathrm{g})\end{array}$ & $\begin{array}{c}\mathrm{PCB}^{b} \\
(\mu \mathrm{g} / \mathrm{g})\end{array}$ \\
\hline $\begin{array}{l}\mathrm{SS} \text { 1 downstream } \\
\text { Big Bayou }\end{array}$ & $<17$ & $<0.5$ & $<0.5$ & $<3$ & 0.53 & 4.6 & $<0.1$ \\
$\begin{array}{l}\text { SS2 downstream } \\
\text { Little Bayou }\end{array}$ & $<17$ & $<0.5$ & $<0.5$ & $<3$ & 0.20 & 107.0 & 0.7 \\
$\begin{array}{l}\text { SS20 upstream } \\
\text { Big Bayou (L-1) }\end{array}$ & $<17$ & $<0.5$ & $<0.5$ & $<3$ & 0.70 & 1.3 & $<0.1$ \\
$\begin{array}{l}\text { SS21 upstream } \\
\text { Little Bayou }\end{array}$ & $<17$ & $<0.5$ & $<0.5$ & $<3$ & 0.61 & 2.8 & $<0.1$ \\
$\begin{array}{l}\text { SS27 below } \\
\text { north/south } \\
\text { diversion ditch } \\
\text { in Little Bayou }\end{array}$ & $<17$ & $<0.5$ & $<0.5$ & $<3$ & 0.29 & 11.6 & $<0.1$ \\
$\begin{array}{l}\text { SS28 Massac } \\
\text { Creek at Hwy 62 }\end{array}$ & $<17$ & $<0.5$ & $<0.5$ & $<3$ & 0.63 & 0.9 & $<0.1$ \\
\hline
\end{tabular}

aSee Fig. 7.1.

'Polychlorinated biphenyl. 


\section{Environmental Report-Paducah, Part 1}

Bayou Creek. Downstream Big Bayou Creek, SSI, contained 3.5 times the concentration of uranium in the sediment at SS20, upstream Big Bayou Creek. These elevated levels can be attributed to plant operations because the assay is lower than normal uranium. The effects of these concentrations are discussed in Part 1, Sect. 2.4, and in Table 2.1. PCB was detected at SS2, downstream Little Bayou Creek. This result confirms past studies in which both $\mathrm{PCB}$ and uranium had been detected and resulted in the posting of Little Bayou Creek to make the public aware that prolonged exposure could result in a dose above background and to warn of $P C B$ contamination. Big and Little Bayou creeks and the Kent:ucky Pollutant Discharge Elimination System-permitted discharge ditches have been investigated during administrative consent order (ACO) activities.
Remedial alternatives have been drafted (Science Applications International Corporation 1991) and are being reviewed by the U.S. Environmental Protection Agency and the Kentucky Department for Environmental Protection. When finalized, the document will become the Record of Decision under the Comprehensive Response, Compensation, and Liability Act in response to the ACO.

\subsection{References}

Jinks, S. M., and M. Eisenbud. 1972. "Concentration Factors in the Aquatic Environment," Radia. Data Rep. 13, 243.

Science Applications International Corporation (SAIC). December 1991. Summary of Phase II (Stage C) Activities, draft, Oak Ridge, Tenn. 


\section{Unusual Occurrences and Special Studies}

8.1 Unusual Occurrences $\ldots \ldots \ldots \ldots \ldots$ 8-3

8.1.1 PGDP Spill Report . . . . . . . . . . . . . . 8-3

8.1.2 Radionuclide Releases . . . . . . . . . 8-6

8.2 Special Studies $\ldots \ldots \ldots \ldots \ldots \ldots$. $6.6 \ldots$

8.2.1 Special Studies-Hydrogeological Services Section (HSS) . . . . . . . . 8-6

8.2.2 Environmental Advisory Committee ... 8- 8-8

8.2.3 Neighborhood Council ... . . . . . . 8. 8-9

8.2.4 Waste Minimization Program ...... 8 $8-9$

8.2.5 PCB Source Identification Project ... . 8-11

8.2.6 C-310 Purge and Product Building

Stack Effluent Sampling

Project

8.2.7 Clean Air Act Amendments of

1990 Activities ............. 8-12

8.3 References ................... 8-13 


\section{Unusual Occurrences and Special Studies}

Paducah Gaseous Diffusion Plant (PGDP) had a total of 573 spills or releases of various types of materials during CY 1992. A record of each incident is kept by the PGDP shift superintendent's office. All generated cleanup debris is handled in accordance with PGDP standard operating procedures. The PGDP shift superintendent's office reports all spills or releases to various levels of PGDP management and to federal and state officials as is appropriate.

Occurrences are categorized and notifications to the Department of Energy (DOE) are made in accordance with Standard Practice Procedure, P-GP-43, Occurrence Reporting System.

Many of the spills during CY 1992 (a total of 311 incidents) were from leaking ventilation duct gaskets containing polychlorinated biphenyl (PCB) oils (Fig. 8.1). All gasket leaks were inside buildings. Troughs were installed beneath leaking gaskets immediately upon discovery.

Highlights of significant incidents are given in Sect. 8.1,

\subsection{Unusual Occurrences}

\subsubsection{PGDP Spill Report}

\subsubsection{Release of Sodium Bicarbonate: C-611 Water Treatment Facility}

On January 7, 1992, during routine outfall sampling, the $\mathrm{pH}$ at Kentucky Pollutant Discharge Elimination System (KPDES) outfall 006 was determined to be 10.7, which exceeded the permit limit of 10.4. Approximately 20 dead or dying fish were observed in the sludge lagoon upstream of the outfall. Other fish were showing signs of stress. The increase in lagoon $\mathrm{pH}$ was caused by an overflow of dilute soda ash from its mixing tank, which was caused by feed pump failure. The dilute soda ash entered the floor trench, which drained to the C-611-V sludge lagoon. The release was immediately reported to DOE and the Kentucky Department for Environmental Protection (KDEP). The lagoon effluent to outfall 006 was restricted by use of a Vetter plug and was later treated with sulfuric acid to lower the $\mathrm{pH}$. An undetermined number of fish died because of the incident. A full investigation of the occurrence was conducted by PGDP personnel with guidance from individuals at Oak Ridge National Laboratory.

\subsubsection{Release of Leachate: C-746-K Inactive Landfill}

On January 30,1992 , during an inspection of the closed sanitary landfill, leachate was found entering a drainage ditch and contributary of Big Bayou Creek. The material had settled in the ditch and in low places in the creek. Booms were placed in the creek, and a temporary sandbag dam was constructed in the ditch near the source of discharge. The KDEP was notified of the discovery. Sampling activities were initiated to determine the hazards of the substance. Since the landfill has been inactive since 1982, the situation has been turned over to the Environmental Restoration Department for remediation.

\subsubsection{Chromate Water Release: C-633-5 South Blending Cooling Tower}

On February 5, 1992, an employee reported a spill in progress at the C-633-5 cooling tower. Approximately $25,000 \mathrm{gal}$ of recirculating cooling water (RCW) containing $8-9 \mathrm{ppm}$ of hexavalent chromium $\left(\mathrm{Cr}^{6+}\right)$ spilled as a result of a 4 -in. fiberglass distribution lateral pipe becoming 


\section{Environmental Report-Paducah, Part 1}

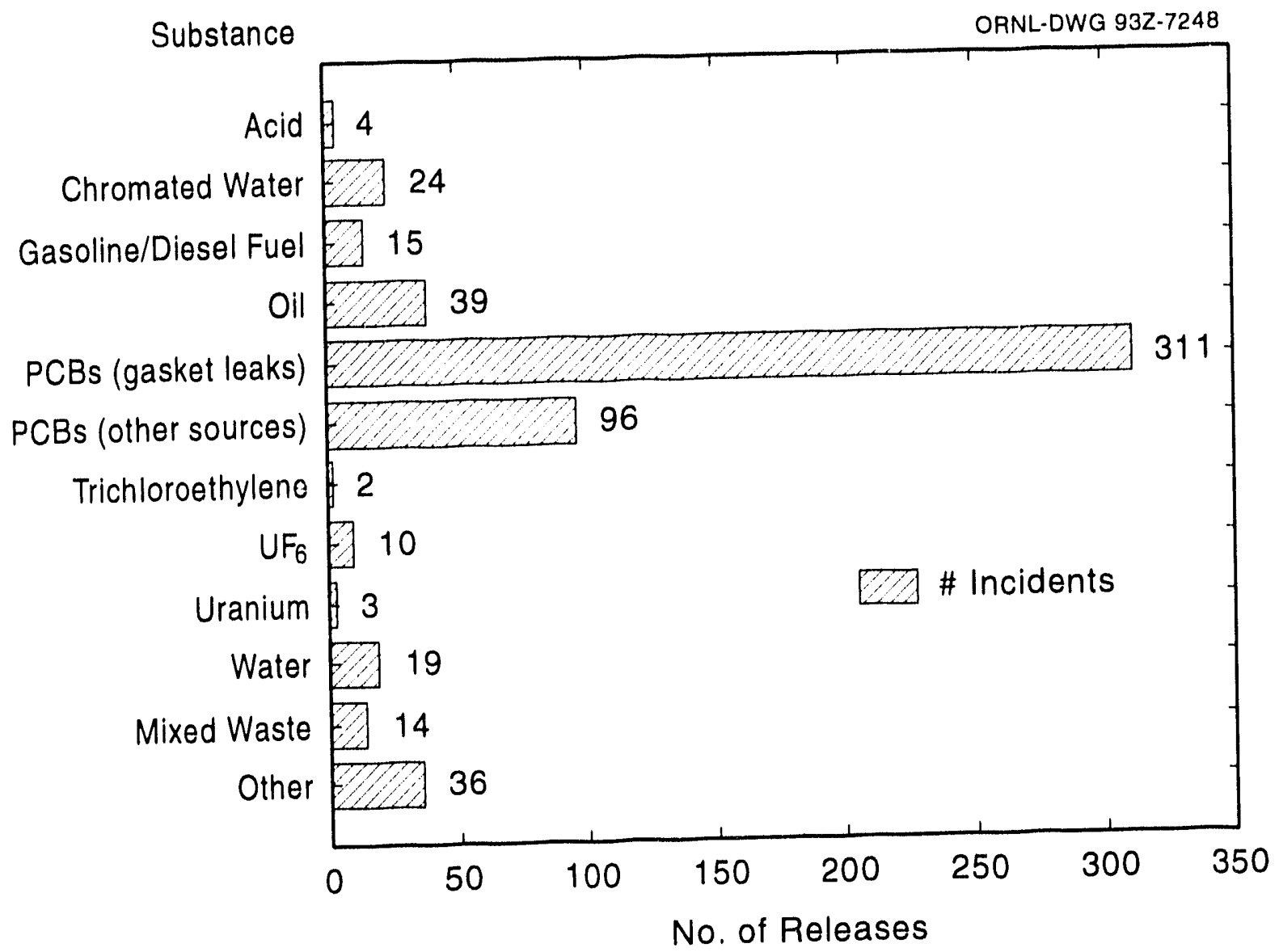

Fig. 8.1. Spills or releases at PGDP in 1992.

disconnected from the main 20-in. header. This allowed cooling water to damage the tower wall and splash out onto the surrounding ground. Response personnel arrived at the scene and valved out the supply riser to stop further spillage. The material was contained at several key locations; the nearby storm sewer was covered with plastic and sandbags; the downstream flow weir was damned with plywood and sandbags; a Vetter's plug was placed in a downstream drainage pipe; and beavers had constructed a dam near the influent of Little Bayou Creek. The amount of chromium released was calculated to be approximately $1.8 \mathrm{lb}$, which is less than the reportable quantity. Notification was made to the Kentucky Division of Water (KDOW) and to the KDEP. The majority of the spill material was recovered by Chemical Operations personnel by use of the King Vac truck.

\subsubsection{Elevated Opacity: C-600 Steam Plant}

On February 7, 1992, the No. 2 north coal mill was removed from service because of obstruction in the classifier section. During the mill outage, firing of fuel oil resulted in elevated stack opacity. The duration of the mill outage was approximately $45 \mathrm{~min}$. A verage opacity readings were noted as 19\% using U.S. Environmental Protection Agency (EPA) method 9. The Paducah Office of the Kentucky Division for Air Quality was notified of emission.

\subsubsection{Uranium Hexafluoride $\left(\mathrm{UF}_{6}\right)$ Leak: Cylinder Valve}

On April 2, 1992, while moving a full $\mathrm{UF}_{6}$ product cylinder to the $\mathrm{C}-310$ purge and product 
building cylinder yard, an operator detected an odor that he suspected was hydrogen fluoride (HF). The operator investigated and found a small leak of $\mathrm{UF}_{6} / \mathrm{HF}$ smoke coming from around the valve cap on the cylinder (PK 1373). The cylinder had been filled on March 31, 1992, and contained $U_{6}$ at an assay of $1.90 \%{ }^{235} \mathrm{U}$. After notifying supervision, operators wearing anti-contamination clothing and respirators stopped the leak by tightening the cylinder valve packing nut and the valve cap and torquing the valve seat. Health physics personnel monitored for contamination, and precautionary urine samples were submitted by those involved.

\subsubsection{Chromate Water Release: C-331 Process Building}

On August 7, 1992, a leak was discovered on the B-loop RCW return header at the northwest corner of the $\mathrm{C}-331$ process building. The source of the leak was determined to be in an underground vault. The RCW had filled the vault and was overflowing onto the surface above. The leak was isolated and contained to the surrounding area by use of sandbags. No water entered the plant drainage system. Upon recovery of the $\mathrm{RCW}$ from the vault, it was determined that a 1 -in. pipe supporting an air relief valve had deteriorated and failed. The failure resulted in the spilling of approximately $200 \mathrm{gal}$ of $8.4 \mathrm{ppm}$ $\mathrm{Cr}^{6+}$ water. Calculations based on this concentration indicated the amount of $\mathrm{Cr}^{6+}$ to be $0.014 \mathrm{Jb}$, which is less than the reportable quantity. Notifications were made to DOE and the KDEP.

\subsubsection{Diesel Fuel Release: C-751 Fuel Dispensing Facility}

On August 8, 1992, fuel was observed coming from the plant fuel truck. Investigations revealed that the fill nozzle to the diesel fuel tank had been stowed in the open position. The valve between the diesel tank and the hose was closed. Approximately $1 \mathrm{gal}$ of diesel fuel spilled to the ground and was entering the plant drainage system to KPDES outfall 009. The drain was immediately plugged, and oil absorbent booms and pads were placed in the outfall, upstream of the oil control dam. Migration of the oil sheen was controlled at this point. The KDEP was notified of the occurrence.

\subsubsection{Chilled Water Release: C-600 Steam Plant}

On August 31, 1992, approximately 2000 gal of water was lost from the plant chilled water system during a 14-h period. The release was caused when a coil drain valve on the plant chill water unit was inadvertently opened. The water from the unit flowed to a drain and to KPDES outfall 008. The chill water system contained $280 \mathrm{ppm}$ sodium molybdate and $0.2 \mathrm{ppm}$ chromate. As soon as the open valve was identified, it was closed and "caution tagged." Sampling activities were initiated in the plant drainage system and at outfall 008 . Approximately $4.7 \mathrm{lb}$ of sodium molybdate, which is not listed or allowed to be discharged by the KPDES permit, was released to the outfall. The KDEP was notified of the occurrence.

\subsubsection{Spill of PCB-Contaminated Fluid: C-722 Acid Neutralization Pit}

On March 17, 1992, during pumping and cleaning operations at the C-722 acid neutralization pit, some of the contents spilled into the diked area and onto transfer equipment and surrounding gravel. Approximately $80 z$ reached the gravel area. Sample results indicated the material contained greater than $50 \mathrm{ppm}$ PCBs resulting in an improper disposal violation of 40 CFR 761.135 (Title 40, Code of Federal Regulations, Part 761.135). The gravel was cleaned up, and the occurrence was reported to the KDEP.

\subsubsection{Failure of PCB Static Capacitors: C-537 and C-533 Switchyards}

On May 8, 1992, PCB-filled static capacitor 33 failed in the C-537 switchyard, bank 7H on C-phase. The bottom of the capacitor ruptured, allowing approximately 3 to 4 gal of PCB fluid to spill onto adjacent capacitors, the diked area beneath the capacitor bank, and on nearby rock and concrete decking. On May 9, 1992, during a routine inspection, capacitor 45B in the C-533 switchyard capacitor bank $3 \mathrm{E}$ was found to be leaking. Approximately 1 quart ( 3 to $4 \mathrm{lb}$ ) had leaked into the diked area beneath the capacitor bank and onto adjacent capacitors. The capacitor banks were 


\section{Environmental Report-Paducah, Part 1}

de-energized for cleanup and repairs. EPA Region 4 and the National Response Center were notified of each occurrence.

\subsubsection{PCB Oil Spill: C-537 Switchyard}

On July 21, 1992, during operations to drain oil from an electrical insulating bushing removed from C-537 switchyard transformer No. 69, approximately 2 gal of PCB oil spilled. The oil spilled when the drain plug was being removed and internal pressure in the bushing caused the oil to spray out. The oil sprayed on two employees' skin and clothing, an adjacent equipment cart, and an area of soil approximately $10 \mathrm{ft}$ in diam. The employees were instructed to shower and bag their clothing. The area was flagged off for cleanup activities. Laboratory analysis of the oil indicated it contained 41 ppm PCB.

\subsubsection{Radionuclide Releases}

In 1992, 13 incident reports were generated as a result of the release of radioactive materials. Ten of the incidents consisted of the release of $U_{6}$ puffs resulting from connecting and disconnecting of cylinder pigtails or leakage from cylinder valves. All puffs except one were controlled by high-efficiency particulate air filter systems. The released amounts were often so minute that they were undetectable. The remaining three occurrences consisted of: (1) the discovery of a small deposit of uranium oxide on the outside of a purge and evacuation pump seal, (2) a slight amount of uranium sludge that leaked to the outside of two storage drums and a wooden pallet, and (3) less than 1 oz of uranium-bearing compound on the exterior surface of seal piping. None of the remaining three incidents were categorized as immediately reportable to the KDEP or other outside agenries.

\subsection{Special Studies}

\subsubsection{Special Studies-Hydrogeological Services Section (HSS)}

Several special studies were conducted under the direction of the HSS during 1992. These studies werdesigned to resolve some data deficiencies and uncertainties in site hydrogeolog $y$. The studies have also defined areas where additional focused investigations should be considered.

\subsubsection{Groundwater Flow Modeling}

During 1992, GeoTrans, Incorporated, was retained to perform numerical modeling of the groundwater flow system beneath PGDP. One of the primary objectives of the modeling was to update a regional three-dimensional groundwater flow model developed by GeoTrans in 1990 using the additional field data obtained in the two years since that model was developed. The field data consist primarily of soil-boring information, monthly water level measurements from monitoring wells, slug tests, and aquifer pump tests. The updated model would be used to provide an increased understanding of groundwater flow pathways and rates of contamination migration at the site. A second objective of the groundwater modeling study was to use the updated model to evaluate a proposed hydraulic containment action for a contaminant plume that extends off-site northwest of the plant. The model would be designed to optimize the selection of the number and location of the recovery wells and to calculate the appropriate pump rates for each well.

A three-phased approach was used to perform the groundwater modeling study. Phase I, completed in March 1992, consisted of a review of the current conceptual models of groundwater flow at the site and a presentation of the new field data. Phase II, completed in August 1992, involved developing a revised three-dimensional groundwater flow model using the new field data. Calibration, particle tracking, and sensitivity analysis were also performed. Phase III evaluated the effectiveness of the proposed hydraulic containment plan using the Phase II calibrated model and a pumpage optimization module developed by GeoTrans. A final report (GeoTrans, Inc. 1992) summarizing the results of all three phases was issued in December 1992.

The first objective of the modeling project, to update the conceptual hydrogeologic model of PGDP, was met and resulted in the following revisions to the 1990 regional groundwater flow model:

- The 1990 model included a corisideration of preferential flow pathways, or paleochannels, in the regional gravel aquifer (RGA) and concluded that

\section{8-6 Unusual Occurrences and Special Studies}




\section{Environmental Report-Paducah, Part 1}

paleochannels do not play a significant role in transport migration. The presence of the hypothesized paleochannels in the RGA was not verified by the new field data, so they were removed entirely from consideration in the updated model.

- The 1990 model assumed hydraulic connection in the RGA across the erosional terrace located near the southern edge of the plant. The revised model does not allow any flow across the terrace face. This scenario provides a lower bound to the estimate of average hydraulic conductivity of the RGA.

- A small percentage of the water movement in the RGA was determined to be downward into the McNairy Formation. For the modeled area, mass balance calculations indicated that less than $4 \%$ of the total water in the RGA flows downward into the McNairy.

- Particle tracking was used to model the pathways and rates of movement of conservative solutes, excluding dispersion effects. It was concluded that a particle introduced to the water table on-site would take from 10 to 28 years to travel downward to the RGA. Once reaching the $\mathrm{RGA}$, the particle wovid move horizontally north-northeast to the Ohio River, reaching it within 25 to 58 years.

- Changes were made in the modeled hydraulic conductivity values for the Upper Continental Recharge System (UCRS) and RGA. In the UCRS, a zone of higher hydraulic conductivity was assigned to the alluvium than to the rest of the UCRS. A zone of reduced hydraulic conductivity in the RGA was assigned at the Ohio River to account for the steep hydraulic gradient observed there.

The approach used to evaluate the hydraulic containment plan for the Northwest Plume involved evaluating two scenarios, a narrow plume containment and a wide plume containment. For the narrow plume scenario, optimal containment, designed to contain a plume $600 \mathrm{ft}$ in width, was obtained with five wells positioned in a broad $U$-shaped configuration and pumping a total of $183 \mathrm{gpm}$. For the wide plume scenario, optimal containment for the $2400-\mathrm{ft}$-wide plume was achieved with 16 wells spaced $150 \mathrm{ft}$ apart in a similar $U$-shaped configuration and pumping a total of $464 \mathrm{gpm}$. A number of other configurations were also generated, and it was concluded that the number of wells could drop as low as nine for the wide-plume scenario without significantly increasing the total pumping rate. GeoTrans is involved in modeling a new scenario and will have the results of this study by March 1993.

The final modeling report (GeoTrans, Inc. 1992) includes a number of recommendations concerning the types of information needed to further characterize the site hydrogeology. The major recommendations are as follows:

- Further characterization of the degree of connection between the McNairy Formation and the RGA is needed to assess the potential for downward migration of contaminants. This need will be addressed in the Phase IV Groundwater Investigation planned for 1993.

- Additional information concerning the erosional terrace at the southern edge of the plant should be gathered. The investigation should focus on the amount of groundwater flow across the terrace face in the RGA and the UCRS.

- Reducing areas of uncertainty regarding recharge is critical. Additional information obtained from continued monitoring of Ohio River stage, precipitation, and groundwater levels should assist in more accurately determining recharge conditions.

- Investigations may be warranted to determine the cause of the discrepancy between modeled and observed water levels in the UCRS at the northwest portion of the site. At present, the cause of groundwater mounding observed in this area cannot be determined.

\subsubsection{Northwest Plume Study}

A field study of the contaminant plume that extends off-site in the northwest corner of the plant was conducted in 1992 by the HSS. The Northwest Plume is a contaminant plume, underlying approximately 1.6 miles $^{2}$, containing both trichloroethylene (TCE) and technetium-99 ("') $\mathrm{Tc}$ ). The study involved the use of a driven discrete-depth sampler developed at Oak Ridge National Laboratory to obtain groundwater samples from 15 separate locations. The focus of the investigation was to further characterize the hydrogeology and extent of contamination in the area. 


\section{Environmental Report-Paducah, Part 1}

A description of the field method and results of the study will be presented in a final report, scheduled to be completed in March 1993. Results of the study will assist in planning future drilling activities and selecting remedial actions in the area. The Northwest Plume Study will also assist in the design of the hydraulic containment plan for the Northwest Plume, scheduled to be initiated during 1993.

\subsubsection{CFC-114 Replacement}

Recent studies and investigations have determined that certain compounds, particularly chlorofluorocarbons (CFCs), deplete the stratospheric ozone layer and allow a greater amount of damaging ultraviolet light to reach the earth, which in turn causes harmful environmental and health effects.

CFCs are widely used as refrigerants and degreasing solutions. The CFCs leak or are released from these operations and travel to the stratosphere, where they chemically react with the stratospheric ozone layer to deplete it. Because of this stratospheric ozone depletion determination, the EPA has mandated a phaseout of production of class I ozone-depleting compounds, which include CFC-114. PGDP uses CFC-114 as coolant in the gaseous diffusion cascade. The cessation of production as a result of the EPA mandate and a presidential executive order is due on or before January 31, 1995. PGDP has initiated a project to identify a suitable replacement for CFC-114. A CFC-114 Replacement Program manager has been named for PGDP and Portsmouth Gaseous Diffusion Plant.

Non-ozone-depleting replacement candidates have been identified, and testing has begun at PGDP to determine if the candidates are suitable replacements for CFC-114. When a suitable replacement is identified, the CFC-114 will be replaced on an as-needed basis.

\subsubsection{Chromium Corrosion Inhibitor Replacement}

PGDP uses a binary system for dissipating the heat generated by the gaseous diffusion cascade. First, the heat of compression of the $\mathrm{UF}_{6}$ is transferred to CFC- 114 by vaporization of this compound. Then, the heat is transferred to the RCW system. The heat is finally transferred from the RCW to the atmosphere via four cooling tower complexes A chromium compound is added to the RCW to prevent corrosion of the RCW piping system. The chromium compound is released to the atmosphere through the cooling tower complexes. In anticipation of regulations to be promulgated under Title III (Hazardous Air Pollutants), PGDP has initiated a project to replace the chromium-based corrosion inhibitor with a phosphate-based corrosion inhibitor. One tower complex has been converted to the new corrosion inhibitor, and it is expected that the other three will be converted by September 1993. It is also expected that PGDP will be in compliance with the new regulation affecting industrial cooling towers when it is promulgated.

\subsubsection{Environmental Advisory Committee}

The PGDP Environmental Advisory Committee is composed of seven individuals (two of which were added in the past year) who represent a cross section of scientists, educators, health professionals, and local businessmen. The committee was established in 1986 and has been chartered with the following responsibilities:

- to review the sources of environmental pollutants, the control systems, and the surveillance activities associated with operation of PGDP:

- to evaluate plans for remedial activities and studies to correct, enlarge, or close waste management facilities and to provide recommendations for appropriate changes in strategy or direction;

- to assess the long-term fate and health effects of trace quantities of uranium, other radionuclides, and other pollutants of concern in PGDP environs;

- to advise the PGDP plant manager or the director of the Office of Environment, Safety, and Health, Martin Marietta Energy Systems, Inc. (Energy Systems), on environmental and health issues of concern to both scientists and the community; and

- to advise on appropriate methods and forms of reporting environmental and health data to the public.

It is anticipated that the PGDP Environmental Advisory Committee will continue until current needs are assessed and remedial action problems are

\section{8-8 Unusual Occurrences and Special Studies}


resolved. In 1992 two additional members (university instructors) were added to the committee to increase the committee's expertise in hydrogeological and physical science disciplines.

During 1992 the PGDP Environmental Advisory Committee continued to participate in reviewing PGDP environmental programs and activities. Two meetings were conducted at the site-one in July and one in September. The committee meetings were attended by many upper- and middle-management and staff personnel from the DOE Oak Ridge Operations and from Energy Systems. Topics of discussion included

- the Resource Conservation and Recovery Act/Mixed Waste Federal Facility Compliance Agreement;

- the Natural Resource Damage Assessment Rule;

- the PCB Federal Facility Compliance Agreement;

- the National Emission Staridards for Hazardous Air Pollutants (NESHAP) Federal Facility Compliance Agreement;

- environmental restoration activities: water policy, the C-746-K landfill, interim corrective measures, and the northwest groundwater plume study;

- K.PDES permitting activities;

- the CFC-114 Replacement Program;

- the Cooling Tower Phosphate Changeover Program; and

- environmental noncompliance reporting.

\subsubsection{Neighborhood Council}

The PGDP Neighborhood Council was formed in September 1992 with eight members, all residents of the general vicinity of the plant. The goal was regular and direct communication between the plant and a group of neighbors to provide information and broaden residents' understanding of PGDP operations. To achieve that goal, the council was given these objectives:

- to hear unclassified presentations on a variety of topics of public interest, including those related to the environment;
- to ask questions and request information from PGDP representatives, who respond as thoroughly as possible at meetings or by mail, telephone, or home visits;

- to evaluate the clarity and adequacy of selected public communications by DOE or Energy Systems on behalf of the plant; and

- to recommend actions the plant can take to improve public understanding or help the community.

The council was chartered to meet a least quarterly and to have from 5 to 12 members serving from six months to two years. Monthly meetings were held from September through December 1992. The members' prevailing interest was environmental issues. Topics of discussion included

- groundwater and surface water contamination and related environmental restoration projects;

- air quality and monitoring;

- the PGDP Water Policy (providing municipal water to residents whose wells contain or may someday contain groundwater contamination);

- a tour of the plant laboratories and an explanation of water sampling analyses;

- the basics of radiation; and

- an overview of the Paducah Gaseous Diffusion Plant Environmental Report for 1991 (PGDP 1992).

\subsubsection{Waste Minimization Program}

The Waste Minimization Program at PGDP has existed since 1987. Objectives of the program include identification of opportunities, goal setting, prioritization of efforts, initiation of projects. identification of responsibilities and resource requirements, and the tracking of project results for waste minimization and waste reduction. This subsection discusses some of the activities of the Waste Minimization Program during 1992.

\subsubsection{Aerosol Can Use Reduction}

The use of aerosol cans for all applications in the plant is being phased out as suitable non-aerosol products become available. Emphasis is on using 


\section{Environmental Report-Paducah, Part 1}

refillable spray bottles and brush-applied paints and eliminating personal aerosol products. The amount of aerosol can wastes generated in 1992 was $20 \%$ less than that generated in 1991.

\subsubsection{Cooling Tower and RCW System Waste Oil Minimization}

A performance improvement process team investigated ways to reduce the generation of waste oil from the cooling towers and recirculating cooling water systems. Several options were available including reuse of pump motor lubricating oil for pumpshaft bearing lubrication, extending lubrication frequencies, and oil quality testing. Waste oil generation will be totally eliminated from each pumphouse and will be greatly reduced from cooling tower fan gearboxes.

\subsubsection{Diesel Fuel/Oil Blending}

A filtration system was ordered in 1992 to recycle used motor oil from diesel engines. The system filters engine crankcase oil and blends the oil with diesel fuel, which is used as fuel for the plant's fleet. The plant benefits by reducing waste oil quantities and diesel fuel consumption.

\subsubsection{Floor-Sweep Use Reduction}

Floor-sweep compound is used in the plant to aide the efficient removal of dust while sweeping plant buildings. Waste floor-sweep was reduced by increasing intervals between sweeping, using less sweeping caspound, and avoiding the use of premixed sweeping compounds. In 1992 floor-sweep wastes were reduced $97 \%$ from 1991.

\subsubsection{Garage Oil-Filter Crusher}

A filter-crushing unit was installed to reduce the volume of automotive-type oil filters.

\subsubsection{Packaging Material Waste Reduction}

Many items are shipped to the plant in boxes containing large amounts of packing material. If this material is allowed inside the plant, it becomes contaminated suspect waste and cannot be shipped off-site or be reused. This material is usually sent to the landfill. The Receiving Department now unboxes and removes packing material before boxes are taken into the plant.

\subsubsection{Paint Shop Lacquer Thinner and Mineral Spirits Recovery}

Material was ordered to set up a paint thinner and mineral spirits recovery system at the paint shop. This system consists of settling drums for recovery of clean fluids. Other Energy Systems plants have had great results in this area.

\subsubsection{Process Lube Oil Leak Repairs}

Major amounts of waste oil and oil-absorbing material are generated each year because of leaks from gaskets and joints in the process lube oil systems. A program was initiated in 1992 to systematically repair these leaks.

\subsubsection{Process Lube Oil Recovery}

Waste oil was generated in the past during routine maintenance activities on process equipment. A system is now in place to collect this oil and return it to the process lube oil system from which it was drained. Major reductions in the amount of waste lube oil is expected.

\subsubsection{Seal Shop Lapping Oil Recovery}

A settling system is now in place to recycle used lapping oil from the seal shop. Large reductions in waste oil generation from this area are anticipated.

\section{2.4.11 TCE/Trichloroethane (TCA) Use Reduction}

TCE and TCA were used in the plant for years as degreasers and were common as solvents in many products. Use of these products is being eliminated through product substitution.

\subsubsection{Waste Machine Coolant Recycling}

During 1992, a machine coolant recycling unit was purchased to minimize the generation of waste oil from the machine shop. Waste machine coolant 
was identified as a major source of storage problems because of the corrosion of metal chips that caused drum overpressure. The coolant recycling unit will enable the machine shop to filter impurities from dirty machine tool coolant and reuse the clean fluid.

\subsubsection{Wood Pallet Waste Reduction}

Wood pallets are used in many areas of the plant for equipment storage and material handling. Broken pallets are potentially contaminated and present disposal problems. Metal pallets are being substituted on a trial basis in the C-720 fabrication, machine, and equipment repair shops. Metal pallets will survive multiple uses better than wood pallets, can be decontaminated if necessary, and contribute to less waste generation.

\subsubsection{PCB Source Identification Project}

The PCB Source Identification Project was completed to identify potential sources of PCB contamination in effluents to Big Bayou and Little Bayou creeks. Additionally, this study was in response to a Notice of Violation issued by the KDOW on August 31, 1990. PGDP was alleged to have violated the water quality standard for PCBs contained in 401 Kentucky Administrative Regulations (KAR) 5:031. Performed by the Nashville District Corps of Engineers, the study began in August 1991 and continued through April 1992.

Two sampling programs were used, the Outfall Program and the Storm Sewer Program. Sampling was conducted twice monthly, once under dry conditions and once during or immediately following a runoff-producing rainfall event. Some sampling sites were sampled only under wet conditions. Laboratory analysis was limited to PCBs identified by specific aroclor and total suspended solids (TSS). The Outfall Program included the collection of water grab samples from 30 discrete locations, which included the KPDES sampling points. Twenty-five storm sewer locations composed the Storm Sewer Program. Sample collection points were adjusted during the study based on field observations and laboratory data.

The purpose of this investigation was to establish data trends indicating the location of PCB sources and the correlation of $\mathrm{PCB}$ and TSS concentrations.
However, it was determined that low-level PCB concentrations occurred on an erratic basis at a number of different sample locations. In addition, no well-defined relationship between PCB and TSS values was observed. Of the 643 samples collected, 19 had a PCB concentration greater than or equal to $0.1 \mu \mathrm{g} / \mathrm{L}$, the lowest concentration reported. Nine positive results were from a wet sampling event, and ten were from a dry sampling event. Of the 17 locations that exhibited a least 1 positive result, 8 were from the Outfall Program, and 9 were from the Storm Sewer Program.

PGDP is conducting several related activities to reduce and clean up PCBs. Specifically related to $P C B$ reduction and cleanup are the Toxic Substances Control Act Federal Facilities Compliance Agreement, collection and treatment of PCB-contaminated water, and Environmental Restoration Program activities. In an effort to further characterize the extent of PCB contamination of sediment in Big Bayou and Little Bayou creeks, sediment sampling, in addition to that already conducted by PGDP and the Environmental Restoration Program, will be conducted by the Corps of Engineers. The results of this investigation will be provided to the KDOW.

PGDP has submitted the final report and related information to the KDOW. This information has been prepared as PGDP's response to the Notice of Violation for PCB discharges. PGDP has requested KDOW's concurrence that the report and the information are satisfactory resolutions to the Notice of Violation. A response has not yet been received.

\subsubsection{C-310 Purge and Product Building Stack Effluent Sampling Project}

In February 1992, a stack sampling project was performed on the C-310 stack. The C-310 stack exhausts minute quantities of radionuclides and lightweight molecular gases that have migrated up the gaseous diffusion cascade. The project was required by the EPA in accordance with the NESHAP Federal Facilities Compliance Agreement to determine whether radionuclide particulates are present in the cascade effluent at the location of the existing sampling point. EPA methods require isokinetic sampling for particulates. According to PGDP radiochemistry personnel, the chemical and physical properties associated with the gaseous 


\section{Environmental Report-Paducah, Part 1}

diffusion process preclude particulate formation in the $\mathrm{C}-310$ stack. The existing C -310 sampler does not provide isokinetic extraction because of the contention that the effluent at the point of sampling is a gas. Effluent gases do not require isokinetic sampling. The project was performed by a subcontractor experienced in stack sampling. Results of the project indicated that there was no particulate activity. Therefore, no isokinetic sampling system is required.

Stack effluent sampling was also performed on other exhausts with the potential to emit cascade gases. In November 1991 and February 1992. personnel from the Oak Ridge K-25 Site sampled the effluent from the C-360) toll transfer and sampling building, pigtail exhaust stack, the C- -337 process building wet air/seal exhaust stack (a common stack), the C -331 process building seal exhaust stack, and the C-331 wet air stack. Results of this sampling project will indicate emissions from other similar cascade effluents in other buildings. Results of this project indicaled detectable but minute quantities of uranium in the $\mathrm{C}-331$ wet air exhaust and plutonium in the C-337 wet air/seal exhaust stacks. Air dispersion modeling of these emissions resulted in an annual dose of only $2.8 \mathrm{E}-5 \mathrm{mrem}$. All other emissions in this study were not distinguishable from zero. These stacks are scheduled to be resampled in 1997.

\subsubsection{Clean Air Act Amendments of 1990 Activities}

The Clean Air Act Amendments of 1990 (the act) resulted in sweeping changes to the existing air pollution regulation. In general, the act is divided into eight titles, three of which have significant impact on PGDP activities.

\subsubsection{Title III: Hazardous Air Pollutants}

This section of the act lists 189 pollutants as hazardous air pollutants (HAPs) and requires the EPA to promulgate a list of source categories that emit these pollutants. The EPA is also required to establish an emission standard for each of the source categories that results in a maximum degree of reduction in emissions of the respective HAP. The following list contains the primary source categories and the scheduled promulgation dates of implementing regulations that could affect operations at PGDP.

\begin{tabular}{lc}
\multicolumn{1}{c}{ Source category } & Scheduled date \\
\hline Industrial boilers & $11 / 15 / 2000$ \\
Stationary internal combustion engines & $11 / 15 / 1997$ \\
Flat wood paneling (surface coating) & $11 / 15 / 20(0)$ \\
Large appliance (surface coating) & $11 / 15 / 200()$ \\
Metal coil (surface coating) & $11 / 15 / 2000$ \\
Miscellaneous metal parts and products & $11 / 15 / 20(6)$ \\
$\quad$ (surface coating) & \\
Plastic parts and products (surface coating) & $11 / 15 / 2000)$ \\
Printing/publishing (surface coating) & $11 / 15 / 1994$ \\
Municipal landfills & $11 / 15 / 1997$ \\
Site remediation & $11 / 15 / 2000$ \\
Solid waste treatment, storage, and disposal & $11 / 15 / 1994$ \\
$\quad$ facilities & $11 / 15 / 2000)$ \\
UFo production & $11 / 15 / 1994$ \\
Halogenated solvent cleancrs & $11 / 15 / 1994$ \\
Industrial process cooling towers & $11 / 15 / 2000$ \\
Paint stripper users & $11 / 15 / 1997$ \\
Wood treatment & $11 / 15 / 1994$ \\
Asbestos processing
\end{tabular}

In response to Title III, the PGDP Air and Water Policy Department has issued a 3-year plan for the reduction of HAP releases from PGDP. This plan outlines HAP emission reduction at PGDP primarily from the elimination of the degreasing agents TCE and methyl chloroform $(1,1,1 . \mathrm{TCA})$ and from the elimination of the chromium-based corrosion inhibitor used in the gaseous diffusion RCW system. PGDP expects 10 discontinue use of these HAPs by the end of CY 1994.

\subsubsection{Title V: Permits}

This section of the act establishes a federal permitting program. Prior to the passage of the amendments, states had the option of establishing a permitting program. The Commonwealth of Kentucky, through the Kentucly Division for Air Quality, established a permitting program and issued an operating permit to PGDP in 1985. This section of the act requires the EPA to establish the minimum requirements for a permitting program. Each state must establish a program that contains the minimum requirements stated in the act. For any state that does not have an EPA-approved permitting program, the EPA is required to establish and enforce a permitting 


\section{Environmental Report-Paducah, Part 1}

program for that state. This section also requires the states, as part of the permitting program, to establish emission fees of not less than $\$ 25.00$ per ton of regulated pollutant per year, unless the EPA determines that a lesser amount is adequate to operate the state's permitting program. To ensure compliance with Title $\mathrm{V}$ of the act, PGDP has completed a stack/vent survey that identified all emission points. Future regulations specific to the emission points will determine permit applicability for each point. Emission estimates have been calculated to help determine future budgetary requirements for the emission fees.

\subsubsection{Title VI: Stratospheric Ozone Protection}

This section of the act requires the EPA to promulgate regulations to protect the stratospheric ozone. Recent studies have indicated that the release of certain ozone-depleting substances (ODSs) such as CFCs, hydrochlorofluorocarbons, halons, carbon tetrachloride, and methyl chloroform (1,1,1-TCA) destroy stratospheric ozone. This stratospheric ozone layer protects the environment from harmful ultraviolet rays that may cause an increase in skin cancer, cataracts, and other harmful effects. In the act, the EPA is required to mandate phasing out the manufacture of class I ODSs by 2000. However, a presidential executive order accelerated this phaseout 10 1995. Furthermore, the EPA is required to promulgate regulations that prohibit the intentional venting of ODSs during maintenance activities and that require warning labcls on substances containing and/or manufactured with ODSs. In response to proposed rules that would implement the requirements of the act, PGDP has established a CFC-114 replacement program manager whose primary responsibility is to identify a replacement for the CFC-114 that is used as heat transfer media in the gaseous diffusion cascade. One replacement candidate, $\mathrm{C}_{4} \mathrm{~F}_{10}$, has been tested in a cascade cell with promising results. PGDP Air and Water Policy personnel also met with EPA Headquarters personnel in February 1993, to discuss compliance problems relating to the prohibition of intentional venting, which is inherent with the gaseous diffusion process. The EPA was receptive to the PGDP issues and indicated that it would consider PGDP's compliance difficulties when issuing the final rule. PGDP has also contacted EPA personnel in charge of regulation development and enforcement to determine the applicability of the labeling requirements to activities at PGDP. The PGDP garage has purchased an ODSs recovery unit for motor vehicle air conditioners, and mechanics have been certified as required in maintenance activities performed on motor vehicle air conditioners. Refrigeration maintenance is complying with the requirements of the act by using ODSs recovery equipment on refrigeration systems at PGDP.

\subsection{References}

GeoTrans. 1992. Groundwater Modeling and Offsite Containment Evaluation at the Paducah Gaseous Diffusion Plant, GeoTrans Project No. 6506-00)3, GeoTrans, Inc., Sterling, $V a$.

Paducah Gaseous Diffusion Plant (PGDP). May 1991. Pollution Prevention Awareness Program Plan, DY/E-100, rev. 1, Paducah, Ky.

Paducah Gaseous Diffusion Plant (PGDP). October 1991. Uranium-Contaminated Waste Oil Minimization, PIP: 49-90-1001, Paducah, Ky.

Paducah Gaseous Diffusion Plant (PGDP). October 1992. Paducah Gaseous Diffusion Plant Environmental Report for 1991. ES/ESH-22/V3, Paducah, Ky.

U.S. Army Corp of Engineers, Nashville District. July 1992. PCB Source Identification Project, Final Report, Paducah Gaseous Diffusion Plant, Paducah, Ky. 


\section{Solid Waste Management Program}

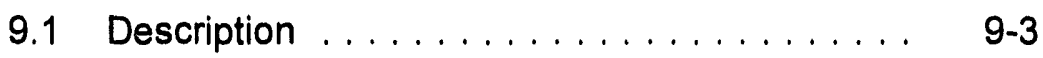

9.1.1 Purpose . . . . . . . . . . . . . . . . 9. 9-3

9.1 .2 Regulatory Review ... . . . . . . . . . . 9-3

9.1.3 Compliance Activities ... . . . . . . . . 9-4

9.1.4 Program Strategy . . . . . . . . . . . . 9. 9-4

9.2 Waste Generation ............... 9-5

9.2.1 Types of Waste Generated . . . . . . . . 9 9-5

9.2.2 Waste-Generating Activities ....... 9. 9-5

9.2.3 Waste Generation Summary ....... 9. 9-6

9.3 Waste Management Activities . . . . . . . . 9. 9-6

9.3.1 Waste Management System . . . . . . . 9-6

9.3.2 Waste Management Facilities ...... . 9-7

9.3.3 Off-Site Waste Disposal Activities .... 9 9-9

9.3.4 Waste Placed in Storage ... . . . . . 9. 9

9.3.5 Special Activities ............ . 9-10

9.4 Reference .................... 9-10 


\section{Solid Waste Management Program}

\subsection{Description}

\subsubsection{Purpose}

The Solid Waste Management Program at the Paducah Gaseous Diffusion Plant (PGDP) is designed to protect the environment, the public, and on-site personnel through the proper management of solid wastes generated by plant operations and eventually to dispose of the wastes in an environmentally acceptable manner. A "cradle-to-grave" system provides management services for all types of waste from the point of generation through ultimate disposal. The system ensures that wastes are managed in accordance with state and federal regulations; U.S. Department of Energy (DOE) Orders 5480.3, 5400.3, $5820.2 \mathrm{~A}$, and $5480.1 \mathrm{~B}$; and accepted industry practices. In addition to waste disposal, the program includes efforts to minimize the quantities of wastes generated and to treat wastes to reduce volume and toxicity.

In addition to the day-to-day waste management activities, the Solid Waste Management Program must anticipate future needs in both the technical and regulatory areas. Staff members provide technology development and regulatory review services to ensure that the program remains in compliance, that future waste management needs are anticipated, and that proper planning in response to these needs occurs. These efforts are coordinated with personnel at the other DOE Oak Ridge Operations Office sites to facilitate the consolidation of work and the enhancement of communication among sites.

\subsubsection{Regulatory Review}

The Resource Conservation and Recovery Act (RCRA) regulates the generation, storage, transportation, treatment, and disposal of hazardous wastes; air emissions of organic sources from permitted units, including piping, process vents, and so forth; and facilities involved in these activities. The state of Kentucky has been authorized by the U.S. Environmental Protection Agency (EPA) to administer specific sections of RCRA in lieu of the federal program. This authorization has resulted in the promulgation of regulations in the Kentucky Administrative Regulations (KAR). The state also administers the disposal of sanitary and inert wastes through regulations published in the KAR. PGDP is subject to most of the requirements of these regulations; however, radioactive wastes such as source, special nuclear, and by-product materials are exempt from RCRA regulation by the Atomic Energy Act of 1954. The hazardous components of mixed waste (i.e., hazardous wastes containing radionuclides) are regulated by RCRA.

Wastes containing polychlorinated biphenyls (PCBs) are regulated by the Toxic Substances Control Act (TSCA). As in the case of mixed wastes, $\mathrm{PCB}$ wastes containing radionuclides are also managed under TSCA. PCB wastes containing hazardous wastes are managed in accordance with RCRA and TSCA by application of the more stringent regulation.

The Clean Water Act (CWA) and the Clean Air Act do not directly affect solid waste management activities; however, the operation of waste management facilities must not adversely affect the ability of PGDP to comply with these regulations. Such compliance is also planned for in accordance with the National Environmental Policy Act requirements, one of which is that the environmental impacts of plant projects be considered during the project planning process.

DOE has issued orders establishing policies in waste management areas. DOE Order 5632.1A 


\section{Environmental Report-Paducah, Part 1}

prescribes requirements for the physical protection of classified wastes. DOL: Order 5400.3 addresses the management of hazardous and mixed wastes at DOF facilities and directs that such wastes will be managed in an environmentally acceptable manner. low-level radionctive wastes (I.LW) without hazardous or toxic constituents are regulated under the federal Atomic Energy Act. These wastes are managed under DOE Order 5820.2A, which was issued in September 1988. 'This order establishes handling and disposal policies and a waste classification system to be implemented throughout DOL:

\subsubsection{Compliance Activities}

Hayardous waste facilities at PGDP are operated under permilted status granted by the state of Kentucky (facility IEPA ID) KY8890()(28982). The Part B permit has been issued for the 5 storage and 15 treatment units on the plant site.

\subsubsection{Program Strategy}

Proper identification, characterization, and classification of waste materials is essential for ensuring that waste management attivities are performed salely, efficiently, and in compliance with regulations and policies. This is an ongoing process that must react to changes within the plant and to changes in regulations and policies beyond the control of plant management. $A$ system of administrative controls assigns responsibilities for waste handling activities and specifies criteria that must be met before a waste is accepted by the Waste Management Operations Department. These controls include plantwide standard practice procedures; job-specific standard operating procedures; waste sampling, analysis, and handling requirements of the facility Part B Permit; and other requirements. For wastes not handled through the Waste Management Operations Department (such as process wastes discharged directly from a (reatment unit), a system of administrative controls and, in some cases, physical controls (e.g., valve lockouts, etc.) are used to ensure that the waste is properly characterized proo to discharge. The primary control in these instances is the Kentucky Pollutant Discharge Elimination Systemi permit under the CWA. RCRA characterizations are performed periodically on these wastes at the point of generation and, where necessary, following treatment.

To facilitate waste management activities, a new Generator Waste Management Program was developed. The program, implemented in 199(), focuses on the proper identification, segregation, and packaging of wastes at the point of generation. following completion of a successful pilot program in the C-720 maintenance and stores building area, a plantwide waste generator tracking program has been implemented, and training of PGDP personnel was completed in September 1991. A less rigorous training course will be given to generators on an annual update basis.

PGDP operates a program to minimize the anount of waste being generated. Under the direction of the Plant Waste Minimization Program manager, a team of waste management, technical, operations, and maintenance personnel is charged with identifying opportunities and strategies for waste minimization and coordinating efforts to accomplish these strategies. Where possible, avoiding or minimising waste is $t 0$ be accomplished through process changes that eliminate the waste stream or recycle it back into use. Given the nature of the processes at P(iDP. however, opportunities for waste elimination and recycling at the soluce are limited.

Oher options include reducing waste stream toxicity and hazard through the use of less toxic or hazardous raw materials, or limiting the use of toxic and hazardous materials. For example, limiting the use of trichloroethylene (TCE) to large degreasing units and using less toxic solvents in the field has reduced the quantity of hazardous waste requiring disposal. Installing new treatment processes or modifying existing processes can also reduce waste stream toxicity and volume. Segregating waste materials to reduce the volume of hazardous or radionuclide-contaminated materials requiring special handling and disposal is a common practice.

Several options are available for waste disposal. Some wastes are treated and disposed of directly (e.g., the neutralization of waste acids). Sanitary and inert wastes are also disposed of on-site. Some types of hazardous and PCB liquid wastes are capable of being incinerated at the $\mathrm{K}-1435 \mathrm{TSCA}$ incinerator located al Oak Ridge, Tennessee. All off-site disposal facilities must meet RCRA and TSCA regulatory requirements. Some wastes (such as mixed and 
low-level radioactive wastes) must be placed in on-site, long-term storage until treatment or disposal technology is developed and demonstrated.

PGDP has prepared a plan including projects and budget requirements for waste management activities needed to ensure regulatory compliance. As part of the overall DOE effort (PGDP February 199()), this plan (discussed in Subsect. 4.4.2) is to be used as a program strategy document. Projects for waste minimization and new storage, treatment, and disposal facilities are part of the plan. PGDP also generates, or has generated in the past, several wastes that cannot be treated or disposed of at this time. For the next several years, PGDP will continue identifying and evaluating technologies for treatment and disposal of these wastes.

\subsection{Waste Generation}

\subsubsection{Types of Waste Generated}

Residential. This waste category includes office, cafeteria, and similar wastes.

Inert (Industrial). Fly ash from coal-fired boilers and construction spoils make up the bulk of this category.

Hazardous. This class of wastes is defined by RCRA regulations. Hazardous wastes at PGDP include waste acids such as sulfuric and nitric acids, solutions containing metals such as chromium, and ignitable wastes such as paint solvents. Other hazardous wastes include TCE and various laboratory chemicals.

Mixed. These wastes consist of RCRA hazardous wastes contaminated with radionuclides. Uranium is the most common contaminant.

PCBs. All wastes containing more than 50 parts per million (ppm) of PCBs by weight and wastes resulting from $P C B$ spill cleanup operations are handled as PCB wastes. Waste containing detectable (i.e., $>1 \mathrm{ppm}$ in soil, $>0.5 \mathrm{ppb}$ in water, and $>2 \mathrm{ppm}$ in oil) PCBs are disposed of as PCB wastes but are not classified as such.

$P C B /$ radioactive. This category consists of $P C B$ wastes (as defined in the preceding paragraph) that are contaminated with $>50 \mathrm{ppm}$ depleted $U$ and $/ o r$ detectable $\mathrm{Np}, \mathrm{Pu}, \mathrm{Th}$, and/or $\mathrm{Tc}$.

Transuranic. These wastes contain more than $100 \mathrm{nCi} / \mathrm{g}$ of transuranic radionuclides. The most common radionuclides are ${ }^{239} \mathrm{Pu}$ and ${ }^{237} \mathrm{~Np}$. A small quantity of this type of waste is stored at PGDP. This waste is not currently produced at the plant.

Low-level radioactive. This category consists of any nonhazardous, non-PCB or PCB-contaminated waste that contains radioactivity and is not classified as high-level waste, transuranic waste, spent nuclear fuel, or $11 \mathrm{e}(2)$ by-product material as defined by DOE Order 5820.2A, "Radioactive Waste Management."

Asbestos. This waste, classified as either "clean" or "contaminated," depending on the absence or presence of uranium, consists of friable asbestos generated by plant maintenance operations.

Scrap metal. This stream, also classified as either "clean" or "regulated," consists of scrap metal generated by maintenance operations and machine shop work.

Nonhazardous. This category consists of miscellaneous wastes not fitting into one of the preceding RCRA categories. An example of this would be nonhazardous liquids not suitable for on-site disposal.

Classified. Wastes considered to contain sensitive security information are accorded special handling. Wastes in any of the preceding categories may also be considered classified.

\subsubsection{Waste-Generating Activities}

Utilities operations. Wastes produced during operation of plant auxiliary systems include fly ash produced by generation of steam from coal-fired boilers, sludge produced by treatment of sewage, and sludges produced by lime-soda ash softening of water from the Ohio River for process use. Sewage treatment sludges contain PCBs and uranium. The sewage sludge is drummed and stored. Another plant waste stream is blowdown from the recirculating cooling water system. The blowdown, which contains about $8 \mathrm{ppm}$ chromium, is hazardous and is treated to remove chromium. PGDP is changing the recirculating cooling water system blowdown from chromium to a nonhazardous phosphate-based inhibitor. The changeover would be completed in CY 1993.

Chemical operations. The majority of the low-level radioactive waste produced at PGDP is produced by the Chemical Operations Department. The major contaminant is uranium; trace quantities of 


\section{Environmental Report-Paducah, Part 1}

${ }^{99} \mathrm{Tc},{ }^{237} \mathrm{~Np},{ }^{230} \mathrm{Th}$, and ${ }^{23.9} \mathrm{Pu}$ are also present. The largest low-level waste stream is filter cake produced by lime precipitation treatment of spent decontamination, cylinder wash, and laboratory waste solutions. Smaller amounts of other low-level wastes include contaminated floor sweep, articles of clothing, small parts, and supplies.

Some hazardous wastes are also produced by the Chemical Operations Department. These include spent TCE used in degreasing, and waste from a small-parts nickel-deplating process. The lime precipitation process waste is occasionally a mixed waste.

Fabrication and maintenance. Maintenance activity is generally divided into two types-shop and field. Shop activities include major equipment repair, rebuilding and construction, metal machining, forming and welding, instrument repair, carpentry, and painting. Scrap metal, both clean and contaminated, is produced by shop activity. A variety of machining fluids (usually oils), lubricating oils, and cutting fluids are used. Most wastes produced from these materials are nonhazardous. Small amounts of spent chlorinated solvents, including TCE and 1,1,1-trichloroethane, are produced by degreasing operations. Other hazardous wastes include painting wastes, which are hazardous because of their ignitability. Most other wastes, such as scrap wood, boxes, and other containers, are classified as nonhazardous sanitary or industrial waste.

Waste lubricating oil forms a large-volume waste stream produced by field maintenance activities. The oil is classified as hazardous, nonhazardous, or contaminated, depending on the chlorinated solvent or radionuclide content. Clean and contaminated asbestos wastes result from repair of systems such as steam-heating systems that were insulated during plant construction. Clean and contaminated scrap metal, nonhazardous construction debris, PCBs and PCB-contaminated wastes, and waste oils also are produced at PGDP through maintenance activity.

Laboratory operations. Small quantities of hazardous, nonhazardous, low-level radioaclive, and PCB wastes are generated by laboratory operations. The bulk of the wastes are residues or leftovers from analytical work. Uranium-salvage solutions are mixed waste. Waste oils, solvents, and other organic materials are also hazardous wastes, as are discarded laboratory chemicals.
Environmental restoration activities. PGDP has begun an extensive Environmental Restoration Program designed to investigate the present groundwater contamination problem and on-site waste management units and spill sites. Drill tailings, grout, equipment wash water, and water from sampling activities are being generated along with personal protective equipment and are managed in accordance with regulations and plant procedures.

\subsubsection{Waste Generation Summary}

Table 9.1 summarizes the waste generated on-site during 1992. The types of waste are described in Sect. 9.2.1. The quantities are indicated in the table.

The most significant change in waste generation rates occurred in the LLW, hazardous, and mixed waste areas. The increase in the hazardous and mixed waste categories stored on-site was primarily a result of the off-site shipment moratorium imposed by DOE in the spring of 1991. Most waste streams within PGDP have the potential to be considered LLW because lower limits have not been established. Until a lower limit for LLW is established, all RCRA, TSCA, and LLWS will continue to be stored on-site. Waste characterization procedures are being developed to identify radioactive contamination in RCRA and TSCA waste streams at PGDP.

\subsection{Waste Management Activities}

\subsubsection{Waste Management System}

Containerized wastes and wastes requiring off-site disposal are managed by the Waste Management Operations Department. All wastes are required to have a request-for-disposal form completed before they can be moved. This form functions as an internal manifest. If information on the form is insufficient, the waste is sampled and characterized before being disposed of or stored. Characterization is routinely performed on several waste streams in accordance with the Waste Analysis Plan in the facility Part B permit; off-site disposal facility requirements; general RCRA, TSCA, and CWA requirements; and other criteria set forth by DOE and internal procedures. 
1992 Environmental Report-Paducah, Part 1

Table 9.1. 1992 PGDP waste generation summary

\begin{tabular}{lcc}
\hline \multicolumn{1}{c}{ Waste type } & ${\text { Volume }\left(\mathrm{ft}^{3}\right)^{a}}^{a}$ & Mass (lb) \\
\hline Low-level radioactive & 17,657 & 857,143 \\
Polychlorinated biph $2 n y l /$ mixed $^{b}$ & 8,730 & 366,720 \\
Hazardous/mixed & 5,728 & 241,237 \\
PCB/hazardous/mixed & & 46,132 \\
Residential & 1,056 & $d$ \\
Inert $^{c}$ & 37,661 & $d$ \\
Scrap metal & 10,567 & $d$ \\
\hline
\end{tabular}

"Includes only characterized wastes. Wastes in accumulation areas and wastes that have not been characterized are not included.

${ }^{h} \mathrm{PCB}$ contribution to waste type is based on preliminary data and is subject to change.

'Open only 6 months of 1992.

dNot applicable.

Once a waste has been properly identified and characterized, it is packaged for shipment or placed in storage. U.S. Department of Transportation (DOT) criteria are used to select containers such as drums. Small quantities of chemicals are lab-packed by either PGDP personnel or off-site disposal facility personnel.

Wastes are managed at several on-site facilities. Residential and industrial waste, clean scrap metal, clean asbestos, and treated medical wastes are disposed of at the on-site landfill. Some hazardous wastes are treated to render them nonhazardous prior to disposal. Some low-level radioactive wastes are treated to reduce their volume. Clean (i.e., without technetium, uranium, or transuranic contamination) PCB and hazardous wastes are disposed of off-site at inspected and permitted incinerators. Off-site landfills are used only under special circumstances. Some wastes, such as mixed and $\mathrm{PCB}$ /radioactive wastes, cannot be disposed of and are placed in indefinite storage. Medical wastes are treated by autoclaving. They are then packaged in containers appropriate for the type of waste and are disposed of in the residential landfill.

All waste management units are operated in accordance with appropriate regulations. Hazardous, mixed, $\mathrm{PCB}, \mathrm{PCB} / \mathrm{mixed}$, and low-level wastes are tracked and accounted for using a computerized inventory system. Each container is assigned a unique identification number that is entered into a computer data base. Bulk liquids are inventoried at the time they are placed in tanks. Quantities of other wastes are estimated.
Wastes not managed by the Waste Management Operations Department are discharged directly from treatment units or activity areas. Such wastes are routinely characterized to ensure that they are being properly handled.

\subsubsection{Waste Management Facilities}

A number of waste management units are located on the PGDP site. Each unit handles a limited number of types of waste. Units are grouped according to three general types-storage, treatment, and disposal. Table 9.2 shows the 1992 waste treatment data; Table 9.3 shows the 1992 on-site disposal information. The PGDP waste management units are listed in the following subsection.

\subsubsection{RCRA Hazardous and Mixed Waste Facilities}

\subsection{RCRA-permitted units}

C.733 hazardous waste storage area. A diked, roofed storage area for container and tank storage. PGDP stores ignitable wastes in this building. Capacity is approximately $160,860 \mathrm{~L}(42,500) \mathrm{gal})$.

C-746- $Q$ hazardous waste storage and treatment area. A diked, totally enclosed area for container storage and treatment of fluorescent and incandescent lamps. No ignitable wastes are to be stored in the area. Capacity is approximately $934,000 \mathrm{~L}$ $(246,800$ gal $)$. 


\section{Environmental Report-Paducah, Part 1}

Table 9.2. 1992 PGDP waste treatment

\begin{tabular}{ccc}
\hline Waste type & Quantity $\left(\mathrm{ft}^{3}\right)$ & Treatment \\
\hline $\begin{array}{c}\text { Uranium salvage } \\
\text { (hazardous mixed) }\end{array}$ & 88.8 & $\begin{array}{c}\text { Neutralization/ } \\
\text { precipitation }\end{array}$ \\
$\begin{array}{c}\text { Machine coolant } \\
\text { (nonhazardous) }\end{array}$ & 0.0 & $\begin{array}{c}\text { Coagulation/ } \\
\text { filtration }\end{array}$ \\
\hline
\end{tabular}

Table 9.3. 1992 PGDP on-site waste disposal

\begin{tabular}{ccc}
\hline Waste type & Disposal method & Quantity $\left(\mathrm{ft}^{3}\right)$ \\
\hline Residential & Landfill & 37,661 \\
Inert $^{a}$ & Landfill & 10,567 \\
\hline
\end{tabular}

"Open only 6 months of 1992.

$C-746-R$ waste solvent storage area. A diked area used for the temporary storage of drummed waste oils during sampling activities. Some mixed, hazardous, and $\mathrm{PCB}$ residues are also stored in tanks and at C-746-A.

C-746-A hazardous waste storage and treatment area. A diked, totally enclosed area for container storage and treatment of fluorescent and incandescent lamps. This building is also used to store PCB wastes.

C-400-B waste solution storage tank. A 18,900-L (5000-gal) stainless steel storage tank. The tank is contained in a concrete, stainless steel-lined containment area. To date, the tank has never been used.

C-400-C nickel stripper evaporation unit. A hazardous waste treatment unit. Nickel stripper solutions are evaporated in a 454-L (120-gal) stainless steel steam-heated tank.

C-400-D lime precipitation tank. A 16,250-L (4300-gal) stainless steel tank used for neutralization and metals precipitation.

C-409 hazardous waste pilot plant. Used for technology development work and limited treatment and disposal of small quantities of hazardous wastes.

\subsection{Permit-by-rule facilities}

C-616 chromium reduction facility. A wastewater treatment unit used to remove chromium from the recirculating cooling water blowdown. This is a RCRA "permit-by-rule" facility.

C-403 neutralization pit. An inground pit used as a holding basin for wastewater from the C-400 building. It has limited use as a permit-by-rule elementary neutralization unit.

C-410-C hydrofluoric neutralization building pit. An inground pit used for the neutralization of spent battery acids and fluorine cell electrolytes. This is a permit-by-rule elementary neutralization unit.

\subsubsection{PCBs and PCB/Mixed Waste Facilities}

C-746-A storage area. A storage area located in the C-746-A warehouse. The area is diked and has a capacity of approximately 7440 drums. PCB and $\mathrm{PCB} / \mathrm{mixed}$ wastes are stored here. The area also contains hazardous wastes.

$C-746-B$ south warehouse and $C-337$ and $C-333$ process building waste stnrage areas. Container storage areas located in the C-746-B warehouse and the $\mathrm{C}-337$ and $\mathrm{C}-333$ process buildings. These areas are lined and diked with a synthetic material meeting EPA requirements. Approximately 12,000 drums can be stored in these areas.

\subsubsection{Nonhazardous Waste Management Areas}

C-746-S new sanitary landfill. Used for the disposal of sanitary trash. The residential landfill comprises three cells. One cell has been closed and capped, the second cell is nearing its capacity, and the third cell has been fully constructed. PGDP is awaiting final authorization from the Kentucky Division of Waste Management to begin operation of the third cell.

C-746-T inert landfill. Used for disposal of fly ash, clean asbestos, and construction debris. This landfill ceased operations on June 30, 1992, in accordance with state landfill regulations and has been closed and capped. PGDP will now begin to conduct post-closure care of the unit.

\subsubsection{Scrap Metal Facilities}

C-746-PI west clean scrap metal yard. Used for accumulation of clean scrap metal for resale. 


\section{Environmental Report-Paducah, Part 1}

C-746.P east regulated scrap yards. Used for storage of scrap metal containing nontransferable radioactive contamination.

\subsubsection{Low-Level Radioactive Waste Facilities}

C-333 LLW storage area. Located within the C-333 process building, which is enclosed. Approximately 5500 drums may be stored here.

C-746-M waste uranium chip storage facility. A diked, totally enclosed drum storage area with a capacity of approximately 60 drums. The area currently contains drums of nonhazardous waste.

C-745-K storage area. A graveled area adjacent to the $\mathrm{UF}_{6}$ cylinder yards. Over 900 steel 55-gal drums of LLW are stored here. In addition, a portion of this area is a concrete pad for storing redwood from cooling tower construction.

C-335 criticality storage area. Restricted storage requirements limit this area to a storage capacity of 147 drums.

C-746-B south warehouse LLW storage area. This area has a capacity for 870 drums.

C-30I LLW storage area. This area has a capacity for 2000 drums.

\subsubsection{Off-Site Waste Disposal Activities}

Incineration is the preferred method for off-site treatment/disposal of waste. Landfills and other types of disposal are used only on a limited basis under special circumstances. All commercial sites are visited and approved annually by Martin Marietta Entigy Systems, Inc., personnel prior to use. These visits are used to inspect the facilities and to review management, permit, and insurance information. No radioactive wastes are shipped off-site except to DOE facilities. In September 1992, PGDP made the first shipment of LLW from Energy Systems to the DOE Hanford Site for disposal. A second shipment is scheduled for 1993.

Off-site treatment/disposal is arranged for by the Waste Management and Purchasing departments. Unless special circumstances warrant other arrangements, all such disposals are awarded to the qualified contractor with the lowest bid. Commercial transporters or transportation provided by the waste management firm are used to move the waste from the PGDP site. Table 9.4 shows the off-site waste treatment/disposal quantities for 1992.

All containers of waste must meet DOT shipping requirements. Packages are inspected and inventoried prior to shipment.

\subsubsection{Waste Placed in Storage}

In some cases wastes are accumulated to provide for cost-effective off-site disposal. These wastes are placed in storage. In some cases waste generated in 1992 will be retained on-site in storage until suitable disposal options are available. Several waste streams, including hazardous/mixed and PCB/mixed wastes, cannot now be disposed of by any means. These wastes are covered by Federal Facility Compliance Agreements (FFCAs) with EPA Region IV. Both FFCAs contain provisions for development and deployment of appropriate treatment and disposal technologies. These wastes are placed in long-term storage on-site.

Table 9.4. 1992 PGDP off-site waste disposal

\begin{tabular}{|c|c|c|}
\hline Waste type & Disposal method & Quantity (lb) \\
\hline $\mathrm{PCB} /$ mixed $^{a}$ & Incineration & 51,100 \\
\hline PCB transformers & Resource recovery & 0 \\
\hline Hazardous & Incineration & 0 \\
\hline PCB/hazardous/mixed & Incineration & 20,840 \\
\hline Hazardous/mixed & Incineration & 21,660 \\
\hline
\end{tabular}

${ }^{u}$ Polychlorinated biphenyl. 


\section{Environmental Report-Paducah, Part 1}

\subsubsection{Special Activities}

\subsubsection{Waste Generation Program}

To improve regulatory compliance and reduce costs associated with waste management activities, a waste generation program was developed and implemented plant wide. The program established waste identification, segregation, packaging, and management standards for waste generators. The program has reduced the presence of unidentified waste containers, improved waste segregation practices, and prevented buildup of wastes in generation areas. All PGDP personnel have received waste generator training, including new employees and subcontractors. Waste generator handbooks, which are easy reference guides for handling waste, were issued to all personnel.

\subsection{Reference}

Paducah Gaseous Diffusion Plant (PGDP). February 14, 1990. Environmental Restoration and Waste Management Site-Specific Plan for Oak Ridge Operations Office, Paducah Gaseous Diffusion Plant (final draft), KY/H-104, Paducah, Ky. 


\section{Quality Assurance}

10.1 Field Sampling and Monitoring $\ldots \ldots \ldots$ 10-4

10.1.1 Basic Concepts and Practices . . . . . . 10-4

10.1.2 External Gamma Monitoring . . . . . . . 10-6

10.1.3 Air Monitoring . . . . . . . . . . . . . . . 10 10-6

10.1.4 Water Monitoring . . . . . . . . . . . . 10-6

10.1.5 Groundwater Monitoring . . . . . . . . . 10 . 10

10.1.6 Biological Monitoring . . . . . . . . . 10 10

10.1.7 Soil and Sediment Sampling . . . . . . 10-7

10.1.8 Solid Waste Monitoring, Site

Characterizations, and Spill

Cleanup ... . . . . . . . . . . . . 10-7

10.2 Analytical Quality Assurance . . . . . . . . 10-7

10.2.1 Internal Quality Control . . . . . . . . . 10-7

10.2.2 External Quality Control . . . . . . . . . 10-8

10.2.3 Independent Quality Control . . . . . . 10 10-8

10.3 Quality Incidents . . . . . . . . . . . . 10-9

10.3.1 Environmental Protection Agency

Discharge Monitoring Report

Quality Assurance Program . . . . . . . 10-9

10.3.2 Proficiency Environmental Testing

Program . . . . . . . . . . . . . . . . . 10 10-9

10.3.3 Proficiency Analytical Testing

Program . . . . . . . . . . . . . . . . . . 10-10

10.3.4 Environmental Measurements

Laboratory Program . . . . . . . . . . . . 10-10

10.3.5 Environmental Measurements Systems

Laboratory-Las Vegas Program . . . 10-10

10.4 Documentation Quality Assurance . . . . . . . 10-10

10.5 References . . . . . . . . . . . . . . . . . . . 10-11 


\section{Environmental Report-Paducah, Part 1}

\section{Quality Assurance}

Quality assurance (QA) planning is integrated into every step of the environmental surveillance and monitoring effort at Paducah Gaseous Diffusion Plant (PGDP), Contributors are totally responsible for the quality of their contributions. Developed and evolved over many years of such activity and careful study of appropriate regulatory guidance, the surveillance and monitoring programs can be roughly divided into three major efforts: sampling of the envircnment, analysis of the samples, and treatment or interpretation of the results.

The Analytical Laboratory Department and the Quality Support Section of the Technical Services Division, in cooperation with the Environmental Sampling Section of the Environmental Services Department, implemented two quality control programs to monitor the quality of analyses of surface water and groundwater samples. These programs use purchased certified standard materials prepared by the Quality Support Section that are submitted according to regulatory guidance to the laboratory groups performing the analyses. Program results are used to assess laboratory performance and to provide more immediate feedback to analysts and customers involved in the programs. The following paragraphs highlight the significant additions to the programs in each section that affect the quality of data or PGDP's overall capacity to provide additional information on environmental activities.

The Technical Services Division has employed two procedure writers matrixed from the Procedures Management Department to coordinate and assist in the development and revision of $\mathrm{QA}$ and quality control (QC) procedures so that they comply with plant procedures and policies.

The Quality Support Section provides surface water monitoring controls and groundwater monitoring controls and routinely issues summary reports to inform lab supervisors and managers of the data quality measurements in the Technical Services Division. The section has upgraded their computer equipment and enlisted the efforts of a statistician to improve computer programming for the evaluation of the data packages. Control charts and trend analysis evaluations complete the statistical evaluations of data.

A project begun in 1991 was completed, and implementation began to incorporate requirements from U.S. Department of Energy (DOE) orders 5400.1 and 5400.5 and DOE/EH-0173T, Environmental Regulatory Guide for Radiological Effluent Monitoring and Environmental Surveillance, as they relate to the Environmental Monitoring Plan (EMP) at PGDP. The EMP was drafted over several years and was approved by DOE in July 1992. Also considered in this project were the Tiger Team findings on air, groundwater, QA, and radiation monitoring. The specific purpose of the project was to analyze the functional responsibilities being coordinated among the Environmental Compliance, Monitoring, and Restoration departments to expedite implementation of the EMP at PGDP. The following benefits were expected from the project:

- better use of the timetable being imposed by Martin Marietta Energy Systems, Inc., Environmental, Safety, and Health Central Staff;

- improved program management and better defined oversight responsibilities;

- enhanced communication among departments in meeting objectives;

- increased efficiency of data review for technical interpretation and reporting; and

- better allocation of available resources for the EMP and the Agreement In Principle with the state of Kentucky. 


\section{Environmental Report-Paducah, Part 1}

The recommendations of this project resulted in the formation of the Environmental Monitoring Department (EMD) in the Environmental, Safety, and Health Division (now the Environmental Management Division). The Environmental Services Department from the Technical Services Division and personnel in the compliance organization were transferred to the monitoring organization where responsibilities were related to DOE order implementation. General responsibilities of the EMD are

- EMP programs (sampling, QA, data management),

- environmental monitoring plans,

- Agreement In Principle coordination for monitoring,

- Annual Environmental Report,

- Environmental Information Management System,

- Internal reporting of environmental data,

- dose assessments,

- input to Sampling and Analysis Plan development, and

- technical support.

Sixty-seven positions were identified in the final project report. The actual number requested was 43 based on known budget restraints. The project team decided that a staff of 43 was adequate to begin implementation. The ideal personnel projection of 67 provided guidance on how to use personnel as funds became available. Because of the reduced levels of staffing, several roles would either not be filled or be partially filled. Surveillance and screening activities would not be increased. Special projects and increased work loads were not planned. Projections for data validation activities were extended into the future. Oversight of external laboratories would not be included.

The resulting organization was aligned according to pathway-related programs in the EMP. Figure 10.1 shows the current organization and responsibilities for the 34 persons and 9 vacancies in the department. From January 1992 to May 1993, there were 16 new hires and 4 transfers added to the 14 existing personnel. The department manager is responsible for financial, technical, and staffing direction and is supported by a secretary responsible for coordinating required reading, Lockout/Tagout training, general training tracking, and Department of Transportation documentation along with normal secretarial duties. Six program managers support the department head in major areas. All of the program managers or coordinators have staff reporting to them.

The department acquired three trailers to store and organize sample containers. The number of persons having direct access to sample containers was reduced. A Total Quality Management/Cycle Time Reduction study was performed on the Polychlorinated Biphenyls Cleanup Verification Program. This lead to defining "TSCA | Toxic Substances Control Act / Good Faith Effort" deadlines for cleanup verification sampling. All deadlines are being met. Additional personnel in all programs attended 40-h Hazardous Material Training and certification, enhancing the health protection and utility of department personnel. Fireproof cabinets were purchased to protect environmental documentation such as field notebrooks and chain-of-custody information.

The department also received two mobile laboratories in CY 1992. These self-propelled laboratories will be used as staging areas for major sampling events as well as for certain routine activities. The mobile labs also provide a controlled environment for employees to recover from environmental exposure during adverse weather conditions in remote sampling locations. In addition, laboratory and office space for the staging of groundwater and surface water monitoring activities were acquired during the year. This additional space was required to house the increased staff and to provide additional fixed laboratory space for field monitoring activities.

Although several of the new functions and activities previously noted are not fully implemented, EMD has made substantial progress during this year of change. FY 1993 promises to build on these accomplishments and enhance the effectiveness of the organization.

\subsection{Field Sampling and Monitoring}

\subsubsection{Basic Concepts and Practices}

From the point of conception of any sampling program, QA plays an important role. Each monitoring or sampling organization plans a project, sets objectives, identifies responsibilities, and selects sampling methods and the appropriate sampling 


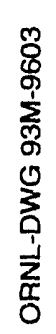
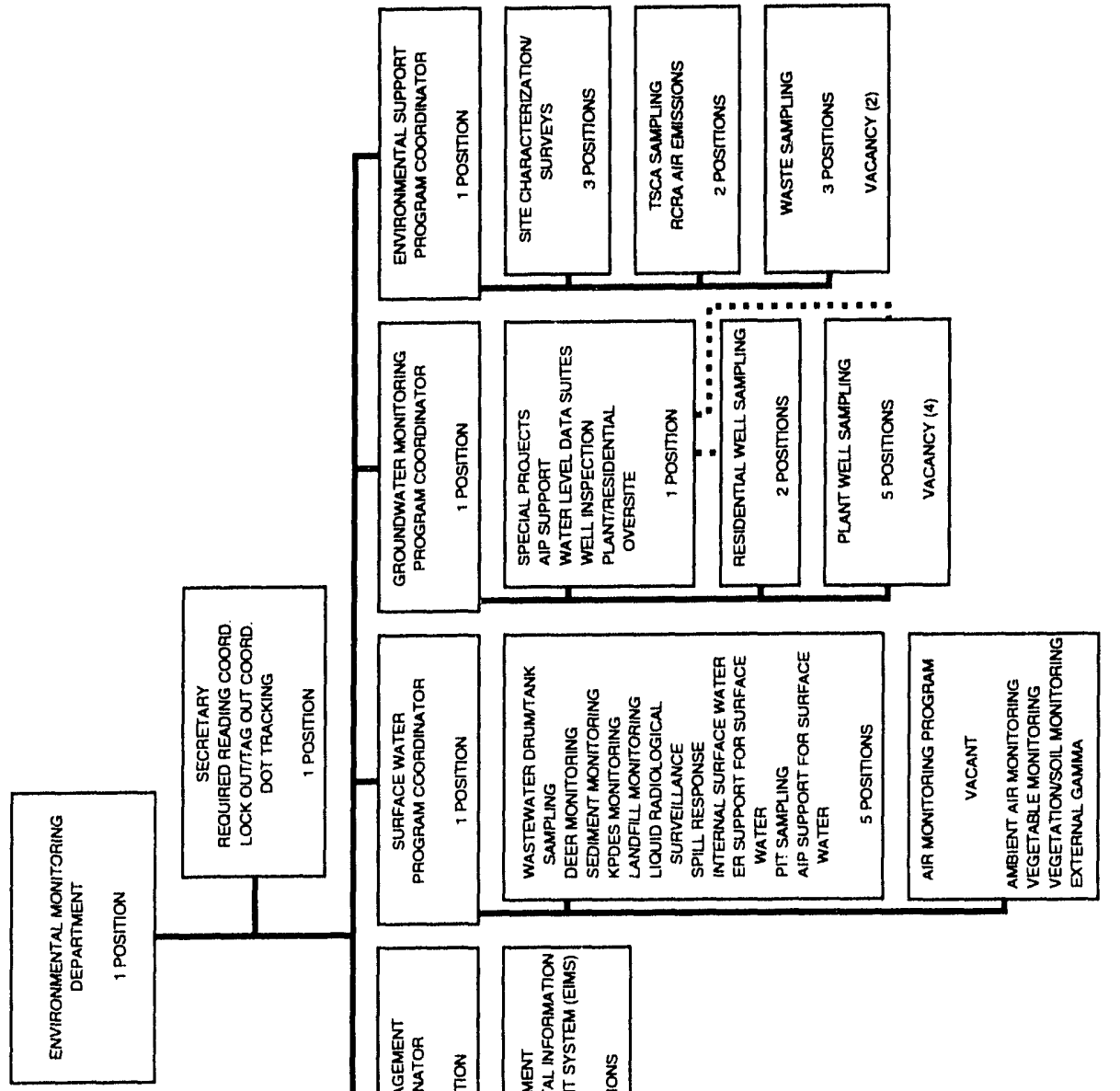

㥈

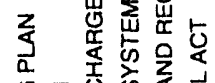

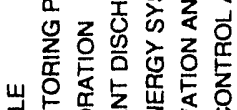

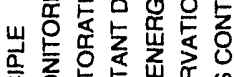

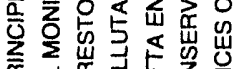

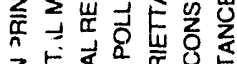

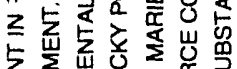

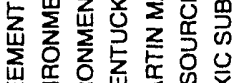

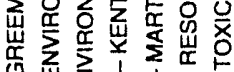

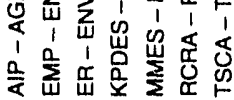

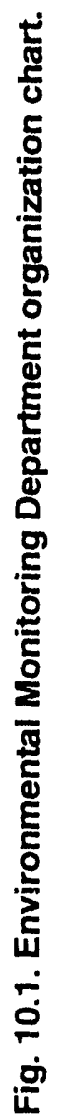

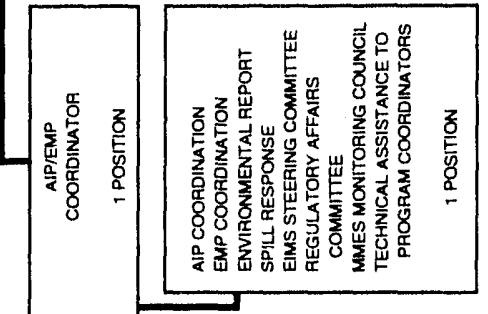




\section{Environmental Report-Paducah, Part 1}

instruments or devices according to use and cleaning practices recommended by the American Society for Testing and Materials, the U.S. Environmental Protection Agency (EPA), or other established authorities. The number of samples, location of sampling sites, sampling methods, sampling schedule, and coordination of sampling and analytical resources to meet critical completion times must all be decided. The rationale for these and other decisions is mainly the responsibility of the sampling organization, receiving input from compliance and analytical organizations. Sampling plans and field documentation are prepared as needed.

Chain-of-custody documentation is maintained from the point of sampling, and samples are properly protected until they are placed into the custody of analytical laboratory control programs. In the laboratory, chain-of-custody procedures are followed until the sample is analyzed. For hazardous waste samples, chain-of-custody procedures are maintained to the point of sample disposal. The performance of all field analytical procedures is documented using EPA-approved methods when available. These procedures are listed in Table 10.7 in Part 2.

\subsubsection{External Gamma Monitoring}

Monitoring for gamma radiation is Inandated by U.S. Department of Energy (DOE) Orders 5400.1 and 5400.5 along with other published guidelines (DOE 1991). Guidance for procedures has also been published (ANSI 1975). The calibration, preparation, and analysis of PGDP thermoluminescent dosimeters is performed by Oak Ridge National Laboratory (ORNL).

\subsubsection{Air Monitoring}

The design of the ambient air samplers is based on an internal study that determined the efficiency of potassium-carbonate-impregnated filter paper for collecting gaseous fluorides. The procedure requires that flow be measured using a calibrated flow meter. If the flow drops by more than $40 \%$ of the initial reading, the sample is not used. This procedure helps to ensure that reported data accurately reflect plant emissions. Air filter sampling data are recorded in the field logs and in the chain-of-custody logs, and they are entered into the computer system. Analytical procedures are listed in Table 10.1 in Part 2. (See Tables 10.21 and 10.22 in Part 2 for QC data.)

\subsubsection{Water Monitoring}

Water sampling is conducted both for PCiDP's information and to meet regulatory requirements. Procedures have been written for surveillance sampling and for Kentucky Pollutant Discharge Elimination System (KPDES) permit sampling. Guidance for developing these procedures has been codified (40 CFR 136.3) and may also be found in other applicable sources. Records are kept in the field logs and in the chain-of-custody logs and are entered into the computer system. The chain-of-custody logs also record the subsampling (i.e., a procedure by which aliquots of a sample are divided for specific analysis) and preservation of each sample. The chain-of-custody logs are stored in the Environmental Sampling office. The analytical procedures for these samples are listed Tables 10.2, 10.3, and 10.7 in Part 2. (See Tables 10.8 through 10.21 in Part 2 for QC data.)

\subsubsection{Groundwater Monitoring}

Water samples from plant wells are collected according to written procedures based on published guidelines (EPA 1987). Field measurements used for reporting analytical data are taken using calibrated instruments to ensure accurate data. Records for wells are kept in the field logbook and in the chain-of-custody logs and are entered into the computer system. The chain-of-custody logs also record subsampling and preservation for each sample. The analytical procedures for these samples are listec in Tables 10.2, 10.3, 10.6, and 10.7 in Part 2. (See Tables 10.8 through 10.21 in Part 2 for $Q C$ data.)

\subsubsection{Biological Monitoring}

Biological monitoring consists of quarterly grass sampling from the surrounding area to determine levels of fluoride concentrations and annual sampling of wildlife, vegetation, and food crops for radioactive analytes. Analytical procedures for these samples are listed in Table 10.4 in Part 2. 


\subsubsection{Soil and Sediment Sampling}

Samples of soil and sediment are collected according to published procedures (Jett 1992; Watson 1989). No field measurements are taken in these sampling procedures. Background soil and sediment samples are used to establish the baseline from which the plant's contribution of contaminants can be calculated. As a QC check on the accuracy of the data, ${ }^{411} \mathrm{~K}$ in the samples is analyzed. Because ${ }^{41} \mathrm{~K}$ levels are not affected by plant operations and are analyzed by the same method as the other parameters, any deviation from expected values indicates procedural problems. Rccords are kept in the field logs and the chain-of-custody logs and are entered into the computer system. The analytical procedures for these samples are listed in Table 10.5 in Part 2.

\subsubsection{Solid Waste Monitoring, Site Characterizations, and Spill Cleanup}

Solid waste sampling and characterizations are conducted to ensure that storage and disposal of solid wastes is in accordance with the Toxic Substances Control Act (TSCA), the Resource Conservation and Recovery Act (RCRA), and DOE Order 5820.2A. Sampling at spill sites is conducted to quantify the magnitude of the spill and to verify cleanup in accordance with applicable regulations. Site characterizations and surveys are performed to ascertain the regulatory status or continuing status of specific areas and to ensure that any wastes resulting from activities in these areas are properly managed.

Requests for both routine and special sampling and characterizations are issued by environmental management and waste management personnel. Specific activities include sampling and characterization of containerized wastes, lagoons, certain waste streams at the point of generation, and construction sites. QA/QC in support of these efforts includes the use of precleaned sample containers, collection of equipment field blanks and field duplicates, and the use of statistically based sampling plans, where possible.

Guidance for sampling and characterization is obtained from EPA documents (EPA 1987) and from other applicable regulations. Records are maintained in field logs, laboratory notebooks, chain-of-custody notebooks, and the AnaLIS data management computer system. Results from RCRA evaluations of waste streams and special RCRA evaluations are summarized in quarterly, semiannual, and annual reports.

\subsection{Analytical Quality Assurance}

The analytical laboratories of PGDP continue a long tradition of QA. Such terms as sound methodology, safe practices, analytical recovery, and $Q C$ are well defined. Also well established is the use of statistical methods to establish precision, accuracy, lowest concentration reported (LCR), and minimum detection level (MDL). Since the beginning of operations at PGDP, the laboratories have been involved in the handling and analysis of hazardous materials, materials for which strict accountability is required, and materials of high purity. QA is, therefore, a daily responsibility.

After receiving the samples from the sampling group or the sample transporter, the laboratory custodian assumes responsibility for proper protection and handling of the samples. Using guidance from the EPA, the laboratories document the steps in handling, analysis, and approval of results. The performance of all analytical procedures is documented using EPA-approved methods when they are available. These procedures for air, water, soil, sediment, biota, and groundwater (with traceability to EPA methods) are listed in Tables 10.1 through 10.6 in Part 2.

A key feature in analytical QA is QC. PGDP participates in programs that are internal to the laboratory (i.e., internal controls), internal to PGDP but external to the laboratory (i.e., external controls), and external to the plant (i.e., independent controls).

\subsubsection{Internal Quality Control}

All analytical activities are supported by the use of standard materials or reference materials. The compositions of these materials are well known and are used in calibration of instruments, method standardization, spike additions for recovery testing, and other practices. Certified standards from the National Institute of Standards and Technology, the EPA, or other DOE laboratories are often used in such work. 


\section{Environmental Report-Paducah, Part 1}

These internal programs are the mainstay of analytical QC. They are the basis for ensuring reliable results on a daily basis and between batches. The total effort in these programs is at least $10 \%$ of the total laboratory effort (in accordance with EPA expectations) and probably reaches $20 \%$ in some activities.

The internal QA and QC programs have become major factors in the environmental analysis procedures because of the low levels of pollutants measured and the relationships of these measured values to regulatory limits. These $\mathrm{QC}$ programs also provide for laboratory analyst training and qualification in the many procedures involved. The daily QC data are stored in a retrievable manner so they can be related to the analytical results they support. Examples of some of these programs are listed in Tables 10.8 and 10.9 in Part 2.

\subsubsection{External Quality Control}

The Technical Services Division has a Quality Support Section (QSS) that is functionally independent of the laboratory. QSS administers external quality control programs at the request of the analytical laboratories and their customers. Through these programs, the QSS generates QC samples of known composition and periodically submits these to the laboratory as known controls of unknown value (blind). Many of these programs include computer-generated notices for immediate feedback of performance. Formal reports summarizing statistical evaluation of data, control charts, and results of trend analyses are issued regularly. Results that exceed the 3-sigma alarm limits are investigated and documented in accordance with formal procedures.

\subsubsection{Independent Quality Control}

PGDP is directed by DOE and by the EPA regulators to participate in external quality control programs. PGDP also participates in voluntary external programs to provide for improved analytical QC. These programs generate data that are readily recognizable as objective measures, allowing the participating laboratories and government agencies a periodic review of performance. Although participation is mandated, the degree of participation is voluntary, so that each laboratory can select parameters that are of particular interest to that plant. The sources of these programs are EPA, DOE, and commercial-sector laboratories. Examples are given in Tables 10.10 through 10.23 in Part 2 for both radiological and nonradiological areas. The QSS coordinates and evaluates the results of the independent QC programs discussed in the following subsections.

\subsubsection{Environmental Protection Agency Discharge Monitoring Report Quality Assurance Program}

The EPA conducts a national QA program in support of the National Pollutant Discharge Elimination System (NPDES) program. All holders of major NPDES permits are required to participate. The EPA furnishes the QC samples annually and evaluates the results. The state of Kentucky monitors PGDP's performance in this program. PGDP is required to analyze those parameters on its permit that are included in the Discharge Monitoring Report (DMR) QA Program. Other parameters may be analyzed on a voluntary basis for documentation or method checking. Table 10.10 in Part 2 shows all 12 analyses within acceptable limits.

\subsubsection{Proficiency Environmental Testing Program}

PGDP participates in the Proficiency Environmental Testing (PET) Program, a voluntary external measurement control program using samples purchased from Analytical Products Group, Inc. (APG), a commercial supplier. Samples at iwo concentration levels are analyzed bimonthly and reported to APG. An evaluation report is received in approximately 3 weeks. Most samples are evaluated by comparing (in standard deviations) the reported value to the mean of the reporting laboratories. Samples for dissolved and suspended solids are compared with average percent of recovery in the same way. The performance evaluation in the tables is derived using the same criteria as those in the EPA DMR QA program. The QSS maintains control charts on these analyses. Tables 10.11 through 10.16 in Part 2 present the results of the 1992 PET testing.

Measurements that have unacceptable recoveries of more than 2.58 standard deviations from the mean 
are investigated to determine the cause. Of 622 measurements, 16 were deemed not acceptable.

\subsubsection{Proficiency Analytical Testing Program}

PGDP participates in the Proficiency Analytical Testing (PAT) Program, an external measurement control program from the National Institute for Occupational Safety and Health (NIOSH). This program targets industrial hygiene analyses but also has application to environmental factors because the concerns in both fields overlap. Of 64 measurements, 1 was an outlier (Tables 10.17 through 10.20 in Part 2). The performance evaluations for these tables are provided by NIOSH. The laboratory maintained a "proficient" rating for all analyses during 1992.

\subsubsection{DOE Environmental Measurements Laboratory Quality Assessment Program}

PGDP participated in the Environmental Measurements Laboratory (EML) measurements control program as required by DOE Order 5400.1 . The results are given in Tables 10.21 and 10.22 in Part 2 . The performance evaluation is determined by using the three ratio ranges given in the EML report to determine "acceptable," "marginal," or "not acceptable" results. There were 3 "not acceptable" results out of the 42 results reported.

\subsection{Quality Incidents}

\subsubsection{Environmental Protection Agency Discharge Monitoring Report Quality Assurance Program}

No results exceeded the acceptable limits for this program in 1992. Program information may be found in Part 1, Sect. 10.2.3.1; data are in Part 2, Table 10.10 .

\subsubsection{Proficiency Environmental Testing Program}

The January 1992 round of testing had one result rated "not acceptable." One control for high-level total hardness as $\mathrm{CaCO}_{3}$ was outside the lower acceptance limit. No problems were apparent in the internal QC for the day. After receiving an exception report, laboratory personnel reanalyzed the solution and determined the result to be $41 \mathrm{mg} / \mathrm{L}$, which was within acceptable limits. The previous result appeared to be a duplicate analysis of the low-level solution. No change in procedure was made at that time.

The March 1992 round had five results rated "unacceptable." The ammonia as $\mathrm{N}$ (level 2) result was outside the control limits. Upon investigation, the vial containing the level-2 solution was found unopened. The flask from which the result was analyzed contained the ammonia solution from the previous round. That solution had been analyzed and reported in error. All technicians have been notified to make note of the date of preparation on the flask before analyzing future samples. The hardness as $\mathrm{CaCO}_{3}$ (level 2) result was outside the high control limit for the solution. Investigation of the result indicated that calcium hardness had been analyzed on the solution instead of total hardness. Total hardness was analyzed after the error was discovered with a result of $54 \mathrm{mg} / \mathrm{L}$, which was within acceptable limits. Three metal analyses (aluminum, arsenic, and selenium) were above acceptable limits. Reanalysis of the original aluminum solution confirmed the reported result. All QC data from the original analysis batch were acceptable. The original data also showed that results from another dilution of the original PET solution would have yielded results within acceptable limits. Isolated contamination is considered the cause of the error. Glassware cleaning has been inspected, and no system-wide problem can be identified. The problem appears to be an isolated incident. Investigation of the arsenic and selenium results indicated that the solution was analyzed on an instrument with insufficient modifier. The instrument modifier has been corrected accordingly.

The May 1992 round had no unacceptable results.

The July 1992 round had one unacceptable result. The mercury (level 1) result was above the control limits for the solution. Originally, several dilutions of the original solution were prepared. The result for the first dilution was within acceptable limits, but instrument problems negated the analysis run. Apparently, contamination from pipetting entered the original vial upon the second dilution, yielding high results for all subsequent dilutions and analysis of this solution. Pipetting methods and washing 


\section{Environmental Report-Paducah, Part 1}

techniques will be reviewed to prevent recurrence of this problem.

The September 1992 round had four unacceptable results. Calculation errors accounted for three of the four errors (mercury, levels 1 and 2, and beryllium, level 2). All three results were reported without correcting for dilutions made. The data-checking system is being reviewed to determine a more efficient method. The arsenic (level 1) sample was above control limits for the sample. Investigation showed that all QA/QC criteria were acceptable for the analysis run. However, analysts noticed that although the QC data were acceptable, the value was in the high range of acceptable results, which probably accounted for the slightly higher reading reported. The acceptable range of the $\mathrm{QC}$ will be reevaluated to ensure better control.

The November 1992 round had six unacceptable results. Both alkalinity results were reported beyond their control limits. Upon investigation of the error, the samples were reanalyzed and found to be within acceptable limits. Apparently the results for the two solutions were switched. In addition, both calcium results were reported beyond their control limits. Investigation revealed that the solutions had been analyzed for calcium hardness instead of total hardness. The solutions were analyzed for total hardness, and the results were within acceptable limits. The nitrate (level 1) result was above the acceptable limit. During the investigation the calculations were checked and the solutions reanalyzed. The nitrate value on the original solution should have been reported as $<1$, the lowest concentration reportable for this method. The high-level aluminum result was also beyond the acceptable limit for the solution. The investigation suggested that a contamination problem may be the cause for the error. In the future, all glassware will be acid washed prior to sample dilution.

In addition to the independent PE'T program, an external program was used in 1992 to monitor environmental results. Standard material from the PET program is submitted along with routine KPDES and groundwater samples to provide quick feedback to the analytical labs. Program information may be found in Part 1, Sect. 10.2.3.2; data are in Part 2. Tables 10.11 through 10.16 .

\subsubsection{Proficiency Analytical Testing Program}

The January, April, and July rounds had no unacceptable results.

The October 1992 round had one cadmium result outside acceptable limits. A calculation error was found in the original data. When corrected, the result was within acceptable limits. Program information may be found in Part 1, Sect. 10.2.3.8; data are in Part 2, Tables 10.17 through 10.20.

\subsubsection{Environmental Measurements Laboratory Program}

The March 1992 round had one uranium result rated as unacceptable. The result was reported in incorrect units. When corrected to proper units for reporting, the result was acceptable.

The September 1992 round had two results rated as unacceptable. Both the ${ }^{134} \mathrm{Cs}$ and ${ }^{137} \mathrm{Cs}$ reported results were low. Upon investigation, laboratory personnel discovered that the cesium had plated out of solution on the beaker used for evaporating the original solution during preparation of the solution for analysis. The preparation procedure has been revised to eliminate evaporation to dryness, and glassware will be checked routinely for residuals in the preparation of solutions. Program information may be found in Part 1, Sect. 10.2.3.4; data are in Tables 10.21 and 10.22 .

\subsubsection{Environmental Measurements Systems Laboratory-Las Vegas Program}

The October round had one result listed as an outlier $\left({ }^{133} \mathrm{Ba}\right.$ in water). A transcription error was made in transferring the result from the raw data to the computer entry. The results in the raw data were within the acceptable range. All other results were within acceptable ranges. Data may be found in Part 2, Table 10.23.

\subsection{Documentation Quality Assurance}

At the request of the project coordinator, the Energy Systems Publications Division assists each Energy Systems site by coordinating the compilation, 


\section{Environmental Report-Paducah, Part 1}

editing, and reproduction of its data. This volume is part of a four-volume set designed to fulfill the DOE 5400.1 annual environmental data reporting requirement for all Energy Systems sites.

The Publications Division appoints a team of editors and electronic publishers to produce the documents. Draft volumes are produced in the spring for internal review and for comment by DOE, and then a final copy is printed for delivery before the June 1 deadline. For each draft and for the final copy, the editors are responsible for ensuring the quality of the document and that all submitted materials are included and accurately reflect the text and data as submitted. The quality and technical accuracy of submissions are the responsibility of the site coordinator.

The editors follow procedures that address recording the submissions of entries (including text, figures, and tables) and the status of submissions (in production, being proofread, etc.). The record-keeping measures are based on the submissions required for the previous year's report (determined from the table of contents) plus any alterations agreed upon by the project coordinator and site coordinators. Tracking sheets for data tables and figures are also kept.
All text, tables, and figures are edited, and questions are directed to the site or project coordinator. All final copy is proofread for accuracy and lidelity to copy. Draft copies of the entire volume are submitted to the site coordinator for technical review and approval.

\subsection{References}

American National Standards Institute (ANSI) 1975

Performance, Testing, and Procedural

Specifications for Thermoluminescent

Dosimeters (Environmental Application).

N545-1975, New York, N.Y.

Jett, T. G. 1992. Soil Sampling, EMD-208, Paducah Gaseous Diffusion Plant, Paducah, Ky.

U.S. Environmental Protection Agency (EPA). 1987. Test Methods for Evaluating Solid Waste, SW-846.

U.S. Department of Energy (DOE). January 1991. Regulatory Guide for Radiological Effluent Monitoring and Environmental Surveillance, DOE/EH-()173T, Washington, D.C.

Watson, D. D. 1989. Environmental Sediment Sampling, ES-7.RI, Paducah Gaseous Diffusion Plant, Paducah, Ky. 
PART 2: Data Presentation 


\section{Introduction}


1992 Environmental Report-Paducah, Part 2

All data for this section are presented in Part 1. 
2. Potential Radiation Dose to the Public 
Table 2.1. 1992 annual dose estimation-worst-case ingestion of groundwater

\begin{tabular}{|c|c|c|c|c|c|c|}
\hline \multirow[b]{2}{*}{ Radionuclide } & \multicolumn{4}{|c|}{ Intake (exposure) values ${ }^{a}$} & \multicolumn{2}{|c|}{ Dose values $^{b}$} \\
\hline & $\begin{array}{l}\text { Concentration } \\
(\mathrm{pCi} / \mathrm{L})\end{array}$ & $\begin{array}{l}\text { Ingestion } \\
\text { rate } \\
(\mathrm{L} / \mathrm{d})\end{array}$ & $\begin{array}{c}\text { Exposure } \\
\text { frequency } \\
\text { (d/year) }\end{array}$ & $\begin{array}{c}\text { Total } \\
\text { intake } \\
\text { (pCi/year) }\end{array}$ & $\begin{array}{l}\text { Ingestion dose } \\
\text { conversion } \\
\text { factor } \\
(\mathrm{nnrem} / \mathrm{pCi})\end{array}$ & $\begin{array}{c}\text { Annual } \\
\text { CEDE }^{c, d} \\
\text { (mrem/year) }\end{array}$ \\
\hline${ }^{99} \mathrm{Tc}$ & 25.000 & 2.0 & 365 & $18,250.00$ & $1.30 \mathrm{E}-06$ & 0.024 \\
\hline
\end{tabular}

aExposure values from U.S. Environmental Protection Agency 600/8-89-043, "Exposure Factors Handbook," July 1989.

${ }^{b}$ Dose factors from U.S. Department of Energy/EH0071, "Internal Dose Conversion Factors for Calculation of Dose to the Public," July 1988.

${ }^{c}$ Committed effective dose equivalent as committed (50-year) dose from 1 year of exposure (mrem/year).

${ }^{d}$ Dose rounded to two significant figures based on ingestion rate.

Table 2.2. 1992 annual dose estimation-worst-case incidental ingestion of sediment in Little Bayou Creek

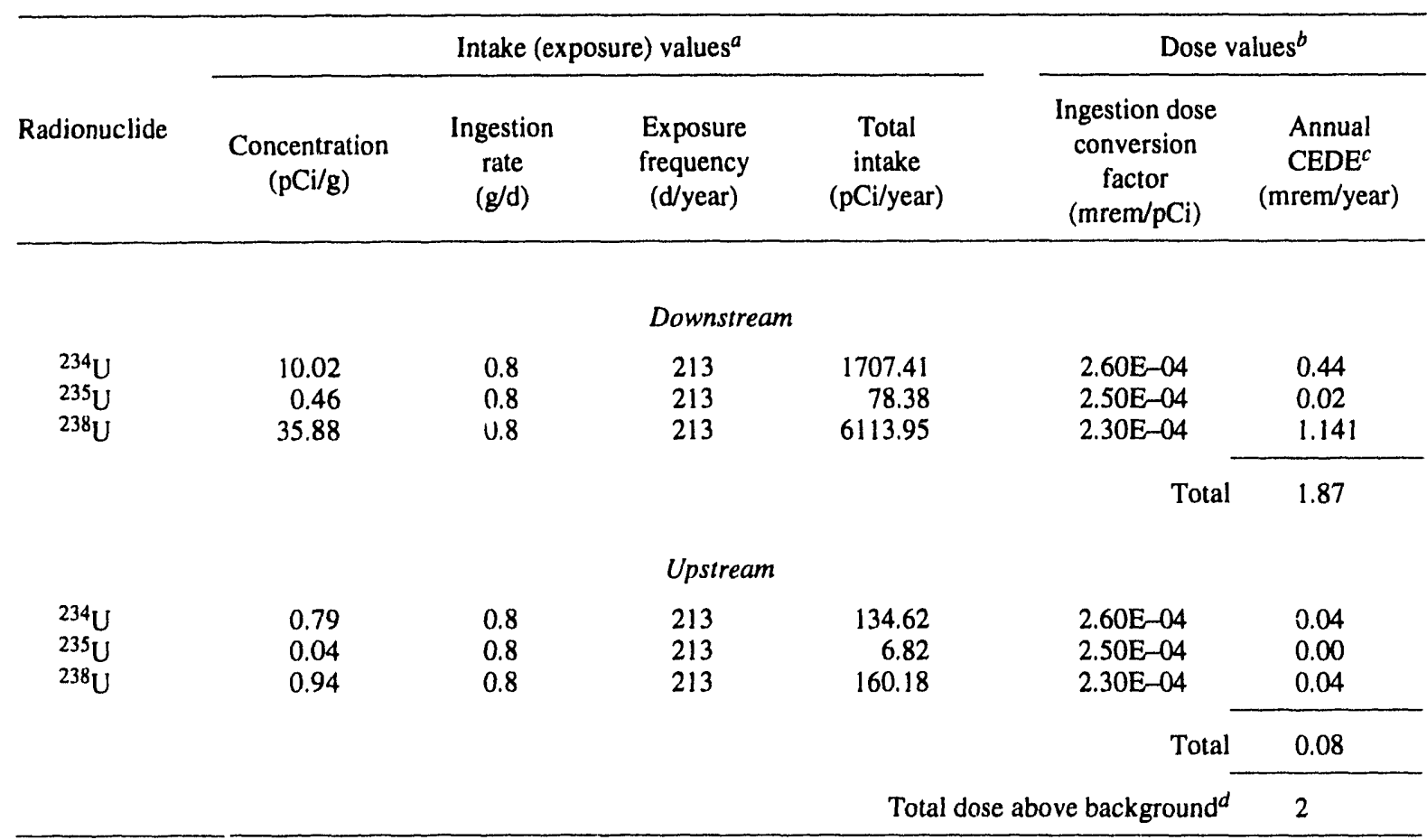

\footnotetext{
${ }^{a}$ Exposure values from U.S. Environmental Protection Agency 600/8-89-043, "Exposure Factors Handbook," July 1989.

'Dose factors from U.S. Department of Energy/EH0071, "Internal Dose Conversion Factors for Calculation of Dose to the Public," July 1988.

cCommitted effective dose equivalent as committed (50-year) dose from 1 year of exposure (mrem/year).

${ }^{d}$ Dose rounded to one significant figr;e based on ingestion rate estimate.
} 


\section{Environmental Report-Paducah, Part 2}

Table 2.3. 1992 annual dose estimation-worst-case ingestion of deer tissue

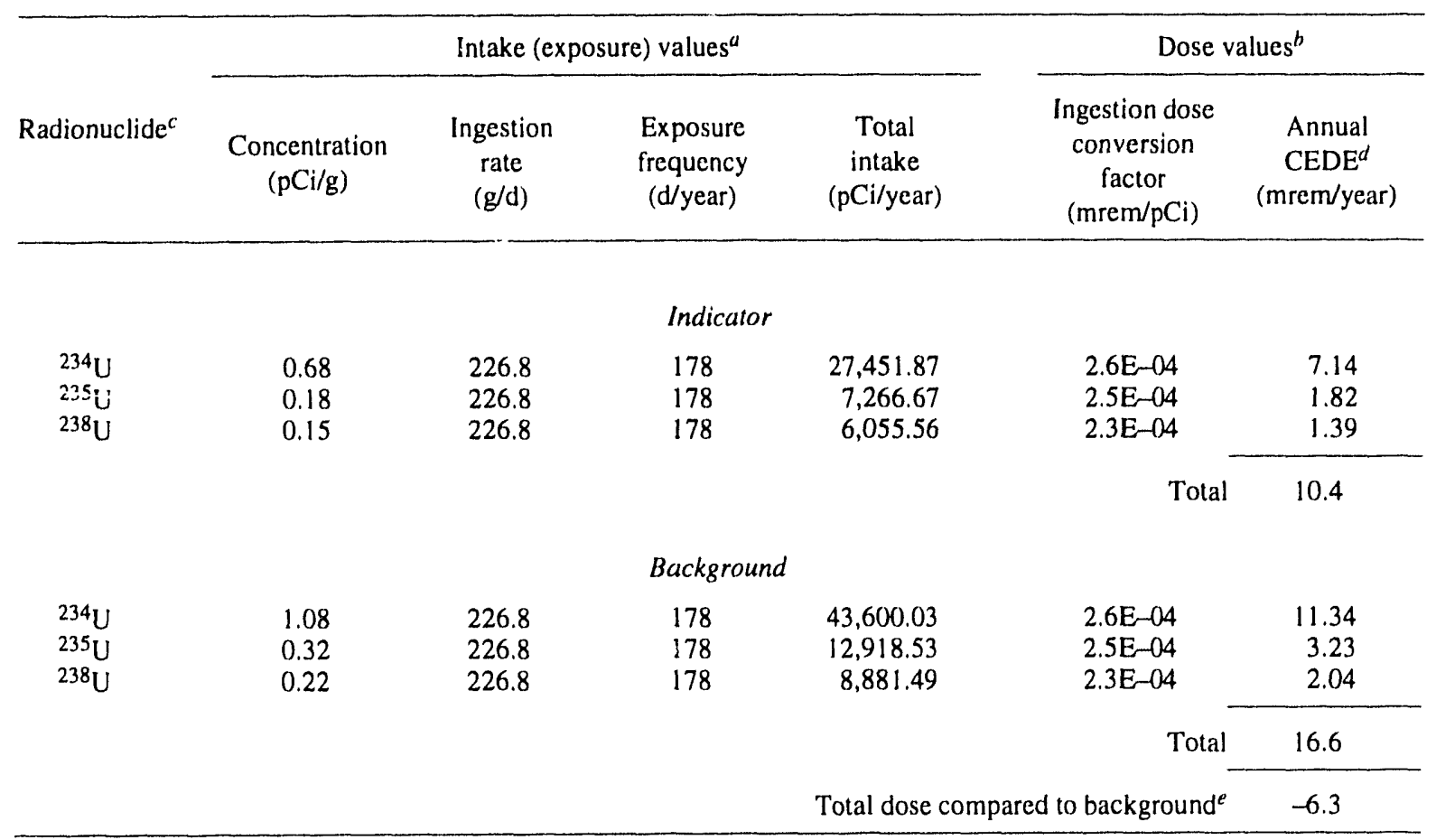

${ }^{a}$ Exposure values as per C. Logsdon. Personal communication with M. G. Guhy, November 27, 1990.

${ }^{b}$ Dose factors from U.S. Department of Energy/EH0071, "Internal Dose Conversion Factors for Calculation of Dose to the Public," July 1989.

${ }^{c}$ Only radionuclides present above detection limits ( $99 \%$ confidence level) are included.

${ }^{d}$ Committed effective dose equivalent as committed (50-year) dose from 1 year of exposure.

${ }^{e}$ Dose rounded to two significant figures based on dose conversion factor. 
1992 Environmental Report-Paducah, Part 2

Table 2.4. 1992 annual dose estimation-worst-case ingestion of food crops

\begin{tabular}{|c|c|c|c|c|c|c|c|}
\hline \multirow[b]{2}{*}{ Type } & \multirow[b]{2}{*}{ Radionusclide $^{c}$} & \multicolumn{5}{|c|}{ Intake (exposure) values ${ }^{a}$} & Dose values $^{b}$ \\
\hline & & $\begin{array}{l}\text { Concentration } \\
(\mathrm{pCi} / \mathrm{g})\end{array}$ & $\begin{array}{l}\text { Ingestion } \\
\text { rate } \\
(\mathrm{g} / \mathrm{d})\end{array}$ & $\begin{array}{c}\text { Exposure } \\
\text { frequency } \\
\text { (d/year) }\end{array}$ & $\begin{array}{c}\text { Fraction } \\
\text { homegrown }\end{array}$ & $\begin{array}{c}\text { Total } \\
\text { intake } \\
\text { (pCi/year) }\end{array}$ & $\begin{array}{l}\text { dose } \\
\text { conversion } \\
\text { factor } \\
\mathrm{CEDE}^{d} \\
(\mathrm{mrem} / \mathrm{mrear}) \\
\end{array}$ \\
\hline
\end{tabular}

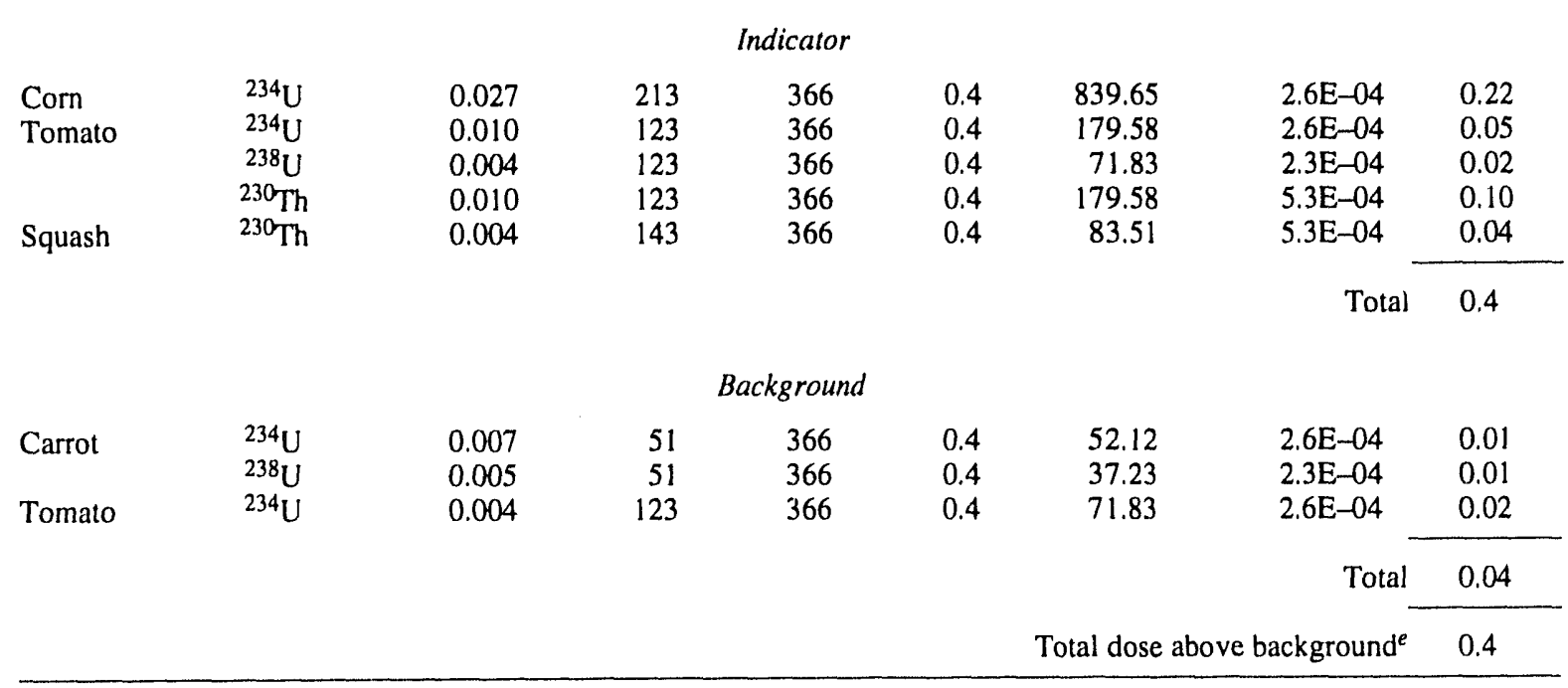

${ }^{a}$ Exposure values from U.S. Environmental Protection Agency 600/8-89-043, "Exposure Factors Handbook," July 1989.

"Dose factors from U.S. Department of Energy/EH0071, "Internal Dose Conversion Factors for Calculation of Dose to the Public," July 1989.

${ }^{c}$ Only radionuclides present above detection limits ( $99 \%$ confidence level) are included.

${ }^{d}$ Committed effective dose equivalent as committed (50-year) dose from 1 year of exposure (mrem/year).

${ }^{e}$ Dose rounded to one significant figure based on fraction homegrown.

Table 2.5. 1992 annual dose estimation-worst-case direct radiation in K011 effluent ditch ${ }^{a}$

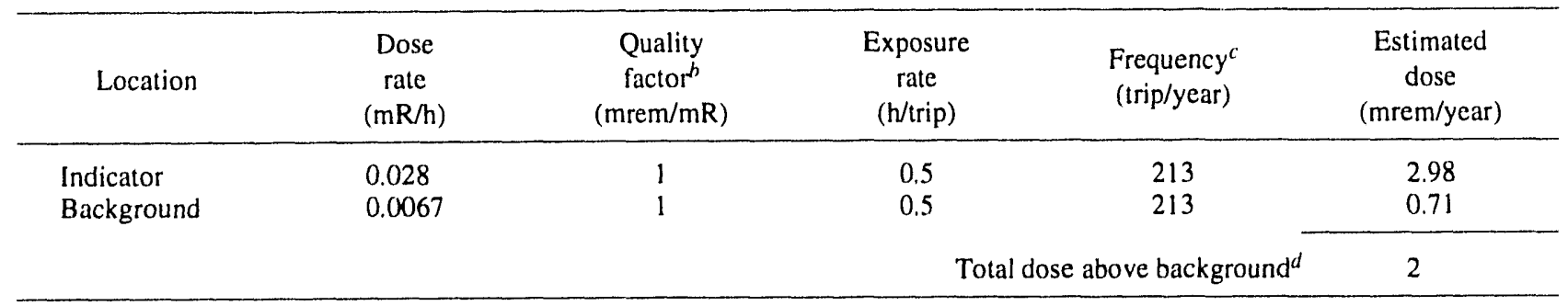

${ }^{a}$ Background dose calculated using the same assumptions is $0.71 \mathrm{mrem} / \mathrm{year}$.

${ }^{b}$ Quality factor for converting gamma radiation from milliroentgen to millirem.

${ }^{c}$ Exposure frequency as per C. Logsdon. Personal communication with M. G. Guhy, May 10, 1991 .

${ }^{d}$ Dose rounded to one significant figure based on quarity factor. 
3. Airborne Discharges, Ambient Air Monitoring, Meteorological Monitoring, and External Gamma Radiation 
1992 Environmental Report-Paducah, Part 2

Table 3.1. Permitted air sources at PGDP ${ }^{a}$

\begin{tabular}{|c|c|c|}
\hline $\begin{array}{l}\text { Source } \\
\text { number }\end{array}$ & Location & Control equipment \\
\hline 1 & C-600 number 2 boiler & $\begin{array}{l}\text { Electrostatic precipitators } \\
\text { and low-sulfur coal }\end{array}$ \\
\hline 2 & C-600 number 3 boiler & $\begin{array}{l}\text { Electrostatic precipitators } \\
\text { and low-sulfur coal }\end{array}$ \\
\hline 4 & C-405 incinerator (north) ${ }^{b}$ & Venturi scrubber \\
\hline 5 & C-405 incinerator (south) ${ }^{b}$ & Venturi scrubber \\
\hline 7 & C-310 purge vent & $\begin{array}{l}\text { Chemical traps, high-speed } \\
\text { centrifuge }\end{array}$ \\
\hline 8 & C-410 fluorine production & Cold condensers ${ }^{c}$ \\
\hline 15 & C-400 UF 4 pulverizer ${ }^{b}$ & Filters \\
\hline 26 & C-746 reverberatory furnace ${ }^{b}$ & \\
\hline 27 & C-746 aluminum sweat furnace ${ }^{b}$ & \\
\hline 29 & C-400 gold recovery $b$ & \\
\hline 31 & C-724 paint spray booth & Water wash scrubber \\
\hline 32 & C-725 paint spray booth & Water wash scrubber \\
\hline 33 & C-746-A rotary calciner ${ }^{b}$ & $\mathrm{CaCO}_{3}$ traps \\
\hline $34(a)$ & Smelter-central dust collector ${ }^{b}$ & Filters \\
\hline 35 & C- 600 number 1 boiler & \\
\hline 36 & Smelter-induction furnace ${ }^{b}$ & Torit filters \\
\hline 37 & C- 600 coal handling equipment & Water sprays \\
\hline 38 & $\begin{array}{l}\text { C- } 400 \text { Detrex open-top vapor } \\
\text { degreaser }\end{array}$ & $\begin{array}{l}\text { Covered systems and } \\
\text { condensing coils }\end{array}$ \\
\hline 39 & $\begin{array}{l}\text { C- } 400 \text { Blakeslee open-top vapor } \\
\text { degreaser }\end{array}$ & $\begin{array}{l}\text { Covered systems and } \\
\text { condensing coils }\end{array}$ \\
\hline 40 & $\begin{array}{l}\text { C-720 Branson open-top vapor } \\
\text { degreaser (trichloroethylene) }\end{array}$ & \\
\hline 41 & C-720 cold cleaning degreaser ${ }^{b}$ & \\
\hline 42 & Chemical unloading & Wet cyclone scrubber \\
\hline 43 & $\begin{array}{l}\text { C-340 uranium alloy remelting } \\
\text { operation }^{b}\end{array}$ & Filters \\
\hline
\end{tabular}

aPermit No. 0-85-110 issued on September 30, 1985.

${ }^{b}$ Shut down with no plans to restart.

${ }^{c}$ Unused as a result of low production. 


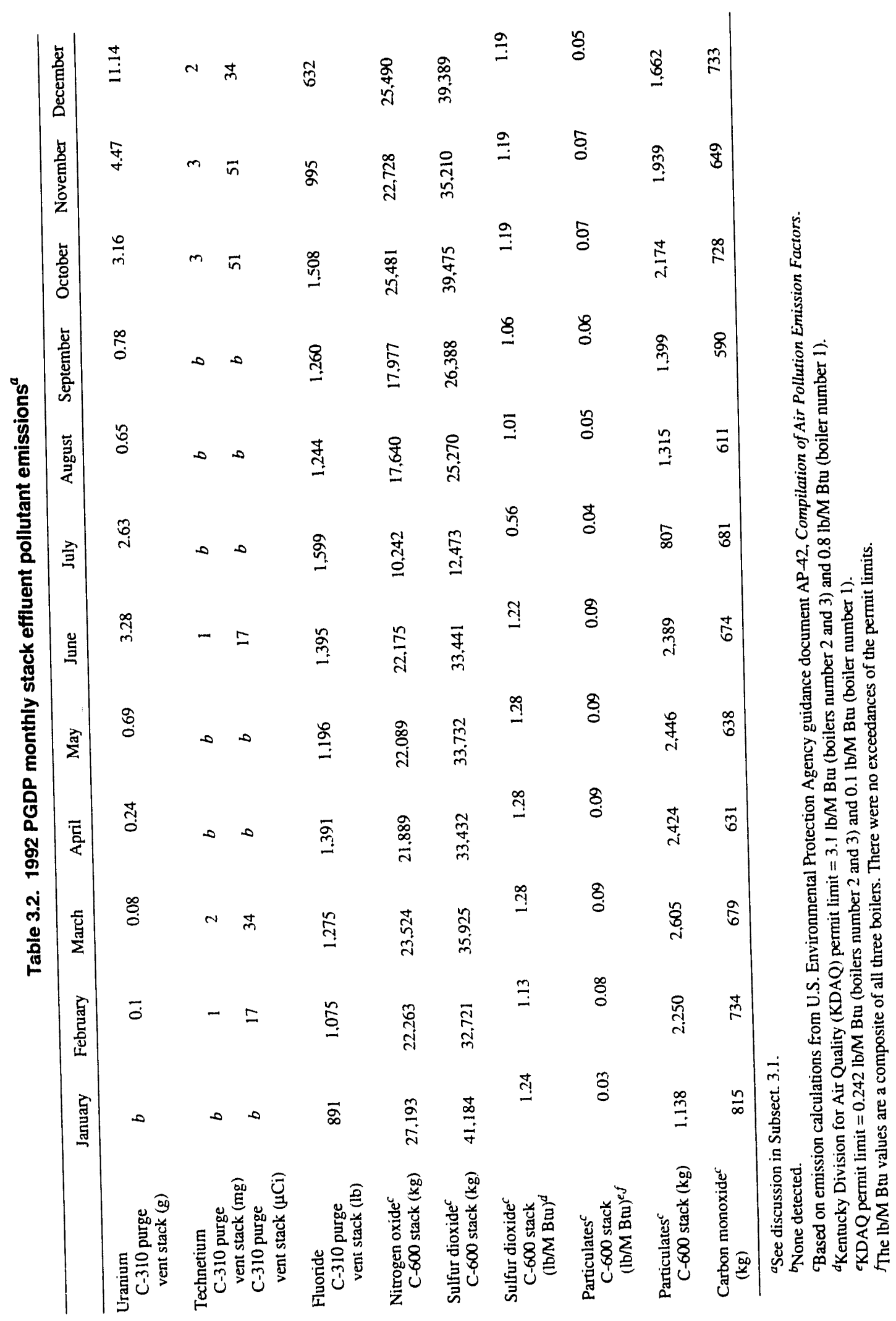


1992 Environmental Report-Paducah, Part 2

Table 3.3. 1992 PGDP annual stack effluent pollutant emissions ${ }^{a}$

\begin{tabular}{|c|c|c|c|c|c|c|c|}
\hline & $\begin{array}{l}1992 \\
\text { Total }\end{array}$ & $\begin{array}{l}1991 \\
\text { Total }\end{array}$ & $\begin{array}{l}1990 \\
\text { Total }\end{array}$ & $\begin{array}{l}1989 \\
\text { Total }\end{array}$ & $\begin{array}{l}1988 \\
\text { Total }\end{array}$ & $\begin{array}{l}1987 \\
\text { Total }\end{array}$ & $\begin{array}{l}1986 \\
\text { Total }\end{array}$ \\
\hline $\begin{array}{l}\text { Uranium }^{b} \\
\text { C-310 purge } \\
\text { vent stack (g) }\end{array}$ & 27.22 & 5.32 & 31.8 & 205 & 16 & 34 & 46 \\
\hline $\begin{array}{l}\text { Technetium }^{b} \\
\text { C-310 purge } \\
\text { vent stack (mg) }\end{array}$ & 12 & 182 & 23 & 211 & 221 & 56 & 520 \\
\hline $\begin{array}{l}\text { C-310 purge } \\
\text { vent stack }(\mu \mathrm{Ci})\end{array}$ & 202 & 3,074 & 386 & 3,566 & 3,732 & 890 & 8,956 \\
\hline $\begin{array}{l}\text { Fluoride } \\
\text { C-310 purge } \\
\text { vent stack (lb) }\end{array}$ & 14,421 & 12,554 & 12,679 & 14,996 & 15,091 & & \\
\hline $\begin{array}{l}\text { Nitrogen oxide }{ }^{c} \\
\text { C-600 stack (kg) }\end{array}$ & 258,696 & 256,234 & 278,613 & 282,380 & 256,800 & 252,900 & 262,900 \\
\hline $\begin{array}{l}\text { Sulfur dioxidec } \\
\text { C-600 stack (kg) }\end{array}$ & 388,648 & 317,922 & 276,380 & 292,309 & 188,000 & 178,700 & 176,400 \\
\hline $\begin{array}{l}\text { Particulates }{ }^{c} \\
\text { C-600 stack (kg) }\end{array}$ & 22,550 & 11,451 & 11,284 & 11,272 & & & \\
\hline $\begin{array}{l}\text { Carbon monoxide }{ }^{c} \\
(\mathrm{~kg})\end{array}$ & 8,164 & 9,117 & 9,091 & 8,179 & & & \\
\hline
\end{tabular}

"See discussion in Subsect. 3.1.

bIncludes only those emissions at or above the lower limit of detection.

'Based on emission calculations from U.S. Environmental Protection Agency guidance document AP-42, Compilation of Air Pollution Emission Factors.

Table 3.4. Comparison of selected actual emissions and limits/standards

\begin{tabular}{|c|c|c|c|}
\hline Source & Poliutant & Emission & Limiu/standard \\
\hline C-310 stack & $\begin{array}{l}\text { Uranium } \\
\text { Technetium-99 } \\
\text { Fluorides }\end{array}$ & $\begin{array}{l}27.22 \mathrm{~g} / \text { year } \\
0.012 \mathrm{~g} / \text { year } \\
19.75 \mathrm{lb} / 12 \mathrm{~h}^{b}\end{array}$ & $\begin{array}{l}7.41 \times 10^{6} \mathrm{~g} / \text { year }^{4} \\
1.7 \times 10^{4} \mathrm{~g} / \text { year }^{\prime} \\
50 \mathrm{lb} / 12 \mathrm{~h}\end{array}$ \\
\hline C-600 stack & $\begin{array}{l}\text { Sulfur dioxide } \\
\text { Particulates }\end{array}$ & $\begin{array}{l}0.81 \mathrm{lb} / \mathrm{M} \mathrm{Btu} \\
0.96 \mathrm{lb} / \mathrm{M} \mathrm{Btu}\end{array}$ & $\begin{array}{l}0.8 \mathrm{lb} / \mathrm{M} \mathrm{Btu} u^{d} \\
3.1 \mathrm{lb} / \mathrm{M} \mathrm{Btu} \\
0.1 \mathrm{lb} / \mathrm{M} \mathrm{Btu^{d }} \\
0.24 \mathrm{lb} / \mathrm{M} \mathrm{Btu}^{e}\end{array}$ \\
\hline
\end{tabular}

"Based on emissions required to exceed the 10 mrem National Emissions Standards for Hazardous Air Pollutants (NESHAP) limit and 1992 meteorological data.

bAnnual average.

cAnnual average of all boilers combined.

"Boiler number 1 .

${ }^{e}$ Boilers number 2 and 3. 
4. Surface Water 
Table 4.1. Interim Iimitations for Agreed Order-Paducah Gaseous Diffusion Plant

\begin{tabular}{|c|c|c|c|c|}
\hline Parameters & Monthly average & Daily maximum & $\begin{array}{c}\text { Sample } \\
\text { frequency }\end{array}$ & $\begin{array}{c}\text { Sample } \\
\text { type }^{a}\end{array}$ \\
\hline
\end{tabular}

Flow

Chromium, total recoverable

Zinc, total recoverable

Chlorine, total residual

Temperature

Iron, total recoverable

Aluminum, total recoverable

Copper, total recoverable

Nickel, total recoverable

Suspended solids, total

Trichloroethylene

Fluoride

Dissolved oxygen

Oil and grease

$\mathrm{pH}$

Uranium

Dissolved alpha

Suspended alpha

Dissolved beta

Suspended beta

Polychlorinated biphenyl

Flow

Chromium, total recoverable

Zinc, total recoverable

Chlorine, total residual

Temperature

Iron, total recoverable

Aluminum, total recoverable

Copper, total recoverable

Nickel, total recoverable

Suspended solids, total

Trichloroethylene

Fluoride

Dissolved oxygen

Oil and grease

$\mathrm{pH}$

Uranium

Dissolved alpha

Suspended alpha

Dissolved beta

Suspended beta

Polychlorinated bipheny!

Flow

Chromium, total recoverable

Zinc, total recoverable

Chlorine, total residual

Temperature

Iron, total recoverable

Outfall 001

$\begin{array}{ll}2.36 \mathrm{mg} / \mathrm{L} & 3.1 \mathrm{mg} / \mathrm{L} \\ & 158 \mathrm{mg} / \mathrm{L} \\ & 0.0807 \mathrm{mg} / \mathrm{L} \\ 3.5 \mathrm{mg} / \mathrm{L} & 4.0 \mathrm{mg} / \mathrm{L} \\ 5 \mathrm{mg} / \mathrm{L}(\mathrm{min}) & \\ 10 \mathrm{mg} / \mathrm{L} & 15 \mathrm{mg} / \mathrm{L} \\ 6.0(\mathrm{~min}) & 10.0\end{array}$

$0.1 \mathrm{mg} / \mathrm{L}$

1/week

$0.15 \mathrm{mg} / \mathrm{L}$

$0.93 \mathrm{mg} / \mathrm{L}$

$0.1 \mathrm{mg} / \mathrm{L}$

$34.3 \mathrm{mg} / \mathrm{L}$

$0.17 \mathrm{mg} / \mathrm{L}$

$3.1 \mathrm{mg} / \mathrm{L}$

$158 \mathrm{mg} / \mathrm{L}$

$4.0 \mathrm{mg} / \mathrm{L}$

10.0

Outfall 002

$0.31 \mathrm{mg} / \mathrm{L}$
$0.17 \mathrm{mg} / \mathrm{L}$
$0.15 \mathrm{mg} / \mathrm{L}$
$89^{\circ} \mathrm{F}$
$6.55 \mathrm{mg} / \mathrm{L}$

$3.5 \mathrm{mg} / \mathrm{L}$

$5 \mathrm{mg} / \mathrm{L}(\mathrm{min})$

$6.0(\mathrm{~min})$

$5.0 \mathrm{mg} / \mathrm{L}$

$0.1 \mathrm{mg} / \mathrm{L}$

Outfall 003

$0.15 \mathrm{mg} / \mathrm{L}$

$0.93 \mathrm{mg} / \mathrm{L}$

$0.1 \mathrm{mg} / \mathrm{L}$

$93^{\circ} \mathrm{F}$

$5.19 \mathrm{mg} / \mathrm{L}$ 1/week

1/week

1/week

1/week

I/week

$2 /$ month

$1 /$ month

$1 /$ month

$1 /$ month

$1 /$ month

$1 /$ month

$2 /$ month

$2 /$ month

$1 /$ month

1/week

1/quarter

1/quarter

I/quarter

1/quarter

1/quarter

1/quarter

1/week

1/week

I/week

I/week

1/week

$2 /$ month
Instantaneous

Composite

.Composite

Grab

Grab

Composite

Composite

Composite

Composite

Composite

Composite

Composite

Grab

Grab

Grab

Grab

Grab

Grab

Grab

Grab

Grab

Instantaneous

Composite

Composite

Grab

Grab

Composite

Composite

Composite

Composite

Composite

Compos e

Composite

Grab

Grab

Grab

Grab

Grab

Grab

Grab

Grab

Grab

Instantaneous

Composite

Composite

Grab

Grab

Composite 
1992 Environmental Report-Paducah, Part 2

Table 4.1 (continued)

\begin{tabular}{|c|c|c|c|c|}
\hline Parameters & Monthly average & Daily maximum & $\begin{array}{c}\text { Sample } \\
\text { frequency }\end{array}$ & $\begin{array}{c}\text { Sample } \\
\text { type }\end{array}$ \\
\hline Aluminum, total recoverable & & & $2 /$ month & Composite \\
\hline Copper, total recoverable & & $0.17 \mathrm{mg} / \mathrm{L}$ & $2 /$ month & Composite \\
\hline Nickel, total recoverable & $0.26 \mathrm{mg} / \mathrm{L}$ & $3.1 \mathrm{mg} / \mathrm{L}$ & 2/month & Composite \\
\hline Suspended solids, total & & $158 \mathrm{mg} / \mathrm{L}$ & $2 /$ month & Composite \\
\hline Trichloroethylene & & $0.027 \mathrm{mg} / \mathrm{L}$ & $2 /$ month & Composite \\
\hline Fluoride & $3.5 \mathrm{mg} / \mathrm{L}$ & $4.0 \mathrm{mg} / \mathrm{L}$ & $2 /$ month & Composite \\
\hline Dissolved oxygen & $5 \mathrm{mg} / \mathrm{L}(\mathrm{min})$ & & $2 /$ month & Grab \\
\hline Oil and grease & $10 \mathrm{mg} / \mathrm{L}$ & $15 \mathrm{mg} / \mathrm{L}$ & $2 /$ month & Grab \\
\hline $\mathrm{pH}$ & $6.0(\min )$ & 10.0 & I/week & Grab \\
\hline Uranium & & & 1/quarter & Grab \\
\hline Dissolved alpha & & & 1/quarter & Grab \\
\hline Suspended alpha & & & 1/quarter & Grab \\
\hline Dissolved beta & & & 1/quarter & Grab \\
\hline Suspended beta & & & 1/yuarter & Grab \\
\hline Polychlorinated biphenyl & & $0.1 \mathrm{mg} / \mathrm{L}$ & 1/quarter & Grab \\
\hline
\end{tabular}

Outfall 004

Flow

BODsb

Suspended solids, total

Fecal coliform

$\mathrm{pH}$

$30 \mathrm{mg} / \mathrm{L} \quad 45 \mathrm{mg} / \mathrm{L}$

$30 \mathrm{mg} / \mathrm{L} \quad 45 \mathrm{mg} / \mathrm{L}$

200

400

$6.0(\mathrm{~min})$

9.0

$2 /$ month

Instantaneous

$2 /$ month

$2 /$ month

$2 /$ month

Composite

Composite

$2 /$ month

Grab

Grab

Outfall 005

Flow

Suspended solids, total

Chemical oxygen demand

Turbidity

$\mathrm{pH}$

$30 \mathrm{mg} / \mathrm{L} \quad 50 \mathrm{mg} / \mathrm{L}$

$1 /$ week

1/week

1/week

1/week

$6.0(\min )$

9.0

1/week

Instantaneous

Composite

Grab

Grab

Grab

Ouffall 006

Flow

Suspended solids, total

Chemical oxygen demand

Turbidity

$\mathrm{pH}$

$30 \mathrm{mg} / \mathrm{L} \quad 50 \mathrm{mg} / \mathrm{L}$

1/week

1/week

1/week

$1 /$ week

$6.0(\mathrm{~min})$

10.4

$1 /$ week

Instantaneous

Grab

Grab

Grab

Grab

Outfall 008

Flow

Chromium, total recoverable

Zinc, total recoverable

Chlorine, total residual

Temperature

Iron, total recoverable

Aluminum, total recoverable

Copper, total recoverable

Nickel, total recoverable

Suspended solids, total

Trichloroethylene

Fluoride

Dissolved oxygen

$3.5 \mathrm{mg} / \mathrm{L}$

Oil and grease

$\begin{array}{llll}\text { Outfall } 008 & & \\ & & 1 / \text { week } & \text { Instantaneous } \\ & 0.1 \mathrm{mg} / \mathrm{L} & 1 / \text { week } & \text { Composite } \\ 0.34 \mathrm{mg} / \mathrm{L} & 1 / \text { week } & \text { Composite } \\ & 0.33 \mathrm{mg} / \mathrm{L} & 1 / \text { week } & \text { Grab } \\ & 89^{\circ} \mathrm{F} & 1 / \text { week } & \text { Grab } \\ & 9.42 \mathrm{mg} / \mathrm{L} & 2 / \text { month } & \text { Composite } \\ & & 1 / \text { month } & \text { Composite } \\ & & 1 / \text { month } & \text { Composite } \\ & & 1 / \text { month } & \text { Composite } \\ & & 1 / \text { month } & \text { Composite } \\ 3.5 \mathrm{mg} / \mathrm{L} & 0.027 \mathrm{mg} / \mathrm{L} & 1 / \text { month } & \text { Composite } \\ 5 \mathrm{mg} / \mathrm{L}(\mathrm{min}) & 5.0 \mathrm{mg} / \mathrm{L} & 2 / \text { month } & \text { Composite } \\ & & 2 / \text { month } & \text { Grab } \\ & & 1 / \text { month } & \text { Grab }\end{array}$

\section{4-4 Surface Water}


1992 Environmental Report-Paducah, Part 2

Table 4.1 (continued)

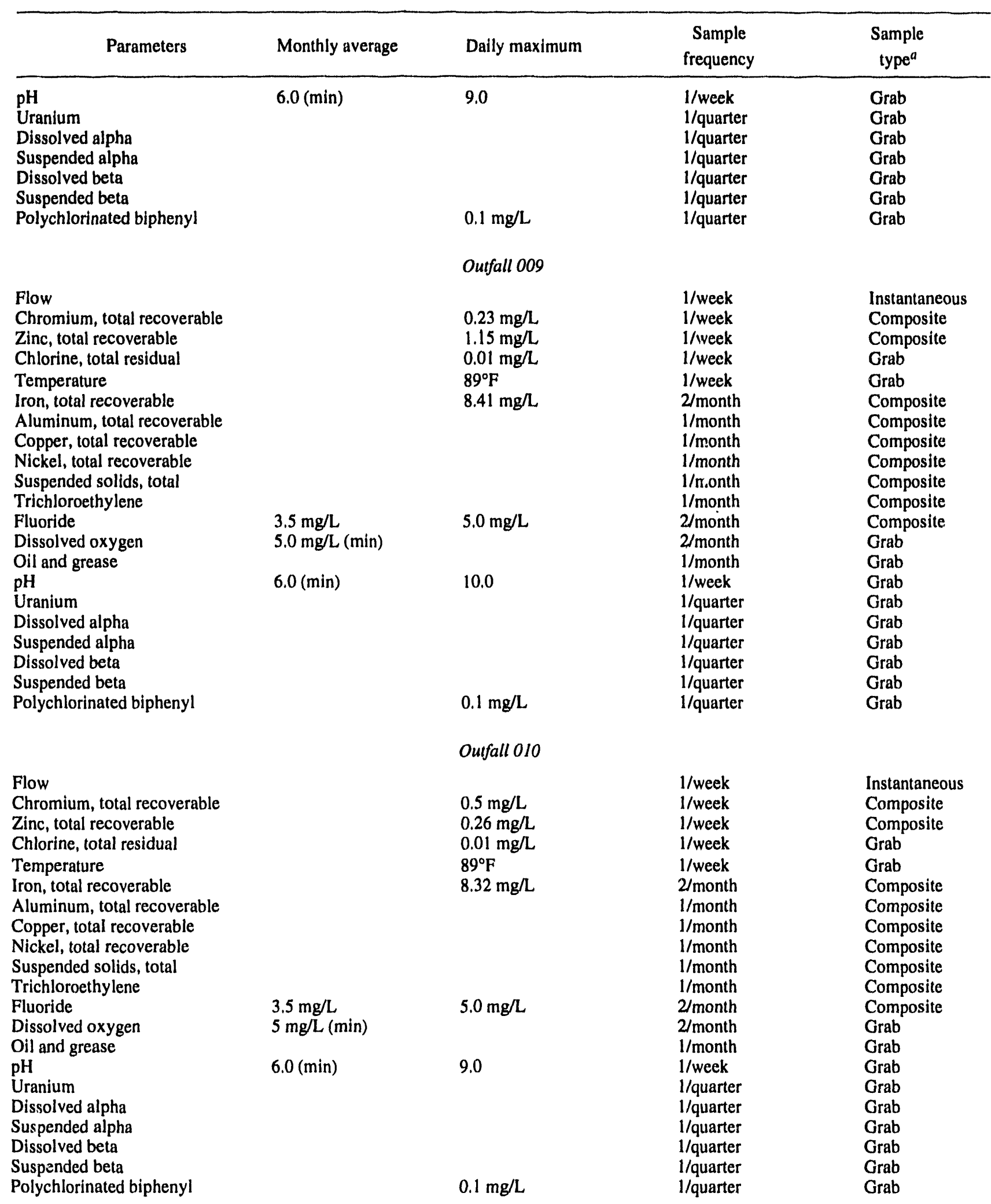




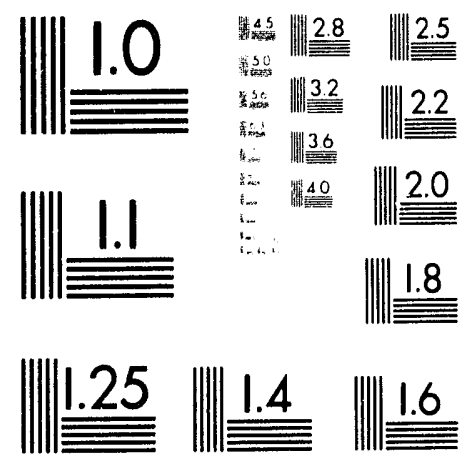



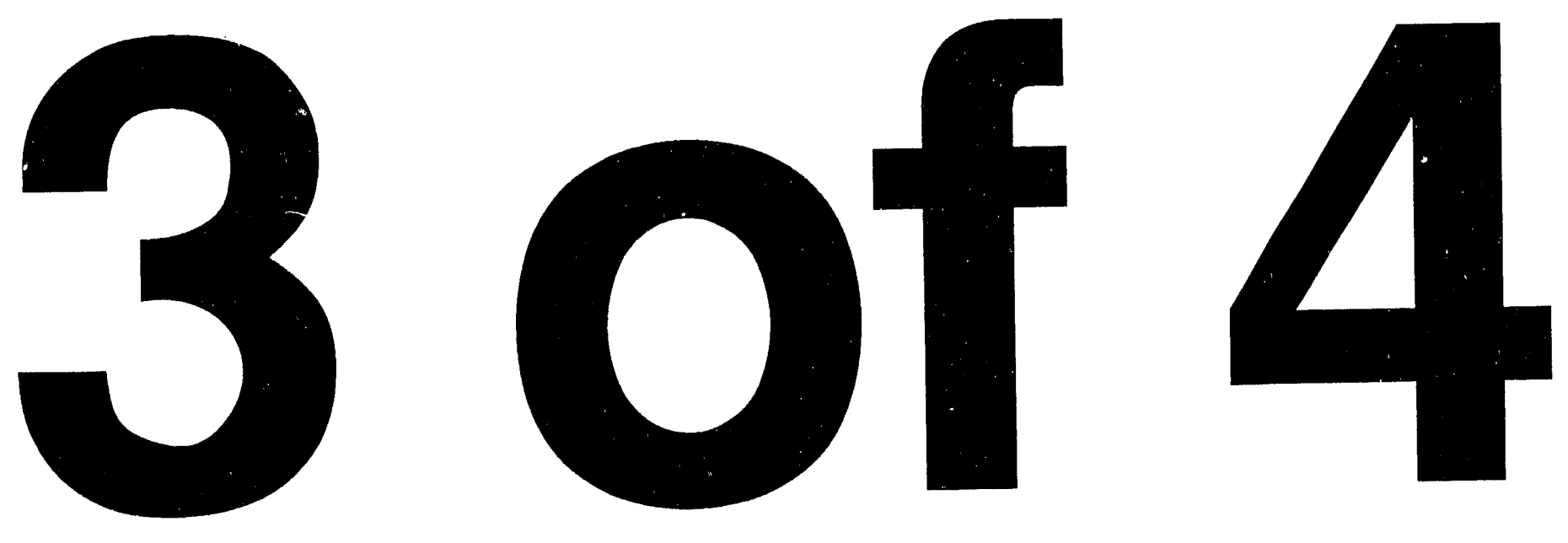


\section{Environmental Report-Paducah, Part 2}

Table 4.1 (continued)

\begin{tabular}{lcccc}
\hline Parameters & Monthly average & Daily maximum & $\begin{array}{c}\text { Sample } \\
\text { frequency }\end{array}$ & $\begin{array}{c}\text { Sample } \\
\text { type }\end{array}$ \\
\hline
\end{tabular}

Flow

Chromium, total recoverable

Zinc, total recoverable

Chlorine, total residual

Temperature

Iron, total recoverable

Aluminum, total recoverable

Copper, total recoverable

Nickel, total recoverable

Suspended solids, total

Trichloroethylene

Fluoride

Dissolved oxygen

Oil and grease

$\mathrm{pH}$

Uranium

Dissolved alpha

Suspended alpha

Dissolved beta

Suspended beta

Polychlorinated biphenyl

Flow

Chromium, total recoverable

Zinc, total recoverable

Chlorine, total residual

Temperature

Iron, total recoverable

Aluminum, total recoverable

Copper, total recoverable

Nickel, total recoverable

Suspended solids, total

Trichloroethylene

Fluoride

Dissolved oxygen

Oil and grease

$\mathrm{pH}$

Uranium

Dissolved alpha .

Suspended alpha

Dissolved beta

Suspended beta

Polychlorinated biphenyl

Flow

Iron, total recoverable

Aluminum, total recoverable

Copper, total recoverable

Nickel, total recoverable

Outfall 011

$0.85 \mathrm{mg} / \mathrm{L}$
$0.16 \mathrm{mg} / \mathrm{L}$
$0.14 \mathrm{mg} / \mathrm{L}$
$95^{\circ} \mathrm{F}$
$5.94 \mathrm{mg} / \mathrm{L}$

$5.0 \mathrm{mg} / \mathrm{L}$

$3.5 \mathrm{mg} / \mathrm{L}$

$5 \mathrm{mg} / \mathrm{L}(\mathrm{min})$

$6.0(\min )$

$0.1 \mathrm{mg} / \mathrm{L}$

Outfall 012

$0.76 \mathrm{mg} / \mathrm{L}$

$0.40 \mathrm{mg} / \mathrm{L}$

$0.01 \mathrm{mg} / \mathrm{L}$

$90^{\circ} \mathrm{F}$

$18.22 \mathrm{mg} / \mathrm{L}$

$3.5 \mathrm{mg} / \mathrm{L}$

$5 \mathrm{mg} / \mathrm{L}(\mathrm{min})$

$6.0(\mathrm{~min})$

9.0

$5.0 \mathrm{mg} / \mathrm{L}$

$0.1 \mathrm{mg} / \mathrm{L}$

Outfall 013

$\begin{array}{ll}1 / \text { week } & \text { Instantaneous } \\ 1 / \text { week } & \text { Composite } \\ 1 / \text { week } & \text { Composite } \\ 1 / \text { week } & \text { Grab } \\ 1 / \text { week } & \text { Grab } \\ 2 / \text { month } & \text { Composite } \\ 1 / \text { month } & \text { Composite } \\ 1 / \text { month } & \text { Composite } \\ 1 / \text { month } & \text { Composite } \\ 1 / \text { month } & \text { Composite } \\ 1 / \text { month } & \text { Composite } \\ 2 / \text { month } & \text { Composite } \\ 2 / \text { month } & \text { Grab } \\ 1 / \text { month } & \text { Grab } \\ 1 / \text { week } & \text { Grab } \\ 1 / \text { quarter } & \text { Grab } \\ 1 / \text { quarter } & \text { Grab } \\ 1 / \text { quarter } & \text { Grab } \\ 1 / \text { quarter } & \text { Grab } \\ 1 / \text { quarter } & \text { Grab } \\ 1 / \text { quarter } & \text { Grab }\end{array}$

1/week

Instantaneous

Composite

Composite

Grab

Grab

Composite

Composite

Composite

Composite

Composite

Composite

Composite

Grab

Grab

Grab

Grab

Grab

Grab

Grab

Grab

Grab

$1 /$ month

$1 /$ month

$1 /$ month

$1 /$ month

$1 /$ month
Instantaneous

Composite

Composite

Composite

Composite 
1992 Environmental Report-Paducah, Part 2

Table 4.1 (continued)

\begin{tabular}{|c|c|c|c|c|}
\hline Parameters & Monthly average & Daily maximum & $\begin{array}{l}\text { Sample } \\
\text { frequency }\end{array}$ & $\begin{array}{c}\text { Sample } \\
\text { type }^{a}\end{array}$ \\
\hline $\begin{array}{l}\text { Suspended solids, total } \\
\text { Fluoride } \\
\text { Oil and grease } \\
\text { pH } \\
\text { Uranium } \\
\text { Dissolved alpha } \\
\text { Suspended alpha } \\
\text { Dissolved beta } \\
\text { Suspended beta } \\
\text { Polychlorinated biphenyl }\end{array}$ & $6.0(\mathrm{~min})$ & $\begin{array}{l}271 \mathrm{mg} / \mathrm{L} \\
9.0 \\
0.1 \mathrm{mg} / \mathrm{L} \\
\text { Outfall } 014\end{array}$ & $\begin{array}{l}1 / \text { month } \\
1 / \text { month } \\
1 / \text { month } \\
1 / \text { month } \\
1 / \text { quarter } \\
1 / \text { quarter } \\
1 / \text { quarter } \\
1 / \text { quarter } \\
1 / \text { quarter } \\
1 / \text { quarter }\end{array}$ & $\begin{array}{l}\text { Composite } \\
\text { Composite } \\
\text { Grab } \\
\text { Grab } \\
\text { Grab } \\
\text { Grab } \\
\text { Grab } \\
\text { Grab } \\
\text { Grab } \\
\text { Grab }\end{array}$ \\
\hline $\begin{array}{l}\text { Flow } \\
\text { Suspended solids, total } \\
\text { Chemical oxygen demand } \\
\text { Turbidity } \\
\text { pH }\end{array}$ & $\begin{array}{l}30 \mathrm{mg} / \mathrm{L} \\
6.0(\mathrm{~min})\end{array}$ & $\begin{array}{l}50 \mathrm{mg} / \mathrm{L} \\
9.0 \\
\text { Outfall } 015\end{array}$ & $\begin{array}{l}\text { 1/week } \\
1 / \text { week } \\
1 / \text { week } \\
1 / \text { week } \\
1 / \text { week }\end{array}$ & $\begin{array}{l}\text { Instantaneous } \\
\text { Grab } \\
\text { Grab } \\
\text { Grab } \\
\text { Grab }\end{array}$ \\
\hline $\begin{array}{l}\text { Flow } \\
\text { Iron, total recoverable } \\
\text { Aluminum, total recoverable } \\
\text { Copper, total recoverable } \\
\text { Nickel, total recoverable } \\
\text { Suspended solids, total } \\
\text { Fluoride } \\
\text { Oil and grease } \\
\text { pH } \\
\text { Uranium } \\
\text { Dissolved alpha } \\
\text { Suspended alpha } \\
\text { Dissolved beta } \\
\text { Suspended beta } \\
\text { Polychlorinated biphenyl }\end{array}$ & $6.0(\mathrm{~min})$ & $\begin{array}{l}427 \mathrm{mg} / \mathrm{L} \\
9.0 \\
0.1 \mathrm{mg} / \mathrm{L}\end{array}$ & $\begin{array}{l}1 / \text { month } \\
1 / \text { month } \\
1 / \text { month } \\
1 / \text { month } \\
1 / \text { month } \\
1 / \text { month } \\
1 / \text { month } \\
1 / \text { month } \\
1 / \text { month } \\
1 / \text { quarter } \\
1 / \text { quarter } \\
1 / \text { quarter } \\
1 / \text { quarter } \\
1 / \text { quarter } \\
1 / \text { quarter }\end{array}$ & $\begin{array}{l}\text { Instantaneous } \\
\text { Composite } \\
\text { Composite } \\
\text { Composite } \\
\text { Composite } \\
\text { Composite } \\
\text { Composite } \\
\text { Grab } \\
\text { Grab } \\
\text { Grab } \\
\text { Grab } \\
\text { Grab } \\
\text { Grab } \\
\text { Grab } \\
\text { Grab }\end{array}$ \\
\hline & & Outfall 016 & & \\
\hline $\begin{array}{l}\text { Flow } \\
\text { Iron, total recoverable } \\
\text { Aluminum, total recoverable } \\
\text { Copper, total recoverable } \\
\text { Nickel, total recoverable } \\
\text { Suspended solids, total } \\
\text { Fluoride } \\
\text { Oil and grease } \\
\text { pH } \\
\text { Uranium } \\
\text { Dissolved alpha } \\
\text { Suspended alpha } \\
\text { Dissolved beta } \\
\text { Suspended beta } \\
\text { Polychlorinated biphenyl }\end{array}$ & $6.0(\mathrm{~min})$ & $45 \mathrm{mg} / \mathrm{L}$ & $\begin{array}{l}1 / \text { month } \\
1 / \text { month } \\
1 / \text { month } \\
1 / \text { month } \\
1 / \text { month } \\
1 / \text { month } \\
1 / \text { month } \\
1 / \text { month } \\
1 / \text { month } \\
1 / \text { quarter } \\
1 / \text { quarter } \\
1 / \text { quarter } \\
1 / \text { quarter } \\
1 / \text { quarter } \\
1 / \text { quarter }\end{array}$ & $\begin{array}{l}\text { Instantaneous } \\
\text { Composite } \\
\text { Composite } \\
\text { Composite } \\
\text { Composite } \\
\text { Composite } \\
\text { Composite } \\
\text { Grab } \\
\text { Grab } \\
\text { Grab } \\
\text { Grab } \\
\text { Grab } \\
\text { Grab } \\
\text { Grab } \\
\text { Grab }\end{array}$ \\
\hline
\end{tabular}




\section{Environmental Report-Paducah, Part 2}

Table 4.1 (continued)

\begin{tabular}{|c|c|c|c|c|}
\hline Parameters & Monthly average & Daily maximum & $\begin{array}{c}\text { Sample } \\
\text { frequency }\end{array}$ & $\begin{array}{c}\text { Sarnple } \\
\text { type }^{a}\end{array}$ \\
\hline \multicolumn{5}{|c|}{ Outfall 017} \\
\hline Flow & & & $1 /$ month & Instantaneous \\
\hline Iron, total recoverable & & & $1 /$ month & Composite \\
\hline Aluminum, total recoverable & & & I/month & Composite \\
\hline Copper, total recoverable & & & $1 /$ month & Composite \\
\hline Nickel, total recoverable & & & $1 /$ month & Composite \\
\hline Suspended solids, total & & $45 \mathrm{mg} / \mathrm{L}$ & $1 /$ month & Composite \\
\hline Fluoride & & & $1 /$ month & Composite \\
\hline Oil and grease & & & $1 /$ month & Grab \\
\hline $\mathrm{pH}$ & $6.0(\mathrm{~min})$ & 9.0 & $1 /$ month & Grab \\
\hline Uranium & & & 1/quarter & Grab \\
\hline Dissolved alpha & & & 1/quarter & Grab \\
\hline Suspended alpha & & & 1/quarter & Grab \\
\hline Dissolved beta & & & 1/quarter & Grab \\
\hline Suspended beta & & & l/quarter & Grab \\
\hline Polychlorinated biphenyl & & $0.1 \mathrm{mg} / \mathrm{L}$ & I/quarter & Grab \\
\hline
\end{tabular}

${ }^{a}$ Composite samples are 24-h samples.

${ }^{h} \mathrm{BOD}_{5}=$ biochemical oxygen demand, $5 \mathrm{~d}$. 
1992 Environmental Report-Paducah, Part 2

Table 4.2. 1992 annual data summary for sampling location $\mathrm{KOO1}^{a}$

Process, cooling, and storm

\begin{tabular}{|c|c|c|c|c|}
\hline Parameters & Max & Min & Av & $\begin{array}{c}\text { Number } \\
\text { of } \\
\text { samples }\end{array}$ \\
\hline Acetone $(\mathrm{mg} / \mathrm{L})$ & $<5.000$ & $<1.000$ & $<1.191$ & 21 \\
\hline Aluminum (mg/L) & 2.290 & 0.212 & 0.686 & 25 \\
\hline Arsenic $(\mathrm{mg} / \mathrm{L})$ & $<0.005$ & $<0.005$ & $<0.005$ & 1 \\
\hline Assay $\%$ uranium-235 (wt \%) & 1.214 & 0.253 & 0.561 & 42 \\
\hline Cadmium (mg/L) & $<0.010$ & $<0.005$ & $<0.008$ & 6 \\
\hline Chlorine, total residual (mg/L) & 0.040 & $<0.010$ & $<0.011$ & 53 \\
\hline Chromium, total recoverable (mg/L) & 0.089 & $<0.050$ & $<0.051$ & 44 \\
\hline Copper, total recoverable $(\mathrm{mg} / \mathrm{L})$ & 0.036 & $<0.010$ & $<0.011$ & 25 \\
\hline Dissolved alpha (pCi/L) & 112.600 & $-14.800^{b}$ & 10.977 & 52 \\
\hline Dissolved beta (pCi/L) & 116.000 & $-17.000^{b}$ & 43.717 & 52 \\
\hline Dissolved oxygen (mg/L) & 10.900 & 6.700 & 8.743 & 21 \\
\hline Fecal coliform (colonies/100 mL) & 115.000 & 6.000 & 48.500 & 4 \\
\hline Flow (Mgd) & 3.430 & 0.384 & 1.661 & 52 \\
\hline Fluoride (mg/L) & 0.850 & 0.250 & 0.512 & 21 \\
\hline Gross alpha $(\mathrm{pCi} / \mathrm{L})$ & 8.100 & $-0.600^{b}$ & 3.750 & 2 \\
\hline Gross beta $(\mathrm{pCi} / \mathrm{L})$ & 57.000 & 39.000 & 48.000 & 2 \\
\hline Hardness as $\mathrm{CaCo}_{3}(\mathrm{mg} / \mathrm{L} \mathrm{CaC})$ & 1009.000 & 194.000 & 419.429 & 14 \\
\hline Hexavalent chromium $(\mathrm{mg} / \mathrm{L})$ & 0.020 & $<0.010$ & $<0.012$ & 6 \\
\hline Iron, total recoverable $(\mathrm{mg} / \mathrm{L})$ & 2.120 & 0.098 & 0.447 & 25 \\
\hline Isopropanol (mg/L) & $<5.000$ & $<1.000$ & $<1.191$ & 21 \\
\hline Lead (mg/L) & $<0.200$ & $<0.030$ & $<0.108$ & 6 \\
\hline Neptunium-237 (pCi/L) & 0.100 & $-0.300^{b}$ & $-0.050^{b}$ & 4 \\
\hline Nickel, total recoverable (mg/L) & $<0.050$ & $<0.050$ & $<5.000$ & 25 \\
\hline Oil and grease $(\mathrm{mg} / \mathrm{L})$ & $<5.000$ & $<5.000$ & $<5.000$ & 31 \\
\hline $\mathrm{pH}$ (standard units) & 10.100 & 6.900 & & 53 \\
\hline Phosphate as phosphorus $(\mathrm{mg} / \mathrm{L})$ & 0.300 & 0.080 & 0.161 & 8 \\
\hline Plutonium-239 (pCi/L) & 0.130 & 0.100 & 0.108 & 4 \\
\hline Polychlorinated biphenyl $(\mu \mathrm{g} / \mathrm{L})$ & $<0.100$ & $<0.100$ & $<0.100$ & 14 \\
\hline Suspended alpha $(\mathrm{pCi} / \mathrm{L})$ & 9.200 & $-4.500^{h}$ & $-0.375^{b}$ & 52 \\
\hline Suspended beta $(\mathrm{pCi} / \mathrm{L})$ & 24.000 & $-15.000^{b}$ & $1.698^{b}$ & 52 \\
\hline Suspended solids (mg/L) & 42.000 & 4.000 & 16.700 & 30 \\
\hline Technetium-99 (pCi/L) & 77.000 & 0.000 & 22.748 & 54 \\
\hline Temperature $\left({ }^{\circ} \mathrm{F}\right)$ & 92.000 & 44.000 & 68.500 & 52 \\
\hline Total phosphorus (mg/L) & 0.240 & 0.120 & 0.165 & 11 \\
\hline Trichloroethylene (mg/L) & $<0.001$ & $<0.001$ & $<0.001$ & 22 \\
\hline Uranium (mg/L) & 0.170 & 0.001 & 0.022 & 52 \\
\hline Zinc, total residual (mg/L) & 0.082 & $<0.005$ & $<0.014$ & 47 \\
\hline
\end{tabular}

${ }^{a}$ See Fig. 4.4 in Part 1.

${ }^{b}$ Negative numbers indicate that analytical result minus background was less than zero. 


\section{Environmental Report--Paducah, Part 2}

Table 4.3. 1992 annual data summary for sampling location $\mathrm{KOO2}^{a}$

Process, cooling, and storm

\begin{tabular}{|c|c|c|c|c|}
\hline Parameters & $\operatorname{Max}$ & Min & Av & $\begin{array}{c}\text { Number } \\
\text { of } \\
\text { samples }\end{array}$ \\
\hline Aluminum (mg/L) & 2.840 & 0.655 & 1.574 & 9 \\
\hline Assay $\%$ uranium-235 (wt \%) & 0.731 & 0.590 & 0.661 & 2 \\
\hline Cadmium (mg/L) & $<0.010$ & $<0.005$ & $<0.008$ & 3 \\
\hline Chlorine, total residual (mg/L) & $<0.010$ & $<0.010$ & $<0.010$ & 10 \\
\hline Chromium, total recoverable (mg/L) & 0.094 & $<0.050$ & $<0.055$ & 9 \\
\hline Copper, total recoverable (mg/L) & 0.014 & $<0.010$ & $<0.011$ & 9 \\
\hline Dissolved alpha (pCi/L) & 9.300 & $-1.900^{b}$ & 3.575 & 4 \\
\hline Dissolved beta $(\mathrm{pCi} / \mathrm{L})$ & 32.000 & 1.000 & 10.250 & 4 \\
\hline Dissolved oxygen $(\mathrm{mg} / \mathrm{L})$ & 11.200 & 6.000 & 8.42 .5 & 8 \\
\hline Flow (Mgd) & 2.570 & 0.019 & 0.688 & 10 \\
\hline Fluoride $(\mathrm{mg} / \mathrm{L})$ & 0.470 & 0.130 & 0.224 & 8 \\
\hline Hardness as $\mathrm{CaCO}_{3}(\mathrm{mg} / \mathrm{L} \mathrm{CaC})$ & 77.000 & 72.000 & 74.500 & 2 \\
\hline Hexavalent chromium (mg/L) & 0.050 & 0.050 & 0.050 & $i$ \\
\hline Iron; total recoverable $(\mathrm{mg} / \mathrm{L})$ & 2.810 & 0.515 & 1.479 & 9 \\
\hline Lead $(\mathrm{mg} / \mathrm{L})$ & $<0.200$ & $<0.070$ & $<0.113$ & 3 \\
\hline Neptunium-237 (pCi/L) & 0.200 & $-0.400^{h}$ & $-0.033^{b}$ & 3 \\
\hline Nickel, total recoverable $(\mathrm{mg} / \mathrm{L})$ & $<0.050$ & $<0.050$ & $<0.050$ & 9 \\
\hline Oil and grease $(\mathrm{mg} / \mathrm{L})$ & $<5.000$ & $<5.000$ & $<5.000$ & 9 \\
\hline $\mathrm{pH}$ (standard units) & 8.000 & 6.500 & & 10 \\
\hline Phospate as phosphorus (mg/L) & 0.230 & 0.230 & 0.230 & 1 \\
\hline Plutonium-239 (pCi/L) & 0.100 & 0.000 & 0.033 & 3 \\
\hline Polychlorinated biphenyl $(\mu \mathrm{g} / \mathrm{L})$ & $<0.100$ & $<0.100$ & $<0.100$ & 8 \\
\hline Suspended alpha $(\mathrm{pCi} / \mathrm{L})$ & 2.300 & $-2.300^{b}$ & $-0.175^{b}$ & 4 \\
\hline Suspended beta $(\mathrm{pCi} / \mathrm{L})$ & 4.000 & $-3.200^{b}$ & 0.450 & 4 \\
\hline Suspended solids (mg/L) & 75.000 & 11.000 & 34.222 & 9 \\
\hline Technetium-99(pCi/L) & 8.000 & 8.000 & 8.000 & 1 \\
\hline Temperature $\left({ }^{\circ} \mathrm{F}\right)$ & 78.000 & 43.000 & 62.700 & 10 \\
\hline Total phosphorus (mg/L) & 0.230 & 0.090 & 0.160 & 2 \\
\hline Trichloroethylene $(\mathrm{mg} / \mathrm{L})$ & $<0.001$ & $<0.001$ & $<0.001$ & 9 \\
\hline Uranium (mg/L) & 0.006 & 0.003 & 0.004 & 4 \\
\hline Zinc, total residual (mg/L) & 0.075 & 0.020 & 0.052 & 9 \\
\hline
\end{tabular}

"See Fig. 4.4 in Part 1.

${ }^{b}$ Negative numbers indicate that analytical result minus background was less than zero. 
Table 4.4. 1992 annual data summary for sampling location $\mathrm{KOO4}^{a}$

Sanitary wastewater

\begin{tabular}{|c|c|c|c|c|}
\hline Parameters & $\operatorname{Max}$ & Min & Av & $\begin{array}{c}\text { Number } \\
\text { of } \\
\text { samples }\end{array}$ \\
\hline Biochemical oxygen demand $(\mathrm{mg} / \mathrm{L})$ & 16.000 & 5.000 & 10.375 & 24 \\
\hline Fecal coliform (colonies/100 mL) & 38.000 & $<1.000$ & $<5.560$ & 25 \\
\hline Flow (Mgd) & 0.505 & 0.288 & 0.336 & 24 \\
\hline Hardness as $\mathrm{CaCO}_{3}(\mathrm{mg} / \mathrm{L} \mathrm{CaC})$ & 120.000 & 120.000 & 120.000 & 1 \\
\hline $\mathrm{pH}$ (standard units) & 8.400 & 6.700 & & 25 \\
\hline Suspended solids (mg/L) & 14.000 & $<4.000$ & $<6.476$ & 21 \\
\hline
\end{tabular}

"See Fig. 4.4 in Part 1.

Table 4.5. 1992 annual data summary for sampling location $\mathrm{KOO6}^{a}$ Water Treatment Plant sludge lagoon 2

\begin{tabular}{|c|c|c|c|c|}
\hline Parameters & $\operatorname{Max}$ & Min & Av & $\begin{array}{c}\text { Number } \\
\text { of } \\
\text { samples }\end{array}$ \\
\hline Aluminum (mg/L) & 1.040 & 0.197 & 0.539 & 4 \\
\hline Cadmium (mg/L) & $<0.010$ & $<0.005$ & $<0.008$ & 6 \\
\hline Chemical oxygen demand ( $\mathrm{mg} / \mathrm{L})$ & 25.000 & $<5.000$ & $<12.326$ & 43 \\
\hline Chlorine, total residual (mg/L) & $<0.020$ & $<0.010$ & $<0.012$ & 10 \\
\hline Chromium, total recoverable (mg/L) & $<0.050$ & $<0.050$ & $<0.050$ & 4 \\
\hline Copper, total recoverable $(\mathrm{mg} / \mathrm{L})$ & 0.018 & $<0.010$ & $<0.012$ & 4 \\
\hline Dissolved oxygen $(\mathrm{mg} / \mathrm{L})$ & 14.900 & 14.900 & 14.900 & 1 \\
\hline Flow (Mgd) & 2.860 & 0.014 & 1.356 & 82 \\
\hline Hardness as $\mathrm{CaCO}_{3}(\mathrm{mg} / \mathrm{L} \mathrm{CaC})$ & 133.000 & 48.000 & 73.071 & 14 \\
\hline Hexavalent chromium (mg/L) & $<0.010$ & $<0.010$ & $<0.010$ & 2 \\
\hline Iron, total recoverable $(\mathrm{mg} / \mathrm{L})$ & 2.020 & 0.242 & 0.817 & 4 \\
\hline Lead $(\mathrm{mg} / \mathrm{L})$ & $<0.200$ & $<0.030$ & $<0.102$ & 6 \\
\hline Nickel, total recoverable $(\mathrm{mg} / \mathrm{L})$ & $<0.050$ & $<0.050$ & $<0.050$ & 4 \\
\hline Oil and grease $(\mathrm{mg} / \mathrm{L})$ & $<5.000$ & $<5.000$ & $<5.000$ & 9 \\
\hline $\mathrm{pH}$ (standard units) & 10.700 & 7.500 & & 88 \\
\hline Phosphate as phosphorus (mg/L) & 0.140 & 0.084 & 0.109 & 4 \\
\hline Polychlorinated biphenyl ( $\mu \mathrm{g} / \mathrm{L})$ & $<0.100$ & $<0.100$ & $<0.100$ & 12 \\
\hline Specific conductance $(\mu \mathrm{mhos} / \mathrm{cm}$ & 316.000 & 192.000 & 258.297 & 37 \\
\hline Suspended solids (mg/L) & 47.000 & $<4.000$ & $<12.789$ & 52 \\
\hline Total phosphorus (mg/L) & 0.140 & 0.080 & 0.100 & 11 \\
\hline Turbidity (nephelometric turbidity units) & 49.000 & 1.700 & 8.071 & 42 \\
\hline Zinc, total residual $(\mathrm{mg} / \mathrm{L})$ & 0.030 & $<0.005$ & $<0.013$ & 4 \\
\hline
\end{tabular}

${ }^{a} \mathrm{Sec}$ Fig. 4.4 in Part 1. 


\section{Environmental Report-Paducah, Part 2}

Table 4.6. 1992 annual data summary for sampling location $\mathrm{KOOB}^{a}$

Process, cooling, and storm

\begin{tabular}{|c|c|c|c|c|}
\hline Parameters & Max & Min & Av & $\begin{array}{c}\text { Number } \\
\text { of } \\
\text { samples }\end{array}$ \\
\hline Aluminum $(\mathrm{mg} / \mathrm{L})$ & 0.567 & $<0.100$ & $<0.212$ & 25 \\
\hline Assay \% uranium-235 (wt \%) & 0.749 & 0.578 & 0.653 & 4 \\
\hline Cadmium $(\mathrm{mg} / \mathrm{L})$ & $<0.010$ & $<0.005$ & $<0.008$ & 6 \\
\hline Chlorine, total residual (mg/L) & 0.150 & $<0.010$ & $<0.013$ & 56 \\
\hline Chromium, total recoverable $(\mathrm{mg} / \mathrm{L})$ & 0.075 & $<0.050$ & $<0.051$ & 63 \\
\hline Copper, total recoverable $(\mathrm{mg} / \mathrm{L})$ & 0.024 & $<0.010$ & $<0.011$ & 25 \\
\hline Dissolved alpha $(\mathrm{pCi} / \mathrm{L})$ & 6.200 & $-5.200^{h}$ & 1.450 & 12 \\
\hline Dissolved beta (pCi/L) & 27.000 & 0.000 & 13.500 & 12 \\
\hline Dissolved oxygen (mg/L) & 11.200 & 5.300 & 7.955 & 29 \\
\hline Flow (Mgd) & 1.190 & 0.257 & 0.754 & 60 \\
\hline Fluoride (mg/L) & 0.240 & 0.110 & 0.169 & 29 \\
\hline Hexavalent chromium (mg/L) & 0.010 & $<0.010$ & $<0.010$ & 3 \\
\hline Iron, total recoverable $(\mathrm{mg} / \mathrm{L})$ & 0.952 & $<0.010$ & $<0.288$ & 34 \\
\hline Gross alpha (pCi/L) & 0.200 & 0.200 & 0.200 & 1 \\
\hline Gross beta $(\mathrm{pCi} / \mathrm{L})$ & 1.000 & 1.000 & 1.000 & 1 \\
\hline Hardness as $\mathrm{CaCO}_{3}(\mathrm{mg} / \mathrm{L} \mathrm{CaC})$ & 127.000 & 35.000 & 67.429 & 14 \\
\hline Lead $(\mathrm{mg} / \mathrm{L})$ & $<0.200$ & $<0.030$ & $<0.107$ & 6 \\
\hline Molybdenum (mg/L) & $<0.050$ & $<0.050$ & $<0.050$ & 1 \\
\hline Neptunium-237 (pCi/L) & 0.300 & $-0.400^{b}$ & $-0.140^{h}$ & 5 \\
\hline Nickel, total recoverable $(\mathrm{mg} / \mathrm{L})$ & $<0.050$ & $<0.050$ & $<0.050$ & 25 \\
\hline Oil and grease $(\mathrm{mg} / \mathrm{L})$ & $<5.000$ & $<5.000$ & $<5.000$ & 29 \\
\hline $\mathrm{pH}$ (standard units) & 9.000 & 6.500 & & 61 \\
\hline Phosphate as phosphorus (mg/L) & 0.640 & 0.510 & 0.590 & 4 \\
\hline Plutonium-239(pCi/L) & 0.490 & 0.000 & 0.118 & 5 \\
\hline Polychlorinated biphenyl $(\mu \mathrm{g} / \mathrm{L})$ & $<0.100$ & $<0.100$ & $<0.100$ & 18 \\
\hline Suspended alpha $(\mathrm{pCi} / \mathrm{L})$ & 2.000 & $-3.600^{b}$ & $-0.525^{b}$ & 12 \\
\hline Suspended beta $(\mathrm{pCi} / \mathrm{L})$ & 15.000 & $-4.500^{b}$ & 1.875 & 12 \\
\hline Suspended solids (mg/L) & 21.000 & $<4.000$ & $<7.759$ & 29 \\
\hline Technetium-99 (pCi/L) & 25.000 & 0.000 & 14.077 & 13 \\
\hline Temperature $\left({ }^{\circ} \mathrm{F}\right)$ & 86.000 & 49.000 & 69.536 & 56 \\
\hline Total phosphorus (mg/L) & 0.740 & 0.510 & 0.612 & 11 \\
\hline Trichloroethylene (mg/L) & 0.087 & $<0.001$ & $<0.013$ & 20 \\
\hline Uranium $(\mathrm{mg} / \mathrm{L})$ & 0.005 & $<0.001$ & $<0.002$ & 15 \\
\hline Zinc, total residual $(\mathrm{mg} / \mathrm{L})$ & 0.124 & $<0.005$ & $<0.025$ & 57 \\
\hline
\end{tabular}

${ }^{a}$ See Fig. 4.4 in Part 1.

${ }^{b}$ Negative numbers indicate that analytical result minus background was less than zero. 
1992 Environmental Report-Paducah, Part 2

Table 4.7. 1992 annual data summary for sampling location $\mathrm{KOOg}^{a}$

Process, cooling, and storm

\begin{tabular}{|c|c|c|c|c|}
\hline Parameters & Max & Min & Av & $\begin{array}{c}\text { Number } \\
\text { of } \\
\text { samples }\end{array}$ \\
\hline Aluminum (mg/L) & 2.180 & 0.325 & 0.742 & 15 \\
\hline Assay \% uranium-235 (wt \%) & 0.823 & 0.630 & 0.750 & 3 \\
\hline Cadmium (mg/L) & $<0.010$ & $<0.003$ & $<0.008$ & 6 \\
\hline Chlorine, total residual (mg/L) & $<0.020$ & $<0.010$ & $<0.010$ & 52 \\
\hline Chromium, total recoverable $(\mathrm{mg} / \mathrm{L})$ & 0.079 & $<0.050$ & $<0.051$ & 47 \\
\hline Copper, total recoverable (mg/L) & 0.031 & $<0.010$ & $<0.011$ & 15 \\
\hline Dissolved alpha (pCi/L) & 5.800 & 0.900 & 2.800 & 4 \\
\hline Dissolved beta $(\mathrm{pCi} / \mathrm{L})$ & 15.000 & 3.000 & 8.250 & 4 \\
\hline Dissolved oxygen (mg/L) & 14.100 & 5.000 & 8.795 & 21 \\
\hline Flow (Mgd) & 1.180 & 0.057 & 0.204 & 52 \\
\hline Fluoride (mg/L) & 0.180 & $<0.100$ & $<0.145$ & 21 \\
\hline Hardness as $\mathrm{CaCO}_{3}(\mathrm{mg} / \mathrm{L} \mathrm{CaC})$ & 132.000 & 19.000 & 70.357 & 14 \\
\hline Hexavalent chromium (mg/L) & 0.020 & $<0.010$ & $<0.015$ & 2 \\
\hline Iron, total recoverable $(\mathrm{mg} / \mathrm{L})$ & 1.640 & 0.295 & 0.749 & 25 \\
\hline Lead (mg/L) & $<0.200$ & $<0.030$ & $<0.123$ & 7 \\
\hline Mercury (mg/L) & $<0.000$ & $<0.000$ & $<0.000$ & 1 \\
\hline Molybdenum (mg/L) & $<0.050$ & $<0.050$ & $<0.050$ & 1 \\
\hline Neptunium-237 (pCi/L) & 0.000 & $-0.400^{b}$ & $-0.125^{b}$ & 4 \\
\hline Nickel, total recoverable (mg/L) & $<0.050$ & $<0.050$ & $<0.050$ & 15 \\
\hline Oil and grease (mg/L) & $<5.000$ & $<5.000$ & $<5.000$ & 20 \\
\hline pH (standard units) & 9.700 & 6.200 & & 52 \\
\hline Phosphate as phosphorus (mg/L) & 0.230 & 0.110 & 0.173 & 4 \\
\hline Plutonium-239 (pCi/L) & 0.400 & $-0.300^{b}$ & 0.025 & 4 \\
\hline Polychlorinated biphenyl $(\mu \mathrm{g} / \mathrm{L})$ & $<0.100$ & $<0.100$ & $<0.100$ & 13 \\
\hline Suspended alpha (pCi/L) & 2.300 & $-3.400^{b}$ & 0.075 & 4 \\
\hline Suspended beta ( $\mathrm{pCi} / \mathrm{L})$ & 5.000 & $-2.000^{b}$ & 0.500 & 4 \\
\hline Suspended solids (mg/L) & 29.000 & $<4.000$ & $<13.150$ & 20 \\
\hline Technetium-99 (pCi/L) & 12.000 & 0.000 & 8.250 & 4 \\
\hline Temperature $\left({ }^{\circ} \mathrm{F}\right)$ & 84.000 & 41.000 & 63.077 & 52 \\
\hline Total phosphorus (mg/L) & 0.240 & 0.110 & 0.180 & 11 \\
\hline Trichloroethylene (mg/L) & $<0.001$ & $<0.001$ & $<0.001$ & 12 \\
\hline Uranium (mg/L) & 0.003 & $<0.001$ & $<0.002$ & 6 \\
\hline Zinc, total residual (mg/L) & 0.152 & $<0.005$ & $<0.047$ & 47 \\
\hline
\end{tabular}

${ }^{a}$ See Fig. 4.4 in Part 1.

${ }^{b}$ Negative numbers indicate that analytical result minus background was less than zero. 
1992 Environmental Report-Paducah, Part 2

Table 4.8. 1992 annual data summary for sampling location ${\mathrm{K} 010^{a}}^{a}$

Process, cooling, and storm

\begin{tabular}{|c|c|c|c|c|}
\hline Parameters & $\operatorname{Max}$ & Min & Av & $\begin{array}{c}\text { Number } \\
\text { of } \\
\text { samples }\end{array}$ \\
\hline Aluminum (mg/L) & 3.000 & 0.586 & 1.663 & 9 \\
\hline Assay \% uranium-235 (wt \%) & 0.713 & 0.240 & 0.384 & 9 \\
\hline Cadmium (mg/L) & $<0.010$ & $<0.005$ & $<0.008$ & 3 \\
\hline Chlorine, total residual (mg/L) & 0.010 & $<0.010$ & $<0.010$ & 12 \\
\hline Chromium, total recoverable $(\mathrm{mg} / \mathrm{L})$ & $<0.050$ & $<0.050$ & $<0.050$ & 9 \\
\hline Copper, total recoverable $(\mathrm{mg} / \mathrm{L})$ & 0.028 & $<0.010$ & $<0.012$ & 9 \\
\hline Dissolved alpha $(\mathrm{pCi} / \mathrm{L})$ & 19.000 & 0.500 & 8.100 & 9 \\
\hline Dissolved beta $(\mathrm{pCi} / \mathrm{L})$ & 65.000 & $-14.000^{h}$ & 21.444 & 9 \\
\hline Dissolved oxygen $(\mathrm{mg} / \mathrm{L})$ & 11.300 & 5.200 & 7.738 & 8 \\
\hline Flow (Mgd) & 1.490 & 0.001 & 0.527 & 10 \\
\hline Fluoride (mg/L) & 0.420 & 0.120 & 0.284 & 8 \\
\hline Hardness as $\mathrm{CaCO}_{3}(\mathrm{mg} / \mathrm{L} \mathrm{CaC})$ & 96.000 & 63.000 & 79.500 & 2 \\
\hline Hexavalent chromium $(\mathrm{mg} / \mathrm{L})$ & $<0.010$ & $<0.010$ & $<0.010$ & 1 \\
\hline Iron, total recoverable $(\mathrm{mg} / \mathrm{L})$ & 2.680 & $<0.010$ & $<1.396$ & 9 \\
\hline Lead (mg/L) & $<0.200$ & $<0.070$ & $<0.113$ & 3 \\
\hline Neptunium-237 (pCi/L) & 0.500 & $-0.300^{b}$ & 0.025 & 4 \\
\hline Nickel, total recoverable (mg/L) & $<0.050$ & $<0.050$ & $<0.050$ & 9 \\
\hline Oil and grease $(\mathrm{mg} / \mathrm{L})$ & $<5.000$ & 5.000 & $<5.000$ & 9 \\
\hline $\mathrm{pH}$ (standard units) & 9.800 & 6.800 & & 9 \\
\hline Phosphate as phosphorus (mg/L) & 0.170 & 0.170 & 0.170 & 1 \\
\hline Plutonium-239 (pCi/L) & 0.000 & 0.000 & 0.000 & 4 \\
\hline Polychlorinated biphenyl $(\mu \mathrm{g} / \mathrm{L})$ & $<0.100$ & $<0.100$ & $<0.100$ & 8 \\
\hline Suspended alpha $(\mathrm{pCi} / \mathrm{L})$ & 3.800 & $-0.560^{b}$ & 1.816 & 9 \\
\hline Suspended beta $(\mathrm{pCi} / \mathrm{L})$ & 18.000 & $-2.000^{b}$ & 4.111 & 9 \\
\hline Suspended solids (mg/L) & 45.000 & 10.000 & 26.000 & 9 \\
\hline Technetium-99 (pCi/L) & 93.000 & 13.000 & 40.500 & 4 \\
\hline Temperature $\left({ }^{\circ} \mathrm{F}\right)$ & 77.000 & 48.000 & 67.000 & 9 \\
\hline Total phosphorus (mg/L) & 0.220 & 0.170 & 0.195 & 2 \\
\hline Trichloroethylene (mg/L) & $<0.001$ & $<0.001$ & $<0.001$ & 9 \\
\hline Uranium (mg/L) & 0.027 & 0.006 & 0.018 & 8 \\
\hline Zinc, total residual (mg/L) & 0.073 & $<0.005$ & $<0.038$ & 9 \\
\hline
\end{tabular}

"See Fig. 4.4 in Part 1.

${ }^{b}$ Negative numbers indicate that analytical result minus background was less than zero. 
1992 Environmental Report-Paducah, Part 2

Table 4.9. 1992 annual data summary for sampling location ${\mathrm{K} 011^{a}}^{a}$

Process, cooling, and storm

\begin{tabular}{|c|c|c|c|c|}
\hline Parameters & $\operatorname{Max}$ & Min & Av & $\begin{array}{c}\text { Number } \\
\text { of } \\
\text { samples }\end{array}$ \\
\hline Aluminum (mg/L) & 0.550 & 0.161 & 0.328 & 15 \\
\hline Assay \% uranium-235 (wt \%) & 0.546 & 0.200 & 0.287 & 50 \\
\hline Cadmium (mg/L) & 0.020 & $<0.005$ & $<0.010$ & 6 \\
\hline Chlorine, total residual $(\mathrm{mg} / \mathrm{L})$ & 0.020 & $<0.010$ & $<0.011$ & 52 \\
\hline Chromium, total recoverable $(\mathrm{mg} / \mathrm{L})$ & 0.156 & $<0.006$ & $<0.054$ & 47 \\
\hline Copper, total recoverable $(\mathrm{mg} / \mathrm{L})$ & 0.010 & $<0.005$ & $<0.010$ & 15 \\
\hline Dissolved alpha (pCi/L) & 30.300 & $-8.100^{b}$ & 8.861 & 51 \\
\hline Dissolved beta $(\mathrm{pCi} / \mathrm{L})$ & 36.000 & $-3.000^{b}$ & 10.569 & 51 \\
\hline Dissolved oxygen (mg/L) & 10.600 & 6.600 & 8.715 & 20 \\
\hline Fecal coliform (colonies $/ 100 \mathrm{~mL}$ ) & 144.000 & $<1.000$ & $<58.667$ & 3 \\
\hline Flow (Mgd) & 1.110 & 0.127 & 0.408 & 50 \\
\hline Fluoride $(\mathrm{mg} / \mathrm{L})$ & 0.210 & 0.100 & 0.142 & 20 \\
\hline Gross alpha $(\mathrm{pCi} / \mathrm{L})$ & 18.000 & 6.800 & 12.400 & 2 \\
\hline Gross beta $(\mathrm{pCi} / \mathrm{L})$ & 31.000 & 8.000 & 19.500 & 2 \\
\hline Hardness as $\mathrm{CaCO}_{3}(\mathrm{mg} / \mathrm{L} \mathrm{CaC})$ & 128.000 & 44.000 & 65.643 & 14 \\
\hline Hexavalent chromium $(\mathrm{mg} / \mathrm{L})$ & $<0.010$ & $<0.010$ & $<0,010$ & 2 \\
\hline Iron, total recoverable $(\mathrm{mg} / \mathrm{L})$ & 0.834 & $<0.010$ & $<0.305$ & 24 \\
\hline Lead $(\mathrm{mg} / \mathrm{L})$ & 0.200 & $<0.030$ & $<0.105$ & 6 \\
\hline Nickel, total recoverable $(\mathrm{mg} / \mathrm{L})$ & 0.050 & $<0.020$ & $<0.048$ & 15 \\
\hline Oil and grease $(\mathrm{mg} / \mathrm{L})$ & $<5.000$ & $<5.000$ & $<5.000$ & 18 \\
\hline $\mathrm{pH}$ (standard units) & 9.400 & 6.500 & & 51 \\
\hline Phosphate as phosphorus (mg/L) & 0.330 & 0.204 & 0.284 & 4 \\
\hline Plutonium-239 (pCi/L) & 0.200 & 0.000 & 0.075 & 4 \\
\hline Polychlorinated biphenyl $(\mu \mathrm{g} / \mathrm{L})$ & $<0.100$ & $<0.100$ & $<0.100$ & 12 \\
\hline Suspended alpha $(\mathrm{pCi} / \mathrm{L})$ & 17.700 & $-5.500^{b}$ & 0.122 & 51 \\
\hline Suspended beta $(\mathrm{pCi} / \mathrm{L})$ & 40.000 & $-13.000^{b}$ & 0.316 & 51 \\
\hline Suspended solids $(\mathrm{mg} / \mathrm{L})$ & 38.000 & $<4.000$ & $<10.421$ & 19 \\
\hline Technetium-, 9 (pCi/lu) & 37.000 & $-7.000^{b}$ & 7.721 & 53 \\
\hline Temperature $\left({ }^{\circ} \mathrm{F}\right)$ & 93.000 & 48.000 & 72.098 & 51 \\
\hline Total phosphorus (mg/L) & 0.380 & 0.190 & 0.298 & 11 \\
\hline Trichloroethylene $(\mathrm{mg} / \mathrm{L})$ & 0.004 & $<0.001$ & $<0.002$ & 11 \\
\hline Uranium (mg/L) & 0.063 & 0.002 & 0.025 & 52 \\
\hline Zinc, total residual (mg/L) & 0.107 & $<0.002$ & $<0.022$ & 46 \\
\hline
\end{tabular}

${ }^{a}$ See Fig. 4.4 in Part 1.

${ }^{b}$ Negative numbers indicate that analytical result minus background was less than zero. 


\section{Environmental Report-Paducah, Part 2}

Table 4.10. 1992 annual data summary for sampling location ${\mathrm{K} 012^{a}}^{a}$

Storm water runoff

\begin{tabular}{|c|c|c|c|c|}
\hline Parameters & Max & Min & Av & $\begin{array}{c}\text { Number } \\
\text { of } \\
\text { samples }\end{array}$ \\
\hline Aluminum (mg/L) & 1.710 & 0.408 & 1.041 & 8 \\
\hline Assay \% uranium-235 (wı \%) & 0.607 & 0.290 & 0.442 & 8 \\
\hline Cadmium (mg/L) & $<0.010$ & $<0.005$ & $<0.008$ & 3 \\
\hline Chlorine, total residual (mg/L) & $<0.010$ & $<0.010$ & $<0.010$ & 11 \\
\hline Chromium, total recoverable (mg/L) & 0.086 & $<0.050$ & $<0.054$ & 9 \\
\hline Copper, total recoverable (mg/L) & 0.012 & $<0.010$ & $<0.010$ & 8 \\
\hline Dissolved alpha $(\mathrm{pCi} / \mathrm{L})$ & 8.100 & $-2.100^{b}$ & 2.500 & 9 \\
\hline Dissolved beta ( $\mathrm{pCi} / \mathrm{L})$ & 21.000 & $-2.800^{b}$ & 8.911 & 9 \\
\hline Dissolved oxygen $(\mathrm{mg} / \mathrm{L})$ & 11.300 & 6.300 & 8.257 & 7 \\
\hline Fluoride $(\mathrm{mg} / \mathrm{L})$ & 0.530 & 0.290 & 0.407 & 7 \\
\hline Iron, total recoverable $(\mathrm{mg} / \mathrm{L})$ & 1.700 & 0.262 & 0.987 & 8 \\
\hline Flow (Mgd) & 2.860 & 0.022 & 0.832 & 10 \\
\hline Hardness as $\mathrm{CaCo}_{3}(\mathrm{mg} / \mathrm{L} \mathrm{CaC})$ & 116.000 & 73.000 & 94.500 & 2 \\
\hline Hexavalent chromium (mg/L) & $<0.010$ & $<0.010$ & $<0.010$ & 1 \\
\hline Lead (mg/L) & $<0.200$ & $<0.070$ & $<0.113$ & 3 \\
\hline Neptunium-237 (pCi/L) & 0.100 & $-0.400^{b}$ & $-0.100^{h}$ & 3 \\
\hline Nickel, total recoverable (mg/L) & $<0.050$ & $<0.050$ & $<0.050$ & 8 \\
\hline Oil and grease $(\mathrm{mg} / \mathrm{L})$ & $<5.000$ & $<5.000$ & $<5.000$ & 8 \\
\hline $\mathrm{pH}$ (standard units) & 8.000 & 6.300 & & 9 \\
\hline Phosphate as phosphorus ( $\mathrm{mg} / \mathrm{L}$ ) & 0.260 & 0.260 & 0.260 & 1 \\
\hline Plutonium-239 (pCi/L) & 0.100 & 0.000 & 0.033 & 3 \\
\hline Polychlorinated biphenyl $(\mu \mathrm{g} / \mathrm{L})$ & $<0.100$ & $<0.100$ & $<0.100$ & 7 \\
\hline Suspended alpha $(\mathrm{pCi} / \mathrm{L})$ & 3.300 & $-2.000^{b}$ & 1.300 & 9 \\
\hline Suspended beta (pCi/L) & 23.000 & $-3.000^{b}$ & 2.000 & 9 \\
\hline Suspended solids (mg/L) & 71.000 & 8.000 & 27.375 & 8 \\
\hline Technetium-99 (pCi/L) & 14.000 & 0.000 & 5.667 & 3 \\
\hline Temperature $\left({ }^{\circ} \mathrm{F}\right)$ & 85.000 & 50.000 & 68.111 & 9 \\
\hline Total phosphorus (mg/L) & 0.260 & 0.180 & 0.220 & 2 \\
\hline Trichloroethylene $(\mathrm{mg} / \mathrm{L})$ & $<0.001$ & $<0.001$ & $<0.001$ & 8 \\
\hline Uranium $(\mathrm{mg} / \mathrm{L})$ & 0.016 & $<0.001$ & $<0.007$ & 8 \\
\hline Zinc, total residual (mg/L) & 0.079 & 0.016 & 0.046 & 9 \\
\hline
\end{tabular}

"See Fig. 4.4 in Part 1.

${ }^{b}$ Negative numbers indicate that analytical result minus background was less than zero. 
Table 4.11. 1992 annual data summary for sampling location $\mathrm{KO13}^{a}$ Storm water runoff

\begin{tabular}{|c|c|c|c|c|}
\hline Parameters & Max & Min & Av & $\begin{array}{c}\text { Number } \\
\text { of } \\
\text { samples }\end{array}$ \\
\hline Aluminum (mg/L) & 3.880 & 0.208 & 1.770 & 12 \\
\hline Assay \% uranium-235 (wt \%) & 0.660 & 0.520 & 0.583 & 3 \\
\hline Cadmium (mg/L) & 0.026 & $<0.005$ & $<0.012$ & 5 \\
\hline Chromium, total recoverable (mg/L) & 6.960 & $<0.050$ & $<2.652$ & 5 \\
\hline Copper, total recoverable (mg/L) & $<0.010$ & $<0.010$ & $<0.010$ & 12 \\
\hline Dissolved alpha $(\mathrm{pCi} / \mathrm{L})$ & 3.500 & $-2.500^{b}$ & 1.700 & 4 \\
\hline Dissolved beta $(\mathrm{pCi} / \mathrm{L})$ & 54.000 & $-24.000^{b}$ & 15.500 & 4 \\
\hline Flow (Mgd) & 3.830 & 0.022 & 0.714 & 13 \\
\hline Fluoride $(\mathrm{mg} / \mathrm{L})$ & 1.100 & 0.260 & 0.582 & 10 \\
\hline Hardness as $\mathrm{CaCO}_{3}(\mathrm{mg} / \mathrm{L} \mathrm{CaC})$ & 158.000 & 60.000 & 109.000 & 2 \\
\hline Hexavalent chromium (mg/L) & 7.880 & $<0.010$ & $<4.930$ & 3 \\
\hline Iron, total recoverable $(\mathrm{mg} / \mathrm{L})$ & 3.980 & 0.128 & 1.642 & 12 \\
\hline Lead $(\mathrm{mg} / \mathrm{L})$ & 0.200 & $<0.030$ & $<0.140$ & 5 \\
\hline Neptunium-237 (pCi/L) & 0.300 & $-0.400^{b}$ & $-0.075^{b}$ & 4 \\
\hline Nickel, total recoverable (mg/L) & $<0.050$ & $<0.050$ & $<0.050$ & 12 \\
\hline Oil and grease $(\mathrm{mg} / \mathrm{L})$ & $<5.000$ & $<5.000$ & $<5.000$ & 12 \\
\hline $\mathrm{pH}$ (standard units) & 7.800 & 6.900 & & 12 \\
\hline Plutonium-239 (pCi/L) & 0.100 & 0.000 & 0.040 & 4 \\
\hline Polychlorinated biphenyl $(\mu \mathrm{g} / \mathrm{L})$ & $<0.100$ & $<0.100$ & $<0.100$ & 12 \\
\hline Suspended alpha $(\mathrm{pCi} / \mathrm{L})$ & 0.000 & $-4.900^{b}$ & $-2.150^{b}$ & 4 \\
\hline Suspended beta (pCi/L) & 8.000 & $-6.000^{b}$ & $-0.500^{b}$ & 4 \\
\hline Suspended solids (mg/L) & 81.000 & $<4.000$ & $<31.083$ & 12 \\
\hline Trichloroethylene (mg/L) & $<0.001$ & $<0.001$ & $<0.001$ & 2 \\
\hline Uranium (mg/L) & 0.005 & $<0.001$ & $<0.002$ & 4 \\
\hline Zinc, total residual $(\mathrm{mg} / \mathrm{L})$ & 0.021 & 0.016 & 0.019 & 2 \\
\hline
\end{tabular}

${ }^{a}$ See Fig. 4.4 in Part 1.

${ }^{b}$ Negative numbers indicate that analytical result minus background was less than zero.

Table 4.12. 1992 annual data summary for sampling location $\mathrm{K014}{ }^{a}$

Filter backwash

\begin{tabular}{|c|c|c|c|c|}
\hline Parameters & Max & Min & Av & $\begin{array}{c}\text { Number } \\
\text { of } \\
\text { samples }\end{array}$ \\
\hline Chemical oxygen demand (mg/L) & 7.000 & 7.000 & 7.000 & 1 \\
\hline Chlorine, total residual (mg/L) & $<0.010$ & $<0.010$ & $<0.010$ & 1 \\
\hline Flow $(\mathrm{Mgd})$ & 0.005 & 0.005 & 0.005 & 1 \\
\hline $\mathrm{pH}$ (standard units) & 9.500 & 9.500 & & 1 \\
\hline Polychlorinated biphenyl $(\mu \mathrm{g} / \mathrm{L})$ & $<0.100$ & $<0.100$ & $<0.100$ & 1 \\
\hline Suspended solids (mg/L) & 9.000 & 9.000 & 9.000 & 1 \\
\hline Turbidity (nephelometric turbidity units) & 1.400 & 1.400 & 1.400 & 1 \\
\hline
\end{tabular}

${ }^{a}$ See Fig. 4.4 in Part 1. 
1992 Environmental Report-Paducah, Part 2

Table 4.13. 1992 annual data summary for sampling location K015

Storm water runoff

\begin{tabular}{|c|c|c|c|c|}
\hline Parameters & Max & Min & Av & $\begin{array}{c}\text { Number } \\
\text { of } \\
\text { samples }\end{array}$ \\
\hline Aluminum (mg/L) & 7.620 & 0.276 & 2.774 & 12 \\
\hline Assay \% uranium-235 (wt \%) & 0.633 & 0.280 & 0.425 & 4 \\
\hline Cadmium (mg/L) & 0.026 & $<0.005$ & $<0.014$ & 4 \\
\hline Chromium, total recoverable (mg/L) & $<0.050$ & $<0.050$ & $<0.050$ & 3 \\
\hline Copper, total recoverable (mg/L) & 0.016 & $<0.010$ & $<0.011$ & 12 \\
\hline Dissolved alpha $(\mathrm{pCi} / \mathrm{L})$ & 111.000 & 4.200 & 45.625 & 4 \\
\hline Dissolved beta (pCi/L) & 218.000 & 0.000 & 71.250 & 4 \\
\hline Flow (Mgd) & 4.630 & $<0.001$ & $<1.138$ & 11 \\
\hline Fluoride $(\mathrm{mg} / \mathrm{L})$ & 0.580 & 0.340 & 0.467 & 9 \\
\hline Hardness as $\mathrm{CaCO}_{3}(\mathrm{mg} / \mathrm{L} \mathrm{CaC})$ & 69.000 & 58.000 & 63.500 & 2 \\
\hline Hexavalent chromium (mg/L) & $<0.010$ & $<0.010$ & $<0.010$ & 1 \\
\hline Iron, total recoverable $(\mathrm{mg} / \mathrm{L})$ & 6.270 & 0.083 & 2.270 & 12 \\
\hline Lead $(\mathrm{mg} / \mathrm{L})$ & $<0.200$ & $<0.030$ & $<0.158$ & 4 \\
\hline Neptunium-237 (pCi/L) & 0.000 & $-1.000^{b}$ & $-0.375^{b}$ & 4 \\
\hline Nickel, total recoverable (mg/L) & 0.162 & $<0.050$ & $<0.059$ & 12 \\
\hline Oil and grease $(\mathrm{mg} / \mathrm{L})$ & $<5.000$ & $<5.000$ & $<5.000$ & 11 \\
\hline pH (standard units) & 8.100 & 6.900 & & 12 \\
\hline Plutonium-239 (pCi/L) & 0.100 & 0.040 & 0.085 & 4 \\
\hline Polychlorinated biphenyl ( $\mu \mathrm{g} / \mathrm{L}$ ) & 0.100 & $<0.100$ & $<0.100$ & 10 \\
\hline Suspended alpha (pCi/L) & 1.600 & $-4.900^{b}$ & $-0.425^{b}$ & 4 \\
\hline Suspended beta $(\mathrm{pCi} / \mathrm{L})$ & 26.000 & $-0.700^{b}$ & 11.575 & 4 \\
\hline Suspended solids (mg/L) & 698.000 & $<4.000$ & $<103.250$ & 12 \\
\hline Trichloroethylene (mg/L) & $<0.001$ & $<0.001$ & $<0.001$ & 2 \\
\hline Uranium (mg/L) & 0.340 & 0.011 & 0.158 & 4 \\
\hline Zinc, total residual (mg/L) & 0.021 & $<0.005$ & $<0.013$ & 3 \\
\hline
\end{tabular}

${ }^{a}$ See Fig. 4.4 in Part 1.

${ }^{b}$ Negative numbers indicate that analytical result minus background was less than zero. 
1992 Environmental Report-Paducah, Part 2

Table 4.14. 1992 annual data summary for sampling location ${\mathrm{K} 016^{a}}^{a}$

Storm water runoff

\begin{tabular}{|c|c|c|c|c|}
\hline Parameters & Max & $\operatorname{Min}$ & Av & $\begin{array}{c}\text { Number } \\
\text { of } \\
\text { samples }\end{array}$ \\
\hline Aluminum (mg/L) & 1.280 & 0.202 & 0.531 & 10 \\
\hline Assay \% uranium-235 (wt \%) & 0.630 & 0.540 & 0.585 & 2 \\
\hline Cadmium (mg/L) & $<0.010$ & $<0.005$ & $<0.008$ & 2 \\
\hline Chromium, total recoverable (mg/L) & $<0.050$ & $<0.050$ & $<0.050$ & 2 \\
\hline Copper, total recoverable $(\mathrm{mg} / \mathrm{L})$ & $<0.010$ & $<0.010$ & $<0.010$ & 10 \\
\hline Dissolved alpha (pCi/L) & 2.300 & $-3.800^{b}$ & 0.600 & 4 \\
\hline Dissolved beta (pCi/L) & 43.000 & $-30.000^{b}$ & 9.000 & 4 \\
\hline Flow (Mgd) & 1.010 & $<0.001$ & $<0.165$ & 10 \\
\hline Fluoride (mg/L) & 0.250 & 0.180 & 0.206 & 8 \\
\hline Hardness as $\mathrm{CaCO}_{3}(\mathrm{mg} / \mathrm{L} \mathrm{CaC})$ & 226.000 & 62.000 & 144.000 & 2 \\
\hline Iron, total recoverable $(\mathrm{mg} / \mathrm{L})$ & 1.050 & 0.090 & 0.431 & 10 \\
\hline Lead $(\mathrm{mg} / \mathrm{L})$ & $<0.200$ & $<0.030$ & $<0.115$ & 2 \\
\hline Neptunium-237 (pCi/L) & 0.600 & $-0.600^{b}$ & 0.113 & 4 \\
\hline Nickel, total recoverable (mg/L) & $<0.050$ & $<0.050$ & $<0.050$ & 10 \\
\hline Oil and grease $(\mathrm{mg} / \mathrm{L})$ & $<5.000$ & $<5.000$ & $<5.000$ & 10 \\
\hline $\mathrm{pH}$ (standard units) & 8.500 & 6.900 & & 10 \\
\hline Plutonium-239 (pCi/L) & 0.230 & 0.000 & 0.108 & 4 \\
\hline Polychlorinated biphenly $(\mu \mathrm{g} / \mathrm{L})$ & $<0.100$ & $<0.100$ & $<0.100$ & 10 \\
\hline Suspended alpha $(\mathrm{pCi} / \mathrm{L})$ & 2.300 & $-2.500^{b}$ & $-0.250^{b}$ & 4 \\
\hline Suspended beta $(\mathrm{pCi} / \mathrm{L})$ & 6.000 & $-7.000^{b}$ & $-1.000^{b}$ & 4 \\
\hline Suspended solids (mg/L) & 19.000 & $<4.000$ & $<10.600$ & 10 \\
\hline Technetium-99 (pCi/L) & 12.000 & 12.000 & 12.000 & 1 \\
\hline Trichloroethylene $(\mathrm{mg} / \mathrm{L})$ & $<0.001$ & $<0.001$ & $<0.001$ & 2 \\
\hline Uranium (mg/L) & 0.008 & $<0.001$ & $<0.004$ & 4 \\
\hline Zinc, total residual (mg/L) & 0.014 & 0.011 & 0.013 & 2 \\
\hline
\end{tabular}

asee Fig. 4.4 in Part 1.

${ }^{b}$ Negative numbers indicate that inalytical result minus background was less than zero. 
1992 Environmental Report-Paducah, Part 2

Table 4.15. 1992 annual data summary for sampling location $\mathrm{KO17}^{a}$

Storn water runoff

\begin{tabular}{|c|c|c|c|c|}
\hline Parameters & Max & Min & Av & $\begin{array}{c}\text { Number } \\
\text { of } \\
\text { samples }\end{array}$ \\
\hline Assay \% uranium-235 (wt \%) & 0.684 & 0.470 & 0.545 & 3 \\
\hline Aluminum $(\mathrm{mg} / \mathrm{L})$ & 14.600 & 0.232 & 1.833 & 12 \\
\hline Cadmium (mg/L) & 0.026 & $<0.005$ & $<0.016$ & 5 \\
\hline Chiromium, total recoverable $(\mathrm{mg} / \mathrm{L})$ & $<0.050$ & $<0.050$ & $<0.050$ & 2 \\
\hline Copper, total recoverable (mg/L) & 0.030 & $<0.010$ & $<0.012$ & 12 \\
\hline Dissolved alpha ( $\mathrm{pCi} / \mathrm{L})$ & 5.100 & $-0.500^{b}$ & 2.800 & 4 \\
\hline Dissolved beta $(\mathrm{pCi} / \mathrm{L})$ & 17.000 & $-6.000^{b}$ & 3.150 & 4 \\
\hline Flow (Mgd) & 1.580 & $<0.001$ & $<0.253$ & 12 \\
\hline Fluoride $(\mathrm{mg} / \mathrm{L})$ & 0.630 & 0.360 & 0.472 & 10 \\
\hline Hardness as $\mathrm{CaCO}_{3}(\mathrm{mg} / \mathrm{L} \mathrm{CaC})$ & 186.000 & 91.000 & 138.500 & 2 \\
\hline Hexavalent chromium (mg/L) & $<0.010$ & $<0.010$ & $<0.010$ & 1 \\
\hline Iron, total recoverable $(\mathrm{mg} / \mathrm{L})$ & 21.500 & 0.162 & 2.388 & 12 \\
\hline Lead $(\mathrm{mg} / \mathrm{L})$ & $<0.200$ & $<0.030$ & $<0.140$ & 5 \\
\hline Neptunium-237 (pCi/L) & 0.100 & $-0.700^{b}$ & $-0.250^{b}$ & 4 \\
\hline Nickel, total recoverable (mg/L) & 0.135 & $<0.050$ & $<0.057$ & 12 \\
\hline Oil and grease $(\mathrm{mg} / \mathrm{L})$ & $<5.000$ & $<5.000$ & $<5.000$ & 12 \\
\hline $\mathrm{pH}$ (standard units) & 8.200 & 7.100 & & 12 \\
\hline Plutonium-239 (pCi/L) & 0.100 & 0.000 & 0.050 & 4 \\
\hline Polychlorinated biphenyl $(\mu \mathrm{g} / \mathrm{L})$ & $<0.100$ & $<0.100$ & $<0.100$ & 12 \\
\hline Suspended alpha $(\mathrm{pCi} / \mathrm{L})$ & 1.100 & $-2.700^{b}$ & $-0.725^{b}$ & 4 \\
\hline Suspended beta $(\mathrm{pCi} / \mathrm{L})$ & 10.000 & $-1.000^{b}$ & 3.250 & 4 \\
\hline Suspended solids ( $\mathrm{mg} / \mathrm{L}$ ) & 1930.000 & 4.000 & 182.167 & 12 \\
\hline Trichloroethylene (mg/L) & $<0.001$ & $<0.001$ & $<0.001$ & 2 \\
\hline Uranium (mg/L) & 0.012 & 0.001 & 0.006 & 4 \\
\hline Zinc, total residual (mg/L) & 0.022 & 0.008 & 0.015 & 2 \\
\hline
\end{tabular}

"See Fig. 4.4 in Part 1.

${ }^{b}$ Negative numbers indicate that analytical result minus background was less than zero. 
1992 Environmental Report-Paducah, Part 2

Table 4.16. 1992 annual data summary for sampling location $\mathrm{KO} \mathrm{s}^{a}$

Landfill runoff

\begin{tabular}{|c|c|c|c|c|}
\hline Parameters & Max & Min & Av & $\begin{array}{c}\text { Number } \\
\text { of } \\
\text { samples }\end{array}$ \\
\hline Aluminum (mg/L) & 119.000 & 0.408 & 20.780 & 11 \\
\hline Assay \% uranium-235 (wt \%) & 0.700 & 0.530 & 0.615 & 2 \\
\hline Cadmium (mg/L) & 0.031 & $<0.005$ & $<0.015$ & 4 \\
\hline Chromium, total recoverable (mg/L) & $<0.050$ & $<0.050$ & $<0.050$ & 2 \\
\hline Copper, total recoverable $(\mathrm{mg} / \mathrm{L})$ & 0.141 & $<0.010$ & $<0.028$ & 11 \\
\hline Dissolved alpha (pCi/L) & 24.200 & 0.000 & 9.050 & 4 \\
\hline Dissolved beta $(\mathrm{pCi} / \mathrm{L})$ & 45.000 & 7.000 & 29.250 & 4 \\
\hline Flow (Mgd) & 10.200 & $<0.001$ & $<1.599$ & 11 \\
\hline Fluoride $(\mathrm{mg} / \mathrm{L})$ & 0.720 & 0.330 & 0.488 & 9 \\
\hline Hardness as $\mathrm{CaCO}_{3}(\mathrm{mg} / \mathrm{L} \mathrm{CaC})$ & 118.000 & 89.000 & 103.500 & 2 \\
\hline Hexavalent chromium $(\mathrm{mg} / \mathrm{L})$ & $<0.010$ & $<0.010$ & $<0.010$ & 1 \\
\hline Iron, total recoverable $(\mathrm{mg} / \mathrm{L})$ & 163.000 & 0.134 & 24.532 & 11 \\
\hline Lead (mgiL) & $<0.200$ & $<0.030$ & $<0.158$ & 4 \\
\hline Neptunium-237 (pCi/L) & 0.600 & $-0.300^{b}$ & 0.125 & 4 \\
\hline Nickel, total recoverable (mg/L) & 0.125 & $<0.050$ & $<0.057$ & 11 \\
\hline Oil and grease $(\mathrm{mg} / \mathrm{L})$ & 8.500 & $<5.000$ & $<5.318$ & 11 \\
\hline $\mathrm{pH}$ (standard units) & 8.200 & 7.200 & & 11 \\
\hline Plutonium-239 (pCi/L) & 0.200 & 0.000 & 0.100 & 4 \\
\hline Polychlorinated biphyenl $(\mu \mathrm{g} / \mathrm{L})$ & $<0.100$ & $<0.100$ & $<0.100$ & 11 \\
\hline Suspended alpha $(\mathrm{pCi} / \mathrm{L})$ & 4.100 & $-1.400^{b}$ & 1.100 & 4 \\
\hline Suspended beta $(\mathrm{pCi} / \mathrm{L})$ & 29.000 & 4.000 & 12.500 & 4 \\
\hline Suspended solids (mg/L) & 2980.000 & $<4.000$ & $<369.182$ & 11 \\
\hline Trichloroethylene (mg/L) & $<0.001$ & $<0.001$ & $<0.001$ & 2 \\
\hline Uranium $(\mathrm{mg} / \mathrm{L})$ & 0.065 & 0.002 & 0.020 & 4 \\
\hline Zinc, total residual (mg/L) & 0.050 & 0.016 & 0.033 & 2 \\
\hline
\end{tabular}

${ }^{a}$ See Fig. 4.4 in Part 1.

${ }^{b}$ Negative numbers indicate that analytical result minus background was less than zero. 
Table 4.17. 1992 annual data summary for sampling location $\mathbf{S W} \mathbf{1}^{a}$

Upstream Big Bayou Creek and landfill runoff location 1, background

\begin{tabular}{|c|c|c|c|c|}
\hline Parameters & Max & Min & Av & $\begin{array}{c}\text { Number } \\
\text { of } \\
\text { samples }\end{array}$ \\
\hline Antimony (mg/L) & 0.060 & $<0.060$ & $<0.060$ & 1 \\
\hline Arsenic $(\mathrm{mg} / \mathrm{L})$ & $<0.005$ & $<0.005$ & $<0.005$ & 1 \\
\hline Assay $\%$ uranium- 235 (wt \%) & 1.080 & 0.650 & 0.769 & 6 \\
\hline Barium (mg/L) & 0.021 & 0.021 & 0.021 & 1 \\
\hline Beryllium (mg/L) & $<0.005$ & $<0.005$ & $<0.005$ & 1 \\
\hline Cadmium (mg/L) & $<0.010$ & $<0.010$ & $<0.010$ & 1 \\
\hline Chloride $(\mathrm{mg} / \mathrm{L})$ & 18.000 & 5.000 & 12.813 & 16 \\
\hline Chromium, total recoverable $(\mathrm{mg} / \mathrm{L})$ & $<0.050$ & $<0.050$ & $<0.050$ & 1 \\
\hline Cobalt (mg/L) & $<0.050$ & $<0.050$ & $<0.050$ & 1 \\
\hline Copper, total recoverable $(\mathrm{mg} / \mathrm{L})$ & $<0.010$ & $<0.010$ & $<0.010$ & 1 \\
\hline Dissolved alpha $(\mathrm{pCi} / \mathrm{L})$ & 4.200 & $-4.800^{b}$ & $-0.308^{b}$ & 12 \\
\hline Dissolved beta (pCi/L) & 19.000 & $-3.000^{b}$ & 6.308 & 12 \\
\hline Dissolved solids (mg/L) & 138.000 & 99.000 & 117.250 & 4 \\
\hline Fluoride (mg/L) & 0.240 & 0.110 & 0.157 & 13 \\
\hline Gross alpha $(\mathrm{pCi} / \mathrm{L})$ & 13.500 & $-1.200^{b}$ & 4.600 & 5 \\
\hline Gross beta $(\mathrm{pCi} / \mathrm{L})$ & 27.000 & $-2.000^{b}$ & 10.200 & 5 \\
\hline Hexavalent chromium (mg/L) & 0.020 & $<0.010$ & $<0.011$ & 12 \\
\hline Iron, total recoverable (mg/L) & 26.000 & 0.997 & 8.427 & 4 \\
\hline Lead (mg/L) & $<0.200$ & $<0.200$ & $<0.200$ & 1 \\
\hline Mercury $(\mathrm{mg} / \mathrm{L})$ & $<0.000$ & $<0.000$ & $<0.000$ & 1 \\
\hline Neptunium-237 (pCi/L) & 1.000 & $-0.500^{b}$ & 0.083 & 12 \\
\hline Nickel, total recoverable $(\mathrm{mg} / \mathrm{L})$ & $<0.050$ & $<0.050$ & $<0.050$ & 1 \\
\hline Nitrate as nitrogen $(\mathrm{mg} / \mathrm{L})$ & 2.600 & $<1.000$ & $<1.150$ & 12 \\
\hline $\mathrm{pH}$ (standard units) & 8.300 & 6.400 & & 16 \\
\hline Phosphate as phosphorus (mg/L) & $<2.000$ & $<2.000$ & $<2.000$ & 12 \\
\hline Plutonium-239 (pCi/L) & 0.100 & 0.000 & 0.065 & 12 \\
\hline Polychlorinated biphenyl $(\mu \mathrm{g} / \mathrm{L})$ & $<0.100$ & $<0.100$ & $<0.100$ & 1 \\
\hline Sclenium $(\mathrm{mg} / \mathrm{L})$ & $<0.005$ & $<0.005$ & $<0.005$ & 1 \\
\hline Silver $(\mathrm{mg} / \mathrm{L})$ & $<0.030$ & $<0.030$ & $<0.030$ & 1 \\
\hline Sodium $(\mathrm{mg} / \mathrm{L})$ & 13.300 & 2.720 & 7.623 & 4 \\
\hline Specific conductance $(\mu \mathrm{mhos} / \mathrm{cm})$ & 248.000 & 54.700 & 165.567 & 3 \\
\hline Sulfate $(\mathrm{mg} / \mathrm{L})$ & 54.000 & 8.000 & 31.125 & 16 \\
\hline Suspended alpha (pCi/L) & 2.000 & $-2.500^{b}$ & 0.225 & 12 \\
\hline Suspended beta ( $\mathrm{pCi} / \mathrm{L}$ ) & 21.000 & $-14.000^{b}$ & $-1.167^{b}$ & 12 \\
\hline Suspended solids $(\mathrm{mg} / \mathrm{L})$ & 1638.000 & 6.000 & 459.500 & 4 \\
\hline Technetium-99 (pCi/L) & 16.000 & $-7.000^{b}$ & 4.023 & 13 \\
\hline Temperature $\left({ }^{\circ} \mathrm{F}\right)$ & 80.000 & 37.000 & 57.258 & 62 \\
\hline Thallium (mg/L) & $<0.090$ & $<0.090$ & $<0.090$ & 1 \\
\hline $\operatorname{Tin}(m g / L)$ & $<0.050$ & $<0.050$ & $<0.050$ & 1 \\
\hline Total organic carbon $(\mathrm{mg} / \mathrm{L})$ & 11.000 & 5.000 & 8.250 & 4 \\
\hline Total solids (mg/L) & 1740.000 & 144.000 & 576.750 & 4 \\
\hline Uranium $(\mathrm{mg} / \mathrm{L})^{\circ}$ & 0.014 & $<0.001$ & $<0.002$ & 17 \\
\hline Vanadium (mg/L) & $<0.050$ & $<0.050$ & $<0.050$ & 1 \\
\hline Zinc, total residual (mg/L) & $<0.005$ & $<0.005$ & $<0.005$ & 1 \\
\hline
\end{tabular}

${ }^{a}$ See Fig. 4.3 in Part 1.

${ }^{b}$ Negative numbers indicate that analytical result minus background was less than zero. 
Table 4.18. 1992 annual data summary for sampling location $S W 5^{a}$ Downstream Big Bayou Creek

\begin{tabular}{|c|c|c|c|c|}
\hline Parameters & Max & Min & Av & $\begin{array}{c}\text { Number } \\
\text { of } \\
\text { samples }\end{array}$ \\
\hline Assay $\%$ uranium-235 (wt \%) & 0.880 & 0.451 & 0.619 & 10 \\
\hline Dissolved alpha $(\mathrm{pCi} / \mathrm{L})$ & 13.100 & $-11.700^{b}$ & 1.617 & 12 \\
\hline Dissolved beta $(\mathrm{pCi} / \mathrm{L})$ & 30.000 & 5.000 & 14.150 & 12 \\
\hline Gross alpha $(\mathrm{pCi} / \mathrm{L})$ & 4.100 & 4.100 & 4.100 & 1 \\
\hline Gross beta $(\mathrm{pCi} / \mathrm{L})$ & 6.000 & 6.000 & 6.000 & 1 \\
\hline Neptunium-237 (pCi/L) & 0.300 & $-0.700^{b}$ & 0.000 & 13 \\
\hline $\mathrm{pH}$ (standard units) & 8.600 & 7.400 & & 2 \\
\hline Plutonium-239 (pCi/L) & 0.200 & 0.000 & 0.065 & 13 \\
\hline Suspended alpha $(\mathrm{pCi} / \mathrm{L})$ & 4.500 & $-6.500^{b}$ & $-0.150^{b}$ & 12 \\
\hline Suspended beta $(\mathrm{pCi} / \mathrm{L})$ & 15.000 & $-4.000^{b}$ & 0.358 & 12 \\
\hline Technetium-99 (pCi/L) & 16.000 & $-9.000^{b}$ & 6.154 & 13 \\
\hline Thorium-230 (pCi/L) & 0.000 & 0.000 & 0.000 & 1 \\
\hline Uranium (mg/L) & 0.017 & $<0.001$ & $<0.005$ & 13 \\
\hline
\end{tabular}

${ }^{a}$ See Fig. 4.3 in Part 1.

${ }^{b}$ Negative numbers indicate that analytical result minus background was less than zero.

Table 4.19. 1992 annual data summary for sampling loca $n \mathrm{SW} 10^{a}$ Downstream Little Bayou Creek

\begin{tabular}{|c|c|c|c|c|}
\hline Parameters & Max & Min & Av & $\begin{array}{c}\text { Number } \\
\text { of } \\
\text { samples }\end{array}$ \\
\hline Assay \% uranium-235 (wt \%) & 0.603 & 0.196 & 0.310 & 13 \\
\hline Chromium, total recoverable $(\mathrm{mg} / \mathrm{L})$ & $<0.050$ & $<0.050$ & $<0.050$ & 3 \\
\hline Dissolved alpha (pCi/L) & 19.000 & $-3.300^{b}$ & 7.325 & 12 \\
\hline Dissolved beta $(\mathrm{pCi} / \mathrm{L})$ & 25.000 & $-28.000^{b}$ & 8.958 & 12 \\
\hline Gross alpha $(\mathrm{pCi} / \mathrm{L})$ & 6.100 & 6.100 & 6.100 & 1 \\
\hline Gross beta $(\mathrm{pCi} / \mathrm{L})$ & 8.000 & 8.000 & 8.000 & 1 \\
\hline Neptunium-237 (pCi/L) & 0.600 & $-0.500^{h}$ & 0.000 & 13 \\
\hline $\mathrm{pH}$ (standard units) & 7.800 & 7.600 & & 2 \\
\hline Plutonium-239 (pCi/L) & 0.100 & 0.000 & 0.049 & 13 \\
\hline Suspended alpha $(\mathrm{pCi} / \mathrm{L})$ & 2.100 & $-2.700^{b}$ & $-0.475^{b}$ & 12 \\
\hline Suspended beta $(\mathrm{pCi} / \mathrm{L})$ & 21.000 & $-11.000^{b}$ & $-0.067^{b}$ & 12 \\
\hline Technetium-99 (pCi/L) & 14.000 & $-10.000^{b}$ & 3.377 & 13 \\
\hline Thorium-230 (pCi/L) & 0.000 & 0.000 & 0.000 & 1 \\
\hline Uranium $(\mathrm{mg} / \mathrm{L})$ & 0.028 & 0.007 & 0.019 & 13 \\
\hline
\end{tabular}

"See Fig. 4.3 in Part 1.

${ }^{b}$ Negative numbers indicate that analytical result minus background was less than zero. 
1992 Environmental Report-Paducah, Part 2

Table 4.20. 1992 annual data summary for sampling location $\mathrm{SW}^{\mathrm{a}}{ }^{a}$

North/south diversion ditch

\begin{tabular}{|c|c|c|c|c|}
\hline Parameters & Max & Min & Av & $\begin{array}{c}\text { Number } \\
\text { of } \\
\text { samples }\end{array}$ \\
\hline Assay \% uranium-235 (wt \%) & 1.280 & 0.560 & 0.690 & 38 \\
\hline Chloride $(\mathrm{mg} / \mathrm{L})$ & 945.000 & 14.000 & 111.596 & 52 \\
\hline Dissolved alpha (pCi/L) & 27.800 & $-36.000^{b}$ & 4.944 & 52 \\
\hline Dissolved beta $(\mathrm{pCi} / \mathrm{L})$ & 130.000 & $-2.000^{b}$ & 19.462 & 52 \\
\hline Fluoride $(\mathrm{mg} / \mathrm{L})$ & 0.940 & $<0.100$ & $<0.261$ & 51 \\
\hline Flow (Mgd) & 1.690 & 0.077 & 0.609 & 52 \\
\hline Hexavalent chromium (mg/L) & 0.050 & $<0.010$ & $<0.013$ & 51 \\
\hline Nitrate as nitrogen $(\mathrm{mg} / \mathrm{L})$ & 3.000 & $<1.000$ & $<1.275$ & 51 \\
\hline $\mathrm{pH}$ (standard units) & 10.000 & 6.500 & & 52 \\
\hline Phosphate as phosphorus (mg/L) & 2.500 & $<2.000$ & $<2.010$ & 52 \\
\hline Sulfate $(\mathrm{mg} / \mathrm{L})$ & 217.000 & 31.000 & 81.039 & 52 \\
\hline Suspended alpha (pCi/L) & 5.400 & $-5.600^{b}$ & 0.035 & 52 \\
\hline Suspended beta ( $\mathrm{pCi} / \mathrm{L}$ ) & 18.000 & $-12.000^{b}$ & 0.156 & 52 \\
\hline Technetium-99 (pCi/L) & 139.400 & $-5.000^{b}$ & 15.539 & 52 \\
\hline Temperature $\left({ }^{\circ} \mathrm{F}\right)$ & 90.000 & 60.000 & 74.596 & 52 \\
\hline Uranium $(\mathrm{mg} / \mathrm{L})$ & 0.120 & 0.001 & 0.020 & 52 \\
\hline
\end{tabular}

"See Fig. 4.3 in Part 1.

${ }^{b}$ Negative numbers indicate that analytical result minus background was less than zero. 
1992 Environmental Report-Paducah, Part 2

Table 4.21. 1992 annual data summary for sampling location $\mathrm{SW}_{29^{a}}$

Upstream Ohio River

\begin{tabular}{|c|c|c|c|c|}
\hline Parameters & $\operatorname{Max}$ & Min & Av & $\begin{array}{l}\text { Number } \\
\text { of } \\
\text { samples }\end{array}$ \\
\hline Assay \% uranium-235 (wt \%) & 0.860 & 0.620 & 0.763 & 7 \\
\hline Aluminum $(\mathrm{mg} / \mathrm{L})$ & 1.950 & 1.950 & 1.950 & 1 \\
\hline Cadmium (mg/L) & $<0.010$ & <i 010 & $<0.010$ & 1 \\
\hline Chloride $(\mathrm{mg} / \mathrm{L})$ & 14.000 & 7.610 & 9.833 & 12 \\
\hline Copper, total recoverable $(\mathrm{mg} / \mathrm{L})$ & $<0.010$ & $<0.010$ & $<0.010$ & 1 \\
\hline Dissolved alpha $(\mathrm{pCi} / \mathrm{L})$ & 14.600 & $-6.800^{b}$ & 1.015 & 13 \\
\hline Dissolved beta $(\mathrm{pCi} / \mathrm{L})$ & 29.000 & $-39.000^{h}$ & 3.885 & 13 \\
\hline 1,2-Dichloroethane $(\mu \mathrm{g} / \mathrm{L})$ & 2.000 & $<1.000$ & $<1.667$ & 3 \\
\hline Fluoride $(\mathrm{mg} / \mathrm{L})$ & 0.130 & $<0.100$ & $<0.107$ & 12 \\
\hline Hardness as $\mathrm{CaCO}_{3}(\mathrm{mg} / \mathrm{L} \mathrm{CaC})$ & 150.000 & 150.000 & 150.000 & 1 \\
\hline Hexavalent chromium (mg/L) & 0.050 & $<0.010$ & $<0.017$ & 13 \\
\hline Iron, total recoverable $(\mathrm{mg} / \mathrm{L})$ & 2.590 & 2.590 & 2.590 & 1 \\
\hline Lead $(\mathrm{mg} / \mathrm{L})$ & $<0.080$ & $<0.080$ & $<0.080$ & 1 \\
\hline Neptunium-237 (pCi/L) & 0.900 & $-0.600^{\mathrm{b}}$ & $-0.100^{b}$ & 12 \\
\hline Nickel, total recoverable (mg/L) & $<0.050$ & $<0.050$ & $<0.050$ & 1 \\
\hline Nitrate as nitrogen $(\mathrm{mg} / \mathrm{L})$ & 1.800 & $<1.000$ & $<1.075$ & 12 \\
\hline Oil and grease $(\mathrm{mg} / \mathrm{L})$ & $<5.000$ & $<5.000$ & $<5.000$ & 1 \\
\hline $\mathrm{pH}$ (standard units) & 8.300 & 7.300 & & 13 \\
\hline Phosphate as phosphorus (mg/L) & $<2.000$ & $<2.000$ & $<2.000$ & 12 \\
\hline Plutonium-239 (pCi/L) & 0.440 & 0.000 & 0.108 & 12 \\
\hline Polychlorinated biphenyl $(\mu \mathrm{g} / \mathrm{L})$ & $<0.100$ & $<0.100$ & $<0.100$ & 1 \\
\hline Sulfate $(\mathrm{mg} / \mathrm{L})$ & 48.000 & 13.000 & 22.417 & 12 \\
\hline Suspended alpha ( $\mathrm{pCi} / \mathrm{L})$ & 4.400 & $-6.200^{h}$ & $-1.000^{b}$ & 13 \\
\hline Suspended beta $(\mathrm{pCi} / \mathrm{L})$ & 17.000 & $-15.000^{h}$ & 0.385 & 13 \\
\hline Suspended solids $(\mathrm{mg} / \mathrm{L})$ & 45.000 & 45.000 & 45.000 & 1 \\
\hline Technetium-99 (pCi/L) & 13.000 & $-5.000^{b}$ & 3.250 & 12 \\
\hline Total phosphorus $(\mathrm{mg} / \mathrm{L})$ & 0.120 & 0.120 & 0.120 & 1 \\
\hline Trichloroethylene $(\mathrm{mg} / \mathrm{L})$ & $<0.001$ & $<0.001$ & $<0.001$ & 1 \\
\hline Uranium (mg/L) & $<0.001$ & $<0.001$ & $<0.001$ & 13 \\
\hline Zinc, total residual $(\mathrm{mg} / \mathrm{L})$ & 0.009 & 0.009 & 0.009 & 1 \\
\hline
\end{tabular}

"See Fig. 4.3 in Part 1.

${ }^{b}$ Negative numbers indicate that analytical result minus background was less than zero. 
Table 4.22. 1992 annual data summary for sampling location SW30 ${ }^{a}$

Downstream Ohio River

\begin{tabular}{|c|c|c|c|c|}
\hline Parameters & Max & $\operatorname{Min}$ & Av & $\begin{array}{c}\text { Number } \\
\text { of } \\
\text { samples }\end{array}$ \\
\hline Assay \% uraniumı-235 (wt \%) & 0.990 & 0.658 & 0.773 & 5 \\
\hline Chloride $(\mathrm{mg} / \mathrm{L})$ & 15.000 & 7.000 & 11.000 & 11 \\
\hline 1,2-Dichloroethane $(\mu \mathrm{g} / \mathrm{L})$ & $<5.000$ & $<1.000$ & $<3.667$ & 9 \\
\hline Dissolved alpha $(\mathrm{pCi} / \mathrm{L})$ & 5.900 & $-4.000^{b}$ & $-0.646^{b}$ & 11 \\
\hline Dissolved beta ( $\mathrm{pCj} / \mathrm{L})$ & 25.000 & $-5.000^{b}$ & 4.482 & 11 \\
\hline Fluoride $(\mathrm{mg} / \mathrm{L})$ & 0.140 & $<0.100$ & $<0.108$ & 11 \\
\hline Hexavalent chromium (mg/L) & 0.030 & $<0.010$ & $<0.013$ & 11 \\
\hline Neptunium-237 (pCi/L) & 0.600 & $-0.300^{h}$ & 0.036 & 11 \\
\hline Nitrate as nitrogen $(\mathrm{mg} / \mathrm{L})$ & 1.700 & $<1.000$ & $<1.091$ & 11 \\
\hline $\mathrm{pH}$ (standard units) & 8.400 & 7.400 & & 11 \\
\hline Phosphate as phosphorus (mg/L) & $<2.000$ & $<2.000$ & $<2.000$ & 11 \\
\hline Plutonium-239 (pCi/L) & 0.200 & 0.000 & 0.055 & 11 \\
\hline Sulfate $(\mathrm{mg} / \mathrm{L})$ & 53.000 & 16.000 & 28.273 & 11 \\
\hline Suspended alpha (pCi/L) & 4.500 & $-7.900^{b}$ & $-0.655^{b}$ & 11 \\
\hline Suspended beta $(\mathrm{pCi} / \mathrm{L})$ & 25.000 & $-11.000^{b}$ & 5.909 & 11 \\
\hline Technetium-99 (pCi/L) & 12.000 & $-15.000^{b}$ & 2.000 & 11 \\
\hline Uranium (mg/L) & $<0.001$ & $<0.001$ & $<0.001$ & 11 \\
\hline
\end{tabular}

${ }^{a}$ See Fig. 4.3 in Part 1.

${ }^{b}$ Negative numbers indicate that analytical result minus background was less than zero.

Table 4.23. 1992 annual data summary for sampling location $S W 45^{a}$

Landfill runoff location 2

\begin{tabular}{|c|c|c|c|c|}
\hline Parameters & Max & Min & Av & $\begin{array}{c}\text { Number } \\
\text { of } \\
\text { samples }\end{array}$ \\
\hline Chloride (mg/L) & 29.000 & 6.000 & 13.500 & 4 \\
\hline Dissolved solids ( $\mathrm{mg} / \mathrm{L}$ ) & 385.000 & 160.000 & 246.000 & 4 \\
\hline Fluoride (mg/L) & 0.790 & 0.790 & 0.790 & 1 \\
\hline Gross alpha (pCi/L) & 8.400 & 0.500 & 4.425 & 4 \\
\hline Gross beta $(\mathrm{pCi} / \mathrm{L})$ & 23.000 & 13.000 & 17.500 & 4 \\
\hline Iron, total recoverable $(\mathrm{mg} / \mathrm{L})$ & 7.950 & 2.500 & 5.528 & 4 \\
\hline Nitrogen $(m g / L)$ & 18.230 & 6.660 & 10.695 & 4 \\
\hline $\mathrm{pH}$ (standard units) & 8.000 & 7.200 & & 4 \\
\hline Sodium $(\mathrm{mg} / \mathrm{L})$ & 18.230 & 6.660 & 10.695 & 4 \\
\hline Specific conductance $(\mu \mathrm{mhos} / \mathrm{cm})$ & 552.000 & 144.000 & 321.667 & 3 \\
\hline Sulfate $(\mathrm{mg} / \mathrm{L})$ & 89.000 & 29.000 & 51.750 & 4 \\
\hline Suspended solids (mg/L) & 1254.000 & 180.000 & 672.750 & 4 \\
\hline Total organic carbon $(\mathrm{mg} / \mathrm{L})$ & 20.000 & 9.000 & 12.750 & 4 \\
\hline Total solids $(\mathrm{mg} / \mathrm{L})$ & 1454.000 & 419.000 & 918.750 & 4 \\
\hline Uranium (mg/L) & 0.009 & 0.002 & 0.005 & 4 \\
\hline
\end{tabular}

${ }^{a}$ See Fig. 4.3 in Part 1. 
Table 4.24. 1992 annual data summary for sampling location SW46 ${ }^{a}$ Landfill runoff location 3

\begin{tabular}{|c|c|c|c|c|}
\hline Parameters & Max & Min & Av & $\begin{array}{c}\text { Number } \\
\text { of } \\
\text { samples }\end{array}$ \\
\hline Chloride $(\mathrm{mg} / \mathrm{L})$ & 29.000 & 6.000 & 15.500 & 4 \\
\hline Dissolved solids (mg/L) & 603.000 & 206.000 & 355.750 & 4 \\
\hline Fluoride $(\mathrm{mg} / \mathrm{L})$ & 0.780 & 0.780 & 0.780 & 1 \\
\hline Gross alpha (pCi/L) & 12.700 & 3.000 & 7.700 & 4 \\
\hline Gross beta $(\mathrm{pCi} / \mathrm{L})$ & 31.000 & 2.000 & 14.000 & 4 \\
\hline Iron, total recoverable $(\mathrm{mg} / \mathrm{L})$ & 13.300 & 4.030 & 10.358 & 4 \\
\hline pH (standard units) & 7.900 & 6.800 & & 4 \\
\hline Sodium (mg/L) & 24.700 & 9.760 & 15.090 & 4 \\
\hline Specific conductance $(\mu \mathrm{mhos} / \mathrm{cm})$ & 790.000 & 139.000 & 407.000 & 3 \\
\hline Sulfate $(\mathrm{mg} / \mathrm{L})$ & 238.000 & 50.000 & 128.500 & 4 \\
\hline Suspended solids (mg/L) & 649.000 & 200.000 & 342.250 & 4 \\
\hline Total organic carbon $(\mathrm{mg} / \mathrm{L})$ & 37.000 & 9.000 & 17.000 & 4 \\
\hline Total solids (mg/L) & 1029.000 & 452.000 & 697.000 & 4 \\
\hline Uranium (mg/L) & 0.010 & 0.001 & 0.005 & 4 \\
\hline
\end{tabular}

${ }^{a}$ See Fig. 4.3 in Part 1.

Table 4.25. 1992 radionuclide coricentrations in effluents

Uranium

\begin{tabular}{|c|c|c|c|c|c|c|}
\hline \multirow{2}{*}{ Location" } & \multirow{2}{*}{$\begin{array}{c}\text { Number } \\
\text { of } \\
\text { samples }\end{array}$} & \multicolumn{3}{|c|}{$\begin{array}{l}\text { Concentration } \\
(\mathrm{mg} / \mathrm{L})\end{array}$} & \multirow{2}{*}{$\begin{array}{c}{ }^{235} \mathrm{U} \\
\text { average }\end{array}$} & \multirow{2}{*}{$\begin{array}{l}\text { Percent of } \\
\text { Derived } \\
\text { Concentration } \\
\text { Guide }\end{array}$} \\
\hline & & $\operatorname{Max}$ & Min & $A v$ & & \\
\hline $\mathrm{K} 001$ & 52 & 0.170 & 0.001 & 0.022 & 0.56 & 1.91 \\
\hline $\mathrm{K} 002$ & 4 & 0.006 & 0.003 & 0.004 & 0.66 & 0.45 \\
\hline K008 & 15 & 0.005 & $<0.001$ & $<0.002$ & 0.65 & 0.22 \\
\hline $\mathrm{K} 009$ & 6 & 0.003 & $<0.001$ & $<0.002$ & 0.75 & 0.21 \\
\hline $\mathrm{K} 010$ & 8 & 0.027 & 0.006 & 0.018 & 0.38 & 1.05 \\
\hline$K() 11$ & 52 & 0.063 & 0.002 & 0.025 & 0.29 & 1.13 \\
\hline $\mathrm{K}() 12$ & 8 & 0.016 & $<0.001$ & $<0.007$ & 0.44 & 0.49 \\
\hline $\mathrm{K} 013$ & 4 & 0.005 & $<0.001$ & $<0.002$ & 0.58 & 0.18 \\
\hline $\mathrm{K} 015$ & 4 & 0.340 & 0.011 & 0.158 & 0.43 & 10.50 \\
\hline K016 & 4 & 0.008 & $<0.001$ & $<0.004$ & 0.59 & 0.35 \\
\hline K017 & 4 & 0.012 & 0.001 & 0.006 & 0.55 & 0.50 \\
\hline $\mathrm{K} 018$ & 4 & 0.065 & ().0()2 & 0.020 & 0.62 & 1.94 \\
\hline
\end{tabular}

"See Fig. 4.4 in Part 1.

berived Concentration Guide for total uranium is 60() $\mathrm{pCi} / \mathrm{L}$. 
1992 Environmental Report-Paducah, Part 2

Table 4.26. 1992 radionuclide concentrations in water

\begin{tabular}{|c|c|c|c|c|c|}
\hline \multirow[t]{2}{*}{ Location $^{a}$} & \multirow{2}{*}{$\begin{array}{l}\text { Number } \\
\text { of } \\
\text { samples }\end{array}$} & \multicolumn{3}{|c|}{$\begin{array}{l}\text { Concentration } \\
(\mathrm{pCi} / \mathrm{L})\end{array}$} & \multirow{2}{*}{$\begin{array}{l}\text { Percent of Derived } \\
\text { Concentration } \\
\text { Guide }^{b}\end{array}$} \\
\hline & & $\operatorname{Max}$ & $\operatorname{Min}$ & Av & \\
\hline K00I & 54 & 77.00 & 0.00 & 22.75 & 0.02 \\
\hline $\mathrm{K} 002$ & 1 & 8.00 & 8.00 & 8.00 & 0.01 \\
\hline $\mathrm{K} 008$ & 13 & 25.00 & 0.00 & 14.08 & 0.01 \\
\hline K009 & 4 & 12.00 & 0.00 & 8.25 & 0.01 \\
\hline $\mathrm{K} 010$ & 4 & 93.00 & 13.00 & 40.50 & 0.04 \\
\hline K011 & 53 & 37.00 & -7.00 & 7.72 & 0.01 \\
\hline $\mathrm{K} 012$ & 3 & 14.00 & 0.00 & 5.67 & 0.01 \\
\hline $\mathrm{K} 016$ & 1 & 12.00 & 12.00 & 12.00 & 0.01 \\
\hline
\end{tabular}

${ }^{a}$ See Fig. 4.4 in Part 1.

${ }^{b}$ Derived Concentration Guide for technetium-99 is $100,000 \mathrm{pCi} / \mathrm{L}$.

Table 4.27. 1992 Paducah Gaseous Diffusion Plant major discharges to surface waters

\begin{tabular}{|c|c|c|c|c|c|c|}
\hline \multirow{2}{*}{ Month } & \multicolumn{3}{|c|}{$\begin{array}{l}\text { Uranium } \\
\quad(\mathrm{kg})\end{array}$} & \multicolumn{3}{|c|}{$\begin{array}{l}\text { Technetium } \\
\text { (mCi) }\end{array}$} \\
\hline & $\begin{array}{c}\mathrm{KPDES}^{a} \\
001\end{array}$ & $\begin{array}{c}\text { KPDES } \\
008\end{array}$ & $\begin{array}{l}\text { KPDES } \\
011\end{array}$ & $\begin{array}{c}\text { KPDES } \\
001\end{array}$ & $\begin{array}{c}\text { KPDES } \\
008\end{array}$ & $\begin{array}{c}\text { KPDES } \\
011\end{array}$ \\
\hline January & 12.0 & 0.21 & 1.60 & 5.14 & 0.62 & 0.42 \\
\hline February & 4.0 & $b$ & 2.83 & 2.53 & $b$ & 0.47 \\
\hline March & 4.96 & $b$ & 1.72 & 3.53 & $b$ & 0.11 \\
\hline April & 2.84 & 0.16 & 0.76 & 2.91 & 1.36 & 0.13 \\
\hline May & 0.51 & $b$ & 0.76 & 2.77 & $b$ & 0.54 \\
\hline June & 0.59 & $b$ & 0.44 & 2.83 & $b$ & 0.16 \\
\hline July & 2.93 & 0.27 & 0.97 & 5.93 & 2.19 & 0.75 \\
\hline August & 2.11 & $b$ & 1.22 & 9.29 & $b$ & 0.02 \\
\hline September & 3.15 & $b$ & 1.46 & 4.75 & $b$ & 0.22 \\
\hline October & 0.75 & 0.16 & 1.13 & 2.82 & 2.82 & 0.50 \\
\hline November & 5.60 & $b$ & 2.14 & 6.08 & $b$ & 0.61 \\
\hline December & 9.66 & $b$ & 1.36 & 5.52 & $b$ & 0.21 \\
\hline Total & 49.10 & 2.4 & 14.39 & 54.1 & 20.97 & 4.14 \\
\hline
\end{tabular}

"See Fig. 4.4 in Part 1.

'Quarterly average assumed to be representative of each month's contribution. 
Table 4.28. 1992 Paducah Gaseous Diffusion Plant (PGDP) state Cabinet of Human Resources (CHR) radiochemical data comparison for surface water

\begin{tabular}{llllllll}
\hline \multirow{3}{*}{ Sample ID } & Date & \multicolumn{2}{c}{ Gross alpha $(\mathrm{pCi} / \mathrm{L})$} & \multicolumn{2}{c}{ Gross beta $(\mathrm{pCi} / \mathrm{L})$} & & ${ }^{99} \mathrm{Tc}(\mathrm{pCi} / \mathrm{L})$ \\
\cline { 3 - 7 } & & PGDP result & CHR result & PGDP result & CHR result & PGDP result & CHR result \\
\hline
\end{tabular}

$4397-92$
$4930-92$
$5488-92$
$6142-92$
Annual maximumc
Annual minimum

4398-92

$4931-92$

$5489-92$

6143-92

Annual maximum

Annual minimum

4399-92

$4932-92$

5490-92

6144-92

Annual maximum

Annual minimum

4400-92

4933-92

$5491-92$

6145-92

Annual naximum

Annual minimum

4401-92

4934-92

$5492-92$

6146-92

Annual maximum

Annual minimum

4402-92

4935-92

5493.92

6147-92

Annual maximum

Annual minimum

\section{Upstream Big Bayou at L-I}

$\begin{array}{rllllll}2-11-92 & \text { Backup }^{a} & <1 & \text { Backup } & 3 \pm 1 & \text { Backup } & \text { NR }^{b} \\ 5-12-92 & \text { Backup }^{\prime} & <1 & \text { Backup } & 4 \pm 1 & \text { Backup } & \text { NR } \\ 8-19-92 & -0.9 & <1 & -2 & <3 & 1 & \text { NR } \\ 11-11-92 & \text { Backup } & <1 & \text { Backup } & 4 \pm 1 & \text { Backup } & \text { NR } \\ & 13.5 & <1 & 40 & 4 \pm 1 & 16 & \\ & -7.3 & & -11 & <3 & -7\end{array}$

Upstream Little Bayou above K013 at L-9

$\begin{array}{rllllll}2-11-92 & 2.8 & <1 & 10 & 4 \pm 1 & 13 & \text { NR } \\ 5-12-92 & \text { Backup } & <1 & \text { Backup } & 5 \pm 1 & \text { Backup } & \text { NR } \\ 8-19-92 & \text { Backup } & <1 & \text { Backup } & 4 \pm 1 & \text { Backup } & \text { NR } \\ 11-11-92 & \text { Backup } & <1 & \text { Backup } & 7 \pm 1 & \text { Backup } & \text { NR } \\ & 2.8^{d} & <1 & 10^{d} & 7 \pm 1 & 13^{d l} & \end{array}$

Downstream Litlle Bayou at Iron Bridge, L-II

$\begin{array}{rllllll}2-11-92 & \text { Backup } & 4 \pm 1 & \text { Backup } & 8 \pm 1 & \text { Backup } & <9 \\ 5-12-92 & 0.4 & 6 \pm 2 & -0.4 & 8 \pm 1 & 14 & <9 \\ 8-19-92 & \text { Backup } & 1 \pm 1 & \text { Backup } & <3 & \text { Backup } & \text { NR } \\ 11-11-92 & \text { Backup } & 2 \pm 1 & \text { Backup } & 7 \pm 1 & \text { Backup } & \text { NR } \\ & 0.4^{d} & 6 \pm 2 & -0.4^{d l} & 8 \pm 1 & 14^{d} & <9 \\ & & 1 \pm 1 & & <3 & & \end{array}$

Downstream Little Bayou below TVA at L-12

$\begin{array}{rllllll}2-11-92 & \text { Backup } & 1 \pm 1 & \text { Backup } & 9 \pm 1 & \text { Backup } & 10 \pm 8 \\ 5-12-92 & \text { Backup } & 4 \pm 2 & \text { Backup } & 9 \pm 1 & \text { Backup } & <9 \\ 8-19-92 & \text { Backup } & <1 & \text { Backup } & 8 \pm 1 & \text { Backup } & <8 \\ 11-11-92 & \text { Backup } & <1 & \text { Backup } & 7 \pm 1 & \text { Backup } & \text { NR } \\ & & 4 \pm 2 & & 9 \pm 1 & & 10 \pm 8 \\ & <1 & & 7 \pm 1 & & <8\end{array}$

Downstream Big Bayou at ${ }^{2 / 4}$ Bridge, L-7

\begin{tabular}{|c|c|c|c|c|c|c|}
\hline $2-11-92$ & Backup & $<2$ & Backup & $11 \pm 2$ & Backup & $<9$ \\
\hline $5-12-92$ & Backup & $<1$ & Backup & $8 \pm 1$ & Backup & $<9$ \\
\hline $8-19-92$ & Backup & $<2$ & Backup & $11 \pm 2$ & Backup & $11 \pm 8$ \\
\hline \multirow[t]{3}{*}{$11-11-92$} & Backup & $<1$ & Backup & $13 \pm 2$ & Backup & $9 \pm 4$ \\
\hline & & $<2$ & & $13 \pm 2$ & & $11 \pm 8$ \\
\hline & & $<1$ & & $8 \pm 1$ & & $<9$ \\
\hline
\end{tabular}

Downstream Big Bayou at Rossington, L-6

$\begin{array}{rllllll}2-11-92 & 3.2 & <2 & 43 & 16 \pm 2 & 15 & <9 \\ 5-12-92 & -2.8 & 3 \pm 2 & 6 & 7 \pm 1 & 11 & \text { NR } \\ 8-19-92 & \text { Backup } & 2 \pm 2 & \text { Backup } & 14 \pm 2 & \text { Backup } & 11 \pm 8 \\ 11-11-92 & \text { Backup } & 7 \pm 2 & \text { Backup } & 16 \pm 2 & \text { Backup } & 14 \pm 4 \\ & 3.2 & 7 \pm 2 & 43 & 16 \pm 2 & 15 & 14 \pm 4 \\ & -2.8 & <2 & 6 & 7 \pm 1 & 11 & <9\end{array}$


1992 Environmental Report-Paducah, Part 2

Table 4.28 (continued)

\begin{tabular}{lccccccc}
\hline \multirow{3}{*}{ Sample ID } & Date & \multicolumn{2}{c}{ Gross alpha $(\mathrm{pC} / \mathrm{L})$} & Gross beta $(\mathrm{pCi} / \mathrm{L})$ & \multicolumn{2}{c}{${ }^{99} \mathrm{Tc}(\mathrm{pCC} / \mathrm{L})$} \\
\cline { 2 - 7 } & & PGDP result & CHR result & PGDP result & CHR result & PGDP result & CHR result \\
\hline
\end{tabular}

Downstream Big Bayou at Iron Bridge, L-4

$\begin{array}{lrllllll}440 \vdots-92 & 2-12-92 & \text { Backup } & 3 \pm 2 & \text { Backup } & 13 \pm 2 & \text { Backup } & <9 \\ 4936-92 & 5-13-92 & \text { Backup } & 3 \pm 2 & \text { Backup } & 11 \pm 2 & \text { Backup } & <9 \\ 5494-92 & 8-18-92 & \text { Backup } & 3 \pm 2 & \text { Backup } & 15 \pm 2 & \text { Backup } & 12 \pm 8 \\ 6148-92 & 11-10-92 & \text { Backup } & 8 \pm 3 & \text { Backup } & 16 \pm 2 & \text { Backup } & 11 \pm 4 \\ \text { Annual maximum } & & & 8 \pm 3 & & 16 \pm 2 & 11 \pm 2 & 12 \pm 8 \\ \text { Annual minimum } & & & 3 \pm 2 & & <9\end{array}$

4404-92

$4937-92$

5495-92

6149-92

Annual maximum

Annual minimum

4405-92

4938-92

$5496-92$

6150-92

Annual maximum

Annual minimum

4406-92

4939-92

$5497-92$

$6151-92$

Annual maximum

Annual minimum

4407-92

4940-92

$5498-92$

6152-92

Annual maximum Annual minimum

4408-92

$4941-92$

$5499-92$

6153-92

Annual maximum

Annual minimum
KPDES ${ }^{e} 001$ at normal sampling location, K001

$\begin{array}{rllll}2-11-92 & 8.1 & <4 & 39 & 17 \pm 4 \\ 5-12-92 & \text { Backup } & <4 & \text { Backup } & 20 \pm 3 \\ 8-19-92 & -0.6 & 8 \pm 4 & 57 & 28 \pm 4 \\ 11-11-92 & \text { Backup } & 8 \pm 4 & \text { Backup } & 32 \pm 4 \\ & 112.4 & 8 \pm 4 & 124 & 32 \pm 4 \\ & -15.5 & <4 & -13 & 17 \pm 4\end{array}$

KPDES 004 at normal location, L-23

$2-11-92$

5-12-92

$8-19-92$

$11-11-92$

$\begin{array}{ll}\text { Backup } & 2 \pm 1 \\ \text { Backup } & 2 \pm 1 \\ \text { Backup } & <1 \\ \text { Backup } & <1 \\ & 2 \pm 1 \\ & <1\end{array}$

KPDES 006 at L-27

2-11-92

5-12-92

$8-19-92$

$11-11-92$

Backup
Backup
Backup
Backup

$<1$

$<1$

$<1$

$<1$

$<1$

$\begin{array}{ll}\text { Backup } & 9 \pm 1 \\ \text { Backup } & 8 \pm 1 \\ \text { Backup } & 5 \pm 1 \\ \text { Backup } & 10 \pm 1 \\ & 10 \pm 1 \\ & 5 \pm 1\end{array}$

Backup

Backup

Backup

Backup

Backup

42

Backup

77

0

$<9$

$<9$

$33 \pm 8$

$27 \pm 4$

$33 \pm 8$

$<9$

$2 \pm 8$
$1 \pm 4$
$2 \pm 8$
$<9$
9
$<9$
$3 \pm 8$
$3 \pm 4$
$3 \pm 8$


1992 Environmental Report-Paducah, Part 2

Table 4.28 (continued)

\begin{tabular}{|c|c|c|c|c|c|c|c|}
\hline \multirow{2}{*}{ Sample ID } & \multirow{2}{*}{ Date } & \multicolumn{2}{|c|}{ Gross alpha (pCi/L) } & \multicolumn{2}{|c|}{ Gross beta (pCi/L) } & \multicolumn{2}{|c|}{${ }^{99} \mathrm{Tc}(\mathrm{pCi} / \mathrm{L})$} \\
\hline & & PGDP result & CHR result & PGDP result & CHR result & PGDP result & CHR result \\
\hline \multicolumn{8}{|c|}{ KPDES 011 at K011 or L-17 } \\
\hline $4409-92$ & $2-11-92$ & 18 & $3 \pm 1$ & 31 & $4 \pm 1$ & 15 & NR \\
\hline $4942-92$ & $5-12-92$ & 6.8 & $4 \pm 1$ & 8 & $7 \pm 1$ & 10 & $<9$ \\
\hline $5500-92$ & $8-19-92$ & Backup & $<1$ & Backup & $<3$ & Backup & NR \\
\hline $6154-92$ & $11-11-92$ & Backup & $8 \pm 1$ & Backup & $8 \pm 1$ & Backup & NR \\
\hline Annual maximum & & 41.7 & $8 \pm 1$ & 76 & $8 \pm 1$ & 37 & $<9$ \\
\hline Annual minimum & & -12.3 & $<1$ & -7 & $<3$ & -7 & \\
\hline \multicolumn{8}{|c|}{ KPDES 002 at L-15 } \\
\hline $4410-92$ & $2-11-92$ & Backup & $2 \pm 1$ & Backup & $6 \pm 1$ & Backup & NR \\
\hline $4943-92$ & $5-12-92$ & Backup & $2 \pm 1$ & Backup & $5 \pm 1$ & Backup & NR \\
\hline $5501-92$ & $8-19-92$ & Backup & $<1$ & Backup & $<3$ & Backup & NR \\
\hline $6155-92$ & $11-11-92$ & Backup & $2 \pm 1$ & Backup & $6 \pm 1$ & Backup & NR \\
\hline Annual maximum & & 11.6 & $2 \pm 1$ & 36 & $6 \pm 1$ & $8^{d}$ & \\
\hline Annual minimum & & -4.2 & $<1$ & -2.2 & $<3$ & & \\
\hline \multicolumn{8}{|c|}{ KPDES 003 at $L-14$} \\
\hline $4411-92$ & $2-11-92$ & Backup & $32 \pm 3$ & Backup & $104 \pm 3$ & Backup & $96 \pm 9$ \\
\hline $4944-92$ & $5-12-92$ & Backup & $11 \pm 2$ & Backup & $25 \pm 2$ & Backup & $25 \pm 8$ \\
\hline $5502-92$ & $8-19.92$ & Backup & $13 \pm 2$ & Backup & $17 \pm 2$ & Backup & $13 \pm 8$ \\
\hline $6156-92$ & $11-11-92$ & Backup & $6 \pm 2$ & Backup & $17 \pm 1$ & Backup & $23 \pm 4$ \\
\hline Annual maximum & & & $32 \pm 3$ & & $104 \pm 3$ & & $96 \pm 9$ \\
\hline Annual minimum & & & $6 \pm 2$ & & $17 \pm 1$ & & $13 \pm 4$ \\
\hline \multicolumn{8}{|c|}{ KPDES 010 at L-16 } \\
\hline $4412-92$ & $2-11-92$ & Backup & $4 \pm 1$ & Backup & $8 \pm 1$ & Backup & NR \\
\hline $4945-92$ & $5-12-92$ & Backup & $8 \pm 2$ & Backup & $10 \pm 1$ & Backup & $<9$ \\
\hline $5503-92$ & $8-19-92$ & Backup & $<1$ & Backup & $<3$ & Backup & NR \\
\hline $6157-92$ & $11-11-92$ & Backup & $4 \pm 1$ & Backup & $8 \pm 1$ & Backup & $<9$ \\
\hline Annual maximum & & 18.44 & $8 \pm 1$ & 67 & $10 \pm 1$ & 93 & $<9$ \\
\hline Annual minimum & & 1.2 & $<1$ & -9 & $<3$ & 13 & \\
\hline \multicolumn{8}{|c|}{ KPDES 012 at $L-18$} \\
\hline $4413-92$ & $2-11-92$ & Backup & $4 \pm 2$ & Backup & $5 \pm 1$ & Backup & NR \\
\hline $4946-92$ & $5-12-92$ & 28 & $8 \pm 3$ & 19 & $7 \pm 1$ & 5 & NR \\
\hline $5504-92$ & $8-19-92$ & Backup & $5 \pm 2$ & Backup & $<3$ & Backup & NR \\
\hline $6158-92$ & $11-11-92$ & Backup & $5 \pm 1$ & Backup & $6 \pm 1$ & Backup & NR \\
\hline Annual maximum & & 28 & $8 \pm 3$ & 32 & $7 \pm 1$ & 14 & \\
\hline Annual minimum & & -1.1 & $4 \pm 2$ & -2 & $<3$ & 0 & \\
\hline \multicolumn{8}{|c|}{ KPDES 013 at L-60 } \\
\hline $4414-92$ & $2-11-92$ & Backup & $3 \pm 2$ & Backup & $5 \pm 1$ & Backup & NR \\
\hline $4947-92$ & $5-12-92$ & Backup & $<2$ & Backup & $5 \pm 1$ & Backup & NR \\
\hline $5505-92$ & $8-19-92$ & Dry & & & & & \\
\hline $6159-92$ & $11-11-92$ & Backup & $2 \pm 1$ & Backup & $3 \pm 1$ & Backup & NR \\
\hline Annual maximum & & 2.9 & $3 \pm 2$ & 62 & $5 \pm 1$ & & \\
\hline Annual minimum & & -3.4 & $<2$ & -30 & $3 \pm 1$ & & \\
\hline
\end{tabular}




\section{Environmental Report-Paducah, Part 2}

Table 4.28 (continued)

\begin{tabular}{|c|c|c|c|c|c|c|c|}
\hline \multirow{2}{*}{ Sample ID } & \multirow{2}{*}{ Date } & \multicolumn{2}{|c|}{ Gross alpha (pCi/L) } & \multicolumn{2}{|c|}{ Gross beta $(\mathrm{pCi} / \mathrm{L})$} & \multicolumn{2}{|c|}{${ }^{99} \mathrm{Tc}(\mathrm{pCi} / \mathrm{L})$} \\
\hline & & PGDP result & CHR result & PGDP result & CHR result & PGDP result & CHR \\
\hline \multicolumn{8}{|c|}{ KPDES 015 at L-34 } \\
\hline $4415-92$ & $2-11-92$ & Backup & $25 \pm 4$ & Backup & $35 \pm 2$ & Backup & $12 \pm$ \\
\hline $4948-92$ & $5-12-92$ & Backup & $129 \pm 9$ & Backup & $110 \pm 4$ & Backup & $33-$ \\
\hline $5506-92$ & $8-19-92$ & Backup & $66 \pm 5$ & Backup & $45 \pm 2$ & Backup & $21 \pm$ \\
\hline $6160-92$ & $11-11-92$ & Backup & $45 \pm 5$ & Backup & $48 \pm 3$ & Backup & 32 \\
\hline Annual maximum & & 112.6 & $129 \pm 9$ & 244 & $110 \pm 4$ & & $33 t$ \\
\hline Annual minimum & & 5.5 & $25 \pm 4$ & -0.7 & $35 \pm 2$ & & 12 \\
\hline
\end{tabular}

4416-92

4949-92

$5507-92$

6161-92

Annual maximum

Annual minimum

$$
\begin{aligned}
& 2-11-92 \\
& 5-12-92 \\
& 8-19-92
\end{aligned}
$$

$11-11-92$

Backup

\section{KPDES 016 at L-57}

$11 \pm 2 \quad$ Backup $\quad 6 \pm 1 \quad$ Backup $\quad$ NR

Dry

Backup $\quad 1 \pm 1 \quad$ Backup $\quad 7 \pm 1$

$11 \pm 2 \quad 36 \quad 7 \pm 1$

$7 \pm 1$

Backup

$12^{d}$

$-2.4$

$1 \pm 1$

$-36$

$6 \pm 1$

KPDES 017 at L-58

4417-92

4950-92

5508-92

6162-92

Annual maximum

Annual minimum

$$
\begin{array}{r}
2-11-92 \\
5-12-92 \\
8-19-92 \\
11-11-92
\end{array}
$$

Backup

$4 \pm 2$

$3 \pm 2$

Backup

$7 \pm 2$

Backup $5 \pm 1$

Backup

Backup

$<9$

Dry

Backup $3 \pm 1$

Backup $5 \pm 1$

$4.1 \quad 4 \pm 2$

$16 \quad 7 \pm 2$

$-1.4$

$3 \pm 1$

51

$7 \pm 2$

Backup

$-4$

31

KPDES 018 at L-59

4418-92

4951-92

5509-92

6163-92

Annual maximum

Annual minimum

4419-92 (source) 4952-92 (point 3) 5510-92 (point 3A) 6164-92 (point 3A) Annual maximum Annual minimum
2-11-92

5-12-92

8-19-92

11-11-92

Backup

Backup

Dry

Backup

22.8

3.7

$45 \pm 4$
$27 \pm 4$
$8 \pm 2$
$45 \pm 4$
$8 \pm 2$

\section{Backup}

$$
\text { Backup }
$$

$43 \pm 2$

$38 \pm 2$

\section{Backup}

$23 \pm 2$

51

$43 \pm 2$

$23 \pm 2$

Landfill C-746K at the source, point 3 and point $3 A$

$\begin{array}{rll}2-11-92 & 1.0 & <9 \\ 5-12-92 & -1.4 & <1 \\ 8-19-92 & \text { Backup } & <3 \\ 11-11-92 & 3.5 & <1\end{array}$

$<9$

$<3$

$<1$
$<18$

$4 \pm 1$

$<8$

$4 \pm 1$
Backup $\quad 30 \pm 8$

Backup $\quad 13 \pm 8$

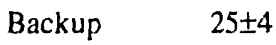

$30 \pm 8$

$25 \pm 8$ 
1992 Environmental Report-Paducah, Part 2

Table 4.28 (continued)

\begin{tabular}{|c|c|c|c|c|c|c|c|}
\hline \multirow{2}{*}{ Sample ID } & \multirow{2}{*}{ Date } & \multicolumn{2}{|c|}{ Gross alpha (pCi/L) } & \multicolumn{2}{|c|}{ Gross beta $(\mathrm{pCi} / \mathrm{L})$} & \multicolumn{2}{|c|}{${ }^{99} \mathrm{Tc}(\mathrm{pCi} / \mathrm{L})$} \\
\hline & & PGDP result & CHR result & PGDP result & CHR result & PGDP result & CHR result \\
\hline \multicolumn{8}{|c|}{ Landfill C-746K at point I upstream } \\
\hline & $2-11-92^{f}$ & & $<1$ & & $3 \pm 1$ & & NR \\
\hline $4953-92$ & $5-12-92$ & Backup & $2 \pm 1$ & Backup & $3 \pm 1$ & Backup & NR \\
\hline $5511-92$ & $8-19-92$ & Backup & $<1$ & Backup & $3 \pm 1$ & Backup & NR \\
\hline $6165-92$ & $11-11-92$ & 4.3 & $<1$ & 1 & $4 \pm 1$ & 4 & NR \\
\hline Annual maximum & & 4.3 & $2 \pm 1$ & 1 & $4 \pm 1$ & 6 & \\
\hline Annual minimum & & -2.1 & $<1$ & -1 & $3 \pm 1$ & 4 & \\
\hline
\end{tabular}

"Samples designated as backup were collected by PGDP at the same time the CHR samples were collected. These samples were not analyzed by PGDP unless the corresponding CHR samples were damaged, lost, or yielded questionable results.

${ }^{b}$ Not run.

'The annual maximum and annual minimum values reported by PGDP are the maximum and minimum values that resulted from all samples taken by PGDP at the specified location in 1992. The total number of samples taken in 1992 differed among sampling locations (e.g., a single sample was collected and analyzed from L-9 in 1992, while approximately 54 samples were collected and analyzed from $\mathrm{KOOI}$ in 1992). A maximum of one sample per location was taken per quarter by the CHR; therefore, the annual maximum and minimum values reported by the CHR are the maximum and minimum of the CHR results reported in this table.

${ }^{d}$ A single sample was collected and analyzed for this constituent by PGDP at the specified location in 1992.

${ }^{e}$ Kentucky Pollutant Discharge Elimination System.

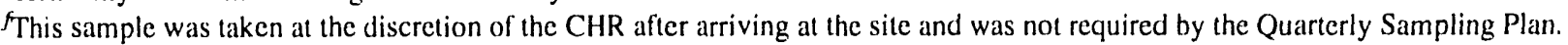
PGDP did not split this additional sample. 
5. Groundwater 


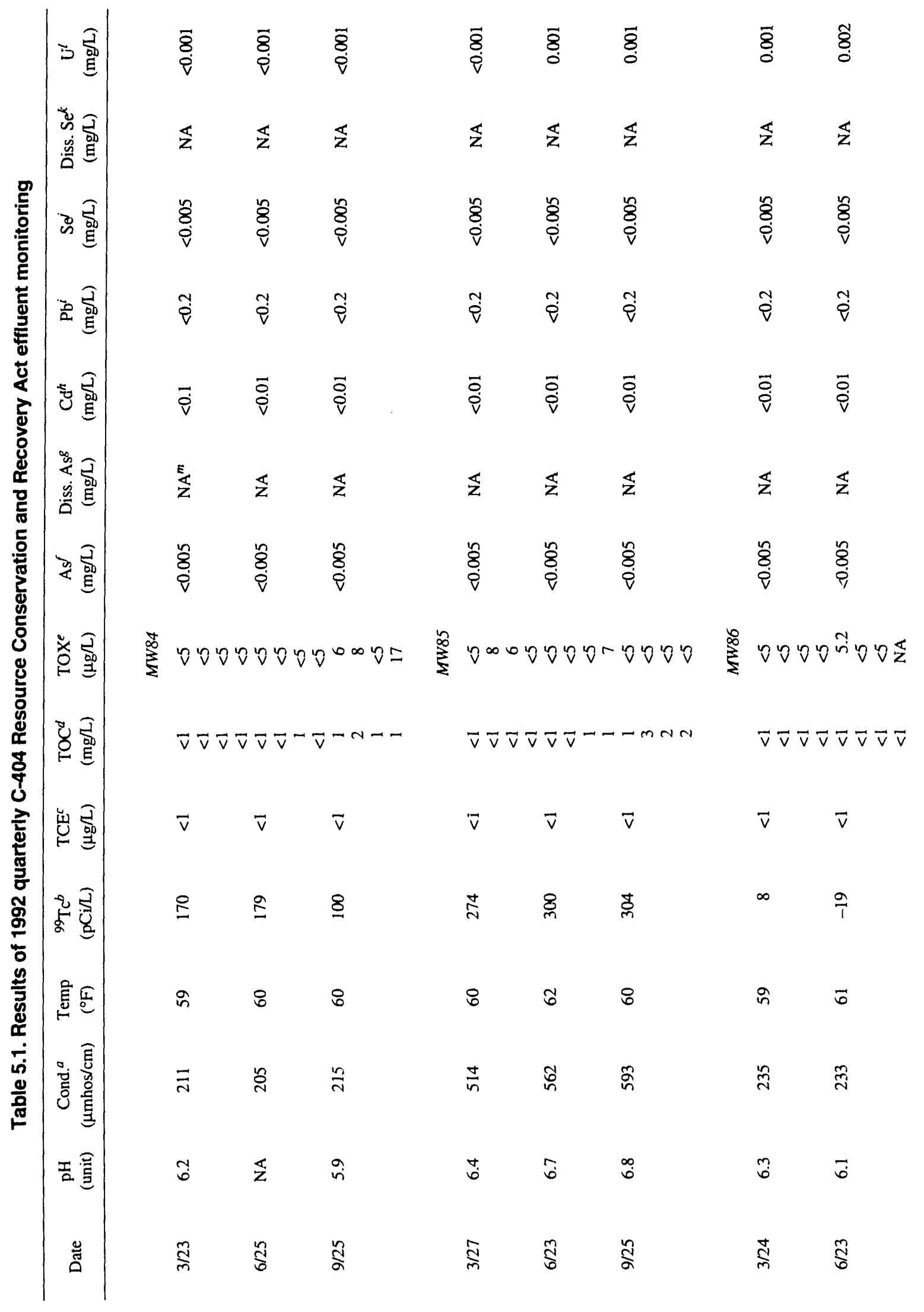


1992 Environmental Report-Paducah, Part 2

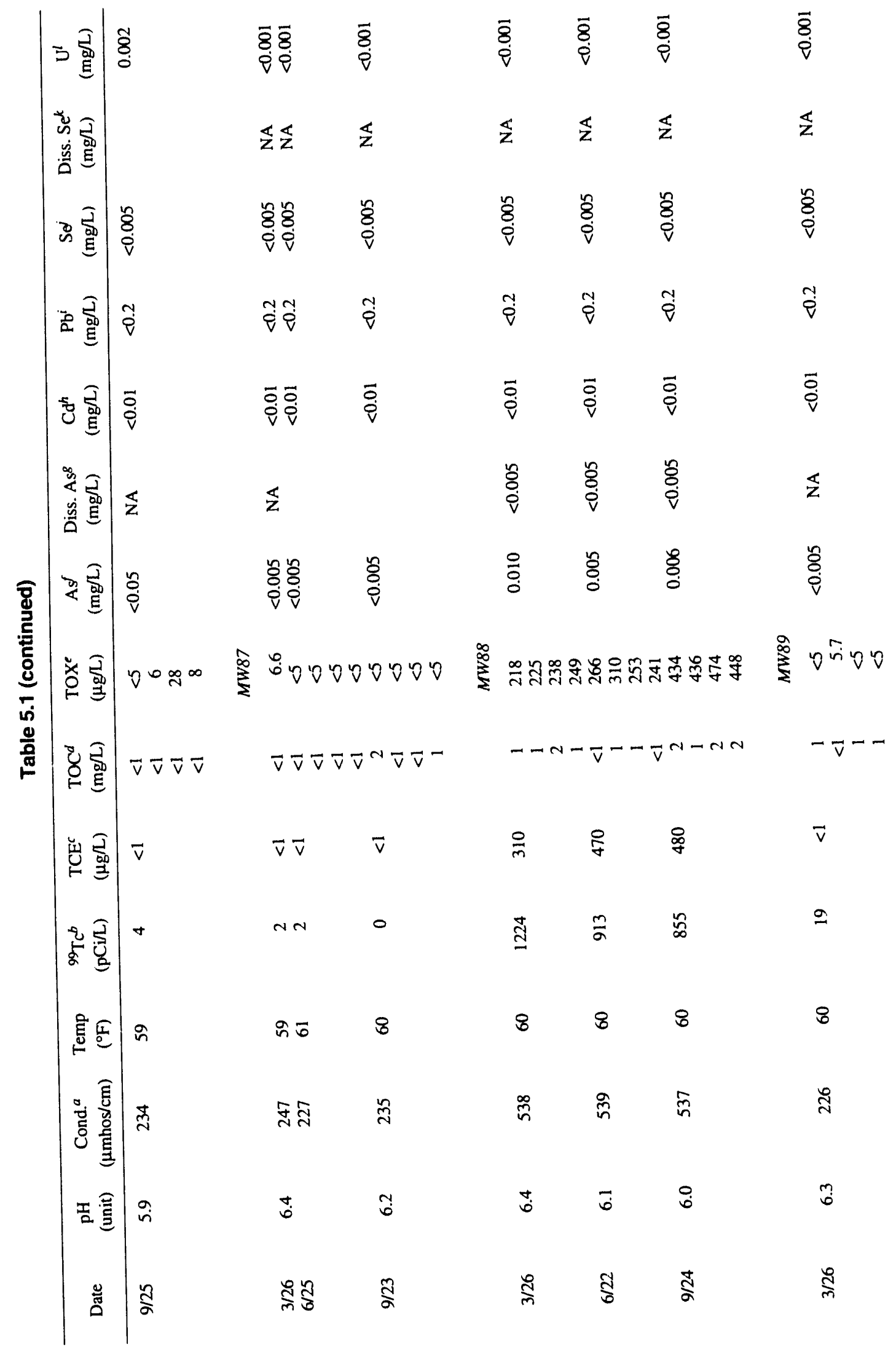




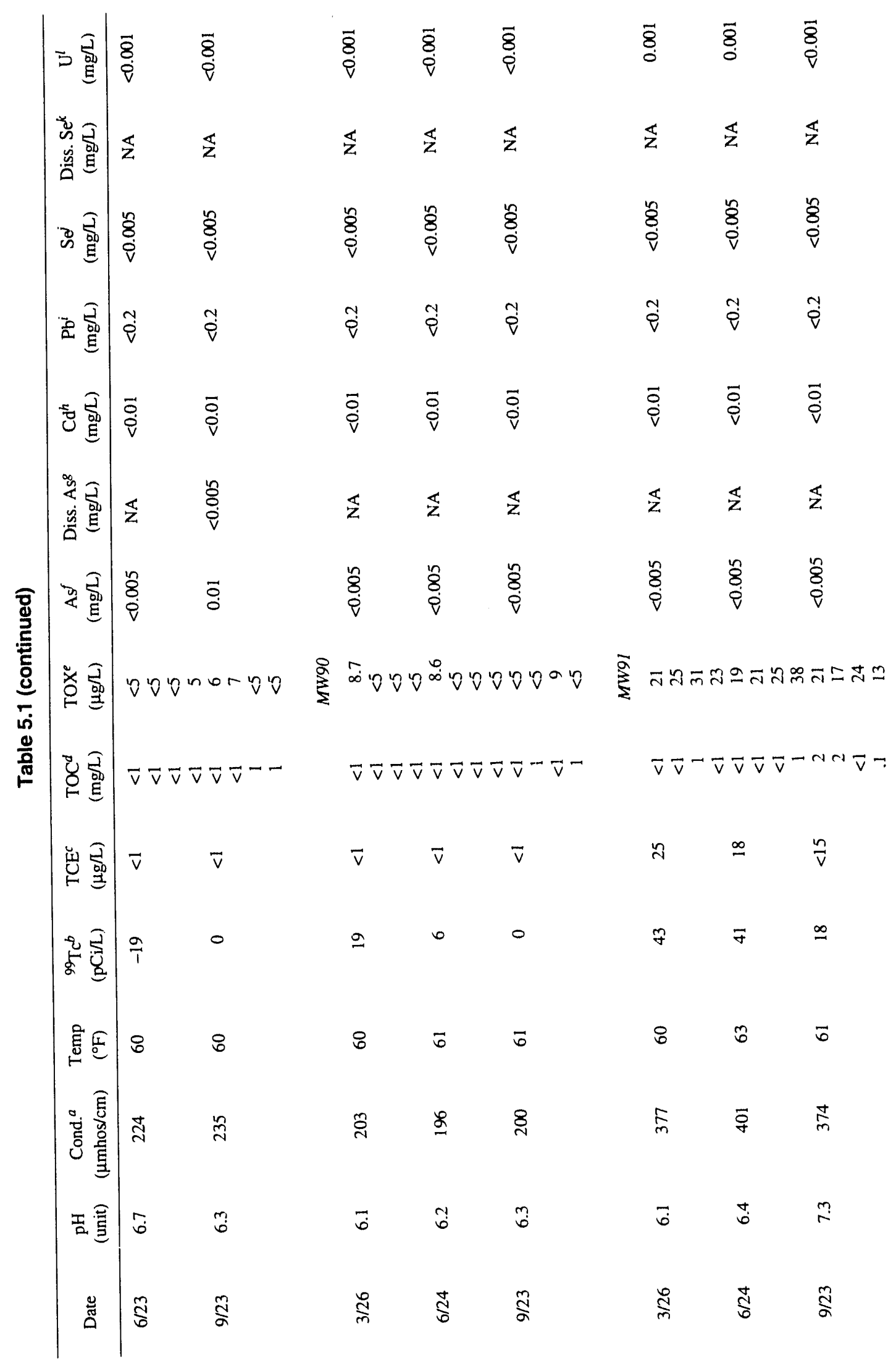


1992 Environmental Report-Paducah, Part 2

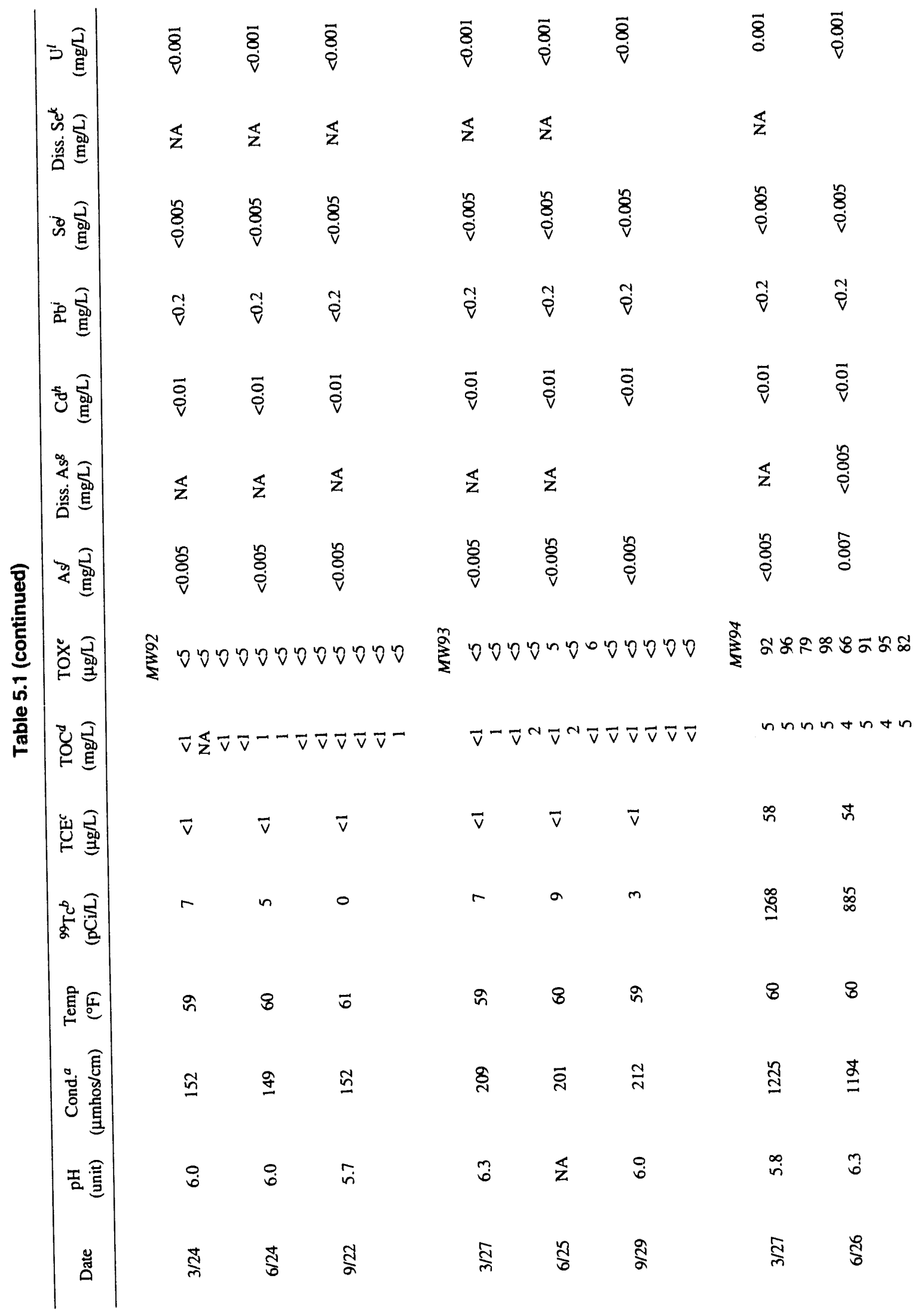




\section{Environmental Report-Paducah, Part 2}

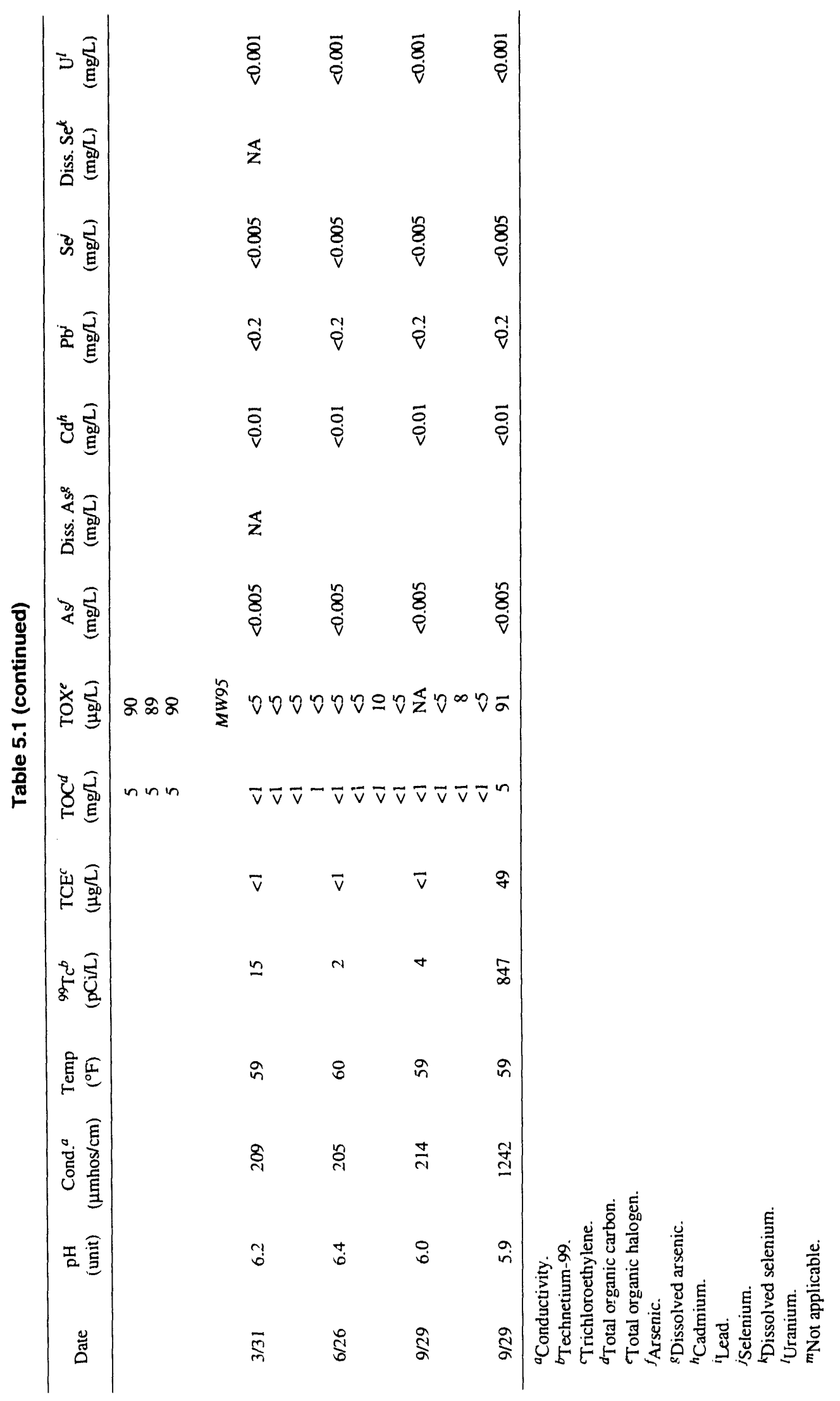


1992 Environmental Report-Paducah, Part 2

Table 5.2. Results of 1992 effluent monitoring at underground storage tanks

\begin{tabular}{|c|c|c|c|c|c|}
\hline Date & $\begin{array}{c}\text { Benzene } \\
(\mu \mathrm{g} / \mathrm{L})\end{array}$ & $\begin{array}{l}\text { Ethyl benzene } \\
\qquad(\mu \mathrm{g} / \mathrm{L})\end{array}$ & $\begin{array}{l}\text { Toluene } \\
(\mu \mathrm{g} / \mathrm{L})\end{array}$ & $\begin{array}{l}\text { Petroleum } \\
\text { hydrocarbon } \\
(\mathrm{mg} / \mathrm{L})\end{array}$ & $\begin{array}{l}\text { Xylene } \\
(\mu \mathrm{g} / L)\end{array}$ \\
\hline \multicolumn{6}{|c|}{$M W 47$} \\
\hline $2 / 19$ & $<5$ & $<5$ & $<5$ & 0.2 & $<10$ \\
\hline $4 / 23$ & $<5$ & $<5$ & $<5$ & 0.4 & $<10$ \\
\hline $6 / 26$ & $<5$ & $<5$ & $<5$ & 0.9 & $<10$ \\
\hline $12 / 11$ & $<5$ & $<5$ & $<5$ & 0.3 & $<10$ \\
\hline \multicolumn{6}{|c|}{$M W 48$} \\
\hline $2 / 19$ & $<5$ & $<5$ & $<5$ & 0.1 & $<10$ \\
\hline $4 / 23$ & $<5$ & $<5$ & $<5$ & 0.2 & $<10$ \\
\hline $5 / 27$ & $<5$ & $<5$ & $<5$ & 0.2 & $<10$ \\
\hline $12 / 11$ & $<5$ & $<.5$ & $<5$ & 0.2 & $<10$ \\
\hline \multicolumn{6}{|c|}{$M W 52$} \\
\hline $2 / 19$ & $<5$ & $<5$ & $<5$ & 0.2 & $<10$ \\
\hline $4 / 03$ & $<5$ & $<5$ & $<5$ & $<0.1$ & $<10$ \\
\hline $8 / 06$ & $<5$ & $<5$ & $<5$ & 0.2 & $<10$ \\
\hline $10 / 13$ & $<5$ & $<5$ & $<5$ & 0.1 & $<10$ \\
\hline $12 / 08$ & $<5$ & $<5$ & $<5$ & 0.2 & $<10$ \\
\hline \multicolumn{6}{|c|}{ MW53 } \\
\hline $2 / 19$ & $<5$ & $<5$ & $<5$ & 0.1 & $<10$ \\
\hline $4 / 08$ & $<5$ & $<5$ & $<5$ & $<0.1$ & $<10$ \\
\hline $8 / 06$ & $<5$ & $<5$ & $<5$ & 0.2 & $<10$ \\
\hline $10 / 13$ & $<5$ & $<5$ & $<5$ & 0.1 & $<10$ \\
\hline $12 / 08$ & $<5$ & $<5$ & $<5$ & 0.2 & $<10$ \\
\hline \multicolumn{6}{|c|}{$M W 54$} \\
\hline $2 / 19$ & $<5$ & $<5$ & $<5$ & 0.1 & $<10$ \\
\hline $4 / 10$ & $<5$ & $<5$ & $<5$ & $<0.1$ & $<10$ \\
\hline $8 / 06$ & $<5$ & $<5$ & $<5$ & 0.2 & $<10$ \\
\hline $10 / 07$ & $<5$ & $<5$ & $<5$ & 0.1 & $<10$ \\
\hline $12 / 08$ & $<5$ & $<5$ & $<5$ & 0.2 & $<10$ \\
\hline \multicolumn{6}{|c|}{ MW68 } \\
\hline $1 / 22$ & $<5$ & $<5$ & $<5$ & $<0.1$ & $<10$ \\
\hline $5 / 15$ & $<5$ & $<5$ & $<5$ & 0.1 & $<10$ \\
\hline $7 / 21$ & $<5$ & $<5$ & $<5$ & 0.2 & $<10$ \\
\hline $10 / 29$ & $<5$ & $<5$ & $<5$ & 0.2 & $<10$ \\
\hline \multicolumn{6}{|c|}{ MW69 } \\
\hline $1 / 23$ & $<100$ & 650 & $<100$ & 1.1 & 290 \\
\hline $5 / 15$ & $<100$ & 480 & $<100$ & 2.1 & 98 \\
\hline $7 / 30$ & $<50$ & 340 & $<50$ & 1.2 & $<50$ \\
\hline
\end{tabular}




\section{Environmenta! Report-Paducah, Part 2}

Table 5.2 (continued)

\begin{tabular}{|c|c|c|c|c|c|}
\hline Datc & $\begin{array}{c}\text { Benzene } \\
(\mu \mathrm{g} / \mathrm{L})\end{array}$ & $\begin{array}{l}\text { Elhyl benzene } \\
\qquad(\mu \mathrm{g} / L)\end{array}$ & $\begin{array}{c}\text { Toluene } \\
\left(\mu_{\mathrm{g}} / \mathrm{L}\right)\end{array}$ & $\begin{array}{l}\text { Petrolcum } \\
\text { hydrocarbon } \\
\text { (mg/L) }\end{array}$ & $\begin{array}{l}\text { Xylene } \\
(\mu \mathrm{g} / \mathrm{L})\end{array}$ \\
\hline \multicolumn{6}{|c|}{$M W 70$} \\
\hline $1 / 23$ & $<5$ & $<5$ & $<5$ & 0.5 & $<10$ \\
\hline $5 / 15$ & $<50$ & $<50$ & $<50$ & 0.2 & $<100$ \\
\hline $7 / 16$ & $<50$ & $<50$ & $<50$ & 0.2 & $<100$ \\
\hline $11 / 19$ & $<5$ & $<5$ & $<5$ & 0.5 & $<10$ \\
\hline \multicolumn{6}{|c|}{$M W 7 I$} \\
\hline $1 / 22$ & $<5$ & $<5$ & $<5$ & $<0.1$ & $<10$ \\
\hline $5 / 15$ & $<5$ & $<5$ & $<5$ & 0.2 & $<10$ \\
\hline $7 / 22$ & $<5$ & $<5$ & $<5$ & 0.1 & $<10$ \\
\hline $10 / 29$ & $<5$ & $<5$ & $<5$ & 0.2 & $<10$ \\
\hline \multicolumn{6}{|c|}{$M W 96$} \\
\hline $5 / 15$ & $<500$ & 20000 & $<500$ & 4.5 & 6400 \\
\hline $7 / 16$ & $<500$ & 1800 & $<500$ & 7.1 & 5100 \\
\hline $11 / 19$ & $<500$ & 1600 & $<500$ & 10.2 & 4900 \\
\hline
\end{tabular}


1992 Environmental Report-Paducah, Part 2

Table 5.3. Results of 1992 semlannual and annual environmental surveillance monitoring

Trichloroethylene, technetium, gross alpha and beta, and radon

\begin{tabular}{|c|c|c|c|c|c|}
\hline Date & $\begin{array}{c}\mathrm{TCE}^{u} \\
(\mu \mathrm{g} / \mathrm{L})\end{array}$ & $\begin{array}{l}{ }^{99} \mathrm{rc}^{b} \\
(\mathrm{pCi} / \mathrm{L})\end{array}$ & $\begin{array}{l}\text { Gross alpha } \\
(\mathrm{pC} \mathrm{C} / \mathrm{L})\end{array}$ & $\begin{array}{c}\text { Gross beta } \\
(\mathrm{pCi} / \mathrm{L})\end{array}$ & $\begin{array}{l}{ }^{222} \mathrm{Rn}^{r} \\
(\mathrm{pCi} / \mathrm{L})\end{array}$ \\
\hline \multicolumn{6}{|c|}{$R 29$} \\
\hline $2 / 03$ & $<1$ & $<25$ & & & 590 \\
\hline \multicolumn{6}{|c|}{$R \sigma I$} \\
\hline $8 / 31$ & $<1$ & $<25$ & & & 32 \\
\hline \multicolumn{6}{|c|}{$R 93$} \\
\hline $9 / 17$ & $<1$ & $<25$ & & & 450 \\
\hline \multicolumn{6}{|c|}{$R \| I I$} \\
\hline $7 / 27$ & $<1$ & $<25$ & & & 499 \\
\hline \multicolumn{6}{|c|}{$R 139$} \\
\hline $2 / 03$ & $<1$ & $<25$ & & & 517 \\
\hline \multicolumn{6}{|c|}{$R 254$} \\
\hline $5 / 13$ & $<1$ & $<25$ & 1.1 & & -1 \\
\hline \multicolumn{6}{|c|}{$R 297$} \\
\hline $5 / 18$ & $<1$ & $<25$ & & & 607 \\
\hline \multicolumn{6}{|c|}{$R 309$} \\
\hline $2 / 06$ & $<1$ & $<25$ & & & 260 \\
\hline \multicolumn{6}{|c|}{$R 396$} \\
\hline $9 / 21$ & $<1$ & $<25$ & & & \\
\hline \multicolumn{6}{|c|}{$R 407$} \\
\hline $7 / 27$ & $<1$ & & & & \\
\hline \multicolumn{6}{|c|}{$R 416$} \\
\hline $1 / 27$ & $<1$ & $<25$ & & & 547 \\
\hline \multicolumn{6}{|c|}{$R 417$} \\
\hline $1 / 27$ & $<1$ & $<25$ & & & 401 \\
\hline
\end{tabular}


1992 Environmental Report-Paducah, Part 2

Table 5.3 (continued)

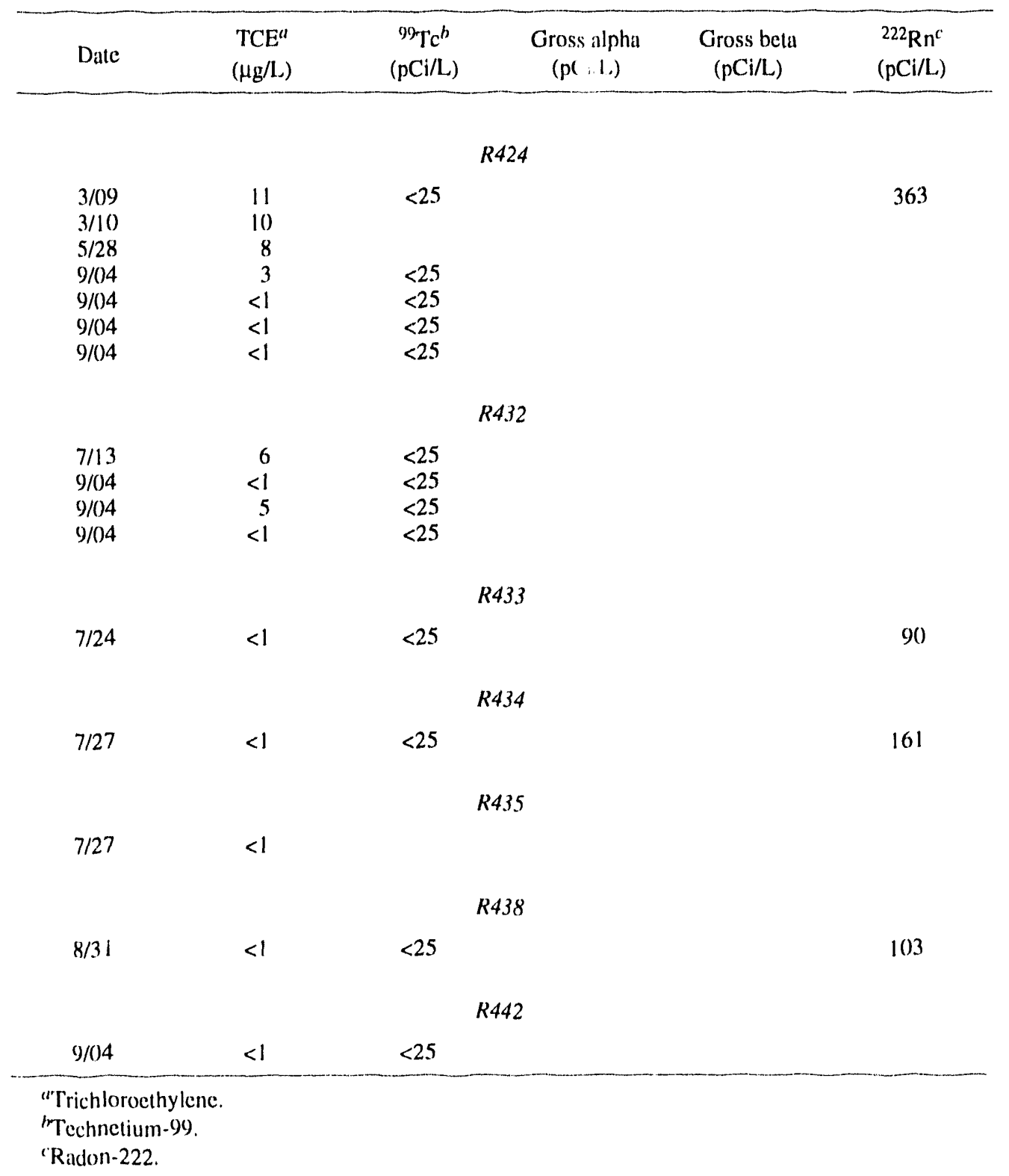


1992 Environmental Report-Paducah, Part 2

Table 5.4. Results of 1992 weekly, monthly, bimonthly, semiannual, and annual ACO/CERCLA ${ }^{a}$ off-site effluent monitoring

\begin{tabular}{|c|c|c|c|c|c|}
\hline Date & $\begin{array}{c}\mathrm{TCE}^{b} \\
(\mu \mathrm{g} / \mathrm{L})\end{array}$ & $\begin{array}{c}{ }^{99} \mathrm{Tc}^{c} \\
(\mathrm{pCl} / \mathrm{L})\end{array}$ & $\begin{array}{l}\text { Gross alpha } \\
\quad(\mathrm{pCi} / \mathrm{L})\end{array}$ & $\begin{array}{c}\text { Gross beta } \\
(\mathrm{pCi} / \mathrm{L})\end{array}$ & $\begin{array}{l}{ }^{222} \mathrm{Rn}^{d} \\
(\mathrm{pCi} / \mathrm{L})\end{array}$ \\
\hline \multicolumn{6}{|c|}{$R 2$} \\
\hline $\begin{array}{r}2 / 12 \\
3 / 27 \\
4 / 29 \\
5 / 13 \\
6 / 25 \\
7 / 29 \\
8 / 18 \\
9 / 30 \\
10 / 21 \\
11 / 10 \\
12 / 08\end{array}$ & $\begin{array}{r}690 \\
850 \\
700 \\
710 \\
790 \\
1040 \\
1100 \\
1300 \\
1200 \\
1400 \\
1300\end{array}$ & $\begin{array}{r}611 \\
515 \\
442 \\
545 \\
632 \\
784 \\
911 \\
1007 \\
921 \\
1102 \\
992\end{array}$ & $\begin{array}{r}-4.8 \\
-2.6 \\
1.6 \\
6.5 \\
-1.4 \\
-8.1 \\
9.8 \\
-1.3 \\
-5.9 \\
2.6 \\
0.2\end{array}$ & $\begin{array}{r}56 \\
329 \\
166 \\
330 \\
360 \\
525 \\
535 \\
509 \\
577 \\
698 \\
500\end{array}$ & \\
\hline \multicolumn{6}{|c|}{$R 5$} \\
\hline $\begin{array}{r}1 / 13 \\
2 / 12 \\
3 / 27 \\
4 / 24 \\
5 / 13 \\
6 / 23 \\
7 / 23 \\
8 / 18 \\
9 / 11 \\
10 / 20 \\
11 / 10 \\
12 / 10\end{array}$ & $\begin{array}{r}<1 \\
<1 \\
<1 \\
1 \\
<1 \\
1 \\
3 \\
1 \\
1 \\
1 \\
1 \\
<1\end{array}$ & $\begin{array}{l}<25 \\
<25 \\
<25 \\
<25 \\
<25 \\
<25 \\
<25 \\
<25 \\
<25 \\
<25 \\
<25 \\
<25\end{array}$ & $\begin{array}{r}2.0 \\
2.5 \\
-2.0 \\
0 \\
1.5 \\
2.3 \\
3.7 \\
1.5 \\
-5.4 \\
-3.4 \\
0.6 \\
1.3\end{array}$ & $\begin{array}{c}-2 \\
4 \\
2 \\
0.5 \\
1 \\
2 \\
2 \\
-3 \\
-1 \\
-6 \\
-3 \\
4\end{array}$ & \\
\hline \multicolumn{6}{|c|}{$R 6$} \\
\hline $\begin{array}{r}1 / 08 \\
2 / 12 \\
3 / 05 \\
4 / 03 \\
5 / 13 \\
6 / 05 \\
6 / 10 \\
7 / 10 \\
8 / 18 \\
9 / 03 \\
10 / 08 \\
11 / 10 \\
12 / 01\end{array}$ & $\begin{array}{l}<1 \\
<1 \\
<1 \\
<1 \\
<1 \\
<1 \\
<1 \\
<1 \\
<1 \\
<1 \\
<1 \\
<1 \\
<1\end{array}$ & $\begin{array}{l}<25 \\
<25 \\
<25 \\
<25 \\
<25 \\
<25 \\
<25 \\
<25 \\
<25 \\
<25 \\
<25 \\
<25 \\
<25\end{array}$ & $\begin{array}{r}4.1 \\
3.7 \\
10.4 \\
0.1 \\
6.0 \\
0.8 \\
-2.1 \\
1.1 \\
2.0 \\
1.1 \\
0.5 \\
3.7 \\
2.9\end{array}$ & $\begin{array}{r}17 \\
8 \\
8 \\
4 \\
6 \\
2 \\
10 \\
5 \\
-2 \\
-1 \\
-4 \\
5 \\
8\end{array}$ & \\
\hline \multicolumn{6}{|c|}{$R 8$} \\
\hline $\begin{array}{r}1 / 07 \\
3 / 06 \\
5 / 06 \\
7 / 16 \\
9 / 03 \\
11 / 03\end{array}$ & $\begin{array}{l}<1 \\
<1 \\
<1 \\
<1 \\
<1 \\
<1\end{array}$ & $\begin{array}{l}<25 \\
<25 \\
<25 \\
<25 \\
<25 \\
<25\end{array}$ & & & \\
\hline
\end{tabular}


1992 Environmental Report-Paducah, Part 2

Table 5.4 (continued)

\begin{tabular}{|c|c|c|c|c|c|}
\hline Date & $\begin{array}{c}\mathrm{TCE}^{b} \\
(\mu \mathrm{g} / \mathrm{L})\end{array}$ & $\begin{array}{c}{ }^{99} \mathrm{Tc}^{c} \\
(\mathrm{pCi} / \mathrm{L})\end{array}$ & $\begin{array}{l}\text { Gross alpha } \\
(\mathrm{pCi} / \mathrm{L})\end{array}$ & $\begin{array}{l}\text { Gross beta } \\
(\mathrm{pCi} / \mathrm{L})\end{array}$ & $\begin{array}{l}{ }^{222} \mathrm{Rn}^{d} \\
(\mathrm{pCi} / \mathrm{L})\end{array}$ \\
\hline \multicolumn{6}{|c|}{$R 9$} \\
\hline $2 / 05$ & $<1$ & $<25$ & & & \\
\hline $4 / 07$ & $<1$ & $<25$ & & & \\
\hline $6 / 12$ & $<1$ & $<25$ & & & \\
\hline $8 / 20$ & $<1$ & $<25$ & & & \\
\hline $12 / 03$ & $<1^{e}$ & $<25$ & & & \\
\hline \multicolumn{6}{|c|}{$R 10$} \\
\hline $1 / 06$ & $<1$ & $<25$ & 2.3 & 2 & 555 \\
\hline $1 / 13$ & $<1$ & $<25$ & & & \\
\hline $1 / 20$ & $<1$ & $<25$ & & & \\
\hline $1 / 27$ & $<1$ & $<25$ & & & \\
\hline $2 / 03$ & $<1$ & $<25$ & 3.2 & 13 & 727 \\
\hline $2 / 12$ & $<1$ & $<25$ & 2.8 & 5 & \\
\hline $2 / 18$ & $<1$ & $<25$ & & & \\
\hline $2 / 24$ & $<1$ & $<25$ & & & \\
\hline $3 / 02$ & $<1$ & $<25$ & 3.2 & 2 & 703 \\
\hline $3 / 09$ & $<1$ & $<25$ & & & \\
\hline $3 / 16$ & $<1$ & $<25$ & & & \\
\hline $3 / 23$ & $<1$ & $<25$ & & & \\
\hline $3 / 30$ & $<1$ & $<25$ & & & \\
\hline $4 / 06$ & $<1$ & $<25$ & 1.1 & 2 & 705 \\
\hline $4 / 13$ & $<1$ & $<25$ & & & \\
\hline $4 / 20$ & $<1$ & $<25$ & & & \\
\hline $4 / 28$ & $<1$ & $<25$ & & & \\
\hline $5 / 04$ & $<1$ & $<25$ & -1.1 & 2 & $\mathrm{NA}^{f}$ \\
\hline $5 / 13$ & $<1$ & $<25$ & 2.4 & 3 & 627 \\
\hline $5 / 18$ & $<1$ & $<25$ & & & \\
\hline $5 / 26$ & $<1$ & $<25$ & & & \\
\hline $6 / 01$ & $<1$ & $<25$ & -1.3 & -1 & 593 \\
\hline $6 / 08$ & $<1$ & $<25$ & & & \\
\hline $6 / 15$ & $<1$ & $<25$ & & & \\
\hline $6 / 22$ & $<1$ & $<25$ & & & \\
\hline $6 / 29$ & $<1$ & $<25$ & & & \\
\hline $7 / 06$ & $<1$ & $<25$ & -0.6 & -1 & \\
\hline $7 / 13$ & $<1$ & $<25$ & & & 593 \\
\hline $7 / 20$ & $<1$ & $<25$ & & & \\
\hline $7 / 27$ & $<1$ & $<25$ & & & \\
\hline $8 / 03$ & $<1$ & $<25$ & 0.8 & -4 & 567 \\
\hline $8 / 10$ & $<1$ & $<25$ & & & \\
\hline $8 / 17$ & $<1$ & $<25$ & & & \\
\hline $8 / 24$ & $<1$ & $<25$ & & & \\
\hline $8 / 31$ & $<1$ & $<25$ & & & \\
\hline $9 / 08$ & $<1$ & $<25$ & -1.9 & -3 & 705 \\
\hline $9 / 14$ & $<1$ & $<25$ & & & \\
\hline $9 / 21$ & $<1$ & $<25$ & & & \\
\hline $9 / 28$ & $<1$ & $<25$ & & & \\
\hline $10 / 05$ & $<1$ & $<25$ & -5.2 & -5 & 727 \\
\hline $10 / 12$ & $<1$ & $<25$ & & & \\
\hline $10 / 19$ & $<1$ & $<25$ & & & \\
\hline $10 / 26$ & $<1$ & $<25$ & & & \\
\hline $11 / 02$ & $<1$ & $<25$ & 2.3 & 0 & 698 \\
\hline $11 / 10$ & $<1$ & $<25$ & -2.0 & -3 & \\
\hline $11 / 16$ & $<1$ & $<25$ & & & \\
\hline
\end{tabular}


1992 Environmental Report-Paducah, Part 2

Table 5.4 (continued)

\begin{tabular}{|c|c|c|c|c|c|}
\hline Date & $\begin{array}{c}\mathrm{TCE}^{b} \\
(\mu \mathrm{g} / \mathrm{L})\end{array}$ & $\begin{array}{c}{ }^{99} \mathrm{Tc}^{c} \\
(\mathrm{pCi} / \mathrm{L})\end{array}$ & $\begin{array}{l}\text { Gross alpha } \\
(\mathrm{pCi} / \mathrm{L})\end{array}$ & $\begin{array}{c}\text { Gross beta } \\
(\mathrm{pCi} / \mathrm{L})\end{array}$ & $\begin{array}{l}{ }^{222} \mathrm{Rn}^{d} \\
(\mathrm{pCi} / \mathrm{L})\end{array}$ \\
\hline $11 / 23$ & $<1$ & $<25$ & & & \\
\hline $\begin{array}{l}12 / 07 \\
12 / 14\end{array}$ & $\begin{array}{l}<1 \\
<1\end{array}$ & $\begin{array}{l}<25 \\
<25\end{array}$ & 1.5 & 2 & 604 \\
\hline $12 / 21$ & $<1$ & $\begin{array}{l}<25 \\
<25\end{array}$ & & & \\
\hline $12 / 28$ & $<1$ & $<25$ & & & \\
\hline \multirow{2}{*}{\multicolumn{6}{|c|}{$R 12$}} \\
\hline $1 / 06$ & $<1$ & $<25$ & & & \\
\hline $1 / 13$ & $<1$ & $<25$ & 1.0 & -6 & 296 \\
\hline $1 / 20$ & $<1$ & $<25$ & & & \\
\hline $1 / 27$ & $<1$ & $<25$ & & & \\
\hline $2 / 03$ & $<1$ & $<25$ & 1.8 & 5 & 308 \\
\hline $2 / 10$ & $<1$ & $<25$ & & & 500 \\
\hline $2 / 18$ & $<1$ & $<25$ & & & \\
\hline $2 / 24$ & $<1$ & $<25$ & & & \\
\hline $\begin{array}{l}3 / 02 \\
3 / 09\end{array}$ & $\begin{array}{l}<1 \\
<1\end{array}$ & $<25$ & 5 & 5 & 366 \\
\hline $\begin{array}{l}3 / 109 \\
3 / 16\end{array}$ & & $<25$ & & & \\
\hline $3 / 23$ & $\begin{array}{l}<1 \\
<1\end{array}$ & $\begin{array}{l}<25 \\
<25\end{array}$ & & & \\
\hline $3 / 30$ & $<1$ & $\begin{array}{l}<25 \\
<25\end{array}$ & & & \\
\hline $4 / 06$ & $<1$ & $<25$ & 0.4 & 2 & 657 \\
\hline $4 / 13$ & $<1$ & $<25$ & & & \\
\hline $4 / 20$ & $<1$ & $<25$ & & & \\
\hline $\begin{array}{l}5 / 04 \\
5 / 11\end{array}$ & $<1$ & $<25$ & 0.2 & 0.3 & 742 \\
\hline $5 / 18$ & $\begin{array}{l}<1 \\
<1\end{array}$ & $\begin{array}{l}<25 \\
<25\end{array}$ & & & \\
\hline $5 / 26$ & $\begin{array}{l}<1 \\
<1\end{array}$ & $\begin{array}{l}<25 \\
<25\end{array}$ & & & \\
\hline $6 / 01$ & $<1^{g}$ & $<25$ & 7.1 & -1 & 359 \\
\hline $6 / 08$ & $<1$ & $<25$ & & & \\
\hline $6 / 15$ & $<1$ & $<25$ & & & \\
\hline $6 / 22$ & $<1$ & $<25$ & & & \\
\hline $6 / 29$ & $<1$ & $<25$ & & -1 & \\
\hline $\begin{array}{l}7 / 06 \\
7 / 13\end{array}$ & $<1$ & $\begin{array}{l}<25 \\
<25\end{array}$ & 0.7 & & 303 \\
\hline $\begin{array}{l}7 / 33 \\
7 / 20\end{array}$ & $\begin{array}{l}<1 \\
<1\end{array}$ & $\begin{array}{l}<25 \\
<25\end{array}$ & & & \\
\hline $7 / 28$ & $\begin{array}{l}<1 \\
<1\end{array}$ & $<25$ & & & \\
\hline $8 / 03$ & $<1$ & $<25$ & -0.2 & -3 & 276 \\
\hline $8 / 10$ & $<1$ & $<25$ & & & \\
\hline $8 / 17$ & $<1$ & $<25$ & & & \\
\hline $8 / 24$ & $<1$ & $<25$ & & & \\
\hline $8 / 31$ & $<1$ & $<25$ & & & \\
\hline $9 / 08$ & $<1$ & $<25$ & -2.3 & -1 & 347 \\
\hline $9 / 14$ & $<1$ & $<25$ & & & \\
\hline $9 / 21$ & $<1$ & $<25$ & & & \\
\hline $9 / 28$ & $<1$ & $<25$ & -2.7 & -3 & 351 \\
\hline $10 / 05$ & $<1$ & $<25$ & -2.7 & & \\
\hline $10 / 12$ & $<1$ & $<25$ & & & \\
\hline $10 / 19$ & $<1$ & $<25$ & & & \\
\hline $10 / 26$ & $<1$ & $<25$ & 1.0 & 1 & 364 \\
\hline $11 / 02$ & $<1$ & $<25$ & & & \\
\hline $11 / 09$ & $<1$ & $<25$ & & & \\
\hline $11 / 16$ & $<1$ & $<25$ & & & \\
\hline $\begin{array}{l}11 / 23 \\
11 / 30\end{array}$ & $\begin{array}{l}<1 \\
<1\end{array}$ & $\begin{array}{l}<25 \\
<25\end{array}$ & & & \\
\hline $11 / 30$ & $<1$ & $<25$ & & & \\
\hline
\end{tabular}


1992 Environmental Report-Paducah, Part 2

Table 5.4 (continued)

\begin{tabular}{|c|c|c|c|c|c|}
\hline Date & $\begin{array}{c}\mathrm{TCE}^{b} \\
(\mu \mathrm{g} / \mathrm{L})\end{array}$ & $\begin{array}{c}{ }^{99} \mathrm{Tc}^{c} \\
(\mathrm{pCi} / \mathrm{L})\end{array}$ & $\begin{array}{l}\text { Gross alpha } \\
(\mathrm{pCi} / \mathrm{L})\end{array}$ & $\begin{array}{l}\text { Gross beta } \\
(\mathrm{pCi} / \mathrm{L})\end{array}$ & $\begin{array}{l}{ }^{222} \mathrm{Rn}^{d} \\
(\mathrm{pCi} / \mathrm{L})\end{array}$ \\
\hline $12 / 07$ & $<1$ & $<25$ & 3.2 & 2 & 352 \\
\hline $12 / 14$ & $<1$ & $<25$ & & & \\
\hline $12 / 21$ & $<1$ & $<25$ & & & \\
\hline $12 / 28$ & $<1$ & $<25$ & & & \\
\hline \multicolumn{6}{|c|}{$R 13$} \\
\hline $1 / 06$ & $<1$ & $<25$ & 2.0 & -2 & 255 \\
\hline $1 / 13$ & $<1$ & $<25$ & & & \\
\hline $1 / 20$ & $<1$ & $<25$ & & & \\
\hline $1 / 27$ & $<1$ & $<25$ & & & \\
\hline $2 / 03$ & $<1$ & $<25$ & 3.3 & 7 & 342 \\
\hline $2 / 10$ & $<1$ & $<25$ & & & \\
\hline $2 / 18$ & $<1$ & $<25$ & & & \\
\hline $2 / 24$ & $<1$ & $<25$ & & & \\
\hline $3 / 02$ & $<1$ & $<25$ & -12.6 & -8 & 365 \\
\hline $3 / 09$ & $<1$ & $<25$ & & & \\
\hline $3 / 16$ & $<1$ & $<25$ & & & \\
\hline $3 / 23$ & $<1$ & $<25$ & & & \\
\hline $3 / 30$ & $<1$ & $<25$ & & & \\
\hline $4 / 06$ & $<1$ & $<25$ & 6.2 & 7 & 384 \\
\hline $4 / 13$ & $<1$ & $<25$ & & & \\
\hline $4 / 20$ & $<1$ & $<25$ & & & \\
\hline $4 / 28$ & $<1$ & $<25$ & & & \\
\hline $5 / 04$ & $<1$ & $<25$ & 0.8 & 0.1 & $\mathrm{NA}$ \\
\hline $5 / 13$ & $<1$ & $<25$ & 3.5 & 3 & 335 \\
\hline $5 / 18$ & $<1$ & $<25$ & & & \\
\hline $5 / 26$ & $<1$ & $<25$ & & & \\
\hline $6 / 01$ & $<1^{g}$ & $<25$ & 0.7 & 9 & 318 \\
\hline $6 / 08$ & $<1$ & $<25$ & & & \\
\hline $6 / 15$ & $<1$ & $<25$ & & & \\
\hline $6 / 22$ & $<1$ & $<25$ & & & \\
\hline $6 / 29$ & $<1$ & $<25$ & & & \\
\hline $7 / 06$ & $<1$ & $<25$ & 0.8 & 1 & \\
\hline $7 / 13$ & $<1$ & $<25$ & & & 310 \\
\hline $7 / 20$ & $<1$ & $<25$ & & & \\
\hline $7 / 28$ & $<1$ & $<25$ & & & \\
\hline $8 / 03$ & $<1$ & $<25$ & -2.5 & 0 & 304 \\
\hline $8 / 10$ & $<1$ & $<25$ & & & \\
\hline $8 / 18$ & $<1$ & $<25$ & 2 & -0.2 & \\
\hline $8 / 24$ & $<1$ & $<25$ & & & \\
\hline $8 / 31$ & $<1$ & $<25$ & & & \\
\hline $9 / 08$ & $<1$ & $<25$ & 1.0 & -2 & 355 \\
\hline $9 / 14$ & $<1$ & $<25$ & & & \\
\hline $9 / 21$ & $<1$ & $<25$ & & & \\
\hline $9 / 28$ & $<1$ & $<25$ & & & \\
\hline $10 / 05$ & $<1$ & $<25$ & -2.5 & 11 & 358 \\
\hline $10 / 12$ & $<1$ & $<25$ & & & \\
\hline $10 / 19$ & $<1$ & $<25$ & & & \\
\hline $10 / 26$ & $<1$ & $<25$ & & & \\
\hline $11 / 02$ & $<1$ & $<25$ & 1.3 & 2 & 372 \\
\hline $11 / 10$ & $<1$ & $<25$ & -1 & -0.8 & \\
\hline $11 / 16$ & $<1$ & $<25$ & & & \\
\hline $11 / 23$ & $<1$ & $<25$ & & & \\
\hline $11 / 30$ & $<1$ & $<25$ & & & \\
\hline $12 / 07$ & $<1$ & $<25$ & 4.9 & 7 & 310 \\
\hline $12 / 14$ & $<1$ & $<25$ & & & \\
\hline
\end{tabular}


1992 Environmental Report-Paducah, Part 2

Table 5.4 (continued)

\begin{tabular}{|c|c|c|c|c|c|}
\hline Date & $\begin{array}{c}\mathrm{TCE}^{b} \\
(\mu \mathrm{g} / \mathrm{L})\end{array}$ & $\begin{array}{c}{ }^{99} \mathrm{Tc}^{c} \\
(\mathrm{pCi} / \mathrm{L})\end{array}$ & $\begin{array}{l}\text { Gross alpha } \\
\qquad(\mathrm{pCi} / \mathrm{L})\end{array}$ & $\begin{array}{l}\text { Gross beta } \\
(\mathrm{pCi} / \mathrm{L})\end{array}$ & $\begin{array}{l}{ }^{222} \mathrm{Rn}^{d} \\
(\mathrm{pCi} / \mathrm{L})\end{array}$ \\
\hline $12 / 21$ & $<1$ & $<25$ & & & \\
\hline $12 / 28$ & $<1$ & $<25$ & & & \\
\hline \multicolumn{6}{|c|}{$R 14$} \\
\hline $1 / 06$ & $<1$ & $<25$ & 1.8 & 2 & 1169 \\
\hline $1 / 13$ & $<1$ & $<25$ & & & \\
\hline $1 / 20$ & $<1$ & $<25$ & & & \\
\hline $1 / 27$ & $<1$ & $<25$ & & & \\
\hline $2 / 03$ & $<1$ & $<25$ & 0.9 & 3 & 1469 \\
\hline $2 / 10$ & $<1$ & $<25$ & & & \\
\hline $2 / 18$ & $<1$ & $<25$ & & & \\
\hline $2 / 24$ & $<1$ & $<25$ & & & \\
\hline $3 / 02$ & $<1$ & $<25$ & 4.7 & 12 & 1575 \\
\hline $3 / 09$ & $<1$ & $<25$ & & & \\
\hline $3 / 16$ & $<1$ & $<25$ & & & \\
\hline $3 / 23$ & $<1$ & $<25$ & & & \\
\hline $3 / 30$ & $<1$ & $<25$ & & & \\
\hline $4 / 06$ & $<1$ & $<25$ & 5.3 & 6 & 1548 \\
\hline $4 / 13$ & $<1$ & $<25$ & & & \\
\hline $4 / 20$ & $<1$ & $<25$ & & & \\
\hline $4 / 28$ & $<1$ & $<25$ & & & \\
\hline $5 / 04$ & $<1$ & $<25$ & 1.9 & 2 & NA \\
\hline $5 / 11$ & $<1$ & $<25$ & & & 1427 \\
\hline $5 / 18$ & $<1$ & $<25$ & & & \\
\hline $5 / 26$ & $<1$ & $<25$ & & & \\
\hline $6 / 01$ & $<1^{g}$ & $<25$ & 3.8 & -5 & 1380 \\
\hline $6 / 08$ & $<1$ & $<25$ & & & \\
\hline $6 / 15$ & $<1$ & $<25$ & & & \\
\hline $6 / 22$ & $<1$ & $<25$ & & & \\
\hline $6 / 29$ & $<1$ & $<25$ & & & \\
\hline $7 / 06$ & $<1$ & $<25$ & 0.4 & 0.1 & \\
\hline $7 / 13$ & $<1$ & $<25$ & & & 1203 \\
\hline $7 / 20$ & $<1$ & $<25$ & & & \\
\hline $7 / 28$ & $<1$ & $<25$ & & & \\
\hline $8 / 03$ & $<1$ & $<25$ & -0.8 & -2 & 1275 \\
\hline $8 / 10$ & $<1$ & $<25$ & & & \\
\hline $8 / 17$ & $<1$ & $<25$ & & & \\
\hline $8 / 24$ & $<1$ & $<25$ & & & \\
\hline $8 / 31$ & $<1$ & $<25$ & & & \\
\hline $9 / 08$ & $<1$ & $<25$ & -1.5 & -3 & 1585 \\
\hline $9 / 14$ & $<1$ & $<25$ & & & \\
\hline $9 / 21$ & $<1$ & $<25$ & & & \\
\hline $9 / 28$ & $<1$ & $<25$ & & & \\
\hline $10 / 05$ & $<1$ & $<25$ & -4.0 & -2 & 1457 \\
\hline $10 / 12$ & $<1$ & $<25$ & & & \\
\hline $10 / 19$ & $<1$ & $<25$ & & & \\
\hline $10 / 26$ & $<1$ & $<25$ & & & \\
\hline $11 / 02$ & $<1$ & $<25$ & 2 & 2.7 & 1565 \\
\hline $11 / 09$ & $<1$ & $<25$ & & & \\
\hline $11 / 16$ & $<1$ & $<25$ & & & \\
\hline $11 / 23$ & $<1$ & $<25$ & & & \\
\hline $11 / 30$ & $<1$ & $<25$ & & & \\
\hline $12 / 07$ & $<1$ & $<25$ & 1.0 & 5 & 1467 \\
\hline $12 / 14$ & $<1$ & $<25$ & & & \\
\hline $12 / 21$ & $<1$ & $<25$ & & & \\
\hline $12 / 28$ & $<1$ & $<25$ & & & \\
\hline
\end{tabular}


1992 Environmental Report-Paducah, Part 2

Table 5.4 (continued)

\begin{tabular}{|c|c|c|c|c|c|}
\hline Date & $\begin{array}{c}\mathrm{TCE}^{b} \\
(\mu \mathrm{g} / \mathrm{L})\end{array}$ & $\begin{array}{c}{ }^{99} \mathrm{Tc}^{c} \\
(\mathrm{pCi} / \mathrm{L})\end{array}$ & $\begin{array}{c}\text { Gross alpha } \\
(\mathrm{pCi} / \mathrm{L})\end{array}$ & $\begin{array}{l}\text { Gross beta } \\
(\mathrm{pCi} / \mathrm{L})\end{array}$ & $\begin{array}{l}{ }^{222} \mathrm{Rn}^{d} \\
(\mathrm{pCi} / \mathrm{L})\end{array}$ \\
\hline \multicolumn{6}{|c|}{$R 17$} \\
\hline $1 / 13$ & 160 & 158 & 2.7 & 124 & \\
\hline $2 / 12$ & 130 & 161 & 5.1 & 121 & \\
\hline $3 / 27$ & 260 & 171 & -2.8 & 157 & \\
\hline $4 / 24$ & 290 & 239 & -1.0 & 149 & \\
\hline $5 / 13$ & 340 & 243 & -0.4 & 160 & \\
\hline $6 / 23$ & 340 & 244 & 0.4 & 183 & \\
\hline $7 / 23$ & 250 & 287 & 0.6 & 136 & \\
\hline $8 / 18$ & 270 & 202 & 2.9 & 127 & \\
\hline $9 / 11$ & 220 & 199 & 5.4 & 127 & \\
\hline $10 / 20$ & 210 & 174 & -2.7 & 181 & \\
\hline $11 / 10$ & 220 & 215 & 3.0 & 119 & \\
\hline $12 / 10$ & 160 & 191 & 0 & 135 & \\
\hline \multicolumn{6}{|c|}{$R / 8$} \\
\hline $1 / 13$ & $<1$ & $<25$ & 2.3 & -3 & \\
\hline \multicolumn{6}{|c|}{$R 19$} \\
\hline $1 / 06$ & $<1$ & $<25$ & 7.0 & 5 & 341 \\
\hline $1 / 13$ & $<1$ & $<25$ & & & \\
\hline $1 / 20$ & $<1$ & $<25$ & & & \\
\hline $1 / 27$ & $<1$ & $<25$ & & & \\
\hline $2 / 03$ & $<1$ & $<25$ & 1.4 & 7 & 485 \\
\hline $2 / 10$ & $<1$ & $<25$ & & & \\
\hline $2 / 18$ & $<1$ & $<25$ & & & \\
\hline $2 / 24$ & $<1$ & $<25$ & & & \\
\hline $3 / 02$ & $<1$ & $<25$ & -0.3 & 9 & 530 \\
\hline $3 / 09$ & $<1$ & $<25$ & & & \\
\hline $3 / 16$ & $<1$ & $<25$ & & & \\
\hline $3 / 23$ & $<1$ & $<25$ & & & \\
\hline $3 / 30$ & $<1$ & $<25$ & & & \\
\hline $4 / 06$ & $<1$ & $<25$ & -1.6 & 3 & 516 \\
\hline $4 / 13$ & $<1$ & $<25$ & & & \\
\hline $4 / 20$ & $<1$ & $<25$ & & & \\
\hline $4: 28$ & $<1$ & $<25$ & & & \\
\hline $5 / 04$ & $<1$ & $<25$ & -3.1 & 0.1 & NA \\
\hline $5 / 11$ & $<1$ & $<25$ & & & 467 \\
\hline $5 / 18$ & $<1$ & $<25$ & & & \\
\hline $5 / 26$ & $<1$ & $<25$ & & & \\
\hline $6 / 01$ & $<1^{g}$ & $<25$ & 1.4 & -1 & 495 \\
\hline $6 / 08$ & $<1$ & $<25$ & & & \\
\hline $6 / 15$ & $<1$ & $<25$ & & & \\
\hline $6 / 22$ & $<1$ & $<25$ & & & \\
\hline $6 / 29$ & $<1$ & $<25$ & & & \\
\hline $7 / 06$ & $<1$ & $<25$ & -1.4 & -2 & \\
\hline $7 / 13$ & $<1$ & $<25$ & & & 387 \\
\hline $7 / 20$ & $<1$ & $<25$ & & & \\
\hline $7 / 28$ & $<1$ & $<25$ & & & \\
\hline $8 / 03$ & $<1$ & $<25$ & -2.3 & -3 & 441 \\
\hline $8 / 10$ & $<1$ & $<25$ & & & \\
\hline $8 / 17$ & $<1$ & $<25$ & & & \\
\hline $8 / 24$ & $<1$ & $<25$ & & & \\
\hline $8 / 31$ & $<1$ & $<25$ & & & \\
\hline
\end{tabular}


1992 Environmental Report-Paducah, Part 2

Table 5.4 (continued)

\begin{tabular}{|c|c|c|c|c|c|}
\hline Date & $\begin{array}{l}\mathrm{TCE}^{h} \\
(\mu \mathrm{g} / \mathrm{L})\end{array}$ & $\begin{array}{c}{ }^{99} \mathrm{Tc}^{c} \\
(\mathrm{pCi} / \mathrm{L})\end{array}$ & $\begin{array}{c}\text { Gross alpha } \\
(\mathrm{pCi} / \mathrm{L})\end{array}$ & $\begin{array}{l}\text { Gross beta } \\
(\mathrm{pCi} / \mathrm{L})\end{array}$ & $\begin{array}{l}{ }^{222} \mathrm{Rn}^{d} \\
(\mathrm{pCi} / \mathrm{L})\end{array}$ \\
\hline $9 / 08$ & $<1$ & $<25$ & -1.4 & -2 & 575 \\
\hline $9 / 14$ & $<1$ & $<25$ & & & \\
\hline $9 / 21$ & $<1$ & $<25$ & & & \\
\hline $9 / 28$ & $<1$ & $<25$ & & & \\
\hline $10 / 05$ & $<1$ & $<25$ & -4.0 & -3 & 498 \\
\hline $10 / 12$ & $<1$ & $<25$ & & & \\
\hline $10 / 19$ & $<1$ & $<25$ & & & \\
\hline $10 / 26$ & $<1$ & $<25$ & & & \\
\hline $11 / 02$ & $<1$ & $<25$ & 2.3 & 4 & 527 \\
\hline $11 / 09$ & $<1$ & $<25$ & & & \\
\hline $11 / 16$ & $<1$ & $<25$ & & & \\
\hline $11 / 23$ & $<1$ & $<25$ & & & \\
\hline $11 / 30$ & $<1$ & $<25$ & & & \\
\hline $12 / 07$ & $<1$ & $<25$ & 3.5 & 3 & 593 \\
\hline $12 / 07$ & $<1$ & $<25$ & 3.1 & 2 & 397 \\
\hline $12 / 14$ & $<1$ & $<25$ & & & \\
\hline $12 / 21$ & $<1$ & $<25$ & & & \\
\hline $12 / 28$ & $<1$ & $<25$ & & & \\
\hline \multicolumn{6}{|c|}{$R 20$} \\
\hline $6 / 12$ & $<1$ & $<25$ & & & \\
\hline $8 / 20$ & $<1$ & $<25$ & & & \\
\hline \multicolumn{6}{|c|}{$R 2 I$} \\
\hline $1 / 08$ & $<1$ & $<25$ & 0.6 & 6 & \\
\hline $2 / 12$ & $<1$ & $<25$ & 1.0 & 13 & \\
\hline $3 / 16$ & $<1$ & $<25$ & -0.3 & 2 & \\
\hline $4 / 10$ & $<1$ & $<25$ & 0.6 & -1 & \\
\hline $5 / 13$ & $<1$ & $<25$ & -0.8 & 0.8 & \\
\hline $6 / 05$ & $<1$ & $<25$ & -1.1 & 0.1 & \\
\hline $7 / 10$ & $<1$ & $<25$ & -4.2 & -1 & \\
\hline $8 / 18$ & $<1$ & $<25$ & 0.3 & -2 & \\
\hline $9 / 03$ & $<1$ & $<25$ & 0.6 & -5 & \\
\hline $10 / 08$ & $<1$ & $<25$ & -7.9 & -7 & \\
\hline $11 / 10$ & $<1$ & $<25$ & -2.8 & 1 & \\
\hline $12 / 01$ & $<1$ & $<25$ & 0 & 5 & \\
\hline \multicolumn{6}{|c|}{$R 22$} \\
\hline $2 / 06$ & $<1$ & $<25$ & & & \\
\hline $4 / 03$ & $<1$ & $<25$ & & & \\
\hline $6 / 10$ & $<1$ & $<25$ & & & \\
\hline $8 / 07$ & $<1$ & $<25$ & & & \\
\hline $10 / 06$ & $<1$ & $<25$ & & & \\
\hline $12 / 03$ & $<1$ & $<25$ & & & \\
\hline \multicolumn{6}{|c|}{$R 23$} \\
\hline $1 / 07$ & $<1$ & $<25$ & & & \\
\hline $3 / 06$ & $<1$ & $<25$ & & & \\
\hline $5 / 06$ & $<1$ & $<25$ & & & \\
\hline $7 / 16$ & $<1$ & $<25$ & & & \\
\hline $9 / 03$ & $<1$ & $<25$ & & & \\
\hline
\end{tabular}

\section{5-18 Groundwater}


1992 Environmental Report-Paducah, Part 2

Table 5.4 (continued)

\begin{tabular}{|c|c|c|c|c|c|}
\hline Date & $\begin{array}{c}\mathrm{TCE}^{b} \\
(\mu \mathrm{g} / \mathrm{L})\end{array}$ & $\begin{array}{c}{ }^{99} \mathrm{Tc}^{c} \\
(\mathrm{pCi} / \mathrm{L})\end{array}$ & $\begin{array}{l}\text { Gross alpha } \\
(\mathrm{pCi} / \mathrm{L})\end{array}$ & $\begin{array}{l}\text { Gross beta } \\
(\mathrm{pCi} / \mathrm{L})\end{array}$ & $\begin{array}{l}{ }^{222} \mathrm{Rn}^{d} \\
(\mathrm{pCi} / \mathrm{L})\end{array}$ \\
\hline \multicolumn{6}{|c|}{$R 24$} \\
\hline $\begin{array}{r}2 / 06 \\
4 / 03 \\
6 / 10 \\
8 / 07 \\
10 / 06 \\
12 / 03\end{array}$ & $\begin{array}{l}<1 \\
<1 \\
<1 \\
<1 \\
<1 \\
<1\end{array}$ & $\begin{array}{l}<25 \\
<25 \\
<25 \\
<25 \\
<25 \\
<25\end{array}$ & & & \\
\hline \multicolumn{6}{|c|}{$R 25$} \\
\hline $\begin{array}{r}1 / 07 \\
3 / 05 \\
5 / 04 \\
7 / 16 \\
7 / 20 \\
9 / 14 \\
11 / 03\end{array}$ & $\begin{array}{l}<1 \\
<1 \\
<1 \\
<1 \\
<1 \\
<1 \\
<1\end{array}$ & $\begin{array}{l}<25 \\
<25 \\
<25 \\
<25 \\
<25 \\
<25 \\
<25\end{array}$ & & & \\
\hline \multicolumn{6}{|c|}{$R 26$} \\
\hline $\begin{array}{r}2 / 12 \\
4 / 03 \\
6 / 10 \\
8 / 07 \\
10 / 06 \\
12 / 03\end{array}$ & $\begin{array}{l}<1 \\
<1 \\
<1 \\
<1 \\
<1 \\
<1\end{array}$ & $\begin{array}{l}<25 \\
<25 \\
<25 \\
<25 \\
<25 \\
<25\end{array}$ & 0.5 & 3 & \\
\hline \multicolumn{6}{|c|}{$R 28$} \\
\hline $\begin{array}{r}1 / 07 \\
3 / 05 \\
5 / 04 \\
7 / 16 \\
7 / 20 \\
9 / 14 \\
11 / 03\end{array}$ & $\begin{array}{l}<1 \\
<1 \\
<1 \\
<1 \\
<1 \\
<1 \\
<1\end{array}$ & $\begin{array}{l}<25 \\
<25 \\
<25 \\
<25 \\
<25 \\
<25\end{array}$ & & & \\
\hline \multicolumn{6}{|c|}{$R 39$} \\
\hline $\begin{array}{l}1 / 06 \\
1 / 13 \\
1 / 20 \\
1 / 27\end{array}$ & $\begin{array}{l}<1 \\
<1 \\
<1 \\
<1\end{array}$ & $\begin{array}{l}<25 \\
<25 \\
<25 \\
<25\end{array}$ & 4.2 & 3 & 453 \\
\hline $2 / 03$ & $<1$ & $<25$ & 0.3 & 5 & 447 \\
\hline $2 / 10$ & $<1$ & $<25$ & & & \\
\hline $2 / 18$ & $<1$ & $<25$ & & & \\
\hline $2 / 24$ & $<1$ & $<25$ & & & \\
\hline $3 / 02$ & $<1$ & $<25$ & 0.8 & 5 & 695 \\
\hline $\begin{array}{l}3 / 09 \\
3 / 16\end{array}$ & $\begin{array}{l}<1 \\
<1\end{array}$ & $\begin{array}{l}<25 \\
<25\end{array}$ & & & \\
\hline $3 / 23$ & $<1$ & $<25$ & & & \\
\hline $3 / 30$ & $<1$ & $<25$ & & & \\
\hline $4 / 06$ & $<1$ & $<25$ & 1.5 & 2 & 846 \\
\hline $4 / 13$ & $<1$ & $<25$ & & & \\
\hline $4 / 20$ & $<1$ & $<25$ & & & \\
\hline
\end{tabular}


1992 Environmental Report-Paducah, Part 2

Table 5.4 (continued)

\begin{tabular}{|c|c|c|c|c|c|}
\hline Date & $\begin{array}{c}\mathrm{TCE}^{b} \\
(\mu \mathrm{g} / \mathrm{L})\end{array}$ & $\begin{array}{c}{ }^{99} \mathrm{Tc}^{c} \\
(\mathrm{pCi} / \mathrm{L})\end{array}$ & $\begin{array}{l}\text { Gross alpha } \\
(\mathrm{pCi} / \mathrm{L})\end{array}$ & $\begin{array}{c}\text { Gross beta } \\
(\mathrm{pCi} / \mathrm{L})\end{array}$ & $\begin{array}{l}{ }^{222} \mathrm{Rn}^{d} \\
(\mathrm{pCi} / \mathrm{L})\end{array}$ \\
\hline $4 / 28$ & $<1$ & $<25$ & \multirow{4}{*}{1.8} & \multirow{4}{*}{10} & \multirow{4}{*}{$\begin{array}{c}\text { NA } \\
284\end{array}$} \\
\hline $5 / 04$ & $<1$ & $<25$ & & & \\
\hline $5 / 11$ & $<1$ & $<25$ & & & \\
\hline $\begin{array}{l}5 / 18 \\
5 / 26\end{array}$ & $<1$ & $<25$ & & & \\
\hline $\begin{array}{l}5 / 26 \\
6 / 01\end{array}$ & $\begin{array}{l}<1 \\
<1^{g}\end{array}$ & $\begin{array}{l}<25 \\
<25\end{array}$ & \multirow[t]{4}{*}{3.4} & \multirow[t]{4}{*}{6} & \multirow[t]{5}{*}{662} \\
\hline $6 / 08$ & $<1$ & $\begin{array}{l}<25 \\
<25\end{array}$ & & & \\
\hline $6 / 15$ & $<1$ & $<25$ & & & \\
\hline $\begin{array}{l}6 / 22 \\
6 / 29\end{array}$ & $<1$ & $\begin{array}{l}<25 \\
<25\end{array}$ & & & \\
\hline $\begin{array}{l}6 / 29 \\
7 / 06\end{array}$ & $\begin{array}{l}<1 \\
<1\end{array}$ & $\begin{array}{l}<25 \\
<25\end{array}$ & \multirow[t]{3}{*}{-1.7} & \multirow[t]{3}{*}{1} & \\
\hline $7 / 13$ & $\begin{array}{l}<1 \\
<1\end{array}$ & $\begin{array}{l}<25 \\
<25\end{array}$ & & & \multirow[t]{3}{*}{471} \\
\hline $7 / 20$ & $<1$ & $<25$ & & & \\
\hline $7 / 27$ & $<1$ & $<25$ & \multirow{5}{*}{1.4} & \multirow{5}{*}{-3} & \\
\hline $\begin{array}{l}8 / 03 \\
8 / 10\end{array}$ & $<1$ & $<25$ & & & \multirow{4}{*}{408} \\
\hline $\begin{array}{l}8 / 10 \\
8 / 17\end{array}$ & $<1$ & $<25$ & & & \\
\hline $8 / 24$ & $\begin{array}{l}<1 \\
<1\end{array}$ & & & & \\
\hline $8 / 31$ & $\begin{array}{l}<1 \\
<1\end{array}$ & $\begin{array}{l}<25 \\
<25\end{array}$ & & & \\
\hline $9 / 08$ & $<1$ & $<25$ & \multirow[t]{3}{*}{-2.0} & \multirow[t]{3}{*}{-4} & \multirow[t]{3}{*}{593} \\
\hline $9 / 14$ & $<1$ & $<25$ & & & \\
\hline $\begin{array}{l}9 / 21 \\
9 / 28\end{array}$ & $<1$ & $<25$ & & & \\
\hline $\begin{array}{r}9 / 28 \\
10 / 05\end{array}$ & $<1$ & $<25$ & \multirow{3}{*}{-4.5} & \multirow[t]{3}{*}{-6} & \multirow{4}{*}{659} \\
\hline $10 / 12$ & $\begin{array}{l}<1 \\
<1\end{array}$ & $\begin{array}{l}<25 \\
<25\end{array}$ & & & \\
\hline $10 / 19$ & $<1$ & $<25$ & & & \\
\hline $10 / 26$ & $<1$ & $<25$ & \multirow{5}{*}{1.0} & \multirow{5}{*}{4} & \\
\hline $11 / 02$ & $<1$ & $<25$ & & & \multirow{4}{*}{668} \\
\hline $\begin{array}{l}11 / 09 \\
11 / 16\end{array}$ & $\begin{array}{l}<1 \\
<1\end{array}$ & $<25$ & & & \\
\hline $\begin{array}{l}11 / 10 \\
11 / 23\end{array}$ & $\begin{array}{l}<1 \\
<1\end{array}$ & $\begin{array}{l}<25 \\
<25\end{array}$ & & & \\
\hline $11 / 30$ & $<1$ & $\begin{array}{l}<25 \\
<25\end{array}$ & & & \\
\hline $12 / 07$ & $<1$ & $<25$ & \multirow[t]{4}{*}{2.7} & 1 & 837 \\
\hline $12 / 14$ & $<1$ & $<25$ & & & \\
\hline $12 / 21$ & $<1$ & $<25$ & & & \\
\hline & $<1$ & $<25$ & & & \\
\hline & & & & & \\
\hline $1 / 06$ & $<1$ & $<25$ & 4.2 & -2 & 248 \\
\hline $1 / 13$ & $<1$ & $<25$ & & & \\
\hline $\begin{array}{l}1 / 20 \\
1 / 27\end{array}$ & $<1$ & $<25$ & & & \\
\hline 2/03 & $\begin{array}{l}<1 \\
<1\end{array}$ & $\begin{array}{l}<25 \\
<25\end{array}$ & 1.4 & 2 & 316 \\
\hline $2 / 12$ & $<1$ & $<25$ & 3.2 & 3 & \\
\hline $2 / 18$ & $<1$ & $<25$ & & & \\
\hline $2 / 24$ & $<1$ & $<25$ & 1 & & 309 \\
\hline $\begin{array}{l}3 / 02 \\
3 / 09\end{array}$ & $<1$ & $<25$ & 1 & 1 & 309 \\
\hline $\begin{array}{l}3 / 109 \\
3 / 16\end{array}$ & $\begin{array}{l}<1 \\
<1\end{array}$ & $\begin{array}{l}<25 \\
<25\end{array}$ & & & \\
\hline $3 / 23$ & $\begin{array}{l}<1 \\
<1\end{array}$ & $<25$ & & & \\
\hline $3 / 30$ & $<1$ & $<25$ & & & \\
\hline $4 / 06$ & $<1$ & $<25$ & -0.1 & 4 & 308 \\
\hline $4 / 13$ & $<1$ & $<25$ & & & \\
\hline $4 / 20$ & $<1$ & $<25$ & & & \\
\hline $\begin{array}{l}4 / 28 \\
5 / 04\end{array}$ & $\begin{array}{l}<1 \\
<1\end{array}$ & $\begin{array}{l}<25 \\
<25\end{array}$ & 4.5 & 10 & 281 \\
\hline
\end{tabular}


1992 Environmental Report-Paducah, Part 2

Table 5.4 (continued)

\begin{tabular}{|c|c|c|c|c|c|}
\hline Date & $\begin{array}{l}\mathrm{TCE}^{b} \\
(\mu \mathrm{g} / \mathrm{L})\end{array}$ & $\begin{array}{c}{ }^{99} \mathrm{Tc}^{c} \\
(\mathrm{pCi} / \mathrm{L})\end{array}$ & $\begin{array}{c}\text { Gross alpha } \\
(\mathrm{pCi} / \mathrm{L})\end{array}$ & $\begin{array}{l}\text { Gross beta } \\
(\mathrm{pCi} / \mathrm{L})\end{array}$ & $\begin{array}{l}{ }^{222} \mathrm{Rn}{ }^{d} \\
(\mathrm{pCi} / \mathrm{L})\end{array}$ \\
\hline $5 / 13$ & $<1$ & $<25$ & 0.9 & 1 & \\
\hline $5 / 18$ & $<1$ & $<25$ & & & \\
\hline $5 / 26$ & $<1$ & $<25$ & & & \\
\hline $6 / 01$ & $<1$ & $<25$ & -2.3 & -3 & 286 \\
\hline $6 / 08$ & $<1$ & $<25$ & & & \\
\hline $6 / 15$ & $<1$ & $<25$ & & & \\
\hline $6 / 22$ & $<1$ & $<25$ & & & \\
\hline $6 / 29$ & $<1$ & $<25$ & & & \\
\hline $7 / 06$ & $<1$ & $<25$ & 0.5 & 1 & \\
\hline $7 / 13$ & $<1$ & $<25$ & & & 246 \\
\hline $7 / 20$ & $<1$ & $<25$ & & & \\
\hline $7 / 27$ & $<1$ & $<25$ & & & \\
\hline $8 / 03$ & $<1$ & $<25$ & 1.0 & -4 & 252 \\
\hline $8 / 10$ & $<1$ & $<25$ & & & \\
\hline $8 / 17$ & $<1$ & $<25$ & & & \\
\hline $8 / 24$ & $<1$ & $<25$ & & & \\
\hline $8 / 31$ & $<1$ & $<25$ & & & \\
\hline $9 / 08$ & $<1$ & $<25$ & -0.8 & -4 & 315 \\
\hline $9 / 14$ & $<1$ & $<25$ & & & \\
\hline $9 / 21$ & $<1$ & $<25$ & & & \\
\hline $9 / 28$ & $<1$ & $<25$ & & & \\
\hline $10 / 05$ & $<1$ & $<25$ & -3.0 & -3 & 319 \\
\hline $10 / 12$ & $<1$ & $<25$ & & & \\
\hline $10 / 19$ & $<1$ & $<25$ & & & \\
\hline $10 / 26$ & $<1$ & $<25$ & & & \\
\hline $11 / 02$ & $<1$ & $<25$ & 0.2 & 1 & 312 \\
\hline $11 / 10$ & $<1$ & $<25$ & 0 & 1 & \\
\hline $11 / 16$ & $<1$ & $<25$ & & & \\
\hline $11 / 23$ & $<1$ & $<25$ & & & \\
\hline $11 / 30$ & $<1$ & $<25$ & & & \\
\hline $12 / 07$ & $<1$ & $<25$ & 1.7 & 3 & 330 \\
\hline $12 / 14$ & $<1$ & $<25$ & & & \\
\hline $12 / 21$ & $<1$ & $<25$ & & & \\
\hline $12 / 28$ & $<1$ & $<25$ & & & \\
\hline \multicolumn{6}{|c|}{$R 42$} \\
\hline $1 / 07$ & $<1$ & $<25$ & & & \\
\hline $3 / 06$ & $<1$ & $<25$ & & & \\
\hline $5 / 06$ & $<1$ & $<25$ & & & \\
\hline $7 / 16$ & $<1$ & $<25$ & & & \\
\hline $9 / 03$ & $<1$ & $<25$ & & & \\
\hline $11 / 03$ & $<1$ & $<25$ & & & \\
\hline \multicolumn{6}{|c|}{$R 43$} \\
\hline $1 / 08$ & $<1$ & $<25$ & 0.8 & 18 & \\
\hline $2 / 13$ & $<1$ & $<25$ & 4.9 & -3 & \\
\hline $3 / 12$ & $<1$ & $<25$ & 12.1 & 24 & \\
\hline $4 / 14$ & $<1$ & $<25$ & $-(0.2$ & -1 & \\
\hline $5 / 18$ & $<1$ & $<25$ & 1.5 & -3 & \\
\hline $6 / 17$ & $<1$ & $<25$ & 3.3 & -0.1 & \\
\hline $7 / 16$ & $<1$ & $<25$ & -1.0 & -4 & \\
\hline $8 / 13$ & $<1$ & $<25$ & -2.3 & -4 & \\
\hline $9 / 16$ & $<1$ & $<25$ & -4.5 & -5 & \\
\hline $11 / 19$ & $<1$ & $<25$ & -1.1 & 5 & \\
\hline
\end{tabular}




\section{Environmental Report-Paducah, Part 2}

Table 5.4 (continued)

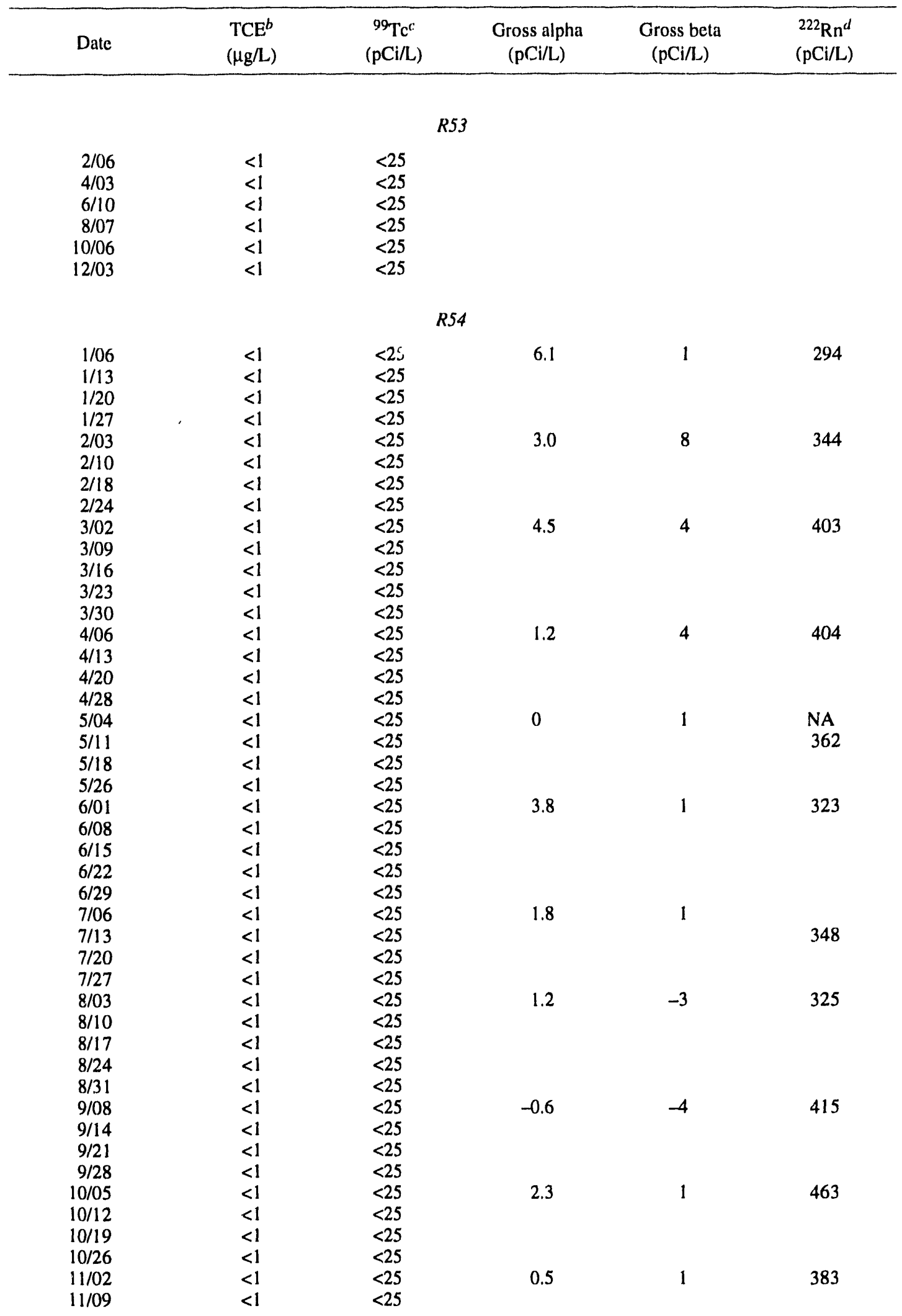

\section{5-22 Groundwater}


1992 Environmental Report-Paducah, Part 2

Table 5.4 (continued)

\begin{tabular}{|c|c|c|c|c|c|}
\hline Date & $\begin{array}{c}\mathrm{TCE}^{b} \\
(\mu \mathrm{g} / \mathrm{L})\end{array}$ & $\begin{array}{c}{ }^{99} \mathrm{Tc}^{c} \\
(\mathrm{pCi} / \mathrm{L})\end{array}$ & $\begin{array}{l}\text { Gross alpha } \\
(\mathrm{pCi} / \mathrm{L})\end{array}$ & $\begin{array}{c}\text { Gross beta } \\
(\mathrm{pCi} / \mathrm{L})\end{array}$ & $\begin{array}{l}{ }^{222} \mathrm{Rn}^{d} \\
(\mathrm{pCi} / \mathrm{L})\end{array}$ \\
\hline $11 / 16$ & $<1$ & $<25$ & & & \\
\hline $11 / 23$ & $<1$ & $<25$ & & & \\
\hline $11 / 30$ & $<1$ & $<25$ & & & \\
\hline $12 / 07$ & $<1$ & $<25$ & 4.5 & 3 & 418 \\
\hline $12 / 14$ & $<1$ & $<25$ & & & \\
\hline $12 / 21$ & $<1$ & $<25$ & & & \\
\hline $12 / 28$ & $<1$ & $<25$ & & & \\
\hline \multicolumn{6}{|c|}{$R 69$} \\
\hline $1 / 07$ & $<1$ & $<25$ & & & \\
\hline $3 / 05$ & $<1$ & $<25$ & & & \\
\hline $5 / 04$ & $<1$ & $<25$ & & & \\
\hline $7 / 16$ & $<1$ & $<25$ & & & \\
\hline $9 / 14$ & $<1$ & $<25$ & & & \\
\hline $11 / 03$ & $<1$ & $<25$ & & & \\
\hline \multicolumn{6}{|c|}{$R 72$} \\
\hline $1 / 08$ & $<1$ & $<25$ & 3.5 & -5 & \\
\hline $2 / 13$ & $<1$ & $<25$ & 3.8 & 5 & \\
\hline $3 / 16$ & $<1$ & $<25$ & 2.3 & 2 & \\
\hline $4 / 10$ & $<1$ & $<25$ & 1.2 & 1 & \\
\hline $5 / 12$ & $<1$ & $<25$ & 0.4 & 2 & \\
\hline $6 / 05$ & $<1$ & $<25$ & -0.8 & -1 & \\
\hline $7 / 10$ & $<1$ & $<25$ & -0.3 & 3 & \\
\hline $8 / 12$ & $<1$ & $<25$ & -1.1 & -2 & \\
\hline $9 / 03$ & $<1$ & $<25$ & -2.9 & -6 & \\
\hline $10 / 08$ & $<1$ & $<25$ & -1.8 & -4 & \\
\hline $11 / 09$ & $<1$ & $<25$ & 0.9 & 5 & \\
\hline $12 / 01$ & $<1$ & $<25$ & -2.5 & 0 & \\
\hline \multicolumn{6}{|c|}{$R 79$} \\
\hline $2 / 05$ & $<1$ & $<25$ & & & \\
\hline $4 / 07$ & $<1$ & $<25$ & & & \\
\hline $6 / 12$ & $<1$ & $<25$ & & & \\
\hline $8 / 20$ & $<1$ & $<25$ & & & \\
\hline $10 / 06$ & $<1$ & $<25$ & & & \\
\hline $12 / 03$ & $<1$ & $<25$ & & & \\
\hline \multicolumn{6}{|c|}{$R 82$} \\
\hline $1 / 08$ & $<5$ & $<25$ & 11.8 & 25 & \\
\hline $2 / 13$ & $<5$ & $<25$ & 0 & 3 & \\
\hline $3 / 16$ & $<5$ & $<25$ & -1.9 & 4 & \\
\hline $4 / 09$ & $<5$ & $<25$ & 1.1 & 9 & \\
\hline $5 / 12$ & $<5$ & $<25$ & -0.9 & 2 & \\
\hline $6 / 05$ & $<1$ & $<25$ & -2.0 & -1.5 & \\
\hline $7 / 10$ & $<5$ & $<25$ & -0.3 & 3 & \\
\hline $8 / 12$ & $<5$ & $<25$ & -1.4 & -5 & \\
\hline $9 / 03$ & $<5$ & $<25$ & -0.8 & -9 & \\
\hline $10 / 08$ & $<5$ & $<25$ & -9.8 & 7 & \\
\hline $11 / 05$ & $<5$ & $<25$ & 1.6 & 5 & \\
\hline $12 / 01$ & $<5$ & $<25$ & -0.6 & 5 & \\
\hline
\end{tabular}


1992 Environmental Report-Paducah, Part 2

Table 5.4 (continued)

\begin{tabular}{|c|c|c|c|c|c|}
\hline Date & $\begin{array}{l}\text { TCE }^{b} \\
(\mu \mathrm{g} / \mathrm{L})\end{array}$ & $\begin{array}{l}{ }^{99} \mathrm{Tc}^{\mathrm{r}} \\
(\mathrm{pCi} / \mathrm{L})\end{array}$ & $\begin{array}{c}\text { Gross alpha } \\
(\mathrm{pCi} / \mathrm{L})\end{array}$ & $\begin{array}{c}\text { Gross beta } \\
(\mathrm{pCi} / \mathrm{L})\end{array}$ & $\begin{array}{l}{ }^{222} \mathrm{Rn}^{d} \\
(\mathrm{pCi} / \mathrm{L})\end{array}$ \\
\hline \multicolumn{6}{|c|}{$R 83$} \\
\hline $1 / 08$ & $<1$ & $<25$ & -2.7 & -1 & \\
\hline $2 / 13$ & $<1$ & $<25$ & 11.3 & 18 & \\
\hline $3 / 16$ & $<1$ & $<25$ & 2.8 & 10 & \\
\hline $4 / 10$ & $<1$ & $<25$ & -5.0 & 0.1 & \\
\hline $5 / 12$ & $<1$ & $<25$ & -0.4 & 2 & \\
\hline $6 / 05$ & $<1$ & $<25$ & -1.0 & -0.1 & \\
\hline $7 / 10$ & $<1$ & $<25$ & -1.1 & -1 & \\
\hline $8 / 12$ & $<1$ & $<25$ & 0 & -4 & \\
\hline $9 / 03$ & $<1$ & $<25$ & -3.3 & -8 & \\
\hline $10 / 08$ & $<1$ & $<25$ & -3.3 & 4 & \\
\hline $11 / 05$ & $<1$ & $<25$ & 8.4 & 11 & \\
\hline $12 / 01$ & $<1$ & $<25$ & 1.1 & 4 & \\
\hline \multicolumn{6}{|c|}{$R 84$} \\
\hline $1 / 08$ & $<1$ & $<25$ & -1.7 & -14 & \\
\hline $2 / 13$ & $<1$ & $<25$ & 3.2 & 2 & \\
\hline $3 / 16$ & $<1$ & $<25$ & -6.4 & 0.3 & \\
\hline $4 / 10$ & $<1$ & $<25$ & 5.9 & -1 & \\
\hline $5 / 12$ & $<1$ & $<25$ & 0.4 & 3 & \\
\hline $6 / 05$ & $<1$ & $<25$ & 0 & 1.2 & \\
\hline $7 / 10$ & $<1$ & $<25$ & -2.3 & -1 & \\
\hline $8 / 12$ & $<1$ & $<25$ & 4.8 & -4 & \\
\hline $9 / 03$ & $<1$ & $<25$ & -2.3 & -7 & \\
\hline $10 / 08$ & $<1$ & $<25$ & -5.1 & -4 & \\
\hline $11 / 05$ & $<1$ & $<25$ & 7.1 & 7 & \\
\hline $12 / 01$ & $<1$ & $<25$ & 1.0 & 6 & \\
\hline \multicolumn{6}{|c|}{$R 88$} \\
\hline $2 / 05$ & $<1$ & $<25$ & & & \\
\hline $4 / 07$ & $<1$ & $<25$ & & & \\
\hline $6 / 12$ & $<1$ & $<25$ & & & \\
\hline $8 / 20$ & $<1$ & $<25$ & & & \\
\hline \multicolumn{6}{|c|}{$R 89$} \\
\hline $6 / 12$ & $<1$ & $<25$ & & & \\
\hline $8 / 20$ & $<1$ & $<25$ & & & \\
\hline \multicolumn{6}{|c|}{$R 90$} \\
\hline $6 / 12$ & $<1$ & $<25$ & & & \\
\hline $12 / 03$ & $<1$ & $<25$ & & & \\
\hline \multicolumn{6}{|c|}{$R 112$} \\
\hline $2 / 05$ & $<1$ & $<25$ & & & \\
\hline $4 / 07$ & $<1$ & $<25$ & & & \\
\hline $6 / 12$ & $<1$ & $<25$ & & & \\
\hline $8 / 20$ & $<1$ & $<25$ & & & \\
\hline $10 / 06$ & $<1$ & $<25$ & & & \\
\hline $12 / 03$ & $<1$ & $<25$ & & & \\
\hline
\end{tabular}


1992 Environmental Report-Paducah, Part 2

Table 5.4 (continued)

\begin{tabular}{|c|c|c|c|c|c|}
\hline Date & $\begin{array}{l}\mathrm{TCE}^{b} \\
(\mu \mathrm{g} / \mathrm{L})\end{array}$ & $\begin{array}{c}{ }^{99} \mathrm{Tc}^{c} \\
(\mathrm{pCi} / \mathrm{L})\end{array}$ & $\begin{array}{l}\text { Gross alpha } \\
(\mathrm{pCi} / \mathrm{L})\end{array}$ & $\begin{array}{l}\text { Gross beta } \\
(\mathrm{pCi} / \mathrm{L})\end{array}$ & $\begin{array}{l}{ }^{222} \mathrm{Rn}^{d} \\
(\mathrm{pCi} / \mathrm{L})\end{array}$ \\
\hline \multicolumn{6}{|c|}{$R / 13$} \\
\hline $\begin{array}{r}1 / 30 \\
2 / 20 \\
3 / 31 \\
4 / 29 \\
5 / 15 \\
6 / 25 \\
7 / 29 \\
8 / 28 \\
9 / 30 \\
10 / 21 \\
11 / 20 \\
12 / 08\end{array}$ & $\begin{array}{r}500 \\
650 \\
710 \\
1100 \\
1200 \\
1100 \\
1080 \\
890 \\
820 \\
1100 \\
980 \\
1000\end{array}$ & $\begin{array}{l}243 \\
339 \\
273 \\
429 \\
440 \\
717 \\
427 \\
405 \\
345 \\
345 \\
410 \\
404\end{array}$ & $\begin{array}{r}9.9 \\
2.0 \\
-2.5 \\
-3.3 \\
-2.4 \\
-1.0 \\
-3.4 \\
-0.2 \\
-2.4 \\
-1.8 \\
0.3 \\
2.3\end{array}$ & $\begin{array}{l}234 \\
244 \\
243 \\
273 \\
586 \\
291 \\
260 \\
298 \\
199 \\
237 \\
248 \\
237\end{array}$ & \\
\hline \multicolumn{6}{|c|}{$R 78$} \\
\hline $\begin{array}{r}2 / 05 \\
4 / 14 \\
6 / 12 \\
8 / 20 \\
10 / 07 \\
12 / 03\end{array}$ & $\begin{array}{l}<1 \\
<1 \\
<1 \\
<1 \\
<1 \\
<1\end{array}$ & $\begin{array}{l}<25 \\
<25 \\
<25 \\
<25 \\
<25 \\
<25\end{array}$ & & & \\
\hline \multicolumn{6}{|c|}{$R 293$} \\
\hline $\begin{array}{r}1 / 07 \\
3 / 06 \\
5 / 06 \\
7 / 16 \\
9 / 03 \\
11 / 03\end{array}$ & $\begin{array}{l}<1 \\
<1 \\
<1 \\
<1 \\
<1 \\
<1\end{array}$ & $\begin{array}{l}<25 \\
<25 \\
<25 \\
<25 \\
<25 \\
<25\end{array}$ & & & \\
\hline \multicolumn{6}{|c|}{$R 294$} \\
\hline $\begin{array}{l}1 / 07 \\
1 / 13 \\
1 / 20 \\
1 / 27\end{array}$ & $\begin{array}{l}<1 \\
<1 \\
<1 \\
<1\end{array}$ & $\begin{array}{l}<25 \\
<25 \\
<25 \\
<25\end{array}$ & 0 & -31 & 307 \\
\hline $2 / 03$ & $<1$ & $<25$ & 2.3 & 5 & 298 \\
\hline $\begin{array}{l}2 / 10 \\
2 / 18 \\
2 / 24\end{array}$ & $\begin{array}{l}<1 \\
<1 \\
<1\end{array}$ & $\begin{array}{l}<25 \\
<25 \\
<25\end{array}$ & & & \\
\hline $3 / 02$ & $<1$ & $<25$ & -3.6 & 9 & 330 \\
\hline $3 / 09$ & $<1$ & $<25$ & & & \\
\hline $\begin{array}{l}3 / 16 \\
3 / 23\end{array}$ & $\begin{array}{l}<1 \\
<1\end{array}$ & $\begin{array}{l}<25 \\
<25\end{array}$ & & & \\
\hline $3 / 30$ & $\begin{array}{l}<1 \\
<1\end{array}$ & $<25$ & & & \\
\hline $4 / 06$ & $<1$ & $<25$ & 2.4 & 6 & 362 \\
\hline $4 / 13$ & $<1$ & $<25$ & & & \\
\hline $4 / 20$ & $<1$ & $<25$ & & & \\
\hline $\begin{array}{l}4 / 28 \\
5 / 04\end{array}$ & $\begin{array}{l}<1 \\
<1\end{array}$ & $\begin{array}{l}<25 \\
<25\end{array}$ & -2.8 & 1 & 193 \\
\hline $5 / 11$ & $<1$ & $<25$ & & & \\
\hline $5 / 18$ & $<1$ & $<25$ & & & \\
\hline $5 / 26$ & $<1$ & $<25$ & & & \\
\hline
\end{tabular}


1992 Environmental Report-Paducah, Part 2

Table 5.4 (continued)

\begin{tabular}{|c|c|c|c|c|c|}
\hline Date & $\begin{array}{c}\mathrm{TCE}^{b} \\
(\mu \mathrm{g} / \mathrm{L})\end{array}$ & $\begin{array}{c}{ }^{99} \mathrm{Tc}^{\mathrm{c}} \\
(\mathrm{pCl} / \mathrm{L})\end{array}$ & $\begin{array}{c}\text { Gross alpha } \\
(\mathrm{pCi} / \mathrm{L})\end{array}$ & $\begin{array}{l}\text { Gross beta } \\
(\mathrm{pCi} / \mathrm{L})\end{array}$ & $\begin{array}{l}{ }^{222} \mathrm{Rn}^{d} \\
(\mathrm{pCi} / \mathrm{L})\end{array}$ \\
\hline $6 / 01$ & $<\left.\right|^{g}$ & $<25$ & -2.3 & 4 & 219 \\
\hline $6 / 08$ & $<1$ & $<25$ & & & \\
\hline $6 / 15$ & $<1$ & $<25$ & & & \\
\hline $6 / 22$ & $<1$ & $<25$ & & & \\
\hline $\begin{array}{l}6 / 29 \\
7 / 06\end{array}$ & $<1$ & $\begin{array}{l}<25 \\
<25\end{array}$ & 0.6 & 0.5 & \\
\hline $\begin{array}{l}7 / 100 \\
7 / 13\end{array}$ & $\begin{array}{l}<1 \\
<1\end{array}$ & $\begin{array}{l}<25 \\
<25\end{array}$ & & 0.3 & 233 \\
\hline $7 / 20$ & $<1$ & $<25$ & & & \\
\hline $7 / 27$ & $<1$ & $<25$ & & & \\
\hline $8 / 03$ & $<1$ & $<25$ & -2.7 & 2 & 226 \\
\hline $8 / 10$ & $<1$ & $<25$ & & & \\
\hline $8 / 17$ & $<1$ & $<25$ & & & \\
\hline $\begin{array}{l}8 / 24 \\
8 / 31\end{array}$ & $<1$ & $\begin{array}{l}<25 \\
<25\end{array}$ & & & \\
\hline $\begin{array}{l}8 / 31 \\
9 / 08\end{array}$ & $\begin{array}{l}<1 \\
<1\end{array}$ & $<25$ & -0.6 & -2 & 269 \\
\hline $9 / 14$ & $<1$ & $<25$ & & & \\
\hline $9 / 21$ & $<1$ & $<25$ & & & \\
\hline $9 / 28$ & $<1$ & $<25$ & & & \\
\hline $10 / 05$ & $<1$ & $<25$ & -5.3 & 2 & 294 \\
\hline $10 / 12$ & $<1$ & $<25$ & & & \\
\hline $10 / 19$ & $<1$ & $<25$ & & & \\
\hline $10 / 26$ & $<1$ & $<25$ & & & \\
\hline $11 / 02$ & $<1$ & $<25$ & 0.7 & 3 & 292 \\
\hline $11 / 09$ & $<1$ & $<25$ & & & \\
\hline $11 / 16$ & $<1$ & $<25$ & & & \\
\hline $11 / 23$ & $<1$ & $<25$ & & & \\
\hline $11 / 30$ & $<1$ & $<25$ & & & \\
\hline $12 / 14$ & $<1$ & $<25$ & & & \\
\hline $12 / 21$ & $<1$ & $<25$ & & & \\
\hline $12 / 28$ & $<1$ & $<25$ & & & \\
\hline \multicolumn{6}{|c|}{$R 302$} \\
\hline $1 / 08$ & $<1$ & $<25$ & 8.0 & 26 & \\
\hline $2 / 13$ & $<1$ & $<25$ & 3.0 & 4 & \\
\hline $3 / 16$ & $<1$ & $<25$ & 7.2 & 5 & \\
\hline $4 / 10$ & $<1$ & $<25$ & 3.4 & 1 & \\
\hline $5 / 12$ & $<1$ & $<25$ & 0 & 3 & \\
\hline $6 / 05$ & $<1$ & $<25$ & 0.3 & -1 & \\
\hline $7 / 10$ & $<1$ & $<25$ & 1.7 & 3 & \\
\hline $8 / 12$ & $<1$ & $<25$ & -1.1 & -7 & \\
\hline $9 / 03$ & $<1$ & $<25$ & -3.8 & -9 & \\
\hline $10 / 08$ & $<1$ & $<25$ & -2.9 & -4 & \\
\hline $11 / 05$ & $<1$ & $<25$ & 11.3 & 9 & \\
\hline $12 / 01$ & $<1$ & $<25$ & -1.1 & 3 & \\
\hline \multicolumn{6}{|c|}{$R 368$} \\
\hline $2 / 05$ & $<1$ & $<25$ & & & \\
\hline $4 / 14$ & $<1$ & $<25$ & & & \\
\hline $6 / 12$ & $<1$ & $<25$ & & & \\
\hline $8 / 20$ & $<1$ & $<25$ & & & \\
\hline $10 / 07$ & $<1$ & $<25$ & & & \\
\hline $12 / 03$ & $<1$ & $<25$ & & & \\
\hline
\end{tabular}


1992 Environmental Report-Paducah, Part 2

Table 5.4 (continued)

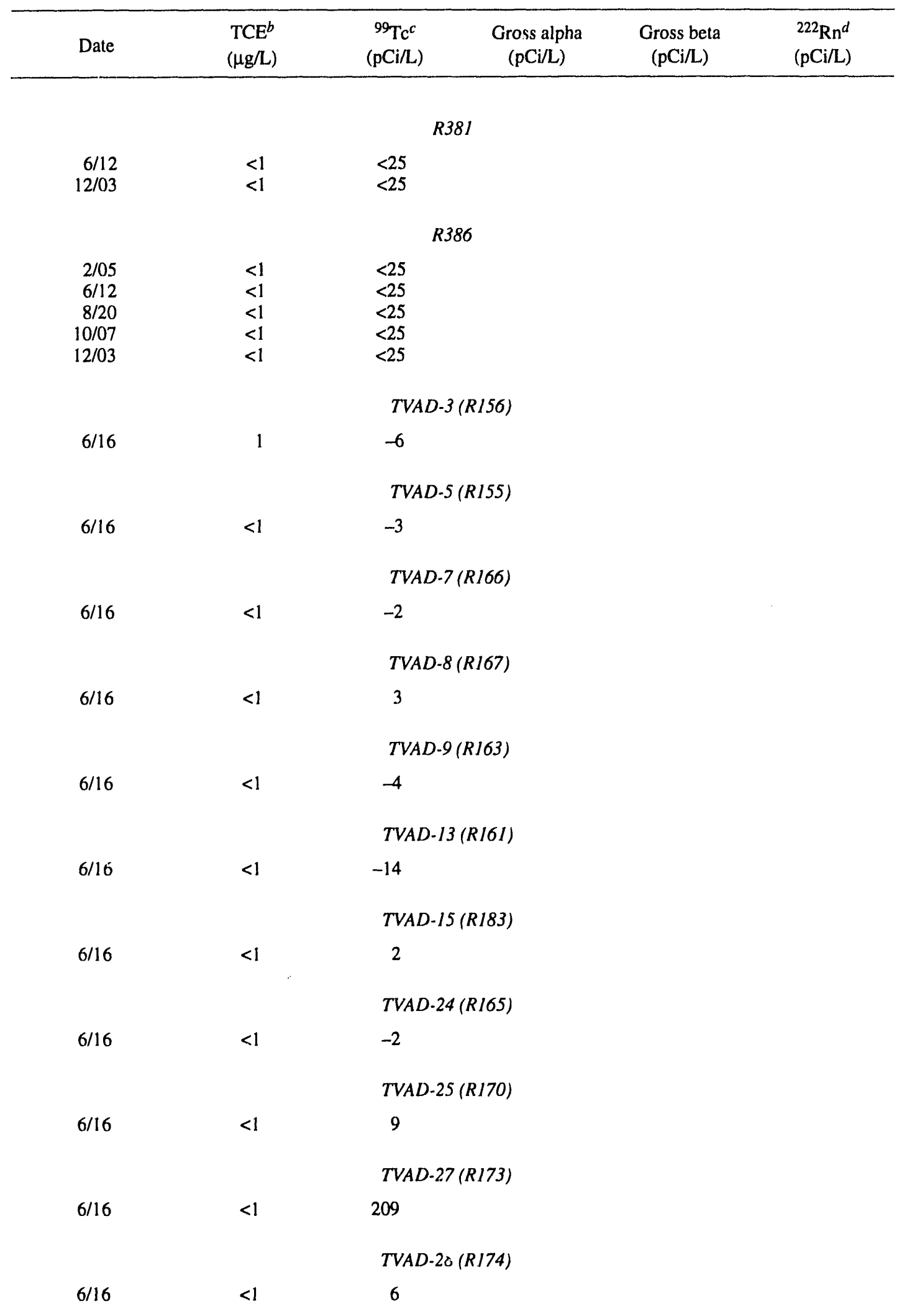


1992 Environmental Report-Paducah, Part 2

Table 5.4 (continued)

\begin{tabular}{|c|c|c|c|c|c|}
\hline Date & $\begin{array}{c}\mathrm{TCE}^{b} \\
(\mu \mathrm{g} / \mathrm{L})\end{array}$ & $\begin{array}{c}{ }^{99} \mathrm{Tc}^{c} \\
(\mathrm{pCi} / \mathrm{L})\end{array}$ & $\begin{array}{c}\text { Gross alpha } \\
(\mathrm{pCi} / \mathrm{L})\end{array}$ & $\begin{array}{l}\text { Gross beta } \\
(\mathrm{pCi} / \mathrm{L})\end{array}$ & $\begin{array}{l}{ }^{222} \mathrm{Rn}^{d} \\
(\mathrm{pCi} / \mathrm{L})\end{array}$ \\
\hline \multicolumn{6}{|c|}{ TVAD-30 (RI62) } \\
\hline $6 / 16$ & $<1$ & -6 & & & \\
\hline \multicolumn{6}{|c|}{ MW38 } \\
\hline $2 / 18$ & 4 & 40 & & & \\
\hline $4 / 22$ & 3 & 8 & -0.3 & 11 & \\
\hline $5 / 08$ & 4 & 22 & & & \\
\hline $7 / 22$ & 4 & 11 & -1.4 & 13 & \\
\hline $8 / 20$ & 4 & 20 & & & \\
\hline $10 / 22$ & 4 & 24 & & & \\
\hline $11 / 17$ & 3 & 44 & 1.6 & 18 & \\
\hline $12 / 09$ & 3 & 14 & 2.9 & 16 & \\
\hline \multicolumn{6}{|c|}{$M W 41$} \\
\hline $2 / 19$ & 19 & 21 & & & \\
\hline $4 / 22$ & 20 & 0 & 3.1 & 5 & \\
\hline $5 / 19$ & 24 & 18 & & & \\
\hline $7 / 22$ & 23 & -0.6 & 0 & 4 & \\
\hline $8 / 21$ & 20 & 0 & & & \\
\hline $10 / 22$ & 21 & 0 & & & \\
\hline $11 / 17$ & 18 & 20 & 0.2 & 4 & \\
\hline $12 / 09$ & 12 & 1 & 1.9 & 8 & \\
\hline $12 / 09$ & 1 & 2 & 3.3 & 4 & \\
\hline \multicolumn{6}{|c|}{$M W 43$} \\
\hline $2 / 19$ & 1 & 23 & & & \\
\hline $4 / 22$ & 1 & 0 & -0.2 & 3 & \\
\hline $5 / 12$ & 1 & 13 & & & \\
\hline $7 / 22$ & 2 & 3.7 & 0.3 & 1 & \\
\hline $8 / 26$ & 2 & 0 & & & \\
\hline $10 / 22$ & 2 & 8 & & & \\
\hline $11 / 17$ & 2 & 22 & 0 & 3 & \\
\hline \multicolumn{6}{|c|}{$M W 44$} \\
\hline $2 / 20$ & 30 & 0 & & & \\
\hline $4 / 22$ & 31 & 0 & -0.6 & 4 & \\
\hline $5 / 11$ & 35 & 5 & & & \\
\hline $7 / 22$ & 35 & 1 & -1.8 & 1 & \\
\hline $8 / 26$ & 31 & 5 & & & \\
\hline $10 / 27$ & 29 & 12 & & & \\
\hline $11 / 17$ & 28 & 31 & 3.8 & 9 & \\
\hline $12 / 09$ & 25 & 1 & 4.8 & 15 & \\
\hline \multicolumn{6}{|c|}{$M W 66$} \\
\hline $1 / 24$ & 1800 & 1033 & & & \\
\hline $2 / 20$ & 2500 & 1076 & 3.2 & 714 & \\
\hline $3 / 31$ & 1600 & & & & \\
\hline $3 / 3 !$ & 610 & & & & \\
\hline $3 / 31$ & 1100 & & & & \\
\hline $3 / 31$ & 1900 & & & & \\
\hline
\end{tabular}




\section{Environmental Report-Paducah, Part 2}

Table 5.4 (continued)

\begin{tabular}{cccccc}
\hline Date & $\begin{array}{c}\mathrm{TCE}^{b} \\
(\mu \mathrm{g} / \mathrm{L})\end{array}$ & $\begin{array}{c}{ }^{99} \mathrm{Tc}^{c} \\
(\mathrm{pCi} / \mathrm{L})\end{array}$ & $\begin{array}{c}\text { Gross alpha } \\
(\mathrm{pCi} / \mathrm{L})\end{array}$ & $\begin{array}{c}\text { Gross beta } \\
(\mathrm{pCi} / \mathrm{L})\end{array}$ & $\begin{array}{c}{ }^{222} \mathrm{Rn}^{d} \\
(\mathrm{pCi} / \mathrm{L})\end{array}$ \\
\hline $3 / 31$ & 2100 & & & & \\
$3 / 31$ & 2600 & & & & \\
$3 / 31$ & 2700 & 1500 & -13.9 & & \\
$4 / 29$ & 4600 & 2397 & 0 & & \\
$5 / 15$ & 4600 & 2063 & 6356 \\
$7 / 22$ & 830 & 698 & & \\
$11 / 19$ & 4200 & 1677 & 2.0 & 922 \\
$12 / 08$ & 4600 & 1948 & 20 & \\
\hline
\end{tabular}

"Administrative Consent Order/Comprehensive Environmental Response, Compensation, and Liability Act.

${ }^{b}$ Trichloroethylene.

Technetium-99.

${ }^{d}$ Radon-222.

eThese data are conditional because of the presence of a 1 -cm-diam bubble in each of the sample vials.

$f_{\text {Not analyzed. }}$

8 This value is believed to be correct. However, the surrogate for the sample for 1,2-dichloroethane-d4 was out of limits $(122 / 121)$. 
1992 Environmental Report-Paducah, Part 2

Table 5.5. Results of 1992 quarterly, semiannual, and annual effluent monitoring at solid waste management units

\begin{tabular}{|c|c|c|c|c|c|c|}
\hline Date & $\underset{\text { (units) }}{\mathrm{pH}}$ & $\begin{array}{l}\text { Conductivity } \\
(\mu \mathrm{mhos} / \mathrm{cm})\end{array}$ & $\begin{array}{c}\text { Temp } \\
\left({ }^{\circ} \mathrm{F}\right)\end{array}$ & $\begin{array}{l}\text { Turbidity } \\
(\mathrm{NTU})^{a}\end{array}$ & $\begin{array}{l}\text { Color } \\
\text { (units) }\end{array}$ & $\begin{array}{c}\text { Depth to water } \\
\text { (ft) }\end{array}$ \\
\hline \multicolumn{7}{|c|}{$M W 16$} \\
\hline $2 / 06$ & 6.0 & 441 & 55 & 6.2 & 12 & 17.81 \\
\hline $2 / 06$ & 6.2 & 447 & & & & \\
\hline $2 / 06$ & 6.2 & 441 & & & & \\
\hline $2 / 06$ & 6.3 & 443 & & & & \\
\hline $5 / 06$ & 6.6 & 476 & 55 & 1.5 & 10 & 18.25 \\
\hline $5 / 06$ & 6.6 & 462 & & & & \\
\hline $5 / 06$ & 6.6 & 461 & & & & \\
\hline $5 / 06$ & 6.6 & 463 & & & & \\
\hline $8 / 27$ & 6.2 & 470 & 66 & 3.3 & 8 & 20.58 \\
\hline $8 / 27$ & 6.3 & 471 & & & & \\
\hline $8 / 27$ & 6.3 & 472 & & & & \\
\hline $8 / 27$ & 6.4 & 474 & & & & \\
\hline $10 / 21$ & 6.6 & 469 & 61 & 3.5 & 9 & 18.12 \\
\hline $10 / 21$ & 6.9 & 467 & & & & \\
\hline $10 / 21$ & 6.7 & 468 & & & & \\
\hline $10 / 21$ & 6.7 & 472 & & & & \\
\hline \multicolumn{7}{|c|}{$M W I 7$} \\
\hline $2 / 06$ & 6.8 & 1143 & 16.5 & 19.5 & 11 & 51.15 \\
\hline $2 / 06$ & 6.7 & 1135 & & & & \\
\hline $2 / 06$ & 6.7 & 1125 & & & & \\
\hline $2 / 06$ & 6.7 & 1137 & & & & \\
\hline $5 / 06$ & 6.8 & 1285 & 62 & 11 & 14 & 54.58 \\
\hline $5 / 06$ & 6.7 & 1272 & & & & \\
\hline $5 / 06$ & 6.8 & 1280 & & & & \\
\hline $5 / 06$ & 6.8 & 1273 & & & & \\
\hline $8 / 18$ & 7.2 & 1420 & 76 & 19 & 10 & 51.50 \\
\hline $8 / 18$ & 7.4 & 1430 & & & & \\
\hline $8 / 18$ & 7.4 & 1420 & & & & \\
\hline $8 / 18$ & 7.4 & 1420 & & & & \\
\hline $10 / 20$ & 7.0 & 1224 & 57 & 20 & 9 & 52.33 \\
\hline $10 / 20$ & 7.0 & 1288 & & & & \\
\hline $10 / 20$ & 7.0 & 1294 & & & & \\
\hline $10 / 20$ & 7.0 & 1390 & & & & \\
\hline \multicolumn{7}{|c|}{$M W 18$} \\
\hline $2 / 05$ & 7.1 & 1271 & 62 & 44 & 34 & 33.10 \\
\hline $2 / 05$ & 7.1 & 1269 & & & & \\
\hline $2 / 05$ & 7.1 & 1278 & & & & \\
\hline $2 / 05$ & 7.1 & 1293 & & & & \\
\hline $5 / 05$ & 7.1 & 1370 & 61 & 46 & 30 & 33.28 \\
\hline $5 / 05$ & 7.1 & 1380 & & & & \\
\hline $5 / 05$ & 7.1 & 1380 & & & & \\
\hline $5 / 05$ & 7.2 & 1380 & & & & \\
\hline $8 / 18$ & 6.8 & 1400 & 61 & 34 & 23 & 34.23 \\
\hline $8 / 18$ & 6.9 & 1400 & & & & \\
\hline $8 / 18$ & 7.1 & 1400 & & & & \\
\hline $8 / 18$ & 7.2 & 1410 & & & & \\
\hline $10 / 20$ & 7.2 & 1279 & 61 & 66 & 17 & 35.10 \\
\hline $10 / 20$ & 7.3 & 1270 & & & & \\
\hline
\end{tabular}


1992 Environmental Report-Paducah, Part 2

Table 5.5 (continued)

\begin{tabular}{|c|c|c|c|c|c|c|}
\hline Date & $\begin{array}{c}\mathrm{pH} \\
\text { (units) }\end{array}$ & $\begin{array}{l}\text { Conductivity } \\
(\mu \mathrm{mhos} / \mathrm{cm})\end{array}$ & $\begin{array}{l}\text { Temp } \\
\left({ }^{\circ} \mathrm{F}\right)\end{array}$ & $\begin{array}{l}\text { Turbidity } \\
(\text { NTU) }\end{array}$ & $\begin{array}{l}\text { Color } \\
\text { (units) }\end{array}$ & $\begin{array}{c}\text { Depth to water } \\
\text { (ft) }\end{array}$ \\
\hline $10 / 20$ & 7.3 & 1265 & & & & \\
\hline $10 / 20$ & 7.3 & 1268 & & & & \\
\hline \multicolumn{7}{|c|}{$M W 19$} \\
\hline $2 / 06$ & 7.2 & 223 & 60 & 9.0 & 22 & 40.15 \\
\hline $2 / 07$ & 6.6 & 225 & & & & \\
\hline $2 / 07$ & 6.8 & 225 & & & & \\
\hline $2 / 07$ & 6.7 & 225 & & & & \\
\hline $5 / 07$ & 7.2 & 212 & 70 & 4.4 & 11 & 32.29 \\
\hline $5 / 07$ & 7.2 & 211 & & & & \\
\hline $5 / 07$ & 7.3 & 211 & & & & \\
\hline $5 / 07$ & 7.3 & 214 & & & & \\
\hline $8 / 20$ & 6.6 & 239 & 69 & 27 & 12 & 40.40 \\
\hline $8 / 20$ & 6.8 & 230 & & & & \\
\hline $8 / 20$ & 7.0 & 228 & & & & \\
\hline $8 / 20$ & 7.0 & 225 & & & & \\
\hline $10 / 21$ & 7.1 & 226 & 65 & 18 & 7 & 41.24 \\
\hline $10 / 21$ & 7.3 & 227 & & & & \\
\hline $10 / 21$ & 7.4 & 222 & & & & \\
\hline $10 / 21$ & 7.5 & 221 & & & & \\
\hline $11 / 10$ & 7.6 & & 51 & & & 41.28 \\
\hline \multicolumn{7}{|c|}{$M W 20$} \\
\hline $2 / 12$ & 6.6 & 322 & 55 & 110 & 7 & \\
\hline $2 / 12$ & 6.4 & 324 & & & & \\
\hline $2 / 12$ & 6.4 & 325 & & & & \\
\hline $2 / 12$ & 6.4 & 325 & & & & \\
\hline $5 / 13$ & 6.5 & 324 & 63 & 33 & 12 & $N A^{b}$ \\
\hline $5 / 13$ & 6.4 & 324 & & & & \\
\hline $5 / 13$ & 6.4 & 324 & & & & \\
\hline $5 / 13$ & 6.4 & 323 & & & & \\
\hline $8 / 17$ & 6.2 & 330 & 63 & 23 & 10 & \\
\hline $8 / 17$ & 6.1 & 331 & & & & \\
\hline $8 / 17$ & 6.1 & 331 & & & & \\
\hline $8 / 17$ & 6.1 & 3.31 & & & & \\
\hline \multicolumn{7}{|c|}{$M W 2 I$} \\
\hline $3 / 17$ & 6.3 & 1550 & 61 & 4.7 & 16 & 46.52 \\
\hline $3 / 17$ & 6.4 & 1540 & & & & \\
\hline $3 / 17$ & 6.5 & NA & & & & \\
\hline $3 / 17$ & 6.5 & 1550 & & & & \\
\hline $6 / 04$ & 6.6 & 1440) & 64 & 0.6 & 25 & 45.18 \\
\hline $6 /(1) 4$ & 6.7 & 1450 & & & & \\
\hline $6 /(1) 4$ & 6.7 & 1460 & & & & \\
\hline $6 / 04$ & 6.7 & 1450 & & & & \\
\hline $9 /(02$ & 6.4 & 1560 & 73 & 1.5 & 9 & 46.83 \\
\hline $9 / 02$ & 6.5 & 1560 & & & & \\
\hline $9 / 02$ & 6.4 & 1560 & & & & \\
\hline $9 /(02$ & 6.5 & 1560 & & & & \\
\hline $12 / 01$ & 6.7 & 1590 & 57 & 1.6 & 4 & 47.27 \\
\hline $12 / 01$ & 6.8 & 1590 & & & & \\
\hline $12 / 01$ & 6.6 & 1590 & & & & \\
\hline$|2 / 0|$ & 6.6 & 1600 & & & & \\
\hline
\end{tabular}


1992 Environmental Report-Paducah, Part 2

Table 5.5 (continued)

\begin{tabular}{|c|c|c|c|c|c|c|}
\hline Date & $\begin{array}{c}\mathrm{pH} \\
\text { (units) }\end{array}$ & $\begin{array}{l}\text { Conductivity } \\
(\mu \mathrm{mhos} / \mathrm{cm})\end{array}$ & $\begin{array}{l}\text { Temp } \\
\left({ }^{\circ} \mathrm{F}\right)\end{array}$ & $\begin{array}{l}\text { Turbidity } \\
\text { (NTU) }^{a}\end{array}$ & $\begin{array}{l}\text { Color } \\
\text { (units) }\end{array}$ & $\begin{array}{l}\text { Depth to water } \\
\text { (ft) }\end{array}$ \\
\hline \multicolumn{7}{|c|}{$M W 21$} \\
\hline $3 / 17$ & 6.2 & 331 & 62 & 1.4 & 8 & 44.48 \\
\hline $3 / 17$ & 6.1 & 327 & & & & \\
\hline $3 / 17$ & 6.1 & 327 & & & & \\
\hline $3 / 17$ & 6.1 & 333 & & & & \\
\hline $6 / 02$ & 6.0 & 343 & 68 & 0.2 & 14 & 43.37 \\
\hline $6 / 02$ & 6.1 & 342 & & & & \\
\hline $6 / 02$ & 6.1 & 343 & & & & \\
\hline $6 / 02$ & 6.1 & 341 & & & & \\
\hline $9 / 03$ & 6.1 & 338 & 77 & 1.4 & 7 & 44.95 \\
\hline $9 / 03$ & 6.1 & 336 & & & & \\
\hline $9 / 03$ & 6.1 & 336 & & & & \\
\hline $9 / 03$ & 6.1 & 339 & & & & \\
\hline $10 / 21$ & 6.2 & & 63 & & & 45.63 \\
\hline $12 / 01$ & 6.4 & 348 & 56 & 1.7 & 7 & 45.34 \\
\hline $12 / 01$ & 6.4 & 349 & & & & \\
\hline $12 / 01$ & 6.4 & 349 & & & & \\
\hline $12 / 01$ & 6.4 & 347 & & & & \\
\hline \multicolumn{7}{|c|}{$M W 23$} \\
\hline $2 / 01$ & 6.4 & 372 & 55 & 7.5 & 21 & 16.70 \\
\hline $8 / 17$ & 6.7 & 329 & 66 & 3.4 & 18 & 16.70 \\
\hline $8 / 17$ & 6.4 & 542 & & & & \\
\hline $8 / 17$ & 5.5 & 566 & & & & \\
\hline $8 / 17$ & 5.6 & 572 & & & & \\
\hline \multicolumn{7}{|c|}{$M W 24$} \\
\hline $2 / 01$ & 6.1 & 219 & 55 & 14 & 17 & 11.20 \\
\hline $8 / 11$ & 7.0 & 206 & 69 & 23 & 27 & 10.30 \\
\hline $8 / 11$ & 6.4 & 220 & & & & \\
\hline $8 / 11$ & 6.4 & 207 & & & & \\
\hline $8 / 11$ & 6.4 & 203 & & & & \\
\hline \multicolumn{7}{|c|}{$M W 26$} \\
\hline $2 / 01$ & 7.4 & 0.16 & 56 & 95 & 65 & 28.87 \\
\hline $8 / 11$ & $\mathrm{NA}$ & & & & & \\
\hline $8 / 11$ & 7.3 & 275 & 73 & 108 & 180 & 32.59 \\
\hline $8 / 11$ & $\mathrm{NA}$ & & & & & \\
\hline $8 / 11$ & NA & & & & & \\
\hline \multicolumn{7}{|c|}{$M W 27$} \\
\hline $2 / 01$ & 6.6 & 0.14 & 56 & 15 & 37 & 19.25 \\
\hline $8 / 11$ & 6.3 & 431 & 74 & 42 & 16 & 19.07 \\
\hline $8 / 11$ & 6.3 & 462 & & & & \\
\hline $8 / 11$ & 6.4 & 454 & & & & \\
\hline $8 / 11$ & 6.5 & 445 & & & & \\
\hline \multicolumn{7}{|c|}{$M W 29$} \\
\hline $1 / 31$ & 4.2 & 502 & 49 & 2.3 & 12 & 7.31 \\
\hline
\end{tabular}


1992 Environmental Report-Paducah, Part 2

Table 5.5 (continued)

\begin{tabular}{|c|c|c|c|c|c|c|}
\hline Date & $\begin{array}{c}\mathrm{pH} \\
\text { (units) }\end{array}$ & $\begin{array}{l}\text { Conductivity } \\
(\mu \mathrm{mhos} / \mathrm{cm})\end{array}$ & $\begin{array}{l}\text { Temp } \\
\left({ }^{\circ} \mathrm{F}\right)\end{array}$ & $\begin{array}{c}\text { Turbidity } \\
\left(^{(N T U)^{a}}\right.\end{array}$ & $\begin{array}{l}\text { Color } \\
\text { (units) }\end{array}$ & $\begin{array}{c}\text { Depth to water } \\
\text { (ft) }\end{array}$ \\
\hline \multicolumn{7}{|c|}{ MW38 } \\
\hline $2 / 18$ & 6.2 & 441 & 59 & 3.7 & 9 & 59.72 \\
\hline $2 / 18$ & 6.3 & 438 & & & & \\
\hline $2 / 18$ & 6.3 & 437 & & & & \\
\hline $2 / 18$ & 6.3 & 438 & & & & \\
\hline $5 / 08$ & 6.3 & 446 & 59 & 2.7 & 13 & 58.49 \\
\hline $5 / 08$ & 6.3 & 430 & & & & \\
\hline $5 / 08$ & 6.3 & 438 & & & & \\
\hline $5 / 08$ & 6.3 & 424 & & & & \\
\hline $8 / 20$ & 6.6 & 443 & 60 & 1.7 & 11 & 59.88 \\
\hline $8 / 20$ & 6.6 & 443 & & & & \\
\hline $8 / 20$ & 6.6 & 444 & & & & \\
\hline $8 / 20$ & 6.6 & 440 & & & & \\
\hline $8 / 20$ & 6.5 & 721 & & & & 60.97 \\
\hline $10 / 22$ & 6.4 & 439 & 59 & 3.2 & 10 & 60.97 \\
\hline $10 / 22$ & 6.4 & 437 & & & & \\
\hline $10 / 22$ & 6.4 & 442 & & & & \\
\hline $10 / 22$ & 6.4 & 443 & & & & \\
\hline \multicolumn{7}{|c|}{ MW39 } \\
\hline $2 / 18$ & 6.5 & 711 & 59 & 16 & 12 & 56.58 \\
\hline $2 / 18$ & 6.5 & 719 & & & & \\
\hline $2 / 18$ & 6.5 & 720 & & & & \\
\hline $2 / 18$ & 6.5 & 719 & & & & \\
\hline $5 / 08$ & 6.5 & 661 & 59 & 6.6 & 16 & 55.53 \\
\hline $5 / 08$ & 6.5 & 665 & & & & \\
\hline $5 / 08$ & 6.5 & 678 & & & & \\
\hline $5 / 08$ & 6.6 & 670 & & & & \\
\hline $8 / 20$ & 6.5 & 714 & 60 & 16 & 9 & 56.95 \\
\hline $8 / 20$ & 6.5 & 715 & & & & \\
\hline $8 / 20$ & 6.5 & 718 & & & & \\
\hline $10 / 22$ & 6.5 & 710 & 59 & 17 & 13 & 57.97 \\
\hline $10 / 22$ & 6.5 & 717 & & & & \\
\hline $10 / 22$ & 6.5 & 718 & & & & \\
\hline $10 / 22$ & 6.5 & 720 & & & & \\
\hline \multicolumn{7}{|c|}{$M W 40$} \\
\hline $2 / 18$ & 6.4 & 335 & 59 & 0.6 & 3 & 57.14 \\
\hline $2 / 18$ & 6.3 & 331 & & & & \\
\hline $2 / 18$ & 6.3 & 330 & & & & \\
\hline $2 / 18$ & 6.3 & 329 & & & & \\
\hline $5 / 12$ & 6.2 & 333 & 59 & 0.4 & 7 & 55.78 \\
\hline $5 / 12$ & 6.2 & 329 & & & & \\
\hline $5 / 12$ & 6.2 & 330 & & & & \\
\hline $5 / 12$ & 6.2 & 329 & & & & \\
\hline $8 / 21$ & 6.2 & 336 & 59 & 0.8 & 12 & 57.50 \\
\hline $8 / 21$ & 6.2 & 331 & & & & \\
\hline $8 / 21$ & 6.2 & 335 & & & & \\
\hline $8 / 21$ & 6.2 & 330 & & & & \\
\hline $10 / 23$ & 6.3 & 324 & 59 & 1.3 & 13 & 58.34 \\
\hline $10 / 23$ & 6.3 & 323 & & & & \\
\hline $10 / 23$ & 6.3 & 323 & & & & \\
\hline $10 / 23$ & 6.3 & 323 & & & & \\
\hline
\end{tabular}


Table 5.5 (continued)

\begin{tabular}{|c|c|c|c|c|c|c|}
\hline Date & $\begin{array}{c}\mathrm{pH} \\
\text { (units) }\end{array}$ & $\begin{array}{l}\text { Conductivity } \\
(\mu \mathrm{mhos} / \mathrm{cm})\end{array}$ & $\begin{array}{l}\text { Temp } \\
\left({ }^{\circ} \mathbf{F}\right)\end{array}$ & $\begin{array}{l}\text { Turbidity } \\
\text { (NTU) }^{a}\end{array}$ & $\begin{array}{l}\text { Color } \\
\text { (units) }\end{array}$ & $\begin{array}{c}\text { Depth to water } \\
(\mathrm{ft})\end{array}$ \\
\hline \multicolumn{7}{|c|}{$M W 4 I$} \\
\hline $\begin{array}{l}2 / 19 \\
2 / 19 \\
2 / 19 \\
2 / 19\end{array}$ & $\begin{array}{l}6.1 \\
6.1 \\
6.1 \\
6.1\end{array}$ & $\begin{array}{l}353 \\
352 \\
351 \\
354\end{array}$ & 59 & 3.7 & 2 & 54.21 \\
\hline $5 / 19$ & 6.4 & 352 & 59 & 3.6 & 13 & 52.90 \\
\hline $5 / 19$ & 6.5 & 352 & & & & \\
\hline $5 / 19$ & 6.5 & 354 & & & & \\
\hline $5 / 19$ & 6.5 & 353 & & & & \\
\hline $8 / 21$ & 6.2 & 362 & 60 & 6.8 & 10 & 54.27 \\
\hline $8 / 21$ & 6.2 & 363 & & & & \\
\hline $8 / 21$ & 6.2 & 363 & & & & \\
\hline $8 / 21$ & 6.2 & 366 & & & & \\
\hline $10 / 22$ & 6.2 & 353 & 60 & 10 & 11 & 59.09 \\
\hline $10 / 22$ & 6.2 & 352 & & & & \\
\hline $10 / 22$ & 6.2 & 353 & & & & \\
\hline $10 / 22$ & 6.2 & 354 & & & & \\
\hline \multicolumn{7}{|c|}{$M W 42$} \\
\hline $2 / 20$ & 6.2 & 676 & 60 & 4.3 & 7 & 38.73 \\
\hline $2 / 20$ & 6.2 & 696 & & & & \\
\hline $2 / 20$ & 6.2 & 699 & & & & \\
\hline $2 / 20$ & 6.2 & 705 & & & & \\
\hline $5 / 19$ & 6.5 & 687 & 60 & 1.6 & 13 & 37.26 \\
\hline $5 / 19$ & 6.5 & 707 & & & & \\
\hline $5 / 19$ & 6.5 & 705 & & & & \\
\hline $5 / 19$ & 6.4 & 702 & & & & \\
\hline $8 / 26$ & 6.6 & 688 & 60 & 5.0 & 9 & 38.69 \\
\hline $8 / 26$ & 6.4 & 710 & & & & \\
\hline $8 / 26$ & 6.4 & 709 & & & & \\
\hline $8 / 26$ & 6.4 & 707 & & & & \\
\hline $10 / 22$ & 6.7 & 671 & 60 & 4.7 & 10 & 39.43 \\
\hline $10 / 22$ & 6.4 & 684 & & & & \\
\hline $10 / 22$ & 6.4 & 690 & & & & \\
\hline $10 / 22$ & 6.4 & 699 & & & & \\
\hline \multicolumn{7}{|c|}{$M W 43$} \\
\hline $2 / 19$ & 6.2 & 303 & 57 & 0.7 & 5 & 49.23 \\
\hline $2 / 19$ & 6.2 & 302 & & & & \\
\hline $2 / 19$ & 6.2 & 302 & & & & \\
\hline $2 / 19$ & 6.2 & 302 & & & & \\
\hline $5 / 12$ & 6.3 & 310 & 58 & 0.7 & 9 & 47.54 \\
\hline $5 / 12$ & 6.2 & 310 & & & & \\
\hline $5 / 12$ & 6.2 & 311 & & & & \\
\hline $5 / 12$ & 6.3 & 310 & & & & \\
\hline $8 / 26$ & 6.5 & 309 & 58 & 2.3 & 9 & 49.26 \\
\hline $8 / 26$ & 6.4 & 308 & & & & \\
\hline $8 / 26$ & 6.4 & 308 & & & & \\
\hline $10 / 22$ & 6.2 & 308 & 58 & 1.6 & 5 & 50.00 \\
\hline $10 / 22$ & 6.4 & 308 & & & & \\
\hline $10 / 22$ & 6.2 & 308 & & & & \\
\hline $10 / 22$ & 6.3 & 309 & & & & \\
\hline
\end{tabular}


Table 5.5 (continued)

\begin{tabular}{|c|c|c|c|c|c|c|}
\hline Date & $\underset{\text { (units) }}{\mathrm{pH}}$ & $\begin{array}{l}\text { Conductivity } \\
(\mu \mathrm{mhos} / \mathrm{cm})\end{array}$ & $\begin{array}{l}\text { Temp } \\
\left({ }^{\circ} \mathrm{F}\right)\end{array}$ & $\begin{array}{l}\text { Turbidity } \\
\text { (NTU) }^{a}\end{array}$ & $\begin{array}{l}\text { Color } \\
\text { (units) }\end{array}$ & $\begin{array}{c}\text { Depth to water } \\
\text { (ft) }\end{array}$ \\
\hline \multicolumn{7}{|c|}{ MW44 } \\
\hline $\begin{array}{l}2 / 20 \\
2 / 20 \\
2 / 20 \\
2 / 20\end{array}$ & $\begin{array}{l}6.0 \\
6.1 \\
6.1 \\
6.1\end{array}$ & $\begin{array}{l}373 \\
372 \\
370 \\
371\end{array}$ & 59 & 1.3 & 6 & 78.81 \\
\hline $5 / 11$ & 6.1 & 375 & 59 & 1.1 & 9 & 77.09 \\
\hline $5 / 11$ & 6.2 & 373 & & & & \\
\hline $5 / 11$ & 6.2 & 370 & & & & \\
\hline $5 / 11$ & 6.2 & 369 & & & & \\
\hline $8 / 26$ & 6.6 & 380 & 60 & 0.6 & 7 & 78.51 \\
\hline $8 / 26$ & 6.5 & 381 & & & & \\
\hline $8 / 26$ & 6.5 & 380 & & & & \\
\hline $8 / 26$ & 6.5 & 381 & & & & \\
\hline $10 / 27$ & 5.9 & 376 & 59 & 0.7 & 7 & 78.86 \\
\hline $10 / 27$ & 5.9 & 375 & & & & \\
\hline $10 / 27$ & 5.9 & 375 & & & & \\
\hline $10 / 27$ & 5.9 & 375 & & & & \\
\hline \multicolumn{7}{|c|}{$M W 46$} \\
\hline $3 / 04$ & 6.4 & 213 & 60 & 17.0 & 16 & 51.25 \\
\hline $3 / 04$ & 6.4 & 216 & & & & \\
\hline $3 / 04$ & 6.4 & 218 & & & & \\
\hline $3 / 04$ & 6.4 & 209 & & & & \\
\hline $5 / 27$ & 6.3 & 240 & 60 & 4.5 & 10 & 50.00 \\
\hline $5 / 27$ & 6.4 & 238 & & & & \\
\hline $5 / 27$ & 6.3 & 228 & & & & \\
\hline $5 / 27$ & 6.3 & 228 & & & & \\
\hline $9 / 09$ & 6.3 & 237 & 61 & 15 & 26 & 51.52 \\
\hline $9 / 09$ & 6.3 & 235 & & & & \\
\hline $9 / 09$ & 6.3 & 235 & & & & \\
\hline $9 / 09$ & 6.3 & 233 & & & & \\
\hline $12 / 11$ & 6.1 & 239 & 59 & 7.2 & 17 & 52.00 \\
\hline $12 / 11$ & 6.1 & 237 & & & & \\
\hline $12 / 11$ & 6.2 & 236 & & & & \\
\hline $12 / 11$ & 6.1 & 235 & & & & \\
\hline \multicolumn{7}{|c|}{$M W 47$} \\
\hline $3 / 20$ & 7.8 & NA & 60 & 2400 & 47 & 10.00 \\
\hline $6 / 26$ & 7.8 & 1630 & 69 & 600 & 18 & NA \\
\hline $9 / 11$ & 5.4 & 1710 & 65 & 27 & 19 & 16.86 \\
\hline $12 / 11$ & 7.1 & 1510 & 57 & 130 & 6 & 14.72 \\
\hline \multicolumn{7}{|c|}{$M W 48$} \\
\hline $3 / 04$ & 6.6 & 196 & 59 & 1.7 & 6 & 52.20 \\
\hline $3 / 04$ & 6.5 & 195 & & & & \\
\hline $3 / 04$ & 6.4 & 195 & & & & \\
\hline $3 / 04$ & 6.4 & 196 & & & & \\
\hline $5 / 27$ & 6.3 & 205 & 59 & 2.5 & 11 & 51.16 \\
\hline $5 / 27$ & 6.3 & 205 & & & & \\
\hline $5 / 27$ & 6.3 & 204 & & & & \\
\hline $5 / 27$ & 6.3 & 204 & & & & \\
\hline $9 / 09$ & 6.1 & 208 & 60 & 1.2 & 14 & 52.36 \\
\hline
\end{tabular}


Table 5.5 (continued)

\begin{tabular}{|c|c|c|c|c|c|c|}
\hline Date & $\begin{array}{c}\mathrm{pH} \\
\text { (units) }\end{array}$ & $\begin{array}{l}\text { Conductivity } \\
(\mu \mathrm{mnos} / \mathrm{cm})\end{array}$ & $\begin{array}{c}\text { Temp } \\
\left({ }^{\circ} \mathrm{F}\right) \\
\end{array}$ & $\begin{array}{c}\text { Turbidity } \\
\text { (NTU) }^{a}\end{array}$ & $\begin{array}{c}\text { Color } \\
\text { (units) }\end{array}$ & $\begin{array}{c}\text { Depth to water } \\
\text { (ft) }\end{array}$ \\
\hline $9 / 09$ & 6.1 & 204 & \multirow{7}{*}{58} & \multirow{7}{*}{2.0} & \multirow{7}{*}{7} & \multirow{7}{*}{52.87} \\
\hline $9 / 09$ & 6.1 & 204 & & & & \\
\hline $9 / 09$ & 6.1 & 203 & & & & \\
\hline $12 / 11$ & 6.1 & 205 & & & & \\
\hline $12 / 11$ & 6.1 & 202 & & & & \\
\hline $12 / 11$ & 6.0 & 200 & & & & \\
\hline $12 / 11$ & 6.1 & 200 & & & & \\
\hline \multicolumn{7}{|c|}{ MW50 } \\
\hline $1 / 29$ & 6.3 & 167 & 59 & 25.5 & 3 & 49.29 \\
\hline $1 / 29$ & 6.3 & 166 & & & & \\
\hline $1 / 29$ & 6.2 & 165 & & & & \\
\hline $1 / 29$ & 6.2 & 164 & & & & \\
\hline $4 / 03$ & 6.1 & 149 & 59 & 6.0 & 22 & 48.21 \\
\hline $4 / 03$ & 6.1 & 152 & & & & \\
\hline $4 / 03$ & 6.1 & 151 & & & & \\
\hline $4 / 03$ & 6.1 & 152 & & & & \\
\hline $7 / 28$ & 6.6 & 168 & 60 & 15 & 26 & 48.35 \\
\hline $7 / 28$ & 6.5 & 163 & & & & \\
\hline $7 / 28$ & 6.4 & 163 & & & & \\
\hline $7 / 29$ & 6.4 & 166 & & & & \\
\hline $10 / 07$ & 5.9 & 163 & 59 & 18 & 9 & 49.30 \\
\hline $10 / 07$ & 5.9 & 161 & & & & \\
\hline $10 / 07$ & 5.9 & 160 & & & & \\
\hline $10 / 07$ & 5.9 & 160 & & & & \\
\hline \multicolumn{7}{|c|}{ MWSI } \\
\hline $1 / 29$ & 6.1 & 184 & 59 & 15.5 & 2 & 48.79 \\
\hline $\begin{array}{l}1 / 29 \\
\end{array}$ & 6.1 & 180 & & & & \\
\hline $1 / 29$ & 6.0 & 178 & & & & \\
\hline $1 / 29$ & 6.0 & 177 & & & & \\
\hline $4 / 07$ & 6.1 & 173 & 60 & 6.1 & 21 & 47.75 \\
\hline $4 / 07$ & 6.1 & 173 & & & & \\
\hline $4 / 07$ & 6.1 & 171 & & & & \\
\hline $4 / 07$ & 6.1 & 171 & & & & \\
\hline $7 / 23$ & 6.4 & 173 & 61 & 5.2 & 17 & 47.86 \\
\hline $7 / 23$ & 6.4 & 170 & & & & \\
\hline $7 / 23$ & 6.3 & 168 & & & & \\
\hline $7 / 23$ & 6.3 & 170 & & & & \\
\hline $10 / 07$ & 6.1 & 186 & 60 & 13 & 6 & 49.00 \\
\hline $10 / 07$ & 6.0 & 181 & & & & \\
\hline $10 / 07$ & 6.0 & 179 & & & & \\
\hline $10 / 07$ & 6.0 & 177 & & & & \\
\hline \multicolumn{7}{|c|}{ MW52 } \\
\hline $1 / 24$ & 6.2 & 198 & 60 & 14 & 6 & 47.65 \\
\hline $1 / 24$ & 6.2 & 196 & & & & \\
\hline $1 / 24$ & 6.2 & 184 & & & & \\
\hline $1 / 24$ & 6.2 & 185 & & & & \\
\hline $4 / 03$ & 6.3 & 182 & 60 & 8.0 & 15 & 46.62 \\
\hline $4 / 03$ & 6.3 & 184 & & & & \\
\hline $4 / 03$ & 6.3 & 183 & & & & \\
\hline $4 / 03$ & 6.3 & 184 & & & & \\
\hline $7 / 23$ & 5.8 & 177 & 61 & 1.5 & 6 & 49.70 \\
\hline
\end{tabular}


1992 Environmental Report-Paducah, Part 2

Table 5.5 (continued)

\begin{tabular}{|c|c|c|c|c|c|c|}
\hline Datc & $\underset{\text { (units) }}{\mathrm{pH}}$ & $\begin{array}{l}\text { Conductivity } \\
(\mu \mathrm{mhos} / \mathrm{cm})\end{array}$ & $\begin{array}{c}\text { Temp } \\
\left({ }^{\circ} \mathrm{F}\right)\end{array}$ & $\begin{array}{l}\text { Turbidity } \\
\text { (N'TU) }\end{array}$ & $\begin{array}{l}\text { Color } \\
\text { (units) }\end{array}$ & $\begin{array}{c}\text { Depth to water } \\
\text { (it) }\end{array}$ \\
\hline $7 / 23$ & 6.7 & 184 & \multirow[t]{4}{*}{61} & \multirow[t]{4}{*}{7.0} & \multirow[t]{4}{*}{22} & \multirow[t]{4}{*}{46.81} \\
\hline $7 / 23$ & 6.6 & 180 & & & & \\
\hline $7 / 23$ & 6.5 & 179 & & & & \\
\hline $7 / 23$ & 6.4 & 182 & & & & \\
\hline $10 / 13$ & 6.1 & 188 & \multirow[t]{4}{*}{60} & \multirow[t]{4}{*}{10} & \multirow[t]{4}{*}{17} & \multirow[t]{4}{*}{47.71} \\
\hline $10 / 13$ & 6.1 & 185 & & & & \\
\hline $10 / 13$ & 6.1 & 186 & & & & \\
\hline $10 / 13$ & 6.1 & 185 & & & & \\
\hline \multicolumn{7}{|c|}{$M W 53$} \\
\hline $1 / 24$ & 6.0 & 178 & \multirow[t]{4}{*}{59} & \multirow[t]{4}{*}{1.5} & \multirow[t]{4}{*}{2} & \multirow[t]{4}{*}{50.53} \\
\hline $1 / 24$ & 6.0 & 171 & & & & \\
\hline $1 / 24$ & 6.0 & 170 & & & & \\
\hline $1 / 24$ & 6.0 & 170 & & & & \\
\hline $4 / 08$ & 6.2 & 173 & \multirow[t]{7}{*}{60} & \multirow[t]{7}{*}{2.0} & \multirow[t]{7}{*}{15} & \multirow[t]{7}{*}{49.30} \\
\hline $4 / 08$ & 6.2 & 170 & & & & \\
\hline $4 / 08$ & 6.2 & 166 & & & & \\
\hline $4 / 08$ & 6.1 & 169 & & & & \\
\hline $7 / 23$ & 5.8 & 169 & & & & \\
\hline $7 / 23$ & 5.8 & 168 & & & & \\
\hline $7 / 23$ & 5.8 & 169 & & & & \\
\hline $10 / 13$ & 6.3 & 188 & \multirow[t]{4}{*}{ 60) } & \multirow[t]{4}{*}{1.5} & \multirow[t]{5}{*}{9} & 50.56 \\
\hline $10 / 13$ & 6.2 & 185 & & & & \\
\hline $10 / 13$ & 6.2 & 184 & & & & \\
\hline $10 / 13$ & 6.2 & 184 & & & & \\
\hline & & & $M W 54$ & & & \\
\hline $1 / 29$ & 6.6 & 256 & 60 & 30 & 7 & 49.29 \\
\hline $1 / 29$ & 0.5 & 251 & & & & \\
\hline $1 / 29$ & 6.4 & 2.54 & & & & \\
\hline $1 / 29$ & 6.4 & 258 & & & & \\
\hline $4 / 10$ & 6.6 & 251 & 61 & 20 & 26 & 48.50 \\
\hline $4 / 10$ & 6.6 & 243 & & & & \\
\hline $4 / 10$ & 6.6 & 241 & & & & \\
\hline $4 / 10$ & 6.5 & 241 & & & & \\
\hline $7 / 23$ & 6.6 & 276 & 62 & 30 & 12 & 48.78 \\
\hline $7 / 23$ & 6.5 & 246 & & & & \\
\hline $7 / 23$ & 6.3 & 247 & & & & \\
\hline $7 / 23$ & 6.3 & 242 & & & & \\
\hline $10 / 07$ & 6.5 & 244 & 62 & 8.9 & 6 & 49.35 \\
\hline $10 /(07$ & 6.6 & 236 & & & & \\
\hline $10 / 07$ & 6.5 & 235 & & & & \\
\hline $10 / 07$ & 6.5 & 234 & & & & \\
\hline & & & $M W 57$ & & & \\
\hline $1 / 30$ & 6.9 & 383 & 59 & 90 & 160 & 21.44 \\
\hline $1 / 30$ & 6.9 & 453 & & & & \\
\hline $1 / 30$ & 6.9 & 422 & & & & \\
\hline $1 / 30$ & 6.7 & 423 & & & & \\
\hline $4 / 30$ & 7.1 & 430 & 64 & 62 & 27 & 21.53 \\
\hline $4 / 30$ & 7.1 & 434 & & & & \\
\hline $4 / 30$ & 7.0 & 420 & & & & \\
\hline $4 / 30$ & 7.0 & 401 & & & & \\
\hline
\end{tabular}


1992 Environmental Report-Paducah, Part 2

Table 5.5 (continued)

\begin{tabular}{|c|c|c|c|c|c|c|}
\hline Date & $\begin{array}{c}\mathrm{pH} \\
\text { (units) }\end{array}$ & $\begin{array}{l}\text { Conductivity } \\
(\mu \mathrm{mhos} / \mathrm{cm})\end{array}$ & $\begin{array}{l}\text { Temp } \\
\left({ }^{\circ} \mathrm{F}\right)\end{array}$ & $\begin{array}{l}\text { Turbidity } \\
\text { (NTU) }^{a}\end{array}$ & $\begin{array}{l}\text { Color } \\
\text { (units) }\end{array}$ & $\begin{array}{c}\text { Depth to water } \\
\text { (ft) }\end{array}$ \\
\hline $7 / 28$ & 6.7 & 434 & \multirow[t]{4}{*}{64} & \multirow[t]{4}{*}{48} & \multirow[t]{4}{*}{25} & \multirow[t]{4}{*}{21.60} \\
\hline $7 / 28$ & 7.1 & 435 & & & & \\
\hline $7 / 28$ & 7.1 & 417 & & & & \\
\hline $7 / 28$ & 6.9 & 415 & & & & \\
\hline $11 / 18$ & 7.4 & 362 & \multirow[t]{4}{*}{75} & \multirow[t]{4}{*}{32} & \multirow[t]{4}{*}{12} & \multirow[t]{5}{*}{21.74} \\
\hline $11 / 18$ & 7.3 & 452 & & & & \\
\hline $11 / 18$ & 7.2 & 449 & & & & \\
\hline $11 / 18$ & 7.2 & 451 & & & & \\
\hline \multicolumn{6}{|c|}{ MWS9 } & \\
\hline $10 / 28$ & 6.0 & 230 & \multirow[t]{4}{*}{58} & \multirow[t]{5}{*}{1.8} & \multirow[t]{5}{*}{6} & \\
\hline $10 / 28$ & 6.0 & 229 & & & & \\
\hline $10 / 28$ & 6.0 & 229 & & & & \\
\hline $10 / 28$ & 6.1 & 230 & & & & \\
\hline \multicolumn{5}{|c|}{ MW60 } & & \\
\hline $10 / 28$ & 6.2 & 488 & \multirow[t]{4}{*}{64} & \multirow[t]{5}{*}{1.0} & \multirow[t]{5}{*}{8} & \\
\hline $10 / 28$ & 6.3 & 485 & & & & \\
\hline $10 / 28$ & 6.4 & 484 & & & & \\
\hline $10 / 28$ & 6.3 & 486 & & & & \\
\hline \multicolumn{5}{|c|}{$M W 61$} & & \\
\hline $10 / 28$ & 6.0 & 380 & \multirow[t]{4}{*}{59} & \multirow[t]{5}{*}{1.6} & \multirow[t]{5}{*}{5} & \\
\hline $10 / 28$ & 6.1 & 378 & & & & \\
\hline $10 / 28$ & 6.1 & 378 & & & & \\
\hline $10 / 28$ & 6.1 & 376 & & & & \\
\hline \multicolumn{5}{|c|}{ MW62 } & & \\
\hline $10 / 28$ & 7.2 & 302 & \multirow[t]{5}{*}{60} & NA & 10 & \\
\hline $10 / 28$ & 7.2 & 301 & & & & \\
\hline $10 / 28$ & 7.2 & 300 & & & & \\
\hline $10 / 28$ & 7.2 & 301 & & & & \\
\hline $11 / 06$ & 6.9 & & & & & \\
\hline & & & MW63 & & & \\
\hline $1 / 09$ & 6.3 & 258 & 58 & 12 & 11 & 48.03 \\
\hline $1 / 09$ & 6.5 & 247 & & & & \\
\hline $1 / 09$ & 6.3 & 247 & & & & \\
\hline $1 / 09$ & 6.3 & 246 & & & & \\
\hline $4 / 09$ & 6.1 & 251 & 60 & 19 & 12 & 46.91 \\
\hline $4 / 09$ & 6.1 & 248 & & & & \\
\hline $4 / 09$ & 6.1 & 243 & & & & \\
\hline $4 / 09$ & 6.1 & 246 & & & & \\
\hline $7 / 08$ & 6.7 & 272 & 61 & 7.7 & 6 & 47.00 \\
\hline $7 / 08$ & 6.6 & 266 & & & & \\
\hline $7 / 08$ & 6.6 & 265 & & & & \\
\hline $7 / 08$ & 6.5 & 264 & & & & \\
\hline $11 / 03$ & 6.2 & 255 & 60 & 14 & 8 & 48.26 \\
\hline $11 / 03$ & 6.3 & 251 & & & & \\
\hline $11 / 03$ & 6.3 & 249 & & & & \\
\hline $11 / 03$ & 6.3 & 249 & & & & \\
\hline
\end{tabular}


1992 Environmental Report-Paducah, Part 2

Table 5.5 (continued)

\begin{tabular}{|c|c|c|c|c|c|c|}
\hline Date & $\underset{\text { (units) }}{\mathrm{pH}}$ & $\begin{array}{l}\text { Conductivity } \\
(\mu \mathrm{mhos} / \mathrm{cm})\end{array}$ & $\begin{array}{l}\mathrm{Tcmp} \\
\left({ }^{\circ} \mathrm{F}\right)\end{array}$ & $\begin{array}{l}\text { Turbidity } \\
\text { (N'TU) }^{a}\end{array}$ & $\begin{array}{l}\text { Color } \\
\text { (units) }\end{array}$ & $\begin{array}{c}\text { Depth lo water } \\
\text { (ft) }\end{array}$ \\
\hline \multicolumn{7}{|c|}{ MW64 } \\
\hline $4 / 24$ & 6.9 & 630 & 61 & 4.9 & 12 & 9.70 \\
\hline $4 / 24$ & 7.2 & 633 & & & & \\
\hline $4 / 24$ & 7.2 & 624 & & & & \\
\hline $4 / 24$ & 7.3 & 623 & & & & \\
\hline $7 / 22$ & 6.5 & 606 & 61 & 3.3 & 12 & 9.52 \\
\hline $7 / 22$ & 6.8 & 6() 1 & & & & \\
\hline $7 / 22$ & 6.7 & 620 & & & & \\
\hline $7 / 22$ & 6.9 & 645 & & & & \\
\hline $11 / 104$ & 7.1 & 641 & 59 & 5.5 & 21 & \\
\hline $11 / 04$ & 7.2 & 621 & & & & 9.62 \\
\hline $11 /(04$ & 7.2 & 620 & & & & \\
\hline $11 /(04$ & 7.2 & 617 & & & & \\
\hline \multicolumn{7}{|c|}{ MW6.5 } \\
\hline $1 / 09$ & 5.9 & 186 & 58 & 2 & 2 & 48.03 \\
\hline $1 / 09$ & 5.9 & 187 & & & & \\
\hline $1 / 09$ & 6.1 & 189 & & & & \\
\hline $1 / 09$ & 6.0 & 187 & & & & \\
\hline $4 / 21$ & 6.0 & 192 & 59 & 0.3 & 7 & 46.43 \\
\hline $4 / 21$ & 6.1 & 195 & & & & \\
\hline $4 / 21$ & 6.1 & 196 & & & & \\
\hline $4 / 21$ & 6.0 & 196 & & & & \\
\hline $7 / 08$ & 6.4 & 195 & 61 & 1.0 & 5 & 47.07 \\
\hline $7 /(08$ & 6.5 & 195 & & & & \\
\hline $7 / 08$ & 6.5 & 195 & & & & \\
\hline $7 / 08$ & 6.4 & 195 & & & & \\
\hline $11 /(03$ & 6.8 & 199 & 60 & 0.5 & 8 & 48.25 \\
\hline $11 / 03$ & 6.8 & 200 & & & & \\
\hline $11 / 03$ & 6.8 & 199 & & & & \\
\hline $11 / 103$ & 6.8 & 199 & & & & \\
\hline \multicolumn{7}{|c|}{ MW66 } \\
\hline $1 / 24$ & 6.1 & 304 & 58 & 2.3 & 4 & 46.38 \\
\hline $1 / 24$ & 6.1 & 318 & & & & \\
\hline $1 / 24$ & 6.1 & 320 & & & & \\
\hline $1 / 24$ & 6.1 & 325 & & & & \\
\hline $4 / 29$ & 6.6 & 335 & 59 & 1.4 & 7 & 44.89 \\
\hline $4 / 29$ & 6.4 & 330 & & & & \\
\hline $4 / 29$ & 6.2 & 335 & & & & \\
\hline $4 / 29$ & 6.2 & 336 & & & & \\
\hline $7 / 22$ & 6.7 & 274 & 61 & 0.9 & 10 & 45.65 \\
\hline $7 / 22$ & 6.4 & 292 & & & & \\
\hline $7 / 22$ & 6.5 & 287 & & & & \\
\hline $7 / 22$ & NA & 218 & & & & \\
\hline $11 / 19$ & 6.6 & 352 & 59 & 7.8 & 6 & 47.01 \\
\hline $11 / 19$ & 6.3 & 357 & & & & \\
\hline $11 / 19$ & 6.3 & 358 & & & & \\
\hline $11 / 19$ & 6.3 & 360 & & & & \\
\hline
\end{tabular}


1992 Environmental Report-Paducah, Part 2

Table 5.5 (continued)

\begin{tabular}{|c|c|c|c|c|c|c|}
\hline Date & $\begin{array}{c}\mathrm{pH} \\
\text { (units) }\end{array}$ & $\begin{array}{l}\text { Conductivity } \\
(\mu \mathrm{mhos} / \mathrm{cm})\end{array}$ & $\begin{array}{l}\text { Temp } \\
\left({ }^{\circ} \mathrm{F}\right)\end{array}$ & $\begin{array}{l}\text { Turbidity } \\
\text { (NTU) }^{a}\end{array}$ & $\begin{array}{l}\text { Color } \\
\text { (units) }\end{array}$ & $\begin{array}{l}\text { Depth to water } \\
\text { (ft) }\end{array}$ \\
\hline \multicolumn{7}{|c|}{ MW67 } \\
\hline $1 / 14$ & 5.9 & 179 & 58 & 0.6 & 4 & 49.72 \\
\hline $1 / 14$ & 6.0 & 180 & & & & \\
\hline $1 / 14$ & 6.0 & 181 & & & & \\
\hline $4 / 28$ & 6.3 & 162 & 60 & 1.2 & 8 & 48.72 \\
\hline $4 / 28$ & 6.4 & 168 & & & & \\
\hline $4 / 28$ & 6.4 & 174 & & & & \\
\hline $4 / 28$ & 6.3 & 173 & & & & \\
\hline $7 / 21$ & 6.1 & 180 & 62 & 2.5 & 10 & 49.07 \\
\hline $7 / 21$ & 6.1 & 178 & & & & \\
\hline $7 / 21$ & 6.1 & 177 & & & & \\
\hline $7 / 21$ & 6.1 & 177 & & & & \\
\hline $11 / 04$ & 6.9 & 175 & 60 & 1.2 & 8 & 50.20 \\
\hline $11 / 04$ & 6.8 & 174 & & & & \\
\hline $11 / 04$ & 6.8 & 173 & & & & \\
\hline $11 / 04$ & 6.8 & 174 & & & & \\
\hline \multicolumn{7}{|c|}{ MW68 } \\
\hline $1 / 22$ & 5.7 & 402 & 59 & 0.5 & 3 & 53.88 \\
\hline $1 / 22$ & 5.9 & 366 & & & & \\
\hline $1 / 22$ & 5.9 & 384 & & & & \\
\hline $1 / 22$ & 5.9 & 389 & & & & \\
\hline $4 / 23$ & 6.8 & 415 & 62 & 5.4 & 3 & 73.21 \\
\hline $4 / 23$ & 6.8 & 413 & & & & \\
\hline $4 / 23$ & 6.5 & 412 & & & & \\
\hline $4 / 23$ & 6.5 & 412 & & & & \\
\hline $7 / 21$ & 6.4 & 408 & 62 & 0.7 & 11 & 53.43 \\
\hline $7 / 21$ & 6.3 & 388 & & & & \\
\hline $7 / 21$ & 6.3 & 398 & & & & \\
\hline $7 / 21$ & 6.3 & 397 & & & & 54.58 \\
\hline $10 / 29$ & 6.1 & 401 & 60 & 2.1 & 4 & \\
\hline $10 / 29$ & 6.2 & 398 & & & & \\
\hline $10 / 29$ & 6.2 & 396 & & & & \\
\hline $10 / 29$ & 6.1 & 398 & & & & \\
\hline \multicolumn{7}{|c|}{ MW69 } \\
\hline $1 / 23$ & 6.3 & 746 & 52 & 38 & 220 & 38.33 \\
\hline $1 / 23$ & 6.5 & 719 & & & & \\
\hline $1 / 23$ & 6.5 & 718 & & & & \\
\hline $4 / 28$ & 6.7 & 732 & 59 & 89 & 23 & 38.53 \\
\hline $4 / 28$ & 6.7 & 733 & & & & \\
\hline $4 / 28$ & 6.9 & 732 & & & & \\
\hline $4 / 28$ & 6.9 & 730 & & & & \\
\hline $7 / 30$ & 6.4 & 714 & 76 & 47 & 17 & 38.64 \\
\hline $7 / 30$ & 6.4 & 750 & & & & \\
\hline $7 / 30$ & 6.7 & 770 & & & & \\
\hline $7 / 30$ & 6.5 & 778 & & & & \\
\hline $11 / 23$ & & & & & & 38.40 \\
\hline \multicolumn{7}{|c|}{$M W 71$} \\
\hline $1 / 22$ & 5.8 & 561 & 60 & 3.3 & 8 & 53.82 \\
\hline $1 / 22$ & 5.8 & 555 & & & & \\
\hline
\end{tabular}


1992 Environmental Report-Paducah, Part 2

Table 5.5 (continued)

\begin{tabular}{|c|c|c|c|c|c|c|}
\hline Date & $\begin{array}{c}\mathrm{pH} \\
\text { (units) }\end{array}$ & $\begin{array}{l}\text { Conductivity } \\
(\mu \mathrm{mhos} / \mathrm{cm})\end{array}$ & $\begin{array}{l}\text { Temp } \\
\left({ }^{\circ} \mathrm{F}\right)\end{array}$ & $\begin{array}{l}\text { Turbidity } \\
\text { (NTU) }^{a}\end{array}$ & $\begin{array}{l}\text { Color } \\
\text { (units) }\end{array}$ & $\begin{array}{c}\text { Depth to water } \\
(\mathrm{ft})\end{array}$ \\
\hline $1 / 22$ & 5.8 & 545 & \multirow{6}{*}{61} & \multirow{5}{*}{2.7} & \multirow{5}{*}{6} & \multirow{5}{*}{53.27} \\
\hline $1 / 22$ & 5.8 & 547 & & & & \\
\hline $4 / 28$ & 6.5 & 547 & & & & \\
\hline $4 / 28$ & 6.4 & 551 & & & & \\
\hline $4 / 28$ & 6.3 & 550 & & & & \\
\hline $4 / 28$ & 6.3 & 554 & & \multirow{3}{*}{1.9} & \multirow{3}{*}{13} & \multirow{3}{*}{53.37} \\
\hline $7 / 22$ & 6.6 & 565 & \multirow[t]{2}{*}{62} & & & \\
\hline $7 / 22$ & 6.3 & 537 & & & & \\
\hline $7 / 22$ & 6.2 & 535 & \multirow{5}{*}{61} & \multirow{5}{*}{2.0} & \multirow{5}{*}{8} & \multirow{5}{*}{54.59} \\
\hline $10 / 29$ & 6.3 & 555 & & & & \\
\hline $10 / 29$ & 6.3 & 550 & & & & \\
\hline $10 / 29$ & 6.2 & 549 & & & & \\
\hline $10 / 29$ & 6.3 & 551 & & & & \\
\hline \multicolumn{7}{|c|}{$M W 154$} \\
\hline $3 / 18$ & 6.3 & 513 & \multirow[t]{4}{*}{59} & \multirow[t]{4}{*}{7.9} & \multirow[t]{4}{*}{2} & \multirow[t]{4}{*}{8.05} \\
\hline $3 / 18$ & 6.3 & 510 & & & & \\
\hline $3 / 18$ & 6.3 & 490 & & & & \\
\hline $3 / 18$ & 6.3 & 495 & & & & \\
\hline $6 / 19$ & 6.0 & 543 & \multirow[t]{4}{*}{62} & \multirow[t]{4}{*}{19} & \multirow[t]{4}{*}{13} & \multirow[t]{4}{*}{10.28} \\
\hline $6 / 19$ & 6.3 & 513 & & & & \\
\hline $6 / 19$ & 6.3 & 482 & & & & \\
\hline $6 / 19$ & 6.4 & 499 & & & & \\
\hline $9 / 08$ & 6.5 & 557 & 66 & 2.5 & 8 & 10.24 \\
\hline $9 / 08$ & 6.7 & 521 & & & & \\
\hline $9 / 08$ & 6.3 & 516 & & & & \\
\hline $9 / 08$ & 6.3 & 520 & & & & \\
\hline $12 / 03$ & 6.9 & 542 & 45 & 3.4 & 8 & 12.00 \\
\hline $12 / 03$ & 6.9 & 539 & & & & \\
\hline $12 / 03$ & 6.8 & 540 & & & & \\
\hline $12 / 03$ & 6.8 & 541 & & & & \\
\hline & & & $M W I 84$ & & & \\
\hline $1 / 31$ & 6.4 & & & 152 & & \\
\hline $3 / 30$ & 6.3 & 1230 & 52 & & & 13.82 \\
\hline $10 / 19$ & NA & & 61 & & & 13.90 \\
\hline & & & $M W 220$ & & & \\
\hline $7 / 09$ & 6.6 & 384 & 61 & & & 56.35 \\
\hline $7 / 09$ & 6.6 & 381 & 61 & & & NA \\
\hline $11 / 16$ & 6.7 & 420 & 59 & & & 57.80 \\
\hline $11 / 16$ & 6.8 & 418 & & & & \\
\hline $11 / 16$ & 6.8 & 430 & & & & \\
\hline $11 / 16$ & 6.8 & 416 & & & & \\
\hline & & & $M W 22 I$ & & & \\
\hline $7 / 09$ & 6.5 & 426 & 61 & & & 66.03 \\
\hline $11 / 16$ & 6.4 & 403 & 59 & & & 67.52 \\
\hline $11 / 16$ & 6.4 & 402 & & & & \\
\hline $11 / 16$ & 6.4 & 404 & & & & \\
\hline $11 / 16$ & 6.3 & 404 & & & & \\
\hline $11 / 16$ & 6.3 & 406 & 59 & & & 67.52 \\
\hline $11 / 16$ & 6.3 & 396 & & & & \\
\hline
\end{tabular}


1992 Environmental Report-Paducah, Part 2

Table 5.5 (continued)

\begin{tabular}{|c|c|c|c|c|c|c|}
\hline Date & $\begin{array}{c}\mathrm{pH} \\
\text { (units) }\end{array}$ & $\begin{array}{l}\text { Conductivity } \\
(\mu \mathrm{mhos} / \mathrm{cm})\end{array}$ & $\begin{array}{l}\text { Temp } \\
\left({ }^{\circ} \mathrm{F}\right)\end{array}$ & $\begin{array}{l}\text { Turbidity } \\
\text { (NTU) }^{a}\end{array}$ & $\begin{array}{l}\text { Color } \\
\text { (units) }\end{array}$ & $\begin{array}{l}\text { Depth to water } \\
\text { (ft) }\end{array}$ \\
\hline $11 / 16$ & 6.3 & 407 & & & & \\
\hline $11 / 16$ & 6.3 & 424 & & & & \\
\hline \multicolumn{7}{|c|}{$M W 222$} \\
\hline $11 / 16$ & 6.4 & 273 & \multirow[t]{4}{*}{59} & & & \multirow[t]{4}{*}{68.60} \\
\hline $11 / 16$ & 6.4 & 283 & & & & \\
\hline $11 / 16$ & 6.5 & 287 & & & & \\
\hline $11 / 16$ & 6.4 & 291 & & & & \\
\hline \multicolumn{7}{|c|}{$M W 223$} \\
\hline $11 / 16$ & 6.2 & 402 & \multirow[t]{4}{*}{59} & & & \multirow[t]{4}{*}{70.62} \\
\hline $11 / 16$ & 6.3 & 399 & & & & \\
\hline $11 / 16$ & 6.3 & 397 & & & & \\
\hline $11 / 16$ & 6.3 & 394 & & & & \\
\hline \multicolumn{7}{|c|}{$M W 224$} \\
\hline $11 / 16$ & 6.3 & 487 & \multirow[t]{4}{*}{59} & & & \multirow[t]{4}{*}{71.84} \\
\hline $11 / 16$ & 6.3 & 481 & & & & \\
\hline $11 / 16$ & 6.3 & 478 & & & & \\
\hline $11 / 16$ & 6.3 & 480 & & & & \\
\hline \multicolumn{7}{|c|}{$M W 225$} \\
\hline $11 / 16$ & 6.3 & 361 & \multirow[t]{4}{*}{59} & & & \multirow[t]{4}{*}{61.92} \\
\hline $11 / 16$ & 6.3 & 361 & & & & \\
\hline $11 / 16$ & 6.3 & 359 & & & & \\
\hline $11 / 16$ & 6.3 & 359 & & & & \\
\hline
\end{tabular}

${ }^{a}$ Nephelometric turbidity units.

${ }^{b}$ Not analyzed. 


\section{Environmental Report-Paducah, Part 2}

Table 5.6. Results of 1992 quarterly, semiannual, and annual effluent monitoring of organic and inorganic parameters at solid waste management units

\begin{tabular}{|c|c|c|c|c|c|c|c|c|c|}
\hline Date & $\begin{array}{c}\mathrm{Cl}^{-a} \\
(\mathrm{mg} / \mathrm{L})\end{array}$ & $\begin{array}{c}\mathrm{SO}_{4} b \\
(\mathrm{mg} / \mathrm{L})\end{array}$ & $\begin{array}{c}\mathrm{NO}_{3}-\mathrm{N}^{c} \\
(\mathrm{mg} / \mathrm{L})\end{array}$ & $\begin{array}{c}\mathrm{F}^{-d} \\
(\mathrm{mg} / \mathrm{L})\end{array}$ & $\begin{array}{l}\mathrm{TOC}^{e} \\
(\mathrm{mg} / \mathrm{L})\end{array}$ & $\begin{array}{c}\text { TOXf } \\
(\mu \mathrm{g} / \mathrm{L})\end{array}$ & $\begin{array}{c}\mathrm{TCE}^{g} \\
(\mu \mathrm{g} / \mathrm{L})\end{array}$ & $\begin{array}{c}{ }^{99} \mathrm{Tc}^{h} \\
(\mathrm{pCi} / \mathrm{L})\end{array}$ & $\begin{array}{c}\mathrm{PCB}^{i} \\
(\mu \mathrm{g} / \mathrm{L})\end{array}$ \\
\hline \multicolumn{10}{|c|}{$M W 16$} \\
\hline $2 / 06$ & 13 & 31 & 2 & 0.38 & $\begin{array}{r}1 \\
2 \\
1 \\
<1\end{array}$ & $\begin{array}{r}<5 \\
15 \\
7 \\
8\end{array}$ & $<1$ & 13 & $<0.1$ \\
\hline $5 / 06$ & 13 & 30 & 2.0 & 0.39 & $\begin{array}{r}2 \\
1 \\
<1 \\
2\end{array}$ & $\begin{array}{r}<5 \\
<5 \\
6 \\
<5\end{array}$ & $<1$ & 22 & $<0.1$ \\
\hline $8 / 27$ & 13 & 29 & 1.9 & 0.38 & $\begin{array}{r}1 \\
1 \\
<1 \\
1\end{array}$ & $\begin{array}{r}5 \\
8 \\
6 \\
<5\end{array}$ & $<1$ & 14 & $<0.1$ \\
\hline $10 / 21$ & 14 & 30 & 2.0 & 0.37 & $\begin{array}{l}2 \\
2 \\
2 \\
2\end{array}$ & $\begin{array}{r}5 \\
13 \\
7 \\
8\end{array}$ & $<1$ & 14 & $<0.1$ \\
\hline \multicolumn{10}{|c|}{$M W I 7$} \\
\hline $2 / 06$ & 18 & 185 & $<1$ & 0.51 & $\begin{array}{l}3 \\
3 \\
3 \\
3\end{array}$ & $\begin{array}{c}41 \\
39 \\
39 \\
38\end{array}$ & $<1$ & 7 & $<0.1$ \\
\hline $5 / 06$ & 18 & 218 & $<1$ & 0.63 & $\begin{array}{l}3 \\
4 \\
3 \\
4\end{array}$ & $\begin{array}{l}43 \\
52 \\
45 \\
51\end{array}$ & $<1$ & 9 & $<0.1$ \\
\hline $8 / 18$ & 25 & 207 & $<1$ & 0.56 & $\begin{array}{l}3 \\
4 \\
3 \\
3\end{array}$ & $\begin{array}{l}32 \\
38 \\
36 \\
39\end{array}$ & $<1$ & 0 & $<0.1$ \\
\hline $10 / 20$ & 25 & 217 & $<1$ & 0.48 & $\begin{array}{l}4 \\
3 \\
3 \\
3\end{array}$ & $\begin{array}{l}22 \\
21 \\
18 \\
21\end{array}$ & $<1$ & 12 & $<0.1$ \\
\hline \multicolumn{10}{|c|}{$M W / 8$} \\
\hline $2 / 05$ & 15 & 145 & $<1$ & 0.89 & $\begin{array}{l}8 \\
8 \\
9 \\
8\end{array}$ & $\begin{array}{l}31 \\
83 \\
50 \\
78\end{array}$ & $<1$ & 4 & $<0.1$ \\
\hline $5 / 05$ & 14 & 143 & $<1$ & 0.90 & $\begin{array}{l}8 \\
9 \\
9 \\
9\end{array}$ & $\begin{array}{l}22 \\
32 \\
42 \\
53\end{array}$ & $<1$ & 11 & $<0.1$ \\
\hline $8 / 18$ & 16 & 119 & $<1$ & 0.91 & $\begin{array}{l}9 \\
8 \\
8 \\
8\end{array}$ & $\begin{array}{l}18 \\
25 \\
17 \\
11\end{array}$ & $<1$ & 6.7 & $<0.1$ \\
\hline $10 / 20$ & 16 & 105 & $<1$ & 0.89 & $\begin{array}{l}8 \\
6 \\
8 \\
7\end{array}$ & $\begin{array}{l}22 \\
20 \\
33 \\
16\end{array}$ & $<1$ & 19 & $<0.1$ \\
\hline
\end{tabular}


1992 Environmental Report-Paducah, Part 2

Table 5.6 (continued)

\begin{tabular}{|c|c|c|c|c|c|c|c|c|c|}
\hline Date & $\begin{array}{c}\mathrm{Cl}^{-a} \\
(\mathrm{mg} / \mathrm{L})\end{array}$ & $\begin{array}{c}\mathrm{SO}_{4} b \\
(\mathrm{mg} / \mathrm{L})\end{array}$ & $\begin{array}{c}\mathrm{NO}_{3}-\mathrm{N}^{c} \\
(\mathrm{mg} / \mathrm{L})\end{array}$ & $\begin{array}{c}\mathrm{F}^{-d} \\
(\mathrm{mg} / \mathrm{L})\end{array}$ & $\begin{array}{c}\mathrm{TOC}^{e} \\
(\mathrm{mg} / \mathrm{L})\end{array}$ & $\begin{array}{c}\text { Tox }^{f} \\
(\mu \mathrm{g} / \mathrm{L})\end{array}$ & $\begin{array}{c}\mathrm{TCE}^{g} \\
(\mu \mathrm{g} / \mathrm{L})\end{array}$ & $\begin{array}{l}{ }^{99} \mathrm{Tc}^{h} \\
(\mathrm{pCi} / \mathrm{L})\end{array}$ & $\begin{array}{c}\mathrm{PCB}^{i} \\
(\mu \mathrm{g} / \mathrm{L})\end{array}$ \\
\hline \multicolumn{10}{|c|}{$M W 19$} \\
\hline $2 / 06$ & 3 & 23 & 3.8 & 0.29 & $\begin{array}{r}1 \\
1 \\
<1 \\
<1\end{array}$ & $\begin{array}{r}8 \\
5 \\
<5 \\
<5\end{array}$ & $<10$ & 0 & $<0.1$ \\
\hline $5 / 07$ & $<5$ & 15 & 2.4 & 0.30 & $\begin{array}{r}2 \\
1 \\
<1 \\
<1\end{array}$ & $\begin{array}{r}7 \\
<5 \\
<5 \\
<5\end{array}$ & $<1$ & 8 & $<0.1$ \\
\hline $8 / 20$ & 6 & 16 & 1.6 & 0.29 & $\begin{array}{r}<1 \\
1 \\
<1 \\
1\end{array}$ & $\begin{array}{r}5 \\
7 \\
<5 \\
<5\end{array}$ & $<1$ & 20 & $<0.1$ \\
\hline $10 / 21$ & 5 & 14 & 2.8 & 0.27 & $\begin{array}{l}1 \\
2 \\
2 \\
2\end{array}$ & $\begin{array}{c}<5^{j} \\
<5^{j} \\
<5^{j} \\
<5^{j} \\
28.0 \\
23.1 \\
13.9 \\
190\end{array}$ & $<1$ & 5 & $<0.1$ \\
\hline \multicolumn{10}{|c|}{$M W 20$} \\
\hline $2 / 12$ & 35 & 11 & $<1$ & 0.13 & $\begin{array}{r}2 \\
1 \\
<1 \\
<1\end{array}$ & $\begin{array}{r}95 \\
102 \\
87 \\
91\end{array}$ & 110 & 48 & $<0.1$ \\
\hline $4 / 24$ & & & & & & & 87 & 26 & \\
\hline $5 / 13$ & & 9 & $<1$ & 0.12 & $\begin{array}{l}<1 \\
<1 \\
<1 \\
<1\end{array}$ & $\begin{array}{r}106 \\
97 \\
84 \\
<5\end{array}$ & 66 & 51 & $<0.1$ \\
\hline $8 / 17$ & & 13 & $<1$ & 0.16 & $\begin{array}{l}<1 \\
<1 \\
<1 \\
<1\end{array}$ & $\begin{array}{l}59 \\
68 \\
60 \\
54\end{array}$ & 92 & 54.8 & $<0.1$ \\
\hline $12 / 10$ & & & & & & & 65 & 65 & \\
\hline \multicolumn{10}{|c|}{$M W 2 I$} \\
\hline $3 / 17$ & 176 & 421 & $<1$ & 0.23 & $\begin{array}{l}2 \\
2 \\
1 \\
2\end{array}$ & $\begin{array}{l}46 \\
54 \\
46 \\
60\end{array}$ & $<1$ & 1 & $<0.1$ \\
\hline $6 / 04$ & & 370 & $<1$ & 0.26 & $\begin{array}{r}3 \\
2 \\
<1 \\
3\end{array}$ & $\begin{array}{l}65 \\
66 \\
54 \\
48\end{array}$ & $N A^{k}$ & -7 & \\
\hline $9 / 02$ & & 6 & $<1$ & 0.22 & $\begin{array}{r}<1 \\
2 \\
2 \\
1\end{array}$ & $\begin{array}{l}23 \\
28 \\
18 \\
17\end{array}$ & $<1$ & 3 & $<0.1$ \\
\hline
\end{tabular}


1992 Environmental Report-Paducah, Part 2

Table 5.6 (continued)

\begin{tabular}{|c|c|c|c|c|c|c|c|c|c|}
\hline Date & $\begin{array}{c}\mathrm{Cl}^{-a} \\
(\mathrm{mg} / \mathrm{L})\end{array}$ & $\begin{array}{c}\mathrm{SO}_{4} b \\
(\mathrm{mg} / \mathrm{L})\end{array}$ & $\begin{array}{c}\mathrm{NO}_{3}-\mathrm{N}^{r} \\
(\mathrm{mg} / \mathrm{L})\end{array}$ & $\begin{array}{c}\mathrm{F}^{-d} \\
(\mathrm{mg} / \mathrm{L})\end{array}$ & $\begin{array}{l}\mathrm{TOC}^{e} \\
(\mathrm{mg} / \mathrm{L})\end{array}$ & $\begin{array}{c}\text { TOXf } \\
(\mu \mathrm{g} / \mathrm{L})\end{array}$ & $\begin{array}{c}\mathrm{TCE}^{g} \\
(\mu \mathrm{g} / \mathrm{L})\end{array}$ & $\begin{array}{c}{ }^{99} \mathrm{Tc}^{h} \\
(\mathrm{pCi} / \mathrm{L})\end{array}$ & $\begin{array}{c}\mathrm{PCB}^{i} \\
(\mu \mathrm{g} / \mathrm{L})\end{array}$ \\
\hline $12 / 01$ & & NA & $<1$ & 0.23 & $\begin{array}{l}2 \\
2 \\
2 \\
2\end{array}$ & $\begin{array}{c}25.5 \\
835 \\
30.7 \\
38\end{array}$ & $<1$ & 23 & $<0.1$ \\
\hline \multicolumn{10}{|c|}{$M W 22$} \\
\hline $3 / 17$ & 47 & 12 & $<1$ & 0.11 & $\begin{array}{l}<1 \\
<1 \\
<1 \\
<1\end{array}$ & $\begin{array}{l}49.6^{j} \\
48^{j} \\
48.9^{j} \\
33.8^{j}\end{array}$ & 64 & 61 & $<0.1$ \\
\hline $6 / 02$ & & 13 & $<1$ & 0.12 & $\begin{array}{l}<1 \\
<1 \\
<1 \\
<1\end{array}$ & $\begin{array}{l}67 \\
61 \\
57 \\
63\end{array}$ & 66 & 60 & $<0.1$ \\
\hline $9 / 03$ & & 17 & $<1$ & 0.12 & $\begin{array}{l}<1 \\
<1 \\
<1 \\
<1\end{array}$ & $\begin{array}{l}40 \\
43 \\
39 \\
45\end{array}$ & 64 & 36 & $<0.1$ \\
\hline $\begin{array}{l}10 / 21 \\
12 / 01\end{array}$ & & 15 & 1.1 & 0.10 & $\begin{array}{r}1 \\
<1 \\
<1 \\
<1\end{array}$ & $\begin{array}{l}72.4 \\
67.4 \\
64.5 \\
82.2\end{array}$ & $\begin{array}{l}64 \\
77\end{array}$ & $\begin{array}{l}57 \\
82\end{array}$ & $<0.1$ \\
\hline \multicolumn{10}{|c|}{$M W 23$} \\
\hline $\begin{array}{l}2 / 01 \\
8 / 17\end{array}$ & $\begin{array}{l}6 \\
8\end{array}$ & $\begin{array}{r}93 \\
182\end{array}$ & $\begin{array}{l}<1 \\
<1\end{array}$ & $\begin{array}{l}0.16 \\
0.18\end{array}$ & $\begin{array}{l}<1 \\
<1 \\
<1 \\
<1\end{array}$ & $\begin{array}{l}<5 \\
<5 \\
<5 \\
<5\end{array}$ & $<1$ & $\begin{array}{l}1.0 \\
6.4\end{array}$ & \\
\hline \multicolumn{10}{|c|}{$M W 24$} \\
\hline $\begin{array}{l}2 / 01 \\
8 / 11\end{array}$ & $\begin{array}{l}15 \\
16\end{array}$ & $\begin{array}{r}10 \\
8\end{array}$ & $\begin{array}{l}<1 \\
<1\end{array}$ & $\begin{array}{l}0.13 \\
0.16\end{array}$ & $\begin{array}{l}<1 \\
<1 \\
<1 \\
<1\end{array}$ & $\begin{array}{l}<5 \\
<5 \\
<5 \\
<5\end{array}$ & $<1$ & $\begin{array}{r}4 \\
16\end{array}$ & $<0.1$ \\
\hline \multicolumn{10}{|c|}{$M W 26$} \\
\hline $\begin{array}{l}2 / 01 \\
8 / 11\end{array}$ & $\begin{array}{l}6 \\
7\end{array}$ & $\begin{array}{l}24 \\
12\end{array}$ & $\begin{array}{l}<1 \\
1.1\end{array}$ & $\begin{array}{l}395 \\
0.22\end{array}$ & 16 & NA & $<1$ & $\begin{array}{c}17.0 \\
3\end{array}$ & $<0.1$ \\
\hline \multicolumn{10}{|c|}{$M W 27$} \\
\hline $\begin{array}{l}2 / 01 \\
8 / 11\end{array}$ & $\begin{array}{l}78 \\
86\end{array}$ & $\begin{array}{l}13 \\
14\end{array}$ & $\begin{array}{l}<1 \\
<1\end{array}$ & $\begin{array}{l}468 \\
0.14\end{array}$ & $\begin{array}{r}2 \\
1 \\
1 \\
<1\end{array}$ & $\begin{array}{r}8 \\
27 \\
24 \\
32\end{array}$ & $<1$ & $\begin{array}{l}1.0 \\
4\end{array}$ & $<0.1$ \\
\hline \multicolumn{10}{|c|}{$M W 29$} \\
\hline $1 / 31$ & 5 & 234 & $<1$ & 0.22 & & & & 4 & \\
\hline
\end{tabular}


1992 Environmental Report-Paducah, Part 2

Table 5.6 (continued)

\begin{tabular}{|c|c|c|c|c|c|c|c|c|c|}
\hline Date & $\begin{array}{c}\mathrm{Cl}^{-a} \\
(\mathrm{mg} / \mathrm{L})\end{array}$ & $\begin{array}{c}\mathrm{SO}_{4} b \\
(\mathrm{mg} / \mathrm{L})\end{array}$ & $\begin{array}{c}\mathrm{NO}_{3}-\mathrm{N}^{c} \\
(\mathrm{mg} / \mathrm{L})\end{array}$ & $\begin{array}{c}\mathrm{F}^{-d} \\
(\mathrm{mg} / \mathrm{L})\end{array}$ & $\begin{array}{c}\mathrm{TOC}^{e} \\
(\mathrm{mg} / \mathrm{L})\end{array}$ & $\begin{array}{c}\text { TOX }^{f} \\
(\mu \mathrm{g} / \mathrm{L})\end{array}$ & $\begin{array}{c}\text { TCE }^{g} \\
(\mu \mathrm{g} / \mathrm{L})\end{array}$ & $\begin{array}{c}{ }^{99} \mathrm{Tc}^{h} \\
(\mathrm{pCi} / \mathrm{L})\end{array}$ & $\begin{array}{c}\mathrm{PCB}^{i} \\
(\mu \mathrm{g} / \mathrm{L})\end{array}$ \\
\hline \multicolumn{10}{|c|}{$M W 38$} \\
\hline $2 / 18$ & 50 & 9 & 3.0 & 0.25 & $\begin{array}{r}<1 \\
<1 \\
1 \\
<1\end{array}$ & $\begin{array}{r}6 \\
10 \\
<5 \\
<5\end{array}$ & 4 & 40 & $<0.1$ \\
\hline $\begin{array}{l}4 / 22 \\
5 / 08\end{array}$ & 39 & 10 & 1.8 & 0.26 & $\begin{array}{r}1 \\
<1 \\
<1 \\
1\end{array}$ & $\begin{array}{r}15 \\
10 \\
9 \\
8\end{array}$ & $\begin{array}{l}3 \\
4\end{array}$ & $\begin{array}{r}8 \\
22\end{array}$ & $<0.1$ \\
\hline $\begin{array}{l}7 / 22 \\
8 / 20\end{array}$ & 39 & 11 & 1.8 & 0.24 & $\begin{array}{r}<1 \\
<1 \\
<1 \\
<1 \\
1\end{array}$ & $\begin{array}{l}<5 \\
<5 \\
<5 \\
<5 \\
11\end{array}$ & $\begin{array}{l}4 \\
4\end{array}$ & $\begin{array}{l}11 \\
20\end{array}$ & $<0.1$ \\
\hline $10 / 22$ & 41 & 11 & 1.9 & 0.24 & $\begin{array}{l}1 \\
1 \\
1 \\
1\end{array}$ & $\begin{array}{l}16 \\
15 \\
14 \\
14\end{array}$ & 4 & 24 & $<0.1$ \\
\hline $\begin{array}{l}11 / 17 \\
12 / 09\end{array}$ & & & & & & & $\begin{array}{l}3 \\
3\end{array}$ & $\begin{array}{l}44 \\
14\end{array}$ & \\
\hline \multicolumn{10}{|c|}{ MW39 } \\
\hline $2 / 18$ & 42 & 59 & 2.2 & 0.29 & $\begin{array}{r}1 \\
<1 \\
1 \\
1\end{array}$ & $\begin{array}{r}17 \\
7 \\
15 \\
13\end{array}$ & $<1$ & 13 & $<0.1$ \\
\hline $5 / 08$ & 37 & 51 & 1.4 & 0.28 & $\begin{array}{l}1 \\
1 \\
1\end{array}$ & $\begin{array}{l}13 \\
<5 \\
14\end{array}$ & 1 & 9 & $<0.1$ \\
\hline $8 / 20$ & 38 & 48 & 1.4 & 0.28 & $\begin{array}{l}1 \\
1 \\
1\end{array}$ & $\begin{array}{c}16 \\
9.0 \\
9.0\end{array}$ & $<1$ & -8 & $<0.1$ \\
\hline $10 / 22$ & 39 & 51 & 1.4 & 0.26 & $\begin{array}{l}2 \\
2 \\
2 \\
2 \\
2\end{array}$ & $\begin{array}{r}11 \\
9 \\
8 \\
13 \\
22\end{array}$ & $<1$ & 15 & $<0.1$ \\
\hline \multicolumn{10}{|c|}{$M W 40$} \\
\hline $2 / 18$ & 46 & 14 & 2.5 & 0.16 & $\begin{array}{l}<1 \\
<1 \\
<1 \\
<1\end{array}$ & $\begin{array}{l}10 \\
16 \\
13 \\
10\end{array}$ & $<1$ & 9 & $<0.1$ \\
\hline $5 / 12$ & 34 & 12 & 1.5 & 0.16 & $\begin{array}{l}1 \\
<1 \\
<1 \\
<1\end{array}$ & $\begin{array}{l}11 \\
<5 \\
22 \\
11\end{array}$ & 1 & 7 & $<0.1$ \\
\hline $8 / 21$ & 41 & 13 & 1.3 & 0.15 & $\begin{array}{l}<1 \\
<1 \\
<1 \\
<1\end{array}$ & $\begin{array}{l}<5 \\
<5 \\
<5 \\
<5\end{array}$ & 1 & 4 & $<0.1$ \\
\hline
\end{tabular}


1992 Environmental Report-Paducah, Part 2

Table 5.6 (continued)

\begin{tabular}{|c|c|c|c|c|c|c|c|c|c|}
\hline Date & $\begin{array}{c}\mathrm{Cl}^{-a} \\
(\mathrm{mg} / \mathrm{L})\end{array}$ & $\begin{array}{c}\mathrm{SO}_{4} b \\
(\mathrm{mg} / \mathrm{L})\end{array}$ & $\begin{array}{c}\mathrm{NO}_{3}-\mathrm{N}^{c} \\
(\mathrm{mg} / \mathrm{L})\end{array}$ & $\begin{array}{c}\mathrm{F}^{-d} \\
(\mathrm{mg} / \mathrm{L})\end{array}$ & $\begin{array}{c}\mathrm{TOC}^{e} \\
(\mathrm{mg} / \mathrm{L})\end{array}$ & $\begin{array}{c}\text { TOXf } \\
(\mu \mathrm{g} / \mathrm{L})\end{array}$ & $\begin{array}{l}\mathrm{TCE}^{g} \\
(\mu \mathrm{g} / \mathrm{L})\end{array}$ & $\begin{array}{c}{ }^{99} \mathrm{Tc}^{h} \\
(\mathrm{pCi} / \mathrm{L})\end{array}$ & $\begin{array}{c}\mathrm{PCB}^{i} \\
(\mu \mathrm{g} / \mathrm{L}) \\
\end{array}$ \\
\hline $10 / 23$ & 33 & 14 & 1.6 & 0.15 & $\begin{array}{r}1 \\
1 \\
1 \\
<1\end{array}$ & $\begin{array}{r}6 \\
10 \\
<5 \\
10\end{array}$ & 1 & 2 & $<0.1$ \\
\hline \multicolumn{10}{|c|}{$M W 4 I$} \\
\hline $2 / 19$ & 44 & 10 & 1.9 & 0.15 & $\begin{array}{l}<1 \\
<1 \\
<1 \\
<1\end{array}$ & $\begin{array}{l}16 \\
11 \\
21 \\
15\end{array}$ & 19 & 21 & $<() .1$ \\
\hline $\begin{array}{l}4 / 22 \\
5 / 19\end{array}$ & 44 & 11 & 1.1 & $0.16^{\circ}$ & $\begin{array}{r}1 \\
<1 \\
<1 \\
<1\end{array}$ & $\begin{array}{l}26.5^{j} \\
25.4^{j} \\
\text { NA } \\
\text { NA }\end{array}$ & $\begin{array}{l}20 \\
24\end{array}$ & $\begin{array}{r}0 \\
18\end{array}$ & $<0.1$ \\
\hline $\begin{array}{l}7 / 22 \\
8 / 21\end{array}$ & 32 & 14 & 1.6 & 0.15 & NA & 11 & $\begin{array}{l}23 \\
20\end{array}$ & $\begin{array}{c}-0.6 \\
0\end{array}$ & $<0.1$ \\
\hline & & & & & $\begin{array}{l}<1 \\
<1 \\
<1\end{array}$ & $\begin{array}{l}15 \\
15 \\
17\end{array}$ & & & \\
\hline $10 / 22$ & 42 & 12 & 1.3 & 0.15 & $\begin{array}{l}1 \\
1 \\
1 \\
1\end{array}$ & $\begin{array}{l}11 \\
21 \\
17 \\
18\end{array}$ & 21 & 0 & $<0.1$ \\
\hline $11 / 17$ & & & & & & & 18 & 20) & \\
\hline $12 / 09$ & & & & & & & 12 & 1 & \\
\hline $12 / 09$ & & & & & & & 1 & 2 & \\
\hline \multicolumn{10}{|c|}{$M W 42$} \\
\hline $2 / 20$ & 43 & 187 & 1.3 & 0.16 & $\begin{array}{l}1 \\
2 \\
2 \\
2\end{array}$ & $\begin{array}{r}8 \\
9 \\
13 \\
9\end{array}$ & $<1$ & 13 & $<0.1$ \\
\hline $5 / 19$ & 35 & 192 & $<1$ & 0.16 & $\begin{array}{l}<1 \\
<1 \\
<1 \\
<1\end{array}$ & $\begin{array}{c}\text { NA } \\
\text { NA } \\
19^{j} \\
25^{j}\end{array}$ & $<1$ & 25 & $<0.1$ \\
\hline $8 / 26$ & 37 & 173 & $<1$ & 0.16 & $\begin{array}{l}<1 \\
<1\end{array}$ & $\begin{array}{l}6 \\
7\end{array}$ & $<1$ & 33 & $<0.1$ \\
\hline & & & & & $<1$ & 13 & & & \\
\hline $10 / 22$ & 38 & 176 & 1.0 & 0.16 & $\begin{array}{r}<1 \\
1\end{array}$ & $\begin{array}{r}<5 \\
6\end{array}$ & $<1$ & 44 & $<0.1$ \\
\hline & & & & & 1 & 5 & & & \\
\hline & & & & & $\begin{array}{l}1 \\
1\end{array}$ & $\begin{array}{r}<5 \\
8\end{array}$ & & & \\
\hline \multicolumn{10}{|c|}{$M W 43$} \\
\hline $2 / 19$ & 30 & 9 & 1.4 & 0.15 & $<1$ & $<5$ & 1 & 23 & $<0.1$ \\
\hline & & & & & $\begin{array}{l}<1 \\
<1\end{array}$ & $\begin{array}{l}<5 \\
<5\end{array}$ & & & \\
\hline & & & & & $<1$ & $<5$ & & & \\
\hline $4 / 22$ & & & & & & & 1 & 0 & \\
\hline
\end{tabular}




\section{Environmental Report-Paducah, Part 2}

Table 5.6 (continued)

\begin{tabular}{|c|c|c|c|c|c|c|c|c|c|}
\hline Date & $\begin{array}{c}\mathrm{Cl}^{-\mathrm{a}} \\
(\mathrm{mg} / \mathrm{L})\end{array}$ & $\begin{array}{c}\mathrm{SO}_{4} b \\
(\mathrm{mg} / \mathrm{L})\end{array}$ & $\begin{array}{c}\mathrm{NO}_{3}-\mathrm{N}^{c} \\
(\mathrm{mg} / \mathrm{L})\end{array}$ & $\begin{array}{c}\mathrm{F}^{-d} \\
(\mathrm{mg} / \mathrm{L})\end{array}$ & $\begin{array}{l}\mathrm{TOC}^{e} \\
(\mathrm{mg} / \mathrm{L})\end{array}$ & $\begin{array}{c}\text { TOX }^{f} \\
(\mu \mathrm{g} / \mathrm{L})\end{array}$ & $\begin{array}{c}\text { TCE }^{g} \\
(\mu \mathrm{g} / \mathrm{L})\end{array}$ & $\begin{array}{c}{ }^{99} \mathrm{Tc}^{h} \\
(\mathrm{pCi} / \mathrm{L})\end{array}$ & $\begin{array}{r}\mathrm{PCB}^{l} \\
(\mu \mathrm{g} / \mathrm{L}) \\
\end{array}$ \\
\hline $5 / 12$ & 31 & 9 & NA & 0.15 & $\begin{array}{l}<1 \\
<1 \\
<1 \\
<1\end{array}$ & $\begin{array}{r}7 \\
<5 \\
7 \\
<5\end{array}$ & 1 & 13 & $<0.1$ \\
\hline $\begin{array}{l}7 / 22 \\
8 / 26\end{array}$ & 31 & 11 & 1.0 & 0.15 & $\begin{array}{l}<1 \\
<1\end{array}$ & $\begin{array}{r}22 \\
5\end{array}$ & $\begin{array}{l}2 \\
2\end{array}$ & $\begin{array}{l}3.7 \\
0\end{array}$ & $<0.1$ \\
\hline $10 / 22$ & 32 & 11 & 1.1 & 0.15 & $\begin{array}{l}1 \\
1 \\
1 \\
1\end{array}$ & $\begin{array}{r}12 \\
15 \\
8 \\
7\end{array}$ & 2 & 22 & $<0.1$ \\
\hline
\end{tabular}

\begin{tabular}{|c|c|c|c|c|c|c|c|c|c|}
\hline \multicolumn{10}{|c|}{ MW44 } \\
\hline $2 / 20$ & 50 & 18 & 1.5 & 0.17 & $\begin{array}{l}<1 \\
<1 \\
<1 \\
<1\end{array}$ & $\begin{array}{l}30 \\
47 \\
34 \\
36\end{array}$ & 30 & 0 & $<0.1$ \\
\hline $\begin{array}{l}4 / 22 \\
5 / 11\end{array}$ & & 16 & $<1$ & 0.18 & 1 & 24 & $\begin{array}{l}31 \\
35\end{array}$ & $\begin{array}{l}0 \\
5\end{array}$ & $<0.1$ \\
\hline $5 / 11$ & & 10 & -1 & & $\begin{array}{l}<1 \\
<1 \\
<1\end{array}$ & $\begin{array}{l}23 \\
26 \\
24\end{array}$ & & & \\
\hline $\begin{array}{l}7 / 22 \\
8 / 26\end{array}$ & & 17 & 1.1 & 0.17 & $<1$ & 17 & $\begin{array}{l}35 \\
31\end{array}$ & $\begin{array}{l}1 \\
5\end{array}$ & $<0.1$ \\
\hline & & & & & $\begin{array}{l}<1 \\
<1 \\
<1\end{array}$ & $\begin{array}{l}24 \\
27 \\
25\end{array}$ & & & \\
\hline $10 / 27$ & 46 & 17 & 1.1 & 0.17 & $\begin{array}{l}<1 \\
<1 \\
<1\end{array}$ & $\begin{array}{l}32 \\
27 \\
25\end{array}$ & 29 & 12 & $<0.1$ \\
\hline $11 / 17$ & & & & & $<1$ & 27 & 28 & 31 & \\
\hline \multicolumn{10}{|c|}{$M W 46$} \\
\hline $3 / 04$ & 14 & 7 & $<1$ & 0.10 & $\begin{array}{l}<1 \\
\mathrm{NA} \\
<1 \\
<1\end{array}$ & $\begin{array}{l}<5 \\
<5 \\
<5 \\
<5\end{array}$ & $<1$ & 2 & $<0.1$ \\
\hline & & & & & $\begin{array}{l}<1 \\
<1\end{array}$ & 13 & & & \\
\hline $9 / 09$ & & 11 & $<1$ & 0.11 & $<1$ & $<5$ & $<1$ & 6 & $<0.1$ \\
\hline & & & & & $\begin{array}{l}<1 \\
<1\end{array}$ & $\begin{array}{l}<5 \\
<5\end{array}$ & & & \\
\hline & & & $<1$ & 0.11 & $<1$ & $<5$ & & 0 & $<0.1$ \\
\hline & & & & & $<1$ & $<5$ & & & \\
\hline & & & & & $<1$ & 46 & & & \\
\hline
\end{tabular}


1992 Environmental Report-Paducah, Part 2

Table 5.6 (continued)

\begin{tabular}{|c|c|c|c|c|c|c|c|c|c|}
\hline Date & $\begin{array}{c}\mathrm{Cl}^{-a} \\
(\mathrm{mg} / \mathrm{L})\end{array}$ & $\begin{array}{c}\mathrm{SO}_{4} b \\
(\mathrm{mg} / \mathrm{L})\end{array}$ & $\begin{array}{c}\mathrm{NO}_{3}-\mathrm{N}^{c} \\
(\mathrm{mg} / \mathrm{L})\end{array}$ & $\begin{array}{c}\mathrm{F}^{-d} \\
(\mathrm{mg} / \mathrm{L})\end{array}$ & $\begin{array}{c}\mathrm{TOC}^{e} \\
(\mathrm{mg} / \mathrm{L})\end{array}$ & $\begin{array}{c}\text { TOX } \\
(\mu g / L)\end{array}$ & $\begin{array}{c}\mathrm{TCE}^{8} \\
(\mu \mathrm{g} / \mathrm{L})\end{array}$ & $\begin{array}{c}{ }^{99} \mathrm{Tc}^{h} \\
(\mathrm{pCi} / \mathrm{L})\end{array}$ & $\begin{array}{c}\mathrm{PCB}^{i} \\
(\mu \mathrm{g} / \mathrm{L})\end{array}$ \\
\hline \multicolumn{10}{|c|}{$M W 47$} \\
\hline $\begin{array}{r}3 / 20 \\
6 / 26 \\
9 / 11 \\
12 / 11\end{array}$ & 128 & $\begin{array}{l}367 \\
228 \\
313 \\
354\end{array}$ & $\begin{array}{l}1.2 \\
<1 \\
<1 \\
<1\end{array}$ & $\begin{array}{r}0.11 \\
0.11 \\
0.10 \\
<0.10\end{array}$ & $\begin{array}{r}10 \\
9 \\
9\end{array}$ & $\begin{array}{c}30 \\
87 \\
120\end{array}$ & $\begin{array}{l}51 \\
33 \\
39 \\
46\end{array}$ & $\begin{array}{r}53 \\
102 \\
317 \\
13\end{array}$ & $\begin{array}{l}<0.1 \\
<0.1\end{array}$ \\
\hline \multicolumn{10}{|c|}{$M W 48$} \\
\hline $3 / 04$ & 11 & 9 & $<1$ & 0.10 & $\begin{array}{l}<1 \\
<1 \\
<1 \\
<1\end{array}$ & $\begin{array}{r}<5 \\
5 \\
<5 \\
<5\end{array}$ & $<1$ & 3 & $<0.1$ \\
\hline $5 / 27$ & & 9 & $<1$ & 0.10 & $\begin{array}{l}<1 \\
<1 \\
<1 \\
<1\end{array}$ & $\begin{array}{r}8 \\
<5 \\
<5 \\
<5\end{array}$ & $<1$ & 11 & $<0.1$ \\
\hline $9 / 09$ & & 11 & $<1$ & 0.10 & $\begin{array}{l}<1 \\
<1 \\
<1 \\
<1\end{array}$ & $\begin{array}{r}8 \\
<5 \\
<5 \\
<5\end{array}$ & $<1$ & 7 & $<0.1$ \\
\hline $12 / 11$ & & 12 & $<1$ & $<0.10$ & $\begin{array}{l}<1 \\
<1 \\
<1 \\
<1\end{array}$ & $\begin{array}{l}<5 \\
<5 \\
<5 \\
<5\end{array}$ & $<1$ & 0 & $<0.1$ \\
\hline \multicolumn{10}{|c|}{ MW50 } \\
\hline $1 / 29$ & 9 & $<5$ & $<1$ & $<0.1$ & $\begin{array}{l}<1 \\
<1 \\
<1 \\
<1\end{array}$ & $\begin{array}{l}<5 \\
<5 \\
<5 \\
<5\end{array}$ & 3 & 12 & $<0.1$ \\
\hline $4 / 03$ & & $<5$ & $<1$ & $<0.1$ & $\begin{array}{l}<1 \\
<1 \\
<1 \\
<1\end{array}$ & $\begin{array}{l}<5 \\
<5 \\
<5 \\
<5\end{array}$ & 2 & 14 & $<0.1$ \\
\hline $7 / 28$ & & $<5$ & $<1$ & $<0.1$ & $\begin{array}{l}<1 \\
<1 \\
<1 \\
<1\end{array}$ & $\begin{array}{l}31^{j} \\
10^{j} \\
20^{j} \\
11^{j}\end{array}$ & 3 & 33.6 & $<0.1$ \\
\hline $10 / 07$ & & 9 & $<1$ & $<0.1$ & $\begin{array}{l}<1 \\
<1 \\
<1 \\
<1\end{array}$ & $\begin{array}{r}<5 \\
6 \\
<5 \\
6\end{array}$ & 3 & 36 & $<0.1$ \\
\hline \multicolumn{10}{|c|}{ MW5I } \\
\hline $1 / 29$ & 10 & 5 & $<1$ & $<0.1$ & $\begin{array}{r}<1 \\
<1 \\
<1 \\
1\end{array}$ & $\begin{array}{l}14 \\
12 \\
14 \\
10\end{array}$ & 1 & 29 & $<0.1$ \\
\hline $4 / 07$ & & 5 & $<1$ & $<0.1$ & $\begin{array}{l}<1 \\
<1 \\
<1 \\
<1\end{array}$ & $\begin{array}{l}8.7 \\
<5 \\
5 \\
5\end{array}$ & $<1^{l}$ & 36 & $<0.1$ \\
\hline
\end{tabular}


1992 Environmental Report-Paducah, Part 2

Table 5.6 (continued)

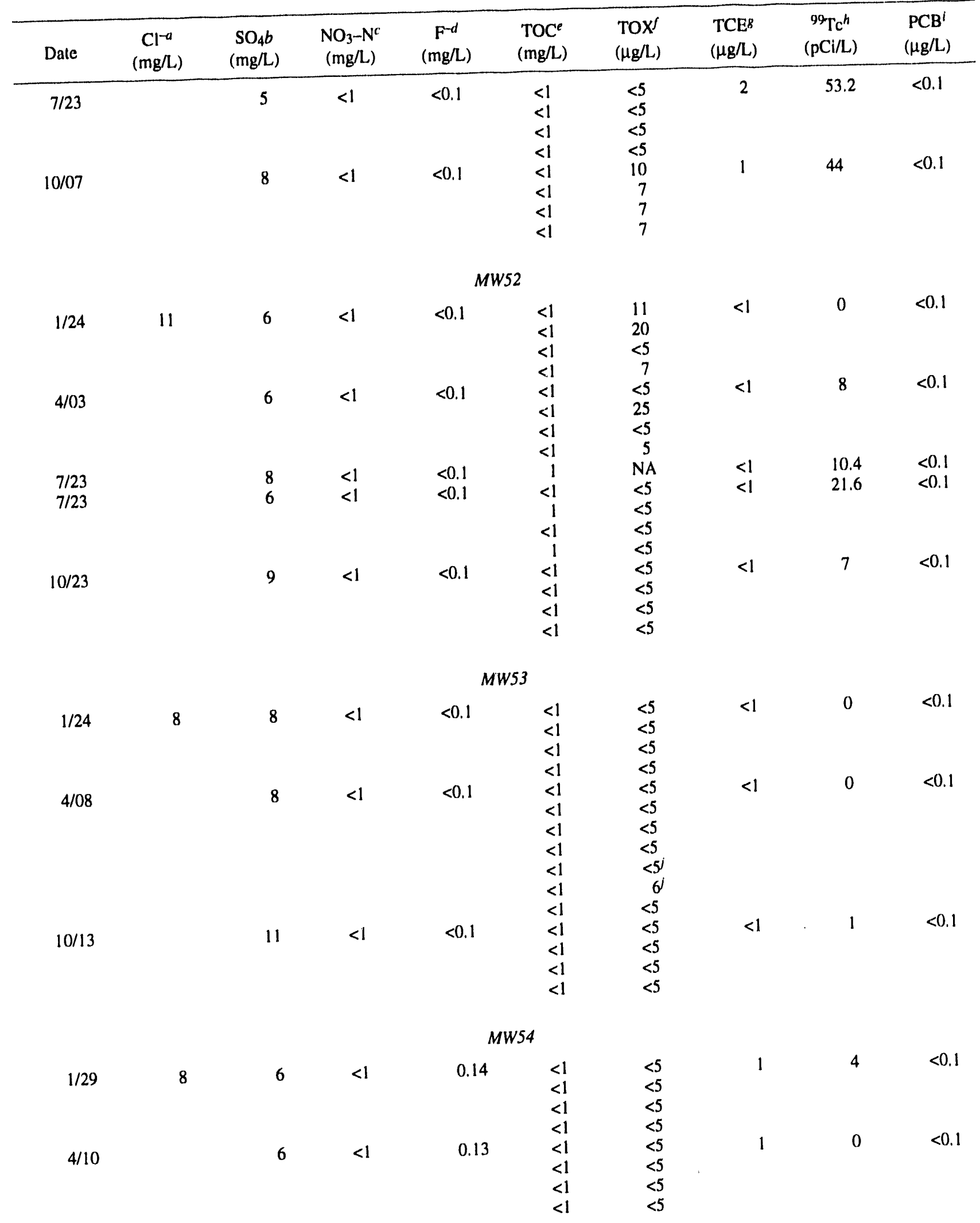


1992 Environmental Report-Paducah, Part 2

Table 5.6 (continued)

\begin{tabular}{|c|c|c|c|c|c|c|c|c|c|}
\hline Date & $\begin{array}{c}\mathrm{Cl}^{-a} \\
(\mathrm{mg} / \mathrm{L})\end{array}$ & $\begin{array}{c}\mathrm{SO}_{4} b \\
(\mathrm{mg} / \mathrm{L})\end{array}$ & $\begin{array}{c}\mathrm{NO}_{3}-\mathrm{N}^{c} \\
(\mathrm{mg} / \mathrm{L})\end{array}$ & $\begin{array}{c}\mathrm{F}^{-d} \\
(\mathrm{mg} / \mathrm{L})\end{array}$ & $\begin{array}{c}\mathrm{TOC}^{e} \\
(\mathrm{mg} / \mathrm{L})\end{array}$ & $\begin{array}{l}\text { TOXf } \\
(\mu \mathrm{g} / \mathrm{L})\end{array}$ & $\begin{array}{c}\mathrm{TCE}^{g} \\
(\mu \mathrm{g} / \mathrm{L})\end{array}$ & $\begin{array}{c}{ }^{99} \mathrm{Tc}^{\prime \prime} \\
(\mathrm{pC} / / \mathrm{L})\end{array}$ & $\begin{array}{c}\mathrm{PCB}^{i} \\
(\mu \mathrm{g} / \mathrm{L})\end{array}$ \\
\hline $7 / 23$ & & $<5$ & $<1$ & 0.12 & $\begin{array}{l}<1 \\
<1 \\
<1 \\
<1\end{array}$ & $\begin{array}{l}<5^{\prime} \\
<5^{\prime} \\
<5^{\prime} \\
<5^{\prime}\end{array}$ & 1 & 10.7 & $<0.1$ \\
\hline 10/07 & & 9 & $<1$ & 0.13 & $\begin{array}{l}<1 \\
<1 \\
<1 \\
<1\end{array}$ & $\begin{array}{l}<5 \\
<5 \\
<5 \\
<5\end{array}$ & 2 & 7 & $<0.1$ \\
\hline \multicolumn{10}{|c|}{$M W 57$} \\
\hline $1 / 30$ & 7 & 17 & $<1$ & 0.10 & $\begin{array}{l}4 \\
3 \\
2 \\
2\end{array}$ & $\begin{array}{r}8 \\
<5 \\
<5 \\
<5\end{array}$ & 4 & 288 & $<0.1$ \\
\hline $4 / 30$ & & 80 & $<1$ & 0.12 & $\begin{array}{l}2 \\
1 \\
2 \\
1\end{array}$ & $\begin{array}{l}10 \\
13 \\
11 \\
16\end{array}$ & 5 & 414 & $<0.1$ \\
\hline $7 / 28$ & & 55 & $<1$ & 0.12 & $\begin{array}{r}3 \\
1 \\
<1 \\
1\end{array}$ & $\begin{array}{r}<5^{j} \\
9^{j} \\
13^{j} \\
12^{j}\end{array}$ & 2 & 736.5 & $\mathrm{NA}$ \\
\hline $11 / 18$ & & 59 & $<1$ & $<0.1$ & $\begin{array}{l}3 \\
2 \\
2 \\
2\end{array}$ & $\begin{array}{l}7.2 \\
6.4 \\
7.5 \\
7.3\end{array}$ & 2 & 102 & $<0.1$ \\
\hline \multicolumn{10}{|c|}{ MW59 } \\
\hline $10 / 28$ & 13 & 6 & 3.8 & $<0.1$ & $\begin{array}{r}<1 \\
1 \\
3 \\
1\end{array}$ & $\begin{array}{l}<5 \\
<5 \\
<5 \\
<5\end{array}$ & $<1$ & $<25$ & $<0.1$ \\
\hline \multicolumn{10}{|c|}{ MW60 } \\
\hline $\begin{array}{r}7 / 27 \\
10 / 28\end{array}$ & 41 & 58 & 3.3 & 0.11 & $\begin{array}{l}1 \\
1 \\
2 \\
1\end{array}$ & $\begin{array}{l}21 \\
35 \\
38 \\
35\end{array}$ & $\begin{array}{l}<1 \\
<1\end{array}$ & $<25$ & $<0.1$ \\
\hline \multicolumn{10}{|c|}{$M W 61$} \\
\hline $10 / 28$ & 46 & 9 & 2.8 & 0.16 & $\begin{array}{r}1 \\
1 \\
<1 \\
1\end{array}$ & $\begin{array}{l}<5 \\
<5 \\
<5 \\
<5\end{array}$ & $<1$ & $<25$ & $<0.1$ \\
\hline \multicolumn{10}{|c|}{ MW62 } \\
\hline $10 / 28$ & $\mathrm{NA}$ & NA & NA & 0.20 & $\begin{array}{l}1 \\
1 \\
1 \\
1\end{array}$ & $\begin{array}{l}<5 \\
<5 \\
<5 \\
<5\end{array}$ & $<1$ & $<25$ & $<0.1$ \\
\hline
\end{tabular}




\section{Environmental Report-Paducah, Part 2}

Table 5.6 (continued)

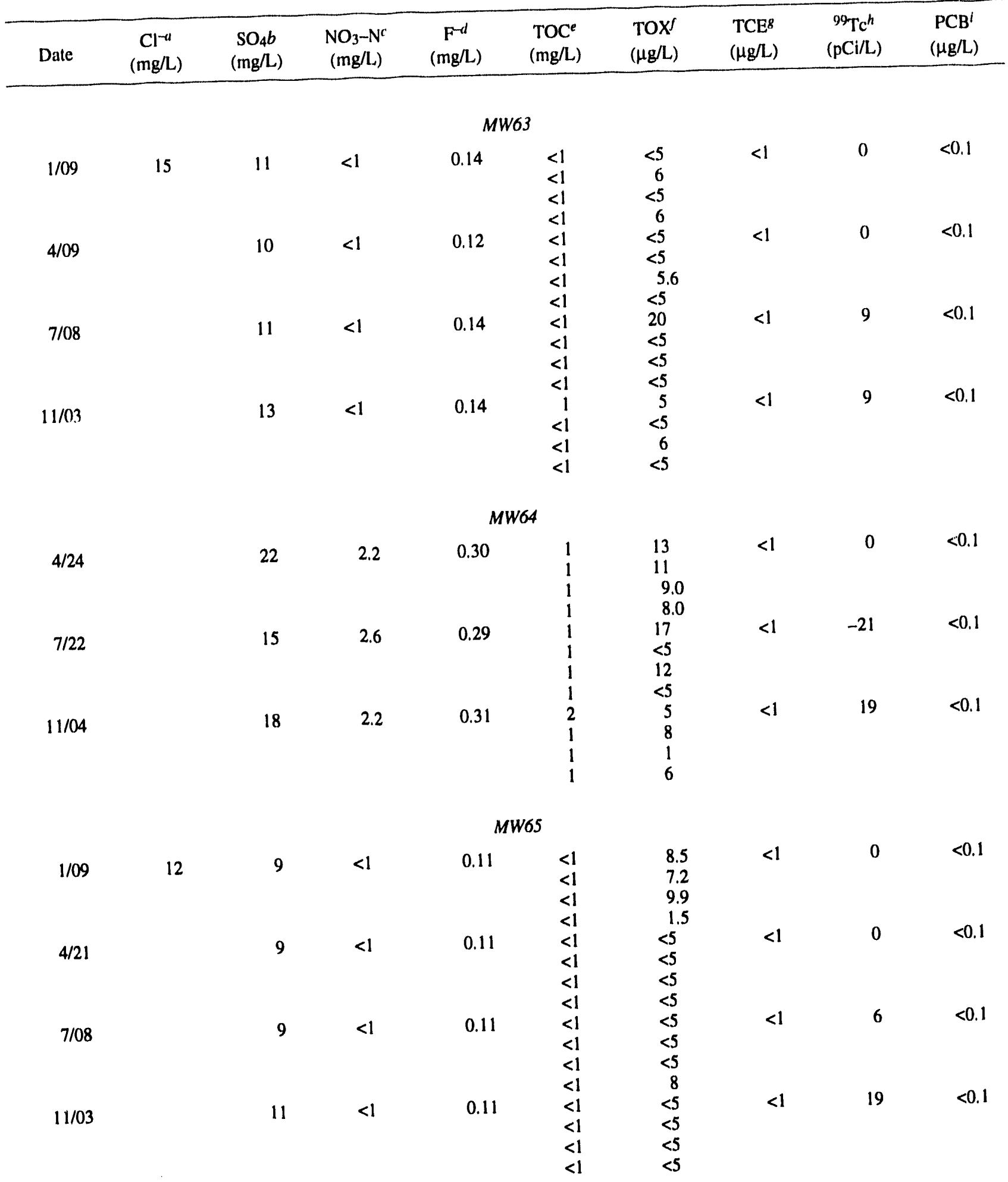


1992 Environmental Report-Paducah, Part 2

Table 5.6 (continued)

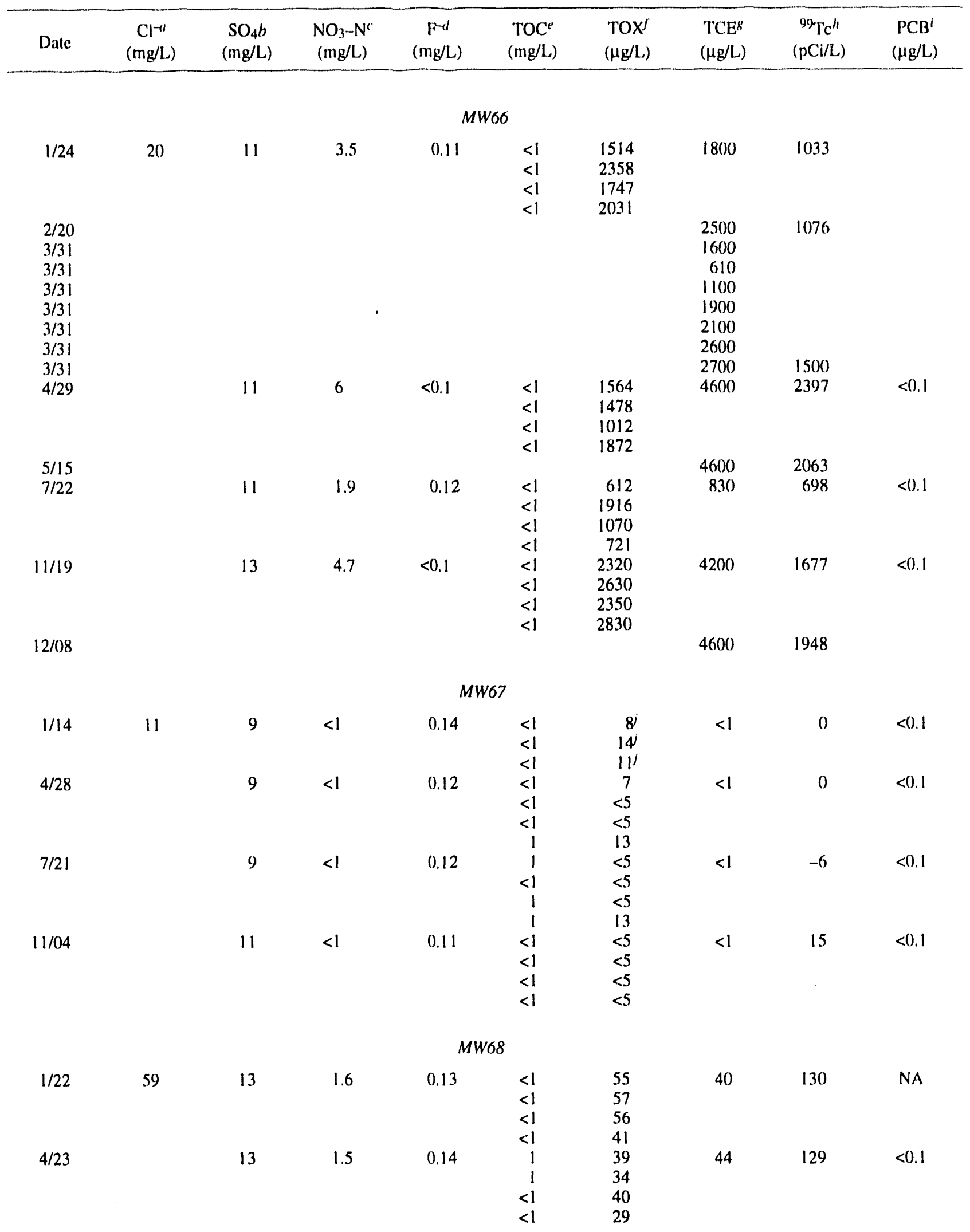


1992 Environmental Report-Paducah, Part 2

Table 5.6 (continued)

\begin{tabular}{|c|c|c|c|c|c|c|c|c|c|}
\hline Datc & $\begin{array}{c}\mathrm{Cl}^{-\mathrm{a}} \\
(\mathrm{mg} / \mathrm{L})\end{array}$ & $\begin{array}{c}\mathrm{SO}_{4} b \\
(\mathrm{mg} / \mathrm{L})\end{array}$ & $\begin{array}{c}\mathrm{NO}_{3}-\mathrm{N}^{\mathrm{c}} \\
(\mathrm{mg} / \mathrm{L})\end{array}$ & $\begin{array}{c}\mathrm{F}^{-d} \\
(\mathrm{mg} / \mathrm{L})\end{array}$ & $\begin{array}{c}\mathrm{TOC}^{e} \\
(\mathrm{mg} / \mathrm{L})\end{array}$ & $\begin{array}{c}\text { TOXf } \\
(\mu \mathrm{g} / \mathrm{L}) \\
\end{array}$ & $\begin{array}{c}\mathrm{TCE}^{8} \\
(\mu \mathrm{g} / \mathrm{L})\end{array}$ & $\begin{array}{c}{ }^{99} \mathrm{Tc}^{h} \\
(\mathrm{pCl} / \mathrm{L})\end{array}$ & $\begin{array}{c}\mathrm{PCB}^{\prime} \\
(\mu \mathrm{g} / \mathrm{L})\end{array}$ \\
\hline $7 / 21$ & & 13 & 1.6 & 0.14 & $\begin{array}{l}<1 \\
<1 \\
<1 \\
<1\end{array}$ & $\begin{array}{l}35 \\
31 \\
36 \\
38\end{array}$ & 42 & 118 & $<0.1$ \\
\hline $10 / 29$ & & 14 & 1.6 & 0.14 & $\begin{array}{r}2 \\
1 \\
<1 \\
<1\end{array}$ & $\begin{array}{l}49 \\
47 \\
51 \\
14\end{array}$ & 33 & 111 & $<0.1$ \\
\hline \multicolumn{10}{|c|}{ MW69 } \\
\hline $1 / 23$ & 91 & $<5$ & $<1$ & 0.20 & $\begin{array}{l}5 \\
5 \\
5\end{array}$ & $\begin{array}{l}50 \\
51 \\
46\end{array}$ & $<20$ & 0 & $<0.1$ \\
\hline $4 / 28$ & & $<5$ & $<1$ & 0.20 & $\begin{array}{l}6 \\
5 \\
6 \\
5\end{array}$ & $\begin{array}{l}33 \\
28 \\
33 \\
34\end{array}$ & $<20$ & 2 & $<0.1$ \\
\hline $7 / 30$ & & $<5$ & $<1$ & 0.22 & $\begin{array}{l}4 \\
4 \\
4 \\
4\end{array}$ & $\begin{array}{l}22^{j} \\
30^{\prime} \\
<5^{j} \\
\mathrm{NA}\end{array}$ & $<10$ & $<25$ & $<0.1$ \\
\hline \multicolumn{10}{|c|}{$M W 7 I$} \\
\hline $1 / 22$ & 72 & 7 & $<1$ & 0.11 & $\begin{array}{l}2 \\
2 \\
1 \\
2\end{array}$ & $\begin{array}{l}81 \\
60 \\
89 \\
81\end{array}$ & 27 & 2 & $<0.1$ \\
\hline $4 / 28$ & & 8 & $<1$ & 0.11 & $\begin{array}{l}2 \\
1 \\
1 \\
1\end{array}$ & $\begin{array}{l}27 \\
33 \\
34 \\
28\end{array}$ & 3 & 13 & $<0.1$ \\
\hline $7 / 22$ & & 8 & $<1$ & 0.11 & $\begin{array}{l}1 \\
1 \\
1\end{array}$ & $\begin{array}{l}26 \\
26 \\
30\end{array}$ & 1 & 9 & $<0.1$ \\
\hline $10 / 29$ & & 10 & $<1$ & 0.11 & $\begin{array}{l}1 \\
2 \\
2 \\
2\end{array}$ & $\begin{array}{l}24 \\
24 \\
29 \\
26\end{array}$ & 2 & 17 & $<0.1$ \\
\hline \multicolumn{10}{|c|}{$M W 154$} \\
\hline $3 / 18$ & 5 & 124 & 1.1 & 0.11 & $\begin{array}{l}2 \\
1 \\
1 \\
1\end{array}$ & $\mathrm{NA}$ & 22 & 687 & $<0.1$ \\
\hline $6 / 19$ & & 130 & $<1$ & 0.11 & $\begin{array}{l}1 \\
2 \\
1 \\
1\end{array}$ & $\begin{array}{l}23 \\
29 \\
27 \\
30\end{array}$ & 13 & 734 & $<0.1$ \\
\hline $9 / 08$ & & 128 & 1 & 0.11 & $\begin{array}{r}1 \\
1 \\
<1\end{array}$ & $\begin{array}{l}17 \\
24 \\
18 \\
15\end{array}$ & 18 & 624 & $<0.1$ \\
\hline
\end{tabular}


1992 Environmental Report-Paducah, Part 2

Table 5.6 (continued)

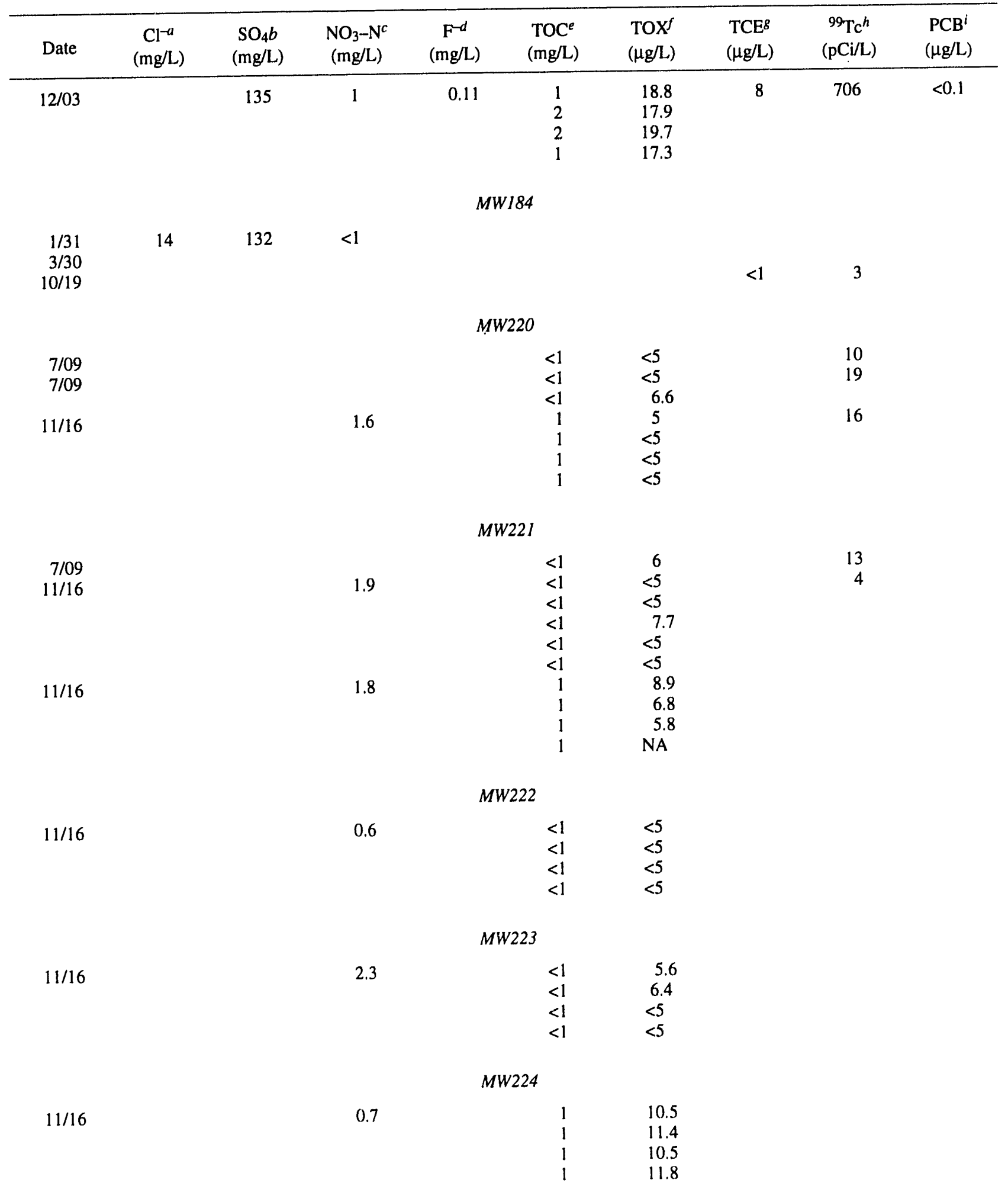


1992 Environmental Report-Paducah, Part 2

Table 5.6 (continued)

\begin{tabular}{|c|c|c|c|c|c|c|c|c|c|}
\hline Date & $\begin{array}{c}\mathrm{Cl}^{-a} \\
(\mathrm{mg} / \mathrm{L})\end{array}$ & $\begin{array}{c}\mathrm{SO}_{4} b \\
(\mathrm{mg} / \mathrm{L})\end{array}$ & $\begin{array}{c}\mathrm{NO}_{3}-\mathrm{N}^{c} \\
(\mathrm{mg} / \mathrm{L})\end{array}$ & $\begin{array}{c}F^{-d} \\
(\mathrm{mg} / \mathrm{L})\end{array}$ & $\begin{array}{c}\mathrm{TOC}^{e} \\
(\mathrm{mg} / \mathrm{L})\end{array}$ & $\begin{array}{c}\operatorname{TOX}^{f} \\
(\mu \mathrm{g} / \mathrm{L})\end{array}$ & $\begin{array}{c}\text { TCEg } \\
(\mu \mathrm{g} / \mathrm{L})\end{array}$ & $\begin{array}{c}{ }^{99} \mathrm{Tc}^{h} \\
(\mathrm{pCi} / \mathrm{L})\end{array}$ & $\begin{array}{c}\mathrm{PCB}^{i} \\
(\mu \mathrm{g} / \mathrm{L})\end{array}$ \\
\hline \multicolumn{10}{|c|}{$M W 225$} \\
\hline $11 / 16$ & & & 2.2 & & $\begin{array}{r}1 \\
<1 \\
2 \\
1\end{array}$ & $\begin{array}{c}13 \\
5 \\
7.2 \\
<5\end{array}$ & & 9 & \\
\hline
\end{tabular}

"Chloride.

${ }^{b}$ Sulfate.

cNitrate as nitrogen.

${ }^{d}$ Fluoride.

'Total organic carbon.

fTotal organic halogen.

sTrichloroethylene.

${ }^{h}$ Technetium-99.

iPolychlorinated biphenyls.

iThis sample was held beyond the holding time limit of $7 \mathrm{~d}$.

${ }^{k}$ Not analyzed.

'The surrogate for the sample for 1,2-dichloroethane-d4 was out of limits. 
Table 5.7. Results of 1992 quarterly, semiannual, and annual effluent monitoring of metals at solid waste management units

\begin{tabular}{|c|c|c|c|c|c|c|c|}
\hline Date & $\begin{array}{c}\text { Chromium } \\
(\mathrm{mg} / \mathrm{L})\end{array}$ & $\begin{array}{l}\text { Chromium }^{6+} \\
\text { (mg/L) }\end{array}$ & $\begin{array}{l}\text { Copper } \\
(\mathrm{mg} / \mathrm{L})\end{array}$ & $\begin{array}{c}\text { Iron } \\
(\mathrm{mg} / \mathrm{L})\end{array}$ & $\begin{array}{c}\text { Lead } \\
(\mathrm{mg} / \mathrm{L})\end{array}$ & $\begin{array}{l}\text { Nickel } \\
(\mathrm{mg} / \mathrm{L})\end{array}$ & $\begin{array}{c}\text { Zinc } \\
(\mathrm{mg} / \mathrm{L})\end{array}$ \\
\hline \multicolumn{8}{|c|}{$M W 16$} \\
\hline $\begin{array}{r}2 / 06 \\
5 / 06 \\
8 / 27 \\
10 / 21\end{array}$ & $\begin{array}{l}<0.05 \\
<0.05 \\
<0.05 \\
<0.05\end{array}$ & 0.02 & $\begin{array}{l}0.121 \\
0.371 \\
0.319 \\
0.171\end{array}$ & $\begin{array}{l}0.098 \\
0.062 \\
0.210 \\
0.936\end{array}$ & $\begin{array}{l}<0.2 \\
<0.2 \\
<0.2 \\
<0.05\end{array}$ & $\begin{array}{l}<0.05 \\
<0.05 \\
<0.05 \\
<0.05\end{array}$ & $\begin{array}{l}0.102 \\
0.297 \\
0.367 \\
0.213\end{array}$ \\
\hline \multicolumn{8}{|c|}{$M W I 7$} \\
\hline $\begin{array}{r}2 / 06 \\
5 / 06 \\
8 / 18 \\
10 / 20\end{array}$ & $\begin{array}{l}<0.05 \\
<0.05 \\
<0.05 \\
<0.05\end{array}$ & $<0.01$ & $\begin{array}{l}0.307 \\
0.546 \\
0.723 \\
2.26\end{array}$ & $\begin{array}{l}2.39 \\
1.32 \\
1.15 \\
1.9\end{array}$ & $\begin{array}{l}<0.2 \\
<0.2 \\
<0.2 \\
<0.05\end{array}$ & $\begin{array}{c}<0.05 \\
0.056 \\
0.083 \\
0.074\end{array}$ & $\begin{array}{l}0.299 \\
0.502 \\
1.07 \\
1.09\end{array}$ \\
\hline \multicolumn{8}{|c|}{$M W I 8$} \\
\hline $\begin{array}{r}2 / 05 \\
5 / 05 \\
8 / 18 \\
10 / 20\end{array}$ & $\begin{array}{l}<0.05 \\
<0.05 \\
<0.05 \\
<0.05\end{array}$ & $<0.01$ & $\begin{array}{c}<0.01 \\
<0.01 \\
<0.01 \\
0.111\end{array}$ & $\begin{array}{l}7.71 \\
8.01 \\
8.26 \\
9.72\end{array}$ & $\begin{array}{l}<0.2 \\
<0.2 \\
<0.2 \\
<0.05\end{array}$ & $\begin{array}{l}<0.05 \\
<0.05 \\
<0.05 \\
<0.05\end{array}$ & $\begin{array}{r}<0.005 \\
<0.005 \\
0.014 \\
0.094\end{array}$ \\
\hline \multicolumn{8}{|c|}{$M W 19$} \\
\hline $\begin{array}{r}2 / 06 \\
5 / 07 \\
8 / 20 \\
10 / 21\end{array}$ & $\begin{array}{l}<0.05 \\
<0.05 \\
<0.01 \\
<0.05\end{array}$ & $<0.01$ & $\begin{array}{l}0.908 \\
0.603 \\
0.7 \\
0.593\end{array}$ & $\begin{array}{l}0.796 \\
0.194 \\
1.63 \\
1.42\end{array}$ & $\begin{array}{l}<0.2 \\
<0.2 \\
<0.2 \\
<0.05\end{array}$ & $\begin{array}{l}0.137 \\
0.124 \\
0.07 \\
0.086\end{array}$ & $\begin{array}{l}1.99 \\
1.56 \\
1.19 \\
1.62\end{array}$ \\
\hline \multicolumn{8}{|c|}{$M W 20$} \\
\hline $\begin{array}{l}2 / 12 \\
5 / 13 \\
8 / 17\end{array}$ & $\begin{array}{l}<0.05 \\
<0.05 \\
<0.05\end{array}$ & 0.01 & $\begin{array}{l}0.205 \\
0.08 \\
0.027\end{array}$ & $\begin{array}{l}41.2 \\
17.5 \\
5.68\end{array}$ & $\begin{array}{l}<0.2 \\
<0.2 \\
<0.2\end{array}$ & $\begin{array}{l}<0.05 \\
<0.05 \\
<0.05\end{array}$ & $\begin{array}{l}0.144 \\
0.134 \\
0.073\end{array}$ \\
\hline \multicolumn{8}{|c|}{$M W 2 I$} \\
\hline $\begin{array}{r}3 / 17 \\
6 / 04 \\
9 / 02 \\
12 / 01\end{array}$ & $\begin{array}{l}<0.05 \\
<0.05 \\
<0.05 \\
<0.05\end{array}$ & $<0.01$ & $\begin{array}{c}<0.01 \\
<0.01 \\
0.011 \\
<0.01\end{array}$ & $\begin{array}{l}1.65 \\
2.25 \\
1.68 \\
1.36\end{array}$ & $\begin{array}{l}<0.2 \\
<0.2 \\
<0.2 \\
<0.03\end{array}$ & $\begin{array}{r}<0.05 \\
<0.05 \\
0.07 \\
<0.05\end{array}$ & $\begin{array}{l}0.024 \\
0.034 \\
0.044 \\
0.023\end{array}$ \\
\hline \multicolumn{8}{|c|}{$M W 22$} \\
\hline $\begin{array}{r}3 / 17 \\
6 / 02 \\
9 / 03 \\
12 / 01\end{array}$ & $\begin{array}{c}<0.05 \\
0.054 \\
<0.05 \\
<0.05\end{array}$ & $<0.01$ & $\begin{array}{l}<0.01 \\
<0.01 \\
<0.01 \\
<0.01\end{array}$ & $\begin{array}{l}5.59 \\
7.03 \\
5.1 \\
3.98\end{array}$ & $\begin{array}{l}<0.2 \\
<0.2 \\
<0.2 \\
<0.03\end{array}$ & $\begin{array}{l}<0.05 \\
<0.05 \\
<0.05 \\
<0.05\end{array}$ & $\begin{array}{r}<0.005 \\
0.097 \\
<0.005 \\
<0.005\end{array}$ \\
\hline \multicolumn{8}{|c|}{$M W 23$} \\
\hline $\begin{array}{l}2 / 01 \\
8 / 17\end{array}$ & $\begin{array}{l}<0.05 \\
<0.35\end{array}$ & $<0.01$ & $\begin{array}{l}<0.01 \\
<0.01\end{array}$ & $\begin{array}{l}2.39 \\
11.7\end{array}$ & $\begin{array}{l}<0.2 \\
<0.2\end{array}$ & $\begin{array}{l}<0.05 \\
<0.05\end{array}$ & $\begin{array}{l}31 ? \\
27.1\end{array}$ \\
\hline
\end{tabular}


Table 5.7 (continued)

\begin{tabular}{|c|c|c|c|c|c|c|c|}
\hline Date & $\begin{array}{l}\text { Chromium } \\
(\mathrm{mg} / \mathrm{L})\end{array}$ & $\begin{array}{c}\text { Chromium }{ }^{6+} \\
(\mathrm{mg} / \mathrm{L})\end{array}$ & $\begin{array}{l}\text { Copper } \\
(\mathrm{mg} / \mathrm{L})\end{array}$ & $\begin{array}{c}\text { Iron } \\
(\mathrm{mg} / \mathrm{L})\end{array}$ & $\begin{array}{c}\text { Lead } \\
(\mathrm{mg} / \mathrm{L})\end{array}$ & $\begin{array}{l}\text { Nickel } \\
(\mathrm{mg} / \mathrm{L})\end{array}$ & $\begin{array}{c}\mathrm{Zinc} \\
(\mathrm{mg} / \mathrm{L})\end{array}$ \\
\hline \multicolumn{8}{|c|}{$M W 24$} \\
\hline $\begin{array}{l}2 / 01 \\
8 / 11\end{array}$ & $\begin{array}{l}<0.05 \\
<0.05\end{array}$ & $<0.01$ & $\begin{array}{l}<0.01 \\
<0.01\end{array}$ & $\begin{array}{l}5.24 \\
9.05\end{array}$ & $\begin{array}{l}<0.2 \\
<0.2\end{array}$ & $\begin{array}{l}<0.05 \\
<0.05\end{array}$ & $\begin{array}{l}34.7 \\
19.3\end{array}$ \\
\hline \multicolumn{8}{|c|}{$M W 26$} \\
\hline $\begin{array}{l}2 / 01 \\
8 / 11\end{array}$ & $\begin{array}{l}<0.05 \\
<0.05\end{array}$ & 0.06 & $\begin{array}{l}0.016 \\
0.031\end{array}$ & $\begin{array}{l}3.52 \\
4.34\end{array}$ & $\begin{array}{l}0.236 \\
0.251\end{array}$ & $\begin{array}{l}<0.05 \\
<0.05\end{array}$ & $\begin{array}{l}31.3 \\
26.1\end{array}$ \\
\hline \multicolumn{8}{|c|}{$M W 27$} \\
\hline $\begin{array}{l}2 / 01 \\
8 / 11\end{array}$ & $\begin{array}{l}<0.05 \\
<0.05\end{array}$ & $<0.01$ & $\begin{array}{l}<0.01 \\
<0.01\end{array}$ & $\begin{array}{c}8.42 \\
10.2\end{array}$ & $\begin{array}{l}<0.2 \\
<0.2\end{array}$ & $\begin{array}{l}<0.05 \\
<0.05\end{array}$ & $\begin{array}{l}53.0 \\
53.4\end{array}$ \\
\hline \multicolumn{8}{|c|}{$M W 29$} \\
\hline $1 / 31$ & $<0.05$ & & $<0.01$ & 0.327 & $<0.2$ & $<0.05$ & 0.104 \\
\hline \multicolumn{8}{|c|}{$M W 38$} \\
\hline $\begin{array}{r}2 / 18 \\
5 / 08 \\
8 / 20 \\
10 / 22\end{array}$ & $\begin{array}{l}<0.05 \\
<0.05 \\
<0.05 \\
<0.05\end{array}$ & 0.01 & $\begin{array}{c}<0.01 \\
<0.01 \\
0.022 \\
<0.01\end{array}$ & $\begin{array}{l}0.242 \\
0.131 \\
0.189 \\
0.348\end{array}$ & $\begin{array}{l}<0.2 \\
<0.2 \\
<0.2 \\
<0.05\end{array}$ & $\begin{array}{l}<0.05 \\
<0.05 \\
<0.05 \\
<0.05\end{array}$ & $\begin{array}{r}0.005 \\
<0.005 \\
0.039 \\
0.007\end{array}$ \\
\hline \multicolumn{8}{|c|}{ MW39 } \\
\hline $\begin{array}{r}2 / 18 \\
5 / 08 \\
8 / 20 \\
10 / 22\end{array}$ & $\begin{array}{l}<0.05 \\
<0.05 \\
<0.05 \\
<0.05\end{array}$ & $<0.01$ & $\begin{array}{l}<0.01 \\
<0.01 \\
<0.01 \\
<0.01\end{array}$ & $\begin{array}{l}2.24 \\
1.37 \\
1.8 \\
1.32\end{array}$ & $\begin{array}{l}<0.2 \\
<0.2 \\
<0.2 \\
<0.05\end{array}$ & $\begin{array}{l}<0.05 \\
<0.05 \\
<0.05 \\
<0.05\end{array}$ & $\begin{array}{r}<0.005 \\
<0.005 \\
<0.034 \\
0.008\end{array}$ \\
\hline \multicolumn{8}{|c|}{$M W 40$} \\
\hline $\begin{array}{r}2 / 18 \\
5 / 12 \\
8 / 21 \\
10 / 23\end{array}$ & $\begin{array}{l}<0.05 \\
<0.05 \\
<0.05 \\
<0.05\end{array}$ & $<0.01$ & $\begin{array}{l}<0.01 \\
<0.01 \\
<0.01 \\
<0.01\end{array}$ & $\begin{array}{l}0.133 \\
0.204 \\
0.046 \\
0.201\end{array}$ & $\begin{array}{l}<0.2 \\
<0.2 \\
<0.2 \\
<0.05\end{array}$ & $\begin{array}{l}<0.05 \\
<0.05 \\
<0.05 \\
<0.05\end{array}$ & $\begin{array}{r}<0.005 \\
0.045 \\
0.007 \\
0.016\end{array}$ \\
\hline \multicolumn{8}{|c|}{$M W 4 I$} \\
\hline $\begin{array}{r}2 / 19 \\
5 / 19 \\
8 / 21 \\
10 / 22\end{array}$ & $\begin{array}{l}<0.05 \\
<0.05 \\
<0.05 \\
<0.05\end{array}$ & $<0.01$ & $\begin{array}{l}<0.01 \\
<0.01 \\
<0.01 \\
<0.01\end{array}$ & $\begin{array}{l}0.454 \\
0.246 \\
0.708 \\
1.85\end{array}$ & $\begin{array}{l}<0.2 \\
<0.2 \\
<0.2 \\
<0.05\end{array}$ & $\begin{array}{l}<0.05 \\
<0.05 \\
<0.05 \\
<0.05\end{array}$ & $\begin{array}{r}<0.005 \\
0.036 \\
0.028 \\
0.009\end{array}$ \\
\hline \multicolumn{8}{|c|}{$M W 42$} \\
\hline $\begin{array}{r}2 / 20 \\
5 / 19 \\
8 / 26 \\
10 / 22\end{array}$ & $\begin{array}{l}<0.05 \\
<0.05 \\
<0.05 \\
<0.05\end{array}$ & $<0.01$ & $\begin{array}{c}<0.01 \\
<0.01 \\
0.015 \\
<0.01\end{array}$ & $\begin{array}{l}0.752 \\
0.314 \\
0.491 \\
0.65\end{array}$ & $\begin{array}{l}<0.2 \\
<0.2 \\
<0.2 \\
<0.05\end{array}$ & $\begin{array}{l}<0.05 \\
<0.05 \\
<0.05 \\
<0.05\end{array}$ & $\begin{array}{l}0.015 \\
0.022 \\
0.044 \\
0.006\end{array}$ \\
\hline
\end{tabular}


Table 5.7 (continued)

\begin{tabular}{|c|c|c|c|c|c|c|c|}
\hline Date & $\begin{array}{l}\text { Chromium } \\
(\mathrm{mg} / \mathrm{L})\end{array}$ & $\begin{array}{l}\text { Chromium } \\
\text { (mg/L })\end{array}$ & $\begin{array}{l}\text { Copper } \\
(\mathrm{mg} / \mathrm{L})\end{array}$ & $\begin{array}{c}\text { Iron } \\
(\mathrm{mg} / \mathrm{L})\end{array}$ & $\begin{array}{c}\text { Lead } \\
(\mathrm{mg} / \mathrm{L})\end{array}$ & $\begin{array}{l}\text { Nickel } \\
(\mathrm{mg} / \mathrm{L})\end{array}$ & $\begin{array}{c}\text { Zinc } \\
(\mathrm{mg} / \mathrm{L})\end{array}$ \\
\hline \multicolumn{8}{|c|}{ MW43 } \\
\hline $\begin{array}{r}2 / 19 \\
5 / 12 \\
8 / 26 \\
10 / 22\end{array}$ & $\begin{array}{l}<0.05 \\
<0.05 \\
<0.05 \\
<0.05\end{array}$ & $<0.01$ & $\begin{array}{l}<0.01 \\
<0.01 \\
<0.01 \\
<0.01\end{array}$ & $\begin{array}{l}0.06 \\
0.159 \\
0.135 \\
0.12\end{array}$ & $\begin{array}{l}<0.2 \\
<0.2 \\
<0.2 \\
<0.05\end{array}$ & $\begin{array}{l}<0.05 \\
<0.05 \\
<0.05 \\
<0.05\end{array}$ & $\begin{array}{r}<0.005 \\
<0.005 \\
0.022 \\
0.005\end{array}$ \\
\hline \multicolumn{8}{|c|}{ MW44 } \\
\hline $\begin{array}{r}2 i 20 \\
5 / 11 \\
8 / 26 \\
10 / 22\end{array}$ & $\begin{array}{l}<0.05 \\
<0.05 \\
<0.05 \\
<0.05\end{array}$ & $<0.01$ & $\begin{array}{l}<0.01 \\
<0.01 \\
<0.01 \\
<0.01\end{array}$ & $\begin{array}{l}0.107 \\
0.076 \\
0.138 \\
0.057\end{array}$ & $\begin{array}{l}<0.2 \\
<0.2 \\
<0.2 \\
<0.05\end{array}$ & $\begin{array}{l}<0.05 \\
<0.05 \\
<0.05 \\
<0.05\end{array}$ & $\begin{array}{c}<0.008 \\
0.01 \\
0.011 \\
0.006\end{array}$ \\
\hline \multicolumn{8}{|c|}{$M W 46$} \\
\hline $\begin{array}{r}3 / 04 \\
5 / 27 \\
9 / 09 \\
12 / 11\end{array}$ & $\begin{array}{l}<0.05 \\
<0.05 \\
<0.05 \\
<0.05\end{array}$ & $<0.01$ & $\begin{array}{l}<0.01 \\
<0.01 \\
<0.01 \\
<0.01\end{array}$ & $\begin{array}{l}11.2 \\
10.8 \\
10.4 \\
13.3\end{array}$ & $\begin{array}{l}<0.2 \\
<0.2 \\
<0.2 \\
<0.2\end{array}$ & $\begin{array}{l}<0.05 \\
<0.05 \\
<0.05 \\
<0.05\end{array}$ & $\begin{array}{l}0.015 \\
0.020 \\
0.006 \\
0.026\end{array}$ \\
\hline \multicolumn{8}{|c|}{ MW47 } \\
\hline $\begin{array}{r}3 / 20 \\
6 / 26 \\
9 / 11 \\
12 / 11\end{array}$ & $\begin{array}{c}0.142 \\
<0.05 \\
0.39\end{array}$ & $<0.01$ & $\begin{array}{l}0.073 \\
0.106 \\
1.95\end{array}$ & $\begin{array}{r}265.0 \\
23.9 \\
537.0\end{array}$ & $\begin{aligned} & 8.43 \\
< & 0.2 \\
< & 0.2\end{aligned}$ & $\begin{array}{c}0.064 \\
<0.05 \\
0.15\end{array}$ & $\begin{array}{l}0.306 \\
0.179 \\
0.655\end{array}$ \\
\hline \multicolumn{8}{|c|}{$M W 48$} \\
\hline $\begin{array}{r}3 / 04 \\
5 / 27 \\
9 / 09 \\
12 / 11\end{array}$ & $\begin{array}{l}<0.05 \\
<0.05 \\
<0.05 \\
<0.05\end{array}$ & $<0.01$ & $\begin{array}{c}<0.01 \\
0.014 \\
0.016 \\
<0.01\end{array}$ & $\begin{array}{l}5.57 \\
6.76 \\
5.96 \\
7.18\end{array}$ & $\begin{array}{l}<0.2 \\
<0.08 \\
<0.2 \\
<0.2\end{array}$ & $\begin{array}{l}<0.05 \\
<0.05 \\
<0.05 \\
<0.05\end{array}$ & $\begin{array}{r}<0.005 \\
0.044 \\
0.030 \\
0.018\end{array}$ \\
\hline \multicolumn{8}{|c|}{$M W 50$} \\
\hline $\begin{array}{r}1 / 29 \\
4 / 03 \\
7 / 28 \\
10 / 07\end{array}$ & $\begin{array}{l}<0.05 \\
<0.05 \\
<0.05 \\
<0.05\end{array}$ & $<0.01$ & $\begin{array}{l}<0.01 \\
<0.01 \\
<0.01 \\
<0.01\end{array}$ & $\begin{array}{l}8.08 \\
7.3 \\
7.5 \\
5.72\end{array}$ & $\begin{array}{l}<0.2 \\
<0.2 \\
<0.2 \\
<0.2\end{array}$ & $\begin{array}{l}<0.05 \\
<0.05 \\
<0.05 \\
<0.05\end{array}$ & $\begin{array}{r}<0.021 \\
0.013 \\
0.014 \\
<0.005\end{array}$ \\
\hline \multicolumn{8}{|c|}{ MW5I } \\
\hline $\begin{array}{r}1 / 29 \\
4 / 07 \\
7 / 23 \\
10 / 07\end{array}$ & $\begin{array}{l}<0.05 \\
<0.05 \\
<0.05 \\
<0.05\end{array}$ & $<0.01$ & $\begin{array}{l}<0.01 \\
<0.01 \\
<0.01 \\
<0.01\end{array}$ & $\begin{array}{c}10.3 \\
12.6 \\
9.64 \\
14.8\end{array}$ & $\begin{array}{l}<0.2 \\
<0.2 \\
<0.2 \\
<0.2\end{array}$ & $\begin{array}{l}<0.05 \\
<0.05 \\
<0.05 \\
<0.05\end{array}$ & $\begin{array}{l}0.011 \\
0.042 \\
0.013 \\
0.008\end{array}$ \\
\hline \multicolumn{8}{|c|}{$M W 52$} \\
\hline $\begin{array}{r}1 / 24 \\
4 / 03 \\
7 / 23 \\
7 / 23 \\
10 / 13\end{array}$ & $\begin{array}{l}<0.05 \\
<0.05 \\
<0.05 \\
<0.05 \\
<0.05\end{array}$ & $<0.01$ & $\begin{array}{l}<0.01 \\
<0.01 \\
<0.01 \\
<0.01 \\
<0.01\end{array}$ & $\begin{array}{l}6.31 \\
5.49 \\
2.12 \\
5.16 \\
4.85\end{array}$ & $\begin{array}{l}<0.2 \\
<0.2 \\
<0.2 \\
<0.2 \\
<0.2\end{array}$ & $\begin{array}{l}<0.05 \\
<0.05 \\
<0.05 \\
<0.05 \\
<0.05\end{array}$ & $\begin{array}{r}<0.005 \\
0.012 \\
0.006 \\
<0.005 \\
<0.005\end{array}$ \\
\hline
\end{tabular}


1992 Environmental Report-Paducah, Part 2

Table 5.7 (continued)

\begin{tabular}{|c|c|c|c|c|c|c|c|}
\hline Date & $\begin{array}{l}\text { Chromium } \\
(\mathrm{mg} / \mathrm{L})\end{array}$ & $\begin{array}{c}\text { Chromium }{ }^{6+} \\
(\mathrm{mg} / \mathrm{L})\end{array}$ & $\begin{array}{l}\text { Copper } \\
(\mathrm{mg} / \mathrm{L})\end{array}$ & $\begin{array}{c}\text { Iron } \\
(\mathrm{mg} / \mathrm{L})\end{array}$ & $\begin{array}{c}\text { Lead } \\
(\mathrm{mg} / \mathrm{L})\end{array}$ & $\begin{array}{l}\text { Nickel } \\
(\mathrm{mg} / \mathrm{L})\end{array}$ & $\begin{array}{c}\text { Zinc } \\
(\mathrm{mg} / \mathrm{L})\end{array}$ \\
\hline \multicolumn{8}{|c|}{ MW53 } \\
\hline $\begin{array}{r}1 / 24 \\
4 / 08 \\
10 / 13\end{array}$ & $\begin{array}{l}<0.05 \\
<0.05 \\
<0.05\end{array}$ & $<0.01$ & $\begin{array}{l}<0.01 \\
<0.01 \\
<0.01\end{array}$ & $\begin{array}{l}2.4 \\
2.84 \\
2.02\end{array}$ & $\begin{array}{l}<0.2 \\
<0.2 \\
<0.2\end{array}$ & $\begin{array}{l}<0.05 \\
<0.05 \\
<0.05\end{array}$ & $\begin{array}{r}0.008 \\
0.011 \\
<0.005\end{array}$ \\
\hline \multicolumn{8}{|c|}{$M W 54$} \\
\hline $\begin{array}{r}1 / 29 \\
4 / 10 \\
7 / 23 \\
10 / 07\end{array}$ & $\begin{array}{l}<0.05 \\
<0.05 \\
<0.01 \\
<0.05\end{array}$ & $<0.01$ & $\begin{array}{l}<0.01 \\
<0.01 \\
<0.01 \\
<0.01\end{array}$ & $\begin{array}{c}5.33 \\
4.48 \\
12.9 \\
3.03\end{array}$ & $\begin{array}{l}<0.2 \\
<0.2 \\
<0.2 \\
<0.2\end{array}$ & $\begin{array}{l}<0.05 \\
<0.05 \\
<0.05 \\
<0.05\end{array}$ & $\begin{array}{r}0.010 \\
0.012 \\
0.006 \\
<0.005\end{array}$ \\
\hline \multicolumn{8}{|c|}{ MW57 } \\
\hline $\begin{array}{r}1 / 30 \\
4 / 30 \\
7 / 28 \\
11 / 18\end{array}$ & $\begin{array}{l}<0.05 \\
<0.05 \\
<0.05 \\
<0.05\end{array}$ & 0.01 & $\begin{array}{l}<0.01 \\
<0.01 \\
<0.01 \\
<0.01\end{array}$ & $\begin{array}{l}17.4 \\
16.5 \\
14.7 \\
85.4\end{array}$ & $\begin{array}{l}<0.2 \\
<0.2 \\
<0.2 \\
<0.04\end{array}$ & $\begin{array}{l}<0.05 \\
<0.05 \\
<0.05 \\
<0.05\end{array}$ & $\begin{array}{l}0.016 \\
0.014 \\
0.009 \\
0.092\end{array}$ \\
\hline \multicolumn{8}{|c|}{ MW59 } \\
\hline $10 / 28$ & $<0.05$ & $\mathrm{NA}^{a}$ & 0.104 & 0.058 & $<0.2$ & $<0.05$ & 0.112 \\
\hline \multicolumn{8}{|c|}{ MW60 } \\
\hline $10 / 28$ & $<0.05$ & $<0.01$ & 0.01 & 0.042 & $<0.2$ & $<0.05$ & 1.03 \\
\hline \multicolumn{8}{|c|}{ MW61 } \\
\hline $10 / 28$ & $<0.05$ & $<0.01^{b}$ & $<0.01$ & 0.077 & $<0.2$ & $<0.05$ & $<0.01$ \\
\hline \multicolumn{8}{|c|}{ MW62 } \\
\hline $\begin{array}{l}10 / 28 \\
11 / 06\end{array}$ & $<0.05$ & $\begin{array}{r}\mathrm{NA} \\
<0.01\end{array}$ & $<0.01$ & 6.31 & $<0.2$ & $<0.05$ & 0.017 \\
\hline \multicolumn{8}{|c|}{ MW63 } \\
\hline $\begin{array}{r}1 / 09 \\
4 / 09 \\
7 / 08 \\
11 / 03\end{array}$ & $\begin{array}{c}<0.05 \\
<0.05 \\
<0.05 \\
0.064\end{array}$ & $<0.01$ & $\begin{array}{l}<0.01 \\
<0.01 \\
<0.01 \\
<0.01\end{array}$ & $\begin{array}{l}0.955 \\
1.25 \\
0.681 \\
1.01\end{array}$ & $\begin{array}{l}<0.2 \\
<0.2 \\
<0.2 \\
<0.2\end{array}$ & $\begin{array}{l}0.227 \\
0.172 \\
0.273 \\
0.264\end{array}$ & $\begin{array}{r}0.024 \\
0.010 \\
0.006 \\
<0.005\end{array}$ \\
\hline \multicolumn{8}{|c|}{ MW64 } \\
\hline $\begin{array}{r}4 / 24 \\
7 / 23 \\
11 / 04\end{array}$ & $\begin{array}{l}0.051 \\
<0.05 \\
<0.05\end{array}$ & & $\begin{array}{l}<0.01 \\
<0.01 \\
<0.01\end{array}$ & $\begin{array}{l}1.11 \\
0.394 \\
0.872\end{array}$ & $\begin{array}{l}<0.2 \\
<0.2 \\
<0.2\end{array}$ & $\begin{array}{l}0.051 \\
0.203 \\
0.246\end{array}$ & $\begin{array}{r}0.023 \\
<0.005 \\
<0.005\end{array}$ \\
\hline \multicolumn{8}{|c|}{ MW65 } \\
\hline $\begin{array}{r}1 / 09 \\
4 / 21 \\
7 / 08 \\
11 / 03\end{array}$ & $\begin{array}{l}<0.05 \\
<0.05 \\
<0.05 \\
<0.05\end{array}$ & $<0.01$ & $\begin{array}{l}<0.01 \\
<0.01 \\
<0.01 \\
<0.01\end{array}$ & $\begin{array}{c}<0.01 \\
0.011 \\
0.032 \\
0.048\end{array}$ & $\begin{array}{l}<0.2 \\
<0.2 \\
<0.2 \\
<0.2\end{array}$ & $\begin{array}{l}<0.05 \\
<0.05 \\
<0.05 \\
<0.05\end{array}$ & $\begin{array}{r}<0.005 \\
0.017 \\
<0.005 \\
<0.005\end{array}$ \\
\hline
\end{tabular}


1992 Environmental Report-Paducah, Part 2

Table 5.7 (continued)

\begin{tabular}{|c|c|c|c|c|c|c|c|}
\hline Date & $\begin{array}{l}\text { Chromium } \\
(\mathrm{mg} / \mathrm{L})\end{array}$ & $\begin{array}{l}\text { Chromium }^{6+} \\
(\mathrm{mg} / \mathrm{L})\end{array}$ & $\begin{array}{l}\text { Copper } \\
(\mathrm{mg} / \mathrm{L})\end{array}$ & $\begin{array}{c}\text { Iron } \\
(\mathrm{mg} / \mathrm{L})\end{array}$ & $\begin{array}{c}\text { Lead } \\
(\mathrm{mg} / \mathrm{L})\end{array}$ & $\begin{array}{l}\text { Nickel } \\
(\mathrm{mg} / \mathrm{L})\end{array}$ & $\begin{array}{c}\text { Zinc } \\
(\mathrm{mg} / \mathrm{L})\end{array}$ \\
\hline \multicolumn{8}{|c|}{ MW66 } \\
\hline $\begin{array}{r}1 / 24 \\
4 / 29 \\
7 / 22 \\
11 / 19\end{array}$ & $\begin{array}{l}<0.05 \\
<0.05 \\
<0.05 \\
<0.01\end{array}$ & $<0.01$ & $\begin{array}{l}<0.01 \\
<0.01 \\
<0.01 \\
<0.01\end{array}$ & $\begin{array}{l}0.23 \\
0.136 \\
0.160 \\
2.87\end{array}$ & $\begin{array}{l}<0.2 \\
<0.2 \\
<0.2 \\
<0.04\end{array}$ & $\begin{array}{l}0.065 \\
0.067 \\
0.08 \\
0.377\end{array}$ & $\begin{array}{r}<0.005 \\
<0.005 \\
<0.005 \\
0.012\end{array}$ \\
\hline \multicolumn{8}{|c|}{ MW67 } \\
\hline $\begin{array}{r}1 / 14 \\
4 / 28 \\
7 / 21 \\
11 / 04\end{array}$ & $\begin{array}{l}<0.05 \\
<0.05 \\
<0.05 \\
<0.05\end{array}$ & $<0.01$ & $\begin{array}{l}<0.01 \\
<0.01 \\
<0.01 \\
<0.01\end{array}$ & $\begin{array}{l}0.272 \\
0.24 \\
0.234 \\
0.13\end{array}$ & $\begin{array}{l}<0.2 \\
<0.2 \\
<0.2 \\
<0.2\end{array}$ & $\begin{array}{l}0.106 \\
0.093 \\
0.077 \\
0.087\end{array}$ & $\begin{array}{r}0.008 \\
<0.005 \\
<0.005 \\
0.050\end{array}$ \\
\hline \multicolumn{8}{|c|}{ MW68 } \\
\hline $\begin{array}{r}1 / 22 \\
4 / 23 \\
7 / 21 \\
10 / 29\end{array}$ & $\begin{array}{l}<0.05 \\
<0.05 \\
<0.05 \\
<0.05\end{array}$ & $<0.01$ & $\begin{array}{l}<0.01 \\
<0.01 \\
<0.01 \\
<0.01\end{array}$ & $\begin{array}{l}0.081 \\
0.076 \\
0.046 \\
0.139\end{array}$ & $\begin{array}{l}<0.2 \\
<0.2 \\
<0.2 \\
<0.2\end{array}$ & $\begin{array}{l}0.086 \\
0.093 \\
0.116 \\
0.129\end{array}$ & $\begin{array}{r}<0.005 \\
0.023 \\
<0.005 \\
0.012\end{array}$ \\
\hline \multicolumn{8}{|c|}{ MW69 } \\
\hline $\begin{array}{l}1 / 23 \\
4 / 28 \\
7 / 30\end{array}$ & $\begin{array}{l}<0.05 \\
<0.05 \\
<0.05\end{array}$ & $<0.01$ & $\begin{array}{l}<0.01 \\
<0.01 \\
<0.01\end{array}$ & $\begin{array}{l}26.3 \\
28.3 \\
32.0\end{array}$ & $\begin{array}{l}<0.2 \\
<0.2 \\
<0.2\end{array}$ & $\begin{array}{l}<0.05 \\
<0.05 \\
<0.05\end{array}$ & $\begin{array}{r}<0.005 \\
0.007 \\
0.005\end{array}$ \\
\hline \multicolumn{8}{|c|}{$M W 7 I$} \\
\hline $\begin{array}{r}1 / 22 \\
4 / 28 \\
7 / 22 \\
10 / 29\end{array}$ & $\begin{array}{c}0.055 \\
<0.05 \\
0.526 \\
0.113\end{array}$ & $<0.01$ & $\begin{array}{l}<0.01 \\
<0.01 \\
<0.01 \\
<0.01\end{array}$ & $\begin{array}{l}0.523 \\
0.361 \\
2.02 \\
0.601\end{array}$ & $\begin{array}{l}<0.2 \\
<0.2 \\
<0.2 \\
<0.2\end{array}$ & $\begin{array}{l}0.055 \\
0.067 \\
0.106 \\
0.098\end{array}$ & $\begin{array}{l}0.014 \\
0.007 \\
0.006 \\
0.016\end{array}$ \\
\hline \multicolumn{8}{|c|}{$M W 154$} \\
\hline $\begin{array}{r}3 / 18 \\
6 / 19 \\
9 / 08 \\
12 / 03\end{array}$ & $\begin{array}{l}<0.05 \\
<0.05 \\
<0.05 \\
<0.05\end{array}$ & $<0.01$ & $\begin{array}{c}<0.01 \\
0.013 \\
<0.01 \\
<0.01\end{array}$ & $\begin{array}{l}0.77 \\
0.271 \\
0.124 \\
0.319\end{array}$ & $\begin{array}{l}<0.2 \\
<0.2 \\
<0.2 \\
<0.03\end{array}$ & $\begin{array}{l}<0.05 \\
<0.05 \\
<0.05 \\
<0.05\end{array}$ & $\begin{array}{r}<0.005 \\
0.067 \\
<0.005 \\
0.008\end{array}$ \\
\hline \multicolumn{8}{|c|}{$M W 184$} \\
\hline $\begin{array}{r}1 / 31 \\
3 / 30 \\
10 / 19\end{array}$ & $\begin{array}{l}<0.05 \\
<0.05\end{array}$ & & $\begin{array}{l}<0.01 \\
<0.01^{b}\end{array}$ & $\begin{array}{l}77.6 \\
76.0 \\
66.5\end{array}$ & $\begin{array}{l}<0.2 \\
<0.2 \\
<0.2\end{array}$ & $\begin{array}{l}<0.05 \\
<0.05 \\
<0.05\end{array}$ & $\begin{array}{l}0.005 \\
0.015\end{array}$ \\
\hline \multicolumn{8}{|c|}{$M W 220$} \\
\hline $\begin{array}{r}7 / 09 \\
7 / 09 \\
11 / 16\end{array}$ & $\begin{array}{l}<0.05 \\
<0.05 \\
<0.05\end{array}$ & & & $\begin{array}{l}2.29 \\
2.06 \\
1.18\end{array}$ & $\begin{array}{l}<0.01 \\
<0.01 \\
<0.05\end{array}$ & & \\
\hline
\end{tabular}


1992 Environmental Report-Paducah, Part 2

Table 5.7 (continued)

\begin{tabular}{|c|c|c|c|c|c|c|c|}
\hline Date & $\begin{array}{c}\text { Chromium } \\
(\mathrm{mg} / \mathrm{L})\end{array}$ & $\begin{array}{c}\text { Chromium }{ }^{6+} \\
(\mathrm{mg} / \mathrm{L})\end{array}$ & $\begin{array}{l}\text { Copper } \\
(\mathrm{mg} / \mathrm{L})\end{array}$ & $\begin{array}{l}\text { Iron } \\
(\mathrm{mg} / \mathrm{L})\end{array}$ & $\begin{array}{c}\text { Lead } \\
(\mathrm{mg} / \mathrm{L})\end{array}$ & $\begin{array}{l}\text { Nickel } \\
(\mathrm{mg} / \mathrm{L})\end{array}$ & $\begin{array}{c}\text { Zinc } \\
(\mathrm{mg} / \mathrm{L})\end{array}$ \\
\hline \multicolumn{8}{|c|}{$M W 221$} \\
\hline $\begin{array}{r}7 / 09 \\
11 / 16 \\
11 / 16\end{array}$ & $\begin{array}{l}<0.05 \\
<0.05 \\
<0.05\end{array}$ & & & $\begin{array}{l}0.82 \\
0.297 \\
2.34\end{array}$ & $\begin{array}{l}<0.01 \\
<0.05 \\
<0.05\end{array}$ & & \\
\hline \multicolumn{8}{|c|}{$M W 222$} \\
\hline $11 / 16$ & $<0.05$ & & & 0.818 & $<0.05$ & & \\
\hline \multicolumn{8}{|c|}{$M W 223$} \\
\hline $11 / 16$ & $<0.05$ & & & 0.337 & $<0.05$ & & \\
\hline \multicolumn{8}{|c|}{$M W 224$} \\
\hline $11 / 16$ & $<0.05$ & & & 0.476 & $<0.05$ & & \\
\hline \multicolumn{8}{|c|}{$M W 225$} \\
\hline $11 / 16$ & $<0.05$ & & & 2.18 & $<0.05$ & & \\
\hline
\end{tabular}

${ }^{a}$ Not analyzed.

${ }^{b}$ Holding time exceeded for this sample. 
Table 5.8. Results of 1992 quarterly, semiannual, and annual effluent monitoring of radionuclides at solid waste management units

\begin{tabular}{|c|c|c|c|c|c|}
\hline Date & $\begin{array}{l}\text { Uranium } \\
(\mathrm{mg} / \mathrm{L})\end{array}$ & $\begin{array}{l}\text { Dissolved alpha } \\
\quad(\mathrm{pCi} / \mathrm{L})\end{array}$ & $\begin{array}{l}\text { Suspended alpha } \\
(\mathrm{pCi} / \mathrm{L})\end{array}$ & $\begin{array}{l}\text { Dissolved beta } \\
(\mathrm{pCi} / \mathrm{L})\end{array}$ & $\begin{array}{l}\text { Suspended beta } \\
\qquad(\mathrm{pCi} / \mathrm{L})\end{array}$ \\
\hline \multicolumn{6}{|c|}{$M W 16$} \\
\hline $\begin{array}{r}2 / 06 \\
5 / 06 \\
8 / 27 \\
10 / 21\end{array}$ & $\begin{array}{l}<0.001 \\
<0.001 \\
<0.001 \\
<0.001\end{array}$ & $\begin{array}{r}7.0 \\
1.9 \\
-0.6 \\
19.4\end{array}$ & $\begin{array}{r}-3.4 \\
-0.2 \\
0.2 \\
2.5\end{array}$ & $\begin{array}{l}22 \\
15 \\
44 \\
35\end{array}$ & $\begin{array}{r}-6 \\
-2 \\
3 \\
3\end{array}$ \\
\hline \multicolumn{6}{|c|}{$M W / 7$} \\
\hline $\begin{array}{r}2 / 06 \\
5 / 06 \\
8 / 18 \\
10 / 20\end{array}$ & $\begin{array}{l}0.01 \\
0.010 \\
0.010 \\
0.010\end{array}$ & $\begin{array}{l}3.8 \\
13.5 \\
-1.0 \\
12\end{array}$ & $\begin{array}{r}-2.3 \\
0.3 \\
-2.3 \\
-0.2\end{array}$ & $\begin{array}{r}-4 \\
12 \\
3 \\
-39\end{array}$ & $\begin{array}{r}-5 \\
6 \\
0 \\
-22\end{array}$ \\
\hline \multicolumn{6}{|c|}{$M W 18$} \\
\hline $\begin{array}{r}2 / 05 \\
5 / 05 \\
8 / 18 \\
10 / 20\end{array}$ & $\begin{array}{l}0.002 \\
0.002 \\
0.003 \\
0.003\end{array}$ & $\begin{array}{r}-16.9 \\
13.5 \\
-8.1 \\
11.3\end{array}$ & $\begin{array}{r}0.2 \\
2.3 \\
1.4 \\
-5.4\end{array}$ & $\begin{array}{r}-4 \\
7 \\
9 \\
-29\end{array}$ & $\begin{array}{r}3 \\
8 \\
4 \\
-19\end{array}$ \\
\hline \multicolumn{6}{|c|}{$M W 19$} \\
\hline $\begin{array}{r}2 / 06 \\
5 / 07 \\
8 / 20 \\
10 / 21\end{array}$ & $\begin{array}{l}<0.001 \\
<0.001 \\
<0.001 \\
<0.001\end{array}$ & $\begin{array}{c}-6.6 \\
-1.0 \\
0 \\
-2.0\end{array}$ & $\begin{array}{r}-4.3 \\
0.7 \\
1.4 \\
-3.6\end{array}$ & $\begin{array}{r}10 \\
7 \\
1 \\
-2\end{array}$ & $\begin{array}{r}6 \\
19 \\
-7 \\
1\end{array}$ \\
\hline \multicolumn{6}{|c|}{$M W 20$} \\
\hline $\begin{array}{l}2 / 12 \\
5 / 13 \\
8 / 17\end{array}$ & $\begin{array}{l}<0.001 \\
<0.001 \\
<0.001\end{array}$ & $\begin{array}{r}0.3 \\
-2.3 \\
-3.2\end{array}$ & $\begin{array}{r}3.8 \\
-3.4 \\
-1.6\end{array}$ & $\begin{array}{r}27 \\
5 \\
17\end{array}$ & $\begin{array}{r}8 \\
-16 \\
-6\end{array}$ \\
\hline \multicolumn{6}{|c|}{$M W 21$} \\
\hline $\begin{array}{r}3 / 17 \\
6 / 04 \\
9 / 02 \\
12 / 01\end{array}$ & $\begin{array}{l}<0.001 \\
<0.001 \\
<0.001 \\
<0.001\end{array}$ & $\begin{array}{l}-6 \\
-5.6 \\
-5.6 \\
0.9\end{array}$ & $\begin{array}{r}-2.3 \\
3.9 \\
0.9 \\
-1.1\end{array}$ & $\begin{array}{r}1 \\
4 \\
2 \\
-3\end{array}$ & $\begin{array}{r}1 \\
18 \\
5 \\
-3\end{array}$ \\
\hline \multicolumn{6}{|c|}{$M W 22$} \\
\hline $\begin{array}{r}3 / 17 \\
6 / 02 \\
9 / 03 \\
12 / 01\end{array}$ & $\begin{array}{l}<0.001 \\
<0.001 \\
<0.001 \\
<0.001\end{array}$ & $\begin{array}{l}2.7 \\
0 \\
3.7 \\
2\end{array}$ & $\begin{array}{r}-5.2 \\
1.4 \\
-3.2 \\
0.3\end{array}$ & $\begin{array}{l}62 \\
26 \\
44 \\
55\end{array}$ & $\begin{array}{r}3 \\
14 \\
-11 \\
-5\end{array}$ \\
\hline \multicolumn{6}{|c|}{$M W 23$} \\
\hline $\begin{array}{l}2 / 01 \\
8 / 17\end{array}$ & $\begin{array}{l}<0.001 \\
<0.001\end{array}$ & -2.30 & -2.00 & -8.0 & -9.0 \\
\hline
\end{tabular}


1992 Environmental Report-Paducah, Part 2

Table 5.8 (continued)

\begin{tabular}{|c|c|c|c|c|c|}
\hline Date & $\begin{array}{l}\text { Uranium } \\
\text { (mg/L) }\end{array}$ & $\begin{array}{c}\text { Dissolved alpha } \\
(\mathrm{pCi} / \mathrm{L})\end{array}$ & $\begin{array}{l}\text { Suspended alpha } \\
(\mathrm{pCi} / \mathrm{L})\end{array}$ & $\begin{array}{l}\text { Dissolved beta } \\
(\mathrm{pCi} / \mathrm{L})\end{array}$ & $\begin{array}{l}\text { Suspended beta } \\
\qquad(\mathrm{pCi} / \mathrm{L})\end{array}$ \\
\hline \multicolumn{6}{|c|}{$M W 24$} \\
\hline $\begin{array}{l}2 / 01 \\
8 / 11\end{array}$ & $\begin{array}{l}<0.001 \\
<0.001\end{array}$ & -5.0 & -3.60 & 5.0 & -6.0 \\
\hline \multicolumn{6}{|c|}{$M W 26$} \\
\hline $\begin{array}{l}2 / 01 \\
8 / 11\end{array}$ & $\begin{array}{l}0.016 \\
0.008\end{array}$ & 2.50 & -2.00 & 21.0 & 1.0 \\
\hline \multicolumn{6}{|c|}{$M W 27$} \\
\hline $\begin{array}{l}2 / 01 \\
8 / 11\end{array}$ & $\begin{array}{l}<0.001 \\
<0.001\end{array}$ & -0.7 & -3.60 & 7.0 & -8.0 \\
\hline \multicolumn{6}{|c|}{$M W 29$} \\
\hline $1 / 31$ & 0.001 & & & & \\
\hline \multicolumn{6}{|c|}{$M W 38$} \\
\hline $\begin{array}{r}2 / 18 \\
5 / 08 \\
8 / 20 \\
10 / 22\end{array}$ & $\begin{array}{l}<0.001 \\
<0.001 \\
<0.001 \\
<0.001\end{array}$ & $\begin{array}{r}5.3 \\
3.8 \\
-5.0 \\
8.1\end{array}$ & $\begin{array}{r}-1.8 \\
0.2 \\
-2.3 \\
1.1\end{array}$ & $\begin{array}{r}15 \\
15 \\
6 \\
22\end{array}$ & $\begin{array}{l}10 \\
-0.3 \\
-3 \\
-7\end{array}$ \\
\hline \multicolumn{6}{|c|}{$M W 39$} \\
\hline $\begin{array}{r}2 / 18 \\
5 / 08 \\
8 / 20 \\
10 / 22\end{array}$ & $\begin{array}{l}<0.001 \\
<0.001 \\
<0.001 \\
<0.001\end{array}$ & $\begin{array}{r}4.5 \\
5.6 \\
1.5 \\
11.5\end{array}$ & $\begin{array}{r}-0.9 \\
-0.6 \\
-2.0 \\
2.3\end{array}$ & $\begin{array}{l}11 \\
4.9 \\
0 \\
17\end{array}$ & $\begin{array}{l}7 \\
-0.2 \\
-4 \\
-8\end{array}$ \\
\hline \multicolumn{6}{|c|}{$M W 40$} \\
\hline $\begin{array}{r}2 / 18 \\
5 / 12 \\
8 / 21 \\
10 / 23\end{array}$ & $\begin{array}{l}<0.001 \\
<0.001 \\
<0.001 \\
<0.001\end{array}$ & $\begin{array}{c}1 \\
-1.9 \\
-2.7 \\
8.2\end{array}$ & $\begin{array}{l}0 \\
-1.01 \\
-2.7 \\
2.5\end{array}$ & $\begin{array}{r}6 \\
7 \\
1 \\
26\end{array}$ & $\begin{array}{r}-11 \\
0 \\
-5 \\
-4\end{array}$ \\
\hline \multicolumn{6}{|c|}{$M W 41$} \\
\hline $\begin{array}{r}2 / 19 \\
5 / 19 \\
8 / 21 \\
10 / 22\end{array}$ & $\begin{array}{l}<0.001 \\
<0.001 \\
<0.001 \\
<0.001\end{array}$ & $\begin{array}{r}-2.1 \\
-3.1 \\
1.4 \\
-1.9\end{array}$ & $\begin{array}{l}-0.2 \\
-5.6 \\
-3.8 \\
-2.5\end{array}$ & $\begin{array}{r}5 \\
-4 \\
1 \\
-2\end{array}$ & $\begin{array}{l}-8 \\
-7 \\
-4 \\
-4\end{array}$ \\
\hline \multicolumn{6}{|c|}{ MW42 } \\
\hline $\begin{array}{r}2 / 20 \\
5 / 19 \\
8 / 26 \\
10 / 22\end{array}$ & $\begin{array}{l}<0.001 \\
<0.001 \\
<0.001 \\
<0.001\end{array}$ & $\begin{array}{r}-7.0 \\
-1.3 \\
1.4 \\
2.7\end{array}$ & $\begin{array}{l}-2.0 \\
-5.0 \\
-0.2 \\
-2.0\end{array}$ & $\begin{array}{l}9.0 \\
10 \\
39 \\
30\end{array}$ & $\begin{array}{l}-9.0 \\
-4 \\
-13 \\
-5\end{array}$ \\
\hline
\end{tabular}


Table 5.8 (continued)

\begin{tabular}{|c|c|c|c|c|c|}
\hline Date & $\begin{array}{l}\text { Uranium } \\
\text { (mg/L) }\end{array}$ & $\begin{array}{l}\text { Dissolved alpha } \\
\quad(\mathrm{pCi} / \mathrm{L})\end{array}$ & $\begin{array}{l}\text { Suspended alpha } \\
(\mathrm{pCi} / \mathrm{L})\end{array}$ & $\begin{array}{l}\text { Dissolved beta } \\
\quad(\mathrm{pCi} / \mathrm{L})\end{array}$ & $\begin{array}{l}\text { Suspended beta } \\
(\mathrm{pCi} / \mathrm{L})\end{array}$ \\
\hline \multicolumn{6}{|c|}{$M W 43$} \\
\hline $\begin{array}{r}2 / 19 \\
5 / 12 \\
8 / 26 \\
10 / 22\end{array}$ & $\begin{array}{l}<0.001 \\
<0.001 \\
<0.001 \\
<0.001\end{array}$ & $\begin{array}{r}-7.0 \\
-1.3 \\
3.5 \\
5.5\end{array}$ & $\begin{array}{r}-3.0 \\
1.1 \\
-3.2 \\
-1.6\end{array}$ & $\begin{array}{c}-11.0 \\
8 \\
6 \\
1\end{array}$ & $\begin{array}{c}-10.0 \\
4 \\
-15 \\
-3\end{array}$ \\
\hline \multicolumn{6}{|c|}{$M W 44$} \\
\hline $\begin{array}{r}2 / 20 \\
5 / 11 \\
8 / 26 \\
10 / 27\end{array}$ & $\begin{array}{l}<0.001 \\
<0.001 \\
<0.001 \\
<0.001\end{array}$ & $\begin{array}{c}-0.4 \\
0 \\
5.1 \\
-1.8\end{array}$ & $\begin{array}{c}1 \\
1.1 \\
-1.4 \\
-0.7\end{array}$ & $\begin{array}{r}-11 \\
3 \\
7 \\
9\end{array}$ & $\begin{array}{r}5 \\
3 \\
-9 \\
1\end{array}$ \\
\hline \multicolumn{6}{|c|}{ MW46 } \\
\hline $\begin{array}{r}3 / 04 \\
5 / 27 \\
9 / 09 \\
12 / 11\end{array}$ & $\begin{array}{l}<0.001 \\
<0.001 \\
<0.001 \\
<0.001\end{array}$ & $\begin{array}{r}0.3 \\
-5.3 \\
2.6 \\
0.3\end{array}$ & $\begin{array}{r}2.0 \\
-4.5 \\
0.9 \\
-2.9\end{array}$ & $\begin{array}{r}8 \\
0 \\
2 \\
-4\end{array}$ & $\begin{array}{r}10 \\
7 \\
-1 \\
-6\end{array}$ \\
\hline \multicolumn{6}{|c|}{$M W 47$} \\
\hline $\begin{array}{r}3 / 20 \\
6 / 26 \\
9 / 11 \\
12 / 11\end{array}$ & $\begin{array}{l}0.035 \\
0.008 \\
0.116 \\
0.021\end{array}$ & $\begin{array}{r}6.6 \\
27.0 \\
103.6 \\
30.4\end{array}$ & $\begin{array}{r}1.7 \\
1.4 \\
-1.8 \\
-1.1\end{array}$ & $\begin{array}{r}9 \\
176 \\
380 \\
295\end{array}$ & $\begin{array}{r}8 \\
3 \\
-14 \\
-3\end{array}$ \\
\hline \multicolumn{6}{|c|}{$M W 48$} \\
\hline $\begin{array}{r}3 / 04 \\
5 / 27 \\
9 / 09 \\
12 / 11\end{array}$ & $\begin{array}{l}<0.001 \\
<0.001 \\
<0.001 \\
<0.001\end{array}$ & $\begin{array}{r}2.0 \\
-2.8 \\
0.6 \\
-2.9\end{array}$ & $\begin{array}{r}8.8 \\
-5.3 \\
0.9 \\
3.6\end{array}$ & $\begin{array}{r}14 \\
6 \\
-1 \\
-12\end{array}$ & $\begin{array}{l}16 \\
-0.8 \\
-5 \\
-8\end{array}$ \\
\hline \multicolumn{6}{|c|}{ MW50 } \\
\hline $\begin{array}{r}1 / 29 \\
4 / 03 \\
7 / 28 \\
10 / 07\end{array}$ & $\begin{array}{l}<0.001 \\
<0.001 \\
<0.001 \\
<0.001\end{array}$ & $\begin{array}{r}2.9 \\
-1.6 \\
-1.2 \\
4.7\end{array}$ & $\begin{array}{r}-2.5 \\
0.6 \\
-4.5 \\
-1.4\end{array}$ & $\begin{array}{r}26 \\
12 \\
6 \\
11\end{array}$ & $\begin{array}{l}-7 \\
2.0 \\
-4 \\
-1\end{array}$ \\
\hline \multicolumn{6}{|c|}{ MWSI } \\
\hline $\begin{array}{r}1 / 29 \\
4 / 07 \\
7 / 23 \\
10 / 07\end{array}$ & $\begin{array}{l}<0.001 \\
<0.001 \\
<0.001 \\
<0.001\end{array}$ & $\begin{array}{r}-8.7 \\
1.1 \\
-1.9 \\
0.4\end{array}$ & $\begin{array}{l}-5.0 \\
-1.8 \\
-3.4 \\
-1.4\end{array}$ & $\begin{array}{l}3 \\
5.4 \\
22 \\
14\end{array}$ & $\begin{array}{r}-11 \\
-6 \\
-3 \\
1\end{array}$ \\
\hline \multicolumn{6}{|c|}{ MWS2 } \\
\hline $\begin{array}{r}1 / 24 \\
4 / 03 \\
7 / 23 \\
7 / 23 \\
10 / 13\end{array}$ & $\begin{array}{l}<0.001 \\
<0.001 \\
<0.001 \\
<0.001 \\
<0.001\end{array}$ & $\begin{array}{r}3.5 \\
-1.2 \\
2.8 \\
0.2 \\
1.5\end{array}$ & $\begin{array}{r}-2.0 \\
3.2 \\
-5.0 \\
-1.4 \\
-1.1\end{array}$ & $\begin{array}{r}23 \\
5 \\
6 \\
-1 \\
14\end{array}$ & $\begin{array}{r}-9 \\
6 \\
-4 \\
-2 \\
3\end{array}$ \\
\hline
\end{tabular}


Table 5.8 (continued)

\begin{tabular}{|c|c|c|c|c|c|}
\hline Date & $\begin{array}{l}\text { Uranium } \\
(\mathrm{mg} / \mathrm{L})\end{array}$ & $\begin{array}{l}\text { Dissolved alpha } \\
\qquad(\mathrm{pCi} / \mathrm{L})\end{array}$ & $\begin{array}{l}\text { Suspended alpha } \\
\qquad(\mathrm{pCl} / \mathrm{L})\end{array}$ & $\begin{array}{l}\text { Dissolved beta } \\
\qquad(\mathrm{pCi} / \mathrm{L})\end{array}$ & $\begin{array}{l}\text { Suspended beta } \\
\qquad(\mathrm{pCi} / \mathrm{L})\end{array}$ \\
\hline \multicolumn{6}{|c|}{ MW53 } \\
\hline $\begin{array}{r}1 / 24 \\
4 / 08 \\
10 / 13\end{array}$ & $\begin{array}{l}<0.001 \\
<0.001 \\
<0.001\end{array}$ & $\begin{array}{r}-5.9 \\
-1.3 \\
1.2\end{array}$ & $\begin{array}{r}-1.4 \\
-1.7 \\
3.3\end{array}$ & $\begin{array}{c}-12 \\
2.4 \\
3\end{array}$ & $\begin{array}{l}-2 \\
-1 \\
0.8\end{array}$ \\
\hline \multicolumn{6}{|c|}{$M W 54$} \\
\hline $\begin{array}{r}1 / 29 \\
4 / 10 \\
7 / 23 \\
10 / 07\end{array}$ & $\begin{array}{l}<0.001 \\
<0.001 \\
<0.001 \\
<0.001\end{array}$ & $\begin{array}{r}0.2 \\
1.6 \\
-1.5 \\
1.6\end{array}$ & $\begin{array}{c}0 \\
2.5 \\
-1.4 \\
-1.4\end{array}$ & $\begin{array}{l}10 \\
4.7 \\
1 \\
6\end{array}$ & $\begin{array}{r}6 \\
-2 \\
4 \\
-2\end{array}$ \\
\hline \multicolumn{6}{|c|}{$M W 57$} \\
\hline $\begin{array}{r}1 / 30 \\
4 / 30 \\
7 / 28 \\
11 / 18\end{array}$ & $\begin{array}{l}0.022 \\
0.010 \\
0.016 \\
0.007\end{array}$ & $\begin{array}{r}6.5 \\
-4.1 \\
8.0 \\
7.1\end{array}$ & $\begin{array}{c}7.0 \\
0 \\
-0.7 \\
0\end{array}$ & $\begin{array}{r}47 \\
185 \\
139 \\
92\end{array}$ & $\begin{array}{r}296 \\
4 \\
33 \\
7\end{array}$ \\
\hline \multicolumn{6}{|c|}{ MW59 } \\
\hline $10 / 28$ & $<0.001$ & 1.1 & 0.7 & 2 & -5 \\
\hline \multicolumn{6}{|c|}{$M W 60$} \\
\hline $10 / 28$ & $<0.001$ & -0.4 & 1.8 & 1 & -7 \\
\hline \multicolumn{6}{|c|}{ MW6I } \\
\hline $10 / 28$ & $<0.001$ & 3.4 & -0.7 & 16 & -4 \\
\hline \multicolumn{6}{|c|}{$M W 62$} \\
\hline $10 / 28$ & $<0.001$ & 2.5 & -1.1 & 8 & -4 \\
\hline \multicolumn{6}{|c|}{$M W 63$} \\
\hline $\begin{array}{r}1 / 09 \\
4 / 09 \\
7 / 08 \\
11 / 03\end{array}$ & $\begin{array}{l}<0.001 \\
<0.001 \\
<0.001 \\
<0.001\end{array}$ & $\begin{array}{r}2.5 \\
-1.1 \\
5.1 \\
3.9\end{array}$ & $\begin{array}{l}-2.7 \\
-1.8 \\
-3.6 \\
-0.5\end{array}$ & $\begin{array}{r}-6 \\
-2 \\
2 \\
5\end{array}$ & $\begin{array}{r}0 \\
-6 \\
3 \\
2\end{array}$ \\
\hline \multicolumn{6}{|c|}{$M W 64$} \\
\hline $\begin{array}{r}4 / 24 \\
7 / 22 \\
11 / 04\end{array}$ & $\begin{array}{l}0.001 \\
0.001 \\
0.002\end{array}$ & $\begin{array}{r}-4.1 \\
-0.2 \\
9.0\end{array}$ & $\begin{array}{c}-0.9 \\
-3.4 \\
0\end{array}$ & $\begin{array}{c}6 \\
-0.7 \\
5\end{array}$ & $\begin{array}{l}-6 \\
-6 \\
-5\end{array}$ \\
\hline \multicolumn{6}{|c|}{ MW65 } \\
\hline $\begin{array}{r}1 / 09 \\
4 / 21 \\
7 / 08 \\
11 / 03\end{array}$ & $\begin{array}{l}<0.001 \\
<0.001 \\
<0.001 \\
<0.001\end{array}$ & $\begin{array}{r}1.7 \\
-6.1 \\
-6.4 \\
4.8\end{array}$ & $\begin{array}{r}-5.6 \\
0.3 \\
-3.0 \\
0.9\end{array}$ & $\begin{array}{l}8 \\
8 \\
3 \\
4\end{array}$ & $\begin{array}{r}2 \\
-7 \\
3 \\
-1\end{array}$ \\
\hline
\end{tabular}


1992 Environmental Report-Paducah, Part 2

Table 5.8 (continued)

\begin{tabular}{|c|c|c|c|c|c|}
\hline Date & $\begin{array}{l}\text { Uranium } \\
(\mathrm{mg} / \mathrm{L})\end{array}$ & $\begin{array}{l}\text { Dissolved alpha } \\
\quad(\mathrm{pCi} / \mathrm{L})\end{array}$ & $\begin{array}{l}\text { Suspended alpha } \\
\quad(\mathrm{pCi} / \mathrm{L})\end{array}$ & $\begin{array}{l}\text { Dissolved beta } \\
(\mathrm{pCl} / \mathrm{L})\end{array}$ & $\begin{array}{l}\text { Suspended beta } \\
(\mathrm{pCi} / \mathrm{L})\end{array}$ \\
\hline \multicolumn{6}{|c|}{ MW66 } \\
\hline $1 / 24$ & $<0.001$ & -10.3 & -4.7 & 831 & -6 \\
\hline $4 / 29$ & $<0.001$ & 3.2 & 0.8 & 2595 & 22 \\
\hline $7 / 22$ & $<0.001$ & -3.5 & -4.3 & 333 & -2 \\
\hline $11 / 19$ & $<0.001$ & 14.5 & -0.8 & 777 & 6 \\
\hline \multicolumn{6}{|c|}{ MW67 } \\
\hline $1 / 14$ & $<0.001$ & 14.2 & -1.4 & 32 & 2 \\
\hline $4 / 28$ & $<0.001$ & 5.8 & -1.0 & -4 & -5 \\
\hline $7 / 21$ & $<0.001$ & -2.4 & 0.9 & -1 & -4 \\
\hline $11 / 04$ & $<0.001$ & -1.1 & -1.1 & 5 & 0 \\
\hline \multicolumn{6}{|c|}{$M W 68$} \\
\hline $1 / 22$ & $<0.001$ & 2.9 & -3.2 & 98 & -4 \\
\hline $4 / 23$ & $<0.001$ & 0.3 & -0.6 & 87 & -8 \\
\hline $7 / 21$ & $<0.001$ & -2.9 & -0.5 & 63 & -5 \\
\hline $10 / 29$ & $<0.001$ & 0 & -1.4 & 82 & 1 \\
\hline \multicolumn{6}{|c|}{ MW69 } \\
\hline $1 / 23$ & $<0.001$ & -12.0 & -4.7 & 0 & -11 \\
\hline $4 / 28$ & $<0.001$ & 3.0 & -0.8 & -18 & -6 \\
\hline $7 / 30$ & $<0.001$ & -1.8 & -4.5 & 4 & -3 \\
\hline \multicolumn{6}{|c|}{$M W 7 I$} \\
\hline $1 / 22$ & $<0.001$ & 3.2 & -3.6 & 11 & 0 \\
\hline $4 / 28$ & $<0.001$ & 0 & -0.9 & 14 & -4 \\
\hline $7 / 22$ & $<0.001$ & 0.9 & -3.6 & 9 & -8 \\
\hline $10 / 29$ & $<0.001$ & 2.1 & -1.0 & 9 & -3 \\
\hline \multicolumn{6}{|c|}{$M W 154$} \\
\hline & 0.013 & -5.9 & -5.6 & 370 & -5 \\
\hline $6 / 19$ & 0.014 & -10.0 & -0.2 & 466 & 5 \\
\hline $9 / 08$ & 0.012 & 15.8 & -0.9 & 410 & -7 \\
\hline $12 / 03$ & 0.012 & 1.5 & 3.6 & 483 & 4 \\
\hline \multicolumn{6}{|c|}{$M W / 84$} \\
\hline $1 / 31$ & $<0.001$ & & & & \\
\hline $10 / 19$ & $<0.001$ & & & & \\
\hline
\end{tabular}


1992 Environmental Report-Paducah, Part 2

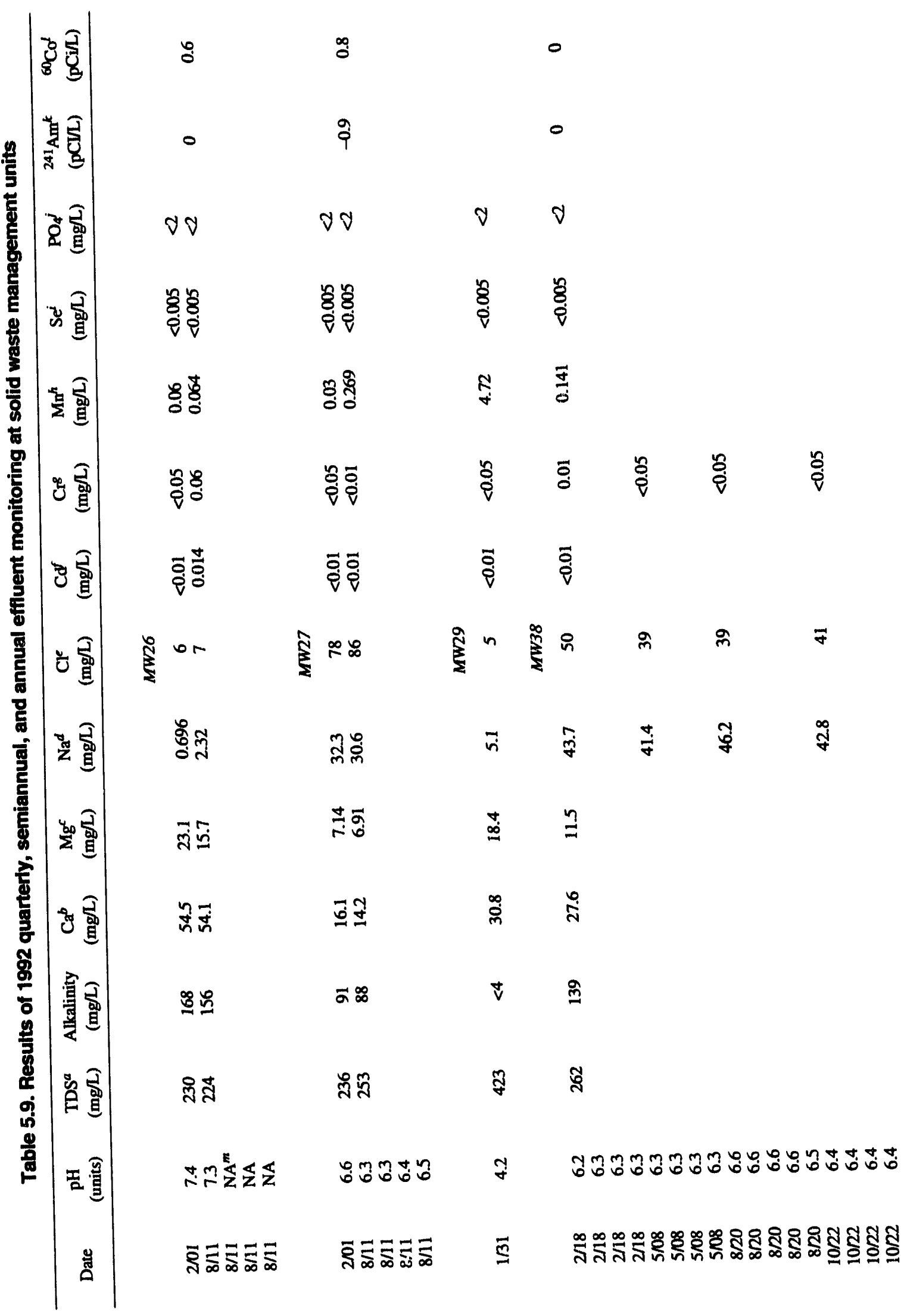




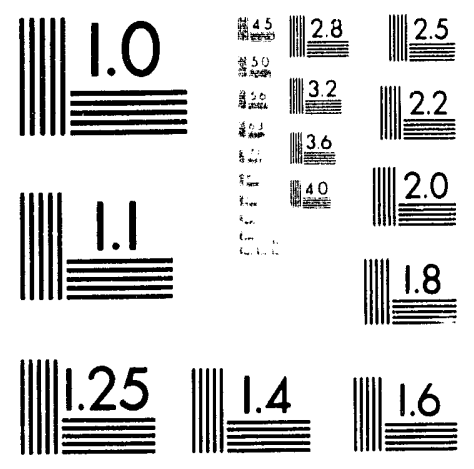



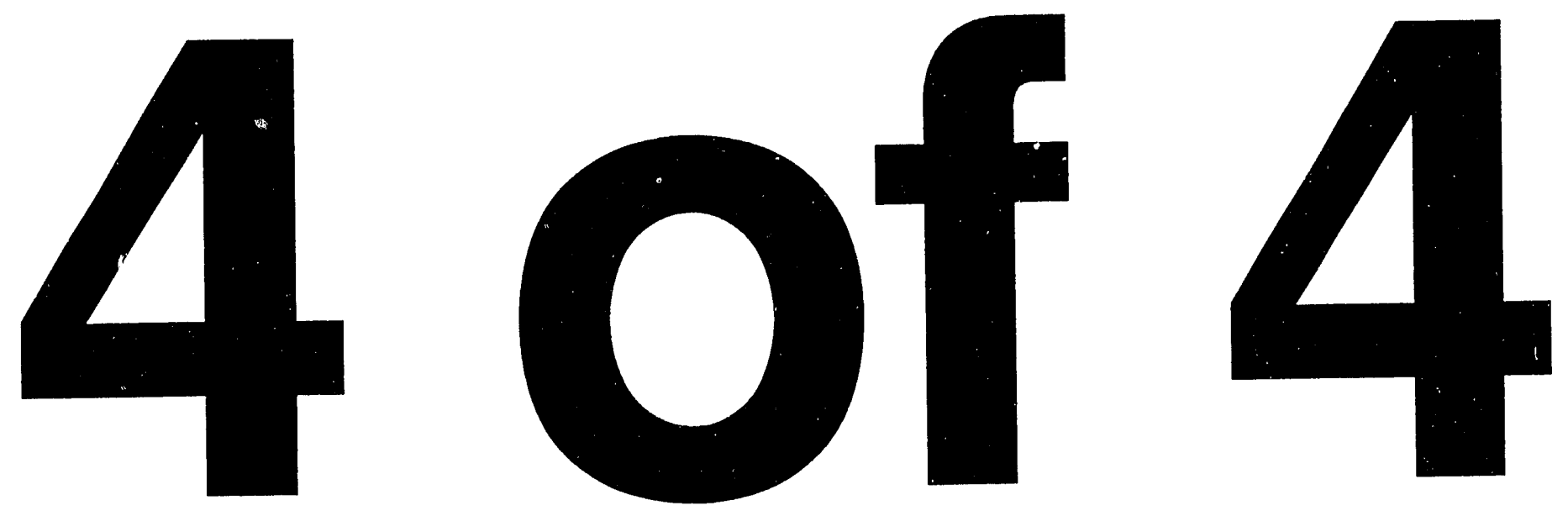
1992 Environmental Report-Paducah, Part 2

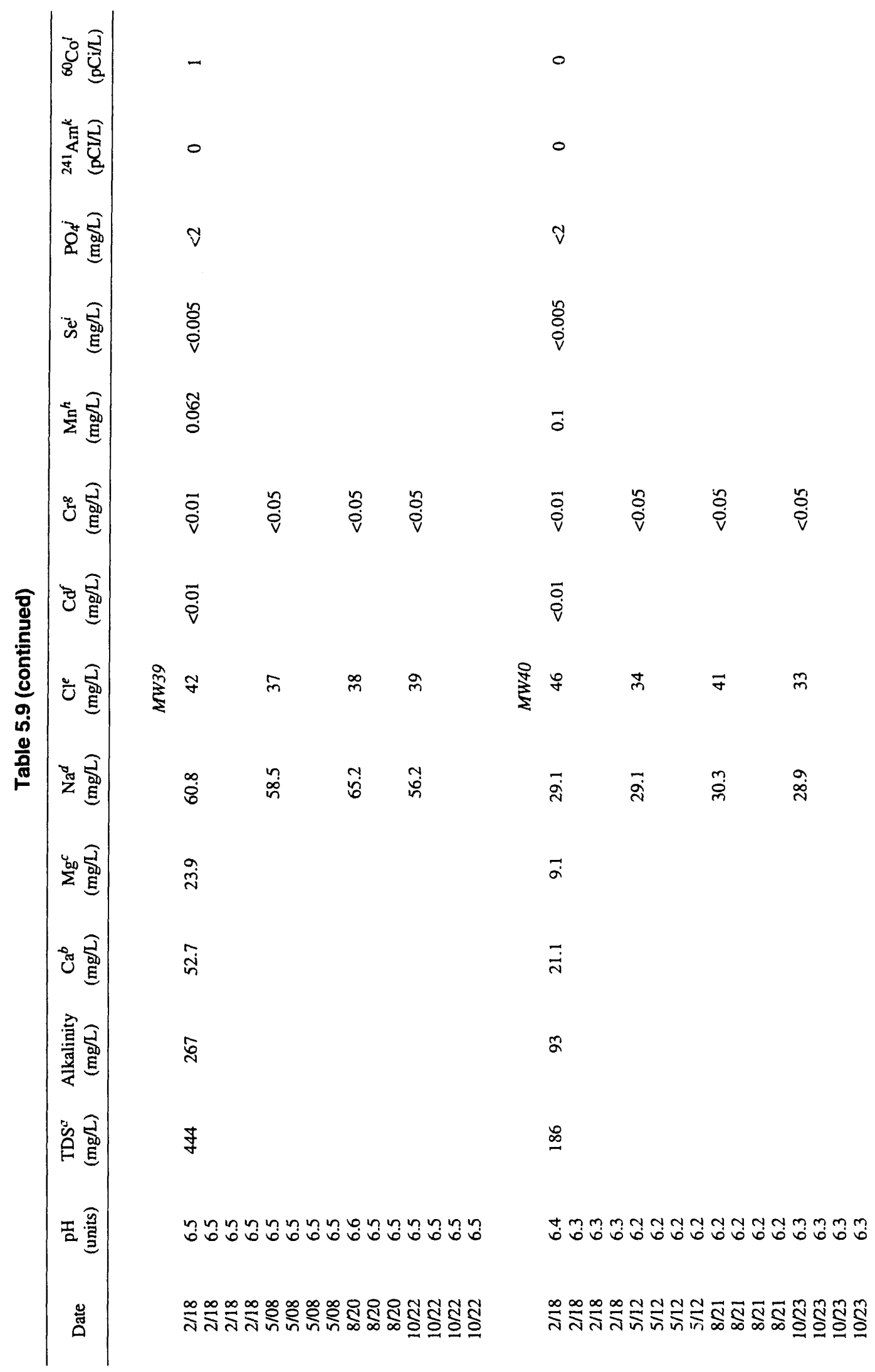


1992 Environmental Report-Paducah, Part 2

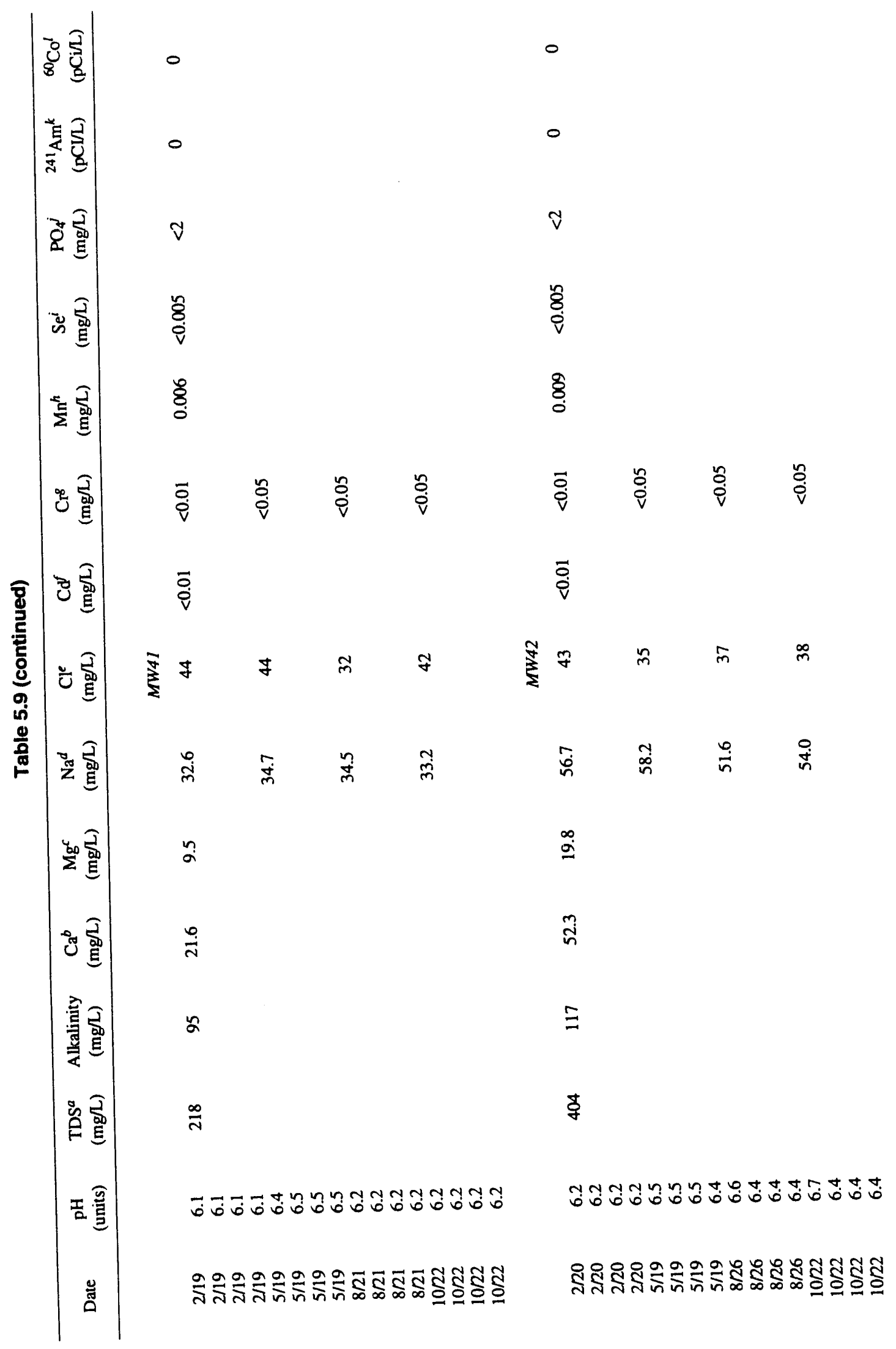


1992 Environmental Report-Paducah, Part 2

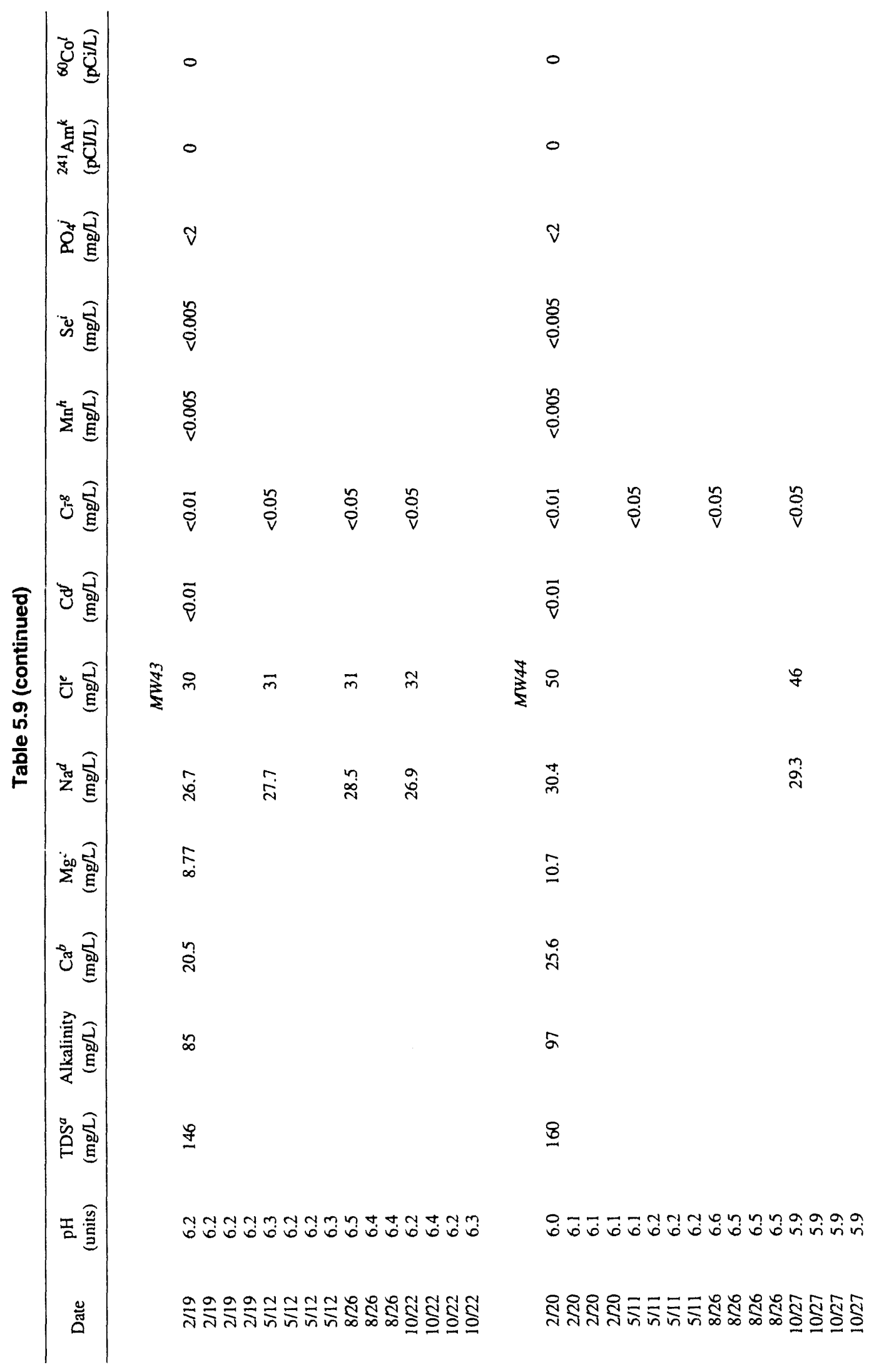

Groundwater 5-71 
1992 Environmental Report-Paducah, Part 2

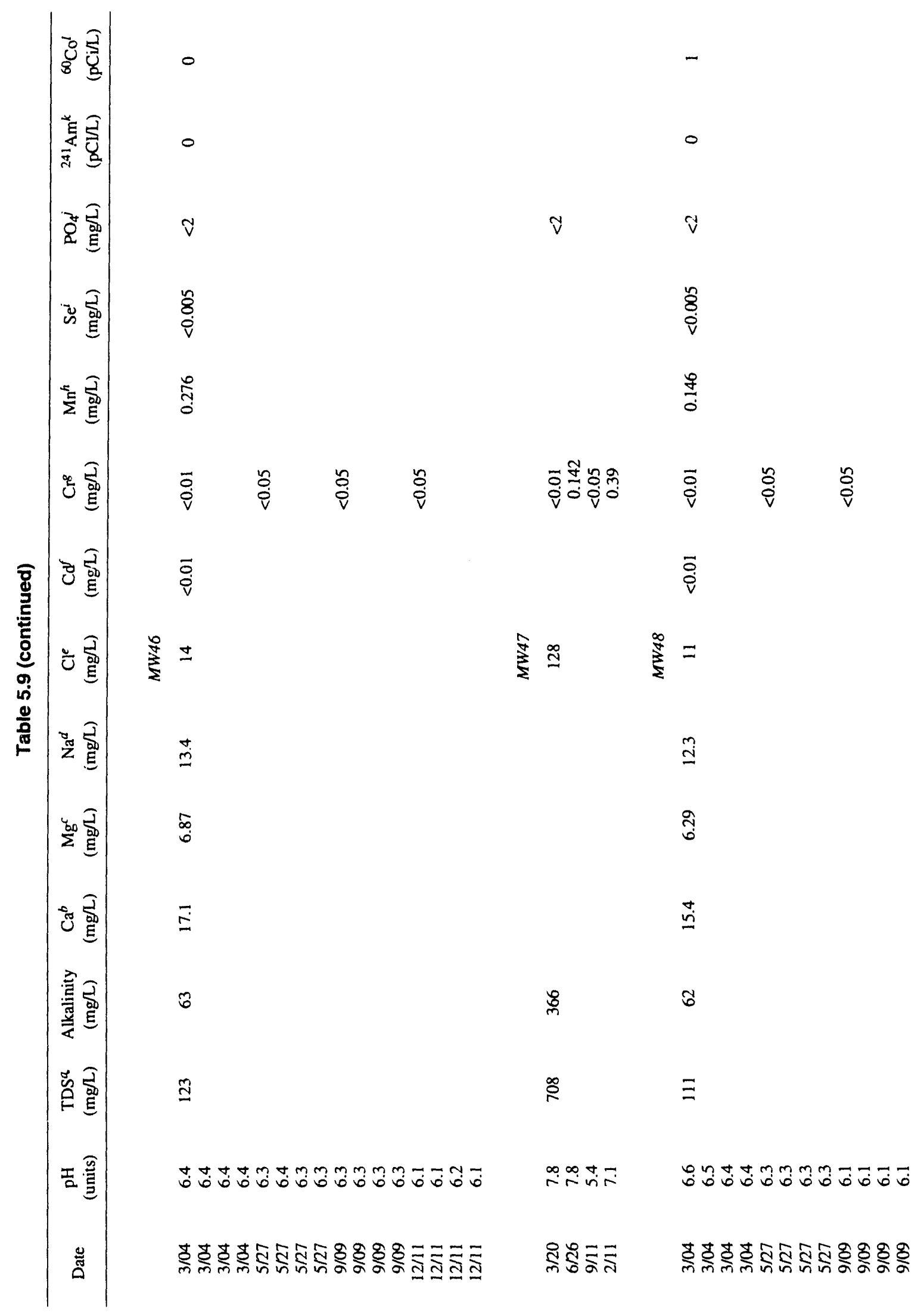




\section{Environmental Report-Paducah, Part 2}

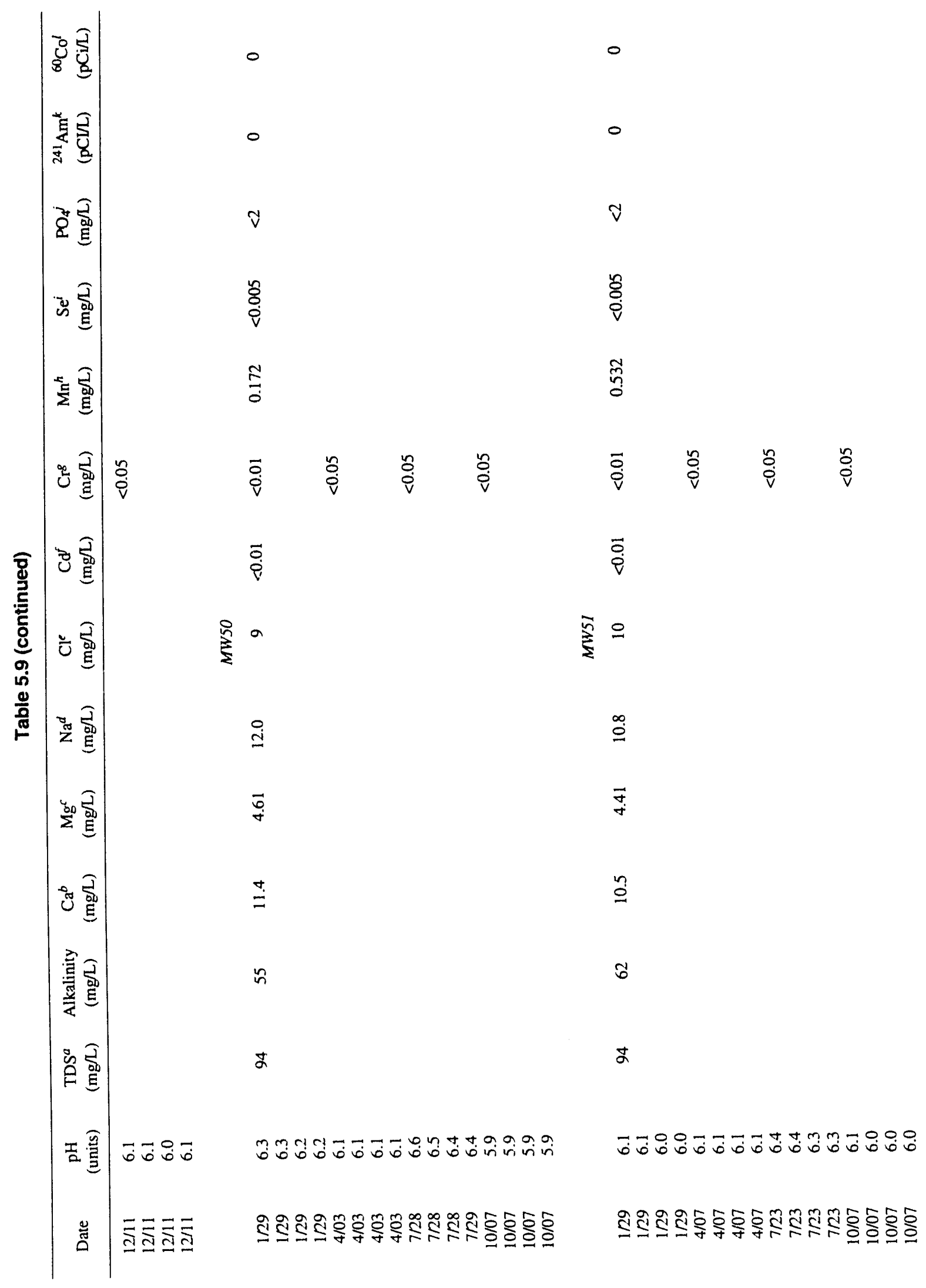


1992 Environmental Report-Paducah, Part 2

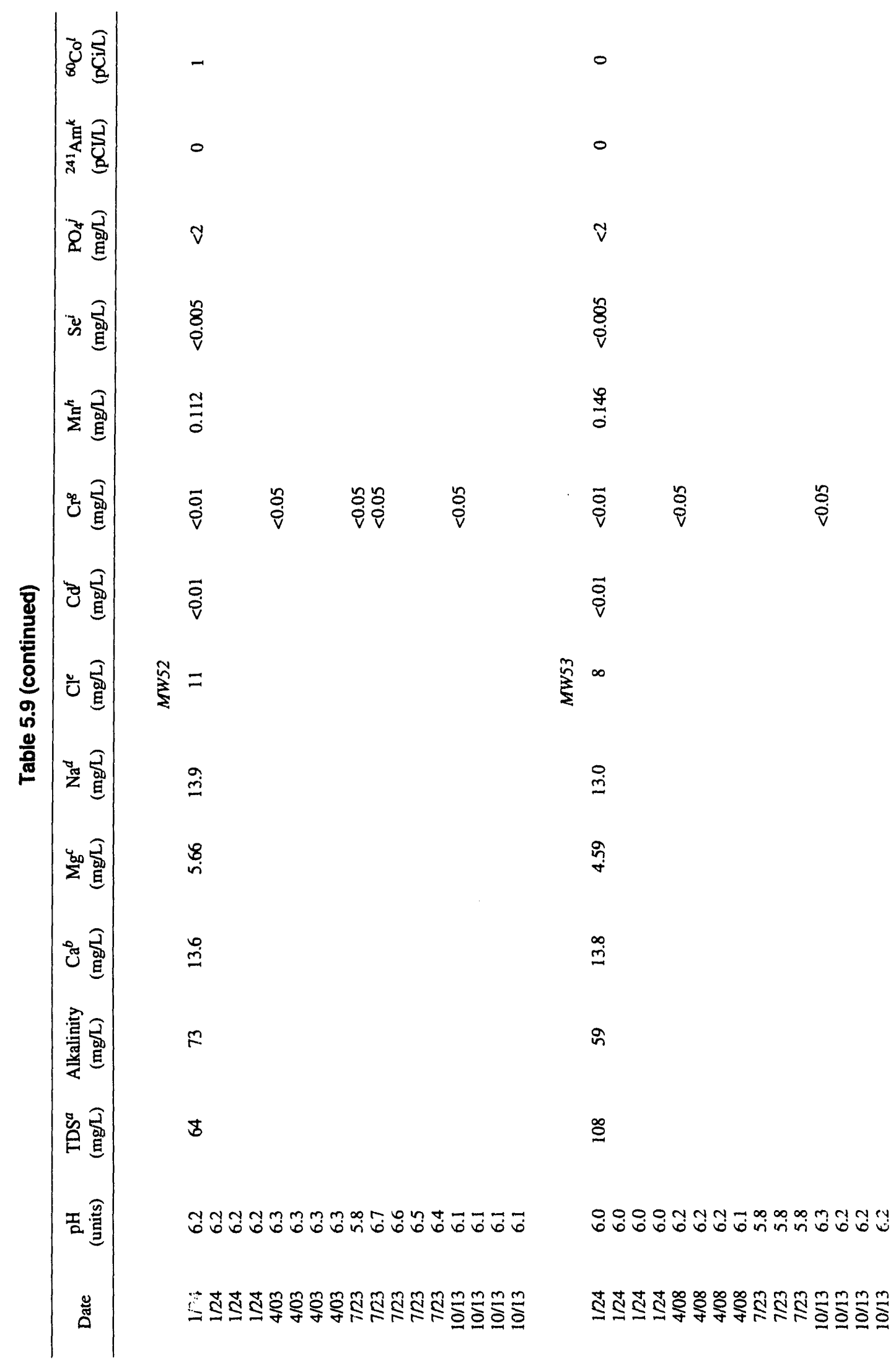


1992 Environmental Report-Paducah, Part 2

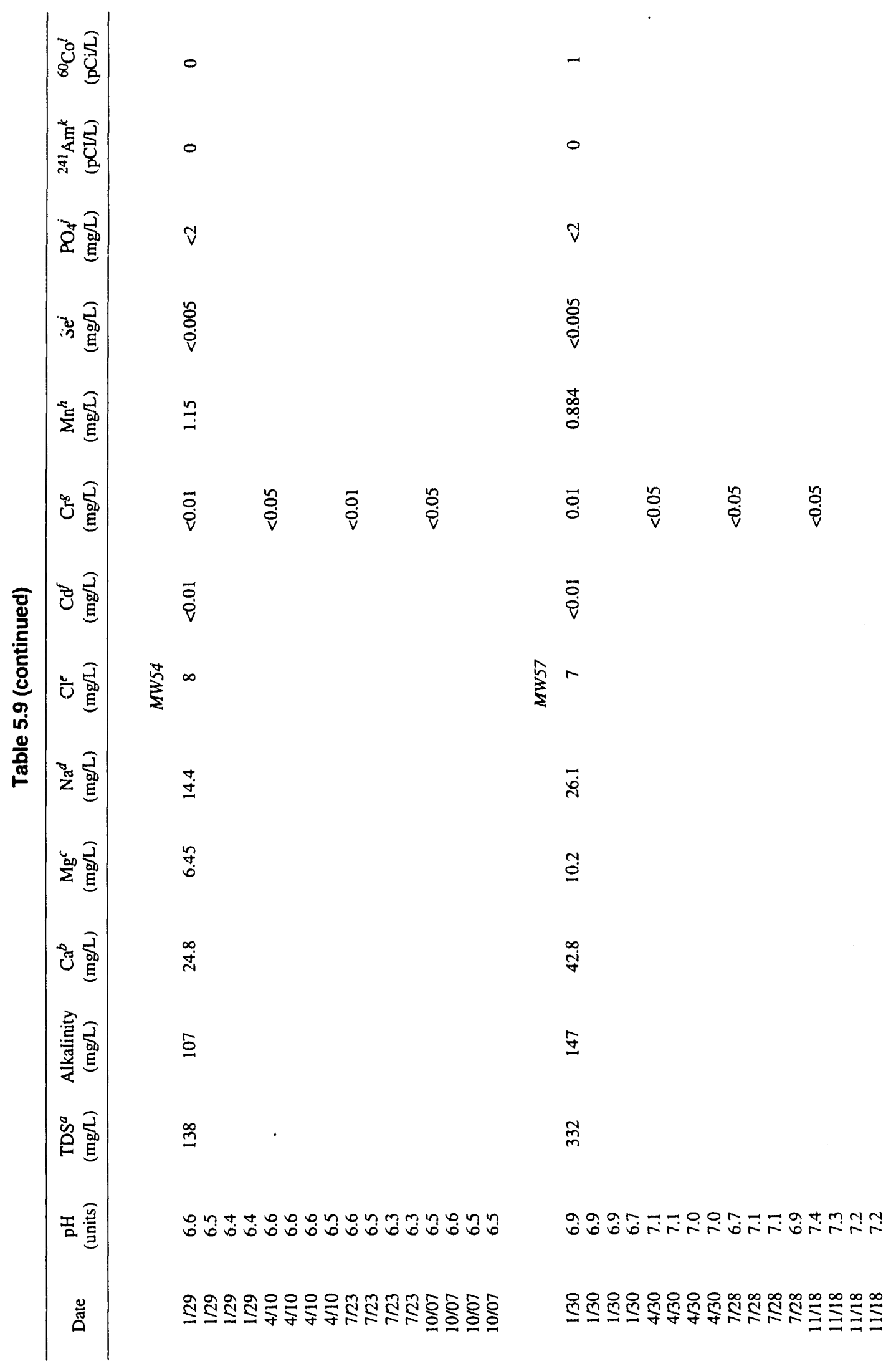




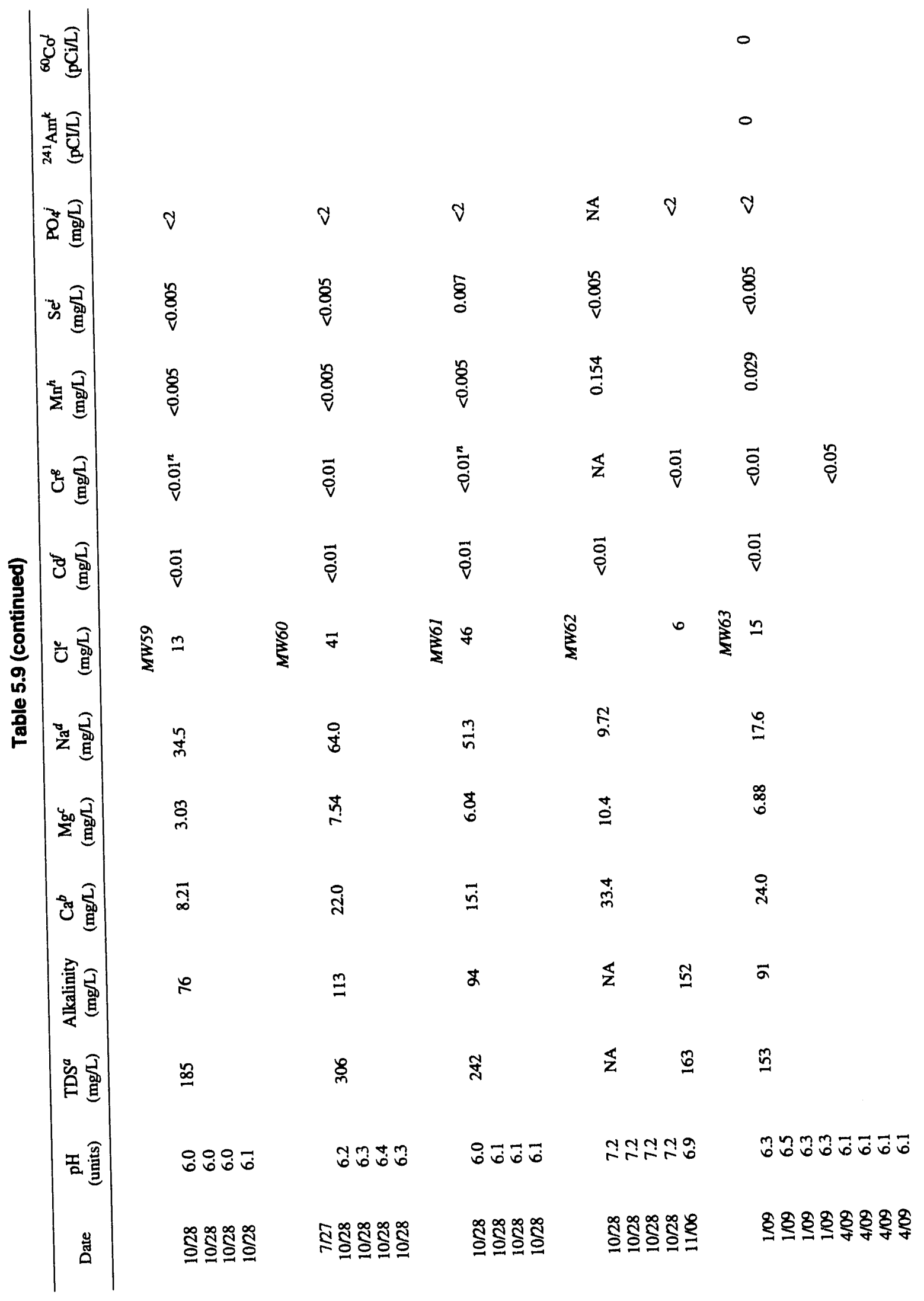




\section{Environmental Report-Paducah, Part 2}

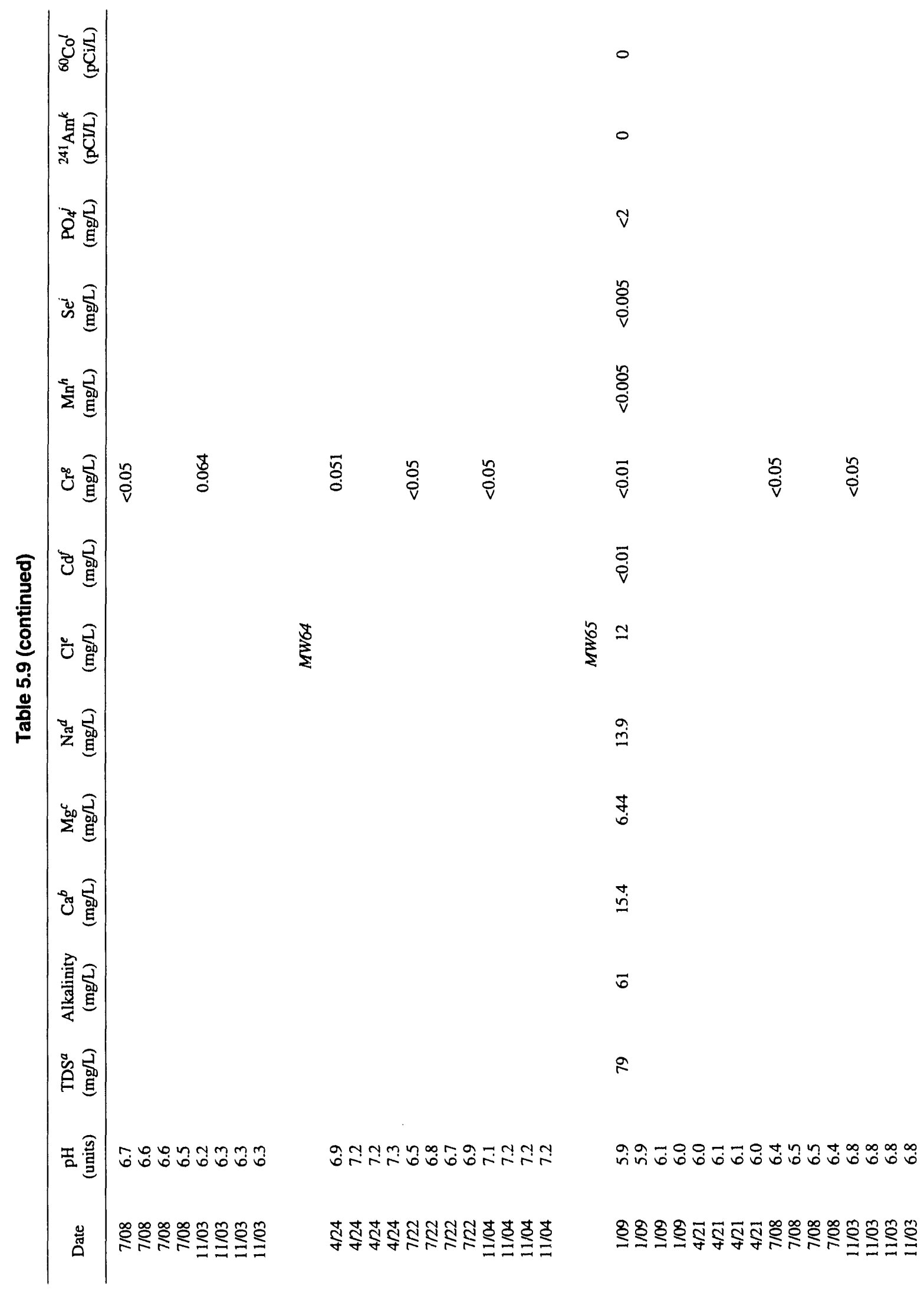




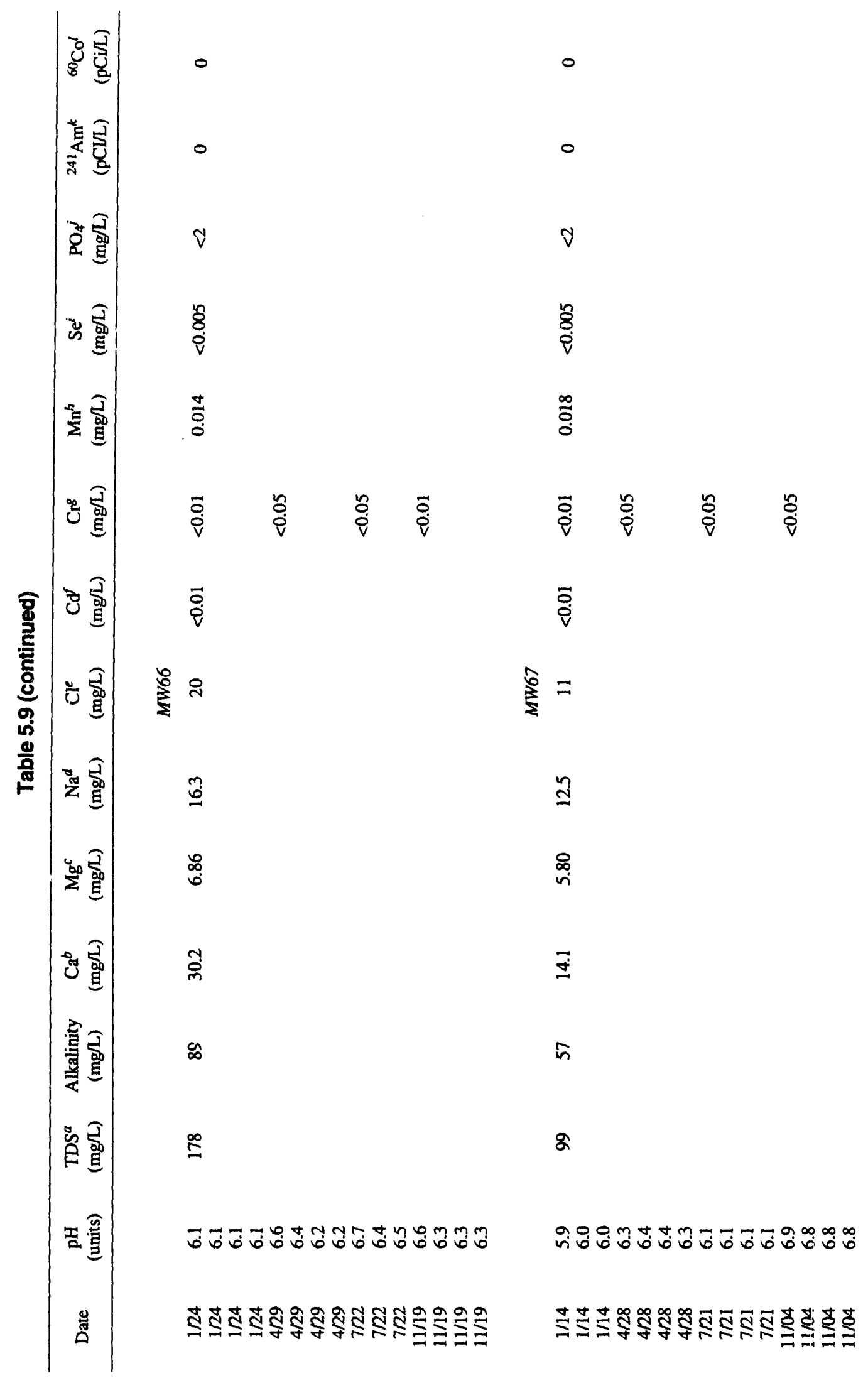


1992 Environmental Report-Paducah, Part 2

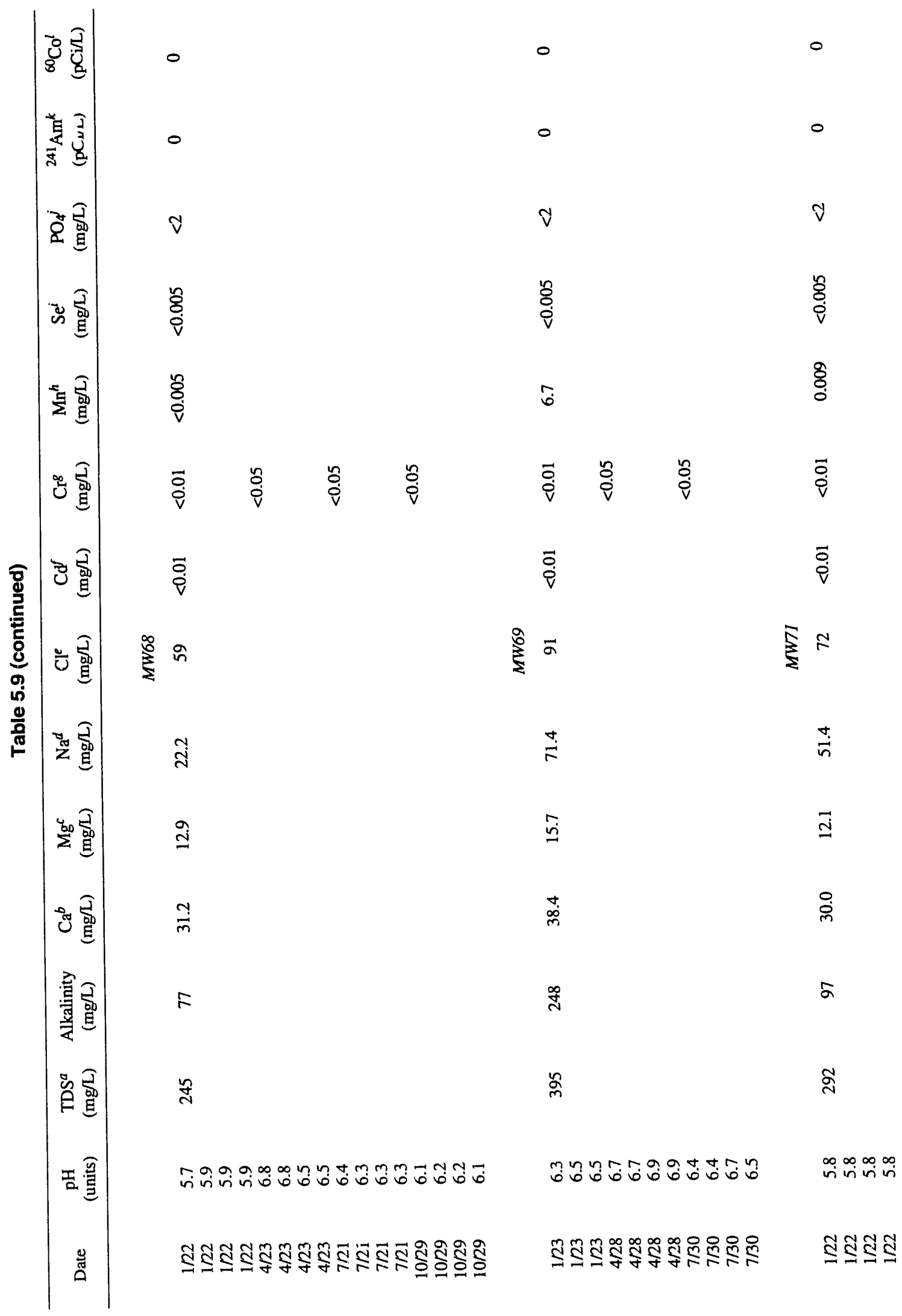


1992 Environmental Report-Paducah, Part 2

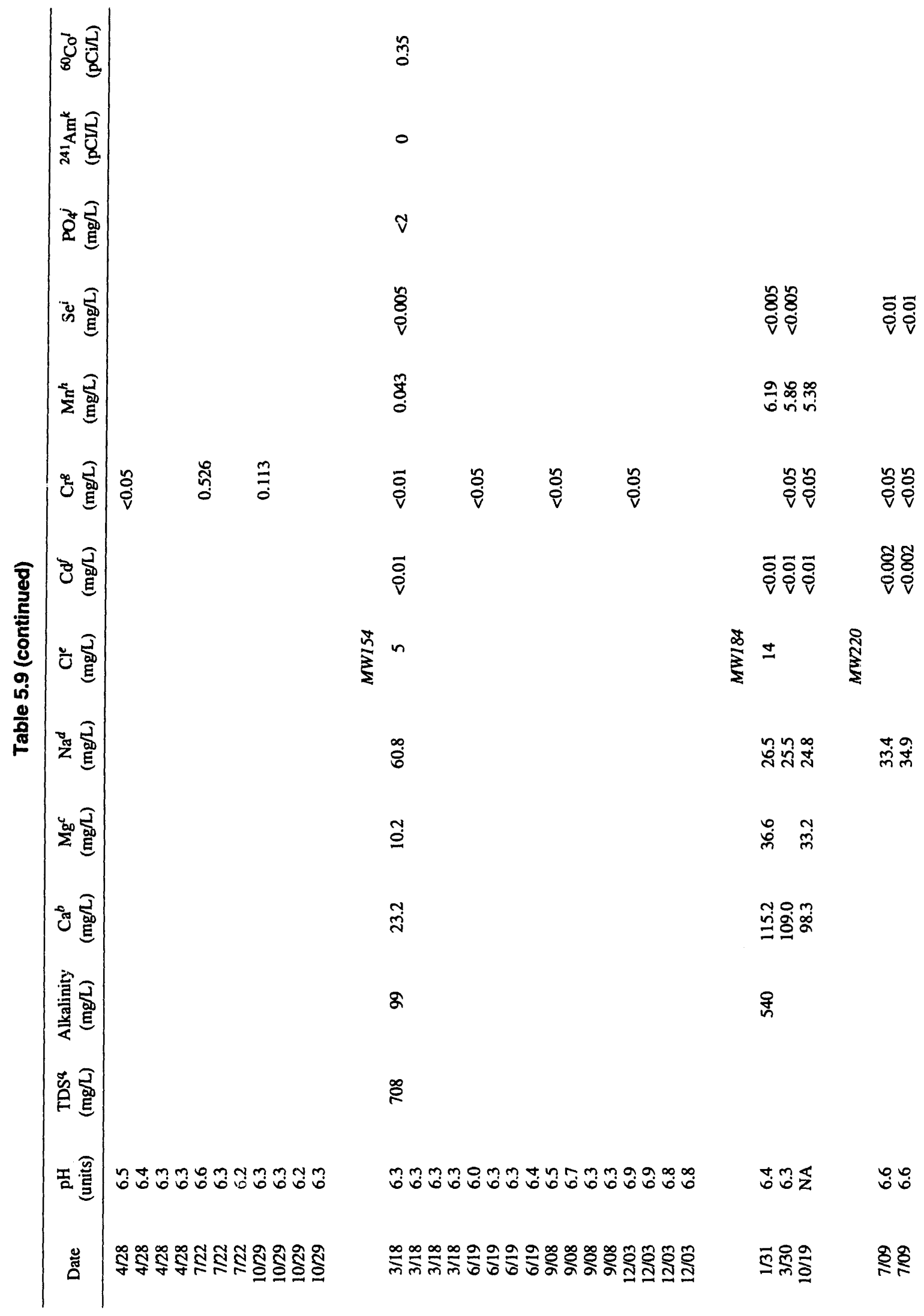


1992 Environmental Report-Paducah, Part 2

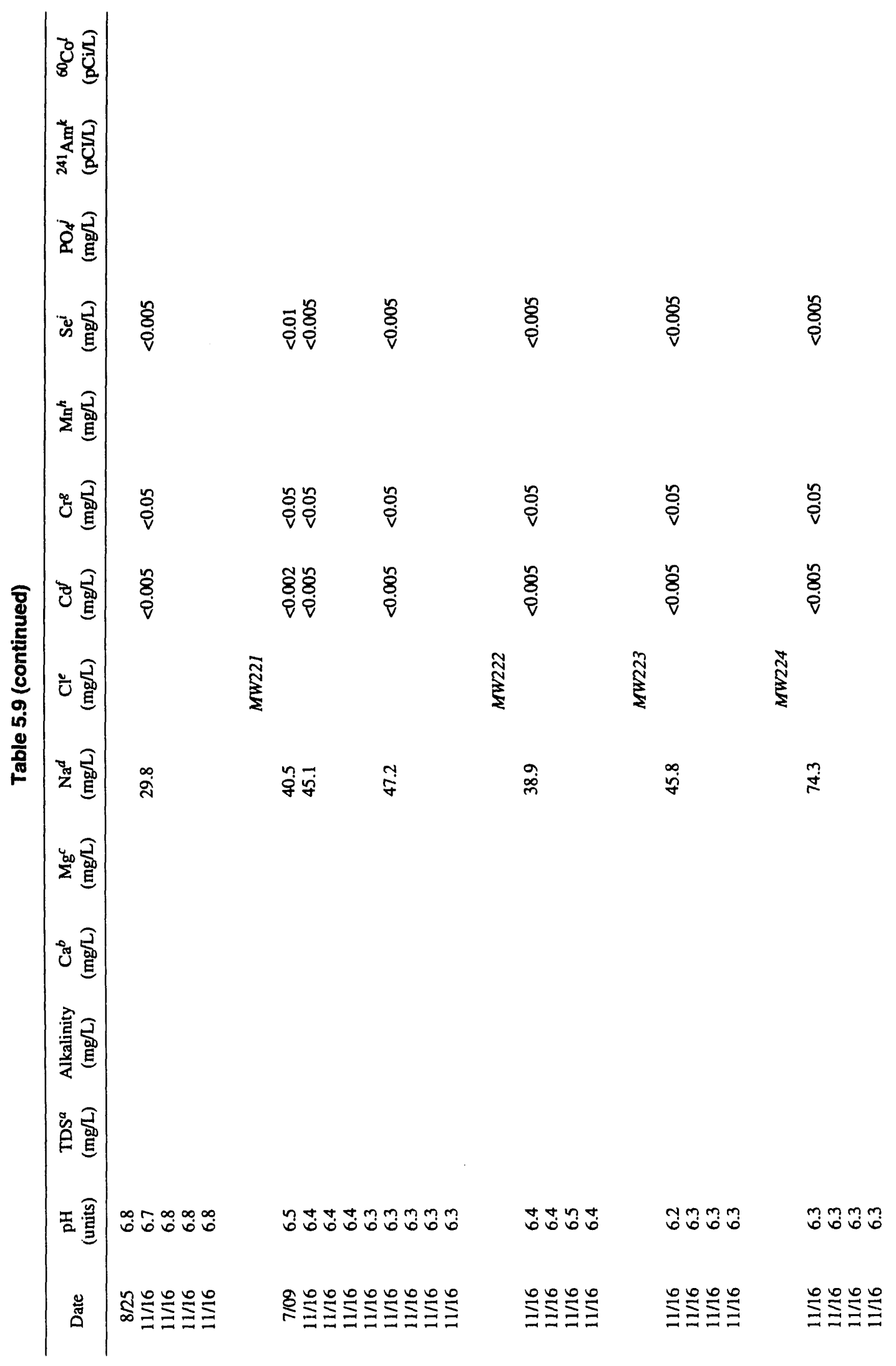


1992 Environmental Report-Paducah, Part 2

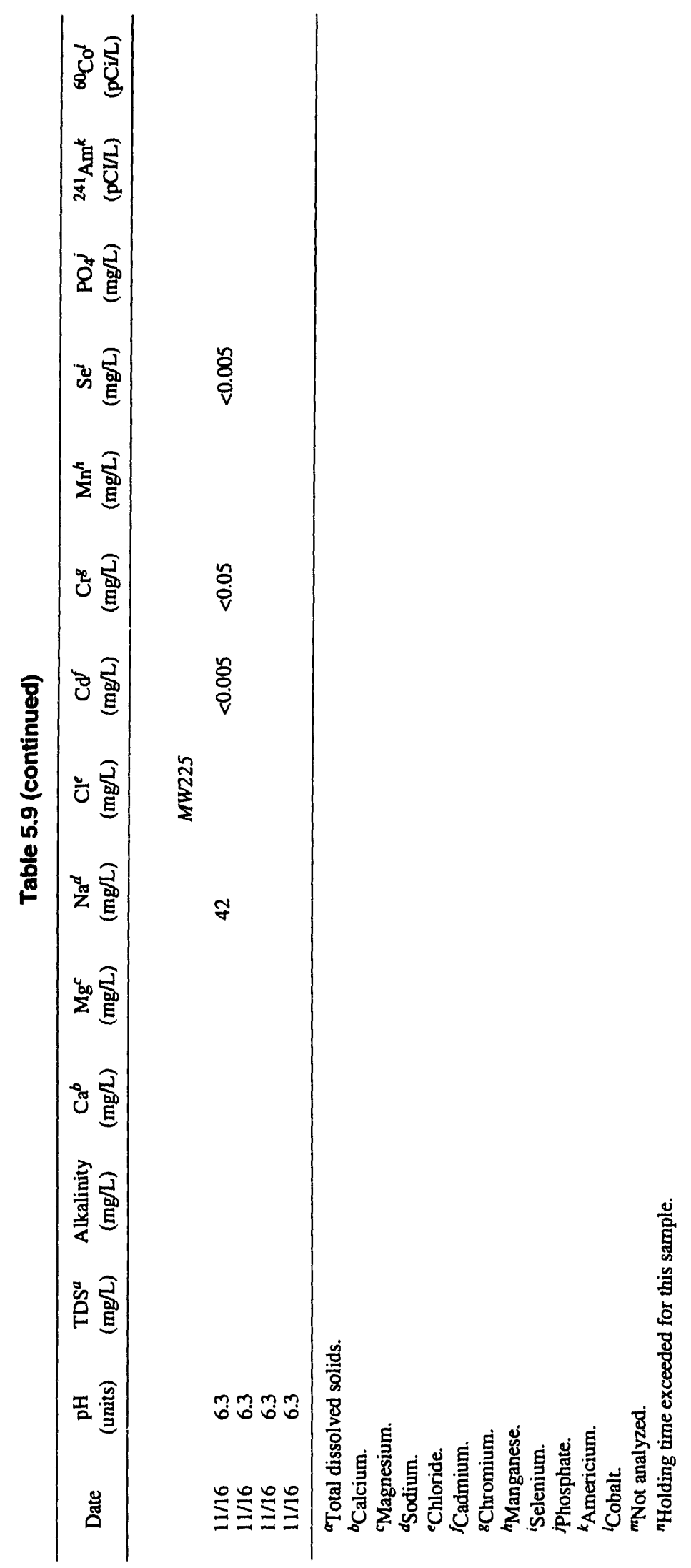


Table 5.10. Results of 1992 Phase III groundwater monitoring

\begin{tabular}{|c|c|c|}
\hline D:te & $\begin{array}{c}\mathrm{TCE}^{a} \\
(\mu \mathrm{g} / \mathrm{L})\end{array}$ & $\begin{array}{c}{ }^{99} \mathrm{Tc}^{b} \\
(\mathrm{pCi} / \mathrm{L})\end{array}$ \\
\hline & MW98 & \\
\hline \multirow[t]{2}{*}{ February 25} & $<1$ & 30 \\
\hline & MWgg & \\
\hline \multirow[t]{2}{*}{ March 3} & $<1$ & 3 \\
\hline & $M W I 02$ & \\
\hline \multirow[t]{2}{*}{ February 28} & $<1$ & 0 \\
\hline & $M W / 03$ & \\
\hline \multirow[t]{2}{*}{ February 28} & $<1$ & 2 \\
\hline & MWI04 & \\
\hline \multirow[t]{2}{*}{ February 27} & $<1$ & 0 \\
\hline & $M W 107$ & \\
\hline \multirow[t]{2}{*}{ April 22} & 1 & \\
\hline & $M W 108$ & \\
\hline April 7 & 1200 & 55 \\
\hline April 7 & 1300 & \\
\hline April 7 & 1800 & 52 \\
\hline April 7 & 1200 & 50 \\
\hline April 8 & 1200 & \\
\hline April 8 & 1100 & \\
\hline April 9 & 920 & \\
\hline April 9 & 1000 & \\
\hline April 9 & 920 & \\
\hline April 9 & 910 & \\
\hline April 9 & 870 & \\
\hline April 9 & 960 & 60 \\
\hline April 10 & 940 & \\
\hline April 10 & 910 & 52 \\
\hline \multirow[t]{2}{*}{ April 10} & 950 & \\
\hline & $M W 109$ & \\
\hline \multirow[t]{2}{*}{ April 16} & 810 & \\
\hline & $M W I 10$ & \\
\hline \multirow[t]{2}{*}{ April 22} & $<1$ & \\
\hline & $M W / / 4$ & \\
\hline April 16 & 9 & \\
\hline
\end{tabular}


1992 Environmental Report-Paducah, Part 2

Table 5.10 (continued)

\begin{tabular}{ccc}
\hline Date & $\begin{array}{c}\mathrm{TCE}^{a} \\
(\mu \mathrm{g} / \mathrm{L})\end{array}$ & $\begin{array}{c}{ }^{99} \mathrm{Tc}^{b} \\
(\mathrm{pCi} / \mathrm{L})\end{array}$ \\
\hline April 20 & $M W 115$ & \\
& $<1$ & \\
April 20 & $M W 117$ \\
\hline${ }^{a}$ Trichloroethylene. & 48 \\
${ }^{b}$ Technetium-99.
\end{tabular}


Table 5.11. Results of 1992 Paducah Gaseous Diffusion Plant (PGDP) state Cabinet of Human Resources (CHR) radiochemical data comparison for groundwater

\begin{tabular}{lllllll}
\hline \multirow{2}{*}{ Sample ID } & Date & & Gross alpha $(\mathrm{pCi} / \mathrm{L})$ & & ${ }^{99} \mathrm{Tc}(\mathrm{pCi} / \mathrm{L})$ \\
\cline { 3 - 5 } & PGDP result & CHR result & PGDP result & CHR result & PGDP result CHR result \\
\hline
\end{tabular}

$4420-92$
$4954-92$
$5512-92$
$6166-92$
Annual maximum
Annual minimum

$4421-92$

4955-92

$5513-92$

6167-92

Annual maximum Annual minimum

4422-92

4956-92

$5514-92$

$6168-92$

Annual maximum

Annual minimum

4467-92

$4957-92$

$5515-92$

6169-92

Annual maximum

Annual minimum

4423-92

4958-92

5516-92

6170-92

Annual maximum

Annual minimum

4424-92

4959-92

5517-92

6171-92

Annual maximum

Annual minimum
$R-2$

$\begin{array}{rll}2-12-92 & -4.8 & 12 \pm \\ 5-13-92 & 6.5 & 13 \pm \\ 8-18-92 & 9.8 & 15 \pm \\ 11-10-92 & 2.6 & 16 \pm \\ & 14.7 & 16 \pm \\ & -8.1 & 12 \pm\end{array}$

$12 \pm 2 \quad 556$

$13 \pm 2 \quad 330$

$15 \pm 2$

$16 \pm 2 \quad 698$

$6 \pm 2 \quad 698$

$12 \pm 2$

\section{2-12-92 5.1}

5-13-92 -0.4

8-18-92 2.9

11-10-92

3.0

5.4

$-2.8$

2-12-92

5-13-92

8-18-92

$11-10-92$

\section{1}

$-1.4$

$-1.4$

2.7

6.5

$-2.4$

2-12-92

5-13-92

8-18-92

$11-10-92$

2.5
1.5
1.5
0.6
3.7
-5.4

$-5.4$

$3 \pm 1$

$4 \pm 1$

$3 \pm 1$

$2 \pm 1$

$4 \pm 1$

$2 \pm 1$

$2 \pm 1$

$<1$

$2 \pm 1$

$<1$

$2 \pm 1$

$<1$

\section{1}

160

127

119

183

119

$R-4$

\section{5}

33

23

27

35

$-4$

$R-5$

$<1$

$<1$

$<1$

$<1$

$<1$

2-12-92

5-13-92

8-18-92

$11-10-92$

\section{8}

2.4

Backupd

$-2$

3.2

$-5.2$

$<1$
$<1$
$<1$
$<1$
$<1$

$<1$

$<1$

$<1$

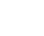

$$
\begin{array}{r}
2-12-92 \\
5-13-92 \\
8-18-92 \\
11-10-92
\end{array}
$$

3.2
0.9
Backup
0
4.5
-3.0

$R-5$

R. 10

R-40

$<1$
$<1$
$<1$
$<1$
$<1$

$333 \pm 5$
321
$498 \pm 6$
$679 \pm 8$
$679 \pm 8$
321

611

545

910.8

1102

1102

442

$107 \pm 3$
$150 \pm 4$
$135 \pm 3$
$115 \pm 3$
$150 \pm 4$
$107 \pm 3$

243

202.2

215

287

158

$574 \pm 13$
$531 \pm 13$
$813 \pm 15$
$1008 \pm 9$
$1008 \pm 9$
$531 \pm 13$
161

$173 \pm 9$
$256 \pm 10$
$222 \pm 10$
$178 \pm 5$
$256 \pm 10$
$173 \pm 9$

$\begin{array}{lll}28 \pm 2 & 48 & 36 \pm 8 \\ 14 \pm 1 & <25 & 16 \pm 8 \\ 21 \pm 2 & 34 & 29 \pm 8 \\ 12 \pm 1 & 39 & 16 \pm 4 \\ 28 \pm 2 & 121 & 36 \pm 8 \\ 12 \pm 1 & <25 & 16 \pm 4\end{array}$

$\begin{array}{ll}<25 & N^{b} \\ <25 & \text { NR } \\ <25 & \text { NR } \\ <25 & \text { NR } \\ <25^{c} & \end{array}$

$\begin{array}{ll}<2 & <25 \\ <2 & <25 \\ <3 & <25 \\ <2 & <25 \\ <3 & <25^{c} \\ <2 & \end{array}$

$\begin{array}{llll}5 & <2 & <25 & \text { NR } \\ 3 & <2 & <25 & \text { NR } \\ \text { Backup } & <3 & \text { Backup } & \text { NR } \\ -3 & <2 & <25 & \text { NR } \\ 13 & <3 & <25^{\circ} & \\ -5 & <2 & & \end{array}$

$\begin{array}{ll}3 & <2 \\ 1 & 3 \pm 1 \\ \text { Backup } & <3 \\ 1 & 3 \pm 1 \\ 10 & 3 \pm 1 \\ -4 & <2\end{array}$


1992 Environmental Report-Paducah, Part 2

Tabile 5.11 (continued)

\begin{tabular}{|c|c|c|c|c|c|c|c|}
\hline \multirow{2}{*}{ Sample ID } & \multirow{2}{*}{ Date } & \multicolumn{2}{|c|}{ Gross alpha (pCi/L) } & \multicolumn{2}{|c|}{ Gross beta $(\mathrm{pCi} / \mathrm{L})$} & \multicolumn{2}{|c|}{${ }^{99} \mathrm{Tc}(\mathrm{pCi} / \mathrm{L})$} \\
\hline & & PGDP result & CHR result & PGDP result & CHR result & PGDP result & CHR result \\
\hline
\end{tabular}

\begin{tabular}{|c|c|c|c|c|c|c|c|}
\hline \multicolumn{8}{|c|}{$R-2 I$} \\
\hline $4425-92$ & $2-12-92$ & 1.0 & $1 \pm 1$ & 13 & $<2$ & $<25$ & NR \\
\hline $4965-92$ & $5-13-92$ & -0.8 & $2 \pm 1$ & 0.8 & $3 \pm 1$ & $<25$ & NR \\
\hline $5519-92$ & $8-18-92$ & 0.3 & $2 \pm 1$ & -2 & $<3$ & $<25$ & NR \\
\hline $6173-92$ & $11-10-92$ & -2.8 & $<1$ & 1 & $2 \pm 1$ & $<25$ & NR \\
\hline Annual maximum & & 1.0 & $2 \pm 1$ & 13 & $3 \pm 1$ & $<25^{c}$ & \\
\hline Annual minimum & & -7.9 & $<1$ & -7 & $<2$ & & \\
\hline \multicolumn{8}{|c|}{$R-26$} \\
\hline $4436-92$ & $2-12-92$ & 0.5 & $<1$ & 3 & $<2$ & $<25$ & NR \\
\hline $4961-92$ & $5-13-92$ & Backup & $2 \pm 1$ & Backup & $2 \pm 1$ & Backup & NR \\
\hline $5520-92$ & $8-18-92$ & Backup & $<1$ & Backup & $<3$ & Backup & NR \\
\hline $6174-92$ & $11-10-92$ & Backup & $<1$ & Backup & $<2$ & Backup & NR \\
\hline Annual maxim:ım & & $0.5^{e}$ & $2 \pm 1$ & $3^{e}$ & $<3$ & $<25^{c}$ & \\
\hline Annual minimum & & & $<1$ & & $<2$ & & \\
\hline \multicolumn{8}{|c|}{$R-13$} \\
\hline $4960-92$ & $5-13-92$ & 3.5 & $<1$ & 3 & $<2$ & $<25$ & $<9$ \\
\hline $5518-92$ & $8-18-92$ & 2 & $<1$ & -0.2 & $<3$ & $<25$ & NR \\
\hline $6172-92$ & $11-10-92$ & -1 & $<1$ & -0.8 & $<2$ & $<25$ & NR \\
\hline Annual maximum & & 6.2 & $<1$ & 11 & $<3$ & $<25^{c}$ & $<9$ \\
\hline Annual minimum & & -12.6 & & -8 & $<2$ & & \\
\hline \multicolumn{8}{|c|}{$R-6$} \\
\hline $4427-92$ & $2-12-92$ & 3.7 & $3 \pm 1$ & 8 & $2 \pm 1$ & $<25$ & NR \\
\hline $4962-92$ & $5-13-92$ & 6.0 & $3 \pm 1$ & 6 & $4 \pm 1$ & $<25$ & NR \\
\hline $5521-92$ & $8-18-92$ & 2.0 & $3 \pm 1$ & -2 & $<3$ & $<25$ & NR \\
\hline $6175-92$ & $11-10-92$ & 3.7 & $2 \pm 1$ & 5 & $2+1$ & $<25$ & NR \\
\hline Annual maximum & & 10.4 & $3 \pm 1$ & 17 & $4 \pm 1$ & $<25^{c}$ & \\
\hline Annual minimum & & -2.1 & $2 \pm 1$ & -4 & $2 \pm 1$ & & \\
\hline \multicolumn{8}{|c|}{$R-253$} \\
\hline $4428-92$ & $2-12-92$ & Backup & $2 \pm 1$ & Backup & $<2$ & Backup & NR \\
\hline $4963-92$ & $5-13-92$ & 6.8 & $<1$ & 6 & $2 \pm 1$ & $<25$ & NR \\
\hline $5523-92$ & $8-18-92$ & 0.8 & $<1$ & 0 & $<3$ & $<25$ & NR \\
\hline $6176-92$ & $11-10-92$ & Backup & $1 \pm 1$ & Backup & $<2$ & Backup & NR \\
\hline Annual maximum & & 6.8 & $2 \pm 1$ & 6 & $<3$ & $<25^{c}$ & \\
\hline Annual minimum & & 0.8 & $<1$ & 0 & $<2$ & & \\
\hline
\end{tabular}


1992 Environmental Report-Paducah, Part 2

Table 5.11 (continued)

\begin{tabular}{|c|c|c|c|c|c|c|c|}
\hline \multirow{2}{*}{ Sample ID } & \multirow{2}{*}{ Date } & \multicolumn{2}{|c|}{ Gross alpha (pCi/L) } & \multicolumn{2}{|c|}{ Gross beta $(\mathrm{pCi} / \mathrm{L})$} & \multicolumn{2}{|c|}{${ }^{99} \mathrm{Tc}(p \mathrm{Ci} / \mathrm{L})$} \\
\hline & & PGDP result & CHR result & PGDP result & CHR result & PGDP result & CHR result \\
\hline \multicolumn{8}{|c|}{$R-254$} \\
\hline $4429-92$ & $2-12-92$ & Backup & $<1$ & Backup & $<2$ & Backup & NR \\
\hline $4964-92$ & $5-13-92$ & 1.1 & $<1$ & -1 & $<2$ & $<25$ & NR \\
\hline $5523-92$ & $8-18-92$ & Backup & $2 \pm 1$ & Backup & $<3$ & Backup & NR \\
\hline $6177-92$ & $11-10-92$ & Backup & $1 \pm 1$ & Backup & $3 \pm 1$ & Backup & NR \\
\hline Annual maximum & & $1.1^{e}$ & $2 \pm 1$ & $-1^{e}$ & $3 \pm 1$ & $<25^{c}$ & \\
\hline Annual minimum & & & $<1$ & & $<2$ & & \\
\hline
\end{tabular}

aThe annual maximum and annual minimum values reported by PGDP are the maximum and minimum values that resulted from all samples taken by PGDP at the specified location in 1992, not those taken in conjunction with the CHR. The total number of samples taken in 1992 differed among sampling locations (e.g., a single sample was collected and analyzed from R-26 in 1992, while approximately 52 samples were collected and analyzed from R-10 in 1992). A maximum of one sample per location was taken per quarter by the CHR; therefore, the annual maximum and minimum values reported by the CHR are the maximum and minimum of the CHR results reported in this table.

'Not run.

'Technetium-99 results for all samples taken at this location in 1992 were $<25 \mathrm{pCi} / \mathrm{L}$.

"Samples designated as backup were collected by PGDP at the same time the CHR samples were collected. These samples were not analyzed by PGDP unless the corresponding CHR samples were damaged, lost, or yielded questionable results.

${ }^{e} \mathrm{~A}$ single sample was collected and analyzed for this constituent by PGDP at the specified location in 1992. 
6. Biological Monitoring 
1992 Environmental Report-Paducah, Part 2

All data for this section are presented in Part 1.

Biological Monitoring 6-3 


\section{Soil and Sediment Monitoring}


1992 Environmental Report-Paducah, Part 2

All data for this section are presented in Part 1. 
8. Unusual Occurrences and Special Studies 
1992 Environmental Report-Paducah, Part 2

All data for this section are presented in Part 1.

Unusual Occurrences and Special Studies 8-3 
9. Solid Waste Management Program 
1992 Environmental Report-Paducah, Part 2

All data for this section are presented in Part 1 . 
10. Quality Assurance 
1992 Environmental Report-Paducah, Part 2

Table 10.1. PGDP environmental analysis procedures for air

\begin{tabular}{|c|c|c|c|}
\hline Parameter & Procedure $^{a}$ & $\begin{array}{l}\text { NIOSH }{ }^{b} \text { or } \\
\text { EPA }^{c} \text { method }\end{array}$ & $\begin{array}{l}\text { Lowest concentration } \\
\text { reported }\end{array}$ \\
\hline $\begin{array}{l}\text { Gross alpha, beta, air filters, } \\
\text { radiochemistry }\end{array}$ & $R-1-A$ & APHA $601,602^{d}$ & Result obtained \\
\hline Fluoride, air, $\operatorname{SIE}^{e}$ ( $\mu \mathrm{g} /$ sample) & SA-F-2 & & 5 \\
\hline Fluoride, stacks, SIE (mg/L) & SA-F-2 & & $\begin{array}{l}0.1 \text { sample } \\
\text { solution }\end{array}$ \\
\hline $\begin{array}{l}\text { Gamma-ray spectroscopy, } \\
\text { air filters }\end{array}$ & $\mathrm{R}-52$ & & Result obtained \\
\hline $\begin{array}{l}\text { Metals in air particulates, } \\
\text { emission spectroscopy } \\
\text { ( } \mu \mathrm{g} / \mathrm{sample})\end{array}$ & SC-35-2 & NIOSH $7300^{\circ}$ & $\begin{array}{l}\text { For } 35 \text { metals, } \\
\text { mostly } 1-10 \\
\text { each }\end{array}$ \\
\hline $\mathrm{Pu}$, air filters, radiochemistry & $R-50$ & EPA-680/4-75-001 & Result obtained \\
\hline${ }^{99} \mathrm{Tc}$, air filters, radiochemistry & $R-46$ & & Result obtained \\
\hline $\begin{array}{l}\text { Th, alpha isotopes, } \\
\text { radiochemistry }\end{array}$ & $\mathrm{R}-17$ & & Result obtained \\
\hline $\begin{array}{l}\mathrm{U} \text { isotopes, air filters, } \\
\text { radiochemistry }\end{array}$ & TIMS 3 & EPA-680/4-75-001 & Result obtained \\
\hline $\mathrm{U}$, stack gases & TIMS 3 & & Result obtained \\
\hline $\begin{array}{l}\text { U, stack samples, fluorometric } \\
(\mathrm{mg} / \mathrm{L})\end{array}$ & $\begin{array}{l}\text { SA-U-10 } \\
\text { (draft) }\end{array}$ & & $\begin{array}{l}0.001 \text { sample } \\
\text { solution }\end{array}$ \\
\hline${ }^{226} \mathrm{Ra}$ & $R-55$ & & Result obtained \\
\hline${ }^{222} \mathrm{Rn}$ & $R-51$ & & Result obtained \\
\hline${ }^{60} \mathrm{Co}$ & $\mathrm{R}-52$ & & Result obtained \\
\hline${ }^{137} \mathrm{Cs}$ & $\mathrm{R}-52$ & & Result obtained \\
\hline${ }^{40} \mathrm{~K}$ & $\mathrm{R}-52$ & & Result obtained \\
\hline
\end{tabular}

${ }^{a}$ Paducah Gaseous Diffusion Plant, Mar. 1, 1991. Technical Procedures, Ky/L-176, Vols. I and II, Martin Marietta Energy Systems, Inc.

${ }^{b}$ National Institute for Occupational Safely and Health.

${ }^{c}$ U.S. Environmental Protection Agency.

${ }^{d}$ APHA Methods, American Public Health Assoc., 1977.

${ }^{e}$ Specific ion electrode.

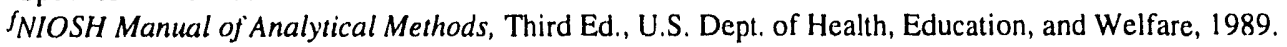


1992 Environmental Report-Paducah, Part 2

Table 10.2. PGDP environmental analysis procedures for water

\begin{tabular}{|c|c|c|c|}
\hline Parameter & Procedure $^{a}$ & $\mathrm{EPA}^{b}$ method & $\begin{array}{l}\text { Lowest concentration } \\
\text { reported }^{c}\end{array}$ \\
\hline Alkalinity $\left(\mathrm{CaCO}_{3}\right)(\mathrm{mg} / \mathrm{L})$ & $W-10$ & 310.1 & 5 \\
\hline Gross alpha activity & $\mathrm{R}-4$ & 900.0 & Result obtained \\
\hline Gross beta activity & $R-4$ & 900.0 & Result obtained \\
\hline${ }^{241} \mathrm{Am}$ & $R-52$ & & Result obtained \\
\hline \multicolumn{4}{|l|}{ As and Se, furnace-AA } \\
\hline As $(\mathrm{mg} / \mathrm{L})$ & SC-ENV-1 & 206.2 & 0.005 \\
\hline $\mathrm{Se}(\mathrm{mg} / \mathrm{L})$ & SC-ENV-1 & 270.2 & 0.005 \\
\hline $\mathrm{BOD}^{d}(5 \mathrm{~d})(\mathrm{mg} / \mathrm{L})$ & W-20 & 405.1 & 5 \\
\hline $\begin{array}{l}\mathrm{COD}_{1}^{e} \text { spectrophotometric } \\
\text { method }(\mathrm{mg} / \mathrm{L})\end{array}$ & $W-40$ & Hach 8000 & 5 \\
\hline \multicolumn{4}{|l|}{ Anions, ion chromatograph $f(\mathrm{mg} / \mathrm{L})$} \\
\hline Chloride $(\mathrm{mg} / \mathrm{L})$ & W-50 & 300.0 & 2 \\
\hline Nitrate $(\mathrm{N})(\mathrm{mg} / \mathrm{L})$ & W-50 & 300.0 & 1 \\
\hline Sulfate $(\mathrm{mg} / \mathrm{L})$ & W-50 & 300.0 & 5 \\
\hline Phosphate (P) (mg/L) & W-50 & 300.0 & 2 \\
\hline $\begin{array}{l}\text { Chlorine (total residual), } \\
\text { amperometric }(\mathrm{mg} / \mathrm{L})\end{array}$ & W-160 & 330.1 & 0.01 \\
\hline $\begin{array}{l}\text { Chromium (VI), } \\
\text { spectrophotometric (mg/L) }\end{array}$ & $W-100$ & USGS $^{g}$ & 0.01 \\
\hline $\begin{array}{l}\text { Coliform bacteria (fecal) } \\
\text { (colonies } / 100 \mathrm{~mL} \text { ) }\end{array}$ & $W-80$ & 909C Std. Mth. ${ }^{h}$ & 1 \\
\hline $\begin{array}{l}\text { Coliform bacteria (total) } \\
\text { (colonies } / 100 \mathrm{~mL} \text { ) }\end{array}$ & W-85 & 909A Std. Mth. & 1 \\
\hline Color (color units) & SA-CLR-1 & 110.2 & 1 \\
\hline $\begin{array}{l}\text { Conductance (specific) } \\
(\mu \mathrm{mho} / \mathrm{cm})\end{array}$ & SA-COND-1 & 120.1 & 0.5 \\
\hline Cyanide (total) (5-cm cell) & EPA-335.2 & 335.2 & 0.004 \\
\hline Fluoride $(\mathrm{mg} / \mathrm{L})$ & SA-F-5, SA-F-7 & 340.2 & 0.1 \\
\hline Gamma-ray emitters & $R-52$ & & Result obtained \\
\hline $\mathrm{Hg}$ (total) $(\mathrm{mg} / \mathrm{L})$ & SC-ENV-2 & 245.1 & 0.0002 \\
\hline${ }^{237} \mathrm{~Np}$ & R-8, R-52 & & Result obtained \\
\hline Nitrogen, ammonia, $\mathrm{SIE}^{i}(\mathrm{mg} / \mathrm{L})$ & SA-NH3-2 & 350.3 & 0.2 \\
\hline Oil and grease, gravimetric $(\mathrm{mg} / \mathrm{L})$ & SA-O-G-1 & 413.1 & 5 \\
\hline Oil and grease, infrared $(\mathrm{mg} / \mathrm{L})$ & GA-28 & 413.2 & 0.1 \\
\hline $\mathrm{pH}$, electrometric $(\mathrm{mg} / \mathrm{L})$ & $W-110$ & 150.1 & $\begin{array}{l}\text { Nearest } 0.1 \\
\mathrm{pH} \text { unit }\end{array}$ \\
\hline $\begin{array}{l}\text { Phosphorus (all forms) } \\
\text { spectrophotometric (mg/L) }\end{array}$ & $W-120$ & 365.3 & 0.05 \\
\hline Pu isotopes & R-50 & & Result obtained \\
\hline $\mathrm{PCBs}^{j}(\mu \mathrm{g} / \mathrm{L})$ & AL-OP-1 & 608 & 0.1 each Arochlor \\
\hline $\begin{array}{l}\text { Priority pollutants, organic } \\
\text { (volatile, purgeable) }\end{array}$ & AL-OP-3, AL-OP-4 & 624 & \\
\hline Trichloroethylene $(\mu \mathrm{g} / \mathrm{L})$ & AL-OP-3, AL-OP-4 & 624 & 1 \\
\hline Acetone $(\mu \mathrm{g} / \mathrm{L})$ & GA-34 & R-3810 & 1000 \\
\hline Isopropanol $(\mu \mathrm{g} / \mathrm{L})$ & GA-34 & R-3810 & 1000 \\
\hline Benzene $(\mu \mathrm{g} / \mathrm{L})$ & AL-OP-3, AL-OP-4 & 624 & 5 \\
\hline Toluene $(\mu \mathrm{g} / \mathrm{L})$ & AL-OP-3, AL-OP-4 & 624 & 5 \\
\hline Ethyl benzene $(\mu \mathrm{g} / \mathrm{L})$ & AL-OP-3, AL-OP-4 & 624 & 5 \\
\hline Total xylene $(\mu \mathrm{g} / \mathrm{L})$ & AL-OP-3, AL-OP-4 & 624 & 10 \\
\hline 1,2-Dichloroethane $(\mu \mathrm{g} / \mathrm{L})$ & AL-OP-3, AL-OP-4 & 624 & 1 \\
\hline 1,1,1-Trichloroethane $(\mu \mathrm{g} / \mathrm{L})$ & AL-OP-3, AL-OP-4 & 624 & 5 \\
\hline Tetrachloroethene $(\mu \mathrm{g} / \mathrm{L})$ & AL-OP-3, AL-OP-4 & 624 & 5 \\
\hline Trihalomethanes $(\mu \mathrm{g} / \mathrm{L})$ & AL-OP-3, AL-OP-4 & 624 & 5 \\
\hline 1,2-Dichloroethene $(\mu \mathrm{g} / \mathrm{L})$ & AL-OP-3, AL-OP-4 & 624 & 5 \\
\hline
\end{tabular}


1992 Environmental Report-Paducah, Part 2

Table 10.2 (continued)

\begin{tabular}{|c|c|c|c|}
\hline Parameter & Procedure $^{a}$ & $\mathrm{EPA}^{b}$ method & $\begin{array}{l}\text { Lowest concentration } \\
\text { reported }\end{array}$ \\
\hline Solids (dissolved) (mg/L) & $W-140$ & 160.1 & 10 \\
\hline Solids (total) $(\mathrm{mg} / \mathrm{L})$ & W-140 & 160.3 & 10 \\
\hline Solids (undissolved) (mg/L) & $W-140$ & 160.2 & 4 \\
\hline${ }^{99} \mathrm{Tc}$ & $R-46$ & & Result obtained \\
\hline Thorium isotopes & R-17 & & Result obtained \\
\hline $\begin{array}{l}\text { Total petroleum hydrocarbons } \\
(\mathrm{mg} / \mathrm{L})\end{array}$ & GA-28 & 418.1 & 0.1 \\
\hline $\begin{array}{l}\text { Total organic carbon, } \\
\text { combustion or oxidation }\end{array}$ & $W-150$ & 415.1 & 1 \\
\hline Turbidity (NTU) ${ }^{k}$ & $W-170$ & 180.1 & 0.05 \\
\hline $\begin{array}{l}\text { Uranium (total), fluorometric } \\
(\mathrm{mg} / \mathrm{L})\end{array}$ & SA-U-8 & & $1 \times 10^{-3}$ \\
\hline Uranium isotopes & TIMS 3 & & Result obtained \\
\hline Uranium isotopic abundances & TIMS 3 & & Result obtained \\
\hline
\end{tabular}

aPaducah Gascous Diffusion Plant, Mar. 1, 1991. Technical Procedures, Ky/L-176, Vols. I and II, Martin Marietta Energy Systems, Inc.

${ }^{b}$ U.S. Environmental Protection Agency.

The lowest concentration reported (LCR) may vary among specific samples, depending on interferences in the sample matrix. However, these LCRs have been assigned to accommodate most minor interferences. Some of the LCRs are higher than the method detection limits (MDLs) listed by the EPA. This is consistent with guidance from the EPA; however, any data reported below the MDLs must be supported by sound documentation. The LCRs applied by Martin Marietta Energy Systems, Inc., laboratories meet the needs of the programs they support.

dBiological oxygen demand.

${ }^{e}$ Chemical oxygen demand.

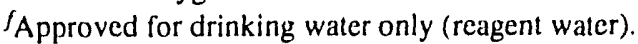

'U.S. Geological Survey, "Methods for Analysis of Inorganic Substances in Water and Fluvial Sediment," Open-File Report 78-679; N. W. Skougstad et al., "Methods for Determination of Inorganic Substances in Water and Fluvial Sediments," Chapter Al, in Techniques of Water-Resources Investigation, Book 5, U.S. Geological Survey, 1979.

${ }^{h}$ All references to Standard Methods for the 16th Edition, 1985.

iSpecific ion electrode.

jPolychlorinated biphenyls.

${ }^{k}$ Nephelometric turbidity unit. 
Table 10.3. PGDP atomic absorption and inductively coupled plasma environmental analysis procedures

for water (lowest concentration reported) ${ }^{a}$

\begin{tabular}{lcc}
\hline Element & $\begin{array}{c}\text { PGDP SC-ENV-1 } \\
\text { EPA 200 series } \\
\text { graphite furnace AA } \\
(\mathrm{mg} / \mathrm{L})\end{array}$ & $\begin{array}{c}\text { PGDP SC-ENV-4 } \\
\text { SC-ICAP-1 }\end{array}$ \\
\hline $\mathrm{Ag}$ & $\begin{array}{c}\text { EPA 200.7 ICP } \\
(\mathrm{mg} / \mathrm{L})\end{array}$ \\
$\mathrm{Al}$ & & 0.03 \\
$\mathrm{As}$ & & 0.1 \\
$\mathrm{Ba}$ & 0.005 & 0.1 \\
$\mathrm{Ca}$ & & 0.005 \\
$\mathrm{Cd}$ & & 0.01 \\
$\mathrm{Cr}$ & & 0.01 \\
$\mathrm{Cu}$ & & 0.05 \\
$\mathrm{Fe}$ & & 0.01 \\
$\mathrm{~K}$ & & 0.01 \\
$\mathrm{Li}$ & & 2.0 \\
$\mathrm{Mg}$ & & 0.02 \\
$\mathrm{Mn}$ & & 0.002 \\
$\mathrm{Mo}$ & & 0.005 \\
$\mathrm{Na}$ & & 0.05 \\
$\mathrm{Ni}$ & & 0.04 \\
$\mathrm{~Pb}$ & & 0.05 \\
$\mathrm{Se}$ & & 0.2 \\
$\mathrm{Zn}$ & & 0.2 \\
$\mathrm{Fg}$ & & 0.005 \\
\hline
\end{tabular}

"The lowest concentration reported (LCR) may vary among specific samples, depending on interferences in the sample matrix. However, these LCRs have been assigned to accommodate most minor interferences. Some of the LCRs are higher than the method detection limits (MDLs) listed by the U.S. Environmental Protection Agency (EPA). This is consistent with guidance from the EPA; however, any data reported below the MDLs must be supported by sound documentation. The LCRs applied by Martin Marietta Energy Systems, Inc., laboratories meet the needs of the programs they support.

${ }^{b}$ Paducah Gaseous Diffusion Plant, Mar. 1, 1991. Technical Procedures, KY/L-176, Vols. I and II, Martin Marielta Encrgy Systems, Inc.

Table 10.4. PGDP environmental analysis procedures for biota

\begin{tabular}{lll} 
Parameter & Procedure & \multicolumn{1}{c}{$\begin{array}{c}\text { Lowest concentration } \\
\text { reported } \\
(\mathrm{mg} / \mathrm{kg})\end{array}$} \\
\hline $\begin{array}{l}\text { Fluoride in vegetation } \\
\text { Gamma ray spectrometry } \\
\text { of vegetation }\end{array}$ & $\mathrm{SA}-\mathrm{F}-3$ & 3 \\
$\begin{array}{l}\text { Uranium (total and isotopic) } \\
\text { in vegetation }\end{array}$ & $\mathrm{R}-53$ & Result obtained \\
\hline
\end{tabular}

apaducah Gaseous Diffusion Plant, Mar. 1, 1991. Technical Procedures, KY/L-176, Vols. I and II, Martin Marietta Energy Systems, Inc. 
1992 Environmental Report-Paducah, Part 2

Table 10.5. PGDP environmental analysis procedures for soil and sediment

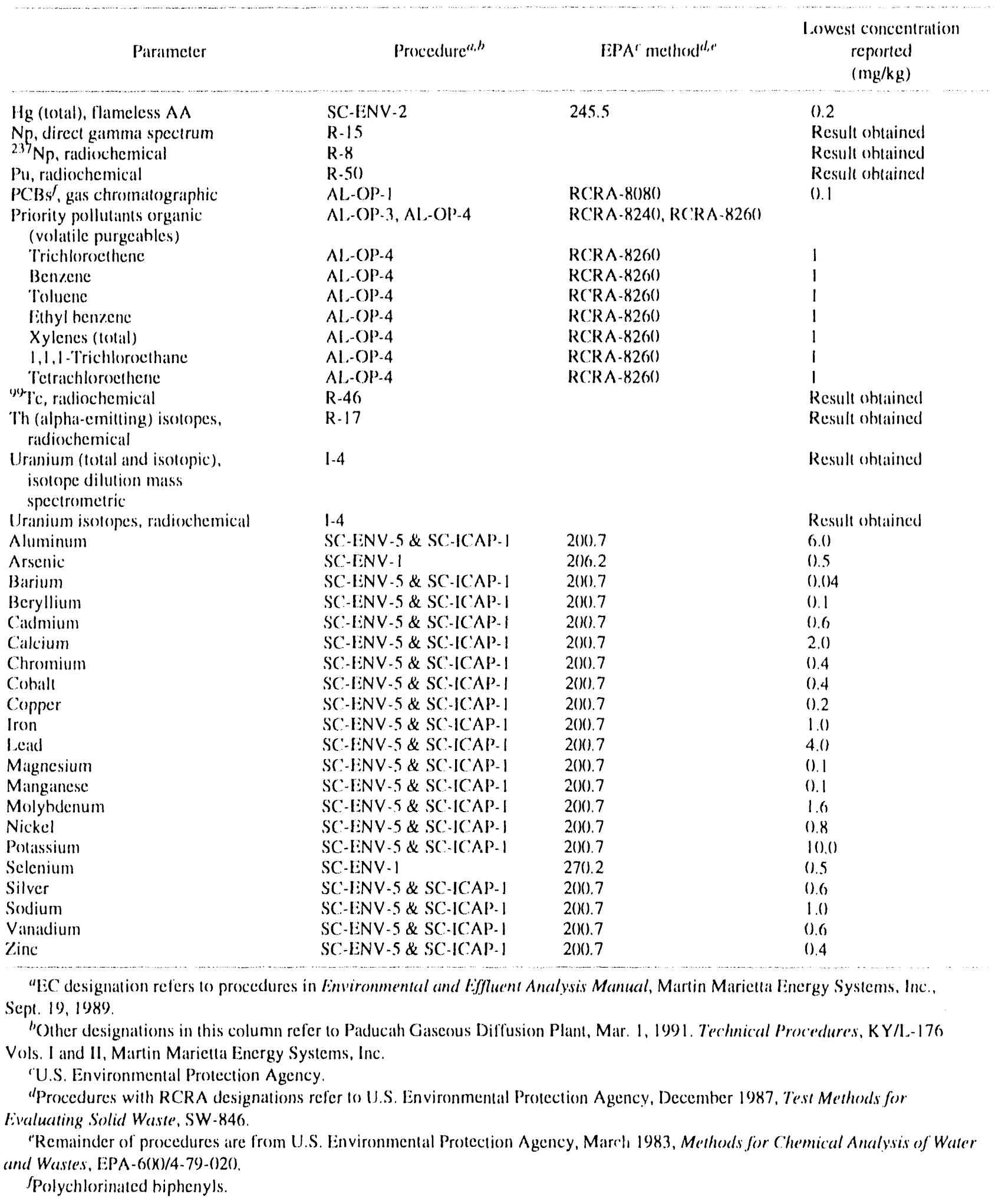




\section{Environmental Report-Paducah, Part 2}

Table 10.6. PGDP analysis procedures for off-site well waters

\begin{tabular}{|c|c|c|c|}
\hline Parameter & Procedure $^{a}$ & $\mathrm{EPA}^{b}$ method ${ }^{c, d}$ & $\begin{array}{c}\text { Lowest concentration } \\
\text { reported }\end{array}$ \\
\hline Gross alpha activity & R-4 & 900.0 & Report result obtained \\
\hline Gross beta activity & $\mathrm{R}-4$ & 900.0 & Report result obtained \\
\hline Benzene $(\mu \mathrm{g} / \mathrm{L})$ & AL-OP-3, AL-OP-4 & RCRA-8240, RCRA-8260 & 5 \\
\hline 1,2-Dichloroethane $(\mu \mathrm{g} / \mathrm{L})$ & AL-OP-3, AL-OP-4 & RCRA-8240, RCRA-8260 & 5 \\
\hline Ethyl benzene $(\mu \mathrm{g} / \mathrm{L})$ & AL-OP-3, AL-OP-4 & RCRA-8240, RCRA-8260 & 5 \\
\hline $\mathrm{PCBs}^{e}(\mu \mathrm{g} / \mathrm{L})$ & OP-1 & RCRA-8080 & 0.1 \\
\hline \multicolumn{4}{|l|}{ Total petroleum } \\
\hline hydrocarbons (mg/L) & GA.28 & 418.1 & 0.1 \\
\hline Toluene $(\mu \mathrm{g} / \mathrm{L})$ & AL-OP-3, AL-OP-4 & RCRA-8240, RCRA-8260 & 5 \\
\hline 1,1,1-Trichloroethane $(\mu \mathrm{g} / \mathrm{L})$ & AL-OP-3, AL-OP-4 & RCRA-8240, RCRA-8260 & 5 \\
\hline $\begin{array}{l}\text { Trichloroethylene }(\mu \mathrm{g} / \mathrm{L}) \\
{ }^{99} \mathrm{Tc}(\mathrm{pCi} / \mathrm{L})\end{array}$ & $\begin{array}{l}\text { AL-OP-3, AL-OP-4 } \\
R-46\end{array}$ & RCRA 8240, RCRA-8260 & $\begin{array}{l}1 \\
25\end{array}$ \\
\hline Xylenes (total, $\mu \mathrm{g} / \mathrm{L}$ ) & AL-OP-3, AL-OP-4 & RCRA-8240, RCRA-8260 & 10 \\
\hline
\end{tabular}

aDesignations in this column refer to Paducah Gaseous Diffusion Plant, Mar, 1, 1991. Technical Procedures, KY/L-176 Vols. 1 and II, Martin Marietta Energy Systems, Inc.

bU.S. Environmental Protection Agency.

CProcedures with RCRA designations refer to U.S. Environmental Protection Agency, Decernber 1987, Test Methods for Evaluating Solid Waste, SW-846.

${ }^{d}$ Remainder of procedures are from U.S. Environmental Protection Agency, March 1983, Methods for Chemical Analysis of Water and Wastes, EPA-600/4-79-020.

ePolychlorinated biphenyls.

Table 10.7. PGDP analysis procedures for field measurements

\begin{tabular}{llcc}
\hline \multicolumn{1}{c}{ Parameter } & Procedure $^{a}$ & EPA $^{b}$ method & $\begin{array}{c}\text { Lowest } \\
\text { concentration } \\
\text { reported }\end{array}$ \\
\hline pH & ES-214 & 150.1 & $0.1^{c}$ \\
Dissolved oxygen (mg/L) & ES-214 & 360.1 & 0.1 \\
Temperature & ES-214 & 170.1 & $0.1^{d}$ \\
$\begin{array}{l}\text { Total residual } \\
\text { chlorine (mg/L) }\end{array}$ & ES-216 & 330.5 & 0.01 \\
Depth (ft) & ES-202 & NA & 0.01 \\
\hline
\end{tabular}

${ }^{a}$ Designations in this column refer to the PGDP Environmental Monitoring Department Standard Operating Procedures Manual.

${ }^{b}$ U.S. Environmental Protection Agency.

'Nearest pH unit.

${ }^{d}$ Nearest degree $\mathrm{F}$. 
1992 Environmental Report-Paducah, Part 2

Table 10.8. PGDP internal measurement control program laboratory control data (inorganic)

\begin{tabular}{|c|c|c|c|c|c|}
\hline $\begin{array}{l}\text { Measurement } \\
\text { jdentification }\end{array}$ & $\begin{array}{l}\text { Accepted } \\
\text { mean }^{a}\end{array}$ & $\begin{array}{l}\text { Observed mean } \pm \\
\text { limil of error }\end{array}$ & $\begin{array}{c}\text { Number } \\
\text { of } \\
\text { analyses }\end{array}$ & $\begin{array}{l}\text { Percent } \\
\text { limil of } \\
\text { error per } \\
\text { analysis" }\end{array}$ & $\begin{array}{l}\text { Percenl } \\
\text { recovery }\end{array}$ \\
\hline
\end{tabular}

Fluorimetric analysis

$\begin{array}{llllll}\text { Low-level uranium } & 0.008 \mathrm{mg} / \mathrm{L}(\mathrm{T})^{\mathrm{r}} & 0.0077 \pm 0.0002 & 84^{d} & 20 & 96.3 \\ & 0.005 \mathrm{mg} / \mathrm{L}(\mathrm{T}) & 0.0049 \pm 0.0001 & 12()^{d} & 17 & 99.2\end{array}$

aSamples sent at various theoretical levels. Statistics are reported on the ratio of reported result lo the theoretical value with 1.000 indicating agreement.

"Limit of error of the $95 \%$ confidence level.

"T $\mathrm{T}=$ theoretical value.

"Excludes one outlier.

Table 10.9. PGDP internal measurement control program laboratory control data (organic)

\begin{tabular}{|c|c|c|c|c|c|}
\hline $\begin{array}{l}\text { Measurement } \\
\text { identification }\end{array}$ & $\begin{array}{l}\text { Accepted } \\
\text { mean }\end{array}$ & $\begin{array}{l}\text { Observed mean } \\
\pm \text { limit of error }\end{array}$ & $\begin{array}{c}\text { Number } \\
\text { of } \\
\text { analyses }\end{array}$ & $\begin{array}{l}\text { Percent limit } \\
\text { of error } \\
\text { per analysis" }\end{array}$ & $\begin{array}{l}\text { Percent } \\
\text { recovery }\end{array}$ \\
\hline
\end{tabular}

Tolal organic halogens (TOX)

$(\mu g / L)$

TOX, as trichlorophenol,

in water

(matrix-well)

Model DX-20

100.0

101.2 11.1

86

$21.0 \pm 0.2$

72

Model MC-3

100.0

$98.4 \pm 1.5$

77

$20.5 \pm 0.2$

90

20.0

$101.1 \pm 3.2$

15

101.2

104.9

98.4

Model 10 sigma

100.0

Polychlorinated biphenyls (PCBs)

$(\mu g / L)$

PCB, spike recovery,

0.10

$0.102 \pm 0.005$

18

20)

1011.6

(matrix-water and well)

Trichloroethylene (TCE)

$(\mu g / L)$

TCE, spike recovery,

5.0

$4.56 \pm 0.07$

96

14

91.2

(matrix-well)

TCE, spike recovery,

5.0

$4.69 \pm 0.12$

26

12

93.8

in water

(matrix-water)

${ }^{a}$ Limit of error of the $95 \%$ confidence level. 


\section{Environmental Report-Paducah, Part 2}

Table 10.10. U.S. Environmental Protection Agency (EPA) Performance Evaluation

Discharge Monitoring Report-Quality Assurance Study Number 012

for the Paducah Gaseous Diffusion Plant, January 1992

\begin{tabular}{|c|c|c|c|c|c|}
\hline Parameter & $\begin{array}{l}\text { Reported } \\
\text { value }\end{array}$ & $\begin{array}{l}\text { True } \\
\text { value }^{a}\end{array}$ & $\begin{array}{l}\text { Acceptable } \\
\text { limits }\end{array}$ & $\begin{array}{l}\text { Warning } \\
\text { limits }\end{array}$ & $\begin{array}{c}\text { Performance } \\
\text { evaluation }\end{array}$ \\
\hline \multicolumn{6}{|c|}{ Trace metals $(\mu g / L)$} \\
\hline $\begin{array}{l}\text { Aluminum } \\
\text { Chromium } \\
\text { Copper } \\
\text { Iron } \\
\text { Nickel } \\
\text { Zinc }\end{array}$ & $\begin{array}{r}937 \\
322 \\
130 \\
515 \\
2280 \\
1480\end{array}$ & $\begin{array}{r}950 \\
315 \\
130 \\
540 \\
2200 \\
1400\end{array}$ & $\begin{array}{l}778-1130 \\
266-371 \\
113-144 \\
471-613 \\
1970-2410 \\
1230-1570\end{array}$ & $\begin{array}{l}823-1090 \\
279-358 \\
117-140 \\
489-595 \\
2020-2360 \\
1270-1520\end{array}$ & $\begin{array}{l}\text { Acceptable } \\
\text { Acceptable } \\
\text { Acceptable } \\
\text { Acceptable } \\
\text { Acceptable } \\
\text { Acceptable }\end{array}$ \\
\hline \multicolumn{6}{|c|}{ Miscellaneous parameters $(\mathrm{mg} / \mathrm{L})^{c}$} \\
\hline $\begin{array}{l}\mathrm{pH} \text { (units) } \\
\text { Total suspended } \\
\text { solids }\end{array}$ & $\begin{array}{l}6.7 \\
39\end{array}$ & $\begin{array}{l}6.80 \\
40.0\end{array}$ & $\begin{array}{l}6.63-6.96 \\
31.6-45.1\end{array}$ & $\begin{array}{l}6.67-6.92 \\
33.2-43.5\end{array}$ & $\begin{array}{l}\text { Acceptable } \\
\text { Acceptable }\end{array}$ \\
\hline Oil and grease & 9.7 & 11.0 & $4.13-15.7$ & $5.59-14.2$ & Acceptable \\
\hline $\begin{array}{l}\text { Total residual } \\
\text { chlorine }\end{array}$ & 0.9 & 0.97 & $0.605-1.20$ & $0.684-1.12$ & Acceptable \\
\hline \multicolumn{6}{|c|}{ Demand $(m g / L)$} \\
\hline $\begin{array}{l}\operatorname{COD}^{d} \\
\mathrm{BOD}^{e}(5 \mathrm{~d})\end{array}$ & $\begin{array}{l}99 \\
66\end{array}$ & $\begin{array}{l}98.8 \\
64.2\end{array}$ & $\begin{array}{l}75.4-117 \\
38.8-89.7\end{array}$ & $\begin{array}{l}80.7-112 \\
45.1-83.3\end{array}$ & $\begin{array}{l}\text { Acceptable } \\
\text { Acceptable }\end{array}$ \\
\hline
\end{tabular}

${ }^{a}$ Based on theoretical calculations or a reference value when necessary.

berformance evaluation by the EPA: 0-1.96 standard deviations for acceptable; 1.97-2.58 standard deviations for check for error; outside 2.58 standard deviations for unacceptable.

CUnits in $\mathrm{mg} / \mathrm{L}$ except for $\mathrm{pH}$, which is reported in $\mathrm{pH}$ units.

${ }^{d}$ Chemical oxygen demand.

'Biological oxygen demand. 
Table 10.11. January 1992 Analytical Products Group, Inc., Proficiency Environmental Testing Program

\begin{tabular}{|c|c|c|c|c|c|c|}
\hline Parameter & Level & $\begin{array}{l}\text { Reported } \\
\text { value }\end{array}$ & $\begin{array}{l}\text { Reference } \\
\text { value }\end{array}$ & $\begin{array}{c}\text { Mean of } \\
\text { reporting } \\
\text { labs }\end{array}$ & $\begin{array}{l}\text { Number of } \\
\text { standard } \\
\text { deviations } \\
\text { from the } \\
\text { mean }\end{array}$ & $\begin{array}{l}\text { Performance } \\
\text { evaluation }\end{array}$ \\
\hline Alkalinity as & 1 & 53 & 57.07 & 55.38 & 0.750 & Acceptable \\
\hline $\begin{array}{l}\mathrm{CaCO}_{3} \\
(\mathrm{mg} / \mathrm{L})\end{array}$ & 2 & 54 & 57.68 & 56.75 & 0.841 & Acceptable \\
\hline Aluminum & 1 & 104 & 83.5 & 86.0 & 1.43 & Acceptable \\
\hline$(\mu \mathrm{g} / \mathrm{L})$ & 2 & 164 & 149.3 & 156.6 & 0.252 & Acceptable \\
\hline Ammonia as $\mathrm{N}$ & 1 & 0.35 & 0.34 & 0.372 & 0.162 & Acceptable \\
\hline$(\mathrm{mg} / \mathrm{L})$ & 2 & 1.6 & 1.52 & 1.52 & 0.414 & Acceptable \\
\hline Antimony & 1 & 80.5 & 106.3 & 99.8 & 1.133 & Acceptable \\
\hline$(\mathrm{mg} / \mathrm{L})$ & 2 & 534 & 552.3 & 537.1 & 0.048 & Acceptable \\
\hline Arsenic & 1 & 20.4 & 19.35 & 19.62 & 0.258 & Acceptable \\
\hline$(\mu \mathrm{g} / \mathrm{L})$ & 2 & 395 & 386.99 & 386.50 & 0.214 & Acceptable \\
\hline Barium & 1 & 247 & 250.4 & 253.28 & 0.331 & Acceptable \\
\hline$(\mu \mathrm{g} / \mathrm{L})$ & 2 & 1797 & 1797.9 & 1780.75 & 0.178 & Acceptable \\
\hline Beryllium & 1 & 64.5 & 67.77 & 66.21 & 0.481 & Acceptable \\
\hline$(\mu \mathrm{g} / \mathrm{L})$ & 2 & 143 & 143.07 & 141.35 & 0.175 & Acceptable \\
\hline BOD & 1 & 181 & 185.0 & 172.1 & 0.29 & Acceptable \\
\hline$(\mathrm{mg} / \mathrm{L})$ & 2 & 28 & 24.4 & 23.1 & 1.239 & Acceptable \\
\hline Cadmium & 1 & 20.5 & 17.43 & 17.59 & 1.477 & Acceptable \\
\hline$(\mu \mathrm{g} / \mathrm{L})$ & 2 & 127 & 116.2 & 119.21 & 0.961 & Acceptable \\
\hline Calcium & 1 & 2.3 & 2.37 & 2.35 & 0.216 & Acceptable \\
\hline$(\mathrm{mg} / \mathrm{L})$ & 2 & 3.4 & 3.33 & 3.36 & 0.144 & Acceptable \\
\hline Chloride & 1 & 23 & 24.5 & 24.35 & 0.843 & Acceptable \\
\hline$(\mathrm{mg} / \mathrm{L})$ & 2 & 43 & 43.5 & 43.61 & 0.229 & Acceptable \\
\hline Chlorobenzene & 1 & 33 & 36.04 & 34.55 & 0.367 & Acceptable \\
\hline$(\mu \mathrm{g} / \mathrm{L})$ & 2 & 52 & 52.11 & 51.44 & 0.149 & Acceptable \\
\hline Chloroform & 1 & 18 & 19.54 & 17.88 & 0.438 & $\therefore$ icceptable \\
\hline$(\mu \mathrm{g} / \mathrm{L})$ & 2 & 83 & 83.49 & 77.93 & 0.470 & Acceptable \\
\hline Chromium & 1 & 30.4 & 31.23 & 31.85 & 0.433 & Acceptable \\
\hline$(\mu \mathrm{g} / \mathrm{L})$ & 2 & 133 & 134.76 & 135.62 & 0.238 & Acceptable \\
\hline Cobalt & 1 & 148 & 147.96 & 147.82 & 0.019 & Acceptable \\
\hline$(m g / L)$ & 2 & 328 & 330.41 & 329.13 & 0.068 & Acceptable \\
\hline $\operatorname{COD}^{i}$ & 1 & 250 & 297.8 & 280.7 & 0.865 & Acceptable \\
\hline (mg/L) & 2 & 31 & 38.8 & 33.9 & 0.339 & Acceptable \\
\hline Conductivity & 1 & 240 & 264.6 & 232.8 & 0.622 & Acceptable \\
\hline$(\mu \mathrm{mho} / \mathrm{cm})$ & 2 & 286 & 311.6 & 277.4 & 0.572 & Acceptable \\
\hline Copper & 1 & 55.5 & 56.8 & 57.4 & 0.387 & Acceptable \\
\hline$(\mu \mathrm{g} / \mathrm{L})$ & 2 & 197 & 203.0 & 206.7 & 0.838 & Acceptable \\
\hline Fluoride & 1 & 1.4 & 1.427 & 1.445 & 0.524 & Acceptable \\
\hline$(\mathrm{mg} / \mathrm{L})$ & 2 & 5.2 & 5.213 & 5.325 & 0.371 & Acceptable \\
\hline Hexavalent & 1 & 0.03 & 0.034 & 0.031 & 0.091 & Acceptable \\
\hline $\begin{array}{l}\text { chromium } \\
(\mathrm{mg} / \mathrm{L})\end{array}$ & 2 & 0.14 & 0.149 & 0.145 & 0.320 & Acceptable \\
\hline Iron & 1 & 98.9 & 94.8 & 93.8 & 0.461 & Acceptable \\
\hline$(\mu \mathrm{g} / \mathrm{L})$ & 2 & 531 & 505.1 & 503.9 & 0.833 & Acceptable \\
\hline Lead & 1 & 168 & 156.0 & 156.0 & 0.815 & Acceptable \\
\hline$(\mu \mathrm{g} / \mathrm{L})$ & 2 & 344 & 328.1 & 326.2 & 0.800 & Acceptable \\
\hline Magnesium & 1 & 0.948 & 0.933 & 0.95 & 0.024 & Acceptable \\
\hline (mg/L) & 2 & 8.2 & 7.96 & 0.58 & 0.278 & Acceptable \\
\hline Manganese & 1 & 34.1 & 33.6 & 33.44 & 0.304 & Acceptable \\
\hline$(\mu \mathrm{g} / \mathrm{L})$ & 2 & 211 & 202.0 & 202.7 & 0.958 & Acceptable \\
\hline
\end{tabular}


1992 Environmental Report-Paducah, Part 2

Table 10.11 (continued)

\begin{tabular}{|c|c|c|c|c|c|c|}
\hline Parameter & Level & $\begin{array}{l}\text { Reported } \\
\text { value }\end{array}$ & $\begin{array}{l}\text { Reference } \\
\text { value }\end{array}$ & $\begin{array}{l}\text { Mean of } \\
\text { reporti ig } \\
\text { labs }\end{array}$ & $\begin{array}{l}\text { Number of } \\
\text { standard } \\
\text { deviations } \\
\text { from the } \\
\text { mean }\end{array}$ & $\begin{array}{l}\text { Performance } \\
\text { evaluation }\end{array}$ \\
\hline Mercury & 1 & 1.2 & 0.910 & 0.994 & 0.723 & Acceptable \\
\hline$(\mu \mathrm{g} / \mathrm{L})$ & 2 & 4.9 & 4.72 & 4.58 & 0.428 & Acceptable \\
\hline Molybdenum & 1 & 167 & 176.8 & 172.1 & 0.197 & Acceptable \\
\hline$(\mathrm{mg} / \mathrm{L})$ & 2 & 297 & 299.5 & 305.8 & 0.258 & Acceptable \\
\hline Nickel & 1 & 36.1 & 31.57 & 32.64 & 0.756 & Acceptable \\
\hline$(\mu \mathrm{g} / \mathrm{L})$ & 2 & 108 & 103.55 & 106.26 & 0.220 & Acceptable \\
\hline Nitrate as $\mathbf{N}$ & 1 & $<1$ & 0.42 & 0.421 & & Not rated \\
\hline$(\mathrm{mg} / \mathrm{L})$ & 2 & 1.4 & 1.29 & 1.31 & 0.654 & Acceptable \\
\hline Oil and grease & 1 & 6.1 & 6.46 & 6.49 & 0.146 & Acceptable \\
\hline$(\mathrm{mg} / \mathrm{L})$ & 2 & 36.5 & 39.62 & 34.84 & 0.216 & Acceptable \\
\hline Orthophosphate as & 1 & $<2$ & 0.43 & 0.43 & & Not rated \\
\hline$P(m g / L)$ & 2 & 2.7 & 2.64 & 2.66 & 0.215 & Acceptable \\
\hline $\mathrm{pH}$ & 1 & 6.75 & 6.79 & 6.707 & 0.233 & Acceptable \\
\hline (units) & 2 & 7.7 & 7.73 & 7.614 & 0.347 & Acceptable \\
\hline Potassium & 1 & 8.5 & 8.41 & 8.46 & 0.050 & Acceptable \\
\hline (mg/L) & 2 & 12.8 & 13.11 & 13.37 & 0.0695 & Acceptable \\
\hline Selenium & 1 & 22.1 & 18.3 & 18.5 & 1.391 & Acceptable \\
\hline$(\mu \mathrm{g} / \mathrm{L})$ & 2 & 98.1 & 85.2 & 87.6 & 0.689 & Acceptablc \\
\hline Silver & 1 & 22.4 & 22.05 & 21.98 & 0183 & Acceptable \\
\hline$(\mu \mathrm{g} / \mathrm{L})$ & 2 & 101 & 111.88 & 111.42 & 1.587 & Acceptable \\
\hline Sodium & 1 & 42.3 & 41.6 & 42.17 & 0.047 & Acceptable \\
\hline$(\mathrm{mg} / \mathrm{L})$ & 2 & 31.5 & 32.7 & 33.59 & 1.099 & Acceptable \\
\hline Sulfate & 1 & 21 & 18.9 & 18.90 & 1.015 & Acceptable \\
\hline$(\mathrm{mg} / \mathrm{L})$ & 2 & 10 & 10.30 & 11.23 & 0.471 & Acceptable \\
\hline TDS $^{d, e}$ & 1 & 65 & 93.3 & 103.4 & 1.283 & Warning \\
\hline (mg/L) & 2 & 273 & 290.5 & 105.3 & 0.526 & Acceptable \\
\hline Thallium & 1 & 52 & 54.56 & 53.39 & 0.175 & Acceptable \\
\hline$(\mu \mathrm{g} / \mathrm{L})$ & 2 & 466 & 491.08 & 486.02 & 0.433 & Acceptable \\
\hline $\operatorname{ToC}^{f}$ & 1 & 114 & 112.1 & 114 & 0.009 & Acceptable \\
\hline$(\mathrm{mg} / \mathrm{L})$ & 2 & 15 & 14.6 & 15.0 & 0.019 & Acceptable \\
\hline Toluene & 1 & 25 & 28.79 & 27.48 & 0.757 & Acceptable \\
\hline$(\mu \mathrm{g} / \mathrm{L})$ & 2 & 49 & 51.03 & 49.25 & 0.052 & Acceptable \\
\hline Total hardness & 1 & 6 & 9.76 & 10.36 & 2.373 & Warning \\
\hline $\begin{array}{l}\text { as } \mathrm{CaCO}_{3} \\
(\mathrm{mg} / \mathrm{L})\end{array}$ & 2 & 9 & 41.09 & 41.06 & 8.380 & Unacceptable \\
\hline Total organic & 1 & 23 & 26.9 & 27.64 & 0.876 & Acceptable \\
\hline $\begin{array}{l}\text { halides } \\
(\mu \mathrm{g} / \mathrm{L})\end{array}$ & 2 & 167 & 207.9 & 186.5 & 0.837 & Acceptable \\
\hline Total residual & 1 & 0.9 & 0.974 & 0.933 & 0.279 & Acceptable \\
\hline $\begin{array}{l}\text { chlorine } \\
(\mathrm{mg} / \mathrm{L})\end{array}$ & 2 & 1.15 & 1.168 & 1.192 & 0.276 & Acceptable \\
\hline $\operatorname{TSS}^{e, g}$ & 1 & 26 & 33.9 & 89.8 & 1.32 & Acceptable \\
\hline$(\mathrm{mg} / \mathrm{L})$ & 2 & 259 & 283.3 & 93.7 & 0.45 & Acceptable \\
\hline 1,1,1-Trichloroethane & 1 & 17 & 19.39 & 18.80 & 0.647 & Acceptable \\
\hline$(\mu \mathrm{g} / \mathrm{L})$ & 2 & 75 & 75.68 & 73.65 & 0.123 & Acceptable \\
\hline 1,1,2-Trichloroethane & 1 & 7 & 7.96 & 7.55 & 0.346 & Acceptable \\
\hline$(\mu \mathrm{g} / \mathrm{L})$ & 2 & 110 & 113.85 & 107.91 & 0.117 & Acceptable \\
\hline Uranium & 1 & 175 & 160.2 & 164.9 & 1.005 & Acceptable \\
\hline$(\mu \mathrm{g} / \mathrm{L})$ & 2 & 935 & 961,0 & 957.2 & 0.429 & Acceptable \\
\hline
\end{tabular}


1992 Environmental Report-Paducah, Part 2

Table 10.11 (continued)

\begin{tabular}{|c|c|c|c|c|c|c|}
\hline Parameter & Level & $\begin{array}{l}\text { Reported } \\
\text { value }\end{array}$ & $\begin{array}{c}\text { Reference } \\
\text { value }\end{array}$ & $\begin{array}{c}\text { Mean of } \\
\text { reporting } \\
\text { labs }\end{array}$ & $\begin{array}{l}\text { Number of } \\
\text { standard } \\
\text { deviations } \\
\text { from the } \\
\text { mean }\end{array}$ & $\begin{array}{l}\text { Performance } \\
\text { evaluation }^{a}\end{array}$ \\
\hline Vanadium & 1 & 48.4 & 45.57 & 45.21 & 0.550 & Acceptable \\
\hline$(\mu \mathrm{g} / \mathrm{L})$ & 2 & 1065 & 1054.8 & 1075.0 & 0.171 & Acceptable \\
\hline Zinc & 1 & 32.6 & 26.95 & 27.75 & 1.014 & Acceptable \\
\hline$(\mu \mathrm{g} / \mathrm{L})$ & 2 & 135 & 123.96 & 125.88 & 1.038 & Acceptable \\
\hline
\end{tabular}

"Performance evaluation made using U.S. Environmental Protection Agency criteria: 0-1.96 standard deviations for acceptable; 1.97-2.58 standard deviations for marginal; more than 2.58 standard deviations for unacceptable.

${ }^{b}$ Biological oxygen demand.

${ }^{c}$ Chemical oxygen demand.

dTotal dissolved solids.

eAverage percent recovery for participating laboratories.

fTotal organic carbon.

s"Total suspended solids. 
Table 10.12. March 1992 Analytical Products Group, Inc., Proficiency Environmental Testing Program

\begin{tabular}{|c|c|c|c|c|c|c|}
\hline Parameter & Level & $\begin{array}{l}\text { Reported } \\
\text { value }\end{array}$ & $\begin{array}{l}\text { Reference } \\
\text { value }\end{array}$ & $\begin{array}{l}\text { Mean of } \\
\text { reporting } \\
\text { labs }\end{array}$ & $\begin{array}{l}\text { Number of } \\
\text { standard } \\
\text { deviations } \\
\text { from the } \\
\text { mean }\end{array}$ & $\begin{array}{l}\text { Performance } \\
\text { evaluation }^{a}\end{array}$ \\
\hline Alkalinity as & 1 & 35 & 34.18 & 33.44 & 0.608 & Acceptable \\
\hline $\begin{array}{l}\mathrm{CaCO}_{3} \\
(\mathrm{mg} / \mathrm{L})\end{array}$ & 2 & 32 & 30.94 & 32.32 & 0.112 & Acceptable \\
\hline Aluminum & 1 & 109 & 59.7 & 58.3 & 5.13 & Unacceptable \\
\hline$(\mu \mathrm{g} / \mathrm{L})$ & 2 & 513 & 497.8 & 495.2 & 0.374 & Acceptable \\
\hline Ammonia as $\mathrm{N}$ & 1 & 0.40 & 0.873 & 0.830 & 2.793 & Unacceptable \\
\hline$(\mathrm{mg} / \mathrm{L})$ & 2 & 1.5 & 1.815 & 1.785 & 1.181 & Acceptable \\
\hline Antimony & 1 & 449 & 459.9 & 445.4 & 0.069 & Acceptable \\
\hline$(\mathrm{mg} / \mathrm{L})$ & 2 & 704 & 689.9 & 683.9 & 0.289 & Acceptable \\
\hline Arsenic & 1 & 81.2 & 58.05 & 55.65 & 2.975 & Unacceptable \\
\hline$(\mu \mathrm{g} / \mathrm{L})$ & 2 & 505 & 445.04 & 428.09 & 1.477 & Warning \\
\hline Barium & 1 & 510 & 527.2 & 527.8 & 0.336 & Acceptable \\
\hline$(\mu \mathrm{g} / \mathrm{L})$ & 2 & 1480 & 1515.7 & 1506.1 & 0.359 & Acceptable \\
\hline Beryllium & 1 & 59.7 & 62.75 & 59.79 & 0.020 & Acceptable \\
\hline$(\mu \mathrm{g} / \mathrm{L})$ & 2 & 124 & 125.5 & 119.49 & 0.547 & Acceptable \\
\hline$B O D^{b}$ & 1 & & 113.9 & 113.9 & & Not reported \\
\hline$(\mathrm{mg} / \mathrm{L})$ & 2 & 22 & 23.1 & 23.9 & 0.329 & Acceptable \\
\hline Cadmium & 1 & 59.2 & 58.1 & 56.67 & 0.426 & Acceptable \\
\hline$(\mu \mathrm{g} / \mathrm{L})$ & 2 & 245 & 232.4 & 226.34 & 0.620 & Acceptable \\
\hline Calcium & I & 3.18 & 3.13 & 3.13 & 0.124 & Acceptable \\
\hline$(\mathrm{mg} / \mathrm{L})$ & 2 & 5.68 & 5.59 & 5.37 & 0.641 & Acceptable \\
\hline Carbon tetrachloride & 1 & 14 & 14.8 & 14.28 & 0.137 & Acceptable \\
\hline$(\mu \mathrm{g} / \mathrm{L})$ & 2 & 65 & 76.7 & 73.78 & 1.166 & Acceptable \\
\hline Chloride & 1 & 19 & 19.97 & 19.97 & 0.679 & Acceptable \\
\hline$(\mathrm{mg} / \mathrm{L})$ & 2 & 85 & 85.70 & 85.52 & 0.113 & Acceptable \\
\hline Chlorobanzene & 1 & 8 & 8.4 & 8.40 & 0.374 & Acceptable \\
\hline$(\mu \mathrm{g} / \mathrm{L})$ & 2 & 110 & 114.1 & 111.90 & 0.169 & Acceptable \\
\hline Chloroform & 1 & 21 & 21.5 & 22.35 & 0.572 & Acceptable \\
\hline$(\mu \mathrm{g} / \mathrm{L})$ & 2 & 111 & 103.6 & 101.76 & 0.775 & Acceptable \\
\hline Chromium & 1 & 54.5 & 57.34 & 56.80 & 0.491 & Acceptable \\
\hline$(\mu \mathrm{g} / \mathrm{L})$ & 2 & 114 & 114.69 & 116.07 & 0.206 & Acceptable \\
\hline Cobalt & 1 & 147 & 150.2 & 149.46 & 0.412 & Acceptable \\
\hline$(\mathrm{mg} / \mathrm{L})$ & 2 & 448 & 450.6 & 445.03 & 0.161 & Acceptable \\
\hline $\operatorname{COD}^{c}$ & 1 & 170 & 183.4 & 180.3 & 0.601 & Acceptable \\
\hline$(\mathrm{mg} / \mathrm{L})$ & 2 & 40 & 37.2 & 36.1 & 0.543 & Acceptable \\
\hline Conductivity & 1 & 174 & 187.0 & 170.4 & 0.274 & Acceptable \\
\hline$(\mu \mathrm{mho} / \mathrm{cm})$ & 2 & 444 & 476.1 & 441.1 & 0.106 & Acceptable \\
\hline Copper & 1 & 63.4 & 64.96 & 64.13 & 0.101 & Acceptable \\
\hline$(\mu \mathrm{g} / \mathrm{L})$ & 2 & 267 & 267.98 & 266.07 & 0.068 & Acceptable \\
\hline 1,2-Dichlorobenzene & 1 & 36 & 87.3 & 47.2 & 1.065 & Acceptable \\
\hline$(\mu \mathrm{g} / \mathrm{L})$ & 2 & 92 & 175.8 & 96.5 & 0.207 & Acceptable \\
\hline \multirow[t]{2}{*}{ 1,2-Dichloroethane } & 1 & 15 & 13.8 & 15.01 & 0.003 & Acceptable \\
\hline & 2 & 143 & 140.7 & 144.91 & 0.088 & Acceptable \\
\hline \multirow[t]{2}{*}{ 2,4-Dinitrotoluene } & 1 & 23 & 23.3 & 16.0 & 1.247 & Acceptable \\
\hline & 2 & 76 & 84.5 & 71.7 & 0.198 & Acceptable \\
\hline \multirow{2}{*}{$\begin{array}{l}\text { Ethyl benzene } \\
(\mu \mathrm{g} / \mathrm{L})\end{array}$} & 1 & 31 & 31.2 & 32.51 & 0.302 & Acceptable \\
\hline & 2 & 62 & 67.2 & 67.16 & 0.765 & Acceptable \\
\hline \multirow{4}{*}{$\begin{array}{l}\text { Fluoride } \\
\quad(\mathrm{mg} / \mathrm{L}) \\
\text { Hexachlorobutadiene }\end{array}$} & 1 & 2.3 & 2.25 & 2.18 & 0.339 & Acceptable \\
\hline & 2 & 5.3 & 5.25 & 5.19 & 0.225 & Acceptable \\
\hline & 1 & 26 & 44.0 & 24.2 & 0.262 & Acceptable \\
\hline & 2 & 37 & 65.2 & 35.8 & 0.117 & Acceptable \\
\hline
\end{tabular}


Table 10.12 (continued)

\begin{tabular}{|c|c|c|c|c|c|c|}
\hline Parameter & Level & $\begin{array}{l}\text { Reported } \\
\text { value }\end{array}$ & $\begin{array}{l}\text { Reference } \\
\text { value }\end{array}$ & $\begin{array}{l}\text { Mean of } \\
\text { reporting } \\
\text { labs }\end{array}$ & $\begin{array}{l}\text { Number of } \\
\text { standard } \\
\text { deviations } \\
\text { from the } \\
\text { mean }\end{array}$ & $\begin{array}{c}\text { Performance } \\
\text { evaluation }^{a}\end{array}$ \\
\hline $\begin{array}{l}\text { Hexavalent } \\
\text { chromium } \\
(\mathrm{mg} / \mathrm{L})\end{array}$ & $\begin{array}{l}1 \\
2\end{array}$ & $\begin{array}{l}0.06 \\
0.11\end{array}$ & $\begin{array}{l}0.057 \\
0.115\end{array}$ & $\begin{array}{l}0.055 \\
0.120\end{array}$ & $\begin{array}{l}0.911 \\
0.601\end{array}$ & $\begin{array}{l}\text { Acceptable } \\
\text { Acceptable }\end{array}$ \\
\hline $\begin{array}{l}\text { Iron } \\
\qquad(\mu \mathrm{g} / \mathrm{L})\end{array}$ & 1 & 85.0 & 78.38 & 81.15 & 0.234 & Acceptable \\
\hline Lead & $\begin{array}{l}2 \\
1\end{array}$ & $\begin{array}{l}437 \\
142\end{array}$ & $\begin{array}{l}435.4 \\
136.7\end{array}$ & $\begin{array}{l}435.1 \\
136.16\end{array}$ & $\begin{array}{l}0.051 \\
0.263\end{array}$ & $\begin{array}{l}\text { Acceptable } \\
\text { Acceptable }\end{array}$ \\
\hline$(\mu \mathrm{g} / \mathrm{L})$ & 2 & 249 & 246.0 & 245.07 & 0.132 & Acceptable \\
\hline Magnesium & 1 & 1.59 & 1.53 & 1.51 & 0.585 & Acceptable \\
\hline $\begin{array}{c}(\mathrm{mg} / \mathrm{L}) \\
\text { Manganese }\end{array}$ & $\begin{array}{l}2 \\
1\end{array}$ & $\begin{array}{l}10.3 \\
60.8\end{array}$ & $\begin{array}{l}9.97 \\
61.5\end{array}$ & $\begin{array}{r}9.86 \\
59.47\end{array}$ & $\begin{array}{l}0.699 \\
0.245\end{array}$ & $\begin{array}{l}\text { Acceptable } \\
\text { Acceptable }\end{array}$ \\
\hline$(\mu \mathrm{g} / \mathrm{L})$ & 2 & 196 & 193.3 & 190.62 & 0.355 & Acceptable \\
\hline Mercury & 1 & 30.7 & 29.74 & 26.70 & 0.330 & Acceptable \\
\hline$(\mu \mathrm{g} / \mathrm{L})$ & 2 & 89.4 & 89.22 & 77.08 & 0.352 & Acceptable \\
\hline Molybdenum & 1 & 125 & 127.5 & 120.7 & 0.211 & Acceptable \\
\hline$(\mathrm{mg} / \mathrm{L})$ & 2 & 318 & 318.6 & 311.6 & 0.117 & Acceptable \\
\hline Nickel & 1 & 57.1 & 61.93 & 61.09 & 0.438 & Acceptable \\
\hline$(\mu \mathrm{g} / \mathrm{L})$ & 2 & 293 & 294.2 & 290.1 & 0.151 & Acceptable \\
\hline Nitrate as $\mathrm{N}$ & 1 & $<1$ & 0.228 & 0.295 & & Not rated \\
\hline$(\mathrm{mg} / \mathrm{L})$ & 2 & 1.4 & 1.585 & 1.593 & 0.736 & Acceptable \\
\hline Oil and grease & 1 & 5.8 & 5.56 & 6.15 & 0.125 & Acceptable \\
\hline$(\mathrm{mg} / \mathrm{L})$ & 2 & 22.5 & 22.46 & 22.47 & 0.004 & Acceptable \\
\hline Orthophosphate & 1 & $<2$ & 0.486 & 0.520 & & Not rated \\
\hline as $\mathrm{P}(\mathrm{mg} / \mathrm{L})$ & 2 & 2.2 & 2.180 & 2.194 & 0.015 & Acceptable \\
\hline Pentachlorophenol & 1 & 56 & 80.4 & 53.17 & 0.182 & Acceptable \\
\hline & 2 & 107 & 158.1 & 124.57 & 0.306 & Acceptable \\
\hline $\mathrm{pH}$ & 1 & 4.3 & 4.28 & 4.26 & 0.223 & Acceptable \\
\hline (units) & 2 & 7.7 & 7.85 & 7.65 & 0.176 & Acceptable \\
\hline Potassium & 1 & 6.38 & 6.31 & 6.24 & 0.315 & Acceptable \\
\hline$(\mathrm{mg} / \mathrm{L})$ & 2 & 17.8 & 17.74 & 17.69 & 0.081 & Acceptable \\
\hline Selenium & 1 & 51.9 & 40.09 & 38.79 & 2.647 & Acceptable \\
\hline$(\mu \mathrm{g} / \mathrm{L})$ & 2 & 166 & 140.3 & 134.28 & 1.724 & Unacceptable \\
\hline Silver & 1 & 71.1 & 71.65 & 71.63 & 0.060 & Acceptable \\
\hline$(\mu \mathrm{g} / \mathrm{L})$ & 2 & 115 & 119.42 & 119.90 & 0.386 & Acceptable \\
\hline Sodium & 1 & 25.6 & 25.47 & 25.46 & 0.065 & Acceptable \\
\hline$(\mathrm{mg} / \mathrm{L})$ & 2 & 52.8 & 52.25 & 52.69 & 0.033 & Acceptable \\
\hline Sulfate & 1 & 15 & 14.93 & 14.46 & 0.397 & Acceptable \\
\hline (mg/L) & 2 & 38 & 38.17 & 37.59 & 0.211 & Acceptable \\
\hline $\operatorname{TDS}^{d, e}$ & 1 & 197 & 199.0 & 109.3 & 0.545 & Acceptable \\
\hline$(\mathrm{mg} / \mathrm{L})$ & 2 & 353 & 357.6 & 103.8 & 0.794 & Acceptable \\
\hline Thallium & 1 & 38.8 & 36.38 & 38.30 & 0.032 & Acceptable \\
\hline$(\mu \mathrm{g} / \mathrm{L})$ & 2 & 649 & 642.64 & 636.04 & 0.176 & Acceptable \\
\hline TOC $^{f}$ & 1 & 77 & 69.0 & 71.7 & 1.072 & Acceptable \\
\hline$(\mathrm{mg} / \mathrm{L})$ & 2 & 15 & 14.0 & 14.9 & 0.029 & Unacceptable \\
\hline Toluene & 1 & 27 & 27.01 & 27.23 & 0.084 & Acceptablc \\
\hline$(\mu \mathrm{g} / \mathrm{L})$ & 2 & 48 & 51.17 & 50.28 & 0.473 & Acceptable \\
\hline Total hardness & 1 & 12 & 14.13 & 14.5 & 1.184 & Acceptable \\
\hline $\begin{array}{l}\text { as } \mathrm{CaCO}_{3} \\
(\mathrm{mg} / \mathrm{L})\end{array}$ & 2 & 13 & 55.0 & 54.5 & 13.959 & Unacceptable \\
\hline $\begin{array}{l}\text { Total organic } \\
\text { halides }\end{array}$ & $\begin{array}{l}1 \\
2\end{array}$ & $\begin{array}{r}27 \\
214\end{array}$ & $\begin{array}{r}34.3 \\
219.5\end{array}$ & $\begin{array}{r}31.54 \\
193.23\end{array}$ & $\begin{array}{l}0.309 \\
0.233\end{array}$ & $\begin{array}{l}\text { Acceptable } \\
\text { Acceptable }\end{array}$ \\
\hline
\end{tabular}




\section{Environmental Report-Paducah, Part 2}

Table 10.12 (continued)

\begin{tabular}{|c|c|c|c|c|c|c|}
\hline Parameter & Level & $\begin{array}{l}\text { Reported } \\
\text { value }\end{array}$ & $\begin{array}{l}\text { Reference } \\
\text { value }\end{array}$ & $\begin{array}{c}\text { Mean of } \\
\text { reporting } \\
\text { labs }\end{array}$ & $\begin{array}{l}\text { Number of } \\
\text { standard } \\
\text { deviations } \\
\text { from the } \\
\text { mean }\end{array}$ & $\begin{array}{l}\text { Performance } \\
\text { evaluation }{ }^{a}\end{array}$ \\
\hline Total residual & 1 & 0.60 & 0.620 & 0.564 & 0.461 & Acceptable \\
\hline $\begin{array}{l}\text { chlorine } \\
(\mathrm{mg} / \mathrm{L})\end{array}$ & 2 & 2.7 & 2.48 & 2.199 & 1.142 & Acceptable \\
\hline TSS ${ }^{e, g}$ & 1 & 59 & 71.3 & 88.6 & 0.666 & Acceptable \\
\hline$(\mathrm{mg} / \mathrm{L})$ & 2 & 144 & 155.7 & 92.2 & 0.040 & Acceptable \\
\hline \multirow{2}{*}{ 1,1,1-Trichloroethane } & 1 & 13 & 13.8 & 13.80 & 0.385 & Acceptable \\
\hline & 2 & 63 & 70.8 & 69.12 & 0.658 & Acceptable \\
\hline \multirow{2}{*}{$\begin{array}{l}\text { 1,1,2-Trichloroethane } \\
\quad(\mu \mathrm{g} / \mathrm{L})\end{array}$} & 1 & 11 & 9.87 & 10.04 & 0.520 & Acceptable \\
\hline & 2 & 71 & 68.7 & 67.48 & 0.353 & Acceptable \\
\hline \multirow[t]{2}{*}{ 2,4,6-Trichlorophenol } & 1 & & 12.4 & 8.74 & & Not reported \\
\hline & 2 & 101 & 130.6 & 111.2 & 0.285 & Acceptable \\
\hline Uranium & 1 & 139 & 140.1 & 127.56 & 0.864 & Acceptable \\
\hline$(\mu \mathrm{g} / \mathrm{L})$ & 2 & 305 & 340.3 & 318.84 & 0.764 & Acceptable \\
\hline Vanadium & 1 & 274 & 281.3 & 280.37 & 0.610 & Acceptable \\
\hline$(\mu \mathrm{g} / \mathrm{L})$ & 2 & 1047 & 1054.8 & 1053.71 & 0.187 & Acceptable \\
\hline Zinc & 1 & 24.1 & 21.6 & 21.62 & 0.543 & Acceptable \\
\hline$(\mu \mathrm{g} / \mathrm{L})$ & 2 & 142 & 134.7 & 135.60 & 0.473 & Acceptable \\
\hline
\end{tabular}

aPerformance evaluation made using U.S. Environmental Protection Agency criteria: 0-1.96 standard deviations for acceptable; 1.97-2.58 standard deviations for marginal; more than 2.58 standard deviations for unacceptable.

${ }^{b}$ Biological oxygen demand.

${ }^{c}$ Chemical oxygen demand.

${ }^{d}$ Total dissolved solids.

${ }^{e}$ Average percent recovery for participating laboratories.

fTotal organic carbon.

\&Total suspended solids. 
Table 10.13. May 1992 Analytical Products Group, Inc., Proficiency Environmental Testing Program

\begin{tabular}{|c|c|c|c|c|c|c|}
\hline Parameter & Level & $\begin{array}{l}\text { Reported } \\
\text { value }\end{array}$ & $\begin{array}{l}\text { Reference } \\
\text { value }\end{array}$ & $\begin{array}{l}\text { Mean of } \\
\text { reporting } \\
\text { labs }\end{array}$ & $\begin{array}{l}\text { Number of } \\
\text { standard } \\
\text { deviations } \\
\text { from the } \\
\text { mean }\end{array}$ & $\begin{array}{c}\text { Performance } \\
\text { evaluation }\end{array}$ \\
\hline Alkalinity as & 1 & 17 & 14.6 & 15.2 & 1.126 & Acceptable \\
\hline $\begin{array}{l}\mathrm{CaCO}_{3} \\
(\mathrm{mg} / \mathrm{L})\end{array}$ & 2 & 29 & 29.8 & 29.9 & 0.534 & Acceptable \\
\hline Aluminum & 1 & 50.9 & 49.8 & 52.8 & 0.132 & Acceptable \\
\hline$(\mu \mathrm{g} / \mathrm{L})$ & 2 & 195 & 199.1 & 201.2 & 0.263 & Acceptable \\
\hline Ammonia as $\mathrm{N}$ & 1 & 0.79 & 0.777 & 0.743 & 0.348 & Acceptable \\
\hline$(\mathrm{mg} / \mathrm{L})$ & 2 & 2.0 & 2.055 & 1.989 & 0.042 & Acceptable \\
\hline Antimony & 1 & 247 & 275.4 & 268.2 & 0.519 & Acceptable \\
\hline$(\mathrm{mg} / \mathrm{L})$ & 2 & 522 & 550.7 & 539.3 & 0.446 & Acceptable \\
\hline Arsenic & 1 & 56.2 & 57.0 & 58.0 & 0.348 & Acceptable \\
\hline$(\mu \mathrm{g} / \mathrm{L})$ & 2 & 147 & 152.0 & 157.7 & 0.565 & Acceptable \\
\hline Barium & 1 & 381 & 392.5 & 395.5 & 0.504 & Acceptable \\
\hline$(\mu \mathrm{g} / \mathrm{L})$ & 2 & 1473 & 1472.0 & 1467.7 & 0.107 & Acceptable \\
\hline Benzene & 1 & 22 & 22.0 & 22.13 & 0.045 & Acceptable \\
\hline$(\mu \mathrm{g} / \mathrm{L})$ & 2 & 85 & 83.3 & 84.30 & 0.046 & Acceptable \\
\hline Beryllium & 1 & 17 & 17.6 & 17.9 & 0.392 & Acceptable \\
\hline$(\mu \mathrm{g} / \mathrm{L})$ & 2 & 188 & 188.2 & 185.4 & 0.220 & Acceptable \\
\hline $\mathrm{BOD}^{b}$ & 1 & 124 & 115.4 & 112.7 & 0.751 & Acceptable \\
\hline$(\mathrm{mg} / \mathrm{L})$ & 2 & 22 & 19.0 & 17.6 & 1.337 & Acceptable \\
\hline Cadmium & 1 & 59.3 & 58.1 & 58.3 & 0.191 & Acceptable \\
\hline$(\mu \mathrm{g} / \mathrm{L})$ & 2 & 246 & 232.4 & 233.5 & 0.770 & Acceptable \\
\hline Calcium & 1 & 2.48 & 2.59 & 2.57 & 0.345 & Acceptable \\
\hline$(\mathrm{mg} / \mathrm{L})$ & 2 & 13.6 & 13.4 & 13.4 & 0.158 & Acceptable \\
\hline Chloride & 1 & 17 & 17.8 & 18.0 & 0.777 & Acceptable \\
\hline$(\mathrm{mg} / \mathrm{L})$ & 2 & 67 & 67.4 & 66.6 & 0.093 & Acceptable \\
\hline Chlorobenzene & 1 & 7 & 7.11 & 7.06 & 0.094 & Acceptable \\
\hline$(\mu \mathrm{g} / \mathrm{L})$ & 2 & 64 & 63.2 & 62.46 & 0.140 & Acceplablc \\
\hline Chloroform & 1 & 22 & 21.4 & 22.2 & 0.071 & Acceptable \\
\hline$(\mu \mathrm{g} / \mathrm{L})$ & 2 & 120 & 121.2 & 122.5 & 0.083 & Acceptable \\
\hline Chromium & 1 & 22.8 & 22.9 & 24.6 & 0.375 & Acceptable \\
\hline$(\mu \mathrm{g} / \mathrm{L})$ & 2 & 111 & 114.7 & 115.6 & 0.490 & Acceptable \\
\hline Cobalt & 1 & 189 & 184.9 & 186.5 & 0.287 & Acceptable \\
\hline$(\mathrm{mg} / \mathrm{L})$ & 2 & 403 & 385.6 & 386.8 & 0.983 & Acceptable \\
\hline $\mathrm{COD}^{c}$ & 1 & 160 & 185.8 & 180.2 & 1.224 & Acceptable \\
\hline$(\mathrm{mg} / \mathrm{L})$ & 2 & 29 & 30.6 & 28.9 & 0.003 & Acceptable \\
\hline Conductivity & 1 & 129 & 134.7 & 129.8 & 0.133 & Acceptable \\
\hline$(\mu \mathrm{mho} / \mathrm{cm})$ & 2 & 422 & 453.8 & 424.7 & 0.110 & Acceptable \\
\hline Copper & 1 & 77.8 & 81.2 & 81.5 & 0.599 & Acceptable \\
\hline$(\mu \mathrm{g} / \mathrm{L})$ & 2 & 201 & 203.0 & 204.6 & 0.289 & Acceptable \\
\hline 1,2-Dichlorobenzene & 1 & 8 & 7.07 & 7.24 & 0.680 & Acceptable \\
\hline$(\mu g / L)$ & 2 & 170 & 144.7 & 148.9 & 0.831 & Acceptable \\
\hline Ethyl benzene & 1 & 8 & 7.8 & 8.16 & 0.145 & Acceptable \\
\hline$(\mu \mathrm{g} / \mathrm{L})$ & 2 & 100 & 97.5 & 102.0 & 0.081 & Acceptable \\
\hline Fluoride & 1 & 3.0 & 2.94 & 2.88 & 0.229 & Acceptable \\
\hline$(\mathrm{mg} / \mathrm{L})$ & 2 & 8.5 & 8.43 & 8.70 & 0.332 & Acceptable \\
\hline Hexavalent & 1 & 0.04 & 0.034 & 0.037 & 0.357 & Acceptablc \\
\hline $\begin{array}{l}\text { chromium } \\
(\mathrm{mg} / \mathrm{L})\end{array}$ & 2 & 0.17 & 0.178 & 0.174 & 0.430 & Acceptable \\
\hline Iron & 1 & 126 & 124.6 & 123.0 & 0.198 & Acceptable \\
\hline$(\mu \mathrm{g} / \mathrm{L})$ & 2 & 344 & 332.3 & 335.4 & 0.348 & Acceptable \\
\hline Lead & 1 & 143 & 156.0 & 156.0 & 0.852 & Acceptable \\
\hline$(\mu \mathrm{g} / \mathrm{L})$ & 2 & 428 & 390.0 & 388.4 & 1.568 & Acceptable \\
\hline
\end{tabular}


1992 Environmental Report-Paducah, Part 2

Table 10.13 (continued)

\begin{tabular}{|c|c|c|c|c|c|c|}
\hline Parameter & Level & $\begin{array}{l}\text { Reported } \\
\text { value }\end{array}$ & $\begin{array}{c}\text { Reference } \\
\text { value }\end{array}$ & $\begin{array}{c}\text { Mean of } \\
\text { reporting } \\
\text { labs }\end{array}$ & $\begin{array}{l}\text { Number of } \\
\text { standard } \\
\text { deviations } \\
\text { from the } \\
\text { mean }\end{array}$ & $\begin{array}{l}\text { Performance } \\
\text { evaluation }\end{array}$ \\
\hline \multirow{2}{*}{$\begin{array}{l}\text { Magnesium } \\
(\mathrm{mg} / \mathrm{L})\end{array}$} & 1 & 1.42 & 1.503 & 1.547 & 0.574 & Acceptablc \\
\hline & 2 & 5.22 & 5.047 & 5.114 & 0.340 & Acceptable \\
\hline \multirow{2}{*}{$\begin{array}{l}\text { Manganese } \\
(\mu \mathrm{g} / \mathrm{L})\end{array}$} & 1 & 82.3 & 79.1 & 80.6 & 0.290 & Acceptable \\
\hline & 2 & 362 & 351.4 & 357.4 & 0.321 & Acceptable \\
\hline \multirow{2}{*}{$\begin{array}{l}\text { Mercury } \\
(\mu \mathrm{g} / \mathrm{L})\end{array}$} & 1 & 0.857 & 0.95 & 1.022 & 0.819 & Acceptable \\
\hline & 2 & 4.52 & 4.77 & 4.816 & 0.619 & Acceptable \\
\hline \multirow{2}{*}{$\begin{array}{l}\text { Methylene chloride } \\
(\mu \mathrm{g} / \mathrm{L})\end{array}$} & 1 & 34 & 34.6 & 36.2 & 0.253 & Acceptable \\
\hline & 2 & 80 & 86.5 & 89.5 & 0.448 & Accepiable \\
\hline \multirow{2}{*}{$\begin{array}{l}\text { Molybdenum } \\
(\mathrm{mg} / \mathrm{L})\end{array}$} & 1 & 112 & 114.7 & 113.3 & 0.133 & Acceptablc \\
\hline & 2 & 251 & 254.9 & 254.7 & 0.161 & Acceptable \\
\hline \multirow{2}{*}{$\begin{array}{l}\text { Nickel } \\
\quad(\mu \mathrm{g} / \mathrm{L})\end{array}$} & 1 & 73.4 & 61.93 & 63.2 & 1.654 & Acceptable \\
\hline & 2 & 248 & 232.2 & 239.9 & 0.492 & Acceptable \\
\hline \multirow{2}{*}{$\begin{array}{l}\text { Nitrate as } N \\
(\mathrm{mg} / \mathrm{L})\end{array}$} & 1 & $<1$ & 0.558 & 0.546 & & Not rated \\
\hline & 2 & 4.1 & 4.109 & 4.011 & 0.186 & Acceptable \\
\hline \multirow{2}{*}{$\begin{array}{l}\text { Oil and grease } \\
(\mathrm{mg} / \mathrm{L})\end{array}$} & 1 & 17.6 & 18.9 & 15.0 & 0.641 & Acceptable \\
\hline & 2 & 44.4 & 47.5 & 39.8 & 0.685 & Acceptable \\
\hline \multirow{2}{*}{$\begin{array}{l}\text { Orthophosphate } \\
\text { as } P(\mathrm{mg} / \mathrm{L})\end{array}$} & 1 & $<2$ & 0.369 & 3.71 & & Not rated \\
\hline & 2 & 7.8 & 7.58 & 7.62 & 0.211 & Acceptable \\
\hline \multirow{2}{*}{$\begin{array}{l}\mathrm{pH} \\
\text { (units) }\end{array}$} & 1 & 9.4 & 9.59 & 9.46 & 0.223 & Acceptable \\
\hline & 2 & 2.7 & 2.62 & 2.64 & 0.583 & Acceptable \\
\hline \multirow{2}{*}{$\begin{array}{l}\text { Potassium } \\
\text { (mg/L) }\end{array}$} & 1 & 2.56 & 3.033 & 3.078 & 0.865 & Acceptable \\
\hline & 2 & 26 & 25.265 & 25.385 & 0.390 & Acceptable \\
\hline \multirow{2}{*}{$\begin{array}{l}\text { Selenium } \\
(\mu \mathrm{g} / \mathrm{L})\end{array}$} & 1 & 28.7 & 25.06 & 24.63 & 0.735 & Acceptable \\
\hline & 2 & 88.4 & 75.2 & 71.60 & 1.562 & Acceptable \\
\hline \multirow{2}{*}{$\begin{array}{l}\text { Silver } \\
\qquad(\mu \mathrm{g} / \mathrm{L})\end{array}$} & 1 & 101 & 95.5 & 95.98 & 1.176 & Acceptable \\
\hline & 2 & 190 & 191.1 & 193.76 & 0.205 & Acceptable \\
\hline \multirow{2}{*}{$\begin{array}{l}\text { Sodium } \\
\quad(\mathrm{mg} / \mathrm{L})\end{array}$} & 1 & 18.4 & 17.8 & 17.6 & 0.437 & Acceptable \\
\hline & 2 & 44.4 & 42.9 & 43.4 & 0.333 & Acceptable \\
\hline \multirow{2}{*}{$\begin{array}{l}\text { Sulfate } \\
\qquad(\mathrm{mg} / \mathrm{L})\end{array}$} & 1 & 15 & 14.9 & 14.8 & 0.077 & Acceptable \\
\hline & 2 & 53 & 52.9 & 52.3 & 0.241 & Acceptable \\
\hline \multirow{2}{*}{$\begin{array}{l}\operatorname{TDS}^{d e} \\
(\mathrm{mg} / \mathrm{L})\end{array}$} & 1 & 163 & 186.3 & 100.4 & 0.697 & Acceptable \\
\hline & 2 & 224 & 245.9 & 99.7 & 0.741 & Acceptable \\
\hline \multirow[t]{2}{*}{ Tetrachloroethene } & 1 & 18 & 18.6 & 18.62 & 0.162 & Acceptable \\
\hline & 2 & 120 & 125.9 & 116.05 & 0.177 & Acceptable \\
\hline \multirow{2}{*}{$\begin{array}{r}\text { Thallium } \\
(\mu \mathrm{g} / \mathrm{L})\end{array}$} & 1 & 41.6 & 42.4 & 42.53 & 0.073 & Acceptable \\
\hline & 2 & 303 & 303.1 & 269.12 & 0.562 & Acceptable \\
\hline TOC $^{f}$ & 1 & 75 & 69.9 & 71.6 & 0.386 & Acceptable \\
\hline$(\mathrm{mg} / \mathrm{L})$ & 2 & 12 & 11.5 & 12.4 & 0.192 & Acceptable \\
\hline Toluene & 1 & 48 & 47.7 & 45.1 & 0.807 & Acceptable \\
\hline$(\mu \mathrm{g} / \mathrm{L})$ & 2 & 55 & 53.5 & 57.0 & 0.145 & Acceptable \\
\hline Total hardness & 1 & 10 & 12.6 & 12.5 & 1.413 & Acceptable \\
\hline as $\mathrm{CaCO}_{3}(\mathrm{mg} / \mathrm{L})$ & 2 & 56 & 54.3 & 54.7 & 0.471 & Acceptable \\
\hline Total organic & 1 & 81 & 36.6 & 42.57 & 1.997 & Acceptable \\
\hline $\begin{array}{l}\text { halides } \\
(\mu \mathrm{g} / \mathrm{L})\end{array}$ & 2 & 164 & 146.2 & 134.38 & 1.191 & Acceptable \\
\hline Total residual & 1 & 0.35 & 0.365 & 0.353 & 0.050 & Acceptable \\
\hline $\begin{array}{l}\text { chlorine } \\
(\mathrm{mg} / \mathrm{L})\end{array}$ & 2 & 4.4 & 5.82 & 5.44 & 1.497 & Acceptable \\
\hline 1,1,1-Trichloroethane & 1 & 8 & 7.9 & 8.57 & 0.336 & Acceptable \\
\hline & 2 & 55 & 53.7 & 56.36 & 0.105 & Acceptable \\
\hline TSS $^{e, g}$ & 1 & 54 & 71.7 & 89.9 & 1.893 & Acceptable \\
\hline$(\mathrm{mg} / \mathrm{L})$ & 2 & 268 & 298.5 & 92.9 & 0.570 & Acceptable \\
\hline
\end{tabular}




\section{Environmental Report-Paducah, Part 2}

Table 10.13 (continued)

\begin{tabular}{|c|c|c|c|c|c|c|}
\hline Parameter & Level & $\begin{array}{l}\text { Reported } \\
\text { value }\end{array}$ & $\begin{array}{l}\text { Reference } \\
\text { value }\end{array}$ & $\begin{array}{l}\text { Mean of } \\
\text { reporting } \\
\text { labs }\end{array}$ & $\begin{array}{l}\text { Number of } \\
\text { standard } \\
\text { deviations } \\
\text { from the } \\
\text { mean }\end{array}$ & $\begin{array}{c}\text { Performance } \\
\text { evaluation }\end{array}$ \\
\hline Uranium & 1 & 136 & 140.1 & 137.08 & 0.168 & Acceptable \\
\hline$(\mu \mathrm{g} / \mathrm{L})$ & 2 & 384 & 440.4 & 413.00 & 1.171 & Acceptable \\
\hline Vanadium & 1 & 41.1 & 42.3 & 42.93 & 0.373 & Acceptable \\
\hline$(\mu \mathrm{g} / \mathrm{L})$ & 2 & 1018 & 1016.1 & 1024.0 & 0.152 & Acceptable \\
\hline Zinc & 1 & 51.9 & 47.69 & 49.19 & 0.432 & Acceptable \\
\hline$(\mu \mathrm{g} / \mathrm{L})$ & 2 & 243 & 238.4 & 238.25 & 0.455 & Acceptable \\
\hline
\end{tabular}

aPerformance evaluation made using U.S. Environmental Protection Agency criteria: 0-1.96 standard deviations for acceptable; 1.97-2.58 standard deviations for marginal; more than 2.58 standard deviations for not acceptable.

${ }^{b}$ Biological oxgen demand.

${ }^{c}$ Chemical oxygen demand.

${ }^{d}$ Total dissolved solids.

${ }^{e}$ Average percent recovery for participating laboratories.

fTotal organic carbon.

gTotal suspended solids. 
Table 10.14. July 1992 Analytical Products Group, Inc., Proficiency Environmental Testing Program

\begin{tabular}{|c|c|c|c|c|c|c|}
\hline Parameter & Level & $\begin{array}{l}\text { Reported } \\
\text { value }\end{array}$ & $\begin{array}{l}\text { Reference } \\
\text { value }\end{array}$ & $\begin{array}{l}\text { Mean of } \\
\text { reporting } \\
\text { labs }\end{array}$ & $\begin{array}{l}\text { Number of } \\
\text { standard } \\
\text { deviations } \\
\text { from the } \\
\text { mean }\end{array}$ & $\begin{array}{l}\text { Performance } \\
\text { evaluation" }\end{array}$ \\
\hline Alkalinity as & 1 & 18 & 15.7 & 16.4 & 0.894 & Acceptable \\
\hline $\begin{array}{l}\mathrm{CaCO}_{3} \\
(\mathrm{mg} / \mathrm{L})\end{array}$ & 2 & 25 & 24.1 & 24.0 & 0.470 & Acceptable \\
\hline Aluminum & 1 & 76.7 & 71.63 & 73.60 & 0.207 & Acceptable \\
\hline$(\mu \mathrm{g} / \mathrm{L})$ & 2 & 207.0 & 204.66 & 205.11 & 0.057 & Acceptable \\
\hline Ammonia as $\mathrm{N}$ & 1 & 0.47 & 0.49 & 0.509 & 0.323 & Acceptable \\
\hline$(\mathrm{mg} / \mathrm{L})$ & 2 & 4.7 & 5.09 & 5.07 & 0.625 & Acceptable \\
\hline Antimony & 1 & 47.4 & 55.07 & 49.4 & 0.236 & Acceptable \\
\hline (mg/L) & 2 & 1316.0 & 1363.03 & 1325.2 & 0.060 & Acceptable \\
\hline Arsenic & 1 & 60.0 & 56.99 & 56.65 & 0.597 & Acceptable \\
\hline$(\mu \mathrm{g} / \mathrm{L})$ & 2 & 283.8 & 284.76 & 284.12 & 0.011 & Acceptable \\
\hline Barium & 1 & 294.6 & 294.4 & 292.5 & 0.113 & Acceptable \\
\hline$(\mu \mathrm{g} / \mathrm{L})$ & 2 & 1478.0 & 1472.0 & 1457.5 & 0.190 & Acceptable \\
\hline Benzene & 1 & 10.8 & 9.8 & 9.85 & 0.820 & Acceptable \\
\hline$(\mathrm{mg} / \mathrm{L})$ & 2 & 102.6 & 103.7 & 102.58 & 0.002 & Acceptable \\
\hline Beryllium & 1 & 15.8 & 15.08 & 14.75 & 0.763 & Acceptable \\
\hline$(\mu \mathrm{g} / \mathrm{L})$ & 2 & 131.4 & 125.6 & 124.30 & 1.028 & Acceptable \\
\hline $\mathrm{BOD}^{b}$ & 1 & 157 & 127.9 & 125.2 & 1.515 & Acceplable \\
\hline$(\mathrm{mg} / \mathrm{L})$ & 2 & 11 & 7.6 & 9.0 & 0.595 & Acceptable \\
\hline Cadmium & $\overline{1}$ & 30.98 & 29.05 & 29.80 & 0.337 & Acceptable \\
\hline$(\mu \mathrm{g} / \mathrm{L})$ & 2 & 122.9 & 116.20 & 116.05 & 0.820 & Acceptable \\
\hline Calcium & 1 & 3.16 & 3.02 & 3.107 & 0.155 & Acceptable \\
\hline$(\mathrm{mg} / \mathrm{L})$ & 2 & 12.7 & 12.51 & 12.53 & 0.194 & Acceptable \\
\hline Chloride & $i$ & 45 & 44.7 & 44.8 & 0.059 & Acceptable \\
\hline$(\mathrm{mg} / \mathrm{L})$ & 2 & 55 & 53.1 & 52.6 & 0.861 & Acceptable \\
\hline Chlorobenzene & $i$ & 8.1 & 8.00 & 8.080 & 0.015 & Acceptable \\
\hline$(\mu \mathrm{g} / \mathrm{L})$ & 2 & 167.9 & 174.90 & 174.197 & 0.273 & Acceptable \\
\hline Chloroform & 1 & 28.9 & 25.70 & 25.57 & 0.951 & Acceptable \\
\hline$(\mu \mathrm{g} / \mathrm{L})$ & 2 & 81.3 & 79.30 & 77.15 & 0.361 & Acceplable \\
\hline Chromium & 1 & 62.6 & 62.54 & 62.81 & 0.040 & Acceptable \\
\hline$(\mu \mathrm{g} / \mathrm{L})$ & 2 & 126.8 & 125.07 & 124.74 & 0.147 & Acceptable \\
\hline Cobalt & 1 & 130.4 & 128.5 & 127.92 & 0.322 & Acceptable \\
\hline$(\mu \mathrm{g} / \mathrm{L})$ & 2 & 263.1 & 257.0 & 253.32 & 0.701 & Acceptable \\
\hline $\mathrm{COD}^{\circ}$ & 1 & 205 & 205.9 & 194.7 & 0.472 & Acceptable \\
\hline$(\mathrm{mg} / \mathrm{L})$ & 2 & 12 & 12.3 & 14.0 & 0.312 & Acceptable \\
\hline Conductivity & 1 & 242 & 249.4 & 241.8 & 0.013 & Acceptable \\
\hline$(\mu \mathrm{mho} / \mathrm{cm})$ & 2 & 331 & 348.1 & 323.0 & 0.378 & Acceptable \\
\hline Copper & 1 & 71.7 & 73.08 & 73.97 & 0.418 & Acceptable \\
\hline$(\mu \mathrm{g} / \mathrm{L})$ & 2 & 156.9 & 162.41 & 163.40 & 0.657 & Acceptable \\
\hline 1,2-Dichloroethane & 1 & 37.0 & 32.4 & 31.76 & 1.394 & Acceptable \\
\hline$(\mu \mathrm{g} / \mathrm{L})$ & 2 & 75.2 & 71.2 & 70.40 & 0.570 & Acceptable \\
\hline Ethyl benzene & 1 & 31.9 & 31.80 & 31.165 & 0.236 & Acceptable \\
\hline$(\mu \mathrm{g} / \mathrm{L})$ & 2 & 57.14 & 67.60 & 67.028 & 1.200 & Acceptable \\
\hline Fluoride & 1 & 2.5 & 2.38 & 2.37 & 0.956 & Acceptable \\
\hline$(\mathrm{mg} / \mathrm{L})$ & 2 & 5.9 & 5.76 & 5.84 & 0.191 & Acceptable \\
\hline Hexavalent & $i$ & 0.07 & 0.078 & 0.075 & 0.543 & Acceptable \\
\hline $\begin{array}{l}\text { chromium } \\
\text { (mg/L) }\end{array}$ & 2 & 0.46 & 0.469 & 0.478 & 0.434 & Acceptable \\
\hline Iron & 1 & 48.4 & 41.53 & 44.13 & 0.460 & Acceptable \\
\hline$(\mu \mathrm{g} / \mathrm{L})$ & 2 & 431.9 & 415.33 & 411.34 & 0.898 & Acceptable \\
\hline Lead & 1 & 121.8 & 105.67 & 106.14 & 1.614 & Acceptable \\
\hline$(\mu \mathrm{g} / \mathrm{L})$. & 2 & 424.6 & 396.26 & 393.06 & 1.217 & Acceptable \\
\hline
\end{tabular}


1992 Environmental Report-Paducah, Part 2

Table 10.14 (continued)

\begin{tabular}{|c|c|c|c|c|c|c|}
\hline Parameter & Level & $\begin{array}{l}\text { Reported } \\
\text { value }\end{array}$ & $\begin{array}{l}\text { Reference } \\
\text { value }\end{array}$ & $\begin{array}{l}\text { Mean of } \\
\text { reporting } \\
\text { labs }\end{array}$ & $\begin{array}{l}\text { Number of } \\
\text { standard } \\
\text { deviations } \\
\text { from the } \\
\text { mean }\end{array}$ & $\begin{array}{l}\text { Performance } \\
\text { evaluation }^{a}\end{array}$ \\
\hline Magnesium & 1 & 3.41 & 3.17 & 3.20 & 0.853 & Acceptable \\
\hline$(\mathrm{mg} / \mathrm{L})$ & 2 & 2.33 & 2.20 & 2.23 & 0.840 & Acceptable \\
\hline Manganese & 1 & 58.4 & 56.01 & 55.66 & 0.667 & Acceptable \\
\hline$(\mu \mathrm{g} / \mathrm{L})$ & 2 & 235.9 & 224.05 & 220.45 & 1.196 & Acceptable \\
\hline Mercury & 1 & 13.8 & 1.67 & 1.732 & 60.657 & Unacceptable \\
\hline$(\mu \mathrm{g} / \mathrm{L})$ & 2 & 4.85 & 4.77 & 4.641 & 0.315 & Acceptable \\
\hline Methylene chloride & 1 & 26.1 & 21.7 & 24.61 & 0.231 & Acceptable \\
\hline$(\mu \mathrm{g} / \mathrm{L})$ & 2 & 100.9 & 93.4 & 92.56 & 0.490 & Acceptable \\
\hline Molybdenum & 1 & 91.2 & 102.0 & 99.65 & 0.784 & Acceptable \\
\hline$(\mathrm{mg} / \mathrm{L})$ & 2 & 241.9 & 254.9 & 251.65 & 0.475 & Acceptable \\
\hline Nickel & 1 & 49.9 & 50.51 & 50.90 & 0.164 & Acceptable \\
\hline$(\mu \mathrm{g} / \mathrm{L})$ & 2 & 155.1 & 154.84 & 156.38 & 0.089 & Acceptable \\
\hline Nitrate as $\mathrm{N}$ & 1 & $<1$ & 0.35 & 0.356 & & Not rated \\
\hline$(\mathrm{mg} / \mathrm{L})$ & 2 & 3.0 & 2.73 & 2.68 & 0.996 & Acceptable \\
\hline Oil and grease & 1 & 5.2 & 5.11 & 5.083 & 0.055 & Acceptable \\
\hline$(\mathrm{mg} / \mathrm{L})$ & 2 & 20.4 & 21.81 & 20.09 & 0.075 & Acceptable \\
\hline Orthophosphate & 1 & $<2$ & 0.79 & 0.80 & & Not rated \\
\hline as $\mathrm{P}(\mathrm{mg} / \mathrm{L})$ & 2 & 7.8 & 7.86 & 7.90 & 0.266 & Acceptable \\
\hline $\mathrm{pH}$ & $i$ & 3.7 & 3.84 & 3.76 & 0.312 & Acceptable \\
\hline (units) & 2 & 8.7 & 8.92 & 8.72 & 0.068 & Acceptable \\
\hline Potassium & 1 & 34.2 & 33.14 & 33.17 & 0.267 & Acceptable \\
\hline$(\mathrm{mg} / \mathrm{L})$ & 2 & 27.3 & 26.55 & 26.49 & 0.363 & Acceptable \\
\hline Sclenium & 1 & 22.0 & 20.98 & 20.73 & 0.470 & Acceptable \\
\hline$(\mu \mathrm{g} / \mathrm{L})$ & 2 & 73.0 & 65.58 & 63.45 & 1.047 & Acceptable \\
\hline Silver & 1 & 48.1 & 47.77 & 47.17 & 0.157 & Acceptable \\
\hline$(\mu \mathrm{g} / \mathrm{L})$ & 2 & 187.6 & 191.07 & 188.15 & 0.030 & Acceptable \\
\hline Sodium & 1 & 14.87 & 14.37 & 14.96 & 0.073 & Acceptable \\
\hline$(\mathrm{mg} / \mathrm{L})$ & 2 & 28.6 & 28.19 & 28.33 & 0.120 & Acceptable \\
\hline Sulfate & 1 & 15 & 14.996 & 14.978 & 0.012 & Acceplable \\
\hline$(\mathrm{mg} / \mathrm{L})$ & 2 & 35 & 35.865 & 35.676 & 0.245 & Acceptable \\
\hline $\operatorname{TDS}^{d, e}$ & 1 & 171 & 173.8 & 101.5 & 0.266 & Acceptable \\
\hline$(\mathrm{mg} / \mathrm{L})$ & 2 & 303 & 309.3 & 101.4 & 0.463 & Acceptable \\
\hline Tetrachloroethene & 1 & 30.6 & 30.70 & 29.33 & 0.349 & Acccptable \\
\hline$(\mu \mathrm{g} / \mathrm{L})$ & 2 & 80.1 & 96.10 & 92.83 & 0.965 & Acceplable \\
\hline Thallium & $i$ & 165.9 & 167.94 & 159.75 & 0.345 & Acceptable \\
\hline$(\mu \mathrm{g} / \mathrm{L})$ & 2 & 343.6 & 335.89 & 322.070 & 0.543 & Acceptablc \\
\hline TOC & 1 & 89 & 77.5 & 79.8 & 1.097 & Acceptable \\
\hline$(\mathrm{mg} / \mathrm{L})$ & 2 & 6 & 4.6 & 5.18 & 0.849 & Acceptable \\
\hline Toluene & 1 & 15.6 & 15.2 & 14.85 & 0.483 & Acceptable \\
\hline$(\mu \mathrm{g} / \mathrm{L})$ & 2 & 57.1 & 65.1 & 63.62 & 0.867 & Acceptable \\
\hline Total hardness & 1 & 23 & 20.6 & 21.08 & 1.249 & Acceptable \\
\hline $\begin{array}{l}\text { as } \mathrm{CaCO}_{3} \\
(\mathrm{mg} / \mathrm{L})\end{array}$ & 2 & 40 & 40.6 & 40.30 & 0.143 & Acceptable \\
\hline Total organic & 1 & 34 & 29.4 & 27.89 & 0.568 & Acceptable \\
\hline $\begin{array}{l}\text { halides } \\
(\mu \mathrm{g} / \mathrm{L})\end{array}$ & 2 & 282 & 249.7 & 238.1 & 2.132 & Warning \\
\hline Total residual & 1 & 0.68 & 0.789 & 0.734 & 0.42 .3 & Acceptable \\
\hline $\begin{array}{l}\text { chlorinc } \\
\text { (mg/lo) }\end{array}$ & 2 & 2.80 & 3.72 & 3.43 & 1.101 & Acceptable \\
\hline 1,1,1-Trichlorocthane & 1 & 42.2 & 37.80 & 36.64 & 1.173 & Acceptable \\
\hline$(\mu g / L)$ & 2 & 49.1 & 52.10 & 50.95 & 0.263 & Acceptable \\
\hline
\end{tabular}




\section{Environmental Report-Paducah, Part 2}

Table 10.14 (continued)

\begin{tabular}{|c|c|c|c|c|c|c|}
\hline Parameter & Level & $\begin{array}{l}\text { Reported } \\
\text { value }\end{array}$ & $\begin{array}{c}\text { Reference } \\
\text { value }\end{array}$ & $\begin{array}{l}\text { Mean of } \\
\text { reporting } \\
\text { labs }\end{array}$ & $\begin{array}{l}\text { Number of } \\
\text { standard } \\
\text { deviations } \\
\text { from the } \\
\text { mean }\end{array}$ & $\begin{array}{l}\text { Performance } \\
\text { evaluation" }\end{array}$ \\
\hline 1,1,2-Trichloroethane & 1 & 16.0 & 15.1 & 14.37 & 0.784 & Acceptable \\
\hline$(\mu \mathrm{g} / \mathrm{L})$ & 2 & 105.5 & 104.3 & 107.38 & 0.090 & Acceptable \\
\hline TSS $^{e, g}$ & 1 & 57 & 73.2 & 89.5 & 1.275 & Acceptable \\
\hline$(\mathrm{mg} / \mathrm{L})$ & 2 & 243 & 261.6 & 93.0 & 0.023 & Acceptable \\
\hline Uranium & $i$ & 154 & 160.2 & 158.0 & 0.450 & Acceptable \\
\hline$(\mu \mathrm{g} / \mathrm{L})$ & 2 & 787 & 800.8 & 763.3 & 0.539 & Acceptable \\
\hline Vanadium & 1 & 44.6 & 42.33 & 42.54 & 0.582 & Acceptable \\
\hline$(\mu g / L)$ & 2 & 128.5 .0 & 1270.2 & 12642.17 & 0.513 & Acceplable \\
\hline Zinc & 1 & 44.9 & 42.92 & 43.07 & 0.305 & Acceplable \\
\hline$(\mu \mathrm{g} / \mathrm{L})$ & 2 & 193.9 & 190.75 & 188.46 & 0.422 & Acceptable \\
\hline
\end{tabular}

"Performance evaluation made using U.S. Environmental Protection Agency criteria: 0-1.96 standard deviations for acceptable; 1.97-2.58 standard deviations for marginal; more than 2.58 standard deviations for unaceptable.

bBiological oxygen demand.

'Chemical oxygen demand.

"Total dissolved solids.

eAverage percent recovery for participating laboratories.

fotal organic carbon.

gTotal suspended solids. 
Table 10.15. September 1992 Analytical Products Group, Inc., Proficiency Environmental Testing Program

\begin{tabular}{|c|c|c|c|c|c|c|}
\hline Parameter & Level & $\begin{array}{l}\text { Reported } \\
\text { value }\end{array}$ & $\begin{array}{l}\text { Reference } \\
\text { value }\end{array}$ & $\begin{array}{l}\text { Mean of } \\
\text { reporting } \\
\text { labs }\end{array}$ & $\begin{array}{l}\text { Number of } \\
\text { standard } \\
\text { deviations } \\
\text { from the } \\
\text { mean }\end{array}$ & $\begin{array}{l}\text { Performance } \\
\text { evaluation" }\end{array}$ \\
\hline Alkalinity as & 1 & 62 & 65.1 & 63.72 & 0.753 & Acceptable \\
\hline $\begin{array}{l}\mathrm{CaCO}_{3} \\
(\mathrm{mg} / \mathrm{l})\end{array}$ & 2 & 16 & 14.6 & 15.43 & 0.293 & Acceptable \\
\hline Aluminum & 1 & 88.5 & 81.86 & 81.58 & 0.627 & Acceptable \\
\hline$(\mu \mathrm{g} / \mathrm{L})$ & 2 & 174.0 & 153.49 & 161.32 & 0.512 & Acceptable \\
\hline Ammonia as $N$ & 1 & 0.56 & 0.60 & 0.619 & 0.486 & Acceptible \\
\hline$(m g / L)$ & 2 & 4.5 & 4.66 & 4.785 & 0.486 & Acceptahlc \\
\hline Antimony & $i$ & 44.8 & 57.26 & 51.15 & 0.894 & Acceptable \\
\hline$(\mathrm{mg} / \mathrm{l})$ & 2 & 863.0 & 954.29 & 892.71 & 0.414 & Acceptable \\
\hline Arsenic & 1 & 127.0 & 94.99 & 91.37 & 3.658 & Unacceptable \\
\hline$(\mu g / L)$ & 2 & 435.0 & 379.94 & 380.11 & 1.620 & Acceptable \\
\hline Barium & 1 & 524 & 522.4 & 511.26 & 0.514 & Acceptable \\
\hline$(\mu g / L)$ & 2 & 1315 & 1306.1 & 1298.19 & 0.282 & Acceptable \\
\hline Benzene & 1 & 9 & 9.5 & 9.45 & 0.434 & Acceptable \\
\hline$(\mu \mathrm{g} / \mathrm{L})$ & 2 & 71 & 69.3 & 68.16 & 0.340 & Acceptable \\
\hline Beryllium & 1 & 12.7 & 12.55 & $12.0(1)$ & 0.462 & Acceplable \\
\hline$(\mu \mathrm{g} / \mathrm{L})$ & 2 & 13.1 & 125.50 & 122.16 & 12.192 & Unacceptable \\
\hline $\mathrm{BOD}^{\mathrm{h}}$ & 1 & 218 & 234.3 & 212.0 & 0.127 & Acceplable \\
\hline (mg/L.) & 2 & 5 & 4.2 & 5.18 & 0.103 & Acceptable \\
\hline Cadmium & 1 & 31.2 & 29.05 & 29.08 & 0.554 & Acceptable \\
\hline$(\mu \mathrm{g} / \mathrm{L})$ & 2 & 154 & 14.5 .2 & 144.85 & 0.583 & Acceptable \\
\hline Calcium & 1 & 27.9 & 29.70 & 30.69 & 0.8 .32 & Acceptable \\
\hline (mg/l.) & 2 & 7.94 & 7.74 & 8.14 & 0.254 & Acceptable \\
\hline \multirow[t]{2}{*}{ Carbon tetrachloride } & $i$ & 39 & 40.3 & 38.54 & 0.105 & Acceptable \\
\hline & 2 & 49 & 52.4 & 51.72 & 0.488 & Acceplable \\
\hline Chloride & 1 & 129 & 135.1 & 134.6 .3 & 1.170 & Acceptable \\
\hline$(\mathrm{mg} / \mathrm{L})$. & 2 & 33 & 36.0 & 35.97 & 0.757 & Acceptable \\
\hline Chlorobenzene & $i$ & 8 & 7.7 & 7.97 & 0.034 & Acceptable \\
\hline$(\mu \mathrm{g} / \mathrm{L})$ & 2 & 66 & 64.9 & 64.57 & 0.274 & Acceptable \\
\hline Chloroform & 1 & 13 & 13.6 & 13.67 & 0.451 & Acceptable \\
\hline$(\mu \mathrm{g} / \mathrm{L})$ & 2 & 68 & 67.7 & 67.31 & 0.107 & Acceptable \\
\hline Chromium & 1 & 22.7 & 21.89 & 22.57 & 0.049 & Acceplable \\
\hline$(\mu \mathrm{g} / \mathrm{L})$ & 2 & 228.0 & 234.51 & 233.99 & 0.3 .36 & Acceplable \\
\hline Cobalt & 1 & 181.0 & 179.9 & 176.30 & 0.407 & Acceplable \\
\hline$(\mathrm{mg} / \mathrm{L})$ & 2 & 493.0 & 488.4 & 483.87 & 0.339 & Acceplable \\
\hline $\mathrm{COD}^{\circ}$ & 1 & 365 & 377.1 & 362.12 & 0.142 & Acceptable \\
\hline$(\mathrm{mg} / \mathrm{L})$ & 2 & 20 & 6.80 & 10.67 & 1.689 & Acceplable \\
\hline Conductivity & 1 & 754 & 839.5 & 749.6 & 0.145 & Acceptable \\
\hline$(\mu \mathrm{mho} / \mathrm{cm})$ & 2 & 192 & 195.8 & 187.4 & 0.573 & Acceptable \\
\hline Copper & 1 & 80.6 & 81.20 & 80.407 & 0.032 & Acceptable \\
\hline$(\mu \mathrm{g} / \mathrm{L})$ & 2 & 204.0 & 203.01 & 203.592 & 0.027 & Acceptable \\
\hline 1,2-Dichlorobenzene & $i$ & 33 & 31.1 & 29.89 & 0.791 & Acceptable \\
\hline$(\mu \mathrm{g} / \mathrm{L})$ & 2 & 58 & 51.4 & 50.52 & 1.032 & Acceptable \\
\hline Ethyl benzene & 1 & 15 & 15.1 & 15.02 & 0.013 & Acceptable \\
\hline$(\mu \mathrm{g} / \mathrm{L})$ & 2 & 84 & 84.9 & 82.83 & 0.109 & Acceptable \\
\hline Fluoride & 1 & 3.0 & 3.14 & 3.033 & 0.131 & Acceptable \\
\hline$(\mathrm{mg} / \mathrm{L})$ & 2 & 5.2 & 5.25 & 5.255 & 0.250 & Acceplable \\
\hline Hexavalent & 1 & 0.09 & 0.094 & 0.092 & 0.222 & Acceptable \\
\hline $\begin{array}{l}\text { chromium } \\
\text { (mg/L) }\end{array}$ & 2 & .12 & 0.125 & 0.124 & 0.382 & Acceplable \\
\hline Iron & 1 & 46.8 & 41.53 & 43.84 & 0.355 & Acceptable \\
\hline$(\mu \mathrm{g} / \mathrm{L})$ & 2 & 424.0 & 415.33 & 413.72 & 0.314 & Acceptable \\
\hline
\end{tabular}


Table 10.15 (continued)

\begin{tabular}{|c|c|c|c|c|c|c|}
\hline Parameter & Level & $\begin{array}{l}\text { Reported } \\
\text { value }\end{array}$ & $\begin{array}{l}\text { Reference } \\
\text { value }\end{array}$ & $\begin{array}{l}\text { Mean of } \\
\text { reporting } \\
\text { labs }\end{array}$ & $\begin{array}{l}\text { Number of } \\
\text { standard } \\
\text { deviations } \\
\text { from the } \\
\text { mean }\end{array}$ & $\begin{array}{l}\text { Performance } \\
\text { evaluation }^{a}\end{array}$ \\
\hline Lead & 1 & 78.8 & 79.25 & 77.969 & 0.140 & Acceptable \\
\hline$(\mu \mathrm{g} / \mathrm{L})$ & 2 & 395.0 & 396.26 & 393.012 & 0.088 & Acceptable \\
\hline Magnesium & 1 & 11.6 & 11.83 & 11.89 & 0.352 & Acceptable \\
\hline$(\mathrm{mg} / \mathrm{L})$ & 2 & 4.48 & 4.34 & 4.36 & 0.472 & Acceptable \\
\hline Manganesc & 1 & 55.7 & 56.01 & 54.96 & 0.206 & Acceptable \\
\hline$(\mu g / L)$ & 2 & 111.0 & 112.02 & 110.77 & 0.034 & Acceptable \\
\hline Mercury & 1 & 0.113 & 0.95 & 0.833 & 2.616 & Unacceptable \\
\hline$(\mu \mathrm{g} / \mathrm{L})$ & 2 & 1.36 & 4.77 & 4.720 & 5.002 & Unacceptable \\
\hline Methylene chloride & 1 & 21 & 20.6 & 23.52 & 0.596 & Acceptable \\
\hline$(\mu \mathrm{g} / \mathrm{L})$ & 2 & 78 & 76.0 & 75.90 & 0.189 & Acceptable \\
\hline Molybdenum & 1 & 96.4 & 101,97 & 99.60 & 0.593 & Acceptable \\
\hline$(\mathrm{mg} / \mathrm{L})$ & 2 & 310.0 & 318.65 & 318.43 & 0.504 & Acceptable \\
\hline Nickel & 1 & 75.4 & 76.28 & 75.37 & 0.005 & Acceptable \\
\hline$(\mu \mathrm{g} / \mathrm{L})$ & 2 & 306.0 & 289.88 & 289.49 & 1.041 & Acceplable \\
\hline Nitrate as $\mathrm{N}$ & 1 & $<1$ & 0.64 & 0.635 & & Not rated \\
\hline$(\mathrm{mg} / \mathrm{L})$ & 2 & 4.6 & 4.5 & 4.511 & 0.245 & Acceptable \\
\hline Oil and grease & $i$ & 6.4 & 7.19 & 5.94 & 0.189 & Acceptabie \\
\hline$(\mathrm{mg} / \mathrm{L})$ & 2 & 32.7 & 3.5 .3 & 29.9 & 0.380 & Acceptable \\
\hline Orthophosphate & 1 & $<2$ & 0.55 & 0.554 & & Not rated \\
\hline as $P(\mathrm{mg} / \mathrm{L})$ & 2 & 7.4 & 7.52 & 7.53 & 0.285 & Acceptable \\
\hline $\mathrm{pH}$ & 1 & 6.6 & 6.78 & 6.66 & 0.312 & Acceplable \\
\hline (units) & 2 & 7.3 & 6.62 & 7.49 & 1.183 & Acceptable \\
\hline Potassium & 1 & 53.9 & 52.28 & 52.943 & 0.256 & Acceptable \\
\hline$(\mathrm{mg} / \mathrm{L})$ & 2 & 9.97 & 9.68 & 9.879 & 0.111 & Acceptable \\
\hline Sclenium & 1 & 45.2 & 39.34 & 38.341 & 1.674 & Acceptable \\
\hline$(\mu g / L)$ & 2 & 57.3 & 52.46 & 55,098 & 0.254 & Acceptable \\
\hline Silver & 1 & 47.5 & 47.77 & 47.279 & 0.029 & Acceptable \\
\hline$(\mu \mathrm{g} / \mathrm{L})$. & 2 & 233 & 238.84 & 237.93 & 0.219 & Acceptable \\
\hline Sodium & 1 & 68.9 & 65.18 & 66.12 & 1.170 & Acceptable \\
\hline$(\mathrm{mg} / \mathrm{L})$ & 2 & 14.3 & 13.04 & 13.16 & 1.026 & Acceptable \\
\hline Sulfate & $i$ & 70 & 74.1 & 74.82 & 0.548 & Acceptable \\
\hline (mg/L) & 2 & 15 & 13.3 & $13 .(0)$ & 1.408 & Acceptable \\
\hline Tetrachloroethylene & 1 & 12 & 12.4 & 12.19 & 0.113 & Acceptable \\
\hline$(\mu \mathrm{g} / \mathrm{L})$ & 2 & 89 & 95.2 & 90.22 & 0.137 & Acceptable \\
\hline Thallium & 1 & 34.6 & 33.59 & 32.87 & 0.506 & Acceptable \\
\hline$(\mu \mathrm{g} / \mathrm{L})$ & 2 & 267.0 & 268.71 & 256.36 & 0.371 & Acceptable \\
\hline TOC $^{d}$ & 1 & 152 & 141,95 & 143.566 & 0.521 & Acceptable \\
\hline$(\mathrm{mg} / \mathrm{L})$ & 2 & 3 & 2.56 & 3.267 & 0.345 & Acceptable \\
\hline Total hardness & 1 & 120 & 123.6 & 119.75 & 0.057 & Acceptable \\
\hline $\begin{array}{l}\text { as } \mathrm{CaCO}_{3} \\
(\mathrm{mg} / \mathrm{L})\end{array}$ & 2 & 38 & 37.4 & 37.12 & 0.543 & Acceptable \\
\hline Total organic & 1 & 35.5 & 29.40 & 29.36 & 0.574 & Acceptable \\
\hline $\begin{array}{l}\text { halides } \\
(\mu \mathrm{g} / \mathrm{L})\end{array}$ & 2 & 172.0 & 149.90 & 146.92 & 0.690 & Acceptable \\
\hline Total residual & 1 & 0.67 & 0.742 & 0.702 & 0.413 & Acceptable \\
\hline $\begin{array}{l}\text { chlorine } \\
\text { (mg/L) }\end{array}$ & 2 & 3.55 & 4.915 & 4.605 & 2.305 & Warning \\
\hline TSS T.f $^{2}$ & 1 & 37 & 48.7 & 89.78 & 2.068 & Warning \\
\hline (mg/L) & 2 & 201 & 228.9 & 92.01 & 0.646 & Acceptable \\
\hline 1,1,1,-Trichloroethane & 1 & 25 & 26.2 & 25.28 & 0.076 & Acceptable \\
\hline$(\mu \mathrm{g} / \mathrm{L})$ & 2 & 94 & 99.7 & 95.64 & 0.112 & Acceptable \\
\hline 1,1,2-Trichloroethane & 1 & 14 & 14.4 & 13.98 & 0.013 & Acceptable \\
\hline$(\mu \mathrm{g} / \mathrm{L})$ & 2 & 60 & 56.8 & 57.86 & 0.297 & Acceptable \\
\hline
\end{tabular}




\section{Environmental Report-Paducah, Part 2}

\section{Table 10.15 (continued)}

\begin{tabular}{|c|c|c|c|c|c|c|}
\hline Parameter & Level & $\begin{array}{l}\text { Reported } \\
\text { value }\end{array}$ & $\begin{array}{l}\text { Reference } \\
\text { vilue }\end{array}$ & $\begin{array}{c}\text { Mean of } \\
\text { reporting } \\
\text { lahs }\end{array}$ & $\begin{array}{l}\text { Number of } \\
\text { standard } \\
\text { deviations } \\
\text { from the } \\
\text { mean }\end{array}$ & $\begin{array}{l}\text { Performance } \\
\text { evaluation" }\end{array}$ \\
\hline \multirow[t]{2}{*}{ Trichloroelhylene } & 1 & 19 & 20.2 & 19.5 & 0.276 & Acceptable \\
\hline & 2 & 109 & 111.7 & 107.3 & 0.135 & Acceptable \\
\hline Uranium & 1 & 79 & 80.1 & 77.67 & 0.107 & . Acceplable \\
\hline$(\mu g / L)$. & 2 & 874 & 880.9 & 846.50 & 0.422 & Acceptable \\
\hline Vanadium & 1 & 4.3 .3 & 42.22 & 41.469 & 0.601 & Acceptable \\
\hline$(\mu g / L)$ & 2 & 1740 & 1689.12 & 1686.78 & 0.910 & Acceptable \\
\hline Zinc & 1 & 27.0 & 23.84 & 25.22 & 0.423 & Acceptable \\
\hline$(\mu g / L)$ & 2 & 19.5 .0 & 190.75 & 188.87 & 0.385 & Acceptable \\
\hline
\end{tabular}

"Performance evaluation made using U.S. Environmental Protection Agency criteria: ()-1.96 standard deviations for acceptable;

1.97-2.58 standard deviations for marginal; more than 2.58 standard deviations for unaceptable.

"Biological oxygen demand.

'Chemical oxygen demand.

'Total organic carbon.

"Average percent recovery lor participating laboratories.

fTotal suspended solids. 
Table 10.16. November 1992 Analytical Products Group, Inc., Proficiency Environmental Testing Program

\begin{tabular}{|c|c|c|c|c|c|c|}
\hline Parameter & Level & $\begin{array}{l}\text { Reported } \\
\text { value }\end{array}$ & $\begin{array}{l}\text { Reference } \\
\text { value }\end{array}$ & $\begin{array}{l}\text { Mean of } \\
\text { reporting } \\
\text { labs }\end{array}$ & $\begin{array}{l}\text { Number of } \\
\text { standard } \\
\text { deviations } \\
\text { from the } \\
\text { mean }\end{array}$ & $\begin{array}{l}\text { Performance } \\
\text { evaluation }\end{array}$ \\
\hline Alkalinity as & 1 & 20) & 59.6 & 58.98 & 14.49 & Unacceptable \\
\hline $\begin{array}{l}\mathrm{CaCO}_{3} \\
(\mathrm{mg} / \mathrm{L})\end{array}$ & 2 & 55 & 20.7 & 21.57 & 12.90 & Unacceplable \\
\hline Aluminum & 1 & 55.8 & 51.16 & 51.603 & 0.646 & Acceptable \\
\hline$(\mu \mathrm{g} / \mathrm{L})$ & 2 & 287.0 & 153.49 & 157.313 & 4.882 & Unacceptable \\
\hline Ammonia as $\mathrm{N}$ & 1 & 0.45 & 0.41 .5 & 0.462 & 0.089 & Acceptable \\
\hline$(\mathrm{mg} / \mathrm{L})$ & 2 & 2.1 & 2.05 & 2.041 & 0.251 & Acceptable \\
\hline Antimony & 1 & 142 & 211.0 & 216.5 & 2.38 & Warning \\
\hline$(\mathrm{mg} / \mathrm{L})$ & 2 & 493 & 633.2 & 692.1 & 2.22 & Warning \\
\hline Arsenic & 1 & 20 & 19.0 & 19.05 & 0.532 & Acceptable \\
\hline$(\mu \mathrm{g} / \mathrm{L})$ & 2 & 119 & 151.9 & 153.41 & 1.364 & Acceptable \\
\hline Barium & 1 & 258 & 261.2 & 259.80 & 0.134 & Acceptable \\
\hline$(\mu \mathrm{g} / \mathrm{L})$ & 2 & 1.302 & 1306.1 & 1313.28 & 0.179 & Acceptable \\
\hline Benzene & 1 & 6.98 & 8.0 & 8.393 & 1.281 & Acceptable \\
\hline$(\mu \mathrm{g} / \mathrm{L})$ & 2 & 92.68 & 98.8 & 102.843 & 0.765 & Acceptable \\
\hline Beryllium & 1 & 17.1 & 17.57 & 17.13 & 0.025 & Acceplable \\
\hline$(\mu \mathrm{g} / L)$ & 2 & 124.0 & 125.5 & 123.31 & 0.110 & Acceptable \\
\hline Cadmium & 1 & 46.2 & 47.13 & 47.005 & 0.284 & Acceptable \\
\hline$(\mu \mathrm{g} / \mathrm{L})$ & 2 & 120.0 & 117.83 & 119.942 & 0.009 & Acceptable \\
\hline Calcium & 1 & 2.78 & 2.861 & 2.788 & 0.028 & Acceptable \\
\hline$(\mathrm{mg} / \mathrm{L})$ & 2 & 29.2 & 30.65 & 30.485 & 0.406 & Acceptable \\
\hline Chloride & 1 & 51 & 51.1 & 50.95 & 0.023 & Acceptable \\
\hline$(\mathrm{mg} / \mathrm{L})$ & 2 & 91 & 91.6 & 91.67 & 0.232 & Acceptable \\
\hline Chlorobenzene & 1 & 10.43 & 11.40 & 11.207 & 0.631 & Acceptable \\
\hline$(\mu \mathrm{g} / \mathrm{L})$ & 2 & 62.83 & 65.90 & 65.985 & 0.268 & Acceplable \\
\hline Chloroform & 1 & 20.66 & 21.00 & 21.046 & 0.104 & Acceptable \\
\hline$(\mu \mathrm{g} / \mathrm{L})$ & 2 & 91.61 & 88.10 & 86.672 & 0.549 & Acceptable \\
\hline Chromium & 1 & 20.4 & 22.25 & 22.425 & 0.741 & Acceptable \\
\hline$(\mu g / L)$ & 2 & 109.0 & 111.27 & 112.984 & 0.531 & Acceptable \\
\hline Cobalt & 1 & 41.8 & 41.13 & 41.76 & 0.013 & Acceptable \\
\hline$(\mathrm{mg} / \mathrm{L})$ & 2 & 259.0 & 257.04 & 259.01 & 0.001 & Acceplable \\
\hline $\mathrm{COD}^{\circ}$ & 1 & 145 & 182.3 & 174.0 & 1.995 & Warning \\
\hline$(\mathrm{mg} / \mathrm{L})$ & 2 & 52 & 56.8 & 53.3 & 0.222 & Acceptable \\
\hline Conductivity & 1 & 460 & 505.3 & 454.7 & 0.271 & Acceptable \\
\hline$(\mu \mathrm{mho} / \mathrm{cm})$ & 2 & 395 & 423.6 & 390.2 & 0.235 & Acceplable \\
\hline Copper & 1 & 50.1 & 48.72 & 49.47 & 0.176 & Acceptable \\
\hline$(\mu \mathrm{g} / \mathrm{L})$ & 2 & 161.0 & 162.41 & 164.23 & 0.348 & Acceplable \\
\hline 1,2-Dichlorobenzene & 1 & 13.79 & 15.40 & 15.226 & 0.750 & Acceptable \\
\hline$(\mu \mathrm{g} / \mathrm{L})$ & 2 & 121.58 & 129.70 & 129.642 & 0.401 & Acceptable \\
\hline Ethyl benzene & 1 & 27.38 & 29.50 & 28.358 & 0.283 & Acceptable \\
\hline$(\mu \mathrm{g} / \mathrm{L})$ & 2 & 79.08 & 84.50 & 84.966 & 0.411 & Acceptable \\
\hline Fluoride & 1 & 2.9 & 3.0 & 3.027 & 0.505 & Acceptable \\
\hline$(\mathrm{mg} / \mathrm{L})$. & 2 & 5.8 & 6.0 & 6.169 & 0.749 & Acceptable \\
\hline Hexavalent & 1 & 0.07 & 0.070 & 0.067 & 0.269 & Acceptable \\
\hline $\begin{array}{l}\text { chromium } \\
(\mathrm{mg} / \mathrm{L})\end{array}$ & 2 & 0.20 & 0.209 & 0.203 & 0.193 & Acceptable \\
\hline Iron & 1 & 125.0 & 124.6 & 123,083 & 0.165 & Acceptable \\
\hline$(\mu \mathrm{g} / \mathrm{L})$ & 2 & 222.0 & 207.6 & 210.069 & 0.761 & Acceptable \\
\hline Lead & 1 & 47.1 & 42.27 & 43.72 & 0.635 & Acceptable \\
\hline$(\mu \mathrm{g} / \mathrm{L})$ & 2 & 223.0 & 211.34 & 213.55 & 0.583 & Acceplable \\
\hline
\end{tabular}


Table 10.16 (continued)

\begin{tabular}{|c|c|c|c|c|c|c|}
\hline Parameter & Level & $\begin{array}{l}\text { Reported } \\
\text { value }\end{array}$ & $\begin{array}{l}\text { Reference } \\
\text { value }\end{array}$ & $\begin{array}{c}\text { Mean of } \\
\text { reporting } \\
\text { labs }\end{array}$ & $\begin{array}{l}\text { Number of } \\
\text { standard } \\
\text { deviations } \\
\text { from the } \\
\text { mean }\end{array}$ & $\begin{array}{l}\text { Performance } \\
\text { evaluation }^{a}\end{array}$ \\
\hline Magnesium & 1 & 2.22 & 2.266 & 2.203 & 0.098 & Acceptable \\
\hline (mg/L) & 2 & 10.8 & 10.853 & 10.853 & 0.043 & Acceptable \\
\hline Manganese & 1 & 38.2 & 39.21 & 39.28 & 0.547 & Acceptable \\
\hline$(\mu \mathrm{g} / \mathrm{L})$ & 2 & 138.0 & 140.03 & 139.70 & 0.241 & Acceptable \\
\hline Mercury & 1 & 1.56 & 1.43 & 1.436 & 0.470 & Acceptable \\
\hline$(\mu \mathrm{g} / \mathrm{L})$ & 2 & 2.57 & 2.38 & 2.517 & 0.175 & Acceptable \\
\hline Mellyylene chloride & 1 & 22.79 & 23.10 & 23.364 & 0.184 & Acceplable \\
\hline$(\mu \mathrm{g} / \mathrm{L})$ & 2 & 54.17 & 64.60 & 69.882 & 0.918 & Acceptable \\
\hline Molybdenum & 1 & 60.9 & 72.35 & 66.987 & 0.749 & Acceptable \\
\hline$(\mathrm{mg} / \mathrm{L})$ & 2 & 214.0 & 241.17 & 229.163 & 0.890 & Acceptable \\
\hline Nickel & 1 & 31.2 & 30.51 & 31.195 & $0.0(0) 2$ & Acceptable \\
\hline$(\mu \mathrm{g} / \mathrm{L})$ & 2 & 125.0 & 122.05 & 123.367 & 0.258 & Acceptable \\
\hline Nitrate as $\mathrm{N}$ & 1 & 1.1 & 0.743 & 0.749 & 4.028 & Unacceptable \\
\hline (mg/L) & 2 & 3.8 & 3.70 & 3.711 & 0.211 & Acceplable \\
\hline Oil and grease & 1 & 8.5 & 7.65 & 7.475 & 0.382 & Acceptable \\
\hline$(m g / L)$ & 2 & 41.6 & 45.51 & 40.116 & 0.220 & Acceplable \\
\hline Orthophosphate & 1 & $<2$ & 0.690 & 0.686 & & Not rited \\
\hline as $P(m g / L)$ & 2 & 7.5 & 7.45 & 7.496 & $0 .(0) 5$ & Acceptable \\
\hline $\mathrm{pH}$ & 1 & 8.7 & 8.99 & 8.87 & 0.704 & Acceptable \\
\hline (units) & 2 & 5.9 & 5.99 & 5.93 & 0.132 & Acceptable \\
\hline Polassium & 1 & 41.4 & 43.39 & 41.97 & (). 1.34 & Acceptable \\
\hline$(\mathrm{mg} / \mathrm{L})$ & 2 & 5.8 & 5.47 & 5.39 & 0.8 .36 & Acceptable \\
\hline Selenium & 1 & 18.2 & 15.74 & 15.911 & 1.003 & Acceptable \\
\hline$(\mu \mathrm{g} / \mathrm{L})$ & 2 & 64.9 & 65.58 & 64.34 .3 & 0.090 & Acceptable \\
\hline Silver & 1 & 31.5 & 33.44 & 34.50 & 0.525 & Acceptable \\
\hline$(\mu \mathrm{g} / \mathrm{L})$ & 2 & 112.0 & 119.42 & 122.11 & 1.051 & Acceptable \\
\hline Sodium & 1 & 57.8 & 59.00 & 58.82 & 0.310 & Acceptable \\
\hline$(\mathrm{mg} / \mathrm{L})$ & 2 & 19.5 & 19.06 & 19.34 & 0.188 & Acceptable \\
\hline Sulfite & 1 & 66 & 66.4 & 66.34 & 0.056 & Acceptible \\
\hline (mg/L) & 2 & 20 & 18.9 & 18.62 & $0.94 !$ & Accepliable \\
\hline TDS $^{c, d}$ & 1 & 127 & 136.7 & 105.09 & 0.803 & Acceptable \\
\hline (mg/L) & 2 & 342 & 35.5 .3 & 101.83 & 0.667 & Acceptable \\
\hline \multirow[t]{2}{*}{ Telrachloroethylene } & 1 & 26.65 & 31.20 & 28.899 & 0.719 & Acceptable \\
\hline & 2 & 57.76 & 62.90 & 59.675 & 0.313 & Acceptible \\
\hline Thallium & 1 & 60.3 & 60.46 & 61.299 & 0.140 & Acceptable \\
\hline$(\mu g / L)$ & 2 & 277 & 268.71 & 265.488 & 0.358 & Acceptable \\
\hline TOC & 1 & 82 & 68.6 & $7(0.37$ & 2.399 & Warning \\
\hline (mg/L) & 2 & 24 & 21.4 & 22.13 & 1.270 & Acceptable \\
\hline Toluene & 1 & 14.84 & 16.80 & 16.558 & 0.975 & Acceplable \\
\hline$(\mu \mathrm{g} / \mathrm{L})$ & 2 & 66.38 & 69.20 & 68.335 & 0.231 & Acceptable \\
\hline Total hardness & 1 & 8.6 & 16.48 & 16.76 & 6.311 & Unacceptable \\
\hline $\begin{array}{l}\text { as } \mathrm{CaCO}_{3} \\
(\mathrm{mg} / \mathrm{L})\end{array}$ & 2 & 77 & 121.2 & 120.75 & 6.875 & Unacceptable \\
\hline Tolal organic & 1 & 3.5 & 29.0 & 31.58 & 0.40 .5 & Acceptable \\
\hline $\begin{array}{l}\text { halides } \\
(\mu \mathrm{g} / \mathrm{L})\end{array}$ & 2 & 354 & 319.4 & 308.82 & 0.990 & Acceptable \\
\hline Total residual & 1 & 0.45 & 0.496 & $(0.477$ & 0.546 & Acceptable \\
\hline $\begin{array}{l}\text { chlorine } \\
\text { (mg/L) }\end{array}$ & 2 & 2.52 & 3.010 & 2.818 & 1.162 & Acceptable \\
\hline TSS' $f$ & 1 & 39 & 43.7 & 91.79 & 0.415 & Acceptable \\
\hline$(\mathrm{mg} / \mathrm{L})$ & 2 & 198 & 221.0 & 94.47 & 0.911 & Acceptable \\
\hline
\end{tabular}




\section{Environmental Report-Paducah, Part 2}

Table 10.16 (continued)

\begin{tabular}{|c|c|c|c|c|c|c|}
\hline Parameter & Level & $\begin{array}{l}\text { Reported } \\
\text { value }\end{array}$ & $\begin{array}{c}\text { Reference } \\
\text { value }\end{array}$ & $\begin{array}{l}\text { Mean of } \\
\text { reporting } \\
\text { labs }\end{array}$ & $\begin{array}{l}\text { Number of } \\
\text { standard } \\
\text { deviations } \\
\text { from the } \\
\text { mean }\end{array}$ & $\begin{array}{l}\text { Performance } \\
\text { evaluation }^{a}\end{array}$ \\
\hline 1,1,1-Trichloroethane & 1 & 12.31 & 15.00 & 14.564 & 1.559 & Acceptable \\
\hline$(\mu \mathrm{g} / \mathrm{L})$ & 2 & 54.89 & 62.00 & 61.802 & 0.915 & Acceptable \\
\hline Trichlorethylene & 1 & 27.51 & 33.30 & 30.441 & 0.839 & Acceptable \\
\hline (units) & 2 & 115.33 & 137.20 & 133.351 & 0.933 & Acceptable \\
\hline Uranium & 1 & 162 & 160.2 & 152.83 & 0.985 & Acceptable \\
\hline$(\mu \mathrm{g} / \mathrm{L})$ & 2 & 312 & 300.3 & 289.29 & 0.765 & Acceptable \\
\hline Vanadium & 1 & 79.6 & 84.45 & 84.683 & 0.826 & Acceptable \\
\hline$(\mu \mathrm{g} / \mathrm{L})$ & 2 & 1019.0 & 1055.70 & 1060.417 & 1.308 & Acceptable \\
\hline Zinc & 1 & 24.0 & 23.84 & 24.854 & 0.258 & Acceptable \\
\hline$(\mu g / L)$ & 2 & 123.0 & 119.22 & 120.057 & 0.312 & Acceptable \\
\hline
\end{tabular}

aPerformance evaluation made using U.S. Environmental Protection Agency criteria: 0-1.96 standard deviations for acceptable; 1.97-2.58 standard deviations for marginal; more than 2.58 standard deviations for unacceptable.

${ }^{b}$ Chemical oxygen demand.

'Total dissolved solids.

${ }^{d}$ Average percent recovery for participating laboratories.

eTotal organic carbon.

fTotal suspended solids. 
1992 Environmental Report-Paducah, Part 2

Table 10.17. January 1992 National Institute for Occupational Safety and Health (NIOSH) Proficiency Analytical Testing (PAT) Program

\begin{tabular}{|c|c|c|c|c|c|c|}
\hline Parameter & $\begin{array}{l}\text { Control } \\
\text { number }\end{array}$ & $\begin{array}{l}\text { Reported } \\
\text { value }\end{array}$ & $\begin{array}{l}\text { Reference } \\
\text { value }^{a}\end{array}$ & $\begin{array}{l}\text { Performance } \\
\text { limits }\end{array}$ & $\begin{array}{l}\text { Performance } \\
\text { evaluation }^{b}\end{array}$ & $\begin{array}{c}\text { Number } \\
\text { of labs }\end{array}$ \\
\hline \multirow{4}{*}{$\begin{array}{l}\text { Asbestos } \\
\quad\left(\text { fibers } / \mathrm{mm}^{2}\right)\end{array}$} & 1 & 608.9 & 748.2 & $471.4-1210.5$ & Acceptable & 1209 \\
\hline & 2 & 417.9 & 495.8 & $282-769.6$ & Acceptable & 1209 \\
\hline & 3 & 184.9 & 232.8 & $116.3-389.3$ & Acceptable & 1209 \\
\hline & 4 & 290.4 & 356.9 & $197.6-562.8$ & Acceptable & 1209 \\
\hline \multirow{4}{*}{$\begin{array}{l}\text { Cadmium } \\
\quad \text { (total } \mathrm{mg} \text { ) }\end{array}$} & 1 & 0.092 & 0.0099 & $0.0084-0.0113$ & Acceptable & 375 \\
\hline & 2 & 0.0144 & 0.0147 & $0.0126-0.0169$ & Acceptable & 375 \\
\hline & 3 & 0.0200 & 0.0190 & $0.0165-0.0215$ & Acceptable & 375 \\
\hline & 4 & 0.0072 & 0.0069 & $0.0059-0.0079$ & Acceptable & 375 \\
\hline \multirow{4}{*}{$\begin{array}{l}\text { Chromium } \\
\text { (total mg) }\end{array}$} & 1 & 0.0722 & 0.0744 & $0.0619-0.0868$ & Acceptable & 370 \\
\hline & 2 & 0.1720 & 0.1713 & $0.1392-0.2034$ & Acceptable & 370 \\
\hline & 3 & 0.1050 & 0.1010 & $0.0839-0.1181$ & Acceptable & 370 \\
\hline & 4 & 0.1518 & 0.1470 & $0.1209-0.1730$ & Acceptable & 370 \\
\hline \multirow{4}{*}{$\begin{array}{l}\text { Lead } \\
\qquad \text { (total mg) }\end{array}$} & 1 & 0.0470 & 0.0494 & $0.0431-0.0556$ & Acceptable & 380 \\
\hline & 2 & 0.0785 & 0.0783 & $0.0676-0.0889$ & Acceptable & 380 \\
\hline & 3 & 0.0320 & 0.0304 & $0.0266-0.0342$ & Acceptable & 380 \\
\hline & 4 & 0.0612 & 0.0592 & $0.0523-0.0662$ & Acceptable & 380 \\
\hline
\end{tabular}

${ }^{a}$ Reference value calculated from transformed variables. See NIOSH PAT protocol for details.

${ }^{b}$ Performance limits set by NIOSH. Those within range are acceptable; those outside range are outliers.

Table 10.18. April 1992 National Institute for Occupational Safety and Health (NIOSH) Proficiency Analytical Testing (PAT) Program

\begin{tabular}{|c|c|c|c|c|c|c|}
\hline Parameter & $\begin{array}{l}\text { Control } \\
\text { number }\end{array}$ & $\begin{array}{l}\text { Reported } \\
\text { value }\end{array}$ & $\begin{array}{l}\text { Reference } \\
\text { value }^{a}\end{array}$ & $\begin{array}{l}\text { Performance } \\
\text { limits }\end{array}$ & $\begin{array}{l}\text { Performance } \\
\text { evaluation }\end{array}$ & $\begin{array}{l}\text { Number } \\
\text { of labs }\end{array}$ \\
\hline \multirow{4}{*}{$\begin{array}{l}\text { Asbestos } \\
\quad\left(\text { fibers } / \mathrm{mm}^{2}\right)\end{array}$} & 1 & 144 & 245 & $67.5-53.3 .2$ & Acceptable & 1209 \\
\hline & 2 & 1158 & 721.2 & $256.5-1420.8$ & Acceptable & 1209 \\
\hline & 3 & 485 & 490.1 & $173.9-966.4$ & Acceptable & 1209 \\
\hline & 4 & 227 & 279.4 & $85.7-584.3$ & Acceptable & 1209 \\
\hline \multirow{4}{*}{$\begin{array}{l}\text { Cadmium } \\
\text { (total mg) }\end{array}$} & 1 & 0.0212 & 0.0218 & $0.0190-0.0245$ & Acceptable & 382 \\
\hline & 2 & 0.0174 & 0.0178 & $0.0154-0.0201$ & Acceptable & 382 \\
\hline & 3 & 0.0080 & 0.0079 & $0.0069-0.0090$ & Acceptable & 382 \\
\hline & 4 & 0.0108 & 0.0118 & $0.01(03-0.0134$ & Acceptable & 382 \\
\hline \multirow{4}{*}{$\begin{array}{l}\text { Lead } \\
\quad \text { (total mg) }\end{array}$} & 1 & 0.0216 & 0.0220 & $0.0144-0.0246$ & Acceplable & 386 \\
\hline & 2 & 0.0378 & 0.0376 & $0.0326-0.0425$ & Acceptable & 386 \\
\hline & 3 & 0.0760 & 0.0743 & $0.0651-0.0835$ & Acceptable & 386 \\
\hline & 4 & 0.0460 & 0.0474 & $0.0416-0.0532$ & Acceptable & 386 \\
\hline \multirow{4}{*}{$\begin{array}{l}\text { Zinc } \\
\text { (total mg) }\end{array}$} & 1 & 0.0760 & 0.0809 & $0.0671-0.0946$ & Acceptable & 380 \\
\hline & 2 & 0.1098 & 0.1142 & $0.0987-0.1297$ & Acceptable & 380 \\
\hline & 3 & 0.1935 & 0.1944 & $0.1708-0.2180$ & Acceptable & 380 \\
\hline & 4 & $0.13 \% 5$ & 0.1536 & $0.1330-0.1743$ & Acceptable & 380 \\
\hline
\end{tabular}

${ }^{a}$ Reference value calculated from transformed variables. See NIOSH PAT protocol for details.

bPerformance limits set by NIOSH. Those within range are acceptable; those outside range are outliers. 


\section{Environmental Report-Paducah, Part 2}

Table 10.19. July 1992 National Institute for Occupational Safety and Health (NIOSH) Proficiency Analytical Testing (PAT) Program

\begin{tabular}{|c|c|c|c|c|c|c|}
\hline Parameter & $\begin{array}{l}\text { Control } \\
\text { number }\end{array}$ & $\begin{array}{l}\text { Reported } \\
\text { value }\end{array}$ & $\begin{array}{l}\text { Reference } \\
\text { value }^{a}\end{array}$ & $\begin{array}{l}\text { Performance } \\
\quad \text { limits }\end{array}$ & $\begin{array}{l}\text { Performance } \\
\text { evaluation }\end{array}$ & $\begin{array}{c}\text { Number } \\
\text { of labs }\end{array}$ \\
\hline \multirow{4}{*}{$\begin{array}{l}\text { Asbestos } \\
\quad\left(\text { fibers } / \mathrm{mm}^{2}\right)\end{array}$} & 1 & 368 & 383.3 & $205.8-615.6$ & Acceptable & 1201 \\
\hline & 2 & 801.2 & 863.1 & $477.9-1361.2$ & Acceptable & 1201 \\
\hline & 3 & 304 & 383.4 & $216.1-598.5$ & Acceptable & 1201 \\
\hline & 4 & 540 & 572.2 & $296.4-938$ & Acceptable & 1201 \\
\hline \multirow{4}{*}{$\begin{array}{l}\text { Cadmium } \\
\text { (total mg) }\end{array}$} & 1 & 0.0053 & 0.0050 & $0.0043-0.0056$ & Acceptable & 378 \\
\hline & 2 & 0.0116 & 0.0117 & $0.0103-0.0131$ & Acceptable & 378 \\
\hline & 3 & 0.0161 & 0.0158 & $0.0141-0.0174$ & Acceptable & 378 \\
\hline & 4 & 0.0090 & $0.0 \times 89$ & $0.0077-0.0101$ & Acceptable & 378 \\
\hline \multirow{4}{*}{$\begin{array}{l}\text { Chromium } \\
\text { (total mg) }\end{array}$} & 1 & 0.2170 & 0.2177 & $0.1648-0.2706$ & Acceptable & 376 \\
\hline & 2 & 0.1900 & 0.1780 & $0.1411-0.2149$ & Acceptable & 376 \\
\hline & 3 & 0.0728 & 0.0748 & $0.0605-0.0892$ & Acceptable & 376 \\
\hline & 4 & 0.1235 & 0.1223 & $0.0950-0.1497$ & Acceplable & 376 \\
\hline \multirow{4}{*}{$\begin{array}{l}\text { Lead } \\
\qquad \text { (total mg) }\end{array}$} & 1 & 0.0540 & 0.0489 & $0.0423-0.0555$ & Acceptable & 382 \\
\hline & 2 & 0.0285 & 0.0275 & $0.0235-0.0315$ & Acceptable & 382 \\
\hline & 3 & 0.0688 & 0.0650 & $0.0555-0.0744$ & Acceptable & 382 \\
\hline & 4 & 0.0833 & 0.0785 & $0.0694-0.0876$ & Acceptable & 382 \\
\hline
\end{tabular}

aReference value calculated from transformed variables. See NIOSH PAT protocol for details.

${ }^{h}$ Performance limits set by NIOSH. Those within range are acceptable; those outside range are outliers.

Table 10.20. October 1992 National Institute for Occupational Safety and Health (NIOSH) Proficiency Analytical Testing (PAT) Program

\begin{tabular}{|c|c|c|c|c|c|c|}
\hline Parameter & $\begin{array}{l}\text { Control } \\
\text { number }\end{array}$ & $\begin{array}{l}\text { Reported } \\
\text { value }\end{array}$ & $\begin{array}{l}\text { Reference } \\
\text { value }^{a}\end{array}$ & $\begin{array}{l}\text { Performance } \\
\text { limits }\end{array}$ & $\begin{array}{l}\text { Performance } \\
\text { evaluation }^{b}\end{array}$ & $\begin{array}{c}\text { Number } \\
\text { of labs }\end{array}$ \\
\hline \multirow{4}{*}{$\begin{array}{l}\text { Asbestos } \\
\quad\left(\text { fibers } / \mathrm{mm}^{2}\right)\end{array}$} & 1 & 625 & 645.9 & $256.2-1212.6$ & Acceptable & 1206 \\
\hline & 2 & 422 & 382.1 & $138.3-747$ & Acceptable & 1206 \\
\hline & 3 & 146 & 163.5 & $43.3-361$ & Acceptable & 1206 \\
\hline & 4 & 354 & 412.9 & $168.1-765.9$ & Acceptable & 1206 \\
\hline \multirow{4}{*}{$\begin{array}{l}\text { Cadmium } \\
\quad \text { (total mg) }\end{array}$} & 1 & 0.0175 & 0.0175 & $0.0152-0.0197$ & Acceptable & 388 \\
\hline & 2 & 0.0100 & 0.0098 & $0.0085-0.0111$ & Acceptable & 388 \\
\hline & 3 & 0.0665 & 0.0059 & $0.0050-0.0067$ & Outlier & 388 \\
\hline & 4 & 0.0138 & 0.0136 & $0.0120-0.0152$ & Acceptable & 388 \\
\hline \multirow{4}{*}{$\begin{array}{l}\text { Lead } \\
\text { (total mg) }\end{array}$} & 1 & 0.0302 & 0.0291 & $0.0249-0.0333$ & Acceptable & 394 \\
\hline & 2 & 0.0770 & 0.0734 & $0.0650-0.0819$ & Acceptable & 394 \\
\hline & 3 & 0.0410 & 0.0414 & $0.0375-0.0454$ & Acceptable & 394 \\
\hline & 4 & 0.0665 & 0.0627 & $0.0552-0.0701$ & Acceptable & 394 \\
\hline \multirow{4}{*}{$\begin{array}{l}\text { Zinc } \\
\quad \text { (total } \mathrm{mg})\end{array}$} & 1 & 0.0738 & 0.0745 & $0.0617-0.0873$ & Acceptable & 386 \\
\hline & 2 & 0.1430 & 0.1434 & $0.1202-0.1665$ & Acceptable & 386 \\
\hline & 3 & 0.2030 & 0.2067 & $0.1724-0.2410$ & Acceptable & 386 \\
\hline & 4 & 0.1780 & 0.1782 & $0.1506-0.2058$ & Acceptable & 386 \\
\hline
\end{tabular}

"Reference value calculated from transformed variables. See NIOSH PAT protocol for details.

${ }^{b}$ Performance limits set by NIOSH. Those within range are acceptable; those outside range are outliers. 
Table 10.21. March 1992 Environmental Measurements Laboratory (EML)

Semiannual Report of the Department of Energy Operational Safety, Health, and Environment Division Quality Assessment Program

\begin{tabular}{|c|c|c|c|c|}
\hline Parameter & EML value & $\begin{array}{l}\text { Reported value } \\
(\mathrm{Rp})\end{array}$ & $\begin{array}{c}\text { Rattio } \\
\text { (Rp/EML) }\end{array}$ & $\begin{array}{l}\text { Performance } \\
\text { evaluation" }\end{array}$ \\
\hline \multicolumn{5}{|c|}{ Air (pCi/filler) } \\
\hline $\begin{array}{l}{ }^{7} \mathrm{Be} \\
{ }^{1+4} \mathrm{Ce} \\
{ }^{57} \mathrm{Co} \\
{ }^{60} \mathrm{Co} \\
{ }^{137} \mathrm{Cs} \\
{ }^{134} \mathrm{Cs} \\
{ }^{54} \mathrm{Mn} \\
{ }^{238} \mathrm{Pu} \\
{ }^{239} \mathrm{Pu}\end{array}$ & $\begin{array}{l}0.286 \mathrm{E}+(02 \\
0.639 \mathrm{E}+(02 \\
0.793 \mathrm{E}+01 \\
05 \times 1 \mathrm{E}+(01 \\
0.576 \mathrm{E}+01 \\
0.444 \mathrm{E}+(01 \\
0.597 \mathrm{E}+01 \\
0.270 \mathrm{E}+(0) \\
0.285 \mathrm{E}+(0)\end{array}$ & $\begin{array}{l}0.276 \mathrm{E}+(02 \\
(0.802 \mathrm{E}+(02 \\
0.657 \mathrm{E}+01 \\
0.578 \mathrm{E}+(01 \\
0.572 \mathrm{E}+01 \\
0.448 \mathrm{E}+01 \\
0.574 \mathrm{E}+(01 \\
0.260 \mathrm{E}+(0) \\
0.264 \mathrm{E}+())\end{array}$ & $\begin{array}{l}0.97 \\
1.26 \\
0.83 \\
0.99 \\
0.99 \\
1.01 \\
0.96 \\
0.96 \\
0.93\end{array}$ & $\begin{array}{l}\text { Acceptable } \\
\text { Marginal } \\
\text { Acceptable } \\
\text { Acceptable } \\
\text { Acceptable } \\
\text { Acceptable } \\
\text { Acceptable } \\
\text { Acceptable } \\
\text { Acceptable }\end{array}$ \\
\hline \multicolumn{5}{|c|}{ Soil (pCi/g) } \\
\hline $\begin{array}{l}{ }^{137} \mathrm{Cs} \\
{ }^{40} \mathrm{~K}\end{array}$ & $\begin{array}{l}0.523 E+(01 \\
0.719 E+(03\end{array}$ & $\begin{array}{l}0.550 E+(01 \\
0.753 E+(03\end{array}$ & $\begin{array}{l}1.05 \\
1.05\end{array}$ & $\begin{array}{l}\text { Acceptable } \\
\text { Acceptable }\end{array}$ \\
\hline \multicolumn{5}{|c|}{ Water $(p(i / m L)$} \\
\hline $\begin{array}{l}{ }^{144} \mathrm{Ce} \\
{ }^{60} \mathrm{Co} \\
{ }^{134} \mathrm{Cs} \\
{ }^{137} \mathrm{Cs} \\
{ }^{54} \mathrm{Mn} \\
238 \mathrm{Pu} \\
239 \mathrm{Pu} \\
\mathrm{U}(\mu \mathrm{g} / \mathrm{mL})\end{array}$ & $\begin{array}{l}0.189 \mathrm{E}+(03 \\
0.940 \mathrm{E}+(02 \\
0.718 \mathrm{E}+(02 \\
0.846 \mathrm{E}+(02 \\
0.566 \mathrm{E}+(02 \\
0.450 \mathrm{E}+(0) \\
0.580 \mathrm{E}+(0) \\
0.330 \mathrm{E}-(01\end{array}$ & $\begin{array}{l}0.240 \mathrm{E}+(0) 3 \\
0.100 \mathrm{E}+(03 \\
0.811 \mathrm{E}+(02 \\
0.940 \mathrm{E}+(02 \\
0.621 \mathrm{E}+(02 \\
0.501 \mathrm{E}+(0) \\
0.424 \mathrm{E}+(0) \\
0.340 \mathrm{E}+(02\end{array}$ & $\begin{array}{l}1.27 \\
1.06 \\
1.13 \\
1.11 \\
1.10 \\
1.11 \\
0.73\end{array}$ & $\begin{array}{l}\text { Marginal } \\
\text { Acceptable } \\
\text { Acceptable } \\
\text { Acceptable } \\
\text { Acceptable } \\
\text { Acceptable } \\
\text { Marginal } \\
\text { Unacceplable }\end{array}$ \\
\hline \multicolumn{5}{|c|}{ Vegetation (pCi/g) } \\
\hline $\begin{array}{l}{ }^{137} \mathrm{Cs} \\
{ }^{40} \mathrm{~K}\end{array}$ & $\begin{array}{l}0.246 \mathrm{E}+(02 \\
0.294 \mathrm{E}+03\end{array}$ & $\begin{array}{l}0.257 E+(02 \\
0.335 E+(0.3\end{array}$ & $\begin{array}{l}1.04 \\
1.14\end{array}$ & $\begin{array}{l}\text { Acceptable } \\
\text { Acceptable }\end{array}$ \\
\hline
\end{tabular}

"Performance evaluation determined by using the ratio of our value to the EML value. Acceptable range is $0.8-1.2$; marginal range is 0.5 to 0.8 and 1.2 to 1.5 ; unace ptable range is $<0.5$ or $>1.5$. 


\section{Environmental Report-Paducah, Part 2}

Table 10.22. September 1992 Environmental Measurements Laboratory (EML)

Semiannual Report of the Department of Energy Operational Safety, Health, and Environment Division Quality Assessment Program

\begin{tabular}{|c|c|c|c|c|}
\hline Parameter & EML value & $\begin{array}{l}\text { Reported value } \\
\text { (Rp) }\end{array}$ & $\begin{array}{c}\text { Ratio } \\
\text { (Rp/EML) }\end{array}$ & $\begin{array}{l}\text { Performance } \\
\text { evaluation }^{\prime \prime}\end{array}$ \\
\hline \multicolumn{5}{|c|}{ Air (pCi/filter) } \\
\hline $\begin{array}{l}{ }^{7} \mathrm{Be} \\
{ }^{144} \mathrm{Ce} \\
{ }^{57} \mathrm{Co} \\
{ }^{60} \mathrm{Co} \\
{ }^{134} \mathrm{Cs} \\
{ }^{137} \mathrm{Cs} \\
{ }^{54} \mathrm{Mn} \\
{ }^{238} \mathrm{Pu} \\
{ }^{239} \mathrm{Pu}\end{array}$ & $\begin{array}{l}0.308 \mathrm{E}+03 \\
0.433 \mathrm{E}+02 \\
0.640 \mathrm{E}+01 \\
0.306 \mathrm{E}+01 \\
0.372 \mathrm{E}+01 \\
0.582 \mathrm{E}+01 \\
0.259 \mathrm{E}+02 \\
0.420 \mathrm{E}-01 \\
0.450 \mathrm{E}-01\end{array}$ & $\begin{array}{l}0.316 \mathrm{E}+03 \\
0.351 \mathrm{E}+02 \\
0.660 \mathrm{E}+01 \\
0.336 \mathrm{E}+01 \\
0.346 \mathrm{E}+01 \\
0.613 \mathrm{E}+01 \\
0.273 \mathrm{E}+02 \\
0.370 \mathrm{E}-01 \\
0.440 \mathrm{E}-01\end{array}$ & $\begin{array}{l}1.03 \\
0.81 \\
1.03 \\
1.10 \\
0.93 \\
1.05 \\
1.05 \\
0.88 \\
0.98\end{array}$ & $\begin{array}{l}\text { Acceptable } \\
\text { Acceptable } \\
\text { Acceptable } \\
\text { Acceptable } \\
\text { Acceptable } \\
\text { Acceptable } \\
\text { Acceptable } \\
\text { Acceptable } \\
\text { Acceptable }\end{array}$ \\
\hline \multicolumn{5}{|c|}{ Soil (pCi/g) } \\
\hline $\begin{array}{l}{ }^{137} \mathrm{Cs} \\
{ }^{40} \mathrm{~K}\end{array}$ & $\begin{array}{l}0.285 E+03 \\
0.384 E+03\end{array}$ & $\begin{array}{l}0.268 E+03 \\
0.372 E+03\end{array}$ & $\begin{array}{l}0.94 \\
0.97\end{array}$ & $\begin{array}{l}\text { Acceptable } \\
\text { Acceptable }\end{array}$ \\
\hline \multicolumn{5}{|c|}{ Water $(p C i / m L)$} \\
\hline $\begin{array}{l}{ }^{144} \mathrm{Ce} \\
{ }^{60} \mathrm{Co} \\
{ }^{134} \mathrm{Cs} \\
{ }^{137} \mathrm{Cs} \\
{ }^{54} \mathrm{Mn} \\
{ }^{238} \mathrm{Pu} \\
{ }^{239} \mathrm{Pu} \\
\mathrm{U}(\mu \mathrm{g} / \mathrm{mL})\end{array}$ & $\begin{array}{l}0.512 \mathrm{E}+02 \\
0.278 \mathrm{E}+02 \\
0.441 \mathrm{E}+02 \\
0.290 \mathrm{E}+02 \\
0.333 \mathrm{E}+02 \\
0.197 \mathrm{E}+01 \\
0.238 \mathrm{E}+00 \\
0.906 \mathrm{E}-02\end{array}$ & $\begin{array}{l}0.414 \mathrm{E}+02 \\
0.240 \mathrm{E}+02 \\
0.176 \mathrm{E}+02 \\
0.112 \mathrm{E}+02 \\
0.289 \mathrm{E}+02 \\
0.166 \mathrm{E}+01 \\
0.337 \mathrm{E}+00 \\
0.900 \mathrm{E}-02\end{array}$ & $\begin{array}{l}0.81 \\
0.86 \\
0.40 \\
0.39 \\
0.87 \\
0.84 \\
1.42 \\
0.99\end{array}$ & $\begin{array}{l}\text { Acceptable } \\
\text { Acceptable } \\
\text { Unacceptable } \\
\text { Unacceptable } \\
\text { Acceptable } \\
\text { Acceptable } \\
\text { Marginal } \\
\text { Acceptable }\end{array}$ \\
\hline \multicolumn{5}{|c|}{ Vegetation $(p C i / g)$} \\
\hline $\begin{array}{l}{ }^{137} \mathrm{Cs} \\
{ }^{40} \mathrm{~K}\end{array}$ & $\begin{array}{l}0.292 E+02 \\
0.101 E+04\end{array}$ & $\begin{array}{l}0.269 E+02 \\
0.952 E+03\end{array}$ & $\begin{array}{l}0.92 \\
0.94\end{array}$ & $\begin{array}{l}\text { Acceptable } \\
\text { Acceptable }\end{array}$ \\
\hline
\end{tabular}

aperformance evaluation determined by using the ratio of our value to the EML value. Acceptable range is $0.8-1.2$; marginal range is $0.5-1.5$; unacceptable range is $<0.5$ or $>1.5$. 
1992 Environmental Report-Paducah, Part 2

Table 10.23. 1992 Environmental Measurements Systems Laboratory-Las Vegas (EMSL-LV) Intercomparison Study

\begin{tabular}{|c|c|c|c|c|}
\hline Parameter/matrix & $\begin{array}{l}\text { Known } \\
\text { value }\end{array}$ & $\begin{array}{l}\text { Control } \\
\text { limits }\end{array}$ & $\begin{array}{l}\text { Reported } \\
\text { average" }\end{array}$ & $\begin{array}{l}\text { Performance } \\
\text { cvaluation }\end{array}$ \\
\hline \multicolumn{5}{|c|}{ January } \\
\hline Plutonium in water & $16.8 \mathrm{pCi} / \mathrm{L}$ & $13.9-19.7$ & 1.5 .27 & Acceptable \\
\hline \multicolumn{5}{|c|}{ February } \\
\hline Gross alpha in water & $30.0 \mathrm{pCi} / \mathrm{L}$ & $16.1-43.9$ & 21.67 & Acceptable \\
\hline Gross beta in water & $30.0 \mathrm{pCi} / \mathrm{L}$ & $21.3-38.7$ & 35.33 & Acceplable \\
\hline lodine in waler & $59.0 \mathrm{pCi} / \mathrm{L}$ & $48.6-69.4$ & 74.33 & $\begin{array}{l}\text { Above control limit } \\
\text { (warning) }\end{array}$ \\
\hline \multicolumn{5}{|l|}{ Gamma in water } \\
\hline${ }^{133} \mathrm{Ba}$ & $76.0 \mathrm{pCi} / \mathrm{L}$ & $62.1-89.9$ & 76.67 & Acceplable \\
\hline${ }^{60} \mathrm{Co}$ & $40.0 \mathrm{pCi} / \mathrm{L}$ & $31.3-48.7$ & 38.67 & Acceptahle \\
\hline${ }^{134} \mathrm{Cs}$ & $31.0 \mathrm{pCi} / \mathrm{L}$ & $22.3-39.7$ & 33.0 & Acceptable \\
\hline${ }^{137} \mathrm{Cs}$ & $49.0 \mathrm{pCi} / \mathrm{L}$ & $40.3-57.7$ & 49.67 & Acceptable \\
\hline${ }^{106} \mathrm{Ru}$ & $203.0 \mathrm{pCi} / \mathrm{L}$ & $168.3-237.7$ & 215.33 & Acceptable \\
\hline${ }^{6.5} \mathrm{Zn}$ & $148.0 \mathrm{pCi} / \mathrm{L}$ & $122.0-174.0$ & 143.0 & Acceptable \\
\hline \multicolumn{5}{|c|}{ March } \\
\hline Uranium in water & $25.3 \mathrm{pCi} / \mathrm{L}$ & $20.1-30.5$ & 23.13 & Acceptable \\
\hline Alphat on air filters & $7.0 \mathrm{pCi} /$ filter & $6.0-15.7$ & 7.33 & Acceptable \\
\hline Beta on air filters & $41.0 \mathrm{pCi} /$ filter & $32.3-49.7$ & 42.67 & Acceptable \\
\hline${ }^{137} \mathrm{Cs}$ on air filters & $10.0 \mathrm{pCi} /$ filler & $1.3-18.7$ & 9.67 & Acceptable \\
\hline \multicolumn{5}{|c|}{$M a y^{\prime}$} \\
\hline Gross alpha in water & $15.0 \mathrm{pCi} / \mathrm{L}$ & $6.3-23.7$ & 14.33 & Acceptable \\
\hline Gross beta in water & $44.0 \mathrm{pCi} / \mathrm{L}$ & $35.3-52.7$ & 53.67 & Acceptable \\
\hline \multicolumn{5}{|c|}{ June } \\
\hline \multicolumn{5}{|l|}{ Gamma in water } \\
\hline${ }^{133} \mathrm{Ba}$ & $98.0 \mathrm{pCi} / \mathrm{L}$ & $80.7-11.5 .3$ & 97.67 & Acceptable \\
\hline${ }^{60} \mathrm{Co}$ & $20.0 \mathrm{pCi} / \mathrm{L}$ & $11.3-28.7$ & 21.00 & Acceptable \\
\hline${ }^{134} \mathrm{Cs}$ & $15.0 \mathrm{pCi} / \mathrm{L}$ & $6.3-2.3 .7$ & 15.00 & Acceptable \\
\hline${ }^{1.37} \mathrm{Cs}$ & $15.0 \mathrm{pCi} / \mathrm{L}$ & $6.3-23.7$ & 14.33 & Acceptable \\
\hline${ }^{106} \mathrm{Ru}$ & $141.0 \mathrm{pCi} / \mathrm{L}$ & $116.7-16.5 .3$ & 143.00 & Acceptable \\
\hline${ }^{65} \mathrm{Zn}$ & $99.0 \mathrm{pCi} / \mathrm{L}$ & $81.7-116.3$ & 103.00 & Acceptable \\
\hline \multicolumn{5}{|c|}{$J u ! y$} \\
\hline Uranium in water & $4.0 \mathrm{pCi} / \mathrm{L}$ & $0.0-9.2$ & 4.13 & Acceptable \\
\hline
\end{tabular}




\section{Environmental Report-Paducah, Part 2}

Table 10.23 (continued)

\begin{tabular}{|c|c|c|c|c|}
\hline Parameter/matrix & $\begin{array}{l}\text { Known } \\
\text { value }\end{array}$ & $\begin{array}{l}\text { Control } \\
\text { limits }\end{array}$ & $\begin{array}{l}\text { Reported } \\
\text { average }^{a}\end{array}$ & $\begin{array}{c}\text { Performance } \\
\text { evaluation }\end{array}$ \\
\hline \multicolumn{5}{|c|}{ August } \\
\hline Alpha on air filter & $30.0 \mathrm{pCi} /$ filter & $16.1-43.9$ & 29.33 & Acceptable \\
\hline Beta on air filter & $69.0 \mathrm{pCi} /$ filter & $51.7-86.3$ & 78.00 & Acceptable \\
\hline${ }^{137} \mathrm{Cs}$ on air filter & $18.0 \mathrm{pCi} /$ filter & $9.3-26.7$ & 15.33 & Acceptable \\
\hline Iodine in water & $45.0 \mathrm{pCi} / \mathrm{L}$ & $34.6-55.4$ & 43.00 & Acceptable \\
\hline Plutonium in water & $9.0 \mathrm{pCi} / \mathrm{L}$ & $7.4-10.6$ & 8.07 & Acceptable \\
\hline \multicolumn{5}{|c|}{ September } \\
\hline Gross alpha in water & $45.0 \mathrm{pCi} /$ filler & $25.9-64.1$ & 35.00 & Acceptable \\
\hline Gross beta in water & $50.0 \mathrm{pCi} /$ filter & $41.3-58.7$ & 55.33 & Acceptable \\
\hline \multicolumn{5}{|c|}{ October } \\
\hline \multicolumn{5}{|l|}{ Gamma in water } \\
\hline${ }^{133} \mathrm{Ba}$ & $74.0 \mathrm{pCi} / \mathrm{L}$ & $61.9-86.1$ & 7.33 & Outlier \\
\hline${ }^{60} \mathrm{Co}$ & $10.0 \mathrm{pCi} / \mathrm{L}$ & $1.3-18.7$ & 10.00 & Acceptable \\
\hline${ }^{134} \mathrm{Cs}$ & $8.0 \mathrm{pCi} / \mathrm{L}$ & $0.0-16.7$ & 7.67 & Acceptable \\
\hline${ }^{137} \mathrm{Cs}$ & $8.0 \mathrm{pCi} / \mathrm{L}$ & $0.0-16.7$ & 8.33 & Acceptable \\
\hline${ }^{106} \mathrm{Ru}$ & $175.0 \mathrm{pCi} / \mathrm{L}$ & $143.8-206.2$ & 160.00 & Acceptable \\
\hline${ }^{65} \mathrm{Za}$ & $148.0 \mathrm{pCi} / \mathrm{L}$ & $122.0-174.0$ & 157.00 & Acceptable \\
\hline
\end{tabular}

"Results reported on three aliquots and averaged by EMSL-LV. 
Appendix A Paducah Gaseous Diffusion Plant
Chemical Release Data 


\section{Appendix A}

\section{Paducah Gaseous Diffusion Plant (PGDP) Chemical Release Data}

In addition to indicating the concentrations of various chemicals present in the environment near U.S. Department of Energy (DOE) facilities, in recent years the annual environmental reports have contained an estimate of the quantities of certain chemicals being emitted to the environment. This appendix contains an expanded list of chemicals with additional information regarding the types of releases, the estimated quantities released, the major processes contributing to the releases, and a brief description of the basis of estimates for CY 1992. Radiological chemical releases for CY 1992 are not included in this appendix; they are reported in the applicable sections in this report.

Three categories of chemical releases at each DOE facility are reported in this appendix:

(1) Superfund Amendments and Reauthorization Act of 1986, Sect. 313 (SARA 313), chemicals, (2) other large inventory chemicals, and (3) steam plant emissions. The SARA 313 chemicals are summarized from information being compiled for the SARA Title III, Sect. 313 report, required by SARA. This report is submitted on July 1 of each year for the previous calendar year and contains chemicals on the U.S. Environmental Protection Agency's (EPA's) toxic substance list. At present, more than 300 specific chemicals and 20 chemical categories must be reviewed and possibly reported under SARA 313. If any of these chemicals were manufactured in excess of $25,000 \mathrm{lb}$, processed in excess of $25,000 \mathrm{lb}$, or "otherwise used" in excess of $10,000 \mathrm{lb}$ at a facility during CY 1992, the chemical must be reported. In many instances the estimate of quantities released was obtained through material balance calculations, monitoring dati, or engineering calculations. In some cases no quantitative monitoring data, inventory estimates, or emission factors were readily available, and release estimates were based on "best engineering judgement." Information obtained from air permits, rates of operation, quantities used, and known treatment efficiencies were used to estimate quantities released into the environment. Typically, assumptions based on best engineering judgement were required to perform the calculations when all variables were not known.

The second category of chemicals reported in this appendix is "other large inventory chemicals." This listing is included to provide the reader with additional chemical information not reportable under SARA 313. Note that this is not a complete listing of all chemicals that may have been released at a site. This list was developed to better inform the reader of the additional chemicals (i.e., those that may be of interest to the general public) that are used and released at PGDP.

The third category, "steam plant emissions," consists of release estimates of certain chemicals from the coal-and/or gas-fired steam plants located at each site.

Information contained in this appendix may not coincide for all chemicals with the information to be reported under SARA, Title III, Sect. 313. The SARA 31.3 report must be submitted to the EPA and the Kentucky Department of Environmental Protection no later than July 1, 1993. The information for this appendix was generated in March and April 1993; additional refinements are under way. It is imperative that information generated in May and June be used as well to ensure compliance under SARA Title III, the community right-to-know law. The following table summarizes the chemical release information for PGDP. 
Paducah Gaseous Diffusion Plant 1992 chemical release Information

\begin{tabular}{|c|c|c|c|c|}
\hline $\begin{array}{c}\text { Chemical } \\
\text { name }\end{array}$ & $\begin{array}{l}\text { Type of } \\
\text { release }\end{array}$ & $\begin{array}{c}\text { Quantity released } \\
(\mathrm{lb} / \mathrm{kg})\end{array}$ & $\begin{array}{c}\text { Major relcase } \\
\text { source }\end{array}$ & $\begin{array}{l}\text { Basis of } \\
\text { estimate }\end{array}$ \\
\hline & & SARA $313^{a}$ & & \\
\hline \multirow[t]{4}{*}{ Chromium" } & Air: fugitive cmissions & $4,433 / 2,015$ & Cooling tower system & Material balance \\
\hline & Watcr: Big Bayou Creck & $29 / 13$ & $\begin{array}{l}\text { C. } 616 \text { chromium } \\
\text { reduction facility }\end{array}$ & Monitoring \\
\hline & Water: Little Bayou Creck & $9 / 4$ & Cooling tower system & Monitoring \\
\hline & $\begin{array}{l}\text { Land: to C-616 sludge } \\
\text { lagoon }\end{array}$ & $15,500) / 7,046$ & $\begin{array}{l}\text { C- } 616 \text { chromium } \\
\text { reduction facility } \\
\text { sludge }\end{array}$ & Monitoring \\
\hline \multirow[t]{3}{*}{ Trichloroethylene } & Air: point source & $22,534 / 10,221$ & $\begin{array}{l}\text { C-400 degreaser/ } \\
\text { slorage tanks }\end{array}$ & Material balance \\
\hline & Water: Big Bayou Creek & $27 / 12$ & $\begin{array}{l}\text { C- } 400 \text { degreasing } \\
\text { operations }\end{array}$ & Monitoring \\
\hline & Water: Little Bayou Creek & $1 / 0.5$ & Degreasing operations & Monitoring \\
\hline Sulfuric acid & Air: fugitive cmissions & & Cooling tower system & $\begin{array}{l}\text { Engineering } \\
\text { calculations }\end{array}$ \\
\hline \multirow[t]{3}{*}{ Chlorine } & Air: fugitive emissions & $9,234 / 4,197$ & Cooling lower system & $\begin{array}{l}\text { Engineering } \\
\text { calculations }\end{array}$ \\
\hline & Water: Big Bayou Creck & $17 / 8$ & $\begin{array}{l}\text { C-615 sewage } \\
\text { treatment plant }\end{array}$ & Monitoring \\
\hline & Water: Little Bayou Creck & $1 / 0.5$ & $\begin{array}{l}\text { Once-through } \\
\text { cooling water }\end{array}$ & Monitoring \\
\hline Freon 114 & Air: fugitive emissions & $376,000 / 170,704$ & Process cooling & $\begin{array}{l}\text { Engincering } \\
\text { calculations }\end{array}$ \\
\hline \multicolumn{5}{|c|}{ Other large inventory chemicals } \\
\hline Fluorides & Air: stack emissions & $14,421 / 6,547$ & C-310 stack emissions & $\begin{array}{l}\text { Engincering } \\
\text { calculations/ } \\
\text { continuous } \\
\text { stack } \\
\text { sampling }\end{array}$ \\
\hline Nitric acid & Air: point source & $6 / 3$ & C-400 storage tank & $\begin{array}{l}\text { Engineering } \\
\text { calculations }\end{array}$ \\
\hline Ammonia & Air: fugitive emissions & $300 / 136$ & Blueprint machines & Material balance \\
\hline
\end{tabular}


1992 Environmental Report-Paducah

Paducah Gaseous Diffusion Plant 1992 chemical release Information (continued)

\begin{tabular}{|c|c|c|c|c|}
\hline $\begin{array}{l}\text { Chemical } \\
\text { name }\end{array}$ & $\begin{array}{l}\text { Type of } \\
\text { release }\end{array}$ & $\begin{array}{c}\text { Quantily released } \\
(\mathrm{lb} / \mathrm{kg})\end{array}$ & $\begin{array}{c}\text { Mujor release } \\
\text { source }\end{array}$ & $\begin{array}{l}\text { Basis of } \\
\text { cstimate }\end{array}$ \\
\hline \multicolumn{5}{|c|}{ Other large inventory chemicals (continued) } \\
\hline Freon 11 & Alr: fugitive emissions & $2,400 / 1,080$ & $\begin{array}{l}\text { Air-conditioning } \\
\text { systems }\end{array}$ & Material balance \\
\hline Freon 22 & Air: fugitive emissions & $360 / 500$ & $\begin{array}{l}\text { Air-conditioning } \\
\text { systems }\end{array}$ & Material balance \\
\hline Freon 113 & Air: fugitive emissions & $2.120 / 964$ & $\begin{array}{l}\text { C-360 flush solution } \\
\text { for sample cooldown }\end{array}$ & Material halance \\
\hline \multicolumn{5}{|c|}{ Steam plant emissions } \\
\hline Sulfur dioxide $e^{r}$ & Air: stack emissions & $856,808 / 388,648$ & Fossil fucls combustion & Emission factors \\
\hline Nitrogen & Air: stack cmissions & $570,318 / 258,696$ & Fossil fuels combustion & Emission factors \\
\hline Particulates $^{t^{*}}$ & Air: stack combustion & $49,713 / 22,550$ & Fossil fucls combustion & Emission factors \\
\hline Carbon monoxide ${ }^{c}$ & Air: stack emissions & $22.550 / 10,238$ & Fossil fucls combustion & Emission factors \\
\hline $\begin{array}{l}\text { Non-methane volatile } \\
\text { organic compounds }\end{array}$ & Air: stack emissions & $2,126 / 964$ & Fossil fucls combustion & Emission factors \\
\hline Methanes & Air: stack emissions & $939 / 426$ & Fossil fucls combustion & Emission factors \\
\hline
\end{tabular}

"Superfund Amendments and Reauthorization Act of 1986, Title III, Sect. 313.

'Quantity calculated as chromium; chemical compound is sodium bichromate.

'U.S. Environmental Protection Agency, October 1986. Compilation of Air Pollutant Emission Factors, Vol. I (Suppl. A). 


\section{Appendix B}

Errata for the Paducah Gaseous Diffusion Plant Environmental Report for 1991 


\section{Appendix B}

\section{Errata for the Paducah Gaseous Diffusion Plant Environmental Report for 1991}

1. Table 4.1 in Part 1 should include the following:

Location SW29 should also list ${ }^{99} \mathrm{Tc},{ }^{239} \mathrm{Pu},{ }^{237} \mathrm{~Np}$, and ${ }^{235} \mathrm{U}$ as parameters. $\mathrm{PO}_{4}$ should be listed as $\mathrm{PO}_{4}-\mathrm{P}$.

Location SW30 should also list suspended alpha and beta, ${ }^{99} \mathrm{Tc},{ }^{239} \mathrm{Pu},{ }^{237} \mathrm{~Np}$, and ${ }^{235} \mathrm{U}$ as parameters.

$\mathrm{PO}_{4}$ should be listed as $\mathrm{PO}_{4}-\mathrm{P}$.

Location SW 13, weekly, should also list ${ }^{99} \mathrm{Tc},{ }^{235} \mathrm{U}$, and temperature as parameters. $\mathrm{PO}_{4}$ should be listed as $\mathrm{PO}_{4}-\mathrm{P}$.

Location SW1, monthly, should also list $\mathrm{PO}_{4}$ as $\mathrm{PO}_{4}-\mathrm{P}$.
The results for all these analyses are listed in Tables 4.16 through 4.22 in Part 2.

2. Tables 4.2, 4.4, 4.6, 4.7, 4.12, 4.13, 4.14, 4.16, 4.17, 4.20 , and 4.21 in Part 2 should all list as a parameter "phosphate as phosphorus" instead of "phosphate."

3. Table 5.6 in Part 1 should list as a parameter "phosphate as phosphorus" instead of "phosphate."

4. Table 5.7 in Part 2 should list $\mathrm{NO}_{3}$ as $\mathrm{NO}_{3}-\mathrm{N}$.

5. Table 5.10 in Part 2 should list $\mathrm{PO}_{4}$ as $\mathrm{PO}_{4}-\mathrm{P}$. 
ES/ESH-36

KY/E-164

\section{Internal Distribution}
1. T. A. Acox
2. D. L. Armstrong
3. D. L. Ashburn
4. J. B. Atwater
5. M. L. Baker
6. F. P. Baxter
7. D. E. Beck
8. C. R. Bieber
9. T. J. Blasing
10. C. W. Broughton
11. R. A. Carson
12. W. W. Chance
13. D. E. Conrad
14. G. T. Cook
15. N. H. Cutshall
16. M. P. DeLozier
17. R. J. Devol
18. F. Dickens
19. L. C. Dolan
20. J. W. Douthitt
21. R. C. Durfee
22. T. O. Early
23. C. J. Ford
24. M. W. Francis
25. D. W. Frazier
26. C. E. Frye
27. C. G. Giltner
28. R. W. Glass
29. G. A. Goslow
30. P. S. Gouge
31. P. A. Gourieux
32. R. L. Grant
33. M. G. Guhy
34. D. R. Guminski
35. J. L. Haymore
36. S. G. Hildebrand
37. C. C. Hill
38. R. L. Hinzman
39. J. W. Hodge
40. S. K. Holshouser
41. F. Homerosky, Jr.
42. C. M. Horak

43. K. Horsley

44. D. D. Huff

45. W. K. Jago

46. T. G. Jett

47. C. G. Jones

48. D. W. Jones

49. R. J. Keeling

50. R. H. Kingrea

51. A. F. Kiriluk

52. M. E. Kirker

53. K. L. Kliewer

54. W. S. Koncinski

55. E. H. Krieg, Jr.

56. S. Y. Lee

57. J. M. Loar

58. L. W. Long

59. P. Y. Lu

60. A. P. Malinauskas

61-76. W. D. Malis

77. F. K. Martin

78. D. C. Mason

79. J. C. Massey

80. J. G. McDonald

81. L. W. McMahon

82. S. A. Meacham

83. L. J. Mezga

84. G. R. Miller

85. J. L. Miranda

86. B. J. Montgomery

87. J. W. Morgan

88. G. L. Murphy

89. J. B. Murphy

90. C. E. Nix

91. F. R. O'Donnell

92. S. E. Payne

93. D. C. Pentecost

94. M. J. Peterson

95. G. V. Pierce

96. P. Potter

97. J. E. Powell

98. R. E. Pudelek

99. H. Pulley 

100. R. Richmond
101. J. G. Rogers
102. J. E. Rushton
103. G. E. Rymer
104. L. B. Ryon
105. D. R. Sampson
106. E. M. Schilling
107. S. L. Shell
108. C. W. Sheward
109. L. G. Shipe
110. S. P. N. Singh
111. N. L. Sinor
112. E. L. Smith, Jr.
113-114. M. C. Smith
115. G. W. Snyder
116. M. L. Socolof
117. G. R. Southworth
118. D. L. Stansberry
119. A. J. Stewart
120. L. E. Stokes
121. A. J. Story
122. S. H. Stow
123. F. G. Taylor, Jr.
124. N. A. Teasley, Jr.
125. K. M. Tomko
126. C. C. Travis

127. J. H. Turner

128. C. J. Van Meter

129. C. W. Walter

130. C. W. Weber

131. L. Welch

132-181. D. C. West

182. D. A. White

183. M. G. White

184. R. K. White

185. J. K. Williams

186. W. R. Williams

187. S. L. Winters

188. P. D. Wooldridge

189. Central Research Library

190. DOE K-25 Site Office

191. DOE Y-12 Site Office

192. ESD Library

193-195. ORNL Laboratory Records

196. ORNL Laboratory Records - RC

197. ORNL Patent Section

198. ORNL Y-12 Technical Library

199. PGDP ER-DMC

200. PGDP Library

201. PORTS Library

202. K-25 CEP Document Center

203. K-25 Site Library

\section{External Distribution}

204. Office of Assistant Manager for Energy Research and Development, U.S. Department of Energy Oak Ridge Operations, P.O. Box 2001, Oak Ridge, TN 37831-8600.

205-206. Office of Scientific and Technical Information, P.O. Box 62, Oak Ridge, TN 37831.

207-306. This report is distributed widely by the Department of Energy's Oak Ridge Operations Office to local, state, and federal government agencies, the Congress, the public, and the news media. 

